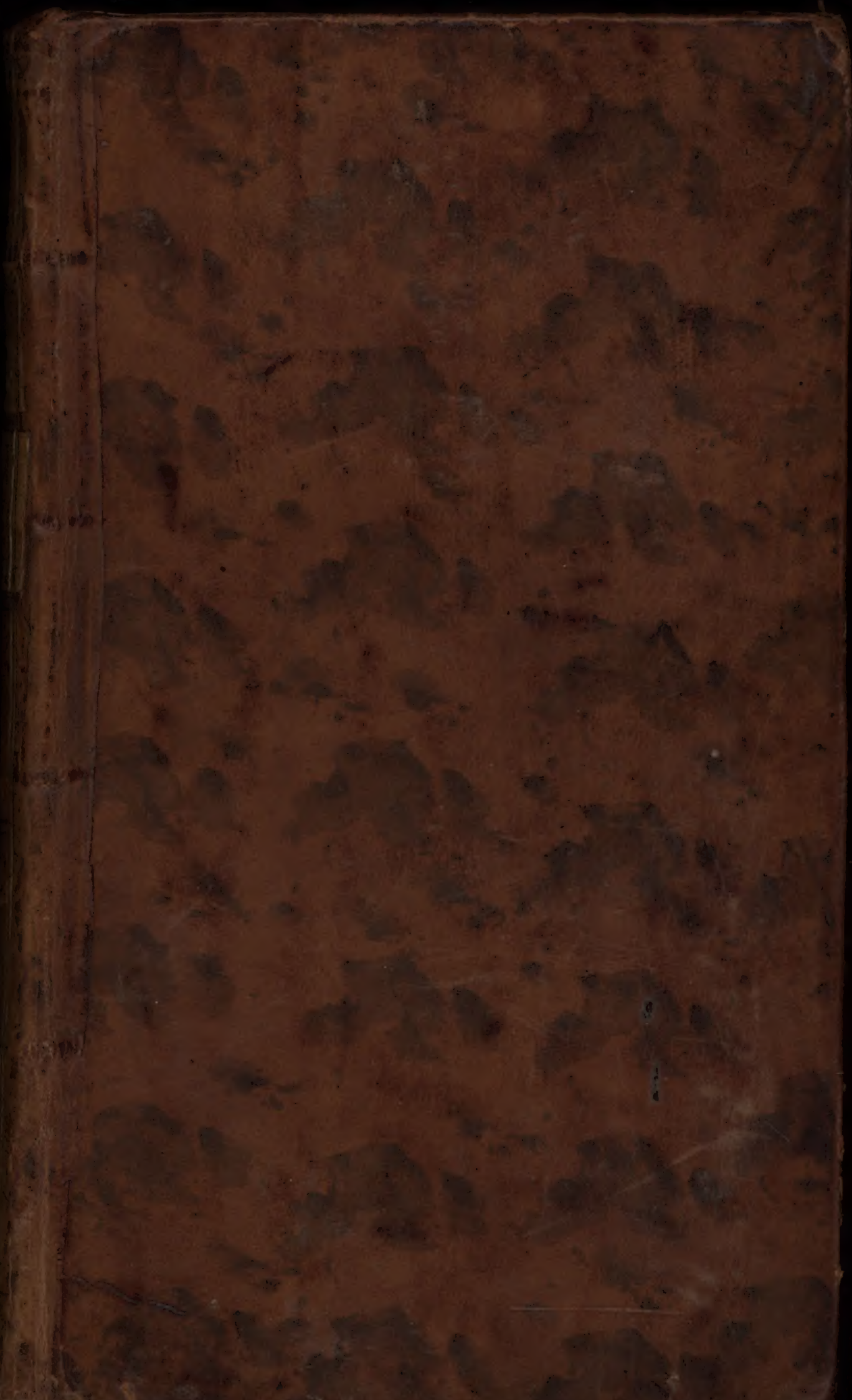

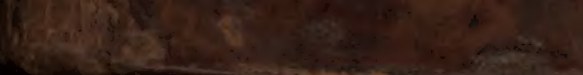



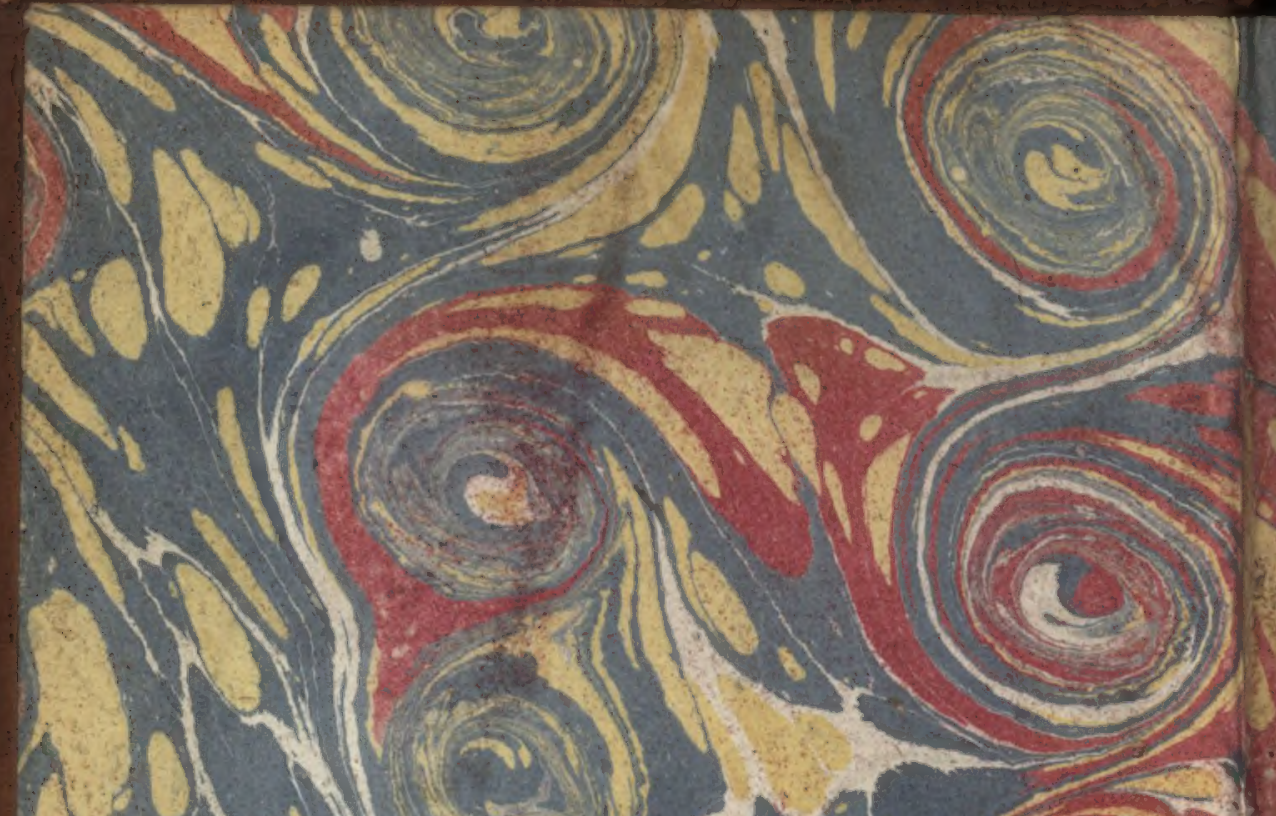

(1) 10 (n)

\section{Nitis $\cdots$}

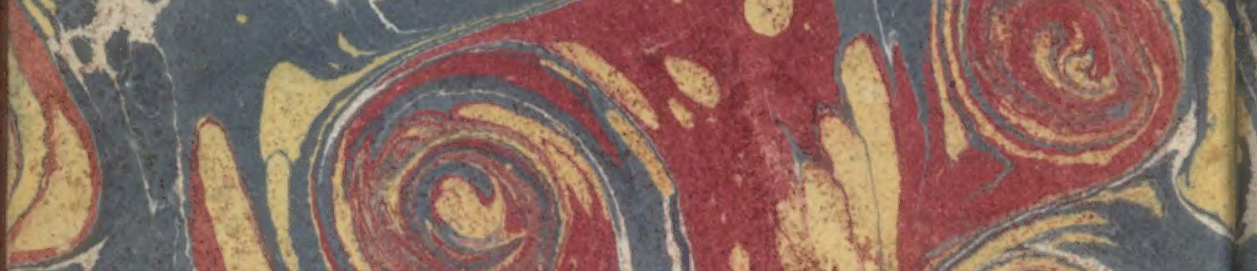

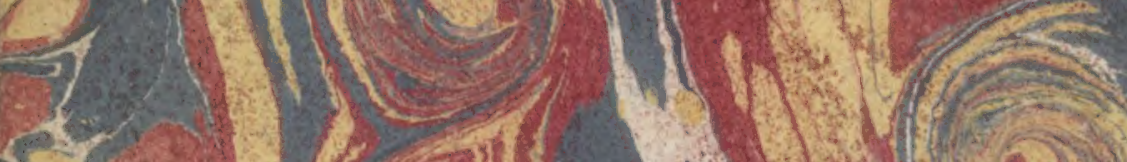

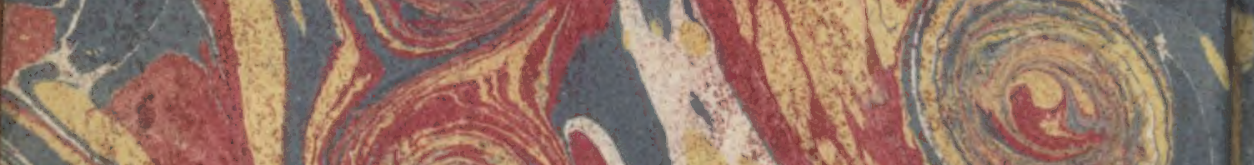

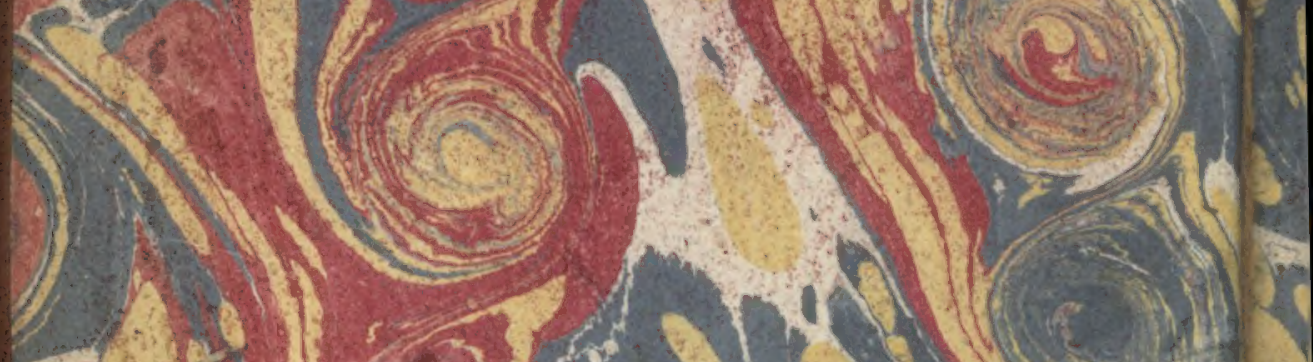

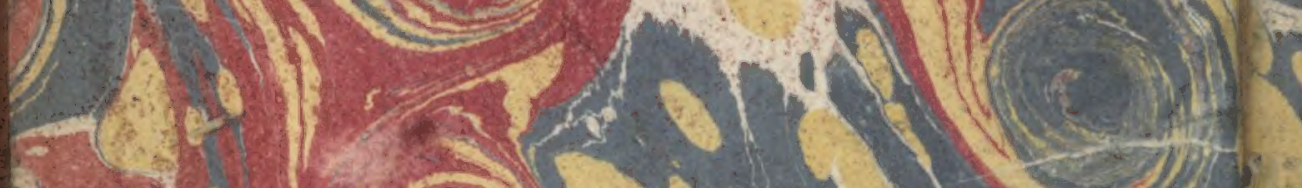

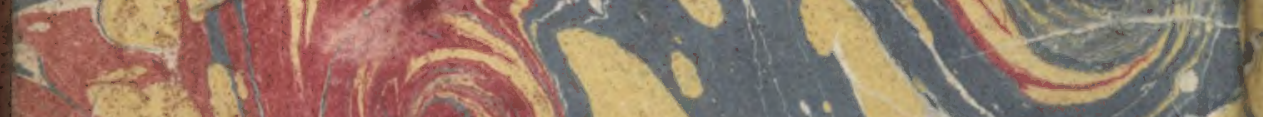

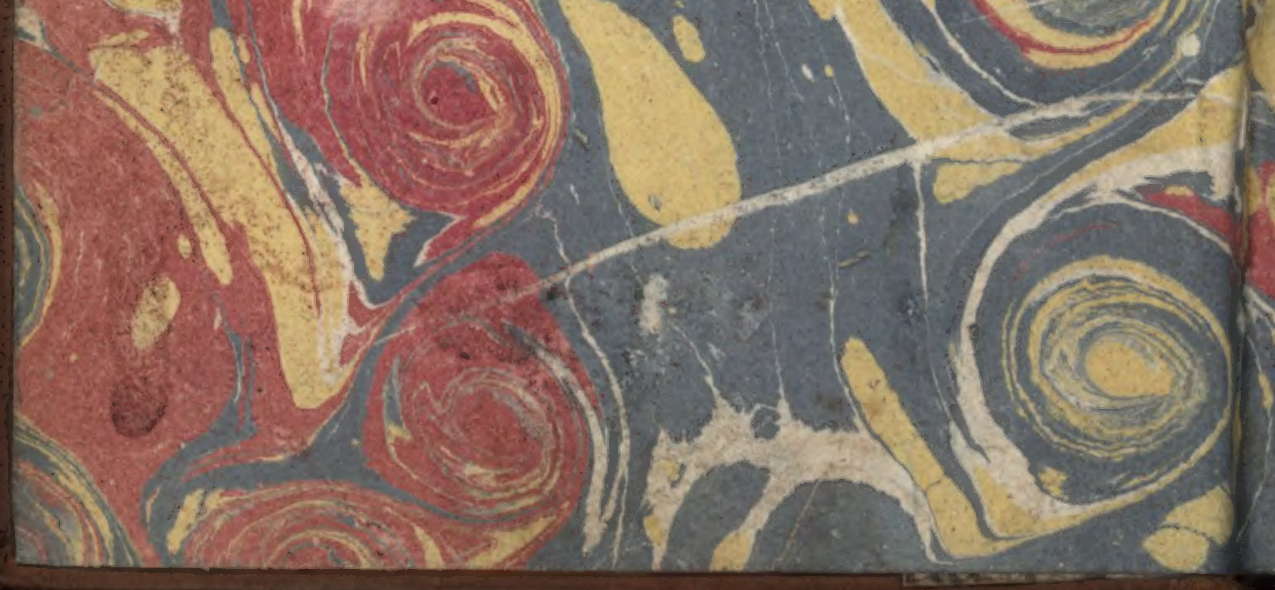




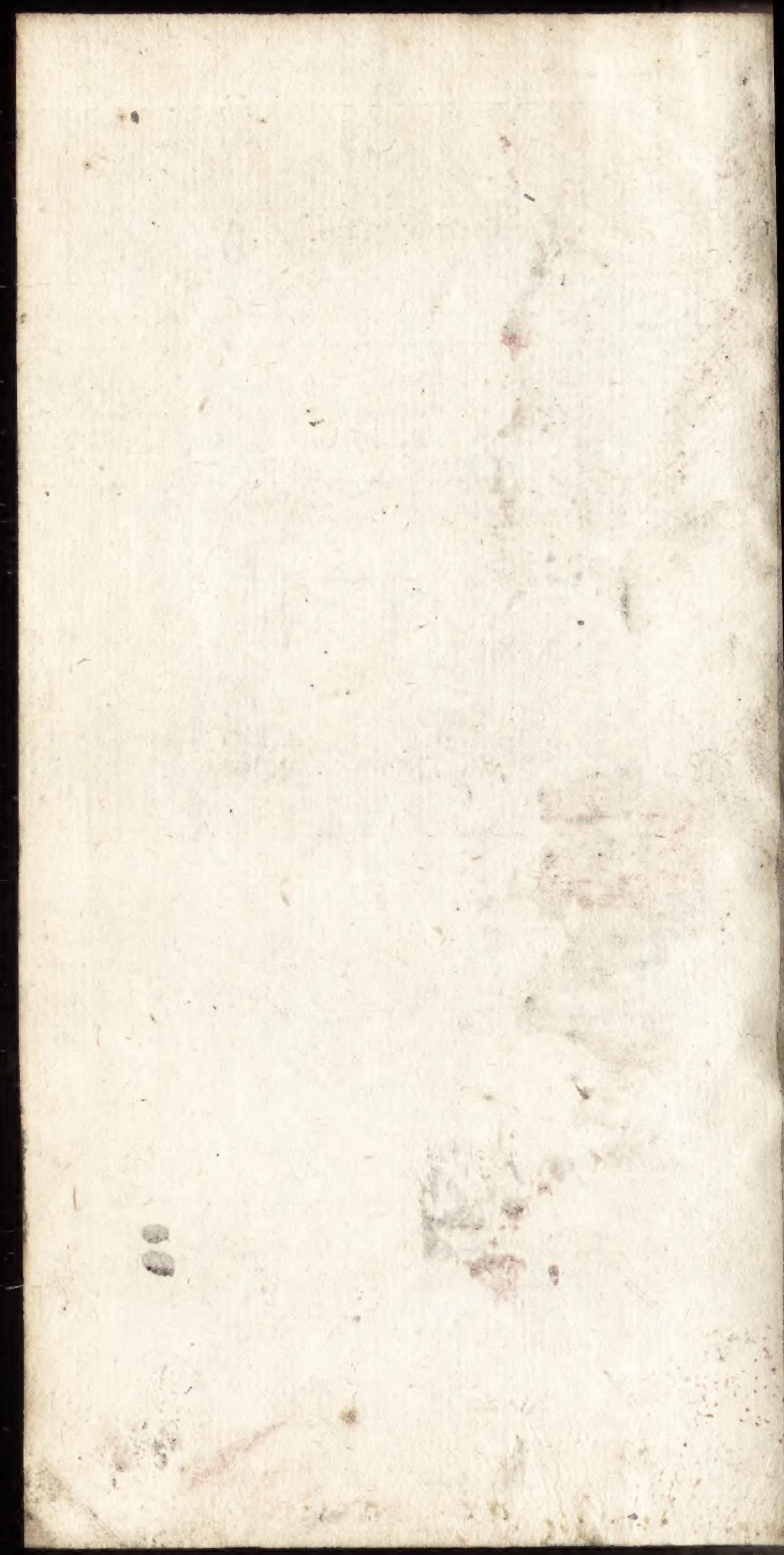


a 


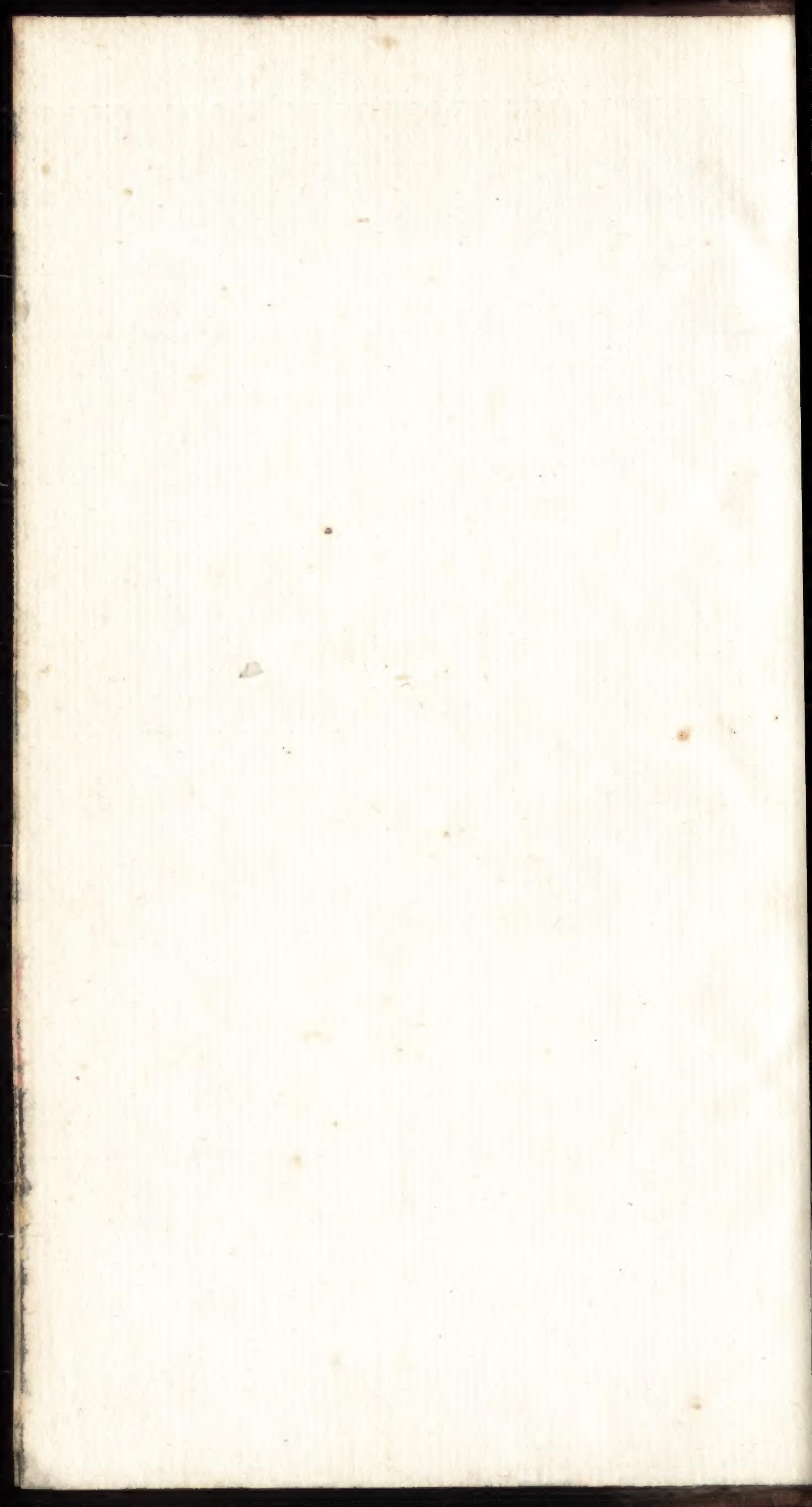


H I S T I R E

D $U$

$J A \mathbb{P} O N$. 


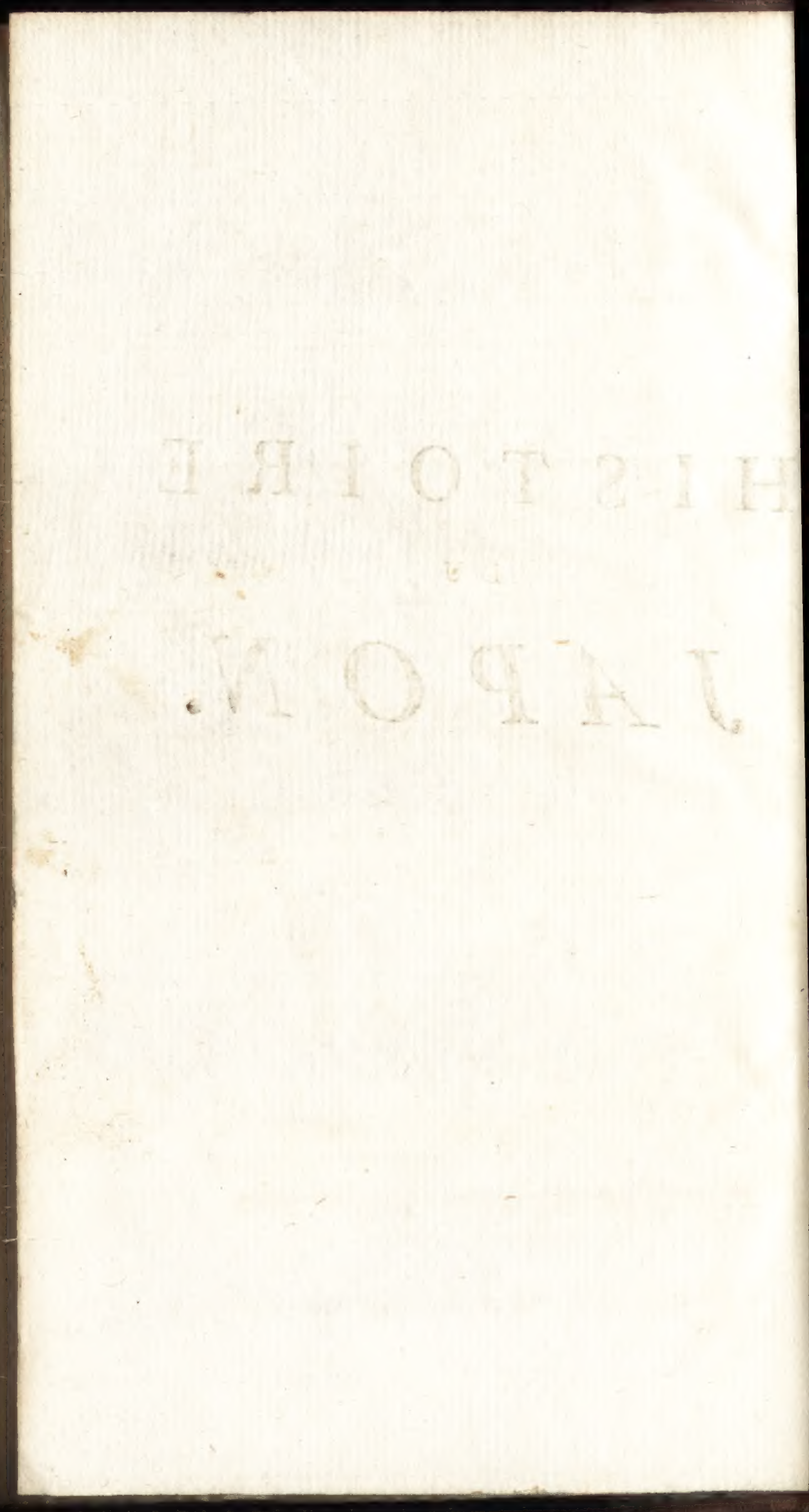


H I S T O I R E

D U
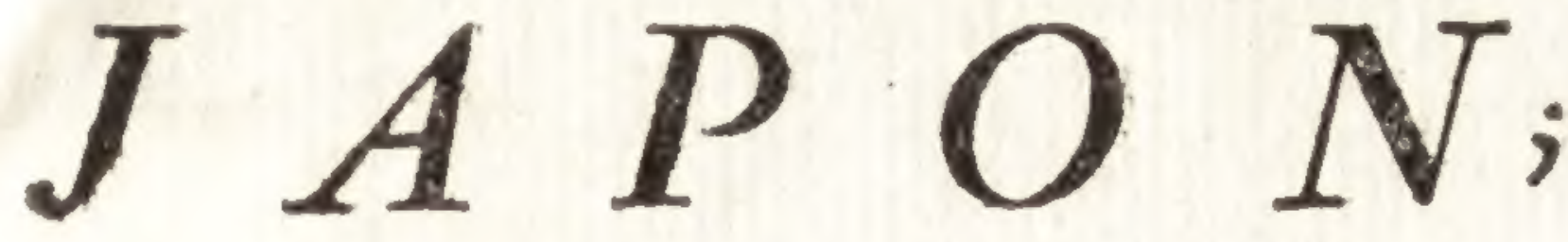

O U L'O N T R O U V E R A

OUT CE QU'ON A PU APPRENDREDE la nature \& des productions du Pays, du caractere \& des Coutumes des Habitants ; du Gouvernement \& du Commerce, des Revolutions arrivées dans l'Empire \& dans la Religion; \& l'examen de tous. les Auteurs, qui ont écrit fur le même fujet.

$$
\text { NOUVELLE EDITION. }
$$

Enrichie de Figures en taille-douce.

Par le Pere de CharleVoIX, de la Compagnie de JESUS.

Revûe, corrigée, augmentée, \& mile dans un nouvel ordre par l'Auteur.

TOME SECOND.

\section{然炶}

A PA R I S.

Chez ROLLIN, Libraire, Quay des

Auguftins, à S. Athanafe

M. DCC. LIV.

Avec Approbation E Privitége du Ras. 


\section{ji Suite Chronolog. Des Datrys;}

ans avant la naiffance de J.C. étant lui-même âgé de foixante \& dix-huit ans (a). Son premier nom étoit Swa Fikono Mikotto; il avoit trois Freres aînez, qui régnerent avant lui; mais comme ils vêcurent peu, \& que leurs regnes furent obfcurs, c'eft a lui que les Japonnois attribuent la fondation de leur Empire, \& ils lui donnent le titre de Nin O, c'eft-à-dire, le plus grand de tous les Hommes. Ce Prince civilifa les Habitans du Jam pon, qui s'appelloit alors Akitsussima; il introduifit parmi eux la Chronologie; il partageale tems en Années, en Mois, \& en Jouris, lans marquer les Semaines; \& s'il ne fut pas le premier Auteur des Loix, il les réforma, les fit obferver, \& régla le fyftême du Gouvernement, tel à pelı près qu'il a été depuis.

En la cinquantiéme année de fon regne, trois cents quarante-fix ans après la mort de Xaca, le quatorzićme jour du neuvićme mois, le grand Philofophe Roosr nâquit à la Chine (b) dans la Province de Sokokf. Il avoit, dit-on, quatre-vingt-un an, \& fa tête grïfonnoir déja, loríqu'il nâquit; c'eft ce qui le fit nommer Roofi, vieux enfant; car Roo veut dire vieux, \& Si Enfant. On croit que l'Ame

(a) Ceci eft conforme aux Tables Chronolugiques de la Chine, que le P. Couplet a publićes.

(b) Le Pere Couplet n'en parle polnt, il dit feulement qu'en la cinquante quatriéme anaée du trentecinquiéme Cycle, qui comınença 857. ans avant J. C. Lav-Krus Autcut de la Secte Epicurienne, qui eft nommé la Secie des Immoricls; mais que fes Sectateurs déplaverent dans la luire, mulirut dans la Province HuQ0AM, âgé de quatte-vingt ans. Ce Philoluphe peut

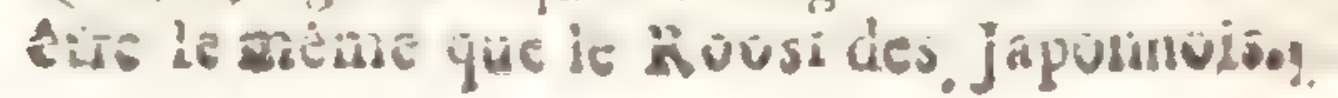


ou Empereurs Heredtr. du Japon. iij de Kaffohofatz, Compagnon de Xaca, \& le principal de fes Difciples, étoit paflée dans fon corps, \& cependant fa Doctrine differe entierement de celle de cet ancien Légiflateur. En effet Xaca enfeignoit $(\alpha)$ l'immortalité des Ames, la récompenfe des Bons dans l'autre vie, \& la néceffité de pratiquer la vertu en ce Monde, fit on velte étre heureux en l'autre; Roofi au contraire nioit abfolument ces vérités importantes, \& foutenoit que notre bonheur confifte uniquement à joüir d'une vie longue \& heureufé. En conféquence de ce principe, il effaya de trouver dans l'Alchymie une Médecine univerfelle, qui pít prolonger fa vie, fi elle ne pouvoit le rendre immortel; entreprife, que fes Dif́ciples \& fes Sectateurs unt pourluivie avec le même luccès, dont peuvent fe vanter parmi les Européens ceux. qui cherchent la Pierre Philofophale. Roof vêcut quatre-vingt-quatre ans.

\section{Introduction des Idoles au Japon.}

Vers le mếme tems ( $b$ ) on vit pour la premiere fois des Idoles Etrangeres au Japon, \& elles furent adorées à Khumano. Syn-Mu ayant régné foixante Eo dix-neuf Ans, \& aflûré le Trône à fa poftérité, qui l'occupe encore aujourd'hui, mourut âgé de cent cin-

(a) L'Auteur de ces faftes ne connoiffoit apparem. ment pas la Doctrine intérieure de $\mathrm{XACA}_{\mathrm{ACA}}$, dont nuus avons parlé dans le Livre Préliminaire. Chap. XII.

(b) Koempfer marque pofitivement cet évenement l'an 660. avant J. C. il doit y avoir de l'erreur dans le Chiffe, puifucil paroft joinde cette époque avec is naifrance, ou la mo.t de Roosi. 


\section{iv Suite Chronorogreue des Dairys;}

quante-fept ans. Avec fon régne commence l'Ere Japonnoife Nin O, ou de Syn-Mu. Au refte, comme cetre fuite Chronologique des Empereurs du Japon eft prife de Kœempfer, qui prétend l'avoir copiée fur l'Original, je ne garantis pas tout ce que l'Auteur y avance, \& qui pourroit être contraire à la Chronologie Chinoife du P. Couplet, laquelle paroît avoir été faite fur de meilleurs Mémoires.

Avane J. C. I I. D A I R Y. De Syn-Mu; 580. SUI SEI: 80.

Le Succeffeur de Syn-Mu fut fon troifiéme Fils; ce Prince avoit cinquante \& un An, brfqu'il commença de régner.

\section{Naifance de Confucius,}

La trentiéme Année de ce régne 399. ans après la Mort de Xaca, \& s F I. ans avant Jefus-Chrif, le quatriéme jour de l'onziéme Mois, le célébre Philofophe Koosı, que les Chinois prononcent Confuçu, \& que les Européens appellent Gonfucrus, nâquit à la Chine (a). Les Auteurs Chinois rapportent qu'au tems de fa Naiffance on entendic un Concert de Mufique dans le Ciel; que les Etoiles le rapprocherent de la Terre; que deux Dragons gardoient l'Enfant, tandis qu'on

(4) Selon le P. Couplet, Confucius nâquit dans la Province de Xameum, la yuarante-leptiéme année du trente-fixieme cycle des Chinois, qui cummenca l'an 597. avant J. C. l'errtur n'elt apres tout que d'un Fin. 
ov Euperevrs Heredrt. du Jaboin. $y$ le lavoit, que la Nature lui avoit marqué le front d'une petite éminence, comme à 'LEnpereur $S_{I U N}$; enfin, qu'il avoit toutes les marques d'un futur SESIN, c'eft-à-dire, d'un Homme d'un efprit incomparable, \& d'un profond Cçavoir. Lorfọulil fut parvenu à l'àye viril, il fut diftingué par une taille $(a)$ majeftueufe, \& un air Noble. Ses Ouvrages, \& fur-tout ceux, qui roulent fur la Morale, ne font pas inconnus en Europe: fes Ecrits, où il déploye es plus Belles connoillances pour l'avantage commun des Hommes; fa vie vertueufe \& exemplaire, \& le grand nombre de fus Difciples, qui n'étoient jamais moins de trois mille, lui attirerent tant de réputation parmi fes Compatriotes, \& dans le Japon, qu'après fa mort on éleva des Temples e fon Honneur, (b) où jufqu'aujourd'hui on lui rend un culte prelque Divin; il meurut en la loixante-quatorziéme année de fon áge (c).

Sui Sei régna trente-trois ans, \& en vîcut quatre-vingt-quatre. Son Fils lui fuccída.

(a) 'I 'Ansiyfte Japonnois dit que Confucius étoit haut de neuf laks, fix de fix Suns, muis il n'explique point ices mefures.

(b) Kumpfer dit allleurs, que les Mordliftes du Tapon, c'clt-à-dire, les Sectateuts de Cunfucius, n'dvoient point de Temples, \& que les premiers Temples qu'on ait bátis au Japon cn lhonnetir ile ce Philofophe, font l'Ouvrage d'un des deralers: Empereurs Cuino Samas.

(c) Kuempfer dit foixante of dis Sept, c'eft une crreur de caicul. 


\section{vj Suite Chronologteu das Datrus,}

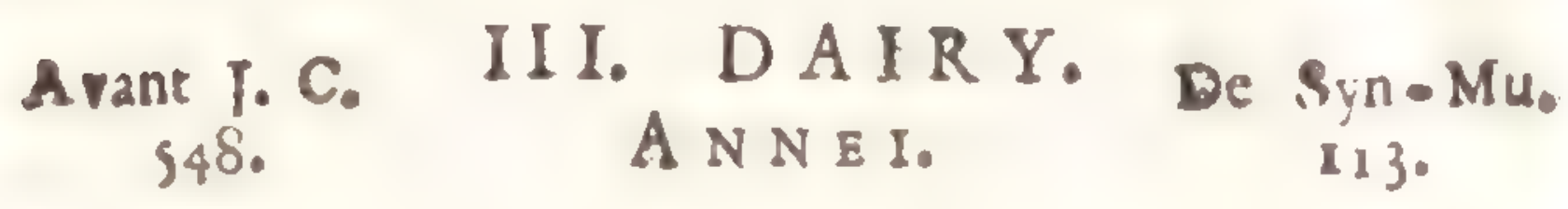

Ce Prince monta fur le Trône à l'âge de vingt ans, la trente-deuxiénze annće de fon régne fut remarquable par la Naillance de GanquaI, Homme Sçavant, \& un des principaux Difiples de Confucius; ce Philolophe náquit à la Chine dans la Province de Rokokf. On dit qu'à dix-huit ans il avoit les Cheveux tous blancs, \& paroilfoit en tout un Vieillard. Il ne vêcut que trente-deux ans; on lui a fait aufi l'Honneur de croire que l'Ame de Kallobofatz étoit palfée dans fon Corps.

Annei régna trente-huit ans, \& mourut dans fa cinquante-huitiéme année. Son fecond Fils fut fon Succeflcur.

$$
\underset{\text { SII. }}{\text { Avant J. C. IV. }} \underset{\text { T OKU. }}{\text { DAIR. De Syn-Mu: }}
$$

Cet Empereur ćtoit âgé de quarante-quatre ans, lorfqu'il fuccéda à fon Pere. La quatriéme année de fon régne il tranfporta fa Cour à Keitz, où il mourut après un régne de trente-cing ans. Il eut auffi pour Succelleur fon fecond Fils.

$$
\underset{476 .}{\underset{4}{\text { Avant J. C. V. DAIRY. De Syn-Mus: }} \text { KOSIO. }}
$$

Ce Prince prit le Sceptre à l'âge de trentetrois ans. La cinquiéme Année de fon régne

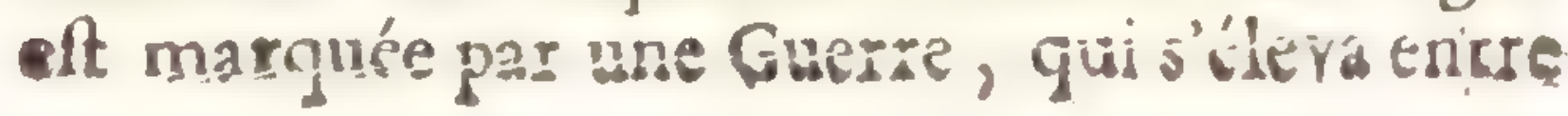


OU EMPEREURS HEREDIT. DU JATON. vif les Provinces de Jetz \& de Go; c'elt la preniere, dont les Annales Japonnoifes fallent mention. Kolio régna près de quatre-vingttrois ans, \& fon fecond Fils régna après lui.

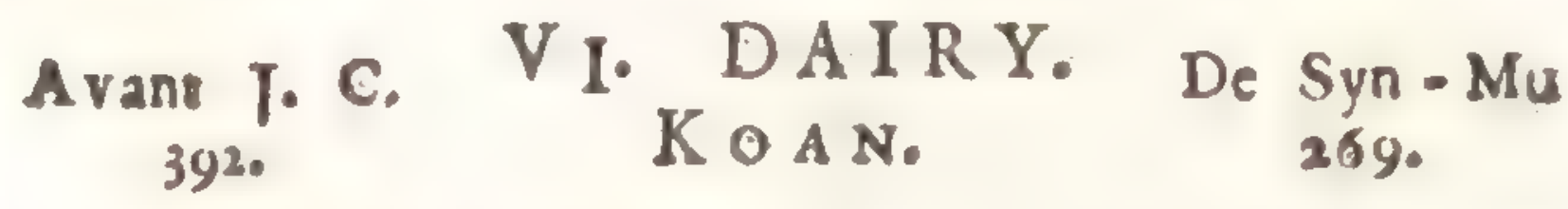

Ce Prince monta fur lis Tróne à l'âge de trente-fix ans. Il tranfporta d'abord fa Cour à Muro, dans la Province de Farima, \& quelques années après à Khuroda. Sous fon régne il parut une Comete à la Chine $(a), \&$ il y eut au Japon une Eclipfe, qui changea le jour en une nuit obfcure. Ce régue fut de cent \& un an. Le Fills âné de Koan lui fuecéda.

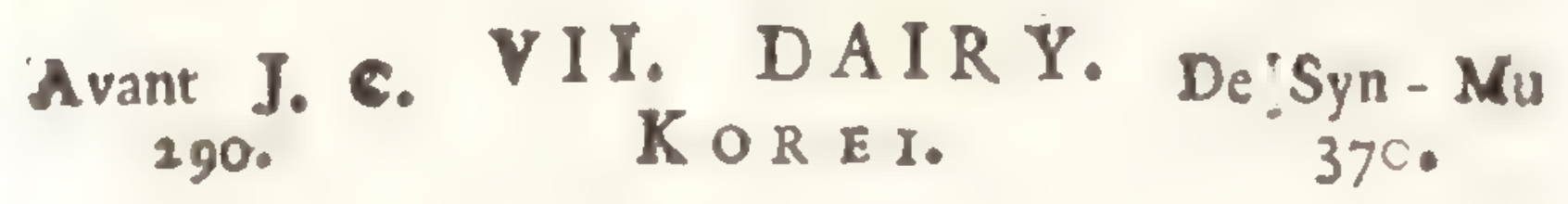

Cet Empereur commença de rígner à l'âge de cinquante-trois ans.

Lac En Riviere d'Ö̈тz, ou d'OMI.

La fixiéme année de fon Iégne un Lac \& une Riviere parurent en une feule nuit dans la Province d'Omi, \& près de la petice Ville d'Oitz.

La trente-troifiéme année, le fameux Ty-

(a) Le P. Couplet marque deux Cometes à la Chine en la cinquante-trols \& la cinquante-cinquiéme année du quarantiéme Cycle, qui conmença $35 \%$ ans avant J. C. $\$$ en la cinquante-feptiéme année du méme $\mathbf{C}_{y}$ cle, une Eclyple rotale du Soleil. 
yiij Suite Chronorogreve des Daimys, ran Sinofikwo (a) nâquit à la Chine.

\section{Premiere divifion du Japon en trente-fix 1 Provinces.}

La quarante-fixiéme année l'Empire du Japon fut divifé en trente-fix Provinces; c'eft la premiere divifion, dont il foit parlé dans l'Hiftoire. Korei régna foixante-feize ans, \& lailla le Sceptre à fon Fils.

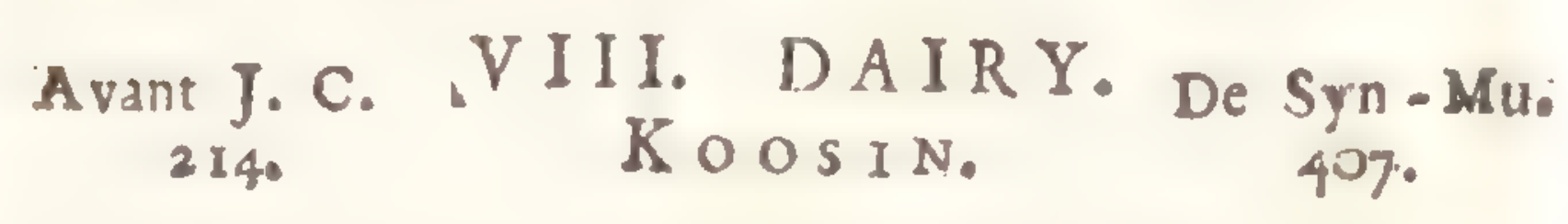

Ce Prince fut couronné à l'âge de foixante ans, \& alla tenir fa Cour à Karutz. Vers ce tems-là régnoit à la Chine Sinofikwo (b); Prince aufi fameux par fes profufions, \& par fa magnificence, que redouté de fes $S_{t l-}$ jets pour fa cruauté \& fa tyrannie. Il monta fur le Trône de la Chine l'an 246. avant J. C. il envoya trois cents jeunes Hommes avec autant de jeunes Filles au Japon, fous la conduite d'un de fos Médecins, qui le lui avoit confeillé, fous prétexte de lui aller cher. cher des Plantes, qui ne fe trouvoient que dans une feule de ces Ines, \& dont il prétendoit, difoit-il, compofer un Reméde univerfel, pour empêcher l'Empereur de mourir.

(b) Le P. Couplet ne parle point de cet Empereur", non plus quele P. Martiui.

(b) Le P. ouplet dit que la trente-deuxiéme année du qua ante-deuxiéme Cycle des Chinois, lequel cominença l'an 237. avant J C. Coozu, zutrement appellé Lieu Pam, Fondateur de la cinquiéme Race,

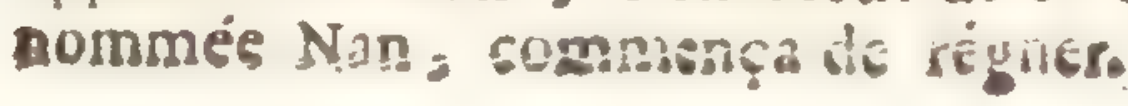


ou Empereurs Hïrenit. du Japon. ix Cette Iroupe étant arrivíce au Japon, s'y établit; le Médecin fe fit Roi, \& bátit un $\mathrm{Pa}$ lais, qui fut appellé Kanjolsu, c'eft-à-dire, grande Maifon, Semblable aux Cieux; les Planchers en étoient couverts d'or \& d'argent, \& tout le Palais étoit d'une grandeur \& d'une magnificence, qui ont palices en proverbe. Kompfer ne s'accorde pas ici avec ce qu'il dit plus bas, qu'alors on n'avoit point encore vû d'or au Japon. D'ailleurs quelle vraifemblance y $a-t-i l$ dans ce qu'il ajoûte, que le Kanjoku fut brûlć l'an 20 s. avant J. C. par l'ordre de Kool, qui s'étoit révolté contre la Famille de Cin, avoit maflacré l'Empereur Syfe, Succefleur de Sinofikwo, \& s'étoit emparé du Trône de la Chine? Il ajoute, que fuivant les Hiftoires de la Chine \& du Japon, l'embrafement de ce fuperbe Edifice dura trois mois. Mais s'il y a du réel dans cette Hiftoire, il faut que ce Palais ait été bâti à la Chine, \& non pas au Japon.

Le P. Martini rapporte le fait du Médecin, \& le place fous l'Empereur Chinois Chingus ou Xius, Fondateur de la Famille Cin, lequel commença à régner la cinquante-deuxiéme annće du quarante-uniéme Cycle des Chinois, 246 ans avant J. C \& dont il dit beaucoup de bien \& beaucoup de nal. Le P: Coupler l'appelle Chuam Siam Vam: Il le fait monter fur le Trône en la quarante-neuviéme añnée du quararte-uniéme Cycle Chinois, \& marque une Eclipfe du Soleil la feconde ann é de fon régne. Koo Kin régna cinquarte-fix Ans. 


\section{* Suite Chronotogieue des Dairyson}

$\underset{\text { Avant 3. C. IX. DAIRY. De Syn-Mwè. }}{\text { K5 }}$

L'Annalifte ne dit point fi ce Monarque étoit Fils de fon Prédécelleur. Il fe contente de marquer, que KоoкIn lui lailla l'Empire, \& qu'il en prit polleffion, ćrant âgé de cinquante-deux ans. Il transféra fa Cour a Ifam gawa en la troifiéme année de fon régne. La dix-feptiéme, le premier Nengo commença à la Chine par l'ordre de l'Empereur Koobu (a). Nous avons dit dans le Livre Préliminaire de cette Hiftoire, que le Nengo eft une efpéce d'epoque particuliere, qu'on date pour l'ordinaire de quelyue Evénement remarquable, \& qu'on exprime par deux Caracteres. Il n'eft pas limité à un certain nombre d'années, \& il dure autant qu'il plaît à l'Empereur. Les Caracteres du premier Nengo étoient Ken Ken.

Kai Kwo tégna cinquante-neuf ans, , \& fon Fils lui fuccéda.

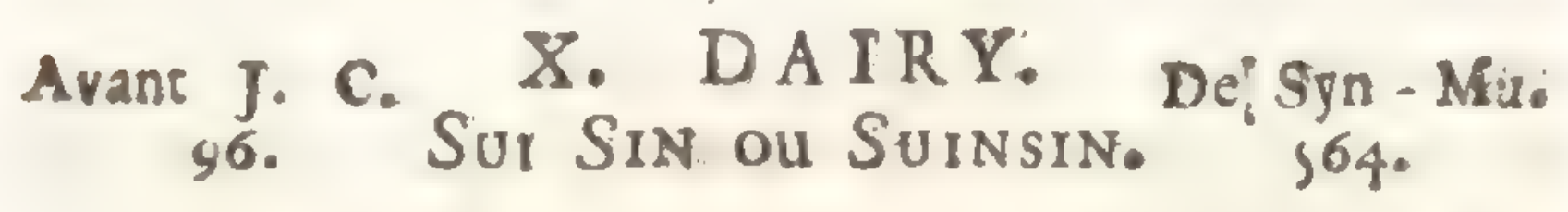

Ce Prince prit en main le Sceptre $\grave{a}$ l'âge de cinquante-deux ans. Il tranfporta la Cour à Siki en la quatriéme année de fon régne. Trois ans après, il y eut une grande morta.

(a) Le P. Couplet ne parle poine de cet étahliffe ment, \& dorne à l'Empercur Chinois, qui rénoit alors, le nuin de Xinits. Le P. Martini l'a,palle Arao kinghus, \& Be fait point nua flus mithion dU NFMEO. 
DU EMPERERS Heredit. du Japun. ij Tité au Japon. L'onziéme année il créa l'O fice de Seogun ou Xogun, il en revêtit un de fes Fils, \& lui donna en vertu de ce titre la Direction générale des Affaires de la Guerre, \& le Commandement des Armées. Enla dix-neuviéme année on conltruifit pour la premiere fois au Japon des Funes, c'elt-àdire, des Vaifleaux. En la foixante-huitiéme; on vit deux Lunes à l'Orient. Cette année fut la derniere du régne de Sui Sin. Son troifiéme Fils lui fuccéda.

Avant J. C. XI. DAIRY. De Syn-Mu,
29.

Ce Prince commença de régner à l'âge de quarante-un ans. En la trente-fixićme annke de fon régne, il plût des Etoiles au Japon. En la quarantiéme, le Ciel étant fort ferein à la Chine, il s'y éleva tout à coup un orage accompagnée de Tonnerres \& d'Eclairs : on: apperçut des Cométes, il parut dans l'Airdes. Dragons \& d'autres Météores furprenants, Il: tomba dir Ciel une pluye de Feu. En la foi. xante-cinquiéme, au feptiéme mois, la grélè\& les ćclairs tuerent plufieurs perfonnes à la. Chine. Cet orage fut fuivi d'une Famine épouz vantable, durant laquelle les Hommes fe maffacroient les uns les autres.

La Mort de J.C. fuppofé qu'elle foit arrivée dans la trente-troifiéme année de ce divin Sauverr, tombe dans la foixante-fixiémeannée du régne de Synin; par conféquent la Naiffance du Meflie fe rapporte à la trentetroifiéne annce de ce réçne, \& la cinquantehuiriéme du quarante-cinquiéme cycle des

$$
\text { ai } 2 j_{i}
$$




\section{xij SUITE Chronologreu des DAIRys;}

Chinois, la premiere de l'Empire de Hian Pim Ti.

En la quatre-vingt-huiriéme année de Synin, on amena des Indes au Japon, un Cheval d'une vitelfe prodigieufe, \& qui faifoit mil. le lieuës par jour.

\section{La Religion des Fo es prêchée au Japor.}

En la quatre-vingt-quinziéme, Bupo, autrement nommé Kobotus, vint des Indes au Japon, où il apporta fur un Cheval blanc le Kio, Livre qui renfermoit fa Doctrine \& fa Religion (a). On lui érigea un Temple fous le nom de Fakubafi, c'eft-à-dire, le Temple du Cheval blanc, qui fublifte encore; mais mon Auteur ne dit point où il eft.

Synin régna quatre-vingt-dix-huit ans. Son troifiéme Fils régna après lui.

$$
\text { De J. C. XII. DAIRY. De Syn-Mu. }
$$

Ce Prince avoit quatre-vingt-quatre ans; Iorfqu'il monta fur le Trône. En la vingttroifiéme annce de fon régne, une nouvelle Inle fortit du fond de la Mer: elle fut nommée Tfikubafima, \& confacrée à Nebis, qui eft te Neptune des Japonnois. Trois ans après on y bâtit uu Temple fous le nom de Taka-

(a) On tient communément que la Religion des Fors fut introduite à la Chine l'an 70. de J. C. \& s'it eft vrai qu'elle ne pafla au Japon que trois ans après, il $y$ a ici une erriur de fix ans. Kro veut dire Livre: celui.ci eft apparenment le Fo.UEK!O de XACA, qui,

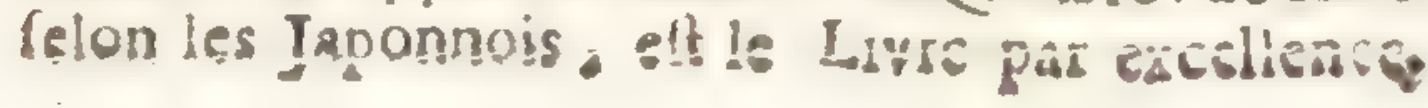


ou Empereurs herrdt: DU Japon.xiij janomia, en l'Honneur de ce même Díeu; \& on y fonda un nombre fuffifant de Prêtres (a) pour le fervice de la Divinité. Ce Temple elt devenu très-célébre \& fort riche. On afsûre que l'ine de Trikubafima a toijours été exempte des tremblements de Terre. Keikoo régna foixante ans, \& laiffa en mourant le Sceptre à fon quatriéme Fils.

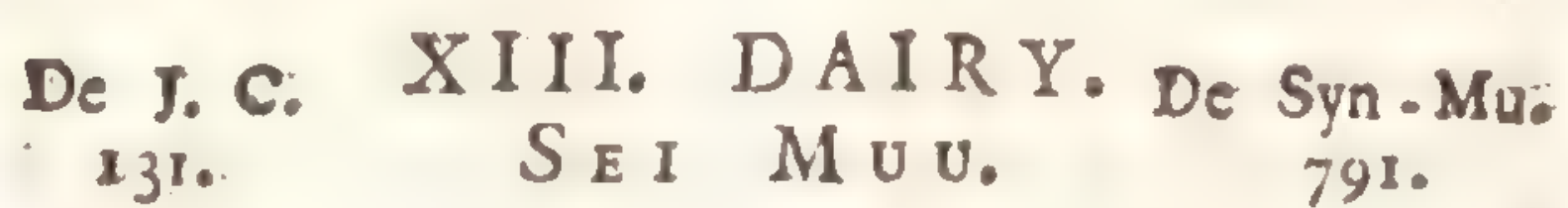

Cette Empereur étoit âgé de quarante-neuf ans, lorfyu'il parvint à l'Empire. Il tranfporta fa Cour à Sigga, dans la Province d'Omi. Dans la fixiéme annće de fon régne, il narqua les bornes de fon Empire; mais on ne nous dit point quelles étoient ces bornes Il régna foixante ans.

$\underset{\text { DeI. }}{\text { T. C. XIV. DAIRY。 De Syn-MU- }}$

Ce Prince étoit Neveu du précédent Empereur, \& le fecond Fils d'une de fes focurs, mariće avec Jamatta Daxino Mikotto. Il étoit âgé de quarante-quatre ans, lorfqu'il fuccéda à fon Oncle, après s'être frayé le Chemin au Trône par le meurtre de Kumafi. Ufomu Kuno Mikotto, lequel étoit apparemment le Fils de Sei Muu; mais mon Auteur ne le dit pas. Cet Empereur ne régna que neuf ans," \& mou-

(a) Kompfer fe fert ici du terme de \$onse, qui eft moderne, \& de l'invention des Portugais, aufit bien que celui de Masidaris: 
*ir Sutte Chronorogrede des Derrys; rut âgé de cinquante-deux ans. Il laiffa le Sceptre à fa Veuve.

De J.C. 20\%.

$$
\text { X V. }
$$

DAIRY.

De Syn-Mur

Singurogu ou Din Guuxwo Guo,. Impératrice.

Cetce Princeffe refta feule fur le Trône 2 lâge de trente ans, elle étorit de la Famille Impériale, \& Parente au cinquiéme dégré de l'Empereur Keikoo. Elle fir la Guerre aux Corćens, \& pafla en Perfonne dans leur Pays dès les premiers jours de fon régne. Mon Auteur ne dit point, fi elle y fit des Conquêtes, mais il ajoûte, que s'étant trouvée enceinte, tandis qu'elle étoit occupée à certe Expédition, elle repaffa au Japon, \& accoucha d'un Fils à Tfikufen dans la Province de Mikalfa, où elle faifoit alors fa réfidence. Le jeune Prince fur nommé d'abord Wakono Oof. L'Impératrice fa Mere transfera fouvent fa Cour d'un endroit de la même Province à l'autre. Elle mourut après un régne. glorieux de foixante \& dix ans. On la mir après fa mort au nombre des Déefles, fous le nom de Kaflino Dai Míofn. De fon tems Ia Chine eut beaucoup à fouffrir des tremblements de Terre, des Rébellions, des Pillages, \& autres Calamités $(a)$. Son Fils luc unccéda.

'(a) Le P. Couplet ne parle point de tremblemens de Terre, mais de Guerres civiles, qui avoient com. soencé avant que cette Princeffe ségnat au Japon. 
ou Empereurs Heredit. du Jaten. $x y$

De J. C. XVI. D A I R Y. De Syn-Mu。 270.

OOSIN. TEN OO. 930.

C'eft le nom, que prit le Fils de l'Impératrice Singukogu, en montant fur le 'Tróne. Il avoit alors foixante \& onze ans. Il fur illuftre clans la Paix \& dans la Guerre, \& le véritable Pere de fes Sujets, qu'il gouverna pendant quarante-trois ans avec beaucoup de fagelle $\&$ de douceur. Il mourut ágé de cent treize ans, \& fut honoré après fa mort du titre de Frere de Tenfio Dai Dfin. On lui donna aufi le titre de Jawatta Fatzman, c'eltà-dire, de Mars de Jawatta. Son quatriéme Fils régna après lui..

\section{De J. C. XVII. DAIRY. De Syn-Miso $3 ! 3$. NINTOKU: 973.}

Ce Prince monta fur lé Trône à l'âge de vingt-quatre ans. En la foixante-huitiéme année de fon régne, il nâquit à Fida un Enfant monftrueux, qui avoit deux Vifages, quatre Bras \& quatre Pieds. Nintoku fut un Prince vertueux, chéri de fes Sujets, qu'il déchargea à diverfes reprifes des Impôts. Il vêcut cent onze ans, \& en régna quatrevingt-fept: On lui érigea un Temple à Tfrnokuni, où il fut adoré fous le titre de $\mathrm{Na}$ riwa Takanno Mia: Korefirano Dai Mio Dón. Il lailla le Trône à fon Fils ainé,.

De T. C. XVIII. DAIRY. De
400.
RITSIU. Mut.
1060.

Ce prince commença de tégner à l'âge do- 
xyj Sutte Chronologreve des Dayrys; foixante \& douze ans. Il tint fa Gour à Koos dans la Province de Jamatto. Il régna fix ans. Son Frere lui fuccéda.

$\underset{406 .}{\text { De J. C. XIX. D AI,R Y. De Syn-Nut: }}$

Ce Prince parvint à l'Empire à l'âge de cinquante-cing ans. Il tint fa Cour à Siwagakidans la Province de Kaarwaatz. Il régna huit ans.

De J. C. XX. DAIRY. De Sym-Mlio

Ce Prince étoit Frere des deux précédents Empereurs, \& le dernier des Fils de Nintoku. Il avoit quarante-neuf. ans, lorfqu'il commença de régner. Il établit fa Cour à Aiska, dans la Province de Jamatto. Il fir venir un Médecin de la Chine : il rógna quarante ans, \& eut pour Succelfeur fon $\int_{\infty}$ cond Fils.

De J. C. XXI. DAIRY. De Syr -Mu:
As4.

Ce Prince monta fur le Trône en la cinquante-quatriéme année de fon âge, \& réfida tout le tems de fon régne, qui ne fut que de trois ans, dans la Province de Jamatto. Un de fes Proches nommé Majuwa fe révolta contre lui, \& le tua. Son Frere régna après lui. 
ou Empereurs Heredit. du Jaton. wrij

De J. C. XXII. D AIRY. De Syn-Mu。 $437^{\circ}$

JUU RIAKU.

On ne fçait point quel âge avoit ce Prince, lorfqu'il fuccéda à fon Frere, mais feulement qu'il étoit le cinquiéme Fils d'Inkioo. On afsûre qu'il étoit né avec des Cheveux gris; \& de-là vient peut-être, dit Kompfer, que plufieurs placent fon Avénement à la Couxonne en la foixante-onziéme année de fon âge, ce qui ne peut-être. Il vengea la mort de fon Frere par celle du Meurtrier. La feptiéme annce de fon régne il époufa la Princelfe Wakaki, la déclara Impératrice, \& ordonna par une Loi, qui fubfifte encore, que tous les Enfans des Femmes du Dairy, qui portoient le titre d'Impératrice, fuffent reconnus pour héritiers de la Couronne. Les premiers Putjes . furent frappés au Japon en la neuviéme année de fon régne par un nommé Sinka. On ne nous a pas inftruit de la valeur de cette Monnoye. Juu Riaku régna vingt-trois ans, \& laifla en mourant le Sceptre à fon fecond Fils.

De f. C. XXIII. DAIRY. De Syn-Mu. 480.

$$
\text { SEI NEI. I } 140 \text { 。 }
$$

Ce Prince étoit âgé de trente-fept ans, lorfqu'il parvint à la Couronne: il ne régna que cing ans, \& eut pour Succefleur fon Coufin ilfu de germain, lequel étoit petit-fils de l'Ems. pereur Ritfu. 
aviij SUITE Chronozog. DES DATRYs;

De T. C. XXIV. DAIRY. De Syn-Mus 485.

G EN SOO.

1145.

Ce Prince monta fur le Tróne à l'âge de quarante-fix ans, \& trois ans après il en delcendit pour y placer fon Frere. Il mourut ágé de quatre-vingt-cing ans.

De J. C. XXV. DAIRY. De Syn-Mu。
$488^{\circ}$
NINKEN.

Ce Prince avoit quarante $\&$ un an, lorfque fon Frere lui remir le Sceptre, \& le porta onze 2ns. Son Fils lui fuccéda.

De J. C. XXVI. D AIRY。 De Syn-Mui 499.

BURETZ.

(avis II) 39.

On ne dit point à quel âge cet Empereur parvint à la Couronne, ni combien de tems il vêcut : peut-être n'a-t-on pas voulu tenir compre des années d'un Prince, qui deshonora le Trône d!I Japon par des vicés, qu'on n'y avoit point encore wûs. It fut cruel juf qu'a la Barbarie; il fe faifoit un plaifir féroce de couper la Tête à des Gens, qui ne s'attendoient à rien moins; \& il ouvroit de fes propres mains le ventre des Femmes enceintes. On afsîre qu'en une de ces occafions, le Feu du Ciel tomba fort près de lui, \& que pour fe garantir de pareils accidents, il fit faire un Appartement tout de Fierre. On rapporte encure d'autres exemples de fa crualtcé : il arrachoit aux uns les orgles des Pied's \& des Mains; \& les Hiftoriens du Japon zjoutconi, gुüil en ál faire des Beficles. Aux. 
ov Expereurs Heredit. du Japon. xix autres il tiroit le Poil de toutes les parties du Corps; il en failoit grimper d'autres fur les plus grands Arbres, \& il les obligeoir à defcendre à coups de fléches, ou bien il farfoir fcier l'Arbse, pour avoir le plaifir de les faire romber; \& plus ces Malheureux fouffroient, plus il éclatoit de rire. Le régne de ce Monftre ne fut que d’ huit ans, \& parut bien long.

De J. C. XXVII. DAIRY. De Syn-Mu。
507.
KEI SEI.

Ce Prince étoit Arriere perit-fils de l'Empereur Oofin, par une de fes petites-filles, nommée Fkoarufi. Il étoit âgé de cinquantequatre ans, lorfqu'il monta fur le Trône. Il tint d'abord fa Cour à Tfutfuki dans la Province de Jamatfiiro, d'où il la tranfporta à Foroguani dans la même Province. La douziéme année de fon régne, Darma fameux Prophéte parmi les Indiens, troifieme Fils de Kafiuwo, \& le vingt-huitiéme, qui occupa le Siége de Xaca, arriva à la Chine venant de Scitenfikíu, c'elt-à-dire, de la Contrée Méeridionale Célefte, par où il faut entendre le Continent de l'Inde, qui eft au Midi de la Chine $(a)$.

Kei Sei après un régne glorieux de vingt. fept ans, mourut dans fa quatre-vingt-deu-

(a) Le P. Coup'et ne parle point de Darma; mais il dir que l'Empereur Cocuruys, qui régnoit alors à la Chine, fut furt adonne aux Fables Pythaguriciones des Bonses, que lui méme fe fit Bonze, \& que l'Iinpé. drice du Nord nommee Nu, fit bâtir un Monaftere pout mille Bonzes, lequel avoit mille quatrem vingt pieds de hau:, \& fut nommé lo Maifon do th pass écrublle. 
x SUtte Chronologidue Des DAirys; xićme année: fon Fils aỉné, qui lui fuccéda ; lui accorda les Honneurs divins à Jerfifin, avec le tite d'Askano Dai Mio Sin.

De T. C. XXVIII. DAIRY. De Syn: Mli. 334. AN KAN. II94.

Ce Prince étoit âgé de foixante-neuf ans, lorfqu'il prit le Sceptre : il ćtablit fa Cour en Jamatto, \& mourut après avoir régnć deux ans. Il fut nis au rang des Dieux, \& fur honoré comme Protecteur de la Province de Jamatto, fous le nom de Kimbo Senno Goirgin (a). Son Frere puiné lui fuccéda.

De T. C. XXIX. DAIRY. De Syn-Mu.
336.

Ce Prince commença de régner à l'âge de foixante \& dix ans. Il tranfporta fa Courdans un autre endroit de la Province de Jamatto, qu'on ne noinme point. Il ne régna pas quatre ans entiers, \& fon Frere lui fuccéda.

\section{De Je C. XXX. D A IRY. De Sin-Mus s40. KIN MEI, OU KIMME. I200.}

Cet Empereur étoit dans fa trente-deuxićme année, lorfqu'il monta fur le Trône, \& il tint fa Cour dans la petite Ville de Skinno Kori. Ce fut un Prince religieux : il favorifa beaucoup la Religion des Foës ou da Budfo, qui fe répandit extrêmement fous fon ré-

(a) Tous les Dairys ont été déifiez apres leut mort. On ne marque apparemment ici que ceus, qui onteu un culte plus folemnel. 
ou Empereus Heredit.Ju Japon。 $x x j$ gne. Il bâtit plufieurs Temples aux Foës, done il fit faire à la Chine quantité de Statuè's. Un Hiftorien Japonnois rapporte à ce fujet ce qui fuit.

"Il y a environ mille ans, qu'il y avoit à ¿ Tfiutenfiku, c'eft-à-dire, dans le Ten " ku mitoyen ( par où il faut entendre la 3) prefqu'Ifte d'en deça du Gange) un illuftre "Fotoque nommé Mokarea, Difciple de Xa»ca: vers le mêne tems la Doctrine de "Jambadan Gonno Riorai, c'elt-à-dire, » d'Amida, le grand Dieu \& le Protecteur des Ames féparées des Corfs, s'introduifie $\Rightarrow$ à Fakkufai (a), ou à la Chine (b), d'oủ "elle fe répandit dans les Etats voifins. Elle " pénétra à Tfinokuni (le Japon) \& s’éta"s blit en un endroit nommé Naniwa, oư s l'Idole d'Amida parut à la bonde d'un s Etang, environnée de rayons dorés, fans `que Perfonne fçut, qui l'y avoit apportće. $\Rightarrow$ En mémoire de cet ćvénement miracua leux, l'Empereur inftitua le premier Nens go, \& le nomma Kon Quo. Cetre Staruë " niraculeufe fut conduite dans le Pays de "Sinono parTonda Jofinimitz Prince d'une "valeur hérơique, \& d'une grande pieté, s placée dans le Temple de Singuofi, out, $\Rightarrow$ fous les noms de Singuofi Norai: Norai, so ou Anida de Singuofi, elle opéra une in» finité de Miracles élatants, qui rendirent

(a) Kumpfer entend ici la Chine par Fakkusai, S. dans fon premier Livre, chap. quatriéme, il dit, que Fak़uai eft la partic Septentrionale de la Corée.

(b) Cette Relation ne s'accorde pas avec ce que l'Annalifte a dit pills hat chr tems, où la Doctrino de Xica fut introduite dass le Tapon, 


\section{wrij SUITE Chronorocreue Des DArRTs,}

3) ce Temple fameux dans tout l'Empire.

L'Empereur Kiname régna trente-deux ans, \& lailfa en mourant le Sceptre à fon fecond Fils.

De J. C, XXXI. D AIRY. De Syn flutuo i S72. Fitatzu, ou Fintatz. 12320

On ne f̧̧ait rien de l'âge de ce Prince. La troifiéme année de lon régne, le premier jour du premier mois, Sotoctais, le grand Apôtre du Japon, nâguit à la Cour de l'Enapereur: fa nailfance fut précédée \& accorizpagnée de circonftances remarquables. Sa Mere, avant que d'étre enceinte de lui, le vit en fange environné de Dragons, qui brilloient comme le Soleil, \& une voix lui adreffa ces Paroles: Moi, le Saint Gufobofatz renaitrai encore pour enfeigner le Monde, E a cet effet, je defcendrai dans ton Jein. A l'inftant elle fe réveilla, \& fe trouva enceinte. Huit mois après elle entendit diltinctement fon Fruit parler dans fon feir $(a)$, \& accoucha le douziéme mois fans peine, \& même avec plaifir d'un Fils, qui fut nommé Fattifino, \& après fa mort Tais, ou Sotoctais. Ce miraculeux Enfant ne tarda pas à donner des fignes d'une grande piété : les Exercices de Religion faifoient toutes fes dé-

(a) Il eft hon d'obferver, que dans le même fiécle des Miffonnaires Neftoriens de Syric, \& felon quelques-uns, des Arméniens pénétrerent dans les Contrées les plus feptentrionales de l'A fie. Les Japonnois peuvent bien avoir appris alors quelque chofe de nos Mylterespar les Lamas de Tartarie, gui avosent connu ces Prédicateus. 
ov Empereurs Heredit. du Jaror. $x x i j$ lices, \& dès fes plus tendres années il fut fort adonné à la priere. Il n'avoit que quatre ans, lorfque, tandis qu'il prioit, les os \& les reliques du grand Xaca parvinrent d'une maniere miraculeufe entre fes mains. Depuis ce tems-là, le culte de ce Dieu s'accrût extraordinairement dans le Japon, \& il y arriva des Pays Etrangers d'outre-mer un trèsgrand nombre d'Idoles, de Statuaires $\&$ de Prêtres.

I.a fixiéme annce de Fitatzu, ce Prince publia un Edit portant qu'en fix différents jours de chaque mois, toutes les Créatures vivantes feroient mifes en liberté, \& que ceux de fes Sujets; qui n'auroient point de telles críatures, en acheteroient, pour s'accuitter de ce devoir, \& avoir occafion de donner ces joursIà des preuves publiques de leur inclination bienfaifante.

La huitiéme année, la premiere Image de Xiaca fut apportée au Japon, \& placée à Nara dans le Temple de Kobufi, nì elle occupe encore la premiere place, \& où on la conferve avec des marques d'une vénération .extraordinaire.

La quatorziéme année, un certain Moria ennemi déclaré de Soroctais, excita de grands rroubles de Religion dans l'Empire. Il portoir une haine mortelle aux Fotoques, qu'il arrachoit des Temples, \& qu'il jertoit au feu, par-tout où il les pouvoit trouver: mais au hout de deux ans il fut mis à mort par fes Ennemis. On ajoûte que cet Homme ayant jetté dans un Lac les Cendres des Idoles, qu'il avoit brûlćes, il s'éleva tout-à-coup une tempête épouvantable, accompagnée de ton- 
wiv Sutte Chronorog. Des Datrys; nerres, d'éclairs \& de pluyes. Fitatzu régna quatorze ans, \& eur pour Succelieur fon qua: triéme Fils.

$$
\begin{gathered}
\text { De J. c. XXXII. DAIRY. De syn.Mu. } \\
\text { j86. Joo MEI }
\end{gathered}
$$

On ne f̧̧ait rien de l'âge de ce Monarque. Ce fut fous fon régne, que Moria fut défait \& tué; \& on bâtit en Mémoire de cet événement le Temple de Sakatatina, dans la petite Province de Tamathukuri. Joo Mei ne régna que deux ans, fon Frere lui fuccéda.

$$
\begin{gathered}
\text { De J. C. XXXIII. DAIRY. De } \\
\text { j88. } \\
\text { SyIU }
\end{gathered}
$$

On ne fçait rien non plus de l'âge de cet Empereur.

\section{Seconde Divifion du Japon on Sept grandes Contrées.}

Le feptiéme mois de la troifiéne année de ce régne, l'Empire du Japon fut divilé en fept grands Territoires ou contrćes, appellces Goki Sitzi Do. Cette divifion fubfifte encore, $\&$ on eft obligé de la marquer dans les Car.. tes, qui fe gravent dans le Pays. Sia Sian mourut après cinq ans de régne.

$$
\begin{aligned}
& \text { De J. C. XXXIV. DAIRY. De Sin-Mue } \\
& \text { - j93. SUIK o ou SIKO. } \quad 3: 53 \\
& \text { Impératrice. }
\end{aligned}
$$

Cette Princeffe étoit la feconde fille de l'Fm- 
OU EMPEREURS HEREDIT. DU JAPON. XXV pereur Kimme, \& veuve de l'Empereur Fin. cacz. On ne dic point à quel âge elie fut déclarée Impératrice. La cinquiéme année de Con régne, lin Prince Erranger vint de Fak. kufai a la Cour du Japon, dans la leule vûe d'alsûrer Sotoctais de les refrects.

La fixiéme année, on snvoya d'outre-mer une Corneille \& un Paon, dont on frailoit préfent à l'Impératrice; ces deux Oifeaux étoient alors inconnus ant Japon, ou ils lè font fort multiplićs depuis ce temps-la; ce qui prouve qu'il y avoit un couple des chacun. Les Corneilles fur-tout lont en fi grand nombre dans ces Illes, quelles y caufent beaucoup de dégât.

La feptióme annce il y eut dans toutres les Provinces des tremblements de Terre terribles; un tris - grands nombre d'Edifices furent renverfez, \& plufeurs engloutis. L'annúe fuivante il tomba des feux du Ciel, \& ils furent fuivis de pluyes, qui cauferent de grandes inondations; plufieurs Villes furent fubmergées toutes entieres. La dixićme annće, on apporta de Fakkufai au Japon un Livre de Religion intituk Rckkutolo." La douzićme annce l'Impératrice fit jetter en fonte une Statuë de Bronze de Kaca, done on fabriqua enfuite de la Monnoye, \& à laquelle on fubritua une Statuc de Plâtre, ou d'une elpéce de Stuc. La même année 012 vit pour h premiere fois de lor au Japon, \& il y fur apporté de Corée. La vingr-mnión me année on dit que Darma apparut à $S_{--}$ toctais dans la Province de Jamatro, fur ia Montagne de Kattajoka, \& qu'ils fe parleren. en Vers. La vingrthuiriéme année, le vingtom Tome I. 
axvj Sutte Chronologigue des Dairys. deuxiéme jour du fecond mois, Sotoctais mourut âgé de quarante-deux ans. La trenre-cinguićme annće un eflain de Mouches d'une figure étrange fe répandit dans le Pays avec un bruit extraordinaire, \& y caufa de grands dommages. Suiko mourut aprìs un 'ígne de trente-fix ans.

$$
\begin{array}{cc}
\text { De J. c. XXXV. DAIRY. De Syn-M11. } \\
\text { 629. } \\
\text { DSIOME. } \\
12 \delta 9_{0}
\end{array}
$$

Le Succeffeur de cette Princeffe étoit pesit-fils de l'Empereur Iintatz; on ne f̧̧ait rien de fon âge; il fit toujours fa réfidence en Jamatto. La troificme annće de fon régne, le premier jour du prenier mois, nâquit au Japon le fameux Gienno Gión, Fondateur des Hermites, nommés ammabus ou Jammabos, dont nous arons parlé au Livre Préliminaire. La même année il parut une Comete. La douziéme on apperçut une Etoile dans la Lune. Dfrome réngna douze ans; l'Impératrice la Femme lui fuccéda.

$$
\begin{gathered}
\text { De J. c. XXXYI. DAIRY. De Syn-MH. } \\
\text { Gi2. } \\
\text { KW O GOKU. } \\
\text { Impératrice. }
\end{gathered}
$$

Cette Princeffe étoit fille adoptive de l'Empereur Fintatz; on ne f̧̧ait rien de fon âge. La feconde annce de fon régne, on remar qua cing couleurs différentes dans les nuès; \& la même année pendant le quatriéme mois, il comba une grande quantité de Gréle. Ce régne ne fut que de trois ans. 
- Eupereurs Heredit. do Jaton. xxuij

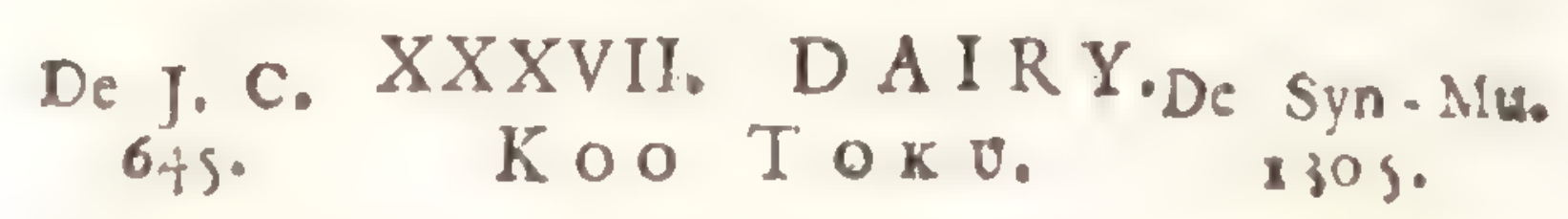

On ne Tçait rien non plus de l'âge de ce Prince, qui étoit le frere puiné de l'Impéra trice Kwogoku. Il transfera fon Miaco, c'eftà-dire, fa Cour à Nagora Tojofaki. Il fut le premier, qui honora les Miniltres \& autres: Officiers de titres \& de marques de diftinction, chacun felon les différents poftes, qu'il. occupoit. Il régla auffi les Honneurs, qu'or ren troit aux Perfonnes en place, qui n'éroient point de fa Cour, c'ent-à-dire, qui n'étoient point de la Tribu Impériale. Juíqu'à ce Prince, les années ne furent comptćes que par I'Epoque Nin O, ou du résne de Syn-Mu. A la vérité, l'Empereur Kinme infitua un Nengo, mais il n'eut point de tuite. Koo Toku en établit lufage, qui n'a point été interrompu depuis. Nous avons expliqué dans le Livre Préliminaire, ce que c'eft que cette Epoque périodique. Le premicr Nengo de Koo Toku fur nommé lakut Sii, \& commença avec la fixiéme année du régne de cet Empereur. Il dura vingt-deux ans. Koo Toku n'en régna que dix.

$$
\begin{aligned}
& \text { De J. C. XXXVIII. D AIRY.De SYI - Mu. } \\
& \text { 635. SIM E. } \quad \text { Simpératrice. }
\end{aligned}
$$

Cette Princeffe, qui ne fut point marice. étoir fille de l'Impératrice Kwo Goku, \& fuccéda à fon Oncle; on ne fçait rien de fon âge. Elle établit fa Cour à Fonga dans la Province de Jamatto, d'où elle la transfe.a

$$
b_{i j}
$$


sxiij SUITE CHRonologrque DEs DAIRYS; la derniere annce de fon régne à ACakura. Elle régna lept ans.

$$
\begin{gathered}
\text { De T. C. XXXIX.DAIRY. DE Swn-Nü } \\
662 . \\
\text { TENTSII. }
\end{gathered}
$$

Ce Prince ćtoit Fils de l'Empereur Dfome \& de l'Itoku, c'eft-à-dire, du Neveu de l'Impératrice Kwo Goku; on ne dit rien de fon áge. La quatriéme année de fon régne, qui flit de dix ans, ent remarquable par l'érection du fameux Temple See Crianfi, \& de ia principale Idole; Ouvrage du famclix Statarire Cafliga, que fon habileté extraordinaire dans fa Profelion fit canonifer après fa More. La fixiéme année, l'Empereur fixa fa Cour á Siga dans la province d'Ootz. Dans In dixicme annće, on montra dans la Province de Tikugo un Cerf, qui avoit huit jambes. Ie Succeficur de Tent-Sil fut fon Frere puinć.

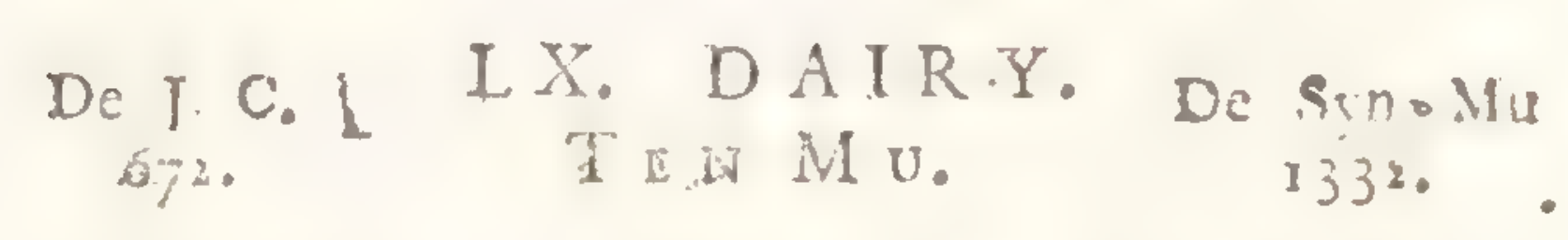

Ce ne fut pas fans peine, aue ce Prince safiermit fur le Trône; fon jeune Frere Oto Mo No Oofi le lui difputa les Armes a la Main, mais il fut défait au bout de cing mois, \& fe fendit le Ventre de défelor L'Enpercur en mémoire de fa Victoire infirua le Nengo Fa Kwo, qui dura qua:orze ans, \& fut fuivi d'un autre, nommé SinWu. Le fameux Temple Midera fut búti la curare annce de ce régne, gui fur escore 
oU EMPEREURS HEREDIT. DU JAPON. xxix célébre par l'arrivée du Livre facré Iilur Kio; c'elt une efpéce de Formulaire de prieres, qui fut apporté de la Chine au Japon. Lannće luivante on y apporta de l'Argent de Tfuffina, ou l'on avoit commencé de travailler aux Mines. La quatriéme année, le qurtrićme jour du quatrićme mois, le premier Matfuri fut célébré a Nara. Nous avons dit dans le Livre I'rćliminaire, ce que c'eft que le Matfuri. Au fepriéme mois de la fixiéme année, il tomba de la Grêle autli grolle que des Pêches. La huitićme année, on vit des Pêches mûres dans le premier mois a Ikodamura. La même année, le troifiéme jour de l'onziéme mois, les Nuages parurent lumineux du côté de l'Orient, on eût dit que le Ciel étoir enflâmé en cet endroit. La neuviéne année, l'ulage de la Monnoye d'Argent fut défendu, \& on frappa à la place des Semis de Bronze, que les Etrangers appellent Putjes.

\section{Troifieme divifion du Japon en Joixante- Jix Provinces.}

Vers ce même tems l'Emprire du Japon, fur divifé en foixante-fix Provinces, andue!

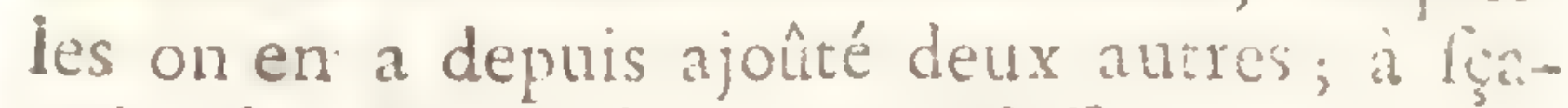
voir, les Inles d'lki \& de Tfufima, qui faifoient partie du Royaume de Corée, \& qui ont ćté conquiles a la fin du feiziéme fiécle de l'Ere Chrétienne par Tayco-Sama.

La treizićme annće, le quatorzićme jour du dixiéme mois du régne de Ten-Mu, il y eur au Japon un violent tremblement de Terre. L'annće fuivante, l'Empereur infitua un nouveau Nengo fous le nom de Sui Wa, lejuch 
xxx SUITE Chronalogroue DES DAIRYs, ne dura qu'un an. La même année, le neuviéme jour du neuviéme mois, l'Empereur mourut, \& fa mort donna lieu à de grands mouvement caufez par la prérention d'Ootzno Ofi. On ne fçait rien de l'âge de TenMu.

$$
\begin{gathered}
\text { De J. C. } \\
687^{\circ} \\
\begin{array}{c}
\text { XLI. DAIRY. De Syn-Mu. } \\
\text { Impératrice. }
\end{array}
\end{gathered}
$$

Certe Princelfe étoit veuve \& Niéce de fon Trédéceffeur; on n'a point marqué fon âge, elle fixa fa réfidence a Fufiwara, dans la Province de Jamatto. La fixićme année de fon xígne, qui fut de dix ans, on commença à bralfer du Sakki, ou de la Bierre de Ris à Jekifinokufi, dans la Province d'Omi.

$$
\begin{array}{cc}
\text { De J. C. XLII. DAIRY. De } S y n-M u_{2} \\
\text { 697. } \\
\text { MONMU. }
\end{array}
$$

Ce Prince étoit Petit-Tils de l'Empereur Ten$\mathrm{Mu}$; on ne dit rien de fon âge. Il conmença fon rógne par linftitution d'un Nengo, qu'il romma Gen, \& qui dura quatre ans. Il en inftitua cnluite un autre, qui fut appellé Tem Po, \& trois ans après un troifiene de quatre ans. fous le nom de Kee Wuum, mais on fit peu d'ufage de ces deux derniers. Mon Mu fut le premier, qui accorda des Típs, ou Armoiries à chaque Province, ce qui arriva la huitićme annce de Con régne. Lannée fuivante il fit faire une mefure quarrée de bois, que les Japonnois appellent Sec \&

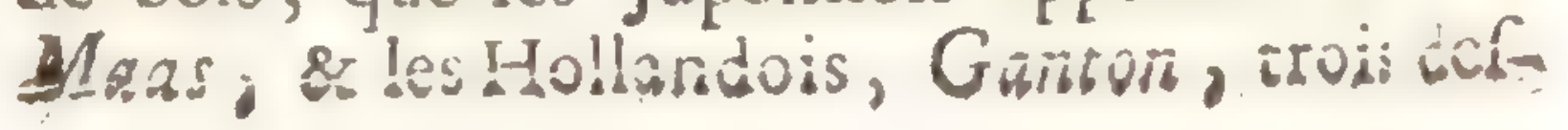


OU EMPEREURS HEREDIT, DU JAFON. $x x x j$ quelles contiennent jutte quatre livres de Ris, poids de Hollande; \& il l'envoya dans toutes les Provinces de fon Empire, pour y fervir d'Etalon, ordonnant fous des peines très-rigoureules de s'y conformer pour les mefures de Ris, de Froment, \& autres Grains. Ce Prince régna onze ans.

De J. C. XLIII. DAIRY. DE Syn-Mu: Impératrice.

Cette Princeffe, dont on n'a point marqué lâge, étoit fille de l'Empereur Tent Sii; elle établit fa Cour à Nara. Elle inftitua d'abord un Nengo fous le titre de Wat To, lequel dura fept ans, c'eft-à-dire, tour le tems qu'elle régna. La premiere année, elle fit frapper de la Monnoye d'Or \& d'Argent; mais lit derniere fut défenduë de nouveau l'année fuivante. La même année fư márquée par la naiffance d'A benoxamer, Prince du Sang Impérial, fameux dans l'Hiftoire du Japon. La troifiéme année, on ćleva le Tcmple Koobokufi, ou il y a une Idole de Xaca, furncé d'un mélange de Bronze \& d'Or, Ourane du célébre Statuaire Taifoquan. La fixiéme année, l'Impératrice donna des noms aux Provinces, Villes \& Villages de Con Empire, \& elle voulut quils fultent margués dans les Regiftres publics $(a)$.

(a) On fera peut - etre furpris dans la fuite de cette Hiltuire de retrouver tres.peu de noms de Provintees \& de Villes; dont il eft purlé dans cette fuite Chironologi . que; mais it fiut fe forluenir de ce que nous avous dit ailleurs des changenens fréquens, qui fe forat dans ies noms propres, \& de leur muitiplicité. 
\#x̃ij SUITE CHRONOZOG. DES DAIR:YS,

$$
\begin{gathered}
\text { De T.C. XLIV. I) AIRY. De Syyn Mu: } \\
\text { 79. GEN s Ioo, } \\
\text { Imperatrice. }
\end{gathered}
$$

Cette Princefle étoit Petite-Fille de l'Empereur Ten Mu; clle inflitua les Nengoss Reiki de deux ans, \& Joovo de fept ans; ffon régne eft fameux par l'Apparition miraculeufe des Dieux Khumano , Gongin, Amidar, Jakuni, Senfiu, Quanwon, \& Billamonten, qui fe montrerent en diférens endrolits de l'Empire. La cincuićme annce, clle fit quelques Réglemens concermant les Habits des Fenmmes. Après qu'elle eur régné neuf: ans, elle remit la Couronne à fon Never, fils de fon Frere. Elle vécut cing ans après lón abdication, \& mourut dans fa quarante-turtićs:ze année; ainfi elle n'avoit que quatorze ans, Inrfqu'elle monta fur le I róne, le neuvićme mois de l'année I $375^{\circ}$ de Syn-Mu, fur quoi il eft bon d'obferver que l'année connuencée $\dot{a}$ la mort dun Empereur, fe compte roure entiere parmi celles de fon régine, $\&$ n'ent point comptée parmi celles du régne de fon Succellieur.

$$
\begin{aligned}
& \text { De J. C. XIV. DAIRY. De syn-Mu. } \\
& \text { 72.4. SIOOMU. } 1384 .
\end{aligned}
$$

Ce Prince fixa d'abord fa Cour à Nora, d'où quatre ans après il la transféra à NANIW A La premiere année de fon régne, il infturua le Nengo Fenki, qui dura cinq ans, \& fut fuivi du Nengo Tenpe, qui en dura vingt. La huitićme annće, la Mer partrt rouge censnue du lang fur les Cútos de Kij, ce qui dura 


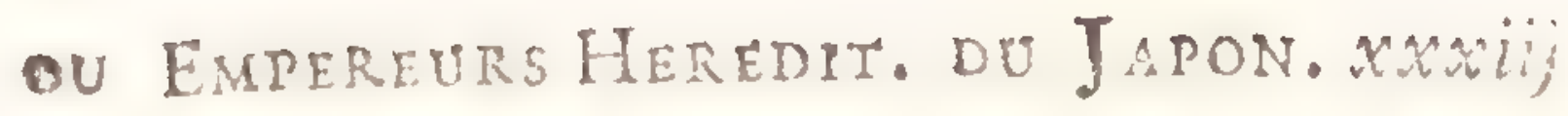
cing jours de fuite. L'année Givance, il y ent des tempêtes épouvantables, une föcherelle \& une ftérilité gćnérale, ce qui caula une grrande famine. La treiziéme annće, on batit les premiers Monafteres de Filles. La vingtiéne annce, on éleva le grand Temple de DAiBods. Sioomu régna vingr-ciny ans, \& fa Fille lui fuccéda. On ne parle point de lon âge.
De J.C. XLVI. DAIRY. De'syn-Ma: $7+9 . \quad$ KOOKEN. I 409. Impératrice.

Cetre Princelle monta fur le Trône de fon Pere le fecond jour du feptiéme mois de lannée 1409 . de Syn-Mu. On ne dit rien de fon âge, \& on ne nous apprend point fi elle fut mariće. Avec fon régne commença le Nengo Tempe Seofo, ou Foofi, qui dura huit ans, \& fut fuivi d'un autre appellé Tempo Singo, La premiere année, on tira pour la premere fois de l'Or de la Province d'Ofio, \& il fur préfenté à l'Impératrice : jufqu'alors les Japonnois avoient tiré ce Métal de la Chine (a). La quatriéme année, l'Impératrice bâtit le Temple Too Daif pour fatisfaire à un voeu de l'Enpereur fon Pere. Tandis qu'on étoic occupé à confacrer cer Edifice, un Giogii implora l'affinance de Barramoas, Dieu cćlébre dans cetre partie de l'Inde, qui eft au Midi du Japon, \& cette Divinité lui apparut à l'inftant. L'Impératrice bâtit auffi If́a Jamma, \& mourut, après avoir régré dixàns.

(a) Ceci ne s'accordz pas avec ce qui a été dit plus haut, que fuus le régne de l'impératrice Sulko XXXIV. Jairy, le premier or gqui fut apporté a Japou, venoit de Coree. 
xumis SuIte Chronozog. Des DAIRTs;

$D=\underset{7599^{\circ}}{\text { XIVII. DAIRY. De syn-M. }}$

Ce Prince étoit arriere Petit-Fils de l'Empezeur Ten-Mu, \& le feptiéme Fils de Tonneri Sin O. La troifiéme année de fon régne, il alla tenir fa Cour à Fora, dans la Province d'Omi, l'annće fuivante à Tairanokio, \& la fixiéme, a Fairo dans la Province d'Awadfi. Il régra fix ans. On ne parle point de fon âge.

De T.C. XLVIII. D A.IRY. De Srn-Muni 760 .

SEO TOKU, Impératrice.

Cette Princeffe étoit Fille aînée de limpératrice Kooken. Avec fon régne commença un nouveau Nengo, qui fut nommć sinkoke Un, lequel dura deux ans, \& fur fuivi d'un autre appellé Fooke, qui fut de trois. Sous ce régne nâquit Kiamar, qui devnt un parfait Kuge. On appelle ainfi tous ceux de Ia Cour du Dairy, qui excellent en quelyue chofe. Seo Toku régna cinq ans. On ze dic point combien il vêcut.

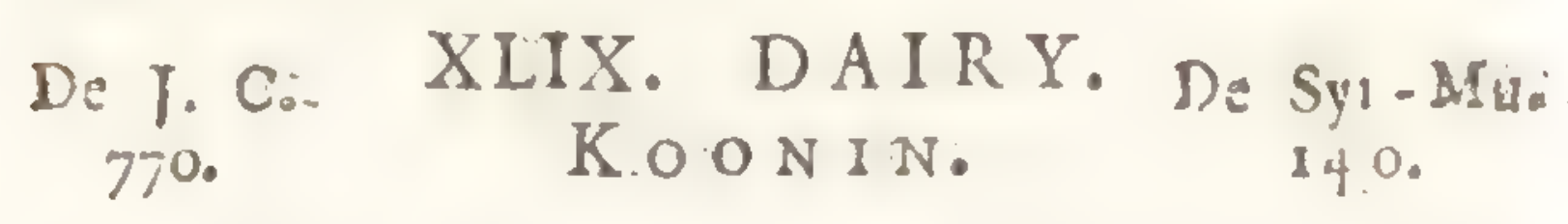

Ce Prince étoit Petit-Fils de l'EmpereurTent sii. On ne parle point de fon âge. En noninut lur le Trone, il inftitua le Nengo Foo$k i$, gui fut d'onze ans. La fcconde anne de

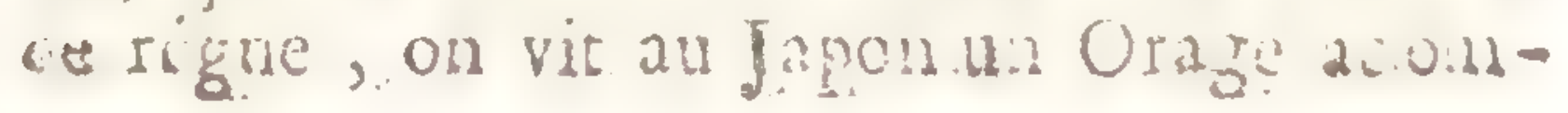


EMPEREURS HEREDT. DU JAPON.XXxu pagné de Tonnerres \& d'Eclairs, qui palla tout ce qu'on avoit jamais vû : il tomba du Ciel des Feux, qui rellembloient à des Etoiles; \& l'Air retentit d'un bruit épouvantable. L'Empereur ordonna qu'on célébrât dans tout l'Empire des Matfuris, pour appaifer les $\int f_{0}-$ kisis, qu'il croyoit irritez; on appelle ainfi les Efprits malins, qui régnent dans' l'Air \& dans les Campagnes. La cinquiéme année, nâquit Kobotais, Prêtre fameux parmi les $\mathbf{J}_{\hat{i}}=$ ponnois. La huitiéme annće, la Riviere Fuju: Ufingawa tarit entierement: La dixiéme année, Abeno Nakemar fameux dans l'Hiftoire Japonnoife, mourut à la Chine. La mîme année, il y eut à Mćaco un incendie, qui en confuma tous les Temples. L'onziéme année, l'Empereur inftitua le Nengo Nen. Wo, qui ne dura qu'un an. Koonin mourue: après douze ans de regne, \& lailla l'Empire: à fon Fils.

$$
\begin{array}{cc}
\text { De T. C. L. DAIRY. De Syn.Min. } \\
\text { 782. }
\end{array}
$$

Cet Emperenr monta fur le Trône à l'ấge de quarante-fix ans. Il inftitua d'aborci le Nengo Jenriaku, qui dura vingr-guatre ans, c'elt-à-dire, tout ce régne. La troifiéme annéc, il transféra fa Cour à Nágajoka dans la Province de Jamatfiro; \& onze ans après à Fejanfor.

Premiere tentative des Tartares fur le Japon,

Ja fixićme antice, des Etrangers ( $\left.a^{2}\right)$ qui

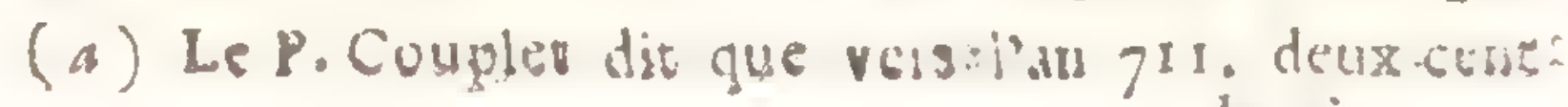




\section{xMmjSUIte CHRonologroue des DAIRYs,} n'ítoient point Chinois, parurent les Armes a la main dans le Japon; dont ils prétendoient fe rendre les Maitres. Les Japronnois le défendirent d'abord avec aflez peu de fuccis, parce que l'Ennemi recevoit fans celle de nouveaux fecours; mais au bout die neuf ans, Tamamar leur Général prir le deflus, \& tua leur Troji, ou Commandant en Chef. Ia Guerre dura néanmoins encore neuf ans, mais enfin ces Barbares furent entiérement challés du Japon.

Kwan Mu régna vingt-quatre ans, \& laiffa l'Empire à fon Fils ainé.

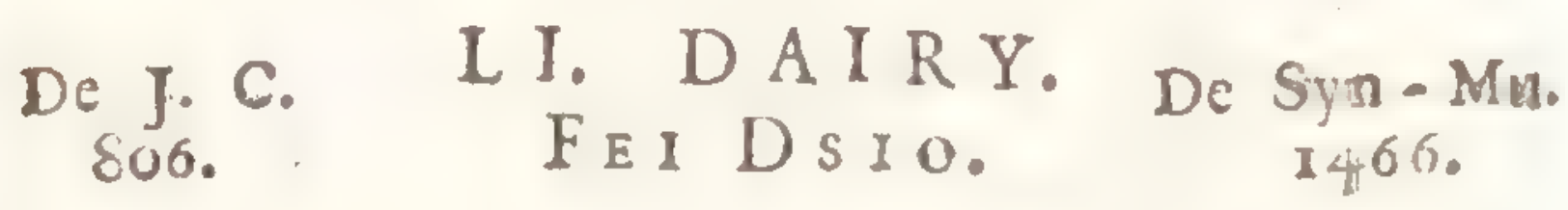

Le régne de ce Prince n'a rien de recommandable; il inftitua le Nengo Taito, lequel aura tout le tems qu'il fut fur le Trône, c'eft-à-dire, quatre ans. On ne dit point combien vêcut cet Empereur, qui lailla en nou. rant l'Empire à Con Frere.

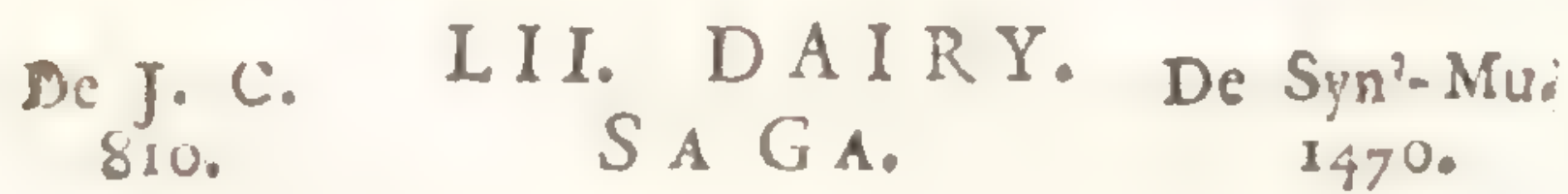

Ce Prince fignala fon Avénement à la Cousronne par l'inftitution du Nengo Koo Nin, qui dura autant que fon régne, c'eft-à-dire, quatorze ans. On bâtit dans cet intervalle plufieurs Temples magnifigues pour les deux Rejiğions. On ne f̧̧ait point combien vêcut cet

mille Tattares frent une irruption dans la partie fepter. srionale de la Chine, \& quapès s'être enrichis for ua grand butin, ils fe retirerent chozeusa 
OU EMPEREURS HEREDIT. DU JAPON.XXYVi: Empcrenr, quilaifla l'Empire à fon fere.

Fe J. c. LIII. DAIRY. De Syn-Mis.

Cet Empereur étoit Frere des deux précédents, \& le troifiéme Fils de Kvvam Mu. A fon Avénement à la Couronne, il inftitua un nouveau Nengo, \& le nomma Ten Tifio. Il dura dix ans. La feconde année, Urafima revint de Foreifan au Japon âgé de trois cents quarante-huit ans: il avoit vêcu pendant tout ce tems-là fous l'Eau avec les Dieux aquatiques, où les Japonnois prétendent que les Hommes ne vieilliflent point. Siun Wa mourut après dix ans de régne: on ne dit point à quel âge il lailla le Sceptre à fon Neveu. $\begin{array}{ccc}\text { De J. C. LIV. DAIRY. De syn-Mu. } \\ \text { 834. } & \text { NIN MIO. } & \text { 1494. }\end{array}$

Ce Prince étoit le fecond Fils de l'Empereur Sa Ga. Il inftitua deux Nengos. Sioa, qui dura quatorze ans, \& Kalloo, qui fut de trois. Ce régne fut de dix-fept ans. On. ne dit point à quel âge mourut l'Empereur, qui lailla le Trône à fon Fils aîné.

De T. C. 'LV. DAIRY. De Syn-Muz 85i. Montoku ou Bontokv. isi.

Ce Prince commença fon régne par l'iufitution du Nengo Nin Fin, qui dura trois ans, \& fut fuivi de deux autres; Sai Je, de trois ans, \& Tan Jan de deux. La quatriéme annće, il y eut au Japon de grands tremblements de Terre, dont l'un, qui arriva le cin- 


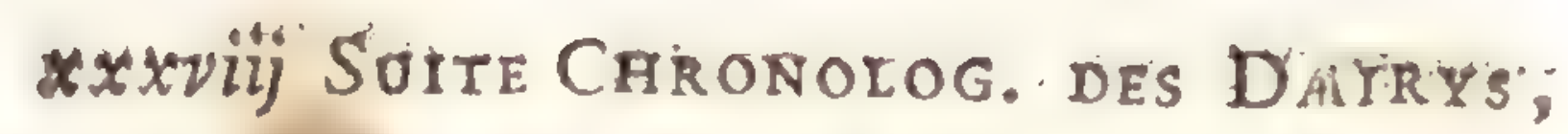
quiéme pur du cinquiéme mois, fit tomber la Tête du grand Daibods $(a)$, ou Idole de Xaca, dans fon Temple à Méaco. Montoku régna huit ans, \& fon quarriéme Filis lui fuccéda. On ne f̧̧ait rien du tems qu'il vêcut.

$$
\begin{aligned}
& \text { De J. C. LVI. DAIRY. De Syn-Mus } \\
& \text { 859. SSE W AO NS }
\end{aligned}
$$

L'Avénement de ce Prince à la Couronne fut marqué par l'inftitution du Nengo To Quam, qui dura dix-huit ans. La cinquiéme année, les Livres de Confucius furent apportés à la Cour du Japon, \& lus avec beaucoup de plaifir. La cinquiéme année nâquit dans la Province de Jamatto Isje Fille de Tfike Kugu Prince du'Sang. Cette Princelfe s'elt rendué célćbre par fon f̧çavoir extraurdinaire. Elle a compolic un Ouvrage, qui eft encore aujourd'hui très-eftimé dans le Japon: Sei Wa, après dix-huit ans de régne, abdiqua l'Empire en faveur de fon Fils ainé, \& mousut quatre ans après, le huitióme jour du cinquiéme mois. On ne fa̧ait rien de-fon. âge.

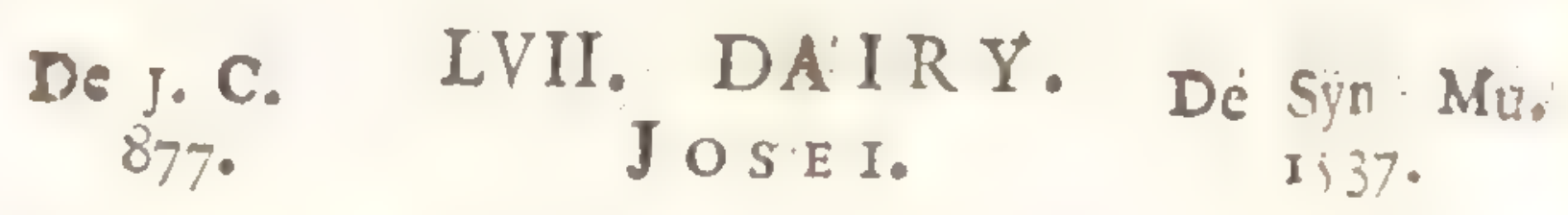

Ce Prince commença fon rćgne par linftiturion du Nengo Geni Wa, qui dura huit ans, c'eft-à-dire, tout le tems çu'il fur: fur le

(a) Kurmpfer dit ailleurs que le DAIBODs éroit à Nara, mais il fe pourroit bien firre que le it a de

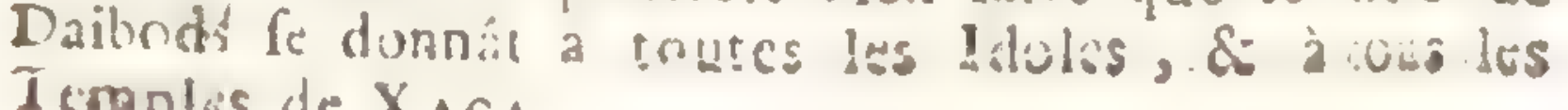
I cmplos de Xaca. 


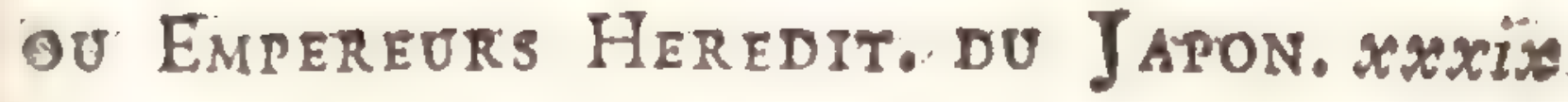
Trône. On ne fçait rien de l'âge de cet Empereur.

$$
\underset{885_{0}}{\text { De J. C. LVIII. DAIRY. De Syn-Mav }}
$$

Ce Prince étoir Fils puîné de l'Empereur Nin Mio, \& Frere de Montoku: La premiere annće de fon regne, le feptiéme mois il plut du fable \& des pierres, qui gâterent prefque toute la récolte de Ris. A fon Avénement à la Couronne, il avoit inftitué le Nengo Nin. Wa, qui dura quatre ans. Kooko n'en régna: gue trois, \& lailla en mourant le Sceptre à: Con troifiéme Fils. On ne dit rien de fon âge.

$$
\begin{array}{ccc}
\text { De Y. C: } & \text { LIX. DAIRY: } \\
8 \& 8 . & \text { UDA. } & \text { Dyn.Mu. } \\
\text { I } \$ 48 .
\end{array}
$$

La feconde année de ce régne, eftmarquée par l'inftitution du Nengo Quan l'e, qui dura neuf ans. La même annće, il y eut de grandes pluyes pendant tout l'Eté, \& elles cauferent de grandes inondations, dont la récolte de Ris fut fort endommagée. Uda? régna dix ans, on ne dit point à quel âge il mourut, fon Fils ainé lui fuccéda.

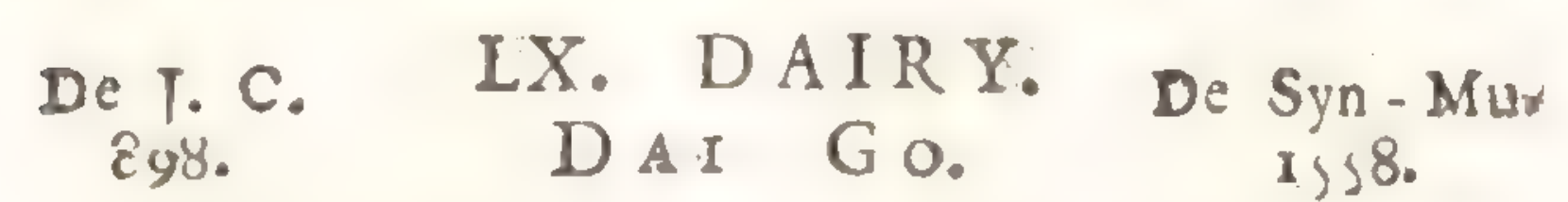

Ce Prince dont on n'a point marqué l'âge; commença fon régne par l'inltitution du Nengo Soo Tai, qui dura trois ans, \& qui fur tuivi d'un autre appellé Jen Gi, qui en dura vingt-deux. La promierc anníe, le troifiéna. 
$x$ Sutte Chronologioue des Dairys, jour du fixićme mois, l'Air s'obfcurcit tout it colip, cie forte quion ne le royoit pas. Le I'. Couplet marque des Eclipfes du Seleil à la Chine vers le même tems. La feconde annce mourut Somme Donno, qui avoit été déclarće Kifleki, c'eft-à-dire, Dame Souveraine: c'eft le titre, quion donne à celle des Fenmes du Dairy, qui a été nommće Impératrice, \& qui elt Mere de l'Hćricier prélomptif de la Couronne. La feizićme année, le fecond jour du cinquiéme mois, il y sut un incendie à Méaco, où réfidoit actuellement l'Empereur; fix cents dix-fept Maifons furent confumées. La vingt-fixiéme année, on envoya de la Province de Jamatto à la Cour un Liévre, qui avoit huit jambes. Dai Go régna trente-trois ans, \& eut pour Succelleur fon douziéme Enfant.

$$
\begin{gathered}
\text { De J. c. IXI. DA IRY. De Syn-Mu. } \\
\text { 93I. } \\
\text { SIUSAKU. }
\end{gathered}
$$

Ce Prince en montant fur le Trône de fon Pere, inftitua les Nengos Seo Fei, qui dura fept ans, \& Ten Kei, qui dura jufju’à la fin de ce régne. La feconde année, Mallakaddo, Prince du Sang, \& fort acerédité à la Cour, fe révolta contre l'Empereur. Cette Révolte ne fut étouffée qu'au bout de fept ans, par la défaite \& la mort de fon Auteur. La troifiéme année, le vingt-Ceptićme jous du feptiéme mois, il y eut un furieux tremblement de Terre, \& un autre la feptiéme année, le quinziéme jour du quatriéme mois. Le Feu du Ciel réduifit auffi en cendres plufieurs Temples \& Monafteres, fir-ivisi la 


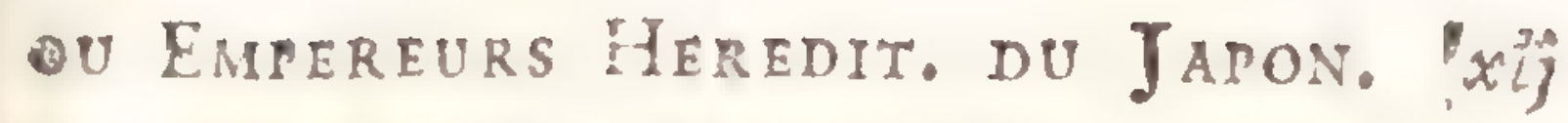
treizićme annce, que les Tonnerres \& les cclairs fe firent fentir dans prefique toute les Provinces. Siufaku régna feize ans. On ne dit rien de fon áge.

$$
\begin{gathered}
\text { De J. C. LXII. DAIRY. De syn. MLo } \\
\text { 947. }
\end{gathered}
$$

Ce Prince étoit le quatorzićme Fils de l'Enpereur Dai Go. Il inftitua d'abord un nouveau Nengo, nommé Ten Riaku, \&e qui duIa dix ans; puis trois autres, Ten Toku de quatre ans, Oo Wa de trois, \& Koo Fu de quatre. La quatorziéme annće de fon régne', il y eut dans la grande Salle de fon Palais, nomnée Seirodeen, une célébre Allemblée fur les Affaires de Religion, où les Chefs de toutes les Sectes fe trouverent, c'eft tout ce qu'on en fçait. Murakami régna vingt \& un ans; on ne dit point à quel âge il mourut; il lailla le Sceptre a lon fecond Fils.

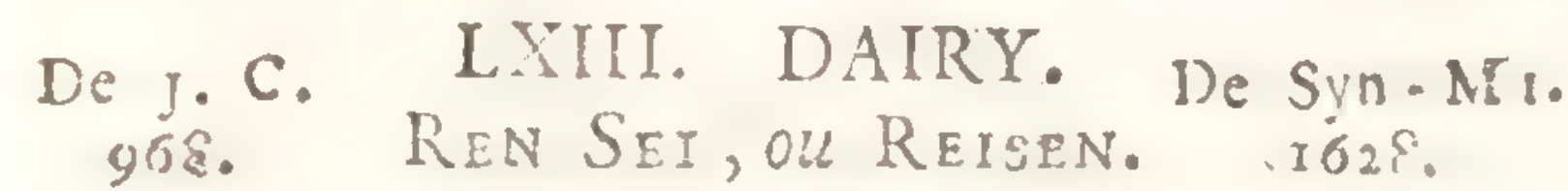

Ce Prince avoit foixante \& un an, lorfqu'il fuccéda à fon Pere, \& il ne régna que deux ans. Il infirua le Nengo An Kwa, qui finit aves fon régne; il cut pour Succelleur fon frere, cinquićme Fils de Murakami.

De J. C. LXIV DAIRY. Da Syn-Mu.
19;0. JENwO, OU JenJo.
1630.

Ce régne commença par l'inftitution du Nengo Ten Rok, Icquel dura trois ans, \& 
xlij Suite Chronolog. des Darrys;

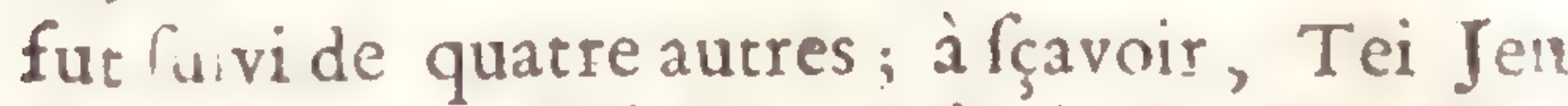
de trois ans, Tei Gnam de deux, Ten Jen de ciny, \& Jei Quan de deux. Jenwo régna quinze ans; on ne dit point combien il vecut.

De I. C. LXV. D AIRY. De Syn-ML ${ }^{3}$ 985. QWASSAN,OUQUASSAN. 1649.

Ce Prince ćtoir Fils an̂né de l'Empereur REN SEI, \& monta fur le Trône dans fa dixfepriéme année. Il inftitua d'abord un nouveau Nengo, qui fut nommé Gen Wâ, \& qui ne dura que deux ans: La feconde année de fon régne, il fut tranfporté d'une fi grande pafion pour la folitude, qu'il fortit fecrettement de fon Palais, \& s'alla enfermer dans le Monaftere de Quamfi, où il fe fit rafer à la maniere des Bonzes, \& prit le nom de N GUGAKE FOOGU; il paffa vingt-deux ans dans cette retraite, \& y mourut âgé de quarante. \& unan.

$$
\begin{gathered}
\text { De Tr. LYYI. DAIRY. De sill-Mu. } \\
\text { 989. }
\end{gathered}
$$

On ne fçait point à quel âge ce Prince fuccéda a Qvvallän, fon Coufin. Il infticua les Nengos Je Jen de deux ans, Jen Gen d'un an, Soorak, de cinq, T fio-Toku de quatre, Tlioo So de cinq, \& Quan Ko de hut. La huitićme année de fon régne, la mortalité fut grande dans tout le Japon; d'ailleurs, ce régne fut célćbre par le nombre de Sçavans, qui fleurifloient à la Cour. Itri Dlio régna vingt-cing ans. 
DU EMPEREUR HEREDT, DU JAPON, xTi

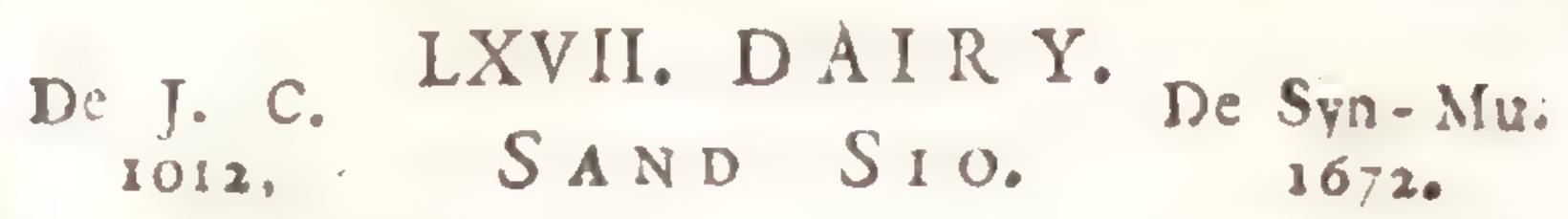

Ce Prince étoit Fils puiné de l'Empereur Ren Sei. Il inftitua en montant fur le Trône le Nengo Dfro A, qui dura cinq ans, c'eft-à-dire; tout fon régne. La troifiéme annće, le palais, où il failoit fa réfidence, fut brûlć. L'année fuivante il en fut encore brûlé me bonne partie. Sand Sio mourut âgé de cinquante \& un an.

$$
\begin{aligned}
& \text { De J.C. LXVIII. DAIRY. De Syn-Mu } \\
& \text { 1017. Go ITsI Dsio. } 1677^{\circ}
\end{aligned}
$$

Go, veut dire, fecond, ainfi Go Itfi Dfio fignifie Itfi Dfro II. Ce Prince étoit Fils pû̂né d'Itfi Dfro I. \& n'avoit que neuf ans, lorfqu'il monta fur le Trône, qu'il occupa 20 ans. Il inftitua d'abord le Nengo Qua Nin, qui dura quatre ans, \& qui fut fuivi de trois autres. Tfi Jan de trois ans, Mans Ju de quatre, \& Troo Quan de neuf. La cinquiéme annce de ce régne, Sai Sin obtint celempereur la permillion de fe faire tramer dans un Khuruma, ou Chariot couvert, \& tiré par deux Bæufs; invention, qui parut fi commode, que toute la Cour fuivit bien-tôt fon exem. ple. La même annće, le vingt-deuxiéme jour du feptiéme mois, il y eut au Japon une furieufe tempcte, qui y caufa de grands dommages. Le móme mois on vit deux Lunes à la Chine $(a)$. La fixiéme annce, le Jeki, ou or la pelte fir de grands ravages dans tcur 
xliy Surte Chronologroue des Dairys; l'Empire. La douziéme annce, le quatriém: mois, qui tépond à notre mois de Juin, it tomba une fi grande quantité de Neige, qu'elle couvric la Terre de quatre $S a C k s$, \& de cinq Suns, c'eft-a-dire, quarre pieds \& demi. Le neuviéme jour du huitićme mois, il y eur encore une furieule tempête.

De J.C. LXIX. DAIRY. De Syn-Mi.
\$03\% GO-SIU SAKU.
$1697^{\circ}$

Ce Prince ćtoir liere cadet de fon prédécelfeur, auquel il fuccéda en la vinge-huitiéme anncé de fon áge. Il inftitua les Nengos Tfio Taku, de quatre ans; \& Quanto Ku, de deux. La premiere année de fon régne, qui fut de neuf ans, il y eut au Japon un furieux tremblement de Terre.

De J.C. LXX. DAIRY. De Syn-ifu.
1046.0 GOREISEN. i jur.

Ce Prince éroir Fils ainé de fon Prédécefreur, \& nonta fur le Trône dans la dirfeptiome année; il incicua les Nengos deilo, de fept ans; Tenki, de cing; Fero, dé fept, \& Thoku, de guatre. La troifime annće de fon régne, Jouri Isje le révolta contre lui dans la Province d'Osju. Les Rébelles fe foutinrent pendant cing ans, jufyúa ce que Jori Jofi, Général de la Courunre, qui commandoit en Chef toutes les Troupes Impúriales, les défit, \& tua leurs plus braves Chefs Abino-Sadato, \& Takano Munto. Catte rébellion eft décrite fort au long dinns un Livre incitulé Osju Gafjen, c'elt-a di:e, les 
ou Empereurs Herents. DU Japon. $x$ t Guerres d'Osju. Go-Reifen mourut âgé de quarante ans, après en avoir régné vingtcrois. Son Frere puiné lui fuccéda.

$$
\begin{aligned}
& \text { De J. C LXXI. DAIRY. De Syn.Mu. } \\
& \text { ro69. Go-SAND SIO. }
\end{aligned}
$$

Ce Prince ne rćgna que quatre ans, \& mourut dans fa quaranticme année. Il inftitua le Nengo Jenkuni, gui fut de cinq ans, \& laifra le Trône à fon Fils aîné.

$$
\text { De T. C. LXXII. DAIRY. De Syn-Mu。 }
$$

On ne firait point l'âge de ce Prince, qui régna quatorze ans. La leconde année de fon xésue il infitia le Nengo Seofo, qui dura trois ans, \& fut fuivi de trois autres; à fçavoir, Seoriaku, de quatre ans, Jeefo, \& Ootoku, chacun de trois ans. La neuviéme année de ce régné, il y eut pendant l'Eté une fécherefle exuŕme, qui ruina prefque tulis les Fruits de la Terre. Sirrakawa lailfa le Trône à fon Fils puiné.

$$
\begin{gathered}
\text { De J. C. LXXIII. IDAIRY. De Syn-Mu, } \\
\text { IU8\% } \\
\text { FORIKAWA. }
\end{gathered}
$$

Ce Prince n'avgit que nenf ans, lorfou'il monta fur le Trône, \& il l'occupa vingt \& uks ans. Il inftitua les Nengos Quanfi, de fept ans; Kolloo, de deux; Jet Sio, d'un an; Sootoku, de deux; Kooa, de cinq; Thoof \& Kafin, chacun de deux. Son Fils ainć lui fuccída. 


\section{alvj Suite Chronologigue des Daikys;}

De J.C. LXXIV. DAIRY. De Syn-Mus 11 8. To B A. 1768.

Ce Prince, dont on n'a point marqué l'âge, inftitua les Nengos Teniri, de deux ans; Tenjei, de trois; Jeikju, de cinq; Guanje, de deur; \& Foan, de quatre; le premier commença, \& le dernier finit avec fon régne, qui fur de feize ans. La preniere année, on entendit dans l'Air un grand bruit, comme de pluieurs I ambours, \& cela dura pluheirs jours. La quatrićme náquit Kijomori, Prince du Sang, que fa rébelion a rendu famelix dans les Hiftoires Japennoifes. To Ba laiila en mourant le Trône a lon Fils ainć.

DE T. C. IXXV. DAIRY. De Syn.Ma.
II24.

On n'a point marqué l'âge de ce Prince; lequel régna dix-hrit ans. Il inltitua les Nengos Tent Si, de fept ans; Tenfio, d'un an; Troofo, de trois; \& Jeerit Si, diun an. Ce fut lous ce regne, que fut bátie la Ville de Kamakura. Sintoku lairira la Couronne à fon Frere.

$$
\begin{gathered}
\text { DE J. c. LXXVI. DAIRY, De syn-M. } \\
\text { II4. }
\end{gathered}
$$

Ce Prince étoit le huitiéme Fils de l'Empereur To Ba. Il inftitua les Nengos Kootfi, de deux ans, Tenjo, d'un an; Kivan, de fix; Nempe, detrois; \& Kijlu, de deux. Jorimalla, Prince du Sang, \& qu'on fourrolt 
ov Empereurs Heredit. do Japon. xlvij nommer l'Hercule Japonnois, vivoit fous ce xegne. Ce Prince avec l'aide de Fatiman, qui eft le Mars du Japon, tua à coup de fléches le Dragon infernal Nuge, qui avoit 12 Tére d'un Singe, la Queuè d'un Serpent, le Corps \& les Griffes d'un Tygre. Ce Monftre fe tenoit dans le Palais du Dairy, \& incommodoit beaucoup, non-feulement la Perfonne du Monarque, mais encore toute fa Cour, fur-tout la nuit, \& l'on ne pouvoit repoter fans crainte.

La fixiéme année de ce régne, le vingtdeuxiéme jour du Ceptiéme mois, il parut une Comete. La dixićme année nâquir à la Cour Joritomo, quile premier fut grand Seogun, ou Général de la Ccuronne (a). Le pouvoir fouverain, \& illimité des Dairys, commençoir des-lors a s'affoiblir. Les Princes de l'Empire dominés par l'ambition, fe relâcherent peu à peu de la foumifion, quilis devoient à leurs Souverains, \& jetterent les premiers Fondementş de ces Royaumes, que l'on a vûs en fir grand nombre dans ces Ifles, en fe rendant peu à peu indépendants dans leurs couvernements. Le mal croillant toujours, le Dairy crut en couper la racine, en revêtant Joritomo de toute l'autorité nécellaire pour metere les Grands à la saifon; mais ce Génćral fe

(a) On affure plus hant que la Charge de Ssugun, cuXogun avoit été crééc par Sicusin X. Dary; peut. etre fut-elle rerablie pat Konjei; peut érre que fes prérogatives furent áugmentées. Le Cuho étvit auls le Général des Armées Japonnoi es; on ne feait pas trop quelle ercil la différencede ces rieux Charges, il pircit feulement que celle-là avuit la préemintnce, mais clles ont éré d puis comme résunits fur la tête des kmporeurs Cubo.Samas. 
arviijSUTE CHRONOROGIQUE DES DAIR TS fervit de fon pouvoir, pour s'ériger lui-même en Souverain, ainfi que nous verrons dans la fuite.

Konjei régna quatorze ans; on ne dit point combien il vêcur. Son Frere ainé, quarrićms Fils de l'Empereur To Ba, fut fon Succelicur.

Ie J. C. LXXVII. DAIRY.de Syn-Mu: IIj6. Go-SIIRAKANA. İ́r.

Ce Prince inficua d'abord le Nengo Foogien, qui dura trois ans. La preniere annće de fon régne, Ssr In (a) fe révolta contrc lui. Cette révolte domna naillance à lane longue \& cruelle Guere, qui par rapport au tems, qu'elle commença, fut appellće Foo Gienno Midairy, c'eft-a-dire, la défolation du tems Foo Gien. La troiféme annće, le huitióme mois, il y eut un grand tremblement de Terre.

Go-Sira Kawa, agris avoir tenu trois ans le Sceptre, le remit à fon Fils ainć. Douze ans après il enrra dans un Monaftere, fe fit

(a) Ce Prince icbelle ne fẹauroit être autre que Kijomori, dent rous avons parlé plus haut, \& qui deroit arvir alors trente-quatre anr. Il fut déf it en 1968. \& fe retira dans le famelix Mloniftere Misara, fur la Montagne de jeCSAN, ou les Bonzes le protegerene contre la Conur, ec contre la ladtion de FEK fui-méme Monze fous le num di Srookar, vécut quarorze and dans cette retraitei, \& mourut dans fa foixartieme Année en 1rSz. d'une fiévre ma'igne Grúlante, qui lui fit devenir le Corps tout ruage; ce qu'on regarila corrme uni punition de fa rérulte, liquelle donna uccafion aux Facison der EEKIs \& des GENDSis, \& fut la principale calolo de l'ufurpation des Cubogatmas.

$$
\text { yeser. }
$$


ov EMPReURs Heredit. DU JAPON. xlix rafer, \& prit le nom de Joollin. Il mourut âgé de quarante-trois ans.

De j. C. LXXVIII. DAIRY. De Syn-Mu.
IIS90
NIDSIOO.

Ce Princè étoit âgé de feize ans, lorfqu'il monta fur le Trône par l'abdication de fon Pere. Il inftitua les Nengos Feitf, d'un an; Jeiraku, d'un an; Oofo, de deux ans; Tfroquan, de deux; \& Jeeman, dun an. La premiere année de fon régne, Nobu Jori, \& Jofitomo, Pere de Joritomo, fe fouleverent contre lui. Cette rébellion \& la Guerre, qu'elle caufa, font décrites daus les Hiftoires, Cous le nom de Feitfi No Midarri, c'eft-à-dire, la défolation du tems Feitf. Deux ans apres, Jo. fitomo fut tuć dans la Province d'Owari, \& Con Fils fut envoyé en exil à Idfu.

La cinquiéme annce, une Fomme accou. cha de trois Enfants, qui avoient chacun deux Têtes, \& quatre Pieds. Nidfioo régna fept ans, \& nourut âgé de vingt-troís ans. Son Fils aîné lui fuccída.

\section{De J. C. IXXIX. D AIRY. De Syn-Mu 1166. ROKU DSI00. 1826.}

Ce Prince étoit dans fa dixiéme année; lorfqu'il monta fur le Trône. Il inftitua le Nengo Nin Jani, qui dura trois ans, c'eft-ìdire, tout le temas de fon régne. Il lailla le Sceptre à fon Oncle.

Trme Il. 


\section{l Suite Chronorog. des Dairys;}

I. C. IXXX. DAIRY. De syn-MU.
IAKAKURA.

Ce Prince ćtoit le troifiéme Fils de l'Enmpercur Go-Siirakawa, \& il époufa la Fille de Kijomori. Il inftitua les Nengos Kavoo, de deux ans; Sioun, de quatre; Angen, de deux ; \& Dfillo, de quatre. La cinquiéme année de fon régne, le vingt-troifiéme jour du premier mois, une grande partie de la Ville Capitale, otil il réfidoit, flit réduite en cendres. La feptićme annće, la petite vérole fit de grands ravages dans tout l'Empire. L'onziéme année, l'Empereur transféra fa Cour à Kuwara.

\section{Empereur Cubo-Sama. Joritomo.}

Ia douziéme année de ce régne, \&la derniere du Nengo Dfiilfo, Joritomo défit tous fes Ennemis dans la Province d'Isju, \& Jorimalfa fut tuć avec toute fa Famille. L'année fuivante, qui fut celle de la mort de Takakura, eft comptée pour l'Epoque du régne des Cubo-Samas.

De J. C. LXXXI. DAIRY. De Syn-Mua
II81.

On ne dit rien de la Naiffance de ce Prince, finon qu'il étoit perit-fils de Kijomori par fa Mere: ce qui peut faire juger, qu'il ćtoit Fils de fon Prédécelfeur, \& par conféguent fort jeune, quand il inunta fur 
ov Empereurs Heredit. du Japon. lj le Trône. Il intitua les Nengos Joowa, d'un an; \& Siu Je, de deux. La premiere année de fon régne, il y eur une grande Famine dans tout l'Empire, caufée en partie par les Guerres civiles. La même année, Kijomori fon Ayeul Marernel mourut dans fon Monaftere (a). Cette même année, le Général Kadfuwara abandonna le parti des Fekis, \& fe joignit à Joritomo, qui fe nommoit alors Tiojenoski. Kadfuvvara étoit de balle extraction, mais par fon courage \& lés actions Héroíques, il devint très-puiffant. La même annce nâquit Jori Je, Fils de Joritomo, \& qui lui fuccéda au Trône des Cubo-Samas. L'Enpereur An Toku fut obligé d'abdiquer la Couronne, après l'avoir portée trois ans.

De J. c. LXXXII. DAIRY. De Syn-Mü
II\&4.
GO-To B A.

Ce Prince étoit le quatrićme Fils de l'Empereur Takaxura. Il inftitua les Nengos Genriaku, d'un an; Buaninz, de cing; \& Kenkiu, de neuf. La premiere annce de fon régne, mourut Joofnaga, Général cćlćbre, \& grand Partifan des Gendzis (b).

La troifićme annce de ce régne, l'Empe-

(a) Voyez la Note fous le regne de Go-Sirno Kaw a LXXVII. Jairy.

(b) Les GENDSis étoient alors fell's dominans: Joritomo leur Chef s'étant emparé du Gouverncment. Ce Parti avoit été long-tems regardte comme le mnins julte, \& le Dairy s'étoit déclaré pourles Lexrs; mais cenx ci ayant uré mal de leur vißtuire, $\boldsymbol{\&}$ ayant voulu fe rendre maitres de l'Empire, le Dairy fe tourna du cóté des Gendzis, qui prévalurent, \& firent ce qu'a. voient roulu faire les $\mathrm{F}$ GK IS, 


\section{עi Suite Chronologive des Datrys;} reur dépolé An Toku, étant pourfuivi pare fes Ennemis, fe noya dans les Mers Orientales. Il avoit pris, en quittant le Sceptre, le nom de Sen Tei; après fa mort, on lui donna celui d'An Tokuten $O$, apparemment dans fon Apothéole. Environ ce même tems mousut Jofinaga, Gendre de Joritomo.

La lixiéme annće de ce régne, Jofitzne autre famelix Général fut tué; fa mort fut fuivie de celle de Fide Fira, fon Lieutenant, \& de l'extirpation de toute fa Famille. L'onziéne année, Joritomo aller faluer l'Enpereur, quil'honora du titre de Sei Sengun. gu'on a toujours donné depuis aux Empereurs Cubo-Samas. La quatorzićme année, on envoya de l'Ifle d'Arvadif à la Cour un Cheral, qui avoit neuf pieds. Go-To Ba régna quinze ans, \& fe démit de la Couronne en friveur de fon Fils ainé. Il mourut âgé de foizante ans.

$$
\begin{aligned}
& \text { De J. 'C. LXXXIII. D A IR Y. De syn-Mu. } \\
& \text { Iny9. Tsetsi MikadDo. ISs9. }
\end{aligned}
$$

Mikaddo eft ici un nom propre, \& non pas le titre fouverain, que portoient tous les E:mpereurs. Ce Irince n'avoit que trois ans, lorfqu'il monta fur le Trône. Il inftitua les Nengos Seotzi, de deux ans; Kennin, de trois; Genkiu, de deux; Ken Je, d'un an; \& Soojen, de quarre.

$$
\begin{gathered}
\text { II. Empereur Cubo-Sama. } \\
\text { Jori Isje. }
\end{gathered}
$$

La premiereannce de ce rúgne, Toritomo pre. 
- Euppereurs Heredit. du Japon. liij mierEmpereur Cubo-Sama mouru apresavoir régne vingt ans. Jori Isje, fon Fils, luifucceda, \& aubout de cinq ans, le Dairy l'honora du titre de Sei Seogun. Il fut tué deux ans après, felon Koempfer, qui cependant ne lui dorne que cinq ans de régne.

\section{Empereur Cubo-Sama. Sonnetonno.}

La fixiéme année du régne de Tfutfi Mikaddo, felon le calcul de Kompfer, Jori Isje Empereur Cubo-Sama fut tué, \& lon Frere puîné lui fuccéda.

Tfutfi Mikaddo après avoir régné douze ans, abdiqua la Couronne en faveur de fon Frere cadet, \& mourut âgé de trente-〔ept ans.

De T. C. LXXXIV. DAIR Y.De Syn-Mu。 1213. SIUNTOKU. 187 1.

On ne dit point à quel âge ce Prince monta fur le Trône, mais feuiement qu'il régna onze ans, qu'il fe demit de la Couronne, \& gu'il mourut âgé de quarante-fix ans. Il ir:ftitua les Nengos Genriaku, de delix ans, Gen Po, de fix ; \& Seokiu, de trois. La quatriéme année de fon régne, mourut FoONEN Sénin, Fondateur de la Secte de Seodosju. La fixiéme année, Somnetonno Empereur $\mathrm{Cu}$ bo-Sama fit conftruire des Vaifleaux de Guerre, pour fe rendre Maitre de la Mer. Le vingt-deuxićme jour du fecond mois die la neuviéme année, les deux magnifiques Temples de Kiomitz \& de Givron, furent brûlez. 


\section{'iv Suite Chronorogreue des Datkys;}

\section{Empereur Cubo-Sama. Joritżne.}

Sonnetonno ayant occupé dix-fept ans le Trône des Cubo Samas, mourut, \& eut pour Succeffeur le Fils du Cambacu Dooka, lequel commença de régner en $122 \mathrm{I}$.

De T. C. LXXXV. DAIRY. De Syn-Mu. 12230 Go-EORIRAW A

Ce Prince étoit petit-fils de l'Empereur Tá kakura. Il inftitua les Nengos Teevvo, de deux ans: Gen In, d'un an; Karoku, de deux; An Te, de deux; Quan Ki, de trois; \& Tee Iei, d'un an. La premiere anncé de fon régne, le premier jour du fecond mois, náquir dans la Province Avva, Nitsitren, fancux Docteur, \& Fondatenr d'une Secte, qu'on ne nomme pas. Go - Forikavva régna onze ans, \& en vêcut vingt-quatre. Son Fils aîné lui fuccéda.

$$
\begin{aligned}
& \text { De J. C. LXXXVI. D AIRY.De Syn-Mu。 } \\
& \text { 1233. SI DSIO. } 1893 \text {. }
\end{aligned}
$$

Ce Prince n'avoit que cing ans, lorfqu'il commença de régner. Il inftitua les Nengos Tempoco, d'un an; Bunriaku, d'un an; Kafliuku, de trois ; Riaknin, d'un an: Jengo, d'un an; \& Nintzi, de trois. Il mourut après dix ans de régne. 
-u Empereurs Heredit. du Japon. ly

\section{Empereur Cubo-Sama. Jori Sane, ou Jorifjuga.}

La neuviéme année de ce méme régne, Joritzne Empereur Cubo-Sama, qui tenvir fa Cour à Kamakıra Seogun, vint à Méaco faluer le Dairy, felon la fuite Chronologique; cependant fuivant le calcul de Kompfer, Jori Sane, ou Joriffuga fon Fils \& fon Succeffeur, avoit commencé de régner en ×239.

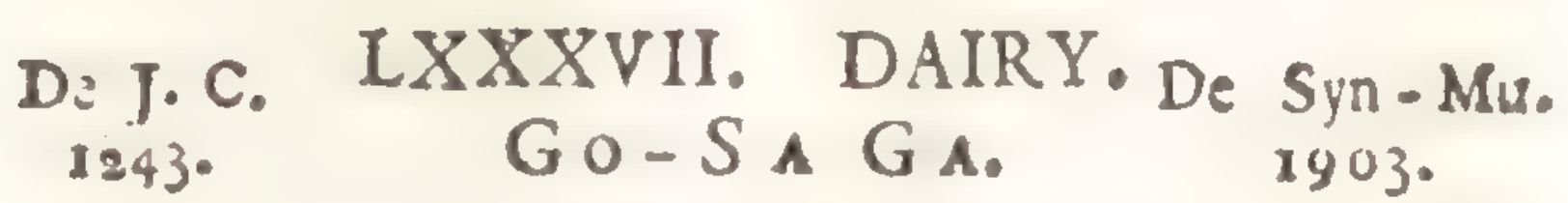

Ce Prince étoit Fils puîné de l'Empereur Tfutfi-Mikaddo. Il régna quatre ans, \& mourut en la cinquante-troifiéme année de fon âge. Il inftitua le Nengo Quan Jun, qui dura tout fon régne.

De J. c. LXXXVIII. DAIRY. De Syn - Mu. 1247. GOFIKAKUSA. 1907 .

On ne dit point qui étoit ce Prince; il infitua les Nengos Quantf, de deux ans; Genfio, de fix; Koogen, Seoka, \& Sooguan, chacun d'un an. L'onziéme année de fon régne, le vingt-troifićme jour du fecond mois, il $y$ eut un grand tremblement de terre au Japon. Go-Fikakufa, après avoir régné treize ans, abdiqua la Couronne en faveur de fon Frere puinne, \& mourut âgé de foixante ans. 
ivj SuIfe Chronolog. Des Darrys:

VI. Empereur Cubo-Sama.

Mune Taka Sinno, ou Soo Son Sinno.

La même année que Go-Fikaxafa monta fur le Trône des Dairys, Mune Taka Sinno, Fils de l'Empereur Go-Saga, monta fur celui des Cubo-Samas.

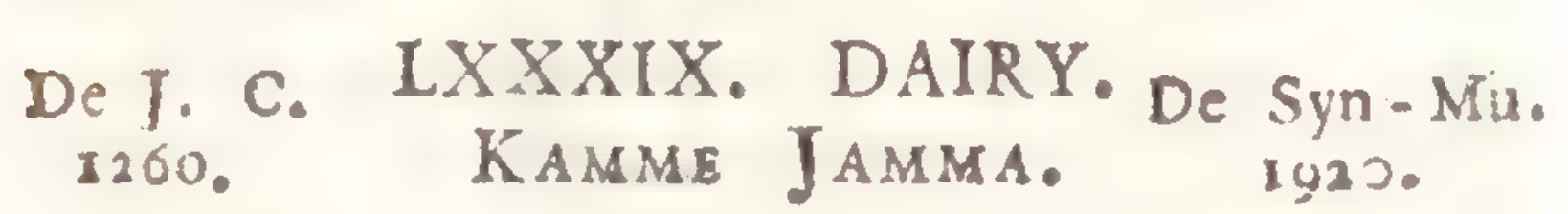

Ce Prince inftitua les Nengos Bunvro: d'un an; Koflo, de trois; \& Bunje, d'onze. La cinquiéme année de fon régne, le vingtuniéme jour de l'onziéne mois, mourut Sinran, Chef de la Secte Ikosiv; \& qui avoit été Difciple de Foonen Seonin, Fondateur de la Secte Seodosju. La feptiéme année, il parut une Comete, qui fut auffi vûè à la Chine (a). La neuviéme année, le huitiéme jour du cinquiéme mois, on vit deux Soleils. Le dix \& l'onze du fecond mois on apperçut trois Lunes. La quinzićme \& derniere annće, l'Empereur Cubo-Sama fixa fa Cour à Kamakura. Le Dairy, après avoir régné quinze ans, fe démit de l'Empire en faveur de fon Fils aîné. Il vêcut encore trente-deux ans après fon abdication, \& mourut âgé de cinquante-fept ans.

(a) Le P. Couplet en marque deux, mais pius de vingt.sinq ans après. 
OU EMPEREURS HEREDIT. DU JAPUN. L"ij

$$
\begin{aligned}
& \text { VII. Empereur Cubo-Sama. } \\
& \text { Korejas-Sinno. }
\end{aligned}
$$

Ce Prince fuccéda à fon pere, qui récrna quinze ans.

$$
\begin{gathered}
\text { De T. C. XC. DAIRY. De syn-Mu: } \\
1275 .
\end{gathered}
$$

Les Nengos inftitués fous ce régne, font Gentfi, de deux; Kentfi, de quatre; Kooan, de quatre, \& Sioo, de trois. Quelques Auteurs n'en marquent que deux, Gentfi, de trois ans, \& Kooan, de dix.

\section{Seconde tentative des Tartares fur le Japon.}

La neuviéme année de ce régne, le Général Tartare Mooko parut fur les Côtes du Japon, avec une Flotte de quatre mille voiles, \& deux cents quarante mille Hommes. L'Empereur Tartare Sijfu, qui régnoit alors, après avoir conquis la Chine environ l'Au de J. C. 1270. (a) fuivant le calcul de Kompfer, enyoya ce Général ponr conquérir aulli le Japon, mais cette Entreprife ne réulfit pas:

(a) Le P. Couplet, quit noinme ce Prince Xiçu; ne marque le commencement de fon regne à la Chine, qu'a la dir-feptiéme année du foixante-dx feptiéme Cycle des Chinois, lequel commenca l'an 1264. de $T$. C. par cosfequent en I I 8 r. Il parie de cette expétition, fans en marquer la date; mais il paroît ne donner aux Turtares, que eent mille liommes, dont il n'en revint a la Chine que truis ou quatse. Nous en avons parlé dans le Livre Préliminaire fur la Relation de Marc pol de Venife. 
iviij SuITE Chronolog. DES DAIRYs; les Camis exciterent une furieufe tempête; qui fit périr toute la Flotie: Мооко lui-mêne fut noyć, \& il ne fe fauva qu'un petit nombre de fes Gens.

Marc Pol de Venife rapporte la chofe tout autrement, ainfi que nous avons vû au Livre Préliminaire, Chap. V. \& pour ce qu: eft du tems, où les Tartares parurent au Japor, il n'eft pas aifé de le marquer au jufte: une Edition de Marc Pol de Venife place cette expédition en I 289. une autre en 1269 . SeIon la premiere, elle n’arriva qu'après la mort de Gouda; felon la feconde, elle précéda le r'gne de ce Prince, fous lequel les Japonnois l'ont placée; peut-ĉtre y a-t-il erreur dans les deux chifres, \& il faut peut-être lire $x 279$.

Quoiqu'il en foit, la dixiéme annéé du régne de Gouda, Nidfinin, dont nous avons déja parlé, mourut dans la Province de $\mathrm{Mu}$ fafi. Ceux de la Secte de Foquefiu célébrent tous les ans une Fête le jour de fa mort. Gouda régna treize ans, \& mourıt âgé de cinquante.

\section{Empereur Cubo-Samia. Kiume Sinno, ou Sanno Oji.}

Ce prince, qui étoit le troifiéme des Fils de l'Empereur Go-Fikakufa, monta fur le Irône en $\mathbf{2 8 6}$. \& régna vingt ans.

$\begin{array}{ccc}\text { De r. C. XCI. DAIRY. } & \text { De Syn-Rir' } \\ \text { x } 2880^{\circ} & \text { FUSIMI. } & 1948 .\end{array}$

Ce Prince étoit le fecond Fils de Go-Fikaxufa, \& Coufin de Gouda fon Prédécelleur. 
OU EMPEREURS HEREDT. DU JAPON. lix Il inftitua les Nengos Soovro, de cinq ans: \& Jenin, de fix. La premiere année de fon regne, le treiziéme jour du troifićme mois! il lui nâquit un Fils, auquel il remit la Couronne, après l'avoir portée onze ans. On ne dit point à quel âge il étoit monté fur le Trône, ni à quel âge il en defcendit. On fe contente de nous apprendre qu'il a vêcu cin. quante-trois ans.

De J. C. XCII. D AIRY De Syn-Mu。
3299.
GO-FU SIMI.

Ce Prince inftitua le Nengo Seoan, qui dura trois ans, c'eft-à-dire, tout fon régne. Il abdiqua enfuite la Couronne, \& mourut âgé de cinquante-huit ans. Il laiffa le Sceptre à fon Coufin, Fils aîné de l'Empereur Gouda.

De J. C. XCIII. D AIR Y. De syn-1!u.

On ne fçait point l'âge de ce Prince. II inftitua les Nengos Kagen, de quatre ans; 2 Tokuds, de deux. La cinquiéme année de fon régne, le huitiénre mois, il y eut un grand tremblement de Terre au Japon. Cette même année eft remarquable par la mort de Kiume, Empereur Cubo-Sama, \& par la naiffance de Takaudf, qui fut auffi Empereur Cubo-Sama. Go-Nidfio, après fix ans de régne, abdiqua la Couronne. 


\section{lin SUite Chronologicue des Datryi,}

\section{Empereur Cubo-Sama. Mori Kori Sinno.}

Ce Prince fuccéda à fon Pere en $1305.8 \%$ régna vingt-cinq âns.

De J. C. XCIV. DAIRY. De Syn-Mur. 2308. FANNA SONNO. 1958.

Ce Prince éroit Frere pruné de Ge-Fufimio Il inftitua les Nengos Jenke, de trois ans; Ootfi Jo, d'un an; Sooa, de deux, \& Bun $O$, de cing. Après qu'il eut rćgné onze ans, il fe démit de la Couronne en faveur d'un Fré re cadet de Go-Nidfio. On ne nous apprend rien de fon âge.

$$
\begin{gathered}
\text { De j. C. XCV. DAIRY. De Syn-Mio. } \\
\text { 1319. } \\
\text { Go-DAIGO. }
\end{gathered}
$$

Cet Empereur inftitua les Nengos Genvro, de deux ans; Genko, de trois; Seorsju, de deux; Karaku, de trois; Gentoku, de deux; \& Genko, d'un an. La derniere année de fon régne fut fort agitée de Guerres civiles trèsfanglantes, qui font décrites dans le Lirre intitulé Teifeki. A la fin de cette même année; il abdigua la Couronne.

\section{Enpereur Cubo-Sama. Sonun ou Sonnun Sinno.}

Ce Prince éroit Fils puinné de Go-Daigo. II monta fur le Trône des Cujo-Sa:aras en I 3 zx. \& ne régng que deux año 
OU. EMPEREURS HEREDTt. DU JAPON. Ixi De J.C. XCVI, DAIRY. De Syn-Mu. 1331. KWO GIEN. I991.

Ce Prince étoit Fils ainé de Go-Fufimi. It inftitua le Nengo Seoke, lerquel dura deux ans.. On ne ç̧ait rien de fon âge.

\section{Empereur Cubo-Sama. Nari Joj Sinn Oo.}

La feconde annće de ce régne, Nari Jofi Sin Oo fuccéda à fon Frere fur le Trône des Cubo-Samas, \& ne garda le Sceptre que trois ans. Kompfer fe trompe daus fon calcul, s'il eft vrai que cette même annće Taxaudfi XII. Empereur Cubo-Sama, vint en cettre qualité rendre fes Hommages au Dairy. Cette même année Такакокu, Gćnéral célébre, fe fendit le Ventre. Kvvo Gien après avoir régné deux ans, rendit le Sceptre à fon Prédécelfeur, lequel l'ayant aćcepté, inftitua les Nergos Kemmu \& Jen Ken, chacun de deux ans. La feconde année.du Nengo Jen Ken, l'Empereur Go-Fufuni mourut, aufi-bien que Kufnoximaka Sugge, fameux Général. La nrêmme année, le huitiéne mois, il y eut de grands tremblements de Terre au Japon. GaDaigo ne regna cette feconde fois que trois ans. On ne dit rien'de fon âge.

\section{Empereur Cubo-Sama. Taka Udj, ou Takad $\imath_{\text {. }}$}

11 paroît qu'il faut ici placer le commeni cement du régne de ce Prince, qui ćtoit Fils d'Afkago Sannoxino Cami Nago Udil, \& qui régna vingt-cing ans. 
Zxij Sutte Chronologtee des Dairys,

$$
\begin{gathered}
\text { De T. C. XCVII. DAIRY. De Syn:Mu. } \\
\text { QU3 }
\end{gathered}
$$

Ce Prince étoit Frere puîné de l'Empereur Kwo Gien, \& le quatriéme Fils de Go-Fulimi. I.e Nengo Jen Ken, inftitué par fon Prédécefleur, continua la premiere année de ron régne, \& fut fuivi du Nengo Riaxuwo, qui dura quatre ans. La feconde année de ce régne, le Dairy honora Taka Udfi, Empereur Cubo-Sama, du titre de Sei Dai Seogun. Les deux Auteurs, dont Kœmpfer nous alsûre qu'il 2 tiré ces Anmales, ne lont pas d'accord fur la durcée de ce régne; l'un dit quil dura douze ans, l'autre prétend que Quo Mio après avoir régné deux ans, eut pour Succelfeur GoMurakami, feptićme Fils de l'Empereur GoDaigo, lequel n'eft pourtant pas compté dans la Lifte des Dairys. Quoiqu'il en foit, aptès que le Nengo Riakuwo eut duré quatre. ans, l'Empereur, qui régnoit alors, en inftitua toue de fuite deux autres, Koo Je, de trois ans; \& Tewa, de quatre; vers la fin duquel Siukwo monta fur le Trône. On ne f̧̧ait rien de l'âge de Quo Mio.

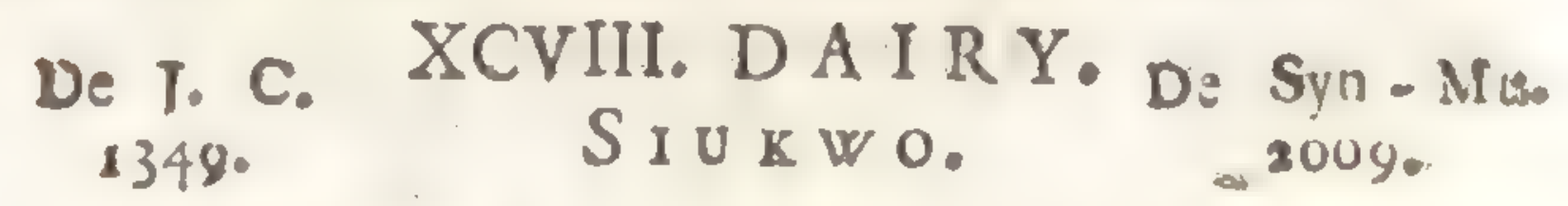

Ce Prince, dont on n'a point marqué l'â.ge, 'étoir Fils aîné de l'Empereur Kwo Gien. II n'inftirua aucun Nengo la premiere année de fon régne: la feconde année il en inftitua un fous le nom de Quano, lequel dura deux ans. La premiere année la Guerre Sidd fo Navint- 
ov Empereurs Heredit, du Japon. lxiu to fut terminée. Siukwo, après avoir régné trois ans, eut pour Succelieur fon Frere puincé.

De T. C. XCIX. DAIRY. De syn-Mu;
2352。 GO-KW O GIEN。
2012.

On ne dit rien de l'âge de ce Prince, qui inftitua les Nengos Bunjvva, de quatre ans; Jen Bun, de cinq; Kooan, d'un an; Teeidfi, de fix; \& Ooan de fept. La troifiéme année de fon régne, Jofi Kaxi troifiéme Fils de l'Empereur Cubo-Sama, vint à la Cour du Dairy, lequel envoya l'année fuivante le $\mathrm{Cu}-$ bo-Sama même dans la Province d'Omi, pour terminer quelques différents, qui $y$ étoient furvenus.

\section{Empereur Cubo-Sama. $J \circ \sqrt{i} K a k i$.}

La huitiéme année, Tака Udfi, Empereur Cubo-Sama, monrut le vingt-neuviéme jour du quatriéme mois. Son troifiéme Fils Jofi Kaki, dont nous venons de parler, lui fuccéda, \& la même annće il obtint du Dairy le titre de Sei Dai Seogun. L'onziéme année, ce Prince fut envoyé dans la Province d'Omi, pour y commander l'Armée Impériale.

\section{Empereur Cubo-Sama.}

Jofimitz.

La dix-huitiéme annće Jofimitz Fils de Jofí Kaki fuccéda à fon Pere, \& occupa quarante ans le Trône des Cubo-Samas.

Go-Kvvo Gien régna vingt ans, \& eut pous Succelleur fon Fils ainé. 
Lxiy SuIte Chronologroue des Darrys;

$$
\begin{aligned}
& \text { De 1. C C. DAIRY. DE Syn-MU } \\
& \text { 1372. GO-JENWO, OH JENJO. 20j2. }
\end{aligned}
$$

Le dernier Nengo intirué fous le précédent régne, continua les trois premieres annćes de celui-ci, \& fur fuivi des Nengos Koora$k u$, quidura quatre ans; Sei Toku, de deux ans; \& Koowa, de quatre. La huitióme année il y eut une grande Famine dans le Japon. La même année, il parut une Cométe. Go-Jenwo régnna onze ans; on ne dit rien de fon âge. Son Fils ainé lui fuccéda.

$$
\begin{array}{ccc}
\text { De T. C. CI. DAIRY. } & \text { De Syn-Mu. } \\
3383 . & \text { GO }
\end{array}
$$

La feconde année de ce régne, l'Empereur inltitua le Nengo Sitoku, qui dura trois ans, \& qui fut fuivi de trois autres: Kakei, de deux ans; Ikoo O, d'un an; Meeroku, de quatre; \& Oojei, de trente-quatre.

La neuvićme annće de ce régne, il y eut une Guerre dans le Pays d'Udfii. La quatorziéme année, le dix-feptiéme jouir de l'onziéme mois, le fameux Temple Kenninfi fur tém duit en cendres. La vingtiéme annce une Cométe parut au Printems : l'Eté \& l'Automne fuivans, il y eut une grande lécherelle, \& de furieux tremblements de terre pendan l' $\mathrm{Hy}$ ver. La vingt-deuxiéme année, une Montagne, qui étoit à Nafino dans la Province de Simatski commença à brûler, \& à jetter des pierres \& des cendres, mais cela dura peu de jours. La vingt-cinquiéme année, l'Automne fut for pluvieux, ce qui caúa des inon= 
OU EMPEREURS HEREDIT. DU JAPON. IXY dations en plufieurs lieux. Il y eut enfuire des tempêtes \& des tremblemenis de Terre. GoKomatz régna trente ans. On ne dit rien de fon âge. Son Fils lui fuccéda.

$$
\begin{aligned}
& \text { XV. Empereur Cubo-Sama. } \\
& \text { Jofimotz, ou Jofinot } b_{\text {. }}
\end{aligned}
$$

Ce Prince, dont le Pere fe nommoit $T_{3}$ Kamirz, monta fur le Trône des Cubo-Samas en $x_{4} I 0 . \&$ l'occupa vingt \& un ans.

$$
\begin{gathered}
\text { De J. C. CII. DAIRY. De Syn-Mu, } \\
\text { 3413. }
\end{gathered}
$$

Le Nengo Oojei commencé fous le précédent régne, continua jufquà la quinziéme annće de celui-ci. L'Empereur en inftitua enfuite un fous le nom de Seootio, qui ne dura qu'un an.

\section{Empereut Cubo-Sama. Joje $K a$ Ju.}

Ce Prince fut affocié par fon Pere Jofi Motfi au Trône des Cubo-Samas, \& il paroît qu'il mourut avant lui.

La quatriéme annce du régne de Seo Kwo, Usje Suggi fe révolta contre cet Empereur. La neuvióme année, le douziéme jour du din sićme mois, il parut deux Soleils.

$$
\begin{gathered}
\text { XVIT. Empereur Cubo-Sama. } \\
\text { Joje Nori. }
\end{gathered}
$$

La feiziéme année, le dix-huiriéme jour du 
ixVjSUITE CHRONOZOGIQUE DES DAIRYS, fremier mois, Jofi Nori, Empereur CuboSama mourut. Son fecond Fils lui luccéda, \& régna quatorze ans.

La même année le Dairy mourut, on ne dit point à quel âge, après avoir régnć feize ans. Son Fils lui fuccéda.

$$
\begin{aligned}
& \text { se J. C. CIII. DAIRY. De Syn-Mw。 } \\
& \text { 1429. GOFUNN A } S \text { O. 2089. }
\end{aligned}
$$

On ne f̧̧ait point quel âge avoit ce Prince, lorfqu'il monta fur le Trône. Il infticua les Nengos Jeiko de douze ans; Kakizz, de trois; Bunjan, de cinq; Fotoku, de cinq; Kofro, de deux; Tfiorok, de trois; \& Qunnisjo, de fix. La premiere année de fon régne, le cinquiéme jour du huiriéme mois, il parut une grande \& terrible Cométe, \& une autre l'onziéme année, le troifiéme mois.

\section{Empereur Cubo-Sama. $J o j K_{a t}$.}

La quinziéme année, Jofi Katz, Fils aîné de Jofi Nori, fut aflocié au Trône des CuboSamas, qu'il n'occupa que trois ans. Il mourut une année après fon Pere. Son Frere puiné lui fuccéda.

$$
\begin{aligned}
& \text { XIX. Empereur Cuba-Sama. } \\
& \text { Joji Mafa, ou Jofimatz. }
\end{aligned}
$$

La feizićme année, Jofi Mallä, Empereur Cubo-Sama, fut honoré du titre de Sei Dai Seogun. La dix-huitiéme année, le Palais du Dairy fut rćduit en cendres. Les Hiftoriens 
- Eupereurs Heredtt. du Japon. lxvij Japonnois remarquent que les lept dernieres annces de ce régne; il parut dans le Ciel des Phénoménes étranges, qui furent fuivis de la famine, de la pefte, \& d'une grande mortalité dans tout l'Empire. Go-Funna So régna rrente-fix ans, \& laifla l'Empire à fon Fils.

De J. C. CIV. DAIRY: De Syn-Mu. . $4695^{\circ}$ Go-Tsutsi Mikaddo. 2125.

Ce Prince inftitua les Nengos Bunfio, d'un an; \& qui commença la feconde année de fon régne: Onin, de deux ans; Fum Jo, de dix-huit; Tfrooko, de deux; Jentoku, de trois; \& $\mathrm{Me} \mathrm{O}$, de neuf.

La premiere année, le deuxiéme mois, il parut une Cométe, dont la queuë paroiffoit avoir trois braffes de long: l'année fuivante, il y eut plufieurs tremblements de Terre, \& particuliérement le vingt-neuviéme jour du douziéme mois. La même année, il y eut une fi grande famine dans la Chine, que les Gens fe tuoient les uns les autres pour fe manger (a). La troifiém eannée, il y eut beaucoup de troubles \& de Guerres civiles, qui commencerent le feizićm@ jour du cinquiéme mois. La cinquićme année, le dixiéme jour du neuviéne mois, il parut une autre Cométe, dont la queué fembloit avoir une bralle de long. Ia feptićme année, il y eut une grande mortalité dans tout l'Empire. La mếme année, le premier jour du douziéme mois, il parut une troifićme Cométe, la plus gran-

(a) Le P. Couplet en marque une trente $\&$ un an plus tard, c'eft a-dire, en 1496. \& dit que les Peres \& les Enfans fo mangevient les uns les autres. 
2xviij Suite Chronologrou des Datrys, de, qu'on eût jamais vûé : elle avoit, dit l'Auteur Japonnois, la longueur d'une rue Ia neuviéme annće, Forfakavva Karzmorto, Général fameux par fon courage \& fes explois, mourut. Après fa mort, il fut honoré du titre de Riu Ans.

\section{Empereur Cubo-Sama. Joj Navo.}

La même année, le titre de Sei Seogura fut donné à Jofi Navo, Empereur Cubo-Sama, que fon Pere avoit allocié au Trône. L'onziéme annce, le fixime jour du huitićme mois, piès d'Amagafaki, dans la Province de Sctz, des Rivieres grofirent de telle forte, qu'une partie du Pays fut inondée, \& plufieurs Perfonnes furent noyées. La vingtcinquićme année, Jofi Navo mourut un an avant fon Pere. On ne dit pas combien de sems il régna.

\section{Empereur Cubo-Sama. Jofi Tanne.}

La vingt-cinquiéme année, Jofi Maffa XIX. Empereur Cubo-Sama mourut fort regrecté, \& laifia la Couronne à Jofi Tanne, fon Fils puiné.

La vingr-neuviéme année, Jofr Tanne, Fils de ce dernier, futhonoré du titre de Sei Dai Seogun $(a)$, \& peu de tems après alla

(a) Cela ne prouve pas quil fut des-lors Enpereas, pulque fufi Tame lon Pere regna dis hut ans, mais it eft fulverenant que jufi Symmi n'ait reçu le mêne titre, que plufieurs annécs après fon lils. Seut-étie y 
ou Empereurs Heredit. do Jaron. 2xix commander l'Armée dans la Province de Jafiro. La trentićme année, le feptiéme jour du huitiéme mois, il y eut un grand trennblement de Terre.

L'Empereur Go-T futf Mikaddo apris avoir régné trente-fix ans, mourut âgé de cinquante-neuf, \&c laifla la Couronne à fon Fils.

De J. c. CV. DAIRY。 De Syn-Mu。
Kjor.

Les Nengos inftitués par ce Prince font, Bunki, de trois ans; Jeefeo, de dix-fept; $\&$ Tei Je, de fept. Ce dernier continua la premiere année du régne de fon Succefleur. La quatriéme année de celui-ci, il y eut une grande famine dans le Japon. La fixiéme, le Leptiéme mois, il parut une Comére. La huiriéme année, le titre de Sei Seogun fur donné à Jofi Tanne, Empereur Cubo-Sama. La dixiéme, il y eut des Guerres fanglantes, \& des rremblements de Terre. La douziéme, le cinquiéme mois, Jofi Tanne alla faluer le Dairy. La feiziéme, il y eur encore une grande famine. Katiuvvabara s'gna vinge-fix ans; on re dit point combien il vêcut. Son Fils lù fuccéda.

XXII. Empereur Cubo-Sama. Jofii Symmi.

Ce Prince commença de régner en I 508. à moins qu'il n'ait régnú avec fon Pere, \& a-t'il ici une tranfpufition, c'uth-àdire; que Jufi Tanne pourroit bien etre le fils, \& nun pas le Pere de Jufii symrit. 


\section{Ixx Sutre Caronolog. des Dairys;}

il n'y a même que ce moyen de juftifier le calcul de Kompfer, qui lui donne quatorze ans de régne, \& trente à Jofi Far, fon Fils \& fon Succeffeur.

\section{Empereur Cubo-Sama. Joj Far.}

Il eft difficile de marquer au jufte en quel tems ce Prince monta fur le Trône.

$$
\begin{array}{ccc}
\text { De J. C. CVI. DAIRY. De Syn-Mu. } \\
\text { G } 2 \% .
\end{array}
$$

- Ce Prince inftitua la feconde année de fon régne un Nengo, qu'il nom:na Kогакu, \& qui dura quatre ans. Il fut fuivi de detix autres, Tembun, de vingt-trois ans; \& Koodfi, de trois. Peu de tems après quil fut monté fur le Trône, la Guerre finic entre Folloкаwa \& Kadfuragawa. Deux ans après, le premier de ces deux Princes fe fendit le Ventre.

Pendant le régne de cet Empereur, le Japon fouffrit deux fois de la Pefte, \& trois fois d'une grande mortalité. Les Saifons y furent extrêmement pluvieures, \& les Eaux fi grofles, qu'elles inonderent une grande partie du Pays. Il y eut auffi, mais on ne dit pas en quelle année, une tempête fi violente, \& fi générale, qu'elle zenverfa plufieurs Edifices magnifiques, \& entrautres une partie du Palais Impérial. La cinquiéme année, le vingtneuvićme jour du fixiéme mois, il parut une Cométe, \& on en vit encore une ausre le douziéme mois de la douziéme année. La feptiéme annće, le huitiéme jour du diriéme 
OU EMPEREURS HEREDIT. DU JAFON: $2 x x j$ mois, il y eut une Eclipfe de Lune.

\section{Découverte du Japon par les Portugais.}

La quinziéme année, le Japon fut décou-i vert par les Portugais. Cette année répond à l'aunée 1542. de J. C. \& 2202. de Syn-Mu. Les Aureurs que Kœmpfer a fuivis, n'en difent rien, non plus que de tom ce qui regarde les Européens, \& la Religion Chrétienne. Il y a bien de l'apparence qu'on aura effacé des Faftes de l'Empire, tout ce qui regarde ces Evénements, afin d'abolir julqu'au fouvesir d'une Religion odieufe aux Japonnois.

\section{Eimpereur Cubo-Sama. Joj Tir.}

La dix-feptiéme anncee, Jofi Tir, Fils de Jofi Far, Empereur Cubo-Sama, reçut. du Dairy le titre de Sei Dai Seogun, \& eut le commandement des Arniées, mais il ne monta fur le Trône qu'en is so. puifqu'il mourut en i 565 . Celon Koempfer, qui s'accorde en cela avec les Lettres des Miflionnaires, \& qu'il ne régna que quinze ans; peut-être auffi régna-t-il conjointement avec fon Pere jufqu'à la mort de celui-ci, arrivée la vingtquatrićme année du régne de Gonara, lequel occupa le Trôte trente \& un ans; on ne dit point à quel âge il mourut. Son Fils lui fuccéda. 


\section{IxxijSutr CHRONOrogreer DES DAIRT';}

$$
\begin{gathered}
\text { De J. C.: CVI. DAIRY. De syn-Míl } \\
\text { ISs8. }
\end{gathered}
$$

On ne dit point à quel âge ce Prince monra fur le Trône. Il inftitua les Nengos Jeekoku, de douze ans; Genki, de trois; \& Jenfoo, de dix-neuf; celui-ci continua pendant les cing premieres années du régne fuivant.

La premiere année de celui-ci, il y ent pendant l'Eté une grande fécherefle, qui fut fuivie d'une extrêne famine. La huitiénse annce, Jofi Tir mourut de la maniere, quon verra dans cette Hiftoire.

\section{Empereur Cubo-Sama. Joji Tira, ou Taira.}

L'onziéme année Jofi Tira, Fils de Jofr Tir, monta fur le Tróne des Cubo-Samas, \& fut honorć du titre de Sei Seogunn $(a)$.

\section{Einpereur Cubo-Sama. Joj Aki.}

Ce Prince, felon les Annales publices par Kompfer, étoir Fils de Joíi Tira, \& régna cing ans.

La feizićme année, on prit au Printems une

(a) Il eft difficile d'accorder ici ces Faltes Chrono. logiques avecle: Letres des Miffionnalres, qui étoiene fur les licux, \& qui ne mettent entre 'yofi, "Tir \& Nohunanga, qu'un icul Culo-Sama, frere du premier, Nuus arons tifcuté ce point dans le cosps de l'Ouyrage. 
oo EMPereurs Heredit. DU Japon. $l x x i j$ Tortuë, qui avoit deux têtes. La même année, le troifiéme jour du quatrićme mois, quelques Scélérats mirent le feu au Kamio, c'elt-a-dire, à la partie a plus élevée de Meaco, ot le Dairy faifoit la rélidence, 3elle fut touteréduite en cendres. La partite balle s'ap. peile Si Mio.

\section{Empereur Cubo-Sama Nobbenaga, ou Nobunanga.}

Ce Prince étoit Fils de Oridano Denfio Tai$r a$; il régra dix ans, felon les Annaliftes de Kompfer. Le vingi-troiliéme jour du neuvićme mois, il parut une grande Cométe, qui ne difparut que l'année fuivante. La vingt \& unićme annće fut trc̀s-pluvieule, \& le douziéme jour du cinquiéme mois, la plus grande partie du Pays fut inondée. La vingttroifiéme annće, il y eut beaucoup de Mala. dies, \& une grande mortalité dans tout l'Empire.

La vingr-cinquiéme année, le deuxiéne jour du fixiéme mois, Nobunanga Général cie la Couronne, \& fon Fils ainé, furent tućs à Méaco.

\section{Empereur Cubo-Sama. Fide Nobu.}

Les Annaliftes de Kompler donnent trois ans de régne à ce Prince, qu'ils font Fils de Nobu Tada, peut-êre veulent-ils parler du troifiéme Fils de Nobunanga, qui fe trouva Mátre de l'Empire à la mort de fon Pere, ou plutôt: du petit-fils du nećme Nobunanga. Tome II. 
Ixxin Sutte Chronologre. Des DAirys; Taico-Sama fit d'abord femblant de n'ètre que Régent de l'Empire.

La vingt-fixiéme annce du régne d'Ookimatz, ce Prince reçut une Amballade des Ines de Riuku, autrement appellćes les Illes Liqueios ou Lequios.

\section{Empereur Cubo-San.x. Fide--Jos.}

La vingt-huitiéme année, Fide Jos plus conau fous le rom de Taico-Sama, fut honoré par le Dairy du titre de Cambacu; c'eft fur-tout depuis ce Prince, que les Dairys ont perdu prefyue toute lecir autorité dans l'Empire. Cette même année, le vingt-neuvióme jour de l'onzićmse mois, il y eut un grand tremblement de Terre, qui continua par des fecoulles réitérées, mais moins violentes, prelque une anníe enticre.

La vingt-neuviéme année, le Dairy abdiyua la Couronne en faveur de fon Petit-fils, \& mourut fept ans après; on ne dit point à quel âgुe.

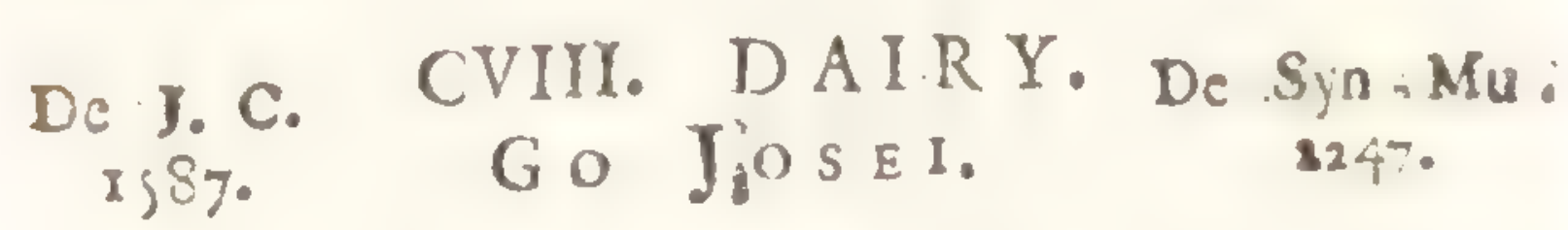

Ce Prince étoit fils du Prince Héréditaire nommé jookwo, mort l'annće précédente, le feprićme jour de l'onziéme nois. Go Jüfei infticua la fixíne année de fon régne le Nengo Bunroku, qui dura quatre ans, \& fur fuivi d'un aurre noamé Keitsjo, qui fub de dix-neuf.

La.troifiéme annce de ce régne, fide Tfu- 
oy Empereurs hSRedit. du Jaron. lxyy gu (a) neveu de Taico-Sama, Prince cruel \& languinaire, tua Fondsjo dans la Province de Sagami, \& extirpa toute fa Famille, conformément aux maximes de la Guerre, fuivies dans le Japon, qui veulent que l'on aille tout d'un coup jufqu'a la racine du nal.

\section{Empereur Cubo-Sama. Fide Tfugu.}

Les Annaliftes de Kompfer mettent ce Prince au rang des Empereurs Cubo-Samas . parce qu'il fut en quelque façon affocić à l'Empire par fon Oncle, qui le fir enfuire mourir. La cinquíme annce, le titre de Cambacu fut donné par le Dairy à ce méme Prina ce. La fixićme année, Taico-Sama déclara la Guerre aux Coréens, \& envoya contre eux une nombreufe Armée, difant que par la conquête de cette Péninfule, il vouloit s'ouvrir un Chemin à celle de la Chine.

La leptićme annće, Ookimatz, Aycul \&c Prédćcelleur du Dairy rćgnant, mourut. L'onzićme annće, l'Empereur honora du titre de Nai Dai Sin le Favori de Taico-Süma, \& fon premier Minifte d'Etat nomné Jefi Jas (a). La mêne année, le douziéme jour du feptiéme mois, il y etit de grands tremble. ments de Terre, \& les fecoufies continuerent à diverfes reprifes pendant un mois. La dou zićme année, le dix-huitióme jour du huirié-

( a) 'C'eft le méme, que les Lettres des Mimionnaires nomment Däinangandono.

(b) C'eft le même, qui elt no:nmé ailleurs Jejas, Geias, \& Geiazo, \& qui eft plus cunnu dans les Lettes des Mifionnaires fous le nom de D.yyfu-Sando 


\section{ixxij Sutte Chronolog. des Dairys;}

me mois, Fide-Jos prit le nom de Taico-Sama, qui fignifie Grand Seigneur, \& mourut la même année, laillant l'Empire à fon Fils unicjue Fide-Jori, fous la Régence de Jefas (a)

\section{Empereur Cubo-Sama. Fide Jori.}

Ce Prince eut pendant quatorze ans le titre d'Enpereur, mais Jejas fon Tuteur, gouverna toujours fons fon nom.

La quatorziéme année, Jofijda Tribbu, qui avoit un Emploi a la Cour de Fide Jori, fe rćvolta contre l'Empereur, mais les Rébelles furent défaits, \& leur Chef fut exterminc avec toute fa Famille (b). La dix-feptiéme année, le Tirre de Sei Dai Seogun, qui appartenoit à l'Empereur Cubo-Sama, fut donné à Jefr Jas, Tuteur de Fide Jori. Son Fils fut honoré la même année de celui de Nai Dai Sin. La dix-neuviéme annće, le titre de $S: i$ Dai Seourun fut donné à Fide Tadda, Fils de Jefi Jas. La même année, le quirzićme jeur du douziéme mois, une Montagne fortit de la Mer en une nuit près de lille Fatfifio. La vingt \& uniéme annće un Amballa-

- (a) Il y a ici bien des faures de Chronologie, car il eft certina parles Lettres des Miffionnaires, que la couziéme année de Goroletei, devoit être l'an is98. OL y9. de J. C. \& que File Jos prit le nom de TaicoSama ell 1592.\& mourtrt en 1598.

(6) 11 y a bien de l'apparence qu'il s'agit ici de le culerre des Regens, que Dayfu-Sana fit parfer pour ure révolte contre l'Fimperenr ion Pupille; quoigu'ils fulf:me armez concre lui foul, en faveur de ce jeune Frince. 
ou Empereurs Heredit. di Japon. $2 x x \nu i j$ deur de l'Empereur de la Chine (a) arriva a Suruga, pour faire compliment à Jefi Jas, qui étoit dès-lors regardé comme Empereur Cubo-Sama. La vingt-troifiéme année, ce Prince fit bâtir un Château dans la Province d'Owan. La vingt-quatriéme année, les Intes Riuku furent conquiles par le Prince de Sa. xuma, \& elles font encore aujourd'hui tributaires de fes Succeffeurs.

Go-Jofei régna vingt-cing ans; on ne parle point defon âge. Son Fils lui fuccéda $(b)$.

De J. C. CIX. DAIRY. De Syn-Mu:
I612.

Le dernier Nengo du régne précédent, continua les trois premieres années de celui-ci. L'Empereur en inftitua enfuite deux, Geniwa, de neuf ans; \& Quan Je, de vingt. La feconde année de ce régne, il plut des Cheveux en plufieurs endroits, particuliérement pendant l'Automne La troifiéme année, le vingt-cinquiéme jour du dixiéme mois, il y eut un furieux tremblement de Terre.

XXXII. Empereur Cubo-Sama. Je.jl Jas.

Les Annaliftes de Kompfer donnent quatorze ans de régne à ce Irince; mais ils y

(a) il eft étonnant que les Annalin s de Kuemifer ne parlent po a de l'A nul ofire que l's mpercur die la Cline, \& avant luile Roi de Cuice, curoyerent à Tayco Sama.

(b) De bons Af moires dilent que ce Prines fut

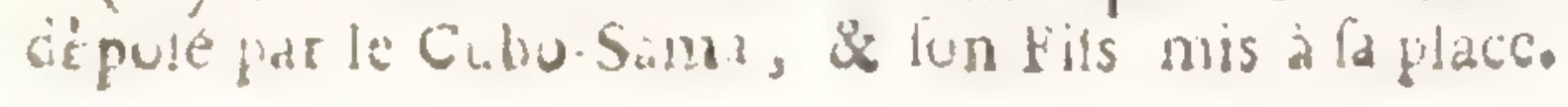




\section{Ixxviij Suite Chronclog. des Darras,}

comprennent une partie du tems quil régna fous le nom de Ficite Jori. Ce qui ent certain, c'eft que ce fut la troisiéme année du régne de Dai Seokwo, que Fide Jori mourut ou cilparut, \& gue derx ans après, Jefr Jas mourut anfí; il fut enterré a Nicquo, \& mis au rang des Dieux fous le nom de Gonierifama.

\section{Empereur Cubo-Sama. Fide Tadda}

Ce Prince étoit le troifiéme Fils de Jefi Jas; \& le Beau-Pcre de Fide Jori.

La huiriéme annće, qui revient à l'an I 6 I 9. de J.C. il parut une Comére fort remarguable. La dixiéme année, le Dairy époufa une Fille de Fide Tadda. La douziéme année Jemitz ou Jiemitzko, Fils de ce Prince, alla à Meaco faluer le Dairy, de qui il obtint le Titre de Sei Dai Seogun. La dix-huitiéme année, Daifeokwo abdiqua la Couronne en faveur de la plus jeune de fes Filles. Il vêcur encore cinquante ans, après être defcendu du Trône, \& mourut âgé de quatre-vingt-huit ans.

$$
\begin{gathered}
\text { De J. C. CX. DAIRY. De syn-Mu. } \\
\text { jo. Nio TE, ou Sio TE; } 2290 . \\
\text { ou, Selon quelques-uns, Fonin, } \\
\text { Impératrice. }
\end{gathered}
$$

Le dernier Nengo inftitué fous le régne prćcédent, dura tout le tems de celui-ci. 
ut Empereurs Herebit. du Jaton.lxxin -

XXXIV. Empereur. Cubo-Sama.

Jemitz, ou Jiemitzko.

La troifiéme année, le vingt-quatriéme jour du premier mois, Fide Tadda, Empereur Cubo-Sama mourue; il fut mis après fa mort parmi les Dieux fous le nom de Taito Konni, ou de Tinto Kuin Sama.

La cinquiéme annće, Jiemitzko, Enppereur Cubo-Sama, alla à la Cour de lTmpératrice. Ia feptićme anncé, le dixiéme mois, on fermit aux Chinois de revenir trafiquer au Japon, ce qui leur avoit été défendu quelque tems auparavant. Le commencement de la fameufe Révolte des Chrétiens à Simabara, dans la Province de Fifen, fe rapporte à l'onziéme mois de la huitiéme année. L'année fuivante, le fecond mois on fit mourir en un feul jour (douziéme d'Avril I638.) trente-fept mille Chrétiens. Ce Mafiacre étouffa tout d'un coup la Rébellion, \& abolit entiérement la Religion Chrétienne dans l'Empire.

La douziéme annće, le cinquiéme jour du huitiéme mois, nâquit Jietznako, Fils de l'Empereur Cubo-Sama, \& Pere de celui, qui régnoir en I692. lorfque Kompfer quitta le Japon (a); la même annće, il $y$ eut une grande famine \& une grande mortalité dans le Japon. Nio Te, après avoir régné quatorze ans, remit le Sceptre à fon Frere puiné. On ne dit point combien elle vêcurt.

(a) Kompfer dit ailleurs en plus d'un endroit, que !e dernier rmpereur Cuho-Sama, dont il par!e; \& yquil a vú, étoit frere de fon Prédéceffiur. 

De J. C. CXI. DAIRY. De Syn-Mu. 1643. GO-QU O MIO. 2303. E par corruption, Gотоміо.

Ce Prince ne prit poffelfion du Trône, que fa Socur lui avoit cédé, que le cinquicime jour de l'onzićme mois, près de deux mois après l'abdication de cette Princelle. Il inftirua les Nengos Seo Fo, de quatre ans; Kie Jan, de pareille durée, \& Seoo, de trois ans.

\section{Empereur Cubo-Sama. Jietźnako.}

La troifićme année de fon régne, le vingttroifíme jour du quatriéme mois, le titre de Seonai Dai Nagon fut donnć à Jietznako, Empereur Cubo-Sama (a). L'onziéme année, le douzićme jour du huitiéme mois, le feu prit au Palais des Dairys, \& en confuma une grande partie arec plufieurs Temples, \& autres Edifices voifins. La même annće, de jeunes Garçons de douze à quatorze ans furent mis en Prifon, ćtant foupçonnés d'être les Auteurs de cet incendie.

La dixićme annće, le fixiéme jour du feptićme mois, INGEN Docteur célćbre arriva de la Chine au Japon, pour y publier une nouvelle Secte. L'onziéme annće, le vingtiéme jour du neuviéme mois, le Dairy mourut, on ne dit point à quel âge; il fut enterré

(a) Si cette datte eft exacte, il faut que le Pradé. ceffeur de ce Prinee lui ait remis le Gouvernement de l'Elat avani fa mort, cas il ne mourut qu'ens $6 j 0$. 
ou Empereurs Heredit. du Japon. $2 x x x j$ avec beaucoup de folemnité dans le Temple de Sen Oufi, le quinziéme jour du mois fuivant. Son troifiéme Frere lui fuccéda.

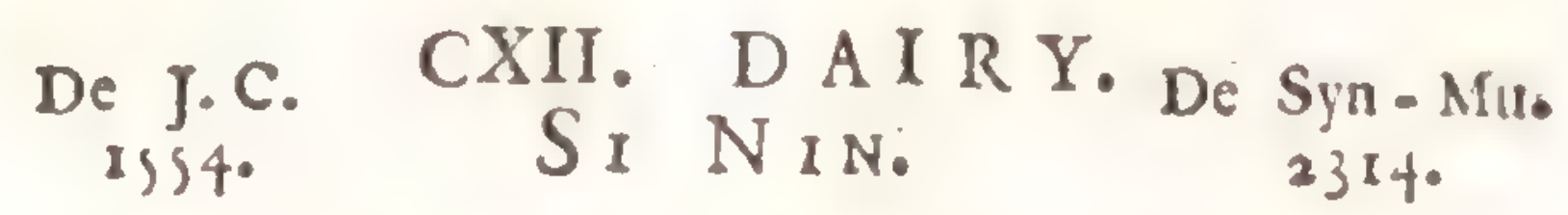

Ce Prince inftitua les Nèngos Meiruku \& Bautfi, de trois ans chacun; \& Seowo, ou felon d'autres, Quan Bun, de douze: mais ce dernier continua jufqu'à l'onziéme annće du régne fuivant. Quelques Auteurs prétendent que ce fut la premiere année de celuici, que les Chinois eurent la permiffion de tràfiquer de nouveau au Japon. La troifiéme année, le treiziéme jour du premier mois, il $y$ eut un furieux incendie à Jedo, réfidence de l'Empereur Cubo-Sama; il continua les deux jours fuivants, \& réduifit en cendres la plus grande partie de cette Ville. La cin juiéime année commença le Rakujo, ou Pélerinage aux trente-trois Temples de Quanwon, dévotion, qui depuis ce tems-là eff fort à la monde. La leptiéme année, une grande partie du lieu de la réfidence du Dairy fut aufr confumée par les flammes. La huitiéme année, le premier jour du cinquiéme mois, il $y$ eut un tremblement de Terre fi terrible, qu'une Montagne de la Province d'Omi, fur la Riviere de Katzira, fut engloutie, fans qu'il en reftât la moindre trace. Si Nin régna huit ans; on ne dit point combien il vêcut. Le plus jeune de fes Freres lui fuccéda. 
xxipij SUIte Chronolog. Des DAIRYs,
De J. C. CXIII. DAIRY. De Syn-Mun 1563. KINSEOXWO TE1. 2323. OU K INSEN.

Le dernier Nengo du régne précédent continua pendant les dix premieres années de celui-ci. L'Empereur en inftitua enfuite trois; Jempo, de huit ant; Tenwa, de trois; \& Dfiokio, de quatre. La troifiéme année de fon régne, le fixiéme mois, il ćtablit un Tribunal dans toutes les Villes \& tous les Villages de l'Empire, pour s'informer de quelle Secte étoient to as les Particuliers. Ia quam triéme année, le quatriéme mois, il ordonna que la Secte Jusja Fufe, qui éroit une Branche de celle de Foquefiu, füt abolie. Ceux de cette Secte avoient des idées fi ridicules de leur pureté, \& de leur fainteté, qu'ils croyoient que le commerce des aurres Hommes les rendoit impurs.

La fixiéme année, le premier jour du fecond mois, \& les quarante jours fuivants, la Ville de Jedo fouffrit beaucoup par le feu, qui paroilloit y avoir été mis à deffein !, \& il feinbloit que les Incendiaires en vouloient furtout aux Magazins des Marchands, \& aux Maifons, où les Soldats étoient logés. La feptiéme année, il y eut une grande famine au Japon, caufée par une excellive fécherefre de l'année précédente. Le Dairy ordonna que cent jours de fuite, à commencer par le vingtićme jour du premier mois, on diftribueroir du Ris boülli aux Pauvres, \& que cette difribution fe feroit dans tout l'Empire à fes dépens. La h'ritiéme année, il y eut de gran 1 des tempêtes à Ozaca, \& dans plufieurs Pro- 
OU Empereurs Heredit. du Japon. $2 x x x i i j$ vinces maritimes. Elles furent fuivies d'inondations, \& d'une grande mortalité fur les Honmmes \& fur le Bétail.

La neuviéme année, le quatriéme mois, en nettoyant le Riviere, qui pafle à Ozaca, on y trouva une grande quantité d'Or \& d'Argent, qui y avoient apparenmeut éré jettée dans le tems des dernieres Guerres civiles. L'onziéme année, le neuviéme jour du cinquiéme mois, le feu prit à quelques Edifices de la Cour du Dairy, \& fut fi violent, qu'une partie confidérable de la Ville de Meaco fut réduite en cendres; \& comme plufieurs Greniers publics avoient été brûlés, le Dairy ordonna qu'on donnât, ou qu'on prêtât trois Kokus de Ris à toutes les Familles, qui en avoieat befoin, comme il fe pratique fouvent dans les tems de famine:

\section{Récensement de Meaco.}

La douziéme année, le fecond mois, ce Prince établit un Tribunal à Meaco, pour faire le recenfement des Habitants dans cette Capitale. On trouva que dans les mille huit cents cinquante Rués, dort elle eft compofiee, il y avoit roso. Perfonnes de la Secte Ten Dai : 10070. de celle ce Singon, s 402. de celle de Folfo, r ror6. de celle de Sen, $\$ 22044$. de celle de Seodo, 99 r2. de celle de Rit, 81 986. de celle de Jooke, 4rs86. de celle de Nis Fonguans, 801 r2. de Figas Fonguans, 7406. de celle de Takata Monto, 306. de celle de Bukvvo, 2ro8o. de celle de Dainembuds, \& 6073 . de celle des Jainmabos, ce qui fait en tout quatre cents cing 
Ixxiv SuIte Chronolog oes Datrys, mille fix cents quarante-trois Perfonnes, ( fans y comprendre la Cour du Dairy) dont 182070. ćtoient mâles, \& 223572 . Femelles.

La même année, le troifićme jour du quatriéme mois, Ingen, ce fameux Docteur Chinois, dont nous avons déja parlé, mourue âgé de quarre-vingt-deux ans dans le célébre Monaftere d'Obaku; les mois fuivants, les Fruits de la Terre fouffrirent beaucoup des pluyes \& de la grêle, ce qui caufa une grande famine, \& le Dairy donna des ordres pour diftribuer du $\mathrm{R}$ is aux Pauvres dans les principales Villes. La dix-huiciéme année, \& la huitiéme du Nengo Jen Po, le huitiéme jour du cinquiéme mois, ce qui revenoit au 24. Juin 1680. Jjietznako, Empereur CuboSama, mourut, \& fut mis au nombre des. Dieux, fous le nom de Gen-Ju In Den.

\section{XXXYI. Empereur Cubo-Sama.} Tjinajofiko, ou Tfinajo-Sama.

On nommoit encore ce Prince Tfijnajofiko , \& fon nom entier, lorfque le Dairy l'eut honoré du titre de Sei Dai Seogun, ce qui arriva l'année fuivante, étoit, Sei Seogun, Nai Dai Sin i Ukon Jeno Tai So: il étoie Frere puiné de fon Prédéceffeur, \& en 1643. il étoit âgé de quarante-trois ans.

La vingtiéme année, \& la feconde du Nengo Tenwa, il y eut une grande famine \&: une grande mortalité au Japon', particuliérement à Meaco, \& aux environs. Le douziéme mois de la même annće, il y eut un: incendie à Jedo, \& la plus grande partie de. cette grande Ville fur réduite en cendres. La: 
ou Empereurs Hered. du Japon. Lxxxy La vingt-uniéme année, Tokumatz, Fils unique du nouveau Cubo-Sama, \& fon héritier prélomptif, mourut; on en "porta le Deitil dans tout l'Empire, \& il fut défendu de joijer d'aucun Inftrument de Mufique, \& de faire aucune Réjoiiiffance pendant trois ans. La même année, le cinquiéme jour du douziéme mois, il y eut encore fune Incendie dans Ville de Jedo.

Kinfen après avoir régné vingt-quatre ans, réfigna la Couronne à fon Fils. On ne dit rien de fon âge.

\section{De T. C. CXIV. DAIR Y. De Syn-Mu。 1687. $2347^{\circ}$ \\ Go Kinsen o ou Kinseokwo Tei。}

Ce Prince inftitua le Nengo Genroku dont la cinquiéme annće eft l'an 1692. de J. C. Les noms de ces cent quatorze Dairys font tirés d'une Chronique Japonnoife, imprimée dans la Langue Sçavante des Chinois. 


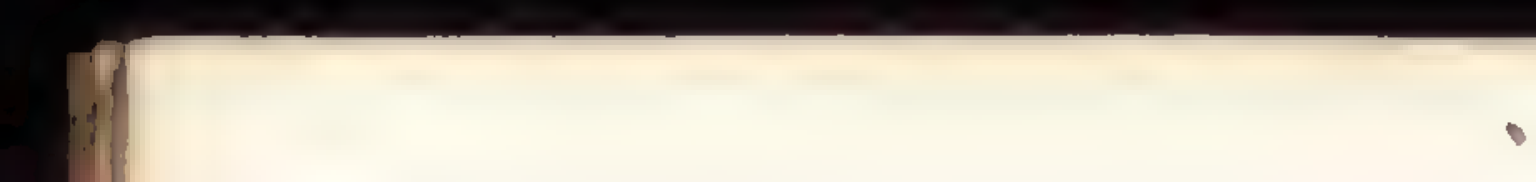




\section{SOMMAIRE}

\section{DU PREMIER LIVRE.}

TDCOUVERTE du Japon. Aventure finguliere de Fernand Mender Pinto d la Cour du Roi de Bungo. Un Gentilhomme Japonnois va chercher aux Indes S. Francois Xavier: Ses diverses Aventures. It y eft baptifé par le Saint avec Ses deux Domeftiques; $\int a$ ferveur. Le Saint pafe au Japon avec deux autres Jéfuites. Vertu de la Croix. Dangers, que l'on court fur les Mers du Japon. Ce que c'eft que les Typhons. Le Saint arrive au Japon. Comment il y eft reçu du Roi de Saxuma. Il prêche publiquement d Cangoxima. Converfions, qu'il y fait. Il refJufcite un Mort. Is eft infulté par un Idolâtre, qui en eft puni fur le champ. Efforts inutiles des Bonzes contre lui. Conduite intérefée du. Roi de Saxuma. Ce Prince fait publier un Edit contre la Religion Chrétienne. Effet qu'il produit. Le Saint part de ce Royausne. Ce qui lui arrive dans un Château. Comment il eft reçu d Firando. Il part pour Meaco: Temple fameux, E a quelle occafion il fut bâti. Le Saint arrive à Amanguchi, Capitale du Royaume de Naugato. Il confond un Bonze en préfence du. Roi. Il pourfuit $\int a$ route vers Meaco. Il prend les devants; ce qu'il fait pour ne pas s'égarer. En quel état il trouve cette Capitale de l'Empire. Il retourne a Firando, Er change fon extérieur trop né- 
gligé. Il va d Ainanguchi, où il eft bien reģu du Roi. It fait un grand nombre de Converfions E de Miracles. Difficulter, qu'on lui propose, Er comment il y répond. Belle action de Jean Fernander, Son Compagnon, Eo quel en fut le fruit. Conver jion d'un jeune Docteur, que le Saint reçoit dans Ja Compagnie. Vains efforts des Bonzes pour rétablir leur crédit. Le Roi changé à l'égard des Mifionnaires. $S$. Frangois Xavier pafe au Royaume de Bungo: les Portugais vont au devant de lui. Caractere du Roi de Bungo. Ce qui lui avoit donné de l'eftime pour la Religion Chrétienne. Il invite le Saint a le venir voir. Comment les Portugais Se conduifent d l'Audience de ce Prince. Comment il en eft reça. Honnieurs, que le Roiluifait.Succès de Ses Prédications. Les Bonzes veulent Soulever la Populace. Succès du $\boldsymbol{P}$.de Torrez à Ainanguchi.Les Bonzes engagent un Seigneur du Naugato à Se, révolter contre le Roi. Ce Prince eft tué. Une Princeffe idolâtre Sauve la vie aux Mifionnaires. Le Frere du Ro: de Bungo eft élu Roi de Naugato. S. Frangois Xavier Se difpose de retourner aux In!es. Tandis qu'il prend congé du Roi de Büngo. Un Bonze célebre demande a difputer contre lui en préfence de ce Prince. Il accepte le déf, Er confond le Docteur. Les Bonzes ex = citent une Sédition. Belle action d'un Capiraine Portugais. La difpure recommence, quel en fut le fuccès. Le Saint retourne aux Indes. Ce qu'il dit au Rui avant que de partir. 


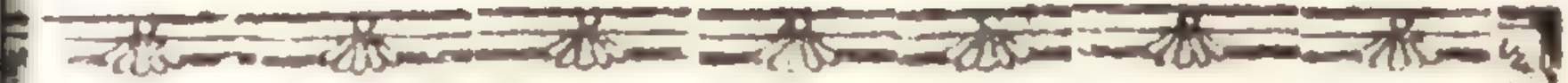

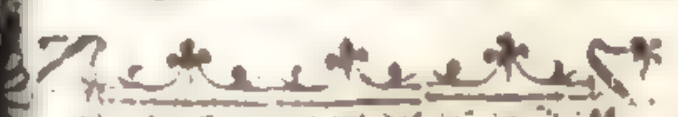
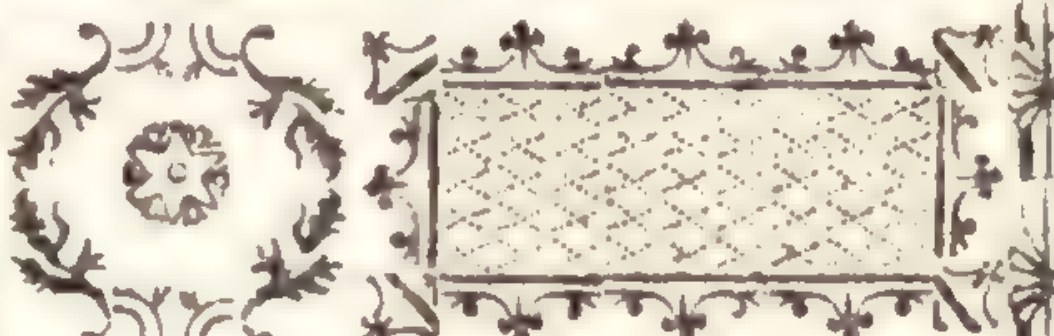

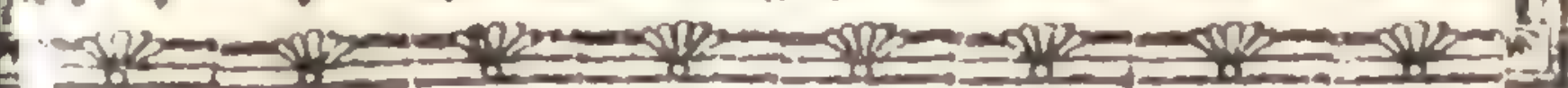

\section{H I S T O I R E \\ D U}

J A P O N.

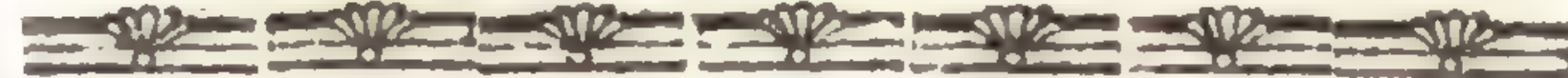

\section{LIVRE PREMIER.}

I n'y a pas liea de s'étonner, ce III I dans les Forêts, \& contens du peu, in que la Terre leur fourniffoit d'ellemêrne , ou qu'ils pouvoient fe procurer par la Challe \& la Pêche: des Hommes fans Société, fans Police, fans Arts, fans Sciences, fans aucun Commerce, fans Tradition, fans connnillance du pallé, fans prévoyance pour l'avenir, Céparez du refte du Monde par d'affreux Léferts, ou de valtes Mers, fur lefouelles il ne leur venoit pas à l'efprit, qu'on pût naviguer au-delà de quelques Ifles voifines: il n'êt pas, dis-je, furprenant que des pumples de ce caractere, ayent ignoré pendant une fi longue fuite de fiecles, qu'il y eût fur la Terredes Nations, qui eulfent une façon de vivre, des Coutu- 
mes $\&$ dees Mours fi différentes des leurs, \& \& n’ayent pasmême eu la penlée de fe livrer à l'Océan, qui les bornoit, four voir s'il ne leur cachoit pas un autre Monde. Il eft biens plus Etonnant, fans doute, qu'avec l'expérience \& les lumieres, qu'avoiene nos Ancêtres, ils ayent découvert fi tard la moitié de la Terre habitée.

Mais qu'une Mmarchie floriflante, une Nation civilife, hardie, curieufe, entreprenante, avide de gloire plus qu'aucuhe autre, \& comprant pour rien les plus grands dangers \& la mort même, ait pendant plus de deux mille ans borné fes découvertes à l'Empire de la Chine, à quelques Provinces de la Tartarie, \& à un petit nombre d'Illes aflez peu éloignces; c'eft qu'il n'elt pas aifé de comprendre, \& peut-être n'y-t'il eu que la difficulté de le croire, qui ait pû faire inaginer fur de vains rapports de noms, \& des étimologirs forcées; qu'une partie de l'Amérique avoit étć peuplće par les Japonnois ( a). D'autre part, quelle dût étre la furprife de ces Infulaires, lorfqu'ils apprirent qu'au-delà de ces Mers, qu'ils avoient regardées comme l'extrémité du monde, il y avoit une fi prodigieufe étenduë de Continent, des Ifles plus grandes que les leurs, des Royaumes fans nombre, \& de fi vaftes Empires, que ce yu'ils avoient connu jufques-là de l'Univers, n'étoit prefque rien en comparaifon de ce qu'ils en avoient ignoré ?

(a) Voyez Grorgi Horve de eriginibus Ameriaswis, où l'Auteur fait venir CHIAPPA de JAPON, \& fais deferadre Motesuma des Japomois, fur ce yule ces Infilaires ont pluficurs terbabailons ude noms en SAMA, đac. 
Quoigu'il en foit, ce fut l'annće de JefusChirit is 42. deux mille deux cents deux ans après la Fondation de la Monarchie Japonnoile par SXN MU, fous le régne du cent fi-droitso xiéme DARY, ou Empereur Hérédicaire, \& $f$ us le Gouvernement fouverain du vingttroifićme CUBO-SAMA, que de purs hazards firent connoître les Illes du Japon aux Europiens.

Ce qu'il y a de fingulier dans cer Evénemene, c'eft que deux accidents affez femblables obligerent deux Navires, l'un Chinois, \& l'autre Portugais, d'aborder à ces Ines, la. mème année, à peu près dans le même teins, \& fans que l'un eût connoilfance de l'autre; enforte que les Portugais, qui étoient fur tous les deux, fe crurent également en droit de s'attribuer l'Honneur de la premiere découverte de ce grand \& fameux Archipel; \& que par le peu de foin, qu'ont eu les uns \& les autres de maryuer les dates; ou par celui, qu'ils prirent de les fupprimer, il n'a jamais ćté poffible de fçavoir au jưte à qui cet Honneur aptrartenoit. Il paroît même que dans le tems, où il étoir aifé de s'inftruire de ce fait, on ne s'eft pas mis en peine de s'en informer, par la raifon fans doute; que pendant plufieurs années, on ne parla gueres, que de la découverte du Japon faite par le Navire Portugais; \& il faut convenir, que lc filence-de prefgue tous les Hiftoriens fur l'Aventure du Navire Chinois, laquelle femb’e n’avoir érế publiée, qu'après que FErNAND MEndez Pinto eut mis au jour fes Mémoires; eft un grand préjugé pour la fairegarder comme un rrai Roman. Voici donc 
4 HISTOIRE DU JAHON;

en peu de mots ce que rapporte ce Voyageur dans fes Mémoires, touchantla découverte, qu'il prétend avoir faite du Japon $(a)$.

Il fe trouvoit avec deux autres portugais, nommés Diego Zeimoto, \& Christolihe BORRELLO, dégradé à LAMPACAO (b) Pore de la Chine, \& fort embarallé a tronver une occafion pour retourner aux Indes; lorfqu'un Corfaire Chinois, nommé SAMrpocheca, qui failoir la courfe dans ces Mers, arriva dans ce Port, \& leur offrit de les recevoir dans fon Bâtinient, qui étoit de ceux, qu'on appelle Joncs au Japon \& a la Chine. Cet Homme leur avoit donné parole de les conduire aux Illes LEQUIOS, qui étoient for connuës des Portugais, mais les vents coutraires ne lui permirent pas d'y aborder; \& après qu'il eut long-tems batcu la Mer, la nćcellité de fe radouber, \& de faire de l'eau $\&$ du bois, l'obligea de toumer vers une Ille du Tapon, appellée T anviximaA (c).

Dès qu'on l'y eut découvert, on envoya deux Barques, pour fçavoir qui il ćtoit , \& ce qu'il prétendoit: il répondit qu'il venoit de la Chine, que fon Bâtiment étoit chargé de Marchandifes, \& que fon delfein éroit de trafiquer, s'il pouvoit en obtenir la permiffion. Celui qui portoit la parole, lui dit yue le Sei. gneur de line, nommé Naura eurm, y con(a) On a regardé cumme fabuleux ce voyage de
Fernard Mendez Pinto.

(b) Ce Port eft le mêtre que $\mathrm{M}_{\text {rcra. }}$

(c) Il y a roub lieu de croire, que cerpe Ine eft ia meme, qu celle de Tacuxima, au Royaumi de 


\section{LIYRE PREMIER。}

Tentirnit volontiers, mais à condition qu'il payeroit les droits: \& comme il ne fit fur cela aucune difficulté, cet Homme le traita fort poliment, lui nıontra le Port, \& l'y conduifit. Ce Port, que Pinto nomme MiaygIMAA (a), ćtoit fort peuplé, \& le Bâtiment Chinois y eut à peine jetté les Ancres, qu'un grand nombre de Barques l'environnerent, \& offrirent à l'Equipage toutes fortes de rafraîchiflements, gu'il acheta.

Deux heures après, Nautaquim parut avec une fuite de plufieurs Gentilshommes, \&r quelques Marchands. La vûë des trois Portugais le furprit, \& il demanda au Capitaine, ou il avoit pris ces Etrangers, \& de quelle Nation ils étoient. Samipocheca répondit qu'ils venoient d'une grande Ville, nommée MaraCA, \& qu'ils ćtoient d'un Royaume de la grande Europe, appellć Portugal. A ces mots, Nautaquim parut interdit, \& quelques moments aprcs, fe cournant vers ceux, qui l'accompagnoient: " Je veux mourir, leur dits il, fí ce ne font point là de ces CHINCHI$\leadsto$ COGIs, dont il eft écrit dans nos anciens "Livres, que volant fur les Eaux, ils doi"vent fe rendre Maitres de toutes les Ter"res, qu'elles environnent, \& fur-tout des $\Rightarrow$ Pays, qui pollćdent de plus grandes richef$\Rightarrow$ fes. Nous ferons fort henreux, ajoûta-t-il, $\Rightarrow$ s'ils veulent bien fe contenter d'être nos $\Rightarrow$ Alliés.

(a) Quoique nous ne connoiffons point au Jayon de Ville qui porte cenom; cela ne deit puint artêter le Lecteur, par la raifon que les noms des Villes \& des Provinces du Japon font fort diverfement rafportez dausles Rei it uns a ies Hiftoires. 
ter la parole, avouë franchement, qu'en répondant aux Queltions, qu'on lui fit, il eut moins ćgard a l'exacte vérité, qu'à la néceffité, où il fe croyoit, de donner aux Japonnois une grande idée de fa Nation, \& de la Puilfance du Roi fon Maitre. Il ajoûte qu'un tel aveu, que rien ne l'obligeoir a faire, doir convaincre fes Lecteurs de la fincérité, \& les empêcher d'être trop en garde contre le merveilleux, qu'ils trouveront dans fes Mémoires.

Nautaquim l'interrogea fur trois choles, que des Chinois \& des Lequiens lui avoient dites: la premiere, sill était vrai que le Portugal fut plus grand \& plus riche que la Chine? la feconde, fi le Roi de Portugal aroit véritablement conquis la plus grande partie du Monde? La troifiéme, fi ce I'rince avoit deux mille Maifons toutes pleines d'Or \& d'Argent? Pinto lui affura qu'on ne lui avoit rien dir de trop fur ces trois Articles; il confefla néanmoins qu'il n'avoit pas une connoillance exacte de tous les Palais du Roi fon Souverain, parce qu'il n'avoit jamais crû avoir befoin de faire ce compre, difficile d'ailleurs dans un Empire fi vafte. Alors le Prince Japonnois fe tournant vers les fiens, “ il n'y $\Rightarrow$ a pasfur la Terre un prince heureux, leur 3 dit-il, sil neef pas Vallal d'un fi Puillant - Monarque. Il retint les Portugais julyues bien avant dans la nuit, \& leur fit préparer un Logis proche de fon Palais. Il en afígna aufi un pour le Capitaine Chinois, afin qu'il y pût faire commodément fa traite: elle le fir de bonne foi de part \& d'autre, \& le Corfaire avoúa aux Portugais, que fa Carguai- 
fon, qui ne lui avoit contté que deux mille cinq cents Taéls, lui en avoit valu trente mille.

Avaniure

Pendant ce tems-là, Pinto \& fes deux Comfinguitere de pagnons de Voyage fe divertilloient a la chafHern nd Mcn- re, \& a la pêche: ils vifiterent auffi les Temdez Panto à ples, qui étoient en grand nombre dans la Ville Kordebungu. \& aux environs. On leur faifoit partout de grandes amitiés, \& ils apperçurent dès-lors, ce que l'on à fouvent remarqué dans la fuiit, que les Japonnois prennent naturellement beaucoup de plaifir à converfer avec les Etran!gers. Zeimoto avoit une très-belle Arquebuie, qu'il avoit achetće en Tartarie; nos Infulaires n'avoient jamais vû d'Armes à feu, \& ils parlerent de celle-ci avec admiration à leur Seigneur, qui voulut en voir l'effet. Il en fut furpris au-delà de ce qu'on peut dire, $\&$ on n'eut pas de peine à lui perfuader, qu'il y avoit là quelque chofe de furnaturel. Zèmoto fut regardé comme un Homme extraordinaire, Nautaquim le fit monter fur un de fes Chevaux, voulut qu'il traverât toute la Ville précédé d'un Hérault, qui déclarât à haute voix, que ce Portugais étoit fon $\mathrm{Pa}$ rent, \& devoit déformais ĉtre regardé comme tel. Lui-même l'accompagna dans cette efpéce de Triomphe, \& lui fit enfuite donner un Appartement dans fon Palais. Zeimo. to répondit a ces marques de diftinction, en failant au Prince préfent de fon Arquebufe, \& Nautaquin lui envoya fur le champ mille Taels. Comme les Japonnois font fort induftrieux, ils imiterent bien-tôt ce qu'ils avoient tant admiré d'abord, \& lorfque les wois Portugais partirent du Japon, oi ils de- 
meurerent cing mois, les Arquebufes étoient déja fort communes dans ce Canton.

Il y avoit un mois que nos Aventuriers étoient à Miaygimaa, \& le Corfaire Chinois fe difpofoir à faire voiles, lorfqu'on vit arriver dans ce I'ort un Bàtiment envoyé par le Roi de Bungo, avec tin. Gentilhomme chargé d'une Letrre de ce Prince ponr Nautaquim; lequel layant lüè, fit appeller les Portugais pour la leur communiquer: Elle ćtoit conçûè en ces termes.

"Ortgendoo Roi de Bungo, Eo de Fa》CATAA.(a), Seigneur de la grande Maifon 》de Fianzima, de Tossa, G de Bandau, $\leadsto$ Souverain des petits Rois des Ifles de Gor»ID, E de Ximonosexr : Mon cher Fils, э) qui m'êres aullicher, qu'à celui, dont vous $\Rightarrow$ avez reçu le jour; j'ai appris qu'il elt arఎ rivé dans votre Ine trois Chinchicogis; que 2) vos Sujets font for charmés de ces Etran2 gers; que ce ne font point des Marchands $\rightarrow$ venus pour trafiquer; mais des Perfonnes 3. de Condition, d'une grande fagene, \& qui s n'ont que l'Honneur en recommendation. $>$ Je comprends bien par-la qu'il y a d'autres s Pays dains le Monde, pius valtes que le s nôtre, habités par une infinité de Peuples э de différentes couleurs, \& l'on m'a infors) mé que ces Etrangers vous ont inftruit de $\leadsto$ tout ce qui regarde ces vaftes Régions: a c'elt ce qui m'engage à vous prier, mon

(a) Facata cft, felon toures les Relations Porens gaifos, la Capiale du Royaume de CHacugers. Ce double $A$, que pinto met ici prefque partout aux finales, peut faire juges g̨he les Japonnois prononcente ain/i.

Tome II. 


\section{HISTOIRE DU JAPON,}

s) cher Fils, de me les envojer avec Frrn"GEANDONO mon Amballadeur, afin qu'ils " puillent me confoler dans les maux, que $\Rightarrow$ je fouffre, \& que vous n'ignorez pas. Si „vous avez quelque peine à vous en priver, s. je-vous donne ma parole royale de vous s les renvoyer dans peu. Je me remets pour s. le refte a mon Ambafladeur, par leyuel s) jattends avec impatience de vos nouvelles, " \& de.celles de ma chere Fille. A Fucheo, s le feptićme de la préfence Lune.

Nautaquim, après avoir communiqué cette Letre aux Portugais, leur dit: " Le Roi » de Bungo, mes chers Amis, elt mon Sei» yneur \& mon Oncle, Frere de ma Mere; s. je le regarde comme mon Pere, \& je ne $)$ lai donne point d'autre nom : d'ailleurs »ma Femme eft fa propre Fille, \& je puis » dire, qu'il me chérit autant qu'aucun de " Ces Enfans. Voili bien des raifons pour ne "L lui rien refufer de tout ce qui eft en mon s) pouvoir; auffi je m'eftimerois Heureux de $\Rightarrow$ le pouvoir fervir aux dépens de tout ce » que je pofféde, \& même de ma vie. C'en s) eft alfez pour: vous faire connoitre que 2) vous mobligeres fenfiblement de vuloir » bien condefcendre a ce qu'il défire de vous. Je ne prétends pas néanmoins que vous $\Rightarrow$ falliez tous trois le V'oyage, il fuffira qu'un 》 de vous aille à Fucheo, \& je ne veux point s que Zeimotos mon Parent, s'éloigne de moi. Fint, \& Borello prirent auffi-tôt la parole, Se dirent au Prince, quils étoient ravis de trouver, une occafion de reconnoitre les obligasions; qu'ils lui avoient, \&x qu'il pourroir choifir celui des deux, qu'il jugeroit à prow 
gos dervoyer au Roi fon Oncle \& fon BenuPere. Le Prince fut quelque-tems fans ré pondre; pais montrant Pinto': ce Celui-ci, " dit-il, qui paroit pius jovial, \& moins fé"rieux, conviendra mieux pour ce que fou" haite le Roi, mon Seigineur; jeftime fort " Ia gravité de fon Compagnon, elle le ren"droit plus propre aux grandes Affaires, " mais elle ne guériroir pas la Mélancholie, 3 que caufe an Roi l'état d'infirmité, où il 3 eft. I appella enfuite l'Amballadeur, \& lui dit quil pouvnit partir, quand il voudroit, \& emmener Pinto avec lui. Il fit toucher deux cents Taèls à celui-ci, lequel ayant pris congé du Prince, \& embralfé fes Compagnons, s'enbarqua fur le Navire de Bungo.

Arrivé à la Forterefle d'O s Qu I I (a), laquelle eft éloignce de fepr lieues de Fucheo; i) y féjourna deux jours, au bout defiquels l'Ambaffadeur \& lui le rendirent par Terre à la Capitale, où ils arriverent le même jour. Le Roi ne l'eut pas plutôt appris", qu'il les envoya complimenter par un de fes rils, jeune Prince de neuf ou dix ans, auquel l'A mbalfadeur remit une Letre, qu'il avoit te Nautaquim, pour le Roi fon Pere. Origendoo l'ayant liè", donna ordre qu'on lui arnenât le Portugais, \& le reçut avec beaucoup de diftinction. Il lui demanda, fi dans les Iays, ou il avoir écé, la goutre, qui le tourmentoit au point de lui rendre la vie infupportable, étoit connuë, \& s il ne fçavoit point de reméde contre ce mal? Pinto lui répondit

(a) Uluqui, ou Vofuquio 


\section{W. HISTOIR DU JAPON;}

qu'il n’éroit pas Méciecin, mais qu'il avoir apporté de la Chine d'un Bois, qui avoit La vertu de faire celler les plus vives douleurs, \& qu'affurément, fr Son Altefle (a) youloir en faire ufage, elle feroit bien-tôt foulagée. Le Roi enyoya aufí-tôt dans l'Ine de Tanuximaa, pour chercher ce Bois, que Pinto y avoit laiffé : celui-ci le fit infufer dans l'Eau, fit boire de cette Eau au Prince, lequel au baut de quelques jours ne fentit plus aucune douleur, \& Ce leva, ce qu'il n'avoit pû fairo depuis deux ans.

On peut juger des Careffes, qu'une telle guérifon attira à pinto, \& il n'y eut point de fortes de divertiffements, qu'on ne cherchât à lui procurer. On n'avoit pas été moins furpris dans cette Cour, que dans celle de Nautaquim, de l'effęt merveilleux des Arquebufes; mais il arriva à cette occafion un accidene, qui penfa coûter cher à Pinto. Le Prince Héritier, qui avoit environ feize à dixfept ans, \& qui felon toutes les apparences eft ce même CIVAN, dont nous aurons dans la fuite tant d'occafrons de parler, voulut avoir le plaifir de tirer quelques coups d'Arquebufe. Pinto s'y oppofa autant qu'il put, en faifantentendre au Prince qu'il y avort du dangur à manier cette Arme, quand on ne la comnoilfoit pas alfez. Le Prince infifta, \& fe plaignit môme au Roi fon Pere du peu de complaifance de l'Etranger. Le Roi pria celui-ci d'accurder à fon Fils ce qu'il fouhaitoit: il fallut fe rendre, \& le lendemain, qui étoir

(a) Pin'o ne polivuit pas donner au Roi de Bun.

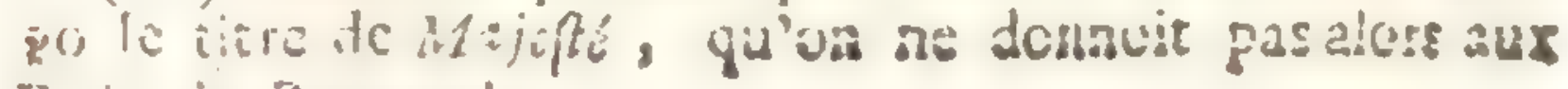
Ruis de Portugal. 


\section{LIYRE PREMIER。}

le cinquiéme d'Août, le jeune Prince alla de grand matin all Logis de Pinto, qui avoit promis de le mener ce jour-là a la Challe. Il le trouva, qui dormoit encore, \& ne vcnltt point qu'on l'éveillât, mais ayant pris fon Arquebufe, it alla dans la Cour du Logis ponr s'ellayer a tirer. Comme il ne Cçavoit pas la mefure de la Poudre, qu'il y falloit metre, il en mit exceffivement, \& ayant voulu tirct, l'Arquebufe créva entre les mains; il eut le rouce de la main droite prefun'emporté, \& un éclat le bleffa à la Tête; il tomba à la renverfe, \& on le crut mort.

La nouvelle de ce malheur fe répandit en un inftant dans toute 12 Ville, \& ait lieu de s'en prendre a l'indifcrétion du jeune Prince, cu à l'imprudence de ceux, yui l'accompagnoient, on publia que l'Arquebule enchantée de l'Erranger avoit tué l'béritier de la Couronne. Ce difcours excita un foulevemene général contre Pinto, qui réveillé par le bruit, courut, fans f̧̧avoir de quoi il s'agiforir, a! lieu, ou l'accident étoit arrivé. Lee premier objer, qui s'offrit à fes yeux, fur le jeune Prince, qui nâgeoit dans fon fang : comme il ignoroit encore la caule de ce malheur, il fe jetta tout perdu \& hors de lui-mene fur ce corps, qu'il croyoit fans vic : le Roi futvint dans le nroment, porté dans une efpéce de Brancard, \& deni mort; la Reine le li:noit à pied fondant en larmes arec bes deu: Filles, qui toutes échevelées, jettoient des cris lamentables. Toute la Cour s'y rendit à l'inftant, \& à la vûè du Prince, qui ne donnoit aucun figne de vie, \& de Pinto, qui écoit couché fur lui, - \& plein de fang, il n'y A iij 
eut Perfonne, qui ne crût que cer Etrangę avoit fait le coup. Deux Soldats coururent aufli-tôt à lui le fabre nu à la Main, \& lui en alloient caffer la Tête, lorfque le Roi leur cria d'arrêter, \& qu'avant que de faire juftice du Meurtrier, il vouloit fçavoir, qui l'avoit engagé à une action fí noire?

Le Prince parloit ainfi, parce que la veille on a voit exécuté à mart quelques Gentilshommes pour crime de Trahifon, \& l'on foupçonnoit leurs Parents d'avoir voulu venger leur mort fur le jeune Prince. Le Roi fit enfuite appeller deux Domeftiques, qui avoient Eté témoins de ce gui s'étoit pallé, \& les interrogea fur ce qu'ils avoient vû. Ils réponcirent que l'Arquebure du Chinchicogi avois ôté la vie à leur Maître, \& que fans doute elle étoir enforcelée. D'autres, qui avoient aufi été préfents, firent la même réponfe, \& tout le Monde s'écria aufli-tôt; que cet Etranger méritoit la mort la plus cruelle, \& gu'on ne devoit pas différer fon fupplice. Le Roi dit qu'il falloit entendre le Coupable lui- même, \& fit appeller linterpríte, gui faif de frayeur s'était enfui. On le chercha $\&$ on le trouva enfin. Le Roi lui ordomna avec les pius terribles menaces de dire la vérité; on fit venir trois Secrétaires pour écrire les réponfes de Pinto, \& cing Bourreaux parurent le Sabre nu à la Main. On avoit commencé par lier les Mains de l'Accufé, \& on le fit mettre à genoux devant le Roi.

Alors un Bonze nommé Asqueram TeIXe, qui éroit Préfident du Tribunal Criminel, s'approcha de lui, \& d'un ton de voix terrible, lui dit: „s Enfant du Diable, qui ne dois 
; attendre d'autre fort, que celui de ces 2Malheureux Criminels, renfermćs dans la 2 profonde Caverne de la nuit, laquelle eft „2 au centre de la Terre, je te conjure de $\leadsto$ ine dire qui t'a poutlé à faire mourir par " tes Enchantements ce jeune Prince, l'or» nement \& l'efpérance de ce Royaume. Pinto ne répondit rien; il étoit encore fi troublé, qu'on auroit pû, dit-il, lui donner le coup de la mort, fans qu'il l'en̂t fenti. Le Bonze choqué de fon filence, lui déclara d'un ton encore plus effrayant, que s'il s'obftinoit à le garder, on le prendroit pour un aveu de fon crime, \& qu'il devoit s'attendre à l'expier par les plus horribles tortures. Pinto n'étoit point encore revenu à lui, \& ne dit mot: alors te Bonze lui donna un grand coup en difant, parles donc, E dis-moi qui t'a poufee a un forfait $f$ odieux! le coup fit fon effet, Pinto reprit fes fens, \& s'écria; Dieu $\int_{\text {crait }}$ que je Juis Innocent de ce qu'on m'impute, E. que je n'ai fcu ce qui eft arrivé, qu'arrès le coup Fatal, qui a ôté la vie au Prince.

A ces mors toute l'affifance jerta un cri de fureur, \& pour obliger le puérendu Criminel à confeller fon crime, \& à découvrir fes Complices, on ćtala devant lui l'appareil des tortures, aufquelles on alloit l'appliquer, s'il perfiftoit à ne rien dire. Dans ce moment le Prince revint à foi, \& voyant le Roi fon Pere abîmé dans la douleur, la Reine \& les Princelles noyées dans les larmes, les Courm tifans la cclere dars les yeux, un grand Pevple furieux, des Bourreaux arnés de tou:es forres d'Inftruments de fupplice, \& le Portugais prêt à enfanglanter certe horrible Scí- 


\section{I6 HISTOIRE DUTATON;}

ne, il protefta d'une voix languillante, gre lui feul étoit la caufe de fon malheur, qae l'Erranger n'y avoit aucune part, \& qu'il fupplroit le Roi de lui faire délier les Mains. Le Roi lui accorda fur le champ certe farisfaction, Pinto fut mis en liberté, \& quatre Bonzes s'avancerent pour panfer le Prince; mais ayant vî la profondeur de fes Playes, ils fe retirerent, en difant qu'il n'y avoit point dans le Monde de Reméde, qui pût le gućrir. Le Malade fut faifi de frayeur, en les entendant parler ainfi, \& pria qu'on lui fit venir d'autres Médecins. Quelques Bonzes s'avancerent, mais ils n'oferent encore mettre la Main à fes Plajes, ils ne lui en témoignerent pourtant rien, mais ils dirent en particulier au Roi ce qu'ils en penfoient. Le R i au déferpoir, demanda fi on ne connoifoit point de Médecins plus habiles que ceux-ci? \& on lui indiqua un autre Bonze nommé TEIXE ANDono, qui avoit une grande réptitation, mais il demeuroit à FACATA, éloigné de foixante \& dix lieués de Fucheo. Le Roi concevait bien que dans l'ćtat, où éroit fon Fils, on n'avoir pas le tems de faire venis ce Bonzo; le Prince lui-nême dit que quand cet Homme le rrouveroit en vie, \& il éreit fi foible, qu'alors le Reméde ne pourroit pas opérer; quion le laillat feul avec l'Etranger, on qui il avoit une entiere confiance; $\varepsilon_{i}$ que s'il avoir à mourir, il aimcit mieux que ce fût entre les Mains d'un Homme, qui avoit tant fouffert à fon occafion, gu'en celle d'un vieux Charlatan, à qui l'âge avoit ôté la vîé.

Le Roi ne fçavoit à quoi fe réfoudre: enfur fe tounant vers PINTo, voyez, lui ditm 
il', $f$ vous pouver me rendre mon Fils: vous m'obligerez d un point, que tout mon Royaume ne fuffira point pour vous en marquer ma reconnoiffance. Pinto lui allura qu'il efpéroit en venir à fon honneur, mais qu'il falloit conmencer par écarter la foule, parce qué les cris, qu'elle faifoit, ne lui perniettoient pas de fe faire entendre. Le Roi trouva cette propofition raifunnable: chacun eut ordre de fe retirer, \& Pinto ayant vilité les Playes du Prince, remarqua que le crâne n'étoit point offenlé, mais que le pouce ne tenoit prefque plus à la Main. Il ne laiffa point de promertre au Roi qu'en moins d'un mois le Prince feroit guéri; \& il fe difpofoit à lui mettre le premier appareil, lorfque les Bonzes protelterent que, fi cet Etranger touchoit aux Playes, le Prince mourroit la nuit fuivante. Ils ajônterent que le plus court étoit d'appaifer au plutôt les Dieux, en coupant la Tếte à un fi dangereux Homme; finon, que le Roi auzoit le chagrin d'avoir lui-niéme contribué à la mort de fon Fils. Le Ròi plns irréfolu que jamais, demeura fans parole." La Reine \& les Princefles étoient dans la dernierè décolation; le Prince, qui fouffroit les plus violentes douleurs, pouffoit des cris ; qui "auroient fend les pierres: les Bonzes faifoient grand bruit, $\&$ vouloient qu'on envoyât chercher leur Confrere de Facata, \& les Courtifans applayoient cet avis, en dißant que le Bonze n'turoit pas plutôt tơché les playes du Malade, qu'il leroit gueri; que ce ne leroit fas la premiere ouvre miraculeufe, que ce farnt Homme aitIoit faite.

Le. Ro éroit fur le point de ferondre, lor i:- 
que le Prince recommença à dire, qu'il ne punvit pas attendre plus long-tems, qu'il fo lifroit trop, \& que certainement le Bonze le trouveroit mort. Le Roi demanda à quelques-uns des plus Sages de fa Cour ce qu'ils en penfoient, \& ils répondirent que le Prince avoit raifon, \& qu'il y avoit moins d'imprudence à tenter les Remédes du Portugais, qu'à lailler fi long-tems le Malade fans foulagement. Alors le Roi prit fon parti, fit mille carelfes à pinto, les accompagra des promeffes les plus flatteules, \& le conjura de ne plus différer à panfer fon Fils. Pinto obéit, \& après s'être recommandé au Seigneur, fít ce qu'il avoit fouvent vû faire en pareilles occalions, aux Chirurgiens de fa Nation dans les Indes. Enfin, il eut alfez de bonheur pour xéuffir, \&z le Prince fut fur pied en moins de vingt jours, de forte qu'il ne lui reftoit plus que les cicatrices, \& un peu d'engourdilfement dans le pouce. Il eft aifé de comprendre quelle furt la joye de toute la Cour s le Roi \& la Reine comblerent l'heureux Médecin de préfents, \& il convient que cette cure Iui valut quinze cent Taëls.

Sur ces entrefaites, il eut nouvelle que le Corfaire Chinois fe préparoit à appareiller, \& il demanda fon congé. On le luri accorda avec regret, \& le Roi liri fit équipper un Bâtiment bien fourni de rafraîchilfements, \& lui donna un Gentillomme pour l'accompagner. Il refta encore quinze jours à MIAYGIMAA; \& s'étant enfin embarqué, il alla prendre terre au Port de L I Chine, où ceux de fa Nation faifoient alors un très grand Carmierce. Au reite, je ne 
prétends point garantir toutes les circonfances de ce récit: l'Auteur, à ce qu'il paroît, aimoit le merveilleux \&, l'on a long-tems éré en garde contre fa fincérité; mais ceux qui ont été après lui fur les lieux, qu'il a parcourus, lui ont rendu la mêne jutrice, que bien des Gens rendent aujourd'hui à XEHOPHON; à f̧̧avoir, que s'il a un peu cherché à orner la vérité, il ne l'a point défigurée. Il eft furtout bien difficile, ce me femble, de regarder tout ce qu'il dit ici, comme un épifode entiérement Fabuleux; furtout, fi l'on confidere qu'il a écrit dans un tems, où plufieurs Perfonnes pouvoient le démentir.

Mais fi pinto en a trop dit fur la découverte du Japon, qu'il prétend avoir faite, ceux, à qui feuls on fait communément honneur de cet Evénement, n'en ont point dit affez; car tout ce que nous fçavons de leur Aventure, c'eft que trois Portugais nommés antorne Mota, Françots Zeimoto, \& Antorne Pexota, qui étoient partis de Do. DrA, au Royaume de Cron, dans l'Ife MACAÇAR, pour aller à la Chine, furent jettés par une tempête fur les Côtes du Japon, prirene terre à Cangoxima, au Royaume de SAXUMA, la neême année 1542. que Dona Martin alphonse de Sosa, Gouverneur géneral des Indes, aborda à GoA, menarit avec lui le P. FRançors XAVIER, un des díx premiers Jéfurites, \& auquel la divine Providence avoir réfervé l'Apoftolat d'une Nation, qui devoit faire tant d'honneut à leglife de Jefus-chrilt.

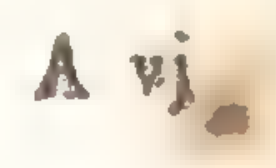




\section{0}

HISTOIRE DU JAPON;

Un Genti. Les trois Marchands ne furent pas long:iromme Ja. tems a Cangoxima, fans faire des hajtudes, gumbis ya qui noiierent allez promptement le CommerYrancois $X_{3}$ ce entre deux Peuples, que la conformité du vieraulndie? Caractere de leur Génie, porté naturellement Scs diverfos au Grand, de la douceur de leurs Mueurs, Aventures. \& d'un extérieur plein d'une gravité bienféante, lia d'une aflez ćtroite amitié, du moment qu'ils le connurent; mais ils frent furtout une connoiffance, qui dès-lors, fi elle eút été bien ménagée, eût introduit la Religion Chrétienne dans le Japon, \& done le ciel fe fervir en effer, quelques années après: pour y faire porter le flambeau de la. Foi, cé la maniere que nous allons voir. Un Habirant de Cangoxima, nommé ANGeroo, âgé de trente-cing ans, riche, \& d'extraction Noble, ayant pratiqué pendant quelques jours ces Etrangers, les igqûta fort, \& ils apprirent de lui que le fouvenir des déréglements de: fa jeuneffe lui caufoient de violents \& de continuels remords de Confcience; que pour les: appaifer, il s'étoit retiré dans une Maifon de. Bonzes, fe flattant que les entretients \&: les bons avis de ces Miniftres des Dieux pourroient mettre fin à fes inquiérudes; mais que ce Reméde, bien loin de guérir fon mal, l'avoit empiré, \& qu'il croilloit de jour en jour.

Ceux à qui il s'ouvroit de la forte, firent. apparemment tout ce qu'ils pûrent pour lo foulager, mais ils le quitterent fans y avoir. réüfli. Deux ans après, un autre Marchand. Portugais nommé AlVARE VAZ, étant allé. trafquer à Congoxima, Angeroo lui communijua aull les peines hatéricures; laz, qui: 


\section{ETRE PREMTERं}

25

comnoiffuit le P. François Xavier, \& qui avoit. conçu une grande idće de fa fainteté \& de fon pouvoir auprès de Dieu, voulut engager. le Gentilhomme: Japonnois à l'aller trouver; as c'elt un Homme chéri du Ciel, Lui dit-il, s) je ne doute nullement que vous ne trou„.. viez dans les charmes de fa converfation, »\& dans la fageffe toute divine de fes conCeils, ce que vous cherchez inutilement de-.

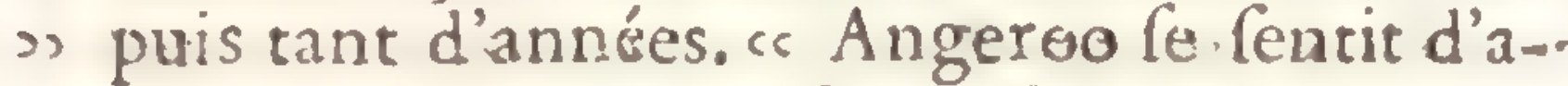
bord extremement preffé de faire ce que lui. difoit le Marchand Portugais; mais confidérant quil lui falloit abandonner pour longtems fa Famille, \& s'expofer fur une Mer, qui de jour en jour devenoik plus fameufe: par les naufrages, il ne pouvoit fe réfoudre,.. loriquayant. malheureufement tué un Hom-. ure dans une rencontre, la crainte de tomber entre les Mains de la Juftice, l'obligea, de s'embarquar fur le premier Navire, qui fir voiles vers Malaca.

Ce Navire étoit commandé par lua trèsm homnête Homme; nommé ('ieorge Alvarez, Ami particulier du. P. Xavier. Ses bons exemles, \& fes difcours édifants, firent réfou:l dre Angeroo à fe faire Chrétien, mais il ne perfíta pas long-tems dans cette réfolution; car n'ayant point trouvé à Malaca le faine Apôtre, qui en éroir parti peu-de jours auparavant, le chagrin, qu'il en conçut; lui fit oublier les raifons, qui l'avoient cuntraine de fortir du Japon, \& il ne: fongea plus qu'à y retourner. Quelques Mémoires difent néan-! moins qu'il fouhaita de, recevoir le Baptê. me, avant que de s'embarquer, \& qu'il fr. cour cela de grandes inftances auprìs de Da 
Alphonse Martinez, Grand-Vicaire de l'Evêque de Goa, mais qu'il ne put obtenir cette grace. Ce qui eft certain, c'eft qu'il partic pour la Chine, n’ayant pas trouvé de Navire, qui le remenât en droiture dans fa patrie.

Il fut quelque tems à errer dans ces Mers, les Vents contraires, \& fes irréfolutions l'arrêtant, tantôt dans un Port, \& tantôt dans un autre; \& il étoit enfin fur le point d'arxiver à Cangoxins, lorique Dieu, qui en vouloit faire le Chef des Prédeltinés de fa Nation, permit qu'une tempête, après l'avoir mis en grand danger de périr, le força de rentrer dans le Port de Chincheo, fur la Côte Orientale de la Chine, d'où il étori forti peu de jours auparavant. Le péril, qu'il venoit de courir, ranima en lui l'ardeur prefqu'éteinte d'embrafler le Chriftianifme; \& un jour quill fe promenoit far le bord de la Mer, roulant dans fon efprit les différentes penfées, quil'avoient fucceflivement agité depuis plus de deux ans, il fut agréablement furpris de voir paroître Alvare Vaz, qui allait mettre à la Voile pour s'en retourner aux Indes.

Ce Marchand Iui reprocha doucement for inconftance, l'obligea de s'embarquer avec lui, \& le remena à Malaca, où le premier Homme, qu'ils rencontrerent en débarquant, fut George Alvarez, qui leur apprit que le Pere Xavier étoit dans la Ville. Ils coururent fur l'heure le chereher, \& les premiers embraffements du Saint produifirent dans l'Ame d'Angerco un effet fi merveilleux, que ce Gentihomme fe troura tout changé, \& com- 
LIV R E R E M I R: 2

mença de fentir renaître une tranquilli: $\mathrm{d}^{\prime} \mathrm{e}$ prit, qu'il ne connoilloit prefque plus. L'Apôtre de fon côté, à la vûé d'un Profelyte venu de fi loin, reflentit une joye, dont il n'y a que les coeurs Apoltoliques, qui foient bien capables. Il s'imaginoit déja renfermer dans fon fein toute cette Nation, dont on publioit depuis quelque tems de grandes chofes, \& pour laquelle il conçut dès-lors une tendreffe, qui alla toujours croilfant. Angeroo lui séitéra fés inftances pour être baptifé, \& comne il s'exprimoit déja paftablement en Portugais, le Saint, qui avoit autant d'empreffement que lui, de le voir Chrétien, quitta prefque toute autre occupation pour l'inftruire; mais une Affaire de conféquence l'ayant appellé à la Côte de la Pefcherie, il envoya Angeroo \& deux Domeftiques, qui l'aroiene zccompagné, au Séminaire de Goa, où ils arriverent au commencement de Mars de l’année 1548 .

De la maniere, dont ils entrerent d'abord dans toutes les pratiques, qui ćtoient en urage dans cette fainte Maifon, d'où font fortic depuis une bonne partie des Apótres \& des Martyrs de l'Orient, on s'apperçut bien-tôt que ce n'étoit point là des Indiens, ni des Barbares; \& le P.Xavier, qui ne tarda point à les rejoindre à $\mathrm{Goa}$, fut extrêmement furpris des progrès, qu'ils avoient faits dans le peu de tems, qu'il ne les avoit point vîs. II crut néanmoins devoir encore différer leur Baptême: il jugea même à propos, que Côme de Torrez, qui de Grand-Vicaire de Goa; venoit de fe faire Novice de la Compagnie, leur donnât de nourelles Inftructions. II 


\section{HISTOYRE DU JAPON';}

aroit remarqué dans ce nouve! Ouvrier; qử étoit d'ailleurs un très-habile Homne, des Qualités font propres à la Miflion du Japon, qu'il méditoit dès-lors, \& il fut bien-aife de lai procurer les moyens d'apprendre la Langue \& les manieres des Japonnois, en lui donnant occafion de converfer fouvent avec ceux-ci. Il penfoit aufli que ce n'étoit pas allez d'une connoillance fuperficielle de nos Myfteres, \& des autres Articles de notre. Foi pour des Homnes âfini fuirituels \& auffi éclai. rés, que l'étoient les trois Catéchuménes., avant que d'êrre régénérés dans les Eaux lacrées du Baptême.

Meftbajtif- Its le furent enfin le jour de la Pentecôte

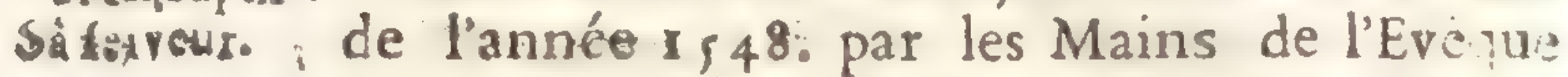
des Indes, Dom JeAn D'AlBUCUERQUE. Ia grace du Sacrement fut fenfible dans tous lo; trois, mais furtout dans 'I'Ame d'Angeroo; où elle établit d'abord cette Paix, après laquelle il foupiroit depuis tant d'années. Il fouhaita de porter le nom de FAUL DE $S_{T E}$ Foy en Mémoire de la Maifón, où il avoit reçu tant de Graces du Ciel, \& qu'on appel loit indifféremment le Collége de faint Paul, \& le Séminaire de Jainte Foi; de fes deux Dameftiques, l'un fut nommé JEAN \& l'autre Antorne. Auffi-tôt après leur Baptêne, le P. Xavier, qui trouvoit dans le Maitre \& daits les Serviteurs de grandes difpofitions à la fainteté, leur-fit-commencer les Exercices fpirituels felon la Méthode de faint Ignace fous la conduite du Pere de Torrez; \& pendane certe Retraite, qui dura trente jours, il eft cronnant avec quelle profution le Ciel tour

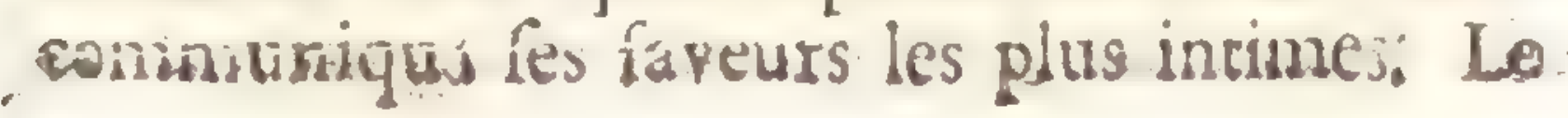
h 


\section{V R E PREMIERO}

Here Xavier, qui les vifitoit fouvent, s'expsine far cela dans fes Lettres en des termes, qui paroîtroient exagérés, s'ils ne partoient pas de la plume d'un Saint. Paul de fainte Foi ne parloir que de Vieu, \& il le faifoit on Homme infpiré; on l'entendoit fouvent, lorfo qu'il étoit feul, témoigner avec ces élans: qui ne peuvent fortir que d'un coeur embrafé d'amnur, le défir qu'il avoit de mourir pour fon Dieu, \& le zéle, dont il étoit dévoré pour le falut de fes Compatriotes. O Japon, s'ecrioit-il, ô ma chere Patrie! Ouvres les yeux, E reconnois les ténébres, qui t’environnent. Tu adores le Soleil Eo la Lune, E. tu ne vois pas que ce Sont des Créatures inanimées, que le Créateur a formées pour le. Service de l'Homme! Quelle folie de refuser au Tout-Puifant un Hommage, que tout nous invite à lui rendre, $E$ de le transporter à des Ouvrages de Ses Mains, qui naturellement devroient nous porter à le reconnoitre $\xi$ d l'adorer?

L'Homme Apoftolique leur donnoit tout le tens, qu'il pouvoir foufraiie à fes occupations; \& pour mieux connoîte le génie de ce Peupie, il s'informoit en même tems des Portugais, qui avoient ććc a Japon, fi tous ces Infulaires étoient du caractere de ceux-ci, ảont il admiroir la pénétration d'efprit \& le bon fens. Tous l'afínirerent qu'il n'étoir pas poffible de trouver une Nation plus raifonn?ble \& plus ingónieule, a qu'ils ne doutoie t pas que la. Foi ne fit en peu de tems de grands progrès dans ces Intes. Paul de fainte Foi lui donnoit les mêmes efpérances, \& écrivit fur ce ton-là au faint Fondateur de la Compannis 


\section{HISTOIRE DU JAPON,}

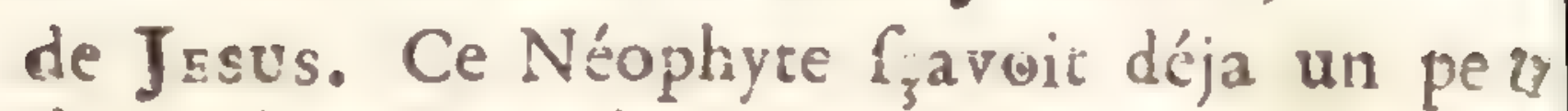
de Latin, \& avoit appris par coeur tout l'E vangile de faint Matthieu. On le voyoit fouvent aur milieu des Rues \& des Places de Goa environné d'une Troupe de Chrétierrs \& d'Infidéles, propofant aux uns des Queltions fort fubtiles, \& tâchant de convaincre les autres de la vérité de notre fainte Religion. Tour cela animoit de plus en plus le zéle du Pere Xavier, qui prienfin faderniere réfolution, que, niles inftances de les Amis, ni la crainte d'une fi longne \& fi périlleufe Naviga. tion, ne pûrent jamais lui faire changer.

5. Trançois Le jour de con départ étant fixé, il noн? Xavier part ma pour l'accompagner le P. Còme de Tor pour le japon req, \& le Frere Jean Fernander, a qui les tres Jefuites. trois Japonnois avoient auffi appris un pe: Vertu de la de leur Langue. Il employa enfuite les der. Groix. niers mois de certe annce, \& la commence. nent de la fuivante à régler fes Affaires, \& s'embarqua au mois d'Avril pour Malaca, où il arriva le dernier jour de Mai 1549. Il y apprit des nouvelles du Japon, qui lui ca'tferent bien de la joye. On lui dit qu'un des Rois de ces thes re difpofot à envoyer une Amballade au Vice-Roi de; Indes, pour lui demander des Ouvriers de l'Evangile, \& voici comment l'on racontoit ce qui lui en avoit fait naitre la penfée. Des Portugnis avoient pris Terre dans fes Etats, \& on les avoit low gés par fon ordre dans une Maifon, qu'on prétendoit être infeftée de malins Effrits; on ne fe trompoit pas, difoit la Letrre, les Portugais, qui n'étoient prévenus de rien, y pallerent deux ou trois nuits fort mauvaifes, \& l'un d'eux fut même très-maliraité; ils en 
devinerent bien-tôt la caufe, \& ils eurent recours au Ciel. Ils firen quantité de prieres, puis ils peignirent des Croix fur toutes les Portes \& les Murailles du Logis. Dieu bénit leur Piété \& leur Foi, ils ne virent \& n'entendirent plus sien. Cela fit du bruit dans la Ville, \& les Idolâtres apprirent avec admi, ration le moyen, done ces Etrangers s'étoient fervis, pour chaffer le Démon. La nouvelle en alla jufqu'au Roi, qui fit appeller les Portugajs, pour s'âsûrer de la vérité, \& s'inftruire des circonftances d'un fait fi fingulier. Il fut frappé du dérail, qu'ils lui en firent, \& donna ordre fur le champ qu'on dreflat des Croix fur tous les grands Chenuins, à tous les Carrefours des Ruès, à toutes les Avenuës des Villes, \& qu'on en peiguit mêne dans tous les Appartements de fon Palais. Ainfi l'Ennemi de notre falut fut le premier, qui donna lieu à ce que le $\mathrm{Si}$ gne adorable de notre Rédemption fût expolé publi juement à la vénération des Peuples dans certe Terre infide'e. Le Roi voulut enfuice f̧aroir d'ol venoit à la Croix tant de vertu : \& la répon'e des Portugais n'ayant 'ervi qu'à exciter davantage fa curiofité, il forma le deflein de faire venir des Docteirs de leur Religion; c'ćtoit-là l'unique o'jet de l'Ambaffade, dont on parloit.

Il y a bien lieu de s'étonner, qu'aurcun des Hiftoriens de la Vie du Saint, ni aucun de ceux, qui ont écrit l'Hiftoire du Japon, ne nous ait appris la fuite de cet Evénement, ni quel étoit le Roi, dont il eft ici parlé, ni enfin ce qui empêcha le Pere Xavier d'aller trouyer ce Prince, comme il ćtoit naturel 


\section{$28^{8}$}

HISTOIRE DU JAPOA'

qu'il fît $(a)$. Ce filence pourroit faire dons ser, qu'on eût véritablement reçû de pareils avis, it le témoignaye de pluheurs Ecrivains, tous dignes de foi, qui racontent ce fait, n'étoit appuyé de l'autorité de l'Apôtre même, qui dans fes Lettres nous en a fait le détail, que je n'ai fait que copier.

- Cependant plufieurs Marchands Portugais fe difpofoient a faire le Voyage du Japon, mais par la feute raifon, qu'ils n'y alloient pas en droiture, ou gu'ils dewoient s'arrêter en Chemin, le P. Xavier leur préféra un petit Bátiment Chinois, de ceux qu'on appelle Joncs. On fut d'autant plus furpris de ce choix, que le Capitaine, qui commandoit se Navire, nommé NECEDA, ćtoit le Pirate le plus frneux de ces Mers, \& tellement décrié pour fes brigandages, gu'on appelloit fon Bátiment le Jonc du Voleur. Ce ne fur done pas fans peine, qu'on vit le Servitenr de Dieu, fe liver à la merci de ce Corfaire, \& il n'eft rien, qu'on ne mît en ulage pour l'en difinacer; mais ce fut en vain: tontefois le Gouverneur de Malaca, DOM PEDRo DE Syt$\mathbf{A}$, prit pour fa fireté une précaution, à laquelle vraifemblablement le Ciel atsacha la confervation de cette Troupe Apoftoligue. II fit jurer Necéda, qu'il mereroir les Peres droit au Japon, \& pours'afsirer encore pius de fa fidćlité, il l'obligea de lui lailleren ótage quelylesuns de fes Einfants.

(a) Il y a bien de lapparence que ce Prince eroit, ou le Roi de Sasuma, ou celui de Bungo. On, ne fẹait roint, que jufupalers les Porrugais ayent tratiqué dans les Etais d'aucun! autre Roi do ripuse. 
Te quatriéme de Juin, le P. Xavier s'embarqua avec fes deux Compagnons, les trois Japonnois, qu'il avoit amenés de Goa, \& quelques Chrétiens, qui devoient lui lervir c.e-Catéchiftes. Le même jour le Vent fe trouva favorable, \& on appareilla. Après qu'on tut fait environ cent lieuës, il fallut fonger à fe prémunir contre les TYPHONs, \& pour cet effet Neceda alla prendre terre à une Ifle voifine. On appelle Typhon dans les Indes, un Vent de tourbillon, qui fouffle de tous côtés, \& qui domine fort fur les Mers de la Chine, \& du Japon. Un Vailleau ainfin invefii de toutes parts, ne fait que pirouëtter, \& les plus habiles pllotes y font bien-tôt au bout de leur Ar:. Ce qu'il y a de plus fâcheux, cieft que ces tourmentes durent ordirairement plufieurs jours de fuite, enforte qu'il faut qu'un Batment foit bon \& bien Eouverné; pour réfinter jufquà la fin. Par Lonheur on peut les prévoir, \& fe mettre en état de n'ctre pas furpris; car on ne manque jamais d'en être averti par un Phénoméne allez fingulier. On voit un peu auparavant vers le Nord trois Arcs-en-Ciel concentriques de couleur de pourpre.

Neceda s'étant fortifié courre les 'Typhons, leva l'Ancre. Il avoit encore fept cents liene's à faire; néanmoins on s'apperçur qu'il n’alloit point en route. Il s'arrêtoit même à tou. tes les Ines, qui fe trouvoient fur fon palfage, tantôt fous un prétexte, \& tantôt fous un autre. Le plus fouvent cela dépendoit d'une Idole, qu'on avoit expolće fur la Poupe du Vaiffeau, \& que le Corfaire confultoit à chaque inftant. Ainf les Miftionnaires avoient 


\section{0 \\ HIstorke Do J.s. On:}

la douleur de fe voir a la difcrétion de ces mémes Puilfances Infernales, dont ils alloient ruiner l'Empire au Japon: outre cela, on leur faifoit tous les jours mille avanies, \& iis coururent plus d'une fris rifque de la vie; deux chofes furtout y contriouerent.

La premiere fut que Neceda savila un jour de demander à fon dole, fir fon Voyage feroit heureux? L'Idole répondit que le Navire arriveroit heureufement au Japon, mais qu'il ne reverroit jamais Malaca. Le pirate crut que cela vouloit dire, qu'il périroit au retour du Japon, \& il réfolut de chercher à ćloigner le p.us qu'il pourroit fon malheureux fort. Peu de jours après, le Bátiment ćtant à l'Ancre vis-à-vis de la Cochinchine, un jeune Chinois Chrétien, de la fuite des Miffonnaires tomba dans ía Centine, que par mégarde on avoir laillée oaverte; mais commé il fut promptement lecouru, il en fut quitte pour une bleflure alfez confidérable à la tête. Tandis qu'on le panfoit, la Fille du Capitaine tomba à la Mer, \& quoique toue l'Equipage s'emprefsât pour la fauver, elle fut engloutie par les vagues à la vî̀i de fon Pere. On peut juger quelle fur la douleur de cet Homme; il $s^{\prime} y$ abandonna fans mefure, \& l'on eut affez de peine à le faire revenir de fes premiers tranfports. Dès qu'ils furent calmés, il voulut fçavoir de fon Idole la caufe d'un fi grand malheur, \& le Démon fit réponfe, que fi le jeune Chrétien n'eûr pas été retiré de la fentine, la Fille Idolâtre n'eût pas péri. Alors le Corfaire enragé contre les Chrériens, entra dans des accés de fureur, gui firent croire, qu'il alloir less inmole: aux 

mânes de fa Fille, mais un bon vent, qu'on attendoir avec impatience, s'éran levé toutà-coup, on ne fongea plus qu'a en profiter, pour fe tirer d'un parage, ou il ne failoit pas sûr de refter, \& qui n'oftroit a l'Efprit, que des idées funeftes.

Enfin après bien des détours, Neceda tourna vers la Chine, \& entra dans le Port de Saint au ou CANTON, réfolu d'y paller l'Hyver; mais à pon. pe ne y avoilil jetté l'Ancre, qu'il clrangea de penfée, 8: fit dellèin d'aller hyverner dans un autre Port. Il n'en étoit pas loin, lorfqu'il eut avis par un Bâtiment Chinois, qu'il Icncontra, que toute cette Côte étoit infeftée ce Forbans. Les Corfaires ne fe cherchent loint, \& n’aiment pas à fe rencontrer: Necéda eut bien voulu retourner à Canton; mais le Vent étoit contraire: le feul parti, qui lui reftoit a prendre, fut d'entrer, comme il fit, dans la Mer du Japon à la faveur d'un petit Vent, qui le conduifit un peu de joursau Port de Cangoxima. Ce fut le yuinzićme d'Août, que les Mifionnaires aborderent a cette Terre fi défirée, après lept femaines de Navigation fur la plus orageufe Mer du Monde, ayant eu pourtant beaucoup moins a fouffrir de la fureur de cet Elément, que de la fírocité de leurs Conducteurs, \& de la malice du Prince des ténébres.

Ce fut un grand fujet de joye pour la $\mathrm{Fa}-\mathrm{Il}$ va aे la mille de Paul de Sainte Foy, que de le re-Cour du Rui voir après une fi longue ablence, \& dans le de Saxumare tems, qu'on le croyoit perdu. Les Miffion- qui s'y pasfe. narres y prirent part, mais ce qui les combla de contolation, c'eft que dès les preniers eniretiens de ce fervent Néophyte avec fa Fa- 
mille, fa Femme, une Fille unique qu'il avoit, \& la plûpart de fes. Farents déclarerent quils vouloient imiter fon exemple. Illes infruific lui-ınême, le P. Xavier les baptifa, $\&$ de fi heureux commencements donnant au faint Apôtre tout lieu de croire que fes travaux ne feroient point infrućtueux dans une Terre fi bien préparée, il s'appliqua if́rieulement avec fes deux Compagnons à l"Erude de la Langue.

J'ai parlé plus haut de la différence de cette Langue avec la Chinoile; j'ajoure ici, qu'elle eft très-abondante, extrênement variée, non feulement, parce que chacque Province a fa dialecte particuliere, mais encore, parce que les Caracteres y ont des fignifications différentes, felon la diverfité des leriannes, à qui on parle; des lujets, que l'on traite; \& du ton, dont on prononce. Elle eft extrêmement énergique; figurće \& métaphorique, comme le font prefique toutes celles de l'Afie, mais elle a cela de propre, qu'en peu de mots elle dit beaucoup, ix que chaque Caracy fait une phrale entiere. Les Japonnois fe fervent d'un Pinceau pour écrire, \& le font avec une vitelfe furprenante. Ils font leurs lignes perpendiculaires, \& le P. Xavier en demandant un jour la raifon a Paul de fainte Foy, celui-ci lui répandit, que l'Ecriture étant l'expreffion de la penfée de l'Homme, elle ne pouvoit avoir trop de reflemblance avec 1 Homme, qui avoir été fait droit par le Créateur.

J'ai lû dans quelques Mémoires, que ce qui forme le langage fçavant dans cet Empire, n'eft qu'un allez léger changement dans les-Caracteres, dont les Japonnois attribuent

l'Invention 
l'Invention à un certain CAMBODAYI, que quelgues-uns difent les avoir apportés de la Chine: mais cela n'elt pas vraiferbiable, fuivant ce que nous avons dit de la différence. des Caracteres Chinois, 2 des Japonnois. Cambodaxi, dit-on encore, faifoit fon féjour ordinaire à Sacai, mais ćtant paivenu a une extrême Vieillelle, il s'enferma dans une Caverne, dont il fit murer l'entrée, \& ou l'on croir qu'il prie fans celle les Mains élevées vers le Ciel. Il doit y demeurer dix mille ans dans cette Polture, \& il a prédit, qu'après ce tems-la, il reparoitroit lur la Terre, pour réfuter un faux Docteur nommé MIRO$z u$, qui doit venir Prêcher une nouvelle Ductrine; \& entreprendre d'établir une nouvelle Religion. Cette Caverne elt, ajoûte-t-on, dans un petit Bourg, appellé Cöia, à treizé lieués de Sacai, où l'on a bâti un Temple magnifigue en l'Elonneur du Prophéte, \& un fuperbe Monafrere. L'Anniverfaire de la Retraite de Cambodaxi fe Célébre dans rout le Japon avec beaucoup de folennité; \& de toutes les Parties de l'Empire on va en Pélerinage au Temple de Cöia. Heureux celui, dont les Dents peuvent être enterrées au même lieu! il eft sûr, dit-on, d'aller tout droit en Paradis.

Cependant Paul de fainte Foy fe crut obligé d'aller rendre fes devoirs au Roi de Caxuma on Souverain, \& lui demander fa grace, pour le meurtre, qui l'avoit obligé à cíparoître. Il en fut bien reçu, \& il en obtint lans peine ce qu'il fouhaitoit. Le Roi lui fit $c n$ fuite bien des Queftions fur les Aventures de fon Voyage, fur le Commerce \& la Puilia $c^{2}$ Tome $I I$. 


\section{HISTOIRE DU JAPON,}

des Portugais dans les Indes, \& fur la Religion, quils y avoient ćtablie. Il fatisfit le "Prince fur tous ces Articles, \& s'étendit beaucoup fur le dernier: comme il s'apperçut qu'on l'ćcoutoit avec flaifir, \& que la plîpart des Afliftants étoient même touchés de ce qu'il venoit de dire, il tira un Tableau, qu'il tenoit caché fous fa Robe, \& le fit voir au Roi; c'ćtoit une Vierge très-bien l'einte, \& qui tenoit entre fes bras l'Enfant Jesos. Le Roi fur î frappé à cette vấ, que par un mouvement fubit, dont apparemment il ne fut pas le Maîre, il mit les deux Genoux en "Terre pour rendre fes Hommages à la Mere, \& au Fils, dont les Vifages lui parurent refpirer quelque chofe d'Augufte \& de Divin. La Reine fa Mere, à qui il voulut qu'on portât cette Image, fe trouva faifie du même fentiment de Religion, \& fe profterna pareille. ment avec tolites fes Dames, pour adorer le Dieu des Chrétiens. Il fallut encore expliquer à cetre Princelle nos principaux Mylteres; elle en fur charmée, \& le P. Xavier n'eut pas platôr appris ce qui s'époir paflé à cette Audience, quil en fit demander une pour luimềne.

Il n'eut pas de peine à l'obtenir, parce que paul de fainte Foy avoit fait naitre dans cetre Cour un grand délir de le voir. Le Saint le prépara à cette action par de ferventes prieres, \& par un redoublement de ferveur. 11 fentoit plus, qu'il n'avoit encore fait, la difficulté de parluader à un Peuple fuperfitieux \&e fuperbe, de changer de Religion; d'obliger des Sçavants arcoutumés a fe voir ćcoutés comme des Oracies, diarvier qu'ils 
avoient été trompés dans la clrole du Mende, où il eft moins pardonnable de l'être; enfin de faire adorer la Croix, \& d'en faire refpecter les opprobres à des Grands, dont le fafte \& l'orgueil n'avoient rien d'ćgal. Il ajoutoit dans les Lettres, qu'il écrivit alors aux Indes \& en Europe, que les plus grands obltacles, qu'il prévoyoir au fuccès de fon Entreprife, leroient fans doute de la part dis Bonzes; qu'il étoit bien réfolu de fe ménager avec ces faux prêtres, dont le crédit éroit grand parmi le Peuple, mais qu'il n'ćtoir pas moins déterniné a faire lon devoir dans toute l'ćrenduè d'un zéle réglé par la prudence: heureux, s'il y trouvoit l'occafion de donner a vie pour Jefus-Chrít !

Ce fut le vingt-neuviéme de Septembre, gu'il fe rendit a la Cour de Saxuma, aprís s'être recommandé à faint Michel, \& mis le Japon fous la protection de ce Chef de la Milice cúlefte. Le Roi \& la Reine Mere reçurent l'Apôtre comme uu Homme extraordinaire, le jour ne fulfit pas pour l'entretenir, \& on le retint jufques bien avant dans la nuit. On ne fe lalloit pas de l'entendre parler de la Religion, \& l'on trouvoit qu'il en parloir d'une maniere ravillante; mais l'on ne revenoit point de la furprife, où jettoit iout le Monde la vîe d'un Homme, qui avec tant de mérite avoit renoncé à tout, \& entrepris de fi périlleux Voyages, pour annoncer à des inconnus \& à des Etrangers, done il n'efpéroir rien, la connoillance du vrai Dieu. Ce noble défintérelfement, \& ce courage Héroique dans les Mifionnaires, furent long-tems ladniration des Japonnois, qui 


\section{HISTOIREDU JAPON,}

fçaventeftiner la grandeur d'Ame; \& après la grace, contribuerent plus, que tout autra chole, à perfuader cette Nation de la vérité d'une Religion, qui infpire de tels fentiments.

Le Roi, qui avoit un grand lens, fir au P. Xavier des Queftions très-fubtiles, \& charmé de les réponles, il lui ajoûta, que in fa Religion étoit la véritable, il devoit s'atte: dre que les Dímons feroient d'étranges ef forts, pour s'oppofer à fon établiflement clans le Japon. Il lu parla enluite du defiein, ol on lui avoir dit qu'il étort, d'aller à Mérco, \& l'avertir que cette Capitale de l'Enpire ćtoit. route en trouble, \& par conféquent peu dif pof'ée à l'éconter: d'ailleurs, que la Saifon étoir bien avancće, pour entreprendre un Voyage fi long, \& que s'il vouloit différer Con depart, il l'y feroit conduire par Mer. Ce qui engageoir ce Prince a parler ainfi, étoit une vầ d'intérét; il vouloit attirer \& fixer Je Commerce des Portagais dans fes Etats, \& il le flattoit d'y réuifir, en y retenant un Homme fi fort comfidéré de ces Marchands. Pour l'y engager davaritage, il le combla de marques de bonté \& de ciftinçion, \& lui donina un ample pouvoir de Précher la Loi Chrétienne à fes Sujets; ce qu'il confima peu de jours après par un Edit.

niprenepu L'Homme Aportolique parut fe rendre, \& Wicument à de retour à Cangoxima, hi \& fes CompaConsan anons, qui par leur application à l'Ende de

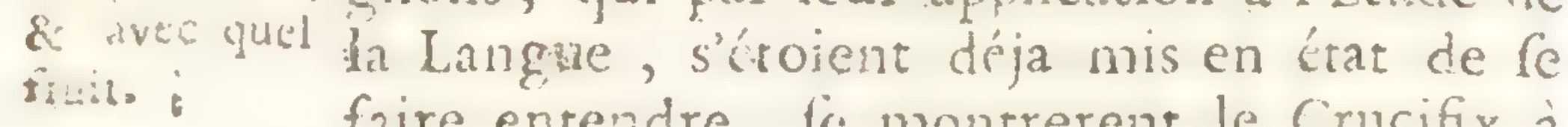
faire entendre, fic montrerent le Crucifix à la Main dans les Places publiques. La nouveauté du Spectacle, \& la réputation, que les Pródicateurs s'éroienr acijuife par la linu- 
rexs de lour vie, \& par les Converlations particulieres, qu'ils avoient euës avec plutieurs Ierfonnes de Confidération, leur attirerent une foule d'Auditeurs, à qui ils amnoncerent le Royaume de Dieu. On ne fe conecntoit pas de les entendre en public; on les fuivoic chez eux, \& on ne leur donnoit pas un momient de repos. Ce concours leur caufoit une farigue extrême, mais ils en étoient bien dédommagés par le plaifr, qu'ils trouvoient à raiter avec ton pemple, quileur paroifloit aimer \& chercher lincérement la véricé, \& yti ne leur objectoir rien, que de folide \& de lenfé.

Dans une Lettre que le P. Kavier ćcrivit alors à fes Freres de Goa, il leur manda qu'ils n'avoient qu'à le préparer tous à venir au Japon; " mais, ajoutoit-il, vours devez-vous $\Rightarrow$ attendre à trouver des Efrrits fultils \& exercés dans la difpute. Il faut auficompter de prêcher d'example, autant \& p'ns \que de paroles; car les Iaponnots, próve2 nis que leurs Bonzes menent me vie fore s Auftere, fe fcandaliferoient, s'ils voyoient les Prédicateurs de l'Evangile moins Péni» tents que leurs Prêtres. c $C e$ que le faint Apôtre propoloit aux Religieux de fa Compagnie, il le pratiquoit lui-même, aufl-bien que fes Compagnons, avec tant de rigueur, qu'on ne comprenoit pas comment ils pouvoient y réfiter. Après avoir fatigué tout le jour, ils palloient la nuit en Prieres; on ne les voyoit prefune jamais dormir, \& leur nourriture n'étoit gu'un peu de Lćgumes à lEau \&z au Sel. Le Salnt écrivit cin Europe dans les mémes termes, qu'il avoit fait a

$$
\text { bi iij }
$$


Goa : il eat même la penl'ée d'écrire au Soü verain Pontife, \& d'exhorter par une Lettre circulaire les plus Célébres Univerfités de l'Europe, à ne pas laiffer perdre une Moiflon mûre \& abondante, pour s'amufer à de vaines fpéculations, \& fe remplir l'Elprit de connoilfances ftériles.

Cependant le Myftere d'un Dieu en trois Perfonnes, \& celui d'un Dieu incarné \& mort fur une Croix, furent d'abord d'ćtranges paradoxes pour un peuple, qui veut tout réduire aux principes du bon fens naturel. Quelques-uns, fans vouloir rien examiner davantage, traiterent les nouveaux Docteurs de vifonnaires, \& leur Doctrine d'extravagante. D'autres plus raifonnables fúpendirent leur Jugement, ne pouvant, difoient-ils, fe perfrader que des Hommes, d'ailleurs fi judicieux, euffent voulu courir tant de rifques pour leur débiter des Fables; ils fe rendirent même plus affidus aux Intructions des Milfionvaires; \& Dieu béniffant leur zéle à chercher la vérité, ils la trouverent, \& s'y foumirent. Le premiar, qui demanda le Baptêne, fut un Homme de balie naifance; le P. Xavier lui donna le nom de Bernarp, \& ce fervent Néophyte quitta tout, pour le mettre à la fuite des Serviteurs de Dieu.

Tn entretien, que le P.Xavier eut avec le Supérieur des Bonzes de Cangoxima, fervit beaucoup à donner du crédit au Chriftianifme. Le TUNDE, (a) qui palloit pour l'Oracle du Pays, fut furpris de trouver an Homme,

(a) On appelle ainfi ies Supérieurs tees xonafteres des Bonzes, \& ce font comme ies E: fues de la Rolia gic!n des Dudínids. 


\section{LIVRE PRE M I E R ;}

qui en fçavöit plus que lui, \& il ne put s'em* pecher d'avoïer, que Perfomne au Monde ne furpalloit en Science \& en Efprit le Chef des Religieux d'Europe. A l'exenple, \& fur le rémoignage de ce Docteur, gui par excellence avoit étć furnomané NINGIT, c'eft-à-dire, le Cour de la vérité, tous les Bonzes de Cangoxima parurent faire une eftime particuliere du Saint; mais le déréglement fecrer de leurs Mocurs, \& la crainte de décheoir da haut rang d'eftime, où ils étoicnt, les retinrent dans l'Idolâtrie; il n'y eut parmi tant d'endurcis, que deux Elus, dont la Converfron ne lailla pas de faire un grand effer fur le Peuple.

Les chofes en étoient-là, \& le faint Apôtre s'attendoir à de nouvelles Conquètes, lorfque les Bonzes, qui venoient de fermer les yeux à la lumiere, les ouvrirent tout-à-coup fur leurs intérêts temporels. Ils firent réfexion, gue fi de bonne heure ils ne s'oppofoient aux progrès de la nouvelle Religion, ne récévant plus les Aumônes, qu'on avoit accoutumé de leur donner, ils n'auroient bien-tôt plus de quoi fuibfeer fur quoi ils prirent leur parti. On les vit anfli-tốt aller de Maifon en Maifon, pour décrier les Miffionnaires; ils n'aifrfoient plus à leurs Inftructions, que pour les tourner en ridicules, \& ils en vinrent jufqua les outrager de paroles. Une conduite fi violente ne leur réuffit pas ; on comprit aifément quel en éroit le motif, \& on lear en fit de fanglants reproches; on leur remontra, que cétoit par de tolides raifons, \& non par des injures, qu'il falloit combartre leurs Adveráaires, \& on leur re- 


\section{O HISTOIRE DU JATON,}

prélenta que ceux-ci menoient une vie exemplaire, \& pratiquoient des vertus, qui donmoient un grand poids à la Dootrine, qu'ils prèchoient: enfin yu'ils établifloient cettedoctrine fur des principes, qu'il n'étoit pas ailé de renverfer.

Il refrefice Les Miracles que le P. Xavier fit alors en un Mort. grand nombre, furent encore plus efficaces, que tout le refte pour faire taire les Bonzes, ou du moins, pour rendre inutiles leurs invertives. Je n'en mpporterai qu'uin Ceul.

Un Homme de Condicion venoit de perdre une Fille nnique, laquelle faifoit toute fa confolation, \& il avoit été frappé de cette perte à un point, qu'on craignit pour la vie. Des Néophytes, qui étoient allés chez lui pour le confoler, touchés de l'état déplorable, où l'avoit réduit fa douleur, lui confeillerent de redemander fa Fille au Dieu des Chrétiens, \& d'employer auprès de lui le créus dit du grand Docteur des Portugais. Il les crut, alla fe jetter aux Pieds du Saint, \& le conjura les larmes aux yeux de lui rendre fa fille. Le Saint fe trouva fi attendri à la víe de cet fomme, a quil'amertume, dont il avoir le coeur pénétré, ótoit prefque le jugement \& la parole, quil ne pût lui-méme profírer un feul mot. Il fe retira allez brifquement, en jettant un grand foupir, s'enferma dans fon Oratoire avec Fernandez, \& tous. deux firent à Dieu une de ces courtes, mais vives Prieres, qui pénétrent les Cieux.

Xavier dans le moment fe fentit exaucé (a),

(a) Ciftce míme Mirrcle que le Pauffin a voulu repréenter dansle magrifijue Tableau, quon voit au

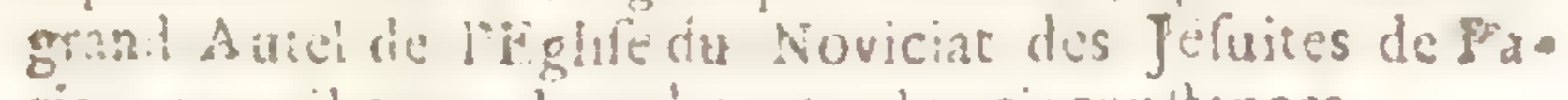
ris; nats il $\mathrm{cm}$ a changi toutes les circonitances. 
LIVRE PREMIER. 4R il rétourna auffitôt à l'endroit, où il avoit laillé ce Pere affligé, l'aborda d'un air infpiré, \& ne lui dit que ces deux mots: Allez, Monfieur, vos voux font accomplis. Le Gentilhomme, qui ne comprenoit rien à ces manieres, en fut choqué, \& fortit fort mécontent; mais à peine avoit-il fait quelques pas, qu'il apperçut un de fes Domettiqnes, qui accouroit vers lui, \& qui du plus loin, qu'il le vit, lui cria, que fa Fille étoit vivante. Il s'arrêta tout interdit, \& un moment aprés it In vit elle-même, qui venoit au-devant de lai. Il doutoit encore, fi fes yeux ne le trompoient point, lorfque fa Fille fe jetta à fon cou, \& le tint étroitement embrall'e Elle lui raconta enfuite qu'au même inftant, qu'elle avoit rendu les derniers foupirs, deux horribles Démons s'étoient jéttés fur elle, \& l'avoient voulu entrainer dans les Enfers, mais qu'elle avoit été arrachée d'entre leurs griffes par deux Hommes vénćrables, qui heureutement s'étoient rencontrés fur fon pallage, \& qu'aulfitôt elle s'étoit trourvée pleine de vie \& de fanté, fans qu'elle pût dire comment cela s'étoit fait. Le Pere pleuroit de joye, tandis que fa Fille parloit; il comprit aifément, quels étoient les deux Hommes, qui lü̈ avoient rendu fa Fille, \& il l'a mena fur l'heure au logis des Miffonnaires. Sitôt ga'elle apperçut le Pere Xavier \& Fernandez, clle s'écria que c'étoit-là fes deux Libúrateurs, \& courut fe profterner à leurs pieds; lon pere ell fit autant, \& l'un \& l'autre demanderent dans le moment à êrre infruits \& bapilées.

Tant de merveilles rendirent le $S$ Apôtre parunidolatre cher \& refpectable aux Cangoximains; mais quicn of puni 


\section{HISTOYRE DU JAFON,}

ure chofe, qui arriva dans le mêne tems, deur fit connoitre combien il étoit dangereux de l'offenfer, \& jufqu'a quel point le Dieu, qu'il leur annonçoit prenoit fes intérêts. Un Idolatre lui parla un jour infolemment \& avec outrage, le Pere ne lui répondit que ces deux mots: Mon Ami, Dieu vous conferve la bouche; \& fur le champ ce malheureux fut frappéd'un chancre à la langue, qui en fut toute rongée avec des douleurs incolérables, \& avec une infection, que lui-même ne pouvoit fupporter. Il y avoit tout lieu de croire, que des évenemens fi inouis, \& des prodiges, dont on ne s'étoit point encore avilé au Japon de croire les Dieux mêmes capables, feroient fuivis de la converfion de toute la Ville, \& de tout le Royaume; les Bonzes en jugerent ainfi, \& ils fe perfuaderent, qu'il n'y avoit pas un moment à perdre, s'ils vouloient détourner les malheurs, qui les menaçoient.

Eforts inu.

Après bien des délibérations fur une affaire tiles des Bon. de cette importance, ils convinrent quil falaes contre lui. loit aller rrouver le Roi, l'intimider, \& l'engager, à quelque prix que ce fut, à abolir dans fes Etats une Religion, qui s'établiffoit vifiblement fur les ruines de lenrs Sectes. Ils choifirent les plus diftingués d'entr'eux, \& il y a bien de l'apparence qu'il y avoit parmi eux des Docteurs des deux Religions, d'autant plus qu'elles y étoient également intéreffées. Ce qui eft certain, c'eft que les Députés parlerent au nom de toutes les Sectes. Ces Députés s'ćtant donc préfentés devant le Prince, celui qui portoit la paroke, lui dit:

„Seigneur, nous venons de la part d'A $\leadsto$ MDA \& de toures les Divirités, quiva ádure 
"dans cet Empire, vous demander fi vous s êtes réfolu d'abolir entićrement leur culte, s \& de vous rend̀re vous-même adorateur "d'un Dieu crucifié, dont les Minifres lont strois milérables, qui ne trouvant pas de ss quoi virre aux Indes, en font venu chers) cher au Japon. Le foin de nos Perfonnes $)$ expofées tous les jours à la rage d'une Popu»lace, que ces Enchanteurs ont feduite, n'eft s pas ce qui nous fair parler: mais pouvons" nous voir lans douleur les Temples aban»donnés, les Autels fans parfuns, \& les "Dieux inmortels deshonorés? Aucun de "nous, Seigneur, n'a pû encore fe perfua"s der, que vous ayez quitté la Religion de "uos Peres, \& qu'il vous foit venu feule"ment à l'efprit que la Chine \& le Japon, „L les deux Nations les plus éclairćes de l'Unis) vers, ayent été l'épace de tant de fiécles "dans l'erreur, fur la chofe du monde, en s quoi il eft moins excufable d'errer. Mais ii "vous leur avez fur cela rendu juftice, peramettez-nous de vous le dire, vous n'en étes si que plus coupable; vous adorez nos Dieux, „\& vous favorifez une Doctrine, qui les dé"grarie : vous reconnoillez qu'ils ont des "foudres en main, \& vous protégez des Ims pies, qui levent contre eux l'étendart de la s rébellion; \& que diront les sutres Rois, "que dirone nos Empereurs, quand ils fçauэ) ront que de votre propre autorité, vours ss avez introduit dans cet Empire une Relisligion, qui en fappe tous les fondemens? s mais, que n'entreprendront pas contre vous s les zélés Sectateurs des Camis \& des Fotoss ques; \& aftiftés du fecours du Ciel, que

$$
\text { B vj }
$$




\section{4t HISTOIRE DU JAFON:}

$\Rightarrow$ n'exécuteront-ils pas? Attendez-vous, Seiz > Gineur, a voir tous vos Voifins entrer à s) main armée dans vos Etats, \& y porter s partout la défolation. Attendez-vous a voir atous ceux de vos Sirjets, qui n'ont pas ens core fléchi le genouil devant le Dieu des. s Chrćtiens, fe joindre a ros Ennemis, per$\gg$ fuadés qu'ils doivent encore plus de fidélité » aux Dieux tutélaire de la Patrie, qu'à Vous, s mortel \& Homme comme eux. Tout eft $\leadsto$ permis dans ces rencontres; \& fil les Rois "n n'ont de pouvoir, que ce qu'ils en ont reçu so des Dieux immortels, du moment qu'ils s reíufent à ces Eires fouverains les hommaas ges, qui leur font dîs, ils fe dépouillene ") eux-mêmes de tout ce qui les difinguoit du »refte des Hommes. Songez donc, Prince à sprofiter de cet avis, que le Ciel vous dome a par notre bouche; ne nous obligez pas à 2) fermer nos Temples, \& à nous retirer avec 2 nos Dieux; car alors n'y ayant plus rien dans s le Saxuma, qui fût capable d'arreter la cos lere divine, nous ne répondrions pas de ce s qui pourroit en arriver s.

roncinite in-

Il faut connoitre toute la fierté des Prêtres du Japon, \& f̧avoir le crédit, quils ont fur $k$ vi de Saxu l'efprit des Peuples, pour fe perfuader qu'une มก. remontrance auff infolente, \& auff remplie de maximes léditieufes, ait été faite à un Roi jaloux de fon autorité au point, que le font tous les Monarques de l'A fie. Rien n'étoit pourtant plus capable d'établir folidenent le Chriftianilme dans ce Royaume, que cette audacieule démarche des Bonzes, \& peut-être de les perdre eux-mêmes. Le Roi de Saxima étoit haut; \& quoigu'il fût du liombre deces 
Princes qui fçavent fe plier \& diffimuler, quand ils y trouvent leur avantage, il n'ćtoit pas d'humeur à Couffrir que fes Sujets lui fillent la loi; mais il le voyoit dans des circonftances, où il crut pouvoir accorder fon intérêt avec lon autorité, en temporifant; il ne parut pas être choqué du difcours des Bonzes, mais il ne leur fit point une réponfe favorable; \& ce qui l'obligea d'en ufer ainfi, c'eft qu'on attendoit de jour en jour des $\mathrm{Na}$ vires Portugais.

Par malheur on apprit peu de tems après, Son Edit que ces Navires avoient pris la route de FIRAN- contre la ReliDo, \& l'on fçut bientôt, quils y avoient ne, \& l'effet moüillé l'ancre. La feule commodité du moiil- qu'il groduir. lage avoit engagé les Portugais à ce changement, mais il ne fut pas polible de faire entendre raifon fur cela au Roi. Ce Prince perdoit doublement; car le Roi de Firando, qui ćtoit fon Ennemi, alloit profiter de ce qui lui échappoit. Il entra en fureur, \& les Bonzes jugerent bien, qu'ils n'avoient plus qu'à le laitier faire. Sa premićre démarche fut d'appeller le P. Xavier, à qui il fit les reproches. les plus fanglans de l'ingratitude des Portugais, qu'il avoit, difoit-il, comblés d'amitié; \& qui de gayeté de coeur, \& fans aucun fujet, Lui préféroient fon Rival, dans le tems même qu'il protígeair leur Religion, \& qu'il engageoit fes Sujets à l'embraffer. On ne dit point, qu'il ait ordonné au Saint de fortir de fon Royaume; il y a même bien de l'apparence qu'il fe polleda affez, pour ne pas faire cer affrone a un Homme, à qui il avoit rendu de fort grands honneurs, \& pour ne pas fe brouiller fans retour avec les Portugais, mais on vit 


\section{HISTOKKE DU JAPON;}

bientôt paroître un Edit, qui portoit défenfe, fous peine de la vie, à tous fes Sujets, de renoncer au culte des Dieux de l'Empire.

Il n'eft pas poffible d'exprimer avec quelle prompritude on déféra à cet Edit. Tout comnerce ceifa d'abord avec les Miflionnaires de la part de ceux, qui n'étoient pas encore Chré. riens; mais la piéré \& la ferveur des nouveaux Fidéles confolerent un peu leurs Pafteurs d'une fa foudaine révolution. Dans ce petit Troupeau, qui n'étcis guéres compolé, que de cent perfonnes, il n'y eut pas un N'́ophyte, qui ne témoignât une reconnoillance infirie, d'avoir été choiíi de Dieu préférablement à tant d'autres, pour lui former un Peuple faint au milieu d'une Nation idolâtre. C'étoit une chofe admirable, de voir fur cela les tranfports de leur zéle; on ne pouvoit les entendre, ni les voir, fans etre attendri jufqu'aux larmes, \& fans êrre étonné de l'abondance des graces, dont le Saint-Efprit avoit rempli leurs cours. Cependant tourt perfuadé yutétoit le P.Xavier, qu'ils donneroient plutôt mille vies, que de renoncer au Chriftianifme, il ne voulut pas, dans la nécelfiré, où il fe voyoit de les quitter, les lailler fans armes \& fans défenfe eu milieu de tant d'Ennemis. Il les affembla plufieurs fois, pour les fortifier dans leurs bons fentimens, \& pour les inftruire de ce quils devoient répondre à ceux, qui entreprendroient d'ćbranler leur foi, \& de féduire leur raifon. Il s'attacha furtout à leur bien expliquer les principaux Myftéres de la Paffion du Sauveur des Hommes, dont les Japonnois cnt toujours été extraordinairement touchés. Eufin ir iccumaranda à Paul de fainte Foy. 
de veiller a la confervation de cette Eglife nailfante, qui alloit être fans Chef \& lans: guide, expofée à toute la fureur, \& aux fauffes fubrilités des Miniltres de l'Idolâtrie. Paul fe. fentir infiniment honoré de cette Commiffion, \& quitta tout pour vacquer uniquement 2 un fr laine Miniftére. Mais Dieu n'avoit pas comblé ce fervent Néophyte de tant de faveurs, pour n'en faire qu'un Chrérien ordinaire. Les Bonzes ne pûrent fouffrir que le départ des Miflionnaires n'eût ramené au culte de leurs Dieux aucun de ceux, qui l'avoient abandonné. Ils s'en prirent à Paul de fainte Foy, \& lai fufciterent tant d'affaires fâcheufes, qu'ils l'obligerent à fe bannir volontairement de fon Pays. Ce petit triomphe fut pourtant' le feul fruit, qu'ils retirerent de leurs véxations, \& tous les mouvemens, quils fe donnerent, pout pervertir les Fidéles, furent inutiles. Ceux-ci chọifirent un d'entr'eux, pour prendre la place de Paul de fainte Foy: \& la bunne odeur, quils répandirent partouts. multiplia confidérablenrent leur nombre en peu de toms, ainfi que nous le verrons dans la fuite de cette Hiftoire.

Cependant le P. Xavier, perfuadé que la même raifon, qui avoit changé le Roi de $\mathrm{Sa}$ numa a en érd numa à fon égard, engageroit celui de Firan- qui lui arrive do à le bien recevoir, réfolut de l'aller trou- dans un Chàver. Il partit de Cangoxima au mois de Sep-teau. tembre de l'année is 50 . après treize mois, ou environ de féjour dans ce Royaume, un des plus confidérables du Ximo, \& même de tout le Japon. A fix lieués de la Ville, il fe trouva au pied d'un Château, qui appartenoit à un Seigneur nommé EKANDOMO, 
4 HISTOIRE DU JAPON;

Vaffal du Roi de Saxuma, \& dont l'efrect le frappa. Il étoit à dix Baftions revêtus de pierxes de Taille environnés d'Eaux, \& il n'y avoir de communication de l'un à l'autre, que par des Ponts-Levis. Les Foffés étoient extraordinairement profonds, quoique creufés dans le Roc. Le Château méne, qroique rrès-vafte, ne paroifloit guéres qu'un Rocher efcarpé au milieu de l'Eau-vive. Ces dehors ne promettuient, ce femble, rien que d'affrenx; mais lorfyion avoit palfé un Chemin étroit, qui conduifoit au-dedans de la Place, on étoit tout furpris de trouver un Palais également fuperbe \& délicieux. Galeries, Portiques, Terraffes, Jardins, Appartements, tout caufoit une furprife, qui n'étoit pas le fruit de la nouveautć feule; chaque piéce étoit travaillće avec un Art \& une délicatefle infinie; \& il régnoit dans le tout un goût naturel, qui plailoit infiniment.

Le P. Xavier fut invité d'entrer dans ce "Château, \& il y fut reçu d'une maniere, qu'il n'avoit pas lieu d'efpérer. Il profita de cer accuéil pour y annoncer Jefus-Chrift. Tous les Domeftiques du Palais, \& tous les Soldats de la Garnifon étoient accourus pour le voir; car on Cçavoit les Merveilles, qu'il avoit operćes à Cangoxima. Le Saint parla avec tant de force, \& Dieu donna tant d'éficace à fes paroles, qne le mûtne jour il baptifa dix-fepr Perfonnes. Prefque tous les autres auroient fuivi cet Exemple, fi Ekandono, qui craignit quon ne lui fit des Affaires à la Cour de Saxuma, ne sy fût oppofé. Mris comme il avoir eu lui-même avec le pere Xavior un Entreiten, done it ayoir cté 
charné, \& que la Religion Chrétienne lui paroilioir bonne, il voulut bien gue fa Fenne \& fon Fils aîné fullent baptifés en fecret. Le faint Apôtre demeura dans ce Château autant de tems, qu'il lui en fallut, pour y donner de la folidiré à fon Ouvrage. Il recommanda enfuite ce petit 'Troupeau à l'Intendant de la Mailon d'Ekandono, Vieillard d'une prudence \& d'une vertu finguliere. II lui lailla une Copie de fon Caréchifme, qu'il avoir traduit en Japonnois; il régla toutes les Pratiques de piété, qu'il crut convenir à ces Níophytes, \& jufgu'aux Exercices de Pénitence, a quoi il voyoit les Japonnois fort portés. Enfin, il continua fa route vers Firando, où il arriva en peu de jours.

Le Royaume de Firando (a) n'a de confidérable, que fa Capicale, fituée vers les tren-il eft itçu a te-trois dégrés, trente ou quarante minures Firando. de latirude Nord, \& quelques petites lltes allés peuplées. Ce feroit très-peu de chofe que ce petit Etat, fans la commodité du Port de Firando, \& la sûreté du moüillage (b). Le $\mathrm{D}$. Xavier entra dans le Port au bruit de toute l'Artillerie des Vaillea ux Portugais, dont

(a) C'Aftres-peu de chole, que ce Royaume, \& j) he fair que la quattióne partie de lancien Kuyarume de rign, le flus grand des neuf, qui divircrent d'aburdinte de ximo De la manieie, dont lís Ho landois farlert du kolde lijando, quils ae nomment jamais, que lo Seisneur de Firanto; c'étuit un Prince furt parve, alant que le commercel'eût ensichi.

(b) L'emboucliure de ce l'ort eft fori etroite \& dangerenfe pour les Vaifecux ; mais le Port ell aficz large, \& ico Navires y font a l'atri de toutis fortes de Vonts \& dOOrages. Li fond eft de Limon, mais l'un y manulua queluguefois d'criu. 
les Capitaines le menerent enfuire malgré lui conme en triomphe au Palais. Le Roi le re. çut avec beaucoup de diltinction. Les Portugais, en le prefentant à ce Prince, lui dirent, qu'il voyoit devant lui l'Homme du Monde, pour qui le Roi leur Maître avoit plus de confidération; puis, comme ils elarent ajoûté, qu'il venoit de Cangoxima, \& les raifons pourquoi il en étoit forri, le Roi le carelia beaucoup, \& lui donna un plein pouvoir de Prêcher Jefus-Chrift duns fes Etats. Auffi-tôt les Milionnaires commencerent leurs Inftructions; \& le fuccès, dès les preniers jours, ayant furpaffé leur attente, le P. Xavier conçut, que fi la faveur d'un auff perit Prince pouvoit tant pour la Convertion de ces Peuples, ce feroit encore tout autre chofe, sil pouvoit avoir la protection des Empereurs.

il y laife

laiffe le Pode Turrez \& pât pou: Medco; Temple fa. meux, \& à quelle occafior il fut bàis.
Il ne lui en fallut pas davantage pour le déterminer au Voyage de Méaco, où le Dairy \& ie Cubo-sama faifoient alors leur f"cjour ordinaire; nais il ne jugea pas à propos d'abandonner entierement fes nouvelles Conquêres; il haiffa donc à Firando le P. de Torrez, \& accompagné de Jean Fernandez, \& de deux Chrétiens, dont l'un étoit ce Bernard, qui le premier avoit reçu le Baptême à Cangoxima, il fe mit en Chemin fur la fin d'Octobre. Il gagna par Mer Facata, Capitale du Royaume de Chicugen, \& apres avoir marché quelyue-iems, il fe rembarqua, \& fit voiles vers Ximunosecur (a), un des plus célébres Port du Japon, \& gui ferr d’embar-

(i) Ou Sibignuseut. 
quadaire à AMANGUCHI Capitale du Royaume de Navgato, le plus Occidental de tous ceux de la grande Hle de Nipon. On voit dans ce Port un fameux Temple de la Religion des Camis, lequel a été bâti à l'occafion gue je vais dire. C'elt un point de l'Ancienne Hiftoire du Japon, que Koempfer a fort embroüillé, \& que je n’ai pû bien éclaircir, qu'a l'aide d'un Mémoire, qui m’a paru dé bonne main. Il eft parlé en plufieurs endroits de la dernicre Hiftoire du Japon, \& dans les Faftes Japonnois, des deux Factions, qui fous la nom de Feris ja de Gendzis, partagerent long-tems tout cet Empire, \& produifrent enfin la grande révolution, qui lui a donné deux Maîtres. L'Aureur paroît fuppofer en plufieurs endroits qu'il s'agilloit du Trône Impérial, \& donne en effet le nom d'Empercur au dernier des Fekis, dont la défaite mit fin à la Guerre Civile. Il fe trompe; il y a bien de l'apparence, que les Fekis \& les Gendzis étoient deux branches de la Maifon Impériale; mais elles ne fe firent la Guerre, que pour avoir le Commandement sénéral des Troupes, \& le Titre de CuboSama, auyuel ce Commandement étoit alors artaché $(a)$.

Il eit citain que cette Guerre fut tris-longue \& tris-fanglante, les Empereurs faifant

( ) Le Géniralat des $T$ roupes \& la direction des affaires de la Guerre étoient dans les commencemen s alf clez au titre de Srooun, on Xogun. Il paroit que dansla fuire, ce tilie devint jurement honorasis, \&x nous voyons par les Faftes Chrunulogique's rics D.ri. rys, que ces Priaces le con croient ordinairement aud Emprérés CUBo.SAMas. 
5. HISTOIRE DU JAPON,

pancher la Belance, tantôt en faveur d'ui: parti, \& tantôt en faveur de l'autre. Enfin les Fekis fuccomberent par la bonne conduite de Joritomo, Chef des Gendzis; il gagna une Bataille décifive, où le Général ennemi fut tué,felon Kompfer dans fon premier Vo lume; mais dans le fecond il dir que ce Prince fe fauva à la Chine, où il avoit par avance envoyć fept Navires chargés d'Or \& d'Argent, \& où après la mort on bâtit un magnifique Temple en fon Honneir. Il ajốte que cet infortuné Feki avoit un Fils âgé de fept ans, que fa Nourrice voulut aufi fauver par Mcr, “ mais que fe voyant pourfuivie de près, \& jugeant qu'il lui étoit im» pollible d'éviter de tomber entre les Mains » de l'Ennemi, elle embralfa fortement le s jeune Prince, \& avec ce courage, \& cette $\Rightarrow$ réfolution, qui eft fi particuliere à la $\mathrm{Na}$ »tion Japonnoife, elle fe jetta avec lui dans " la Mer. Ce fut, dit-il encore, pour conferver la Mémoire de la mort prématurée du jeune Feki, que fut báci le Temple de Ximonofeyui. On le nomine AmadAis, \& le même Ecrivain rapporte, que l'é:ant allé vifiter avec le Directeur du Commerce des $\mathrm{HCl}$ landois, qu'il accompagnoit à la Cour de Iedo, un jeune Prêtre les reçut à l'entrée, \& les conduifit dans une efpéce de Salle tendué de crêpe noir, à la façon des Théatres du Japon, \& que le Ilancher ćtoit convere dans le milieu d'un Tapis broché d'A rgent. On voyoit, ajoûte--il, fur un Autel l'Image dut FrKI; elle repréfentoit un argréable Enfant, gai avoit de grands Cheveux noirs; à fes deux cốtés. étoient les Figures do dcur Frinces du Sang 


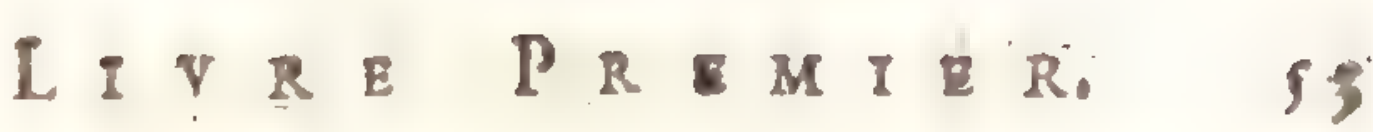

Impérial, grands comme nature, \& vétus com-
me on l'elt a la Cour du Dairy. L.e Prêre qui avoit conduit les Hollandois en ce lieula, alluma une Lampe, \& fit un Difcours fort touchant fur l'infortune du Feki; puis il les mena dans une aurre Chambre, qui joignoit celle-ci, où il leur montra les Portraits de plufieurs Perionnes, dont il avoit fait mention dans fon Difcours; delà il les fit entrer dans une troifićme Chambre fort grande, ou le Supérieur de la Maifon entra avec eux : il ćtoit vétu comme les autres Canusis $(a)$, d'une Robe de crêpe noir, avec un Rubin d'Argent, qui venant de l'Epaule droite, lui pendoit au côté gauche. Une piéce quarrée de mîme Etolle, lui pendoit par derriere entre les deux Epaules, \& c'ćtoit la marque de ia Dignité. Je reviens au Voyage du P. Xavier.

Amanguchi, Capitale du Naugato, étair te Saint aralors une des plus grandes, desplus peuplées, rive à Amandos plus riches, \& par conféquent une des guchi, \& conplus débordées Villes du Japon; \& ce qui la zond un Banrencioit an confidérable, ćtoit fon heurenfe fl-du Roi. tuation pour le Coinmerce, car elle ćtoit comme l'entre-pôt de celui, qui fe friloir alors cutre les deux grandes Ines de Niron \& de XImo; la fertilité de lon Terroir, la douceur de fon Climat, par les trente-quatre dégrés vingt minutes de latitude Nord; \& des Mines d'Or \& d'Argent, qu'on avoit découvertes dans fon voifinage. Le P. Xavier avoic pris fon Chemin par cette Ville; mais quoiqu'il n'eút aucun deliein de s'y arrêter, rou-

(a) Il fut le fourenir qu'on nomme ainfi les PrêIres de l'ancienne Relizion. 
94

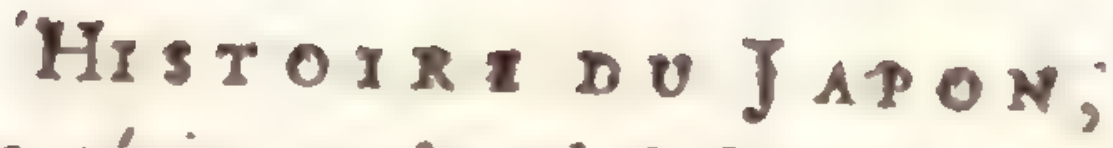

tefois au récit, quon lai fit, c'es défordres; qui y régnoient, il ne put retenir fon zé.e. 11 fe montra au Peuple le Crucifix à la main, \& il parla du Royaume de Dieu avec certe lin berté, que le Sauveur du Monde a tant recommandée à fes Apôtres.

Un certain air plus qu'humain, qui paroirfoit dans toute fa Perionne, les étonnantes véritćs qu'il l'rêchoit, l'autorité, qu'il çaroit fe conciliẹ, tout cela le fit écouter d'abord; quelques-uns même goitterent fâ Dofirine, quils trouverent fondée en raifon. Ils s'informerent qui étoit cet Homme fi extraori:naire; ils apprirent fes Travaux, les Vo;ages, la fainteté de fá vie, fon courage, fon défntéreffement, fes Miracles; ils l'admirerent, mais ils s'en tinrent là. Le jourdu far lut n'ćtoit point encore venu pour ce Peaple. La Populace méme, qui n'examine jamais les chofes à fond, \& gui juge beaucoup des Hommes par l'extérieur, fe mojua di Docteur Erranger, gui ćtoit pauvrenent vếtu, l'outragea de paroles, \&v alla jufiquà le pourfuivre a coups de pierres. Une Audience, que le Serviteur de Dieu eut d'OXINDONo, Roi de Navgato; \& dans laquelle il confondit un fameux Bonze en préfence de toute la Cour, calma un peu cette fureur; quelcjues-uns demanderent le Baptême; mais le nombre de ces Elûs fut très-pety: enfin les Mifionnaires, après un mois, de féjour dans Amanguchi, pourfuivirent leur route vers Méaco.

Il unà Mea. C'étoit fur la fin de Décembre les Pluyes, co. Marticulás de ce Vents, les Neiges, les Torrepits rendoient rujage. les Chemins imprâtiquables, furotult les Cte- 
mins détournés, qu'il falloit prendre pour éviter de tomber dans des Partis de Guerre, dont toutes ces Provinces étoient templies. A chaque pas nos Voyageurs s'égaroient, \& couroient rifque de tomber dans quelque précipice, ou de fe noyer en paffant des Rivieres rapides \& profondes, ou d'être écralés par des glaçons énormes, qui pendoient du haut des Rochers, fous lefquels il falloit parfer. Avec cela leur nourriture n'étoir qu'un peu de Ris, que Bernard portoit dans un fac. A feize lieués de Méaco, le P. Xavier tomba malade; il manquoit de tout, \& néanmoins il gućrren peu de tems.

A peine la fićvre l'eut-elle quitté, qu'il fe remit en marche; il étoit fort peu couvert, \& il marchoit ordinairement pieds nuds; mais c'étoit prefque une néceflité, à caufe des Ruiffeaux \& des Ravines, qu'il falloit continuellement traverfer. Ce qui l'inquićtoit davantage, eft qu'il ignoroit les Chenins. Un jour, qu'il fe trouvoit fort embaraflé, pour éviter certains endroits dangereux, dont on l'avertit: (quelques Auteurs difent qu'il s'écoit égaré ; il apperçur un Cavalier, qui alloit du côté de Méaco; il courut à lui, le pria de vouloir bien lui fervir de Guide, \& s'offrit à porter fa malle. Le Cavalier accepta l'offie, \& ne lailla pas d'aller le rrot, ce qui dura prefque tout le jour. Si.tôt que les dangers furent palfés, le Pere fut obligé de s'arríter. \& Ces Compagnons, qui avoient eu bien de la peine à le fuivre de fort loin, l'ayant enfin Ićjoint, le trouverent dans un état digne de compafion, les Ronces \& les Cailluux lui avoient déchiré les Pieds, \& les Jambes lui 


\section{S6 HISTOIRE D U JAPON,}

creverent peu de tems après en plufieurs endroits.

Voilà de quelle maniere la plûpart des Hiftoricns du Saint racontent ce fait; mais Fernander plus croyable que tous, en change dans fes Lettres plufieurs circonftances, ou plutôt il en ajoûte, qu'on n'auroit pas dû omettre. Il dit quion les avoit avertis que des Maraudeurs couroient la Campagne; que cer avis les obligea de prendre un détour, \& que le P. Xavier craignant de s'égarer, fe donna en qualité de Valet à plufieurs Marchands, qui s"étoient joints enfemble, pour faire plus sûrement le Voyage de Méaco: qu’un de ces Marchands, fans confidérer, que lè laint Hom. me ćtoit à pied, \& chargé de fon propre paquet, lui donna encore fa valife à porter, \& quaprès avoir couru toujours le Galop, pour éviter les Partis, ils l'obligeoient, tout épuifé quil ćtoir, à prendre cncore foin de leurs chevaux. Il ne dit point combien de jours dura cetie Marche, ni ce que lui, \& les deux Japonncis, qui l'accompagnoient, devinrent pendant ee tems-la; il fait feulement entendre, que le Saint n'en fut pas quitte pour un ou deux jours, \& il ajôtte, gu'après une $f$ excenive fatigue, on ne put l'engager a le repoler, \& quil tiroit tant de force de la Priere, quil ćtoit encore le premier à encourager fes Compagnons.

Comme il lui fallut pafter que!ques Bras de Mor, il y courut le mêne danger, quil avoit efinyć fur Terre, parce que toutes les Côtes ćtoient infeltées de Pirates. Outre cela, comne dans les Villes \& les Bourgades, oul il

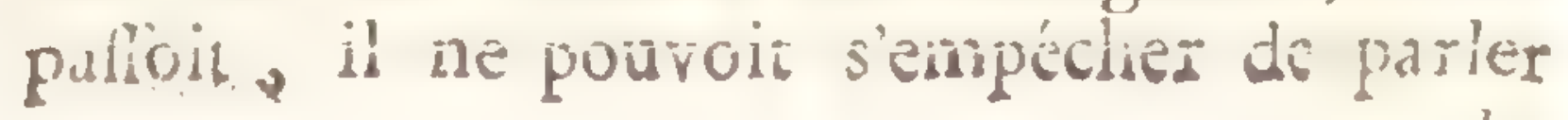
de 
de Dieu à ceux, qui s'attroupoient autour ce lui; il ne retiroit point ordinairement d'atitre fruit de fon zéle, que des infultes. Il fur même deux fois blellé a coups de fićches, \& dans deux endroits différents il auroit ćté accablé fous les pierres, qu'on commençoit à lui jetter, fi a chaque fois des Orages furvenus tcut-à-coup n'euflent écarté la multitude, dont il ćtoit invêti : il fut pourtant allez heureux pour baptifer quel fues Enfants, qu'il trouva horibondo \& apparammen expof́ćs dans la Rué, ou tur les Chemins; a la joye qu'il reflentoit, en procurant ainfile Royaume du Ciel a ces petits Innocents, fenbloit lui rendre en un moment toute la force, \& lui faire oublicr tous fes matix.

Enfin il arriva a Mćaco. Cette Ville eft dans la Province de J A M A T S R O, une des cinc, qui compoènt la TENSE, c'elt-a-dire, Capitali. le Domane de l'Empereur. Sa fituation n'a sien de baa ; clle cit loin de la Mer, bâtie dans une plaine férile, \& eirvironnce de Montagnes fort hautes, firr lefquelles on voyoit alors quanties de ruines de Monafeses, \& qui étant toujours couvertes de Neige pendant l'Hyver, caufent un Froid excellif, outre que le feul Vent, qui fouffle bien librement entre ces Montagnes; eft celui du Nord. On précend que Méaco avoit eu aurrefois vingt milles de long, \& neuf de large; \& il paroilioir bien par les ruines des. Fdifices, quon voyoit encore tout autour de la ville, \& fort loin dans la Campagne, qu'elle ćroit véritablement d'une grandeur immente. Auff un des noms, qu'on lui domoit, fignifoit, chore digne d'être z Torre II. 
S8 HISTOIRE DU JADON,

de grand, que fes ruines, \& la Guerre, qui y paroilloit plus allumée que jamais, la menaçoit d'une entiere défolation. Quelques Au.. reurs difent qu'on y comptoit pourtant encore cent mille Maifons, mais en y compremant les Monafteres, dont le nombre étoit prodigieux. D'ailleurs les deux Empereurs y avoient alors toutes leurs Cours.

Quoiqu'il en foit, Méaco tous les jours à la veille de devenir un Champ de Bataille ( $a$ ). in'étoit pas propre à receroir la lamiere de l'Evangile, \& le P. Xavier ne tarda pas à s'en appercevoir. Il ne put même obtenir audierce, ni des Empereurs, ni du Xaco (b), \& il fe vit réduit â faire dans les quartiers les plus fréquentés ce qu'il avoit fait ailleurs, c'eft-à-dire, à Prêcher à la Populace, qui s'alfembloit autour de lui par curiofité. Mais comme il fentit bien-tôt qu'il perdoit fon tems à parler à un Peuple tout occupé de Factions \& du tracas des Armes, il reprit, quoiqu'avec bien du regret, la route de Firando. Il fe confola néanmoins dans la penfée, qu'il avoit Prêché Jesus-Christ dans la Capitale du Japon, \& qu'il avoit beawcoup fouffert pour y arriver; ce qui dans les Hommes Apoftoliques, elt un vrai dédommagement du peu de fuccis de leurs Entreprifes. Il lui fut mê-

(a) Komifer dans fa Suite Chronulugique des Dairys, parle d'une Guerre Civile entre deus factions puifantes, qui avoit commencé l'an 15II. \& qui frisit vers l'an I $2 \%$. Il ajoute qu'cenviron l'an I 60 le CuboSama : qu il numme Yosr Tir, fe fendit le Ventre; tout ceci s'accorde affez mal arce notre Hiftoire. sunzeso

(b) C'ett le Grand Pretre de la Religion des 
me dit intérieurement, que cette femence divine, qu'il croyoit avoir jettće dans une Terre ingrate, ne leroit pas perduë, mais proportionnée aux fatigues, qu'il avoit elfiyées dans une fi pénible Expédition. Nous netarderons pas à voir que ce fentiment étoit une de ces infpirations, dont les Saints f̧̧avent mieux que les autres faire le difcernement.

Le faint Apôtre arriva à Firando en allez bonhe fanté, \& fans aucun accident fâcheux; mais il n'y refta qu'autant de tems, qu'il lui en fallut, pour changer fon extérieur trop négligé. Il avoit eu le loifir de fe convaincre de la néceflité de ce changement, \& il lçavoit qu'une des premieres Régles d'un Prédicateur de l'Evangile, eft de fe faire tout à tous, pour gagner tout le Monde a JefusChrift. Il ne ciédaigna pas même de fe charger de quelques raretez d'Europe, que le $\mathrm{Vi}$ ce-Roi des Indes, \& le Gouverneur de Malaca lui avoient donnćes, pour faire des prélents aux Princes Japonnois, \& dont il avoit cru d'abord pouroir le paller, aufl-bien que des Letres, de recommandation, que ces deux Seigncurs lui avoient encore remiles, \& qu'il jugea alors pouvoir lui ctre de que!que utilité. Après quelques jours de repos, il partit pour Amanguchi avec les mêmes Perfonnes, qui l'avoient accompangné a Méaco. On en fut furpris à Firando; la maniere dont il avoit ćté traité la premiere fois dans cette Ville, \& le peu de difpofition, qu'il y avoit trouvée à l'écouter, ne devoient pas, ce femble, l'engager à y retourner; mais les Saints ont des lunitres, que les aurres Hommes nont pas, \& la fuite fit voir, que ćétoir l'É

Il retourne à Firando, de change lun ex. téricur trop vìg gé. 


\section{Go H.ISTOIRE DU JAPON}

prit de Dieu, qui conduifoir le P. Xavierà Amanguchi.

Il parfe à Il çommença par demander une audience Amanguhi, au Roi, \& Oxindono voyant les Millionnai\& eft biea re. res dans un autre équipage, qu'ils n'avoient cu du Roi. paru d’abord, les reçut bien, agréa les prétents, que le Saint lui fit, témoigna qu'il auroit égard à la récommandation du VicePoi des Indes, \& du Gouverneur de Malaca; \& le même jour il lui envoya une alfez groffe conme d'Argeni. Il la refuía, \& le Roi charmé d'une vertu fi rare, marqua fa furprife en des termes, qui ne plûrent pas aux Bonzes. Dis le lendemain, il accorda aux deux Prédicateurs la permiffion de publier la Loi du vrai Dieu dans toutes les Terres de Ion obćiflance, \& en fit afficher les Patentes dans les endroits ercinaires. Peu de jours après, fur ce qu'on lui repréfenta que ces Religicux n'avoient point de demeure fixe, \& que fouvent même ils ne fçavoient où le re. rirer, il leur donna une Maifon de Bonzes, qui depuis yuelyue tems in ćţoit pas habitće.

II v rite 'un

Le P. Xavier \& les Compagnons ne furent grand nombre pas plutôr logés, \& en ćtat das faire comce Cunrero modément les Fonations de leur minitere, liuns, \& de Mlirasles. que tout Amanguchi fe remua, \& que, comme fi ce Peup!e fût tout-à-coup forti d'une profonde léthargie, il fe fit chez eux un concours, qu'on auroir peine a imaginer. Le P. Xavier écrivir alors au Pere I G N A C.E de Loyora, fon Général, \& au P. SLMon RoDRIGUEZ, que du matin au foir fon Logis ne décemplifo point, \& que les Miffionnairet, qui viendroientab Japon, devoient s'atcondre à de grandes importinitez, furtout 
LIVRE PRE MIE R : G de la part des Perfonnes de Condition: quon ve leur lailleroit pas toujours le tems, ni de dire la Melle, ni de réciter leur Brém viaire, encote moins de repofer \& de prendre leurs repas. En effet, dans ces commencements rous venoient chez eux en mêmetems, la filtpart y demeuroient tout le jour; tous vouloient a la fois qu'on éclaircit leurg doutes, \& qu'on répondît a leurs Queftions; de lorte, gu'on n'entendoit qu'un bruit confus de Gens, qui parloient tous enfemble, \& qui crioient a pleine tête.

Dieu tira fon Serviteur de cet cmbarras par un prodige, peut-être inoiii jufqu'à lui. On avoit vû renouveller dans les Indes en fa faveur le Miracle, qui furprit fi fort Jérufalem le jour de la Pentecôte, lorfque les Apôtres Prêchant dans leur Langue naturelle, fe firent entendre à quantité de Perfonnes dans la Langue d'un chacun. Ici le Saine ćtant. interrogé fur des matieres fort oppofées entr'elles, il fatisfaifor à plufieurs Queftions d'une feula réponfe. D'abord la confufion empêcha, qu'on ne fît réflexion à une chofe aufr merveilleufe, \& bien des Gens mêmes, qui ne fongeoient quà ce qu'ils avoient dans l'éprit, ne s'aviferent jamais de fenfer, qu'il y eût du merveilleux dans la maniere prompte \& précife; dont le Docteur Eiranger leur répondoit. De-là vient gue, comme les Miffionnaires, qui fuccéderent au Pere Xavier, mettoient plus de tems à fatisfaire ceux, qui les interrogeoient, on difoit gu'ils n'aroient pas autant de fcience, ni d'efprit, que hii. L'Honme Apoftolique reçut encore à Amangushi le don des Lingues, qui lui avoit été C iij 


\section{G2 HISTOIREDU JAPON,}

tant de fois communiqué depuis fon arrivée en Orient; car outre qu'il parloit le Japonnois avec une facilité \& une élégance, où les Naturels même du Pays parviennent rarement, il Prêchoir tous les jours en Chinois aux Marcliands de cette Nation, qui trafiquoient dans cette Ville, quoiqu'il n'eût jamais ćtudié leur Langue.

Ce n'étoit plus feulement le Peuple, qui vouloit entendre les Docteurs Etrangers, les Grands les invitoient à venir chez eux; \& ce fut en cette occafion, que le P. Xavier s'appercevant qu'on lui parloit quelquefois avec trop de hauteur, \& un certain air de mépris, qui lui parut rejaillir fur fon miniftere, il montra de fon côté une grandeur d'Ame, \& même une fainte \& noble fierté, qui imprima dans l'Ame de fes Auditeurs un profond refpect pour le Dieu, qu'il leur annonçoit. Il recommanda la même chofe à Fernandez, qui dans ces occalions marquoit trop de modeftie, \& peut-être de timidité; \& cela réuflit: on s'accoutuma à regarder les Prédicateurs de l'Evangile, comme les Envoyés d'un Dieu Puillant, \& on les écouta avec refpect. Ils ne tarderent pas à recuëillir les fruits de tant de travaux, \& ce fuccès leur donnoir une nouvelle vigueur. "Je fuis tout s blanc, écrivoit alors le Pere Xavier à fes »Freres en Europe, néanmoins je fuis plus $\Rightarrow$ robufte que jamais. Aufli faut-il convenir, $\leadsto$ que les fatigues, qu'on effuye pour infs truire un Peuple ingénieux, qui aime la vés rité, qui prend la raifon pour Guide, \& " qui veut fincérement fe fauver, caufent ") une jnye bien fenfible s. Au bout de gucl- 
que-tems, le Serviteur de Dieu fe trouvant un peu de loifir, entreprit les Bonzes, qui malgré l'animofité des Sectes, s'étoient tous Iéunis contre leur Ennemi commun. Il les défia plus d'une fois a la difpute : il fe tint plufieurs .Conférences publiques, ol ces Prêtres Idolâtres furent confondus, \& ces victoires achevant ce que l'autorité, que le Saint s'étoit acquife par fa fainteté \& fes Miracles, avoit heureufement commencé, en moins de deux mois plus de cing cents Perfonnes, la plûpart Gens de marque, reçurent le Baptême.

On voyoit furtout ceux, qui dans les commencemens avoient paru plus animés contre la nouvelle Religion, témoigner plus d'empreffement à l'embralfer, \& travailler enfuite avec plus de zéle à la faire embrafier aux autres. Ce zele du falut des Ames fut tou;ours depuis la vercu favorite des Japonnois convertis; on eût dit, qu'ils ne fe croyoient Chrém tiens, qu'autant qu'ils faifoient paroitre d'ardeur pour la propagation du Chriftianifme.

Le plus grand avantage que le P. Xavier tira de ces premieres faillies de ferveur, ce qu'onluifut, fut d'être inftruit à fonds des endroits foi- \& comment al bles, par où on pouvoit attaquer avec plus de y répond. fuccès les Ennemis du nom Chrétien, \& il en fçut profiter en habile Homme. Une chofe arrêtoit pourtant encore le progrès de l'Evangile. On avoit eu de la peine à prouver aux Japonnois que ceux, qui pendant leur vie n'auroient pas adoré le vrai Dietr, brûleroient ćternellement dans les Enfers. Ils ne pouvoient concilier ce point de Foi avec la bonté infinie du Seigneur. Si la Verbe incarné, di- 
64 HISTOIRE DU JATON,

foient-ils, eft mort pour tous, pourqui fä. mortin'efl-eile pas utile d tous? S'il coindamne. $\grave{a}$ des Jupplices éternels tous ceux, qui n'ont. pas einbrafé $\int a$ Loi, pourquoi a-t-il différé pendant plus de quinze cents ans à nous la faire annoncer? Les Bonzes ne manquoient pas d'appuyer ces objections, \& ajoûtoient, que les Prétres des Chrériens nétoient bons à rien, puifgu'ils n'avoient pas le crédit de tirer une teule Ame des Enfers, comme ils faifoient eur. tous les jours par les mérites de leurs jeûnes \& de lcurs priéres: que ce Dieu même étoit, ou bien cruel, s'il ne vou!oit pas faire cefler le peinces des Damnés; oubien impuiffant, s'il ne le pouvoit pas.

Le faint Apôtre ne fut pas fort embarralfé à répondre à ces difficultez, aufquelles les Peres de l'Eglife ont répondu tant de fois. Il fit furtout bien fentir que la Religion du vrai Dieu, qu'il prêchoit, eft auffi ancienne que le Monde, \& que la Nature même en a gravé tous les principes dans nos Ames avec des traits ineffaçables. Il fit convenir les plus Sçavants; que la Morale de Jefus-Chritt étoit en vigueur au Japon, avant qu'aucune Secte Idolâtre y eût été introduite; il perfuada à tous que la feule malice des Hommes en avoit pû obf́curcir la lumiére. Il foutint, fuivant la Doctrine de S. Thomas, que tous ceux, qui s'étoient perdus, n'étoient tombés dans ce malheur, qu'après avoir altéré la pureté de cette même Morale, dont il n'étoit pas poffible de s'écarter, fans reflentir au-dedans de foi-même des remords, qui y rappelloient; enfin il conclut par allîrer que perfonne ne reffentiroit les uriftes effets de la Juftice divine, gui no fît if 


$$
\text { LIVRE } \Gamma R E M I E R \text {. TS }
$$

prenier a fe condamner, \& a rendre támogisage à l'éguité de l'arret, qui l'auroit précipité dans l'abíne; que ce qu'ils ne comprenoient pas prélentement, parce que c'útoit un nyftere impénétrable, ils le comprendroient dans l'éternité, oil ils verroient avec évidence, \& loueroient fans celle cette Juftice fouveraine, qu'ils devoient préfenteinent fe contenter de croire \& d'adorer.

Ils fe rendirent à ces raifons; mais fi lé Saint fut allez heureux pour convaince leurs efprits, il ne vint pas fitồ à bout de calmer leurs cours. Les Japonnois aiment tendrement tous ceux, qui leur font attachés par les liens du fang, \& la mémoire de leurs Ancếtres leur eft chere \& précieufe. Ils ne pouvoient digérer; qu'on les obligât à les regarder comme des Réprouvés: Quoi donc, s'écrioient ils fondant en larmes, nos Peres, nos Enfans, nos Parens; nos Amis Seront pendant toute une éternité les malheureu fes victimes, El'objet des vengerinces d'un Dieu, qu'ils euffent fans doute adoré, s'ils l'eufent connu? E ce grand Dieu, qu'on nous repréSente, comme la bonté Er l'équité même , n'aura aucun égard à leur ignorance? Ils fondoient en pleurs en parlant ainf, tout retentifoit de leurs fanglots, \& des cris, qu'une penfée $f$ toucliante leur faifnit poufler vers le Ciel, \& les Miffonnaires ne pouvoient s'empêcher de mêler leurs larmes avec celles de leurs chers Nćophytes:

Une belle action de Fernandez contribud beaucoup alors à dúterm ner quantité de perfonnes, qui flottoient encore entre l'erreur \& la.vérité, Un jour que ce faint Religianx pre

$$
\text { C.r. }
$$

Bëlle action? de Fermandez Ion Cum: pagnon, \&: quci en furte: fruifo.. 
66 HISTOIRE DU TAPON;

choit dans une Place publique, un Homme de la lie du Peuple s'approcha, comme pour lni dire un mot a l'oreille, le Prédicateur s'arréta, fe tourna de fon côté; \& dans le moment ce Brutal lui couvrit le vifage d'un crachat. Il s'ćleva aufitôt quelques éclats de rire; néinmoins prefque toute l'affemblée fut indignée; mais comme on eut vû Fernandez, qui fans faire paroitre la moindre émotion, s'elfuyoit , \& continuoit fon difcours; la fotte joye des uns, \& l'indignation des autres fe tournerent en admiration: chacun fe retira plus perluadé par l'exemple d'une vertu fi héroique, que par tous les raifonnemens du Prédicateur.

Converfion Un jeune Docteur, qui avoit une grande d'un jeune réputation de fçavoir, fut fi frappé de cette Ducteur; le action, que dès le lendemain il demanda le Sans ra Com-Baptême, \& fa converfion fut la fource de pagnic un jeu- plufieurs autres. Entre ces nouveaux Profélyac klomme de tes, il y en eût un, dont le changement caufa zance. efpé- bien du chagrin aux Bonzes, parmi lefquels il

étoit fur le point de s'engager. C'étoit un jeune Homme de vingt-cing ans, d'une grande efpérance, \& d'une nailfance diftinguće. Il avoit été toujours fort affidu aux inftructions des deux Religieux : Ion efprit éroit convaincu, la patience de Fernandez l'avoit ébranlé, la converfion du jeune Docteur le détermina. Le P. Xavier lui donna au Baptême le nom de LAURENT, \& peu de tems après le reçut dans la Compagnie de Jesus. Nous verrons dans la fuite de cette Hiftoire, qu'il fit honneur au choix du faint Apôtre.

Vains effors Laurent ne fut pes le feul, qui manqua pour des Bonzes lors aux Bonzes; perfonne ne prenoit plus parti pulr réablir parmi eux, \& leurs jeunes Gens les quirtoient 
par troupes. Les Miffionnaires inftruits par ces Transfuges des mylteres d'iniquité, que ces Impofteurs cachoient fous les dehors de la plus auftere vertu, les démafquoient aux yeux du Peuple; \& comme, en micme tems qu'ils découvroient la corruption de leurs moeurs, ils faifoient fentir la foibleffe de leurs raifonnements, ils invitoient les Fidéles à entrer en lice avec eux, ce qui eut un tel fuccès, qu'on voyoit tous les jours des Enfans \& des Femmes faire tomber en contradiction les plus fameux Docteurs. Ceux-ci, pour fe rétablir dans l'efprit du Public, tenterent de nouveau la voye de la difpute, \& propoferent d'allez bonnes difficultez; mais on y répondit d'une maniere qui leur ferma la bouche, \& ils furent contraints d'abandonner de nouveau cette batterie.

Ils réuffirent un peu mieux à la Cour par Le Roi chan: une intrigue, qu'ils y avoient fait jouer lecré- $g^{t}$ à l'égard tement; \& l'on s'apperçut bientôt, qu'ils des Mifíunavoient gagné le Roi. Oxindono ne révogua point fes Edits, mais il dépouilla quelques Néophytes de leurs biens; ce qui ne fit pour. tant qu'augmenter le nombre de ceux, qui demandoient le Baptême, \& animer davantage la ferveur de ceux, quil l'avoient reçu; jufques-là que le P. Xavier ne craignit point de mander en Europe, que de trois mille Chrétiens, qu'on pouvoit bien compter dans Amanguchi, il n'y en avoit aucun, qui ne füt fincérement dans la difpofition de perdre tout ce qu'il pollédoit au monde, \& la vie méme, pour conferver fa foi. Il arriva même que les Bonzes ayant écrit de toutes parts, pour décrier les Miftionnaires, ces Lettres engagerent les Peuples des Royaumes circonvoifins à s'innaires.

$C$ vj 


\section{HISTOIREDU JAPON;}

former de ce que cétoit, que ces Dofecurs Etrangers, dont on diloit tant de bien \& tant de mal, \& quapprenant par des témoignanges non furpects les grandes chores, quils faifoient à Amanguchi; leurs noms devinrent célebres dans tout l'Empire.

$\therefore$ Françcis Cependant le P. Xavier fongea tomt de bon at fur wekoyau. prendre des mefures, pour établir folidement me de Burgu. une Miffion, qui commençoit à prendre un fi W's lormgris ton train, \& réfolut de retourner aux Indes, vent au de. afin d'y chercher des Ouvriers tels, qu'il jugeoir que le Japon en demandoit; laborieux, içavants, humbles fans baflefle, courageux, fermes, réfolus à tout fouffrir; d'une conduite irréprochable, maîtres d'eux-mêmes, julquà ne laiffer entrevoir aucun mouvement de paffion, \& fuffifanment verfés dans les controw verfes \& dans la difpute, pour fe d'́mêler des fophifmes des Bonzes. Il eur en même tems nouvelle, qu'un Vaiffeau Portugais commandé par Edouard de GAMA, venoit d'arriver alu Port de Figr (a), dans le Royaune de Bungos, un des plus confitérables du XIMO, \& qu'il ne tarderoit pas à reprendre la route des Indes, où il apprit par la même voye que fa préfence étoit nécelfaire. Sur cet avis, il fit venir de Firando le P. de Torrez, l'ćtablit en fa place à Amanguchi, \& partit pour Figi accompagné feulenent de fes deux fidéles Catéchiftes. I1 iit une bonne partie du voyage à pied, quoiqu'il le pût faire tout entier par.Mer.; mais il fe trouva fi mal à ure lieue de Figi, quil fut contraint de sarrêter. Alors fes deux Compagnons prirent les devants, pour avertir les

(a) Quelques Auteu:s le nomment Figen, je croi que celt une faste. 
Portugais de favenué, \& Ganra monta fur lè champ à cheval avec environ trente Portugars pour aller au-devant de-l'Hómme de Dieu.

Ils le rencontrerent, qui s'étoit déja remis en chemin, \& ils furent aflez furpris de le voir feut, marchant à pied, \& portant fa Chapelle fur fon dos. Ils defcendirent de cheval, dc's qu'ils l'apperçurent, \& l'ayant joint, ils le faluerent de la maniere la plus'refpectueufé. Enfuite Gama lui préfenta un cheval, qu'il lui avoit fait amener; mais il le prefla inutilement de l'accepter, ce qui l'obligea lui \& tous fes Gens de marcher auli à pied, \& de faire fuivre leurs Chevaux. Sitôt que l'Ápôtre arut à la vîe du Port, le Navire orné comme dans les plus grandes cérémonies, 2 l'Équipage étant fous les Armes, le falua de quatre décharges de toute fon Artillerie. Le bruit du Ganon, qu'on entendit à Fucheo Capitale de Bungo, \& qui n'eft gnerres qu'à une lieue de Figi, fit craindre au Roi, que les Portugais ne fulfent attaqués par certains Corlaires, qui cournient la Cóte; \& il leur envoya offrir cu fecours; mais il fut bien étonné, lorfqu'il fçut que l'arrivée d'un feul Homme avoit cautfé tout ce fracas; \& que les Portugais s'eftimoient plus heureux de le polféder, que fi leur Navire eût ćté chargé des plus précieufes Marchandifes de l'Orient. Ce Prince a tant de part à l'Hiftoire que j'écris, que j'ai cru néceflaire d'en tracer ici le Portrait.

Civan (a) Roi de Bungo, étoit alors un

(a) On ne peut gueres douter que ce Prince ne foit Cáractere dus Roil deBungo. Ic. julune Prince de Bungo, dont il eft parlé dans la Ke'ajion que Yernand Mendez Pinto a falte de la dé. corvertede Japuno. 


\section{$7^{\circ}$}

\section{HISTOIRE DU JAPON;}

Prince âgé d'environ vingt-deux ans; \& dans une fi grande jeunclfe il n'étoir pas feulement confidéré, comme un des plus braves \& des plus fpirituels Monarques du Japon; mais il palloit encore pour un des plus fages. Il polfédoit prefque toutes les vertus morales; furrout une grande équité, beaucoup de modération, une prudence confommsée. Il étoit fobre, libéral, bienfaifant; il avoit les inclinations nobles, le naturel heureux, l'efprit excellent, le fens droit; il s'attachoit à fes A mis, conime auroit pí faire un fimple particulier, \& il les combloit de biens en Souverain. En un mot, on peut dire que le Roi de Bungo avoit une belle Ame, \& une grande Ame, un cour vraiment royal, \& digne d'un Trône pluséclatant. On ne lui connoifloit qu'un feul foible; c'ćtoit la diflolution, qu'il portoit fort loin. Il en avoit honte lui-nême; mais il ne faifoit que de vains effurts pour furmonter une fi infame paffion.

Cc q̧ui lui Il y avoit déja quelque tems, que ce Prince avoit donné de connoiffoit la Religion Chrétienne, \& voici l'eftime pour qu'elle fut l'occafion, qui la lui fit connoître. Chrétienne. Des Portugais du vivant de fon Pere avoient abordé à un Port du Royaume de Bungo; leur Navire étoit richement chargé, \& quelques Courtifans voulurent engager le Roj. à s'en faifir. Ce Prince y étoit prefque rélolu, lorfque Civan également touché de compaffion pour des Etrangers, qui n'avoient pas mérité un traitement fi injufte, \& chagrin du deshonneur, qu'une action $f i$ indigne alloit attirer fur fon Pere, l'alla trouver, \& lui parla avec tant de force, qu'il lui fit prendre des rentiments plus défintéreflés, Ies I'ortugàis ap-: 


\section{I TRE PREMIER: $\gamma$ I}

prirent bientôt, \& le danger, qu'ils avoient couru, \& à qui ils avoient obligation de l'avoir échapé. Ils en témoignerent leur reconnoiffance au jeune Prince, qui les, reçut bien, leur marqua qu'il les verroit volontiers, \& les engagea par ce favorable accueil à lui faire fouvent leur Cour.

Comme la plîpart de ces Marchands étoient Gens de bien, leurs bons exemples \& leurs Saint à le veq difcours édifians touchérent le Prince de Bun- nir voir. go. Il voulut fçavoir quelle étoit la Religion, que profeffoient des Perfonnes fi réglées, \& an d'entr'eux nommé Diego VAz, lui donna quelque teinture du Chriftianifme. Depuis ce tems-là il avoit entendu parler du P. Xavier, \& fans trop s'arrêter à ce que les Bonzes d'Amanguchi en avoient publié, il le regardoit comme un Homne favorifé du Ciel, \& défiroit paffionnément de le voir \& de l'entretenir. Il apprit avec joye que le Saint devoit pafler par fes Etats; \& dès qu'il le fçut arrivé a Figi, il lui écrivit la Lettre du monde la plus aimable \& la plus honnête, \& la lui envoya par un jeune prince de fa Maifon, à qui il donna une fuite fort lefte.

L'Homme de Dieu reçut la Lettre du Roí avec les marques du plus profond refpect; mais il fit paroître dans cette rencontre tant de noblefle \& de grandeur d'Ame, que Civan, fur le rapport de fon Ambaffadeur, ordonna qu'on n'omit rien pour faire au grand Docteur des Portugais la plus magnifique réception. Edouard de Gama de fon côté, entreprit de perfuader au Saint, de quelle importance il étoit de rendre cette action la plus célebre, qu'il feroit poffible. Il lui reprélenta, que lui: 


\section{2: HISTOIRE DU JAPON,}

riêne avoit ćprouvé en plus d'une occafion combicr les Jáponnois méprifent la pauvreté : qu'il étoit nécelfaire de les convaincre une bonne fois que, fi les Prédicateurs de l'Evangile n'étoient pas environnés de ce fafte, qu'affectoient les Miniftres des Dieux du Japon " leur paurreté \& leur modeftie ne venoient point d'une indigence forcée, mais du mépris, qu'ils faifoient des biens \& des honneurs de ce. Monde; qu'il devoit fe fouvenir qu'il étoit revêtu du caractére de Légat du S. Siége; enfin qu'il falloit détromper la Populace, qui au. Japon, plus quailleurs, fe prend par les apparences, \& lui faire changer les idćes extravagantes, que les Bonzes tâchoient de lui donner des Religieux d'Europe.

Quoiqu'il pût dire, il s'apperçut affez, que cómment lis fon difcours n'avoit pas fait impreflion fur conduifent à l'humble Milfionnaire, à qui l'exemple des l'audience de Apôtres \& du Prince même des Apôtres, qui ce Prince. avoit criomphé de la fierté Romaine parl'humilité de la Croix, fourniffoir des réponfes à fon rifounement, qui lui paroilloient fans réplicue; mais Gama lui déclara qu'il n'en fercit pas le maître, \& aprés avcir concerté avec fes Gens la maniére, dont ils le meneroient à l'audience dı Roi, ils travaillerent toute la nuit aux préparatifs. Dís que le jour parut, on partit au bruit du Camon fur deux Barques, \& une Chaloupe, toutes couvertes des plus beaux Tapis de la Chine, \& ornées de Banniéres magnifiques. Dans une des Barques étoient des Trompettes, des Hautbois \& quantité d'autres Infruments, qui annorçQient de fort loin la yenuë du Serviteur de 


\section{I R E P. R E I E R. 7 \%}

Dieu. Quantité de Portugais étoient dars l'autre. Le P. Xavier accompagné d'Edouard de Gama éroit dans la Chaloupe, qui: tenoit le milieu. On remonta ainf lentement une rivićre, qui méne de Figi à la Eapitale.

Toute la Ville étoir accouru à ce fpectacle, \& le Saint fut reçî à la defcente de la Cha- commencil loupe par un Corps de Troupes réglées, conımandé par un Otficier de marque, lequel lui offrit un Norimon, qu'il refufa. Alors les Portugais commencerent à marcher en cee ordre. Edouard de Gama paroilloit le premier, tête nuë, \& une canne de Bengale à la main: quatre autres l'ortugais le fuivoient, portane tous quelque chofè l'ufage du Pere, qui venoit eniuite, ayant fur une Soutane de camelot, un Surplis \& une Etole brodée en Or d'un fort grand prix. Environ trente Portugais marchoient apris avec une contenance fort noble, \& chacun fuivi de fon Valet. Ils étoient tous fuperbement vêtus, \& portoient des Chấnes d'or: qui levr domnoient un fort grand air. Ce Cortége traverfa toute la Ville au fon des Flûtes, des Trompettes, \& des Hautbois ; les ruès, les fenćtres \& les toits mêmes, étoient remplis d'une multicude innombrable de Peuple, \& tout rerentilicir des bénédictions, que l'on donnoit à. l'Homme Apoftique, qu'une majefté douce, qui brilloir fur fon virage, \&s une modeftie religieufe relevoient infiniment; de Corte que tcus les yeux ćroient tournés furlui.

A l'entrée de la place du palais, il trouva fix cents Garủes richement vécus, rangés dans un très-bel ordre, \& dont les armes brillantes. jetroient un ćlar, quíćbloibilioir les youx.. A 


\section{HISTOIRE DU JAPON,}

la vîe du Saint, ces Gardes firent plufieurs évolutions, \& lui rendirent tous les honneurs militaires, qu'on ne rend 'qu'à la perfonne du Roi, puis lui ouvrirent un paffage au milieu d'eux. Avant que de paller la porte, par oull'on entre dans la premiere cour, le Cortége s'arrêta, \& les cinq premiers Portugais, s'étant mis à genoux devant le Pere, Edouard de Gama lui préfenta la Canne de Bengale, un autre lui chaulfa des mules très-précieufes, un troifiéme étendit fur fa tête un magnifique parafol. Les deux derniers fé rangerent à fes côtés; l'un portoit fon Catéchíme dans un fac de fatin bleu, \& l'autre un Tableau de la Vierge, enveloppé d'un voile de damas rouge. Il s'éleva en mêne-tems un fort grand bruit de Gens, qui s'écrioient: Efl-ce donc-là ce Miférable, dont les Bonzes d'Amanguchi ont publié que. la vermine, dont il étoit couvert, avoit horreur de se nourrir d'une chair aufl infecte, que la Jienne? ont-ils quelqu'un parmi eux, qui ait cet air de grandeur ? E s'il étoit tel, qu'ils ont voulu nous perfuader, ces Gens-ciluirendroient-ils tant d'honneurs?

Le Pere entra d'abord dans une longue Galerie, qui le conduifit à une grande Salle, on un Enfant de fept ans, qu'un vénérable Vieillard tenoit par la main, le complimenta, \& lui dit avec une grace finguliere des choles fi relevées, que les Afriftans en parurent furpris. Le Pere, qui ne douta point, que ce Compliment n'eût ćté appris par cocur, répondit à l'Enfant; felon que le demandoir fon âge; mais il trouva dans fes répliques tant de raifon \& de folidité, qu'il crut devoir changer de Atyle. Il a toujnurs été pcríladé 
depuis que cet Enfant avoit été en ce moment in!piré du Ciel.

De cetre premiere Salle, l'Enfant, qui fervoit au Pere d'Introducteur, le mena dans un autre Appartement, qui étoit tout rempli de Noblelle, \& dès que le Serviteur de Dieu parut, tous fe profternerent jufqu'à frapper la Terre du Front, ce qu'ils recommencerent jufqu'à trois fois. Cette maniere de faluer eft la plus refpectueufe, qui foit en ufage au Japon (a). Enfuite deux jeunes Seigneurs s'avancerent, \& firent au Serviteur de Dieu un Compliment en Vers, d'un ftyle extrêmement figuré. On palfa de-là fur une Terrafle bordée d'Orangers; \& de la Terrafle on entra dans une troifiéme Salle forr fpatieufe; ou Facarandono, Frere unique du Roi, attendoit l'Homme Apoftolique, accompagné des principaux Officiers de la Couronne. Alors l'Enfant fe retira un peu à l'écart, \& le jeune Prince fit au Pere toutes les civilités, qu'on a coûtume de faire aux Perfonnes du premier rang. Entre plufieurs chofes obligeantes, qu'il lui dit, il l'aflûra, que ce jour étoit pour le Roi fon Frere le plus beau de fa vie, \& un jour de Réjouilifance pour toure la Cour, \& pour toute la Ville. Il le conduifit enfuite à l'Anti-Chambre, \& lui donna toujours la main.

Enfin la Chambre du Roi fut ouverte, \& tous les yeux furent ébloiiis par l'éclat de l'Or, qui y brilloit de toutes parts. Ce Prince étoit debout, \& paroifloit fouffrir impatiemment, que fa grandeur l'eût arrêtée. Il fit trois ou

(a) Quclques Mémoires la nomment Gromenar f. 


\section{HistoIRE DU JAPON;}

quatre pas, dès qu'il vir le Serviteur de Dieu; tut frappé de je ne fçai quoi de grand, qu'il remarqua dans toute fa Perfonne, \& augrand étonnement de tout le monde, il s'inclina par trois fois jufyu'à Terre. Le Pere tout confus, fe jetta aux pieds du Roi, \& les voulut toucher du Frond, fuivant l'ufage du Pays; mais Civan ne le permit pas, \& l'ayant nris par la main, il le fit alleoir à fon côté. Le Prince fon Frerefut placé au-delfous, \& les Portugais vis-a-vis, mêlez avec les Courtifans. Le Roi dit d'abord au Pere tout ce qui fe peut dire d'honnéte, \& ne l'apnella jamais que fon Ami. Le Saint, aurès avoir répondiz a tant de marques de bonté par toutes celles de refpect \& de dévouëment, qu'il put imaginer, parla de Jefus-Chrift, \& le fit en Homme, qui, auffi-bien que $S$. Paul, fe pouvoir. dire fon. Amballadeur. Son difcours fut long, mais accompagné de tant de graces, de folidité, \& d'éloquence, que le Roi charmé, s'écria: Nos Bonzes ne parlent point comme cela: il ajoutita quanticé de chofes à l'avantage du Chriftinnime, \& retombant fur les Bonzes, il paria vivement contre les Fabics, que cés Inpolteurs débitent avec impudence, \& fur les contradictions, où l'on ne manque jamais de les furprendre, pour peu qu'on veüille les fuivre dans leurs raifonnements.

Un Bonze s'emporte a !a vië des Hon. meurs que le Aoi lui fait. II $y$ avoit parmi les Courifans un Pretres Idolatres, nommée Homme vain \& capble FA X I A DONO, porremens. Il prit la liberte plus grands emRoi, qu'il ne lui appartenoir pasontrer au reuls Ministes des Dieurenoit pas, mais aut il s'agifion de Religion. Ciran d'avord ne ñt 


\section{I V R P R M I E R. 77}

gu'en rire; mais cette modération du Prince n'ayant fait qu'accroitre l'infolence du Bonze, il n'eft point d'abfurdité, qu'il ne dit; il s'étendit principalement fur la grande fainteré des Bonzes; fur la profondeur de leur doctrine; fur les auftéritez, qu'ils pratiquoient, fur les vifites céleftes qu'ils recevoient très-fouvent; enfin fur la préćminence de leur prafeffion, qui les mettoit en quelque façon audeflus des Rois, \& des Empe-eurs mêmes: de-là il s'emporta jufqu'à parler avec hauteur au Roi, qui fans s'émouvair fit figne au Prince fon Frere de lui impoler filence, \& de le faire fortir cie fa place: il lui ordonna enfuite lui-même de lè retirer, ajoûtant par maniere de raillerie, gu'il avoit fort bien prouvé la fainteté des Bonzes; puis prenant un ton plus férieur: Aller, dit-il, des Hommes comme vous ont plus de commerce avec les Démons, quiarec les Dieux. Alors le Bonze ne polfedant plus, dit tout ce que la fureur lui put infpirer, jufinà ce que le Roi latie de l'entendre, le fit challer. Il fe retira, mais écumant de rage, \& il fe lailfa aller à de fi grandes extravagances, que la folie fit compaltion aux plus fages. Civan fut toujours celui, qui fit paroître plus de fang froid; \& apris que le Bonze fut forti, il continua jufqu'au diner à s'entretenir familierement avec le Pere Xavier.

Dés gu'on eut fervi, le Roi fe leva; prit

Le Roi fait le Saint Homme par la main, \& lui dit: munger les.ins s Les Souverains dans le Japon ne peuvent à fa Table.

s Conner une plus grande marjue de dif" tinction à ceux, quils veulent honorer, s qu'en les faifant manger à leur Tuble; mais 


\section{HISTOIRE DU JAFON:}

" pour vous, mon cher Pere, je vous de" mande en grace de me faire cet honneur, »\& je vous conjure inftamment de ne me » point refufer cettte grace c. Le Pere s'inclina profondément, \& dit qu'il prioit le vrai Dieu de reconnoitre pour lui tant de faveurs en éclairant un figrand Prince de Ces plusvives lumieres: Plaise au Maitre, Er au Seigneur du Ciel E de la Terre, dit Civan, d'accomplir vos défirs; ce Jont aufiles miens: en achevant ces mots, il fe mit à table.

Jamais au Japon deux Perfonnes ne fone affies à la même Table, chacun a la fienne; elles font fort petites \& fort baffes, parce qu'on eft affis à Terre fur des Nartes plus ou moins ćlevées, fuivant la condition d'un cha. cun. On ne les couvre point de Nappes, mais on les leve à chaque fervice; \& comme elles font verniffées, \& que les Japonnois font fort propres, elles ne fe gâtent point, ou du moins on en eft quitte pour les efluyer. Le P. Xavier mangea feul auprès du Roi, \& ce Prince fit toujours les honneurs de fa Table, tandis que les Portugais étoient à genoux, \& les Gardes affis fur leurs Talons, ce qui eft pour eux la pofure la plus refpectueufe, comme je crois l'avoir déja oblervé.

Succès de res Le repas fini, le P. Xavier prit congé du Iréilications. Roi, \& s'en retourna au logis des Portugais dans le mêne ordre \& avec les mêmes honneurs, qu'il éroit venu au Palais. Dès le lendemain il prêcha en public, \& toute la Ville accourut pour l'entendre; jamais Homme ne fut écouté avec plus d'avidité; on le regardoit comme un Prophéte envoyé du Ciel pour confondre l'orgueil des Eonzcs, \& l'on ćioir 
perfuadé avant qu'il parlât. Le Saint profita de certe favorable dilpofition, \& annonça le Royaume de Jefus-Chrift avec une autorité, qu'il ne s'etoit point encore donnée depuis qu'il étoit au Japon. Cela lui réiifit, \& il ne le paffoit point de jour, qu'on ne vît quelque converfion d'éclat.

Mais il n'y en eut point, qui fit plus d'honneur à la Religion, que celle d'un Bonze d'un grand mérite, nommé SACAI-EERAN.Ce Docteur avoir entrepris de difputer contre le P. Xavier, \& s'étoit fait un point d'honneur de Coutenir la caufe des Dieux. Il défia le P. Xavier, qui accepta le défi avec joye. A peine la difpute étoit commencée, que le Prêtre Idolâtre entrevit la lumiere, il ne fe rendic pas pour cela, \& voulut faire bonne contenance; mais il ne put tenir long-tems contre la grace, qui agiffoit puiflamment fur fon coeur. On le vit tout à coup comme un Homme interdit, fans parole $\&$ fans mouvement : un moment après il fe jetta à Genoux, leva les jeux \& les mains vers le Ciel, \& d'une voix forte s'écria: Je me rends à vous, JeJus-Chrif, Fils unique du Pere Eternel; Je confeffe que vous êtes le Dieu Tout-Puiffant: vous Jeul méritez les adorations des Hommes qui font l'ouvrage de vos.mains: mes Freres, pardonnez-moi, $\sqrt{ }$ jufqu'à préent je ne vous ai débité que des menfonges; j’avois été trompé le premier. Il eft plus aić d'imaginer, que d'exprimer, combien une action de cet éclat ćnut toute la Ville. Plus de cinq cents Perfonnes demanderent avec inftance à ctre baptifées, mais le P.Xavier n'étoit pas dans un Pays, où ce fût allez d'un bon mouvement, 
\& d'une inftuction lćgere pour faire des Chrétiens: il fçavoit les combats, que les Prêtres des Idoles livroient aux Néophytes, \& hors le cas d'une véritable nécellité, il ne cunféroit ordinairement le Baptême à aucun Adulte, qu'il ne l'eût auparavant bien fortifié contre les chicanes de ces Sophistes. Il ne baptifa donc le Bonze Profélyte, quaprics l'avoir inftruit fuffíamment; \& s'être bien aulûré de la fincérité de fa converfion.

Il ne fe palloit point de jour, qu'il n'allàt au Palais, \& il sappliquait avec foin à profiter du bon accueil, que lui faifoit le Roi, pour ménager la Converfion de ce Prince, qu'il avoit extrêmenent à cocur, \& furlaquelle il avoit fondé de grandes efpérances. Il commença par lui inlpirer de l'horreur pour fes déréglements, \& s'il ne le rondit pas tout-à-fair chafe, il lui donna de l'efime pour la chafteté, \& lui śt rompre certains Commerces fcanialeux, qui le deshonoroient. Il travailla avec plus de ficcès encore à le délabuer de mille farafos opintors, que les Benzes fingerent avec foin, furtout aux Grands. Une des plus aisturdes, \& que l'Homme Apofoligue conbattit auli plus vivement; c'eft que la pativreté reud les Hommes criminels; quon péche, en faifant du bien aux Pauvres, \& qu'il y a de la juftice à les maltruirer, comme fi l'on entront alors dans les vuès des Dieux, quiles ont maudits. Le P. Xavier fit voir lans peine à Civan le ridicule de cette Dołrine, \& le fit changer de fentiment \& de conduite à l'égard des Miférables, pour léqquels il fut toujours depuis pénécré d'une comparinon tendre \& efficace.

Une 
Une fuite du principe des. Bonzes touchane les Pauvres, étoit, ainfi que nous l'avons remarqué ailleurs, que. les Femmes, qui n'avoient pas aflez de bien pour ćlever de nombreufes Familles, fo croyoient en droit d'étouffer, ou d'expofer leurs Enfants, dès qu'ils étoient nés, ou même de fe faire avorter. Le Saint s'éleva hautement contre ce défordre, d'où s'enfuivoit un libertinage affreux. Le Roi n'eut aucune peine à entrer fur cela dans fes fentiments, \& défendit lous les peines les plus féveres de fi énormes abus. Enfin le Serviteur de Dica tronva pour la réforme de la Cour \& de la Ville des facilitez, qu'on ne trouve pas toujours dans les Etats des Princes Chrétiens. Le Roi avoiioit qu'il lè lènroit ćmû julqu'au fond de l'Ame, dìs quil le voyoit, \& que certe émotion ne manquoit jamais de produire dans fon cocur un fentiment d'horreur pour toutes les abominations de fa vie.

Les Bonzes de leur côté ne s'endormoient pas, \& comme ils virent que leur crétit tomboit de jour en jour, \& qu'ils deviendroient bicn-tôt la Fable des Grands \&: des Petits, s'ils n'y apportoient un prompt reméde, ils nirent tout en ufage pour prévenir ce mallieur: ils tâcherent, mais en vain, de décrier l'Apôtre dans l'efprit du Public; ils ne réufirent pas mieux auprés du Roi, quils entreprirent d'intimider. Ils crurent qu'il leur feroit plus facile de foulever la Populace, \& ils fe flatterent yue, dans la confufion d'une ćmeute populaire, rien ne les empêcheroit de fe défaire de leurs Ennemis, mais le Roi informé de leur deflein, donna partout de Tome II. ver la Pupusso ce. 
82 HISTOIR DU JAPON;

Ii bons ordres, que Perfonne n'ofa remur. Ceftratagène réifit mieux aux Bonzes d'Amanguchi, que le Pere de Torrez ne menoit gueres moins mal, que le P. Xavier faifoit ceux de Fucheo, \& il eut des fuites bien funeftes pour le Naugato.

Succes du $P$. de Torrez à A manguchi. $\mathbf{L} \approx$ sonzes engigent un Seigneur à le révolter. Le Rui fo tuï.
Ces faux Prêtres aroient tenté de confondre le Mifionnaire dans la difpute, mais ils n'en avoient retiré que de la confufion. Ils ellayerent enfuire la voye de la calomnie, puis celle des remontrances au Roi, qui n'agiffoit pas allez vivement à leur gré contre les Chrétiens, \& qui fouffroit les Docteurs Etrangers dans fes Etats. Comme ils virent que tout cela ćtoit inutile, ils engagerent un Seigneur de la Cour à prendre les Armes. Celui-ci charmé de trouver une fi belle occa. fion de colorer fa révolte du prétexte de la Religion, leve des Troupes, \& vient brufquement fondre fur Amanguchi. Le Roi pris au dépourvî, \& qui crut le mal bien plus grand, qu'il n'étoit, s'enferma dans fon $\mathrm{Pa}$ lais, ordonna qu'on y mit le feu, poignarda de fa propre Main fon Fils unique, \& ie fendit lui-même le Ventre. Tel fut le fort déplorable d'OXINDONO, qui pour avoir voulı fe mínager entre lés Bonzes \& les Miffionnaires, ne gagna ni les uns, ni les autres, attira fur lui la colere divine, \& fut la malheureufe Victime d'une politique prefcue toujours funefte, \& que l'exemple ne corrige point.

Une prin- Après la mort de cet infortuné Prince, ceffe Hoiâtre les Rébelles, guoiqu'ils ne rencontralfent plus fiuve lis Mif- nulle part de réfifance, firent main-balle fur
fiundids. 
Égorgerent un nombre confidérable de PerConnes de tout âge \& de tout Sexe, \& mirent le feu à plufieurs Quartiers de la Ville. Ce qu'il y eur de plus iurprenant, \& ce qui ne peut gućres s'attribuer qu'à un Miracle de la Providence de Dieu, c'efr qua aucun Chrétien ne périt dans ce Malfacre, \& que les deux Miflionnaires, qu'on cherchoit partout, pour les immoler a la haine des Bonzes, trouverent un afyle chez leurs Ennemis mếmes. Ils en furent redevables a l'efrime, qu'une Princefle avoit conçuë pour eux. Les Bonzes, à qui elle faifort beaucoup de bien, s'óm toient allez déclarés qu'ils en vouloient furtout à ces Religieux; mais elle leur fit dire, qu'ils lui répondroient de tout ce qui pourroit leur arriver; deforte quils le virent obligés d'être eux-mênmes les Gardicns de ceux, contre qui ils avoient excité cette Tempête. Ils les retirerent d'abord dans un te leurs Monafteres; mais comme ils ne s'y étoient réfolus, quapris que leur Bienfaictrice les eut menacé de les faire challer de la ville, s'ils le refuloient; elle ne les crut pas encore alliz en sûreté entre leurs Mains, \& les fit conduire fous bonne garde dans fon $\mathrm{Pa}$ lais.

Enfin l'Orage ceffa, comme il avoit commencé, lorfqu'on avoit moins fujer de l'ếp'erer. Les Conjurćs difparurent, fans qu'on ait jamais bien fçu, ni ce qui les y avoit contraints, ni ce qu'ils éroient devenus. Alors les principaux Seigneurs sallemblerent, pour ćlire un Roi, \& le choix tomba fur EACARANDONo, Frere du Roi de Bungo, jeune Prince, en qui l'on admiroir une grande

$$
\text { C is }
$$

Le Preredu Rui de Bunga elt elu Raide Niugatu. 


\section{HISTOIRE DU.JAPON;}

douceur, jointe à beaucoup d'efprit \& de comrage. La Cour de Civan reçut avec joye les Députés du Naugato, \& célébra l'Election du. Nouveau Roi avec toute la magnificence polible. Le P. Xavier ne manqua point d'aller féliciter les deux Rois fur un Evénement fi heureux, \& Facarandono lui donna parole, qu'il ne feroir pas moins favorable aux Chrétiens, que l'étoit le Roi de Bungo fon Aîné.

S. Fiançois Cependant il y avoit déja plus d'un mois; Xavier fe dif- que le. Serviteur de Dieu ćtoit à Eucheo, atpule à setour-. ner aux lindes. Cequifeparfe vigation des Indes: enfin le jour du départ cnerelui \& le. fut fixé, \& il alla en cérémonie prendre RoideBungo.congé du Roi. L'Audience fut longue, \& fe - palla toute en regrets de la part de Civan, lequel témoigna plufieurs fois aux Portugais, quil leur portoit envie de ce qu'ils alloient avoir le plaifr de jouiix fi long-tems de la compagnie d'un Homme, qu'il s'eftimeroit heureux de pouvoir conferver dans fa Cour. le Pere de fon côté, après avoir donné à ce bon Prince toutes les marques de refpect \& de reconnoilance, quil huidevoit, Iui remit en peu de mots devant les yeux tout ce qu'il Iui avoit dit dans les différents Entretiens, Gu'ils arojent eus enfemble. Il infinta beaucoup fur la briéveté du tems, \& le terme fatal, ol aboutifient tous les plaifirs \& tontes les Grandeurs de la Terre. Il le pria de réfićchir fouvent furce qu'étoient devenus tous les Empereurs \& tous les Rois du Japon, gui avoient régné jufques-là arec plus de gloire, \& avoient mené une vie plus délicienfe; il le conjura de penfer; que bien-tôt il 


$$
\text { L TRE PREM IER。 }
$$

se feroit plus lui-même, quece qu'ils étoient, c'eft-à-dire, un peu de Cendre \& de Poutl:ere; avec cette différence, qu'ayant ćté inftruit \& convaincu des véritez du Salut, il auroit à rendre à Diea un terrible compre d'une grace, qui n’avoit été accordée à aucun d'eux. Le Roi touché juffu'aux larmes, l'embraffa tendrement, \& fe retira lans lui. rien répondre.

Les Bonzes cependant vouloient abfolument fe venger \& laver la honte de leurs défaites efforts des dâns le fang de tous ceux, qu'ils en regar-Bonzes contre doient comme les Aureurs. Ils ne pouvoient le Sainto fe réfoudre à voir tranquillement partir leur Ennemi couvert de gloire, \& pour ainfi dire, la palme à la Main, \& ils ne digeroient point d'être devenus odieux \& méprifables à Ia Cour \& à la Ville: Ils reprirent d'abord: la penfée d'exciter une Sédision, comme avoient fait leurs Confreres d'Amanguchi : \& à la faveur du tumulte, ils comploterent de piller le Navire Portugais, d'y metrre le feu, \& de faire paffer au fil de l'Epće tons les Européeng \& les Chrériens. Leur deflein étoit même d'exterminer toute la Famille Royale; mais leurs mefures fe trouverent faulfes. Tout le Peuple avoit pour le P. Xavier une vénération parfaite, $\&$ tous les efforts, qu'on fie pour lui infpirer d'autres fentiments, furent inutiles. Les Bonzes eurent beau publiér, que le Docteur Etranger étoir un Enchanteur; qu'il fe nourriffoit de chair humaine; yu'il déterroit les Corps pendant la nuit; qu'un Démon parloit par fa Bouche; que les Dieux irrités menaçoient de faire un Exemple du Roi pour tout le Japon; \& que pour fe foul: 
traire à la colere du Ciel prête à éclater, il ne lui reftoir qu'un feul moyen, qui étuit de leur immoler les Sacrilćges, gui détruiloient leur culte, \& tous ceux, qui participoient à leur impiécé: ils ne gagnerent rien. Enfin, comme les Portugais preffoient leur départ, ils craignirent que le Miffionnaire ne leur ćchappât, avant qu'ils pûffent zyoir leur revanche de toutes les Victoires, qu'il avoir remportées fur eux, \& ils réfolurent, ne pouvant faire micur, de ienter encore une fois de le confondre dans la difpute.

Il eft defís à Un jour donc que le Saint étoit retourné la difpute par Palais, pour prendre encore une fois congé un fameux du Roi; on avertit ce Prince, que FucaranDocteur. Dono demandoit une audience, \& fouhaitoit de l'avoir en prélence du Docteur des Portugais. Fucarandono étoit alors un des plus fameux Bonzes du Japon. Il avoit profeflé trente ans la Théologie de Xaca, \& s'étoit acquis une fi grande séputation, que fes décifions étoient regardćes comme des Oracles; c'eft un Grade parmi les Bonzes, où peu de Docteurs parviennent ; \& ceux, qui y font parvenus, font cenfés réellement infaillibles. Les Bonzes de Fucheo avoient mancié à celui-ci les progrès du Chriftianifme, \& le danger, o.i le trouvoit le Japon, de voir cette Religion Errangere s'établir fur les ruines de toutes les Sectes de l'Empire; qu'ils ne connoiffoient plus d'autre Reméde à un fi grand mal, que de bien faire fentir à ceux, qui s'ćtoient laillez réduire, que leur nouveau Mấtre ćtoit un ignorant, mais que lui feul pouvoit défabufer le Peuple prévenu en fa faveur, renger las Lieux des artentars de cer Impol- 


$$
\text { LIVRE PREMIER. }
$$

pofteur, \& ramener les Japonnois au culte, qui leur ćtoit ồ ; qu'il vînt donc au plutóc au fecours des Immortels, dont les Temples éroient fur le point d'ctre abandonnćs. Le Docteur fans fe faire prier, fe mit aulfi-tôt en Chemin; \& fe flattant d'une Victoire, quil croyoit facile, il fe hâta de joindre fon Adverfaire, qu'il apprit être fur le point de s'embarquer.

Au nom de Fucarandono le Roi parut un peu déconcerté; il comprit d'abord quel étoit le defrein de ce Bonze, \& il a depuis avoüé, que quelqu'idée, qu'il eût du Ç̧avoir, \& de l'efprit du P. Xavier, il avoit craint de le commettre avec un Homme, quil croyoir n'avoir point fon pareil dans le Monde. Le Serviteur de Dieu s'apperçut de l'embarras du Prince, en devina la caufe, \& le conjura de faire entrer le Bonze. Civan ralsuiré par la réfolution, que faifoit paroître le Saint, confentit à ce qu'il forhaitoit. Fucarandono entrá; \& apres quil eut rendu fes devoirs a Roi, il prit fans façon la Place, que le Pere Xavier lui céda par modcttie. Il le regarda enfuite fixement, \& lui demanda, s'il le reconnoilloit? Le Serviteur de Dieu lui répondit, qu'il ne fe fouvenoit pas de l'avoir jamais vâ. Alors le Bonze faifant l'étonné, cela eft il poffible, lui dit-il? "Tu ne te fou»viens pas, qu'il y a quinze cents ans, que "nous trafiquions enfemble à Frenoyama? « Je vois bien, ajoûta-t-il, din ton moqueur, \& regardant l'Allemblée d'un air triomphant, " je vois bien, que j'auras bon mars ché de cet Homme-li.

Le Pere comprir aifémenr que le Dorteur

Il acioptele défi, \& confond le Dus. teur. 
tenoit la Tranfimigration des Ames; pour: le tirer defes principes d'une maniere, qui fút à la portée de fes Auditeurs, il commer.-. ça par lui demander, s'il n'ćtoir pas conftane par les. Annales du Japon que Frenoyama n'étoit habité, que depuis environ neuf cents. ans ? Le Bonze fe tira mal de cette objection, qu'il n'ayoit pas prévîé de la part d'un Etranger ; \& comme pour cacher fon embar-. ras, il fe far attaché à prouver que l'oubli du paffé étoit une punition des Dienx, pour avoir mal vêcu; il ne s'apperçut pais qu'il mettoit contre lui toute l'Affiftance, \& donnoit à fon Ennemi un grand avantage fur lui; aufh le. Pere en f̧̧utr-il bien profiter, \& il le rendit mưt fut cet Article. Fucarandono ne pouvant donc avançr de ce côté-là, fit au Pere quantité de Queftions, que la pudeur ne permet point de rapporter. Il efpéroit en fe jettant fur cette matiere, fe rendre favorables les Courrifans, qu'il f̧̧avoir être plon. gés pour le plûpart dans les plus infâmes débauches; mais il fut trompé dans fon attente. Il batrit enfuire quelque tems la Campagne, comme un Homme, qui fe perd, \& enfin il. s'emporta de telle forte, que tout le Monde. en fut choqué. On l'avertit de faire réflexion, que le Docteur Européen, , fans fortir des bornes de la modération \& de la bienféance, fans s'échauffer, fans rien dire, qui ne fût établi fur les principes du bon fens, prouvoit folidement tout ce qu'il avançoit, \& donnoir à tout ce qui lui étoit objecté, des. réponfes, qui fatisfaifoient; bien loin de profiter d'un avis fi fage, il parla avec tant de hauteur \& d'infolençe: que. le. Roci le fir challer. 
Il n'en falloit pas tane pour mettre en fureur tous les Bonzes; ils ferment les Tem-excitens un ples, ils refufent les offrandes du Peuple, féditiun. ils publient, que les Dieux font irrités; cnfin ils viennent à bout d'émouvoir la populace. Les Portugais, qui virent les efprits difpolés à un foulévement général, ne fe crurent pas ent sûreté dans une Ville, où l'autorité du Prince n'étoit plus refpectée. Ils rentrerent dans leur Navire, \& s'ćloignerent de Terre; mais un moment après , Gama faifant réflexion que le P. Xavier étoit refté à Fuchéo, où leur retraite l'expofoit à la rage des Bonzes \& de leurs Suppors, il fe mit dans fa Chaloupe, \& courut le chercher. Il le trouva dans la Maifon d'un Pauvre Catéchumene, ou yuelques Chrétiens s'étoient allemblés. L'A pớre les confoloit, les animoit au Martyre; \& comme il ne doutoir 'point' qu'on ne vint incelfamment pour l'égorger, il bénilloit le Ciel de luí avoir enfin accordé ; ce qui failoit dépuis fi long-tems toute fon Ambition.

Gama n'onnt rien pour-l'obliget à chercher un afyle dans fon bord, mais ce fut $\mathrm{cn}$ vain. "Y penfez - vous; hi dit l'Honnie Bclie antion d'ün Captiatilie portugais. "A pottolique! Quoi ! j'aban tonnerois mont 》Troupeau à la merci des Loups? A Dieu " ne plaife, que je deshomore ainfi mon "miniftere, \& que les Bonzes puillent fe » vanter de in'avoir contraine de leur céder s) le Champ de Bataille 's. Gama touche d'une réfolution fi Héroïue, le retira fans rien répliquer, rentra dans ton Navire, a ffembla fes Officiers \& fes Alfociós, leur d clara que le Pere Xayier étoit déreminéc 
monrir avec les Néophyres, leur ajoûta, que lui-même étoit dans le dellein de fuivre jufqu'au bout la fortune du Serviteur de Dieu; que pour eux, ils pouvoient prendre leur parti, qu'il leur abandonnoit tout ce qui lui revenoit des effets du Navire, \& le Navire même; qu'ils avoient de bons Pilotes, \& des vivres en abondance; qu'il ne s'étoir point engagé à les conduire en Perfonne, \& qu'il alloir rejoindre le Saint, \& mourir avec lui, s'il ne pouvoit pas lui fauver la vie. Ce difcours attendrit les Portugais; ils eurent honte de leur fuite précipitće; ils rapprocherent le Navire, delcendirent à Terre, \& rentrerent dans la Ville en polture de Gens déterminés à tout rifquer pour la confervation du I. Xavier. Ce retour leur fir honneur; les Fidéles en furent édifiés, \& les Mutins intinidés; le tumulte cella, \& les Bonzes fe virent encore une fois réduits à confier leur caufe au hazard d'une difpute.

Les difputcs renr, \& quel l'agrément du Roi, qui ne l'accorda, après co fut le tuc-bien des inftances, qu'à des conditions for cess. dures. La principale fut, que ce qui feroit une fois décidé à la pluralité des voix, feroit regardé comme inconteftable, \& qu'il ne feroit plus permis d'y revenir. Les autres renfermoient de fort bons réglements, pour éviter le bruit, \& metre de lordre dans les Queftions \& dans les Réponfes. Le lendemain on avertit le Roi de grand matin, que Fucarandono étoit dans la premiere Cour du Palais a la Tête de tous les Bonzes de Fucheo, \& des environs; qualques Mémoires en font mointer le nombre à trois mille. Cis 


$$
\text { LIYRE PREMIER. }
$$

van pour le déaire de Gens, qui lui fendbloient avoir un autre deflein, que de difpurer, leur fit remontrer, qu'il n'ćtoit, ni railionnable, ni de leur honneur, guils fullent en fi grand nombre contre un Homme feul; il ajoûta, qu'il vouloit bien nćanmoins que Fucarandono amenât avec lui trois ou guatre de fes Confreres, mais qu'il n'en fouffiroit pas davantage. Il fallut obéir, l'Armée des Bonzes fut congédiće, \& Fucarandono étoit à peine entré dans la Salle, où fe devoit tenir la Confórence, que le Pere Xavier arriva avec encore plus d'appareil, que le jour de fa premiere audience, les Portugais, qui l'accompagnoient, ne lui parlant qu'a genoux. Cette efpéce de triomphe du Saint, fie bien du dépir à fes Ennemis; les difcours, qu'ils entendirent, qu'on tenoit dans l'Allemblée, ne les chagrinerent pas moins; mais ce qui acheva de les déconcerter, ce fut laccucil que le Roi fit au Serviteur de Dieu. Ce prince s'avança allez loin pour le recevoir, l'embrafía, le fit afleoir auprès de lui, \& l'entretint quelque - tems en particulier avec beaucoup de faniliarité.

Enfin la Conférence commença; elle roula d'abord fur l'exiftence \& l'unité de Dieu. Le P. Xavier prouva l'une \& l'autre d'une man ere également folide \& fentible: puis s'étendit fur les principaux Attributs de la Divinité, fur les Myfteres de l'Incarnation da Verbe, \& de la Rédemption des Hommes, \& après avoir répondu à toutes les Objections, qu'on lui fit fur tous ces points, \& qui furent abfolument les mêmes, qui cnt ćté faites aux premiers Apologiftes du ChriftianifD $v j$ 


\section{HISTOIRE DUTA PON,}

me: il appuya beaucoup fur le mérite de la: Foi, \& fur la nécenté des bonnes ceuvres. II le failoit pour détruire certaines Fables, dont nous avons vâ que les Bonzes amufoient IES. Peuples, en leur faifant accroire que pour. être heureux en l'autre vie, il fuffifoit de mourir revétu de Robes de Papier, ou chargé de Letrres de Change, dont ces Intpolteurs. tiroient un gros proht, ce qu'il ne inanqua. pas de faire obferver à fes Auditeurs. On en demeura là dans cette féance; l'Homme Apofolique fut fouvent interrompu par les applaudiffements de toute l'Afiftance, \& il leur paroiffoit qu'on leur ôtoit conmms un bandeau de devant les yeux. Ils furent furpris d'avoir été fi long-tens les Dupes de tart dinpoltures gronlieres, \& fur-tout d'avoir adoré comme des Dieux, des Hommes aufi foibles qu'eux, \&: la plîpart plus vicieux ein core.

Nous ne fçavons point ce qui fapalfa dans Ia féance fuivante; le Portugais, dont on a fuivi les Mémoires pour cet endroit de la vie du Saint, \& qui étoit prélent, avouë ingénument, que tout ce qui y avoit été traité y. furpalfor de beaucoup la portée de fon efprit. Il marque feulenent, que le P.: Xavier, furs pris de la fubtilité de quelques raifonnements; qu'on luif fre, dit aux Portugais, quil avoic befoin, pour les refucer, d'un fecours extraordinaire du Ciel, \& lespria de joindre leurs Prieres aux fiemnes, pour l'obtenir. Cet Homne ajouta quaprès que le Saint eut cellé de parter; les Borzes múmes fe confellerent 7aincus, \& convinrent, qu'ils navoient rien

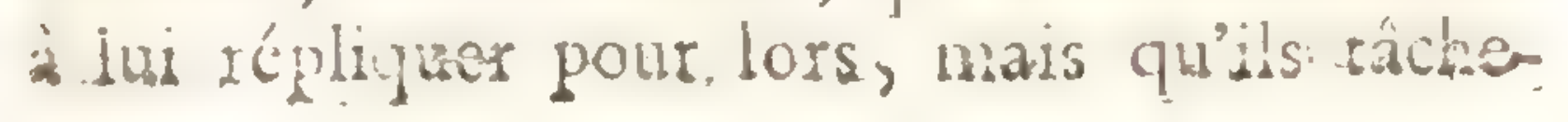


sent de mettre leur Honneur à couvert, en faifant entendre qu'ils cédoient plutôt à la fubtilitć d'elprit de leur Adverfaire, qu'à la bonté ce fa caule.

Le jcur fuivant on parla des Pauvres, \& les Bonzes entreprirent de faire voir, que la conduite cu Ciel à leur égard, étoit une convic. tion de la malédiction portće contre eux. Le Serviteur de Dieu réfuta fi ailément, \& d'uno manié:e fi plaufible leurs principaux argumens, que toas les Afrittans lui applaudirent. Il s'at+ tacha furtout à montrer par des raifons tirées de l'exórience, que ce qu'on appelle communćmant les biens, \& les maux de la vie, no font ni de véritables biens, ni des maux réels, \& le flence de fes Adverfaires lui donna une victoise complette. Comme on étoit fur le point de congédier l'Allemblée, les Bonzes ne pouvant s'accorder entre eux fur un point de Doctrine, dont on ne nous a pas inftruits, fe querellerent aflez, vivement, \& en alloient venir aux mains, fi on ne les eut fait fortir.

Surle foir le Roi, qui-vouloit finir ces difputes, alla prendre le P. Xavier à fon logis, \& le conduifit au Palais parmi les acclamations du Peuple, après avoir averti Fucarandono de s'y rendre. D'abord tout $\{$ e paffa en excufes \& en civilités réciproques; \& le Roi charmé de cetre conduite des Bonzes, leur en témoigna beauboup de fatisfaction. Dis que chacun eut pris fa place, un de ces Religieux Idolâtres demenda au Pere, comment dl accordoit le péché originel \& la chute des Anges, avec la bonté infinie, la fupreme fagefle, \& la toute-puiflance de Dieu? "c Carentin, ou votre Dieu pré2o yoyoit ces péchés \& les terribles fuites, qu'ils 
s) devoient avoir, ou il ne les prévoyoit pas: ss'il ne les prévoyoit pas, fes lumićres fone "bornées, \& il n'eft pastel, que vous le prés tendez. S'il les prévoyoit, pourquoi n'a-t-il 2) pas empêché ce qui devoit être la caule de stant de maux? " Un autre prit auflitôt la parole, \& demanda pourquoi Dieu n'avoit pas racheté le Monde aufitôt après la défobéillance du premier Homme? \& ce qu'aroient fait ceux, qui étoient morts avant JESUS. CHRIST, pour être fruftrés d'une Rédemption, gui a nuvert le Ciel àcelix, qui lont venus depuis. L'Apôtre ne fut, ni furpris, ni embarallé de ces objections, fi fouvent reluatues dans les premiers fiécles du Chriftianifme. Il n'ignoIoit pas ce que difent les Peres \& les Théologiens, à fçavoir, qu'il importoit à la gloire de Dieu, qu'il fût fervi \& adoré par des créa tures libres \& intelligentes; c'eft-a-dire, qui connuffent le bien, qu'elles devoient pratiquer, \& le mal, qu'elles devoient éviter, \& qui pulfent prendre leur parti par une détermination exempte de toute contrainte \& de toute néceffité; que notre propre intérêt demandoit que cela fût ainfi, puif́que nos mérites croiffent à mefure, que nous ufons bien de notre libre arbitre, \& que notre bonheur doit être la récompenfé de nos mérites, aufiquels it faut qu'il foit proportionné; que pour convenir de ces points, il fuffifoit de confulter la raifon, \& de fuppofer, que Dieu eft équitable: Que tous les maux, qui ont fuivi le péchédu premier Homme, \& celui des Anges rebelles, font de deux efpéces: le péché, \& les miléres de la vie, que Dieu en permettant l'un, \& en nous envoyant les autres, ne failoit rien, dont 
rous pûfirons raifonnablement nous plaindre, puifqu'il nous donne allez de graces, pour éviter le péché, \& que les calamitez de la vie préfente, fi nous les fouffrons avec parience, \& a vec une réfignation parfaite à fes ordres, font autant de dégrez, qui nous élevent à la fouveraine félicitć.

Quant au délai de la Rédemption, le Pere fit voir qu'il n'avoit apporté aucun préjudice à ceux qui ont précédé le Rédempteur; par la raifon qu'on pouvoit avoir part à cet ineftimable bienfait, avant que l'ouvrage fût confommé. Il prit de-là occafion de parler des $\mathrm{Na}$ tions, anfyuelles l'Evangile n'avoit pas été prêché d'abord; il montra qu'elles étoient inexcufables, de n'avoir pas adoré le vrai Dieu; puifqu'elles avoient la Loi naturelle, qui les devoit conduire à la connoiffance de cet Etre fuprême, \& dont l'exacte obfervation leur auroit mérité fans doute d'être éclairées des plus ellentielles véritez de la Religion Chrétienne. Je fuppofe donc, continua-t-il , qu'un Infidele cité au Tribunal de Dieu, \& obligé de dire, pourquoi il n'a pas rendu à fon Créateur les ho:nnages fouverains, qui lui font dîs, s'aviè de répondre? «Seigneur; je ne f̧̧avois د pas ce que c'étoit que ces hommages, que s) vous exigiez de moi. Votre raifon, lui ré»pondra le fouverain Juge, vous apprenoit » une partie de vos devoirs; fivous les aviez »remplis, je vous aurois fair connoître les " autres $\%$. Qu'aura-t-il à répliquer? Le Saint fortifa ce raifonnement d'un précis exact des: des motifs de crédibilité, fur quoi font appuyćes la foi en Jesus-CHRIST, \& toutes les. vérités du Chriftianime; \& il en conclut, que 


\section{H HISTOIRED H-JAPOH;}

$l_{a}$ Mifion du Fils de Dieu, \& la réalité de prédication, de fa Mort \& de fa Réfurrection, étant une fois démontrées, il ne s'agfloit plus de vouloir fonder les Mytéres impénétrables de la fagelle du Créateur; ni la profóndeur de fes jugemens fecrers; mais qu'il falloit fe rendre avec docilité à l'autorité infaillible de fes decrets; autorité, qu'il a dépofée entre les mains de fes Miniftres, qui, quoiqu'Hommes fujets à l'erreur, ont dû être revêtus d'uncaractére infaillible; pour être en érat de condure les autres Hommes. Toute l'Affemblée fe récria dèsque le Saint ent ceffé de parler, \& on l'admira d'autant plus, que d'abord on avoir jugé fans réponfe les difficultez', qui lui avoient été propofées.

Perfonne ne dontoit qu'à ce coup les Bonzes ne fe rendiffent; mais leur obftination \& l'endurciffement de leur cour leur tenant lieu de raifon, ils parurent plus éloignés que jamais de reconnoitre la vériré, qui' fe découre vroit fous des traits fi lunineux; \& ils tombérent dans des excès, dont on eut honte pout eux. Ils nioient tour, jufyuar principes, \& ils ne s'appercevoient pas que leur Adverfaire tiroit avantage de ce qu'ils avançoient, \& rejettoient inconfidérément, \& qu'il les faifort tomber dans de continuelles contradictions. Enfin le Roi fatigué leur fir impofer filence. II s'éleva auffitôt parmi les Affiftans un petit fourire accompagnć de quelques railleries, dorí ces faux Prêtres fe tinrent étrangement offenfés: ils s'en plaignirent aur Roi: Quoi, Seigneur; lui dirent-ils, vous fouffrez qu'on nous infulte en votre préfence! Alors le P. Xavier prit la parole, \& par fonientremife ilfe fir wie 
efrece d'accommodement, qui engagea tout de nouveau la difpute.

Un Bonze s'avifa de dire qu'il ćtoit affez inutile de venir de $f$ loin annoncer un Paradis, quine convenoit qu'aux Bêtes: que celui des Hommes éroit fur la Terre, \& qu'ils en jouif-. foient pendant la vie, plus ou moins, fuivant, leurs mérites: que celui, dont le Docteur. ćtranger parloit, étoit dans le.Ciel, mais qu'il étoir tans doute deftiné pour les Animaux privés de raifon, qui pendant leur vie n'avoient. que du mal, \& qui par conféquent devoient. avoir leur récompenfe dans l'Empirée, fi Dieu: étoit julte. Il n'étoit pas difficile de renverfer un fyftême aufi abfurde, \& fuivant lequel le feul Animal raifonnable étoit privée de l'immortalité, qu'on fembloit affurer aux Bêtes. Aufi le Bonze fut-il univerfellement traité d'extravagant. Le faint Apôtre n'eut guéres. plus de peine à détruire la prétention d'un autre, qui vouloit prouver, que la différence des états \& des fituations, où fe trouvent les Hommes fur la Terre, ne peut venir que de la diverfité de leurs mérites; mais il prit occafion de ces abfurdités; pour dire de rrès-belles chofes fur la nature de nos Ames, fur notre fin derniére, \& fur la fagelfe \& la providence de Dieu. Les Bonzes n'y répliquérent rien de fenfé; \& le Roi, qui les vit fur le point de re. tomber dans leur premier défordre, fe leva fans dire mot, prit le Serviteur de Dieu par la main, \& le remena chez lui.

Ainfin finirent ces fameufes difputes de $\mathrm{Fu}$ cheo, dont le bruit fe répandit bientôt par tout tourne aux In le Japon. La véritable Religion y triompha diune maniére bien éclatante; mais l'Homme. 
98 HISTOIRE DU JAPON;

Apoftolique n'en recueillit point le fruit; le Roi ne fe déclarant point, alicun des Courti. fans ne parla d'embraffer une Loi, a laquelle ils venoient tous de donner unanimement la préférence fur ioutes les Sectes de l'Empire. Le vingriéme de Novembre, le P. Xavier alla dire un dernier adieu au Roi, \& fit de nouveau efforts pour engager ce Prince dans les voyes du falur; mais il ne put en tirer que des promelles vagues, \& quelques foupirs. Il s'embarqua au fortir du Palais, \& dès le même jour on leva les ancres. Bernard, \& fon Compagnon, qui avoit nom MATHIEU, s'embarquerent avec le Saint. Celuti-ci mourut prefqu'en arrivant à Goa. Bernard paffa en Europe, alla jufqu'a Rome, puis s'étant retiré en Portugal, il entra dans la Compagnie de JEsus, \& finit faintement fes jours au College de Conimbre.

On apprit bientôt aux Indes les grands fuc-i cès, que le zéle du P. Xavier avoit eu au Ja pon; \& partout on donna des marques publiques de la part qu'on y prenoit; mais celui, qui fit paroître fa joye d'une maniére plus éclatante, fut DOM PEDRO DE SYLVA, Gouverneur de Malaca. Ce Seigneur fir rendre à Dieu de folemnelles actions de graces d'une fi belle ouverture à l'Evangile chez une Nation, dont on eftimoit déja fi fort la fagelle \& le courage. Tous les Ordres de la Ville allerent en Proceffion à l'Eglife de Notre-Dame du Mont, oủ le P. Xavier, lorfqu'il étoit à Malaca, ivoir accoutumé de dire la Melfe, \& de faire les principales fonctions de fon Minifére. Le Gouverneur y parut lui-même à la tête des Troupes, qui ćtoient fous, les armes, \& $1 \mathrm{~s}$ 
Grand.Vicaire de l'Evêque de Goa y chanta $1 a$ Grand-Mefle. Tout le refte du jour il y eat de grandes réjouiffances par toute la Ville, les rues demeurerent tapiffées jufyu'au foir, \& on y brula des parfums, qui embaumoient l'air. Il y eut pendant la nuit des illuminations dans tous les quartiers, \& la Fête fut terminée par le Baptę̧me de quatre Japonnois, qui ćtoient venus aux Indes, pour s'inftruire par leurs propres yeux, de lavérité de tout ce qu'on leur aroit dit chez eux touchant la majefté des Temples du Dieu des Chrétiens, \& la dignité du culte, que les Portugais lui rendoient. Nous verrons bientôt combien il êir éré à louhaiter, que Dom Pedro de Sylva n'eût pas eu fitôt de Succeffeur, ou qu'on lui en eú: donné un, qui lui rellemblât.

Au refte, il y a bien de l'apparence que le P. Xavier, quelques preflantes que fulfent les affaires, qui le rappelloient aux Indes, n'eût pas quitté le Japon, avant que d'avoir pourvû de Pafteurs les Eglifes qu'il avoit fondées dans' le Bungo, dans le Firando, \& même dans le Saxuma, s'il avoit pû fe réfoudre à confier à d'autres le foin de choifir les Ouvriers, qu'il convenoit d'envoyer dans cette nouvelle Vigne. Car quoiqu'il fût très-perfuadé que les Bonzes n'omettroient rien pour pervertir les Fidéles; \& pour gagner ou intimider les Princes; qu'il n'ignorât point le grand afcendant, que donnoient à ces faux Prêtres fur les Peuples \& fur les Souverains, la réputation de doctrine \&e de fainteté, qu'une longue prefcription fembloit leur affurer; leur éloquence, qu'il n'avoit pû s'empêcher d'admirer lui-même; leurs fophifines, \& l'air impolant, avec lequel ils 


\section{TOO HISTOIRE DU JATON,}

débitoient leurs fables; $\&$ : la haute naiffanco de plufreurs: quoigu'il dît connoître par plus d'une expérience, qu'il eft bien plus difficile de rétablir une Chrétienté ruinée, que d'en fonder une nourelle; il étoit encore plus convaincu, que le fuccès d'une Miftion dépend furtout après la grace de Dieu, du choix des Miftionnaires; que ce choix le doit faire fuivant le caractére des Peuples, qu'on entreprend de convertir, \& qu'on y eft fouvent rromfé, quand on le fait fur le rapport d'alstriti.

Fin du premier Litré 


\section{SOMMAIRE}

\section{DUSECOND LIVRE.}

Conduite du Roi de Bungo après le déC part de 'S. Frangois Xavier. Le Saint Se difipose à paffer à la. Chine, Ev pourquoi ? Nouveaux Miffonnaires au Japon. Converfion de deux Bonzes, qui deviennent de zèlés Miffionnaires. Révolte dans le Bungo. L'intrépidité d'un Mifronnaire fauve le Roi. Pinto engage le Provincial des Jéfuites des Indes a aller au Japon. Révolution dans le Naugato. Le Roi eft tué. Mouvemens dans le Bungo. Le - Provincial eft bien regú du Roi. Il eft obligé de retcurner aux indes. Inconftance de Pinto. Louis Almeyda se friit Jéfuite. Etat florifant de la Religion dans le Bungu. Le Roi étend confluérablement. Son Domaine. Converfion d'un Prinie de la Maifon Royale de Firando. Son zelle pour la converfion de Ses Sujets. Mort d'un zèlé Miffonnaire. Converfions en grand nombre dans le Firando: les Bonzzes s'y oppofent inutileinent. Indifcrétion des Chrétiens E. fes firites. Premier Martyr du Japon. Le Roi de Firando devient Tributaire du Roi de Bungo. Facata perduë pour ce Prince par.la-trahifon des Bonzes. Dangers, que courent les Mifionnaires en cette occafion. Leur Maifon Eu leur Eglife brûlées. Comment ils font recûs par les Fideles du Bungo. Defcrintion ciu Lac dOitz E de la Montagne de Jefan. Un Su périe ur de Bonzes demande des Mifionnai- 
re, Es ceux, qu'on lui envoit le trouvent mort. Providence de Dieu Jur les. Miffonnaires. Le SucceJeur du Bonze Se déclare Chrétien. Le $P$. Vilela nbtient la permifion de prêcher l'Evangile par-tout le Japon. Plufieurs Bonzes fe convertiffent. Orage excité contre le P. Vilela, E comment il se difipe. Grand nombre de converfions. Des Neophiftes publient un Traité de la Jupériorité du Chrifianifme fur les Sectes du Japon. Trifte exemple de la foiblefe humaine. Le P. Vilela à Sacai; defcription de cette Ville. Prodige de Sainteté dans un Enfant de quatorze ans. Almeyda vifite les Eglifes du Ximo: en quel état illes trouve. Defcription de la Principauté d'Omura. Caractere du Prince, qui $\int e$ difpose à $\int e$ faire Chrétien. Il introduit les Portugais dans $\int a$ Principauté. Avantages, qu'il leur offre. Le Roi de Firando en fait aufic de fort grandes pour le traverser. Defcription du Port de Vocoxiura cedé aux Portugais. Le P. de Torrez s'y tranfporte. Il s'y forme une Ville. Le Prince Se prépare à recevoir le Baptême. Il gagne d la Religion le Roi a'Arima, Son Frere. Almeyda à Ximabara, E à Cochinotyu; en quel difpofition il trouve ces deux Villes par rapport à la Religion. Zele du Prince d'O. mura. Il reçoit le Baptîme avec trente Gentils-Hormes. Il ruine un Temple, E met une Idule en pieces. Il gagne une grande Ba:aille. Il s'oppofe avec fermeté a Son propre Pere, qui perfécutoit les Chrétiens. Converfion de la Princeffe, Son Epoufe. Violence des Bonzes de Ximabara. 


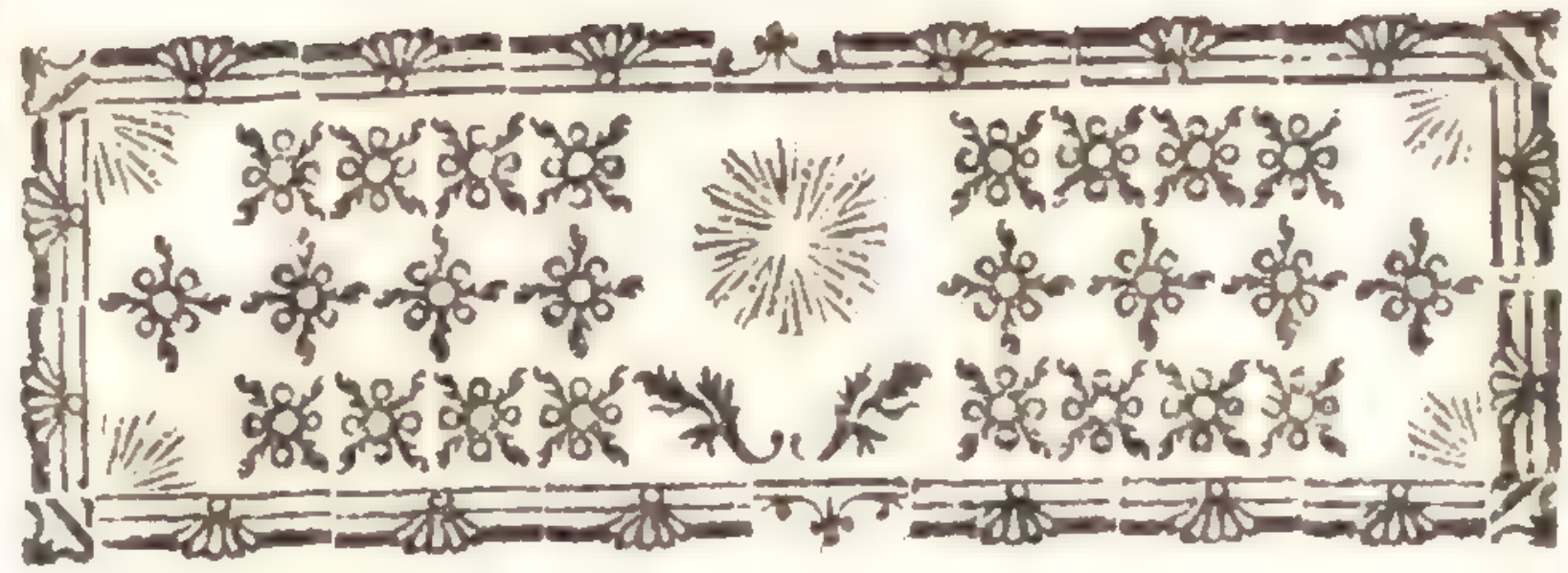

\section{H I S T O I R E \\ D U}

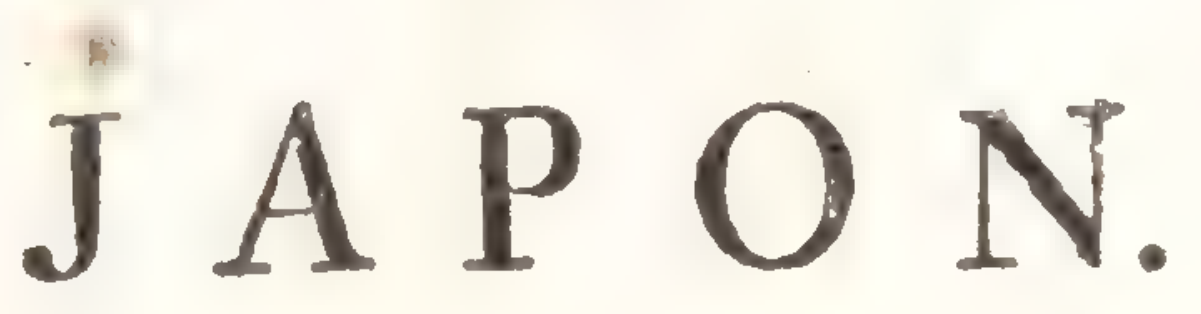

a.s.

\section{$L I V R E S E C O N D$.}

$\sqrt{\mathrm{S}} \mathrm{OU}$ R pea qu'on foit infruit de Hon ce qui s'eft pallé dans les Indes . P X pendant tour le cours des Conx.x.m quêtes, qui en avoient donné l'Empire aux Portugais, on conviendra fans peine, qu'il y avoit beaucoup plus à craindre, qu’à efpérer, pour le progrès de la Religion Chrétienne au Japon, des mefures que cette Nation prenoit pour établir fon commerce dans ces Ines. La manićre furtout, dont elle s'étoit consportée à la Chine, d'où la mauvaile conduite de Simon D'ANDRADE l'avoit fait challer, pouvoit donner lieu aux Prédicateurs de l'Evangile d'appréhender que guelquaccident femblable ne l'exclût du Japon, \& qu'elle n'entraînât le Chrifianilme kans $f a$ digrace. Il ne falloit, en tfer, pour 


\section{HISTOIRE DU JARON:}

De J. C. cela qu'une de ces incartades, qui étoient par: I 12. tont ailleurs fi fréquentes.

Mais Dieu, qui tient en fa main le cocur I. $S_{\mathrm{in}}$-Mu des Parkiculiers, aufi bien que celui des Rois, 3213. \& qui vouloit renouveller dans cette extréarité de l'Orient, toutes les merveilles, qui ont étomné l'Univers à la naillance de l'Élife, eut foin d'écarier tous les.obfacles, que po'dvoient mettre à l'exécution de fés deffetins l'ambition \& l'avarice de ces nouveaux Conquérans de l'Afie; \& c'eft peut-êrre la le plus grand miracle, que le Ciet ait opéré én faveur des Japonnois. Véritablement: ce miracle ne fubfifta qu'un certain tems, \& avec lui s'évanouirent toutes les efpérances, qu'on avoit xonçûes de voir le vrai Dieu adoré feul dans ce vafte Archipel; mais il faut croire que les vîes de la divine Providence lur ces Infulaires ćtoient alors remplies, \& s'ablenir de Londer ia profondeur des. Décrets Eternels.

Quoiqu'il en foit, il eft certain que ce fus le commerce des Portugais, qui introduifit la Religion Chrétienne dans le Jaron; mais bien que pendane plufieurs années leur conduice y ait été exemte de tout reproche, il eû́ ćté -néannoins à fouhaiter, que les laponnois reulfent point pratigué d"itures Européens, gie cenx, qui leur annongont le Royame de Dien; c'eft ce qui re protra point douteux, fi l'on fait réflexion que les. Drovinces de cet Empire, ou le Chritianifune a été plus florif fint, font celles, cui on les a moins connus.

Contuie du Il eft étonnant que le Royaume de Bungo $R$ oide linu ait été une des Provinces du Japon, ou l'on ait apress fun déo moins vâ de Navire de Portugal, puigu'il n'y en avoit aucun, ou ils puitent fe flatter d'c- 


\section{I R R E S E C O N D. IOS}

tre nieux reçûs. Il y a bien de l'anparence que les Ports n'y font pas aufli conmodes, \& auffi ailés à aborder, que les autres du Ximo. Mars ce qui fe palla à la Cour de Bungo aprés le dé- De Syn-1?i. part du P. Xavier, doit caufer encore bieir plus

$D=J \cdot C$. Is is. 2:12. d'ćtonnement. Dans la difpofition, s' l'on avoit cru veir le Roi par rapport à la Religion Chrétienne \& aux Sectes du Japon; furtout après les Conférences de Fucheo, ceux qui ne jugeoient des choles, que par les apparences, comme fait ordinairement la Multitude, ne doutoient point que ce Prince n'embrallat incellamment la premićre, \& n'abolit les autres dans les Etats. Il n'eir étoit pas de mốre de ceux, qui le connoilfoient plus particuliérement; ils prévoyoient bien que fon penchan: pour les plaibis, fes patrons fortinges par l'ha bitude, la crante d'une rivolurion femblable à celle, qui venoit d'arriver dans le Nangato, l'ćloquence \& le crédit des Bonzes; extin les préjugés de la nailfance \& de l'éducarion, qu'il eft filficile d'effacer entiérement, \& is aife de faire revivre, furtoit quand is font d'accord avec le penchant de la Nature; le feroient longrems balancer, \& pourroient à la sin repiendre le deffus dans lon coeur.

Mais, ni les uns, ni les autres ne fe feroient jamais anifé de croire que Ciran, qui avoit beaucoup de fermeté d'ame, un efprit droit, un graind fens, \& qui venoit de confeiler pubiquement la fupériorité du Chrifianifme fur toutes les Sectes du Japon, füt capable d'une conduite aufli peu fuivie, que celle, quil tin après le départ du P. Xavier, fondant dos Maifons des Bonzes, fe déclarant pour une des plus ahominables Sectes du Japon; en ćcu-

Tome II. 


\section{IO6 HISTOIRE DU JAPON:}

De J.C. diant les principes, en pratiquant les maxi $1 \iint 2$. mes; tandis qu'il appelloit \& établiffoit $l^{S}$ Miffionnaires dans fes Etats, qu'il fe faifoit

De Syn- Mlu. ouvertement le Protecteur des Chrétiens, qu'il 2212. prenoit en main leurs interêts, \& qu'il permettoit à fes Enfans d'embrafler leur Religion. Malgré cela, Dieu le combla de profpéritez; \& ce qui eft rare, ces profpéritez ne furent pas fa récompenfe en ce monde, \& ne l'endurcirent point. Le Seigneur ne le lailfa pas même s'égarer trop loin dans la voye de fon coeur, \& ne dédaigna point de fe fervir de lui, dansle tems cu'il réfiftoit davantage à fes graces, pour l'affermillement de fon culte dans l'Empire du Japon.

S. Françuis D'autre part, l'A pôtre des Indes de retoưr Xavier fe dif-à Goa, n'oublioit point les Japonnois, mais fes rufe à paller a vies s'ćtendoient bien plus loin; car fur l'eftoutes fes me-tinne, que ces Infulaires lui avoient paru faire turcs funt de la fagelle des Chinois, il s'étoit fortement rumplies. per/uadé que l'Idolâtrie tomberoit d'elle-même dans le Japon, s'il pouvoit l'exierminer à la Chine, \& il en forma le deffein. La preniere Perfonne à qui il souvrit fur cela, fut JAcQUES PEREYKA fon Ami, un des plus riches Négociants, qui fût alors aux Indes, mais qui avort le cocur infiniment au-deflus de fá fortune, \& un zćle pour la propagation de la Foi, qui étoit moins d'un Homme de fa condition, cue d'un Apôtre. Auffi le Saint le trouva-t-il fi difpofé a le feconder de tout fon pouvoir, \& à yemplover même, s'il ćtoit nécellaire, tout fon bien, qu'il le fir nommer Ambalfadeur du Vice-Roi auprès de l'Empereur de la Chine.

Pereyra s'épuifa en équipage pour cette Amballade, dont il fit tous les frais, \& en pré- 


\section{LIVRE SECON D. 107}

fents pour le Monarque Chinois, pour les Princes \& pour les pruncipaux Miniftes de cette Cour. Les préparatifs d'une Expédition, fur laquelle le P. Xavier fondoit l'efpérance, De Syn-\$u. qu'il avoit conçué de convertir tout l'Orient à la Foi, fe firent avec une diligence incroyable, \& rien, ce lemble, ne devoit faire obItacle a une Entreprife fi digne de la Nation Portugaife, \& $\mathrm{f}$ bien concertée, lorfque la jaloufie du nouvenu Gouverneur de Malaca, DOM ALVARE D'ATAYDE, renverfa en un moment de fi beaux projets, arrêta l'Apôtre des Indes au milieu de fa courfe, \& réduifit Pereyra prefique à la mendacité. D'Atayde avoit fouhaité pour lui l'Amballade de la Chine, mais il n'en avoit tien témoigné; il fur choqué de voir une fi belle Commiffion entre les mains d'un Marchand, \& d'un Homme de balfe extraction, \& ne prenant confeil que de fa paftion, il confifqua le Navire de Pereyra, \& l'envoya trafiquer pour fon compte à $S_{A N}$ CIAN, après y avoir mis un Equipage a fa dévotion. Ce fut le premier acte d'autorité, qu'il fit en qualité de Capitaine général de la Mer, gue le Pere Xavier lui avoit obténuë, \& done il lui avoit lui-même apporté les Provifions.

En vain le Serviteur de Dieu employa toute fon éloguence, pour le détourner d'une Sa most, action, qui devoit le perdre, \& qui le perdit en effer: en vain dans une maladie dangereufe, qui fur ces entrefaites furvint à ce Seigneur, s'attacha-t-il, pour le gagner; à lui rendre les fervices les plus bas \& les plus humiliants; en vain lui remit-il devant les yeux le terrible compte, qu'il rendroit à Dieu, s'il s'obftinoit à traverler une Entreprife, du fuc-

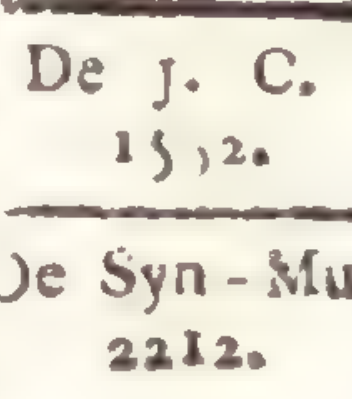




\section{IO, H.ISTOIRE DU JAFON;}

Jie T. C. cés de laquelle dépendoit peutêtre la conver, $1\}\{2$.

De Syn-Mu. munia, prćdir la terrible veangeance, que 23:2: Lifurireroit de fon injuftice \& de les violences; \& ne pouvant faire mieux, il s'embarqua fur le mêne Navire, qui venoir d'être enlevé à Pereyra, auyuel il prédit aufi le rétabliffement de fa fortune. Il efpéroit de rencontrel a Sancian quelqu'occafion favorable pour la Chine; mais après avoir vû rompre toutes les iniélurer, gu'il avuit prifes poui l'exécurion de fon projet, il y mouruten peu de jours d'une ficvie ardente, dans une cabanne ouverte à tous les vents, \& fans prefoue aucun fecours; mort d'autant plus digne d'un Apôtre, qu'elle lui donnoit plus de relfemblance avec celui,de qui les Apôtres tiennent leur Milion, \& qui les a avertis, que non-feulement il les envoyoit, comme fon Pere l'avoit envoyé lui-méme; mais qu'ils devoient s'attendre à n'être pas mieux traitós que lui.

xomenx Le Saint, avant que de metrie à la voile Mrifionimies" pcur Sancian, avoit envoyé at Japon le Pere au Julu. Patthasar Gago Portugais, avec deux jeunes Religieux de la même Nation, qui n'éroient pas encore Prêtres, dont l'un fe nomhioit Pierre o’Alcaceva, \& l'autre, Edotard LE Sylva. Ces trois Mifionnaires prireizt teire à Cangoxima vers la mi-Août de l'anriće Is 52. \& fǘent bien reçûs du Roide Saxurna, qui s'étoit reconcritic avec les Portugais. Ils ne sarricterent pourtant point dans ce Royame, \& ils fe rendirent à la Cout du Poi de Bungofur la fin du mois de Sepssubäe. Ils aroient des Lctires \& des prólens 
du Vice-Roi des Indes pour ce Prince, qui regardant cette politelle \& ces attentions, comme un effet de l'amitié du Pere Xavier, y parut tres-fenfible. Il afigna d'abord anx De Syn-Mu. ncuveaux Minionnaires un logement commode, il leur fit entendre qu'ils lui feroient plaifir de le fixer dans fes Etats; il pourvut à leur entretien, \& il les affura de toute fá protection. Le Pere Gagolui répondit, que cette invitation ćtois pour lui un ordre, a!rquel il déféreroit d'autant plus volonticis, qu'il éroir conforme à ceux du Pe é Xavie, fon Supćricur.

Qualques jours apris, lu \& les deux Com- Les Minom pagnons fircnt, avec la permilion, \& aux nairesconcerdépens du Roi, qui leur donna même un tent !a manimDomeltique pour leur fureté, le yoyage d'Amanguchi Leur deflein éroit de confer avec pone all ixle

le $\mathrm{P}$. de Torrez fur la maniere de le comporter dans l'exercice de leur miniftere, \& d'ctablir partout une conduite uniforme. Dis qu'ils furent arrivez, le P. de Torrez, qui avoit ćś déciaré par le pere Xavici, Supúrieur Gúnćral de la Miffion, commença par convoquer une Alfemblée des plus dítin gucz d'entre les Chrétiens d'Amanguchi; afin d'avoit leur avis fur diverfes chofes, qui ne pouroient fe régler, quivec une parfaire connoilfance du Pays; \& apres plufeurs conférences il fut arrété, qu'on s'attacheroit fu:tour à foulager les Pauvres fans aucune diltinction de Chrétiens \& d'Infideles; que four cer ellet on établircit des Hôpitaux, qu'on en domneroit la direction, \& yue l'on conficroit la diftribution des Anonones à ccux d'entre les fidćles, qui par lour rang \& leus

$$
\text { E iij }
$$


It HISTOIRE DV JAPON,

crélit, étoient plus en fituation de donner

1) j. C. du poids à cesbonnes ocuvres. Il falloit cela

1532. pour ôteraux Bonzes un prétexte de publier,

De Syn-Mu. comme ils n'avoient pas manqué de faire d'a2312. bord, que la plûpart des nouveaux Conververtis n'avoient embralfé le Chriftianifme, que pour fe difpenfer de leur faire les Aumónes ordinaires.

La magnificence, avec laquelle nous avons vû que fe font les obleques au Japon, \& l'u fage des Tables garnies des meilleurs Mets aupris du Bucher, ou l'on a brílé le Corps, ce gue le petit Peuple imite auff fur les Tomteaux de fes Parens, donnerent lieu de tégler un cérémonial pour les Enterrements, dâns kequel on eut foin d'allier tellement la pompe excérieur avec la piété, que le Peuple, qui veut du fpectacle, en füt frappé, \& que tout fervit à faire refpecter la Religion. Outre cela il fut réglé que pendant le mois de Novembre on diroit tous les jours une Mefle pour les Morts, \& qu'au Lortir de cette Mefle, on donneroit un grand Repas aux Pauvres. Les Peres firent enfuite en leur particulier des reglemens fort fages, \& l'exactitude aveo laquelle ils furent obfervés, produifit partout un concert \& une uniformité, qui contribua beaucoup au progrès de la Religion, mais dont on connut encore mieux la nécer fité, quand d'autres Miffionnaires eurent pris dans la fuite des tems une autre conduite.

Le nombre des Chrétiens croiffoit tous les jours d'une façon furprenante, mais leur ferveur avoit quelque chofe de plus merveilleux encore, yir leur nombre. Jamais furprife ne fut égale a celle des nouveaux Ouvriers, lorf- 
qu'après avoir un peu pratiqué les Fidćles d'Ananguchi, ils eurent découvert lestréfors de graces, dont Dieu a voit enrichicette Chrćtienté naiflante. Ils voyoient des Courtifans, qui à peine régénérés dans les eaux du Baptéme, ne confervoient plus rien de cette fierté fi naturelle aux Grands du Japon, \& fembloient n'avoir plus d'autre ambition, que de s'abailfer au-dellous des plus pauvres. Tous faifoient paroître une piétć angélique dans leurs exercices de Religion, \& fe portoient à des aufteritez, qu'on avoit peine à modérer: les Religieuxles plus dégagnćs de la chair $\&$ du fang, ne font pas plus dútachés de leurs Proches, que ces Néophires l'écoient de leurs parens Idolatres, avec lefque!s ils ne vouloient plus avoir de commerce, qu'autant que la bienféance \& la charité l'exigeoient. Les biens ćtoient en quelque façon communs entr'eux, \& les Riches ne fe regardoient gueres, que conme les oconomes des Pauvres. Mais ce qui marquoit plus que toute autre chofe com. bien l'efprit de Dieu polfédoit leurs cours, c'eft qu'on admiroit parmi en: une union, une paix, une charité prévenante, qui charmoient les Infidéles mómes.

Un autre effet de la vie exemplaire, qu'ils menoient, fut qu'elle fit tomber certains difcours, que les Bonzes affestuient de répandre par-tout, \& qui eullènt pû nuire confidétablement aux progrics de l'Evangile: à fçvoir, que la Religion Chrórienne ne difru roit prefque en rien de celle des Foroyues qu'elles étoient fondées fur les mêmes pri. cipes, qu'elles enfeignoient la méme Morali, qu'elles prelcrivoient les mêmes devoirs; que

De J.C. 1552.

De Sin $\mathrm{Nu}_{0}$ 2212. 


\section{HISTOIRE DU YATON,}

De T. IC. \& peu de diverfite, qui fe trouvoit entre l'une 1532.

DC Syn-Mu.

2212. \& l'autre, \& qui le réduifoit a un petir 1 onbre de menucs pratiques, fort indifférentes en elles-mêmes, ne valoir pas la peine, qu'on laillä̀ des Etrangers troubler l'Etat, \& nuctrie la divifion dans les Familles. La différence de la conduite des Chrétiens, \& de celle des Idolâtres, futfifoir feule, pour détruire ce que ces difcours avoient de lpécieux; les efprits les plus prévenus en étoient frappés, \& les Millionnaires mímes avoübient dans leurs Let. tres à leurs Freres des Indes \& de l'Europe, qu'ils ne pouvoient pas tenir contre les exem. ples de vertu, que leur donnoient leurs Néophytes, \& quils avoient honte d'être réduits a luivre fouvent d'aftez loin les traces, que leur marugoient dans la carriere de lavertu, les plus novices dans la Foi; que rien ne les humilioit davantage, que de voir des Perfonnes de tout áge \& de rout fexe, chercher au fortir des Fonis du Baptême, à répandre leur Sang pour un Dicu, quils ne connoiffoient, que depuis peu de jours; \& d'entindre des Femmes, des Enfans, de pauvies Artifans, qui ne pouvoient prefoue pas s'axphiytuer fur les affaires les plus communes, parler de la Religion d'une maniere ravillante, toucher les cocurs les plus endurcis, \& firire des converfions, quiavoient échoüé entre leurs mains.

Ces confidérations \& la vie pénitente, dont les Bonzes gardoient au moins les apparences, obligerent ces Religieux à mener cuxmênes une vie extrômenent auftere. Quelques-uns de ceux, qui vinrent dans la fuite jour partager leurs isaraux, en furen: of- 
frayés; il y en eut méme, gui avec la meilléure volonté du Monde, ne pureut la foutenir; \& l'on ne doit peut-être pas regarder comme uue des moindres merveilles, que Dieu ait operées dans l'Etablifiement de la Chrétienté du Japon; que ceux, dont il a

De T. C. 3534 De $S_{j n}-N_{i u}$ 221 . bien voulu fe fervir pour un fi grand ouvarge, ayent pû réfifter à une auftérité de vie, dont l'excès ne pouvoit êcre excul'ć, que par la né.. celfité, qui les y avoient réduits. Il eft vrai aulf, que rien ne contribua tant, que cette vie pénitente, \& les travaux d'une fi pénible Milition. à former ces Héros, qui ont foutenu avec tant de gloire la plus terrible perfécution, quaic jamais elfuyél'Eglife de Jesus-CHRist.

Tout érant concerté entre les Miflionnaires de la maniere, que j'ai dit, le Pre de Torrez retint avec lui Edouard de Sylva, \& Laurent, ce jeune Docteur Japonnois, que le Pere Xavier avoit reçû́ dans la Compargnie. Le Pere Gago partit pour Fucheo avec Fernandez; \& Pierre d'Alcaceva fut renvoyé aux Indes, pour informer les Supérieurs du befoin. preffant, qu'on avoit de Miffionnaires au Japon. Il eft vrai qu'on tircit un fecours infini des nouveaux Chrétiens, dont la plûpart, ainfi yue je l'ai déja remarqué, ćtoient Catéchiftes, aufi-tôt que Fidéles, \& Dieu donnoit tant de bénédiction à leur zele, qu'en is s 4 . on comptoit jufqu'a quinze cents Perfonnes baptilíes dans le Royaume d'Arima, ou aucun Miftionnaire n'avoit encore pénétré. Il ćtoit très-ordinaire de voir des Familles entieres recevoir le Bantême en un mêne jour. NAYTONDONO, Gouverneur d'Amanguchi, ayant enbralié le Chriftianilune, plus de trois cemts perfonnes. 


\section{HISTOIRE DU JAPON;}

fes Alliés, ou fes Vallaux fuivirent auti-tốt De J. C. fon exemple; mais rien ne contribua davan1552. taģe à faire entrer un grand nombre d'I dolàDe Syn-Mu. tres dans le fein de l'Eglife, que ce yui arriva 2212.

Converfion dans ce même tems dans le Bungo à deux Bonzes fort célebres dans tout l'Empire.

Ils éroient venu exprès de Méaco a Fucheo de deux Bon- pour voir les Docteurs Portugais, dont on parzes, qui de loit fort diverfennent dans tout le Japon, \& viennent de pour s'aflurer par eux-mêmes, fi ce qu'on voit naires. publić de leur Sainteté \& de leur doctrine, n’étoit point exaggeré. Ils fe donnerent tout le loifur d'examiner leur conduite, \& celle des. nouveaux Chrétiens; ils fe rendirent très-afi. dus aux Inftructions, que ces Religieux faifoient tous les jours en public; \& comme ils étoient fans pafion \& fans préjugez, \& qu'ils avoient un défir fincere de connoître la vérite, ils conçurent bien-tôt une très-grande eftine pour notre Religion. Ils ne laifferent pas d'entrer fouvent en difpure avec le Pere Gago; mais ils le firent toujours avec une modération, qui les fir regarder au Miffonnaire, comme Gens, qui n'étoient pas éloignés du Royaume de Dieu: il efpéra même bien-tót qu'ils feroient un jour les défenfeurs d'une Religion, qu'ils ne paroiffoient combattre, que pour s'en mieux infruire.

Enfin un jour qu'il prêchoit dans une Place de la Ville, les deux Bonzes vinrent à leur ordinaire lui propofer de très-bonnes difficulrez; il y répondit d'une maniere, quiles fatisfit parfaitement; après quoi continuant fon difcours, comme il eut cité un pafiage de $S$. Paul, un des deux Docteurs lui deminda, 'qui étoit ce Paul, fur l'autorité du juel il ap- 
puyoit fi fort? Le Pere commença par lui raconter en peu de mots l'Hiftoire de l'A pôtre des Gentils; \& il avoit à peine fini, que le Bonze prenant la parole, \& le tournant vars De Syn-Mu* l'affiltance, s'écria: Écouter, Japonnois, je Suis Chrétien, Ev puifque j’ai inité Paul en combattant contre la Dotrine de JES U SCHRIst, je veux l'imiter en la prêchant aux Infidéles: Ev vous, mon cher Compagnon, ajoûta-t'il, en s'adrellant à l'autre Bonze, fuiver mon exemple, E comme nous avons enfeignél'erreur de compagnie, il faut que nous allions en fernble annoncer la vérité d̀ ceux. qui ne la connoifent pas. Ils fe jetterent aufitôt l'un \& l'autre aux preds du Prédicateur, \& le fupplierent de les baptifer au plûtôt. Le Pere ne crut pas devoir différer de leuraccorder certe grace, \& il donna au premier lé nom de PAUL, \& au fecond celui de BARNABÉ, comme ils l'en avoient eux-mêmes prié.

Ils furent bien-tôt en état de travailler au falur des Ames, \& $\because$ inrent exactement la parole, quils en avoient publiquement donnée. Paul fur-tout s'érudia tellement à le former fur fon Saint Parron, qu'on peut dire, qu'il étoit une copie vivante du Docteur des Nations. Tout ce que la Pénitence a de plus auftere, n'coit pas trop rigoureux pour lui, on le voyoir fans celle avec Barnabé, parcourant les Bourgs \& les Villages, \& femant le grain de la parole divine, avec des fruits d'autant plus adondants, que le Ciel y concourut plus d'une fois par des prodiges (On peut bien juger avec quel chagrin les Ennemis de l'Evangile voyoient ce triomphe de la Foi. Ils eflayerent encore de ruiner le cródit des MifE vj 


\section{I16 HISTOIRE DU JAPON;}

De 1. C fomnaires par les calomnies les plus atroces' I) 2 .

$2+\infty$

$\mathrm{He} \operatorname{Sin} \cdot \mathrm{Mu}$. $22+7$ \& n'y ayant pấcéufler, ils revinrent à vouloir perfuader le l'ablic que la murale des Chrésiens ne différoit point de la leur : mais cet artifice fut encore aurn in arile que la premiere fois, qu'ils l'avoient employé.

Révo"recans Une révolte, qui fut fur le point de renverEe Eungos. fer l'Etat, \& mit le Roi de Bungo en danger de fa vie, fit courir un plus grand rifque alr Chriftianifme. Le bonheur \& la réfolution de Civan le tirerent de ce mauvais pas. Il' marcha contre les Rebelles avec une promptitude; qui les déconcerta, \& il les poufla avec une termeté, qui leur fit tomber les armes des mains. Il fe litit lui-mêne des Chefs de la confpiration, \& les ayant fait punir livivant la rigrusur des Loix, la tranquilité fư bientôt rétablie partout. On accula les Bonzes d'avoir eu beaucoup de part à ce foulevement; \& certe accufation, dont ils ne fe purgerent pas bien, acheva d'indilpofer le Prince contre eux, \& leur fit grand tort dans le public. Le contre-coup en retonjon fur it caufe, qu'il's fourenoient, fur-tout giand on eut fait réfe. xio.s a la conduite des Chrétiens, gun témoiguerent en certe occafion une grande fidélité pour leur Prince. Mais ce qui fervit encore davantage à atumenter le credit du Chriftianilme, ce fut l'intrépidité; que fit paroître Fernendez au plus fort du turnulte, \& quifaura le Rojaume.

Iintre-idi.

Le Roi enfermé, \& en quelque façon affégé 26. d'ua isic dans for Palais, ne fçavoit trop, fur qui il sumara devoit comoter. Il ne faifoit pas tûr pour les zuLkel. Miflonnaires de fe montrer dans une Ville,

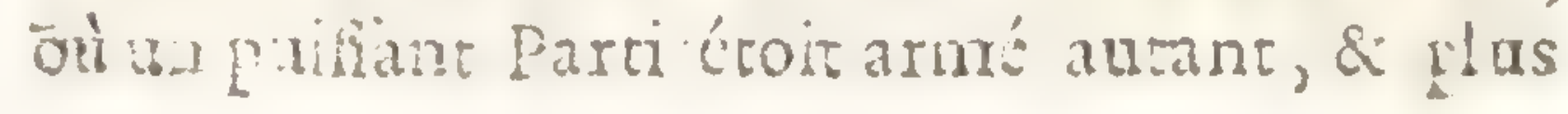




\section{CIVRE SECON Di}

même contr'eux, que contre le Souverain : toutefois Fernandez perfuadé que le plus grand fèrvice qu'on pût $r$ ndreau Roi, ćtoit de l'inf$B=$ J. C. $1354^{\circ}$ truire de l'état des choles, \& convaincu que De Syn-M l'intcrét de la Religion deniandoit qu'il s'expolà à tout pour le falut d'un Prince, qui en étoit le Protecteur, paffa généreufeinent au travers des Troupes rébelles, entra dans le Palais, rendit compte au Roi de ce qui fe palloit, \& le mit en état d'agir, comme il fit, contre les Séditieux. Cette action; \& le zele que les Fidćles firent éclater en cette rencontre pour leur Brince légitime, confirmerent Civan dansles fentimens d'eftime \& d'affection, où il étoit à l'égard du Clrriftianifme. Il aflura même après fa victoire; qựil croyoit en être uniquement rederable au Dieu, que le Pere Xavier lui avoic annonce, \& que dans le fort du péril il avoit mis en lai toute fa confiance.

Il arriva en cette rencontre une chofe, qui ne fit pas moins d'impreffion fur le Peup!e, que la maniere inefpérće, dont le Roi avoit triomphé de fes Sujets révoltés. Ce Prince ayant fait mettre le feu aux Maifons des Coupables, un vent impécueux s'éleva tout-à-coup, \& porta les ffammes $f i$ loin, que rout le Quar. tier fut confumé en un moment, à l'exception de la Maifon d'un Chrétien; d'autres difent, des Miftiomaires, qui fut confervée feule au malieu de l'incendie. Le Roi ayant été averti en nême-tems que les' Peres avoient tous les jours à effuger mille avanies de la part des Bonzes, fir publier que leurs Voifins lui rćpondroient de tout ce qui leur arriveroit de ficineux, \& certe menace eut forr effet. 


\section{HISTOIRE DU JAPON,}

Tandis que ces chofes fe pafioient au JaDe J. C. pon, Pierre d'Alcaceva, que le P. de Torrez 15S4. avort renvoyé aux Indes, pour y folliciter un

De Syn-Mu. 2314.

Fernand Mendez Yinto en. gage le P. Nu- du vier que lon Corps enterté deux fois dans gnez à pafter vier, que fon Corps enterré deux fois dans au Japon, \& la Chaulx vive, y étoit demeuré fans corrup(1). tion, \& qu'on fe difpofoit à le tranfporter à Goa; il fut même chargé de l'y conduire avec Jacques Pereyra, \& après quiil eur remis ce facré dépôt entre les Mains de fes Supérieurs, il s'acquitta de la Commifion, qui faifort le fujet de fon Voyage. Dom ArHHON SE DE NOROgna, qui gouvernoit alors les Indes Portugaifes, ayant lu les Lettres, que lui remit l'Envoyé du Roi de Bungo, fur furpris des avantages, que ce Prince offroic de faire à la Religion Chrétienne, \& le Pere Merchior Nugnez Barretto, Vice-Provincial des Jéluices, étant entré dans ce momoment chez lui: s Que faites-vous aux Ins des, mr n Pere, lui dit-il ? flon peur s compter fur ce que le Roí de Bungo me s) mande: quand tout ce que vous êtes ici $\Rightarrow$ de Religieux de vorre Compagnie, iriez $\gg$ au Japon, vous ne feriez pas enccte aflez » pour recuéillir l'ample Moiffon, qui s'y prés pare. " Rien ne pouvoit être plus au gré du Pere Nugnez, que cette invitation du Vice-Roi : "Monfeigneur, lui répondit-il, je \) venois pour confulter Votre Excellence fur 2) c? Voyage, que je me fens fort porté à enstreprendre. ss Il y penfoit effectivement; 
2 voici ce qui lui en avoit fait naître la penrée.

Fernand Mendez Pinto, celui-là même, 1514. dont nous avons parlé au commencement du De Syn-Mu. Livre précédent, avoit eu de grandes liaifons d'amitié avec le P. Xavier, \& s'étoit trouvé avec lui à la Cour du Roi de Bungo. Las de mener une vie errante \& toujours agitée, ou plutôt conduit par une inquiétude d'efprit, qui lui étoit naturelle, il fongeoit à repalfer en Portugal, \& croyoit n'avoir point d'autre vîé en prenant ce parti, que de fe retires du tracas des Affaires, pour aller joiiir tranquillement dans fa Patrie des grands biens, qu'il avoit amallés dans l'Orient. Avant que de s'embarquer pour l'Europe, il voulut mettre fa conicience en repos, \& fit une Confeftion générale au P. Nugnez. Sa Confeffion finie, il entretint quelque-tems fon Confeffeur des grandes choles, qu'il avoit vû faire au P. Xavier, \& des Miracles, que le Saint avoit opérés en plufieurs endroits des Indes \& du Japon. C'étoit alors l'entretien de toute la Ville: la vûë du Corps de l'Apôtre, qui étoit encore expofé à la vénération publique, \& auprès duryuel il fe faifoit tous les jours de nouveaux prodiges, tenoit tout le Monde en admiration, \& ceux qui avoient eu part à la confidence du Saint, ou qui étoient en état de faire connoître quelque circonftance de fa vie, qu'on ne fçavoit pas, ne pouvoient futtire a contenter fur cela la curiofité des Petits \& des Grands, des Fidéles \& des Idolâtres mêmes.

Pinto étoit de ce nombre. Il avoit vû le D. Xavier en plufieurs endroits de l'Orient, 


\section{HISTOIRE DU JAFON;}

De J.C. \& il ne pouvoit fe laffer d'en parler. Aprés I34. qu'il eut long-tems entretenu le P. Nugnez de fon jlluftre Ami, il fit tomber la Conver-

De Syn-Mu. fation fur l'óminente fainteté des Chrériens 2214. du Japon, \& fur les admirables difpofitions, qu'aroit ce peuple à embrafter le Chriftianilme; puis, comme il fe' fur apperçu que ce difcours faifoit impreffion fur l'efprit du Vice-Provincial, fe fentant lui-méme exraordinairemenémấ; Ah! mon Pere, s'écria-il, Seriez-vous Homme à aller au Japon prendre la place du Pere Xavier? je vous y accompaginerois valontiers: Eq que je m'eltimerois heureus, $\int \mathrm{d}$ Dieu me faifoit la grace de répandre mon fang pour la gloire de fon Nom! Le Pes re furpris de ce dilcours, douta quelque tems; 6 l'into parloit férieufement. Pour s'en éclaircir, il lui exagréra les difficultés d'une Entretreprile de cette nature, \& lui fit comprendre qu'une telle réfolution ne devoit pas fe prendre légerement. Rinto répondit que rien ne l'arrêteroit, quail prévoyoit tout, \& que c'étoit avec d'autant plus de comoillance de caufe, qu'il avoir déja été fur les lieux, \& qu'il ne pouvoit ignorer: à quoi il s'enga geoit. Il ajoûta que for deflein étoit d'envoyer deux mille écus en Portugal à quekques Parents Pauvres, qu'il y avoit; de fonder un Séminaire à Amanguchi, d'où la foi pourroit aifément fe répandre par tout le Japon, \& d'employer le refte de fon bien aus frais du Voyage, \& en magnifiques préfents pour les Princes du Japon, yai lui parûtroi nit les mieux difpolés à favorifer be Chriftianifme.

Le Pcre Nugnez, après avoir donné à fon 


\section{I $Y$ R E SECON D. III}

Pénitent le loifir de réféchir encore fur ce gu'il propofoit, \& pris les avis de tout ce qu'il y avoir à Goa de Perfonnes zélćes \& prudentes, ne douta plus que Dieu ne l'appellât au Japon. L'exemple dur P. Xavier, done il cccupoit la place, \& qui ne s'éroit jamais ar-

De. J:C. 1534. De $S y n-M u$. $221^{\circ}$ rété à Goa; ce que le Saint lui avoit dit un jour à lui-même, qu'il le croyoit plus propre au Japon, que partout ailleurs; \& le fentiment unanime de tous ceux, à qui il devoit, ce femble, s'en rapporter, l'avoient prefque déterminé à ce Voyage: le difcours du Vice-Roi lewa tout ce qui lui reftoit encore de doute, \& dès le même jour il commença à prendre des nrefures pour fon départ. Il nomma pour l'accompagner le Pere GASPAR D VILELA, Homme dun grand mérite, \& Ouvrier infatigable, MELCHIOR \& ANTUINE Diaz, Etienne Goez, Louis Froez, qui n'ćtoient pas Prêtres, \& cinq jeunes Orphelins, du nombre de ceux, qu'on élevoit dans. le Séminaire de Sainte Foy. Il deftinoit ces Enfants à fervir de Catéchiftes atzx Mifionmáizes, 2 il vouloit qu'iis appriffent de bonne heure la Langue Japonnoife. Plufieurs Perfonnes de diffirents ćtats, des Femmes mêmes de Qualité voulurent fe joindre à lui , \& il eur toutes les peines du Monde à s'en débarafter. I a Mifficn du Japon étoir le srand o'sjet de l'attention de tout le Monde, chacun vouloit avoir part à la Converfion d'un Peuple fi célébre, \& qui paroilloir fi propre au Royaume de Dieu, \& il n'y eur pas une Perfonne aifće dans les Indes, qui ne voulût au moins y contribuer de les biens; majs les Miflonnaires navoient garde d'ar- 


\section{HISTOIRE DU JANON;}

De T. C $C_{2}$ le défintéreffement \& la pauvreté Evancréli$1554^{\circ}$

De Syn-Mi: 2214. que cévoient étre le principal fondement.

Le Vice-Roi de ton côré nomma Pinto fon Ambaliadeur auprès du Roi de Bungo, \& lui fit délivrer de fort beaux préfents pour ce Prince. Toute la Troupe Apoftolique s'embarqua pour Malaca, où elle prit Terre au mois de Juin de cette annće Is 4 . Divers incidents, \& une grande Maladie, dont le P. Nugnez y fut attaqué, l'y retinrent onze mois entiers, \& le refte du Voyage ne fut pas plus heureux. Les Minionnaires, aprìs avoir efluyć plufieurs Tempêtes, furent contraints de fe réfugier dans le Port de Sancian; ils fe rendirent enfure à MACAO, Port de la Chine, où ils demeurerent jufqu'à Pâques de l'année is 6 . puis ils palferent à CANton, oul le P. Nugnez fit plufieurs tentatives inutiles pour introduire la Religion dans ce vafte Empire. Il entreprit même apparemment pour ce fujet plufieurs Vayages dans le Pays; car je trouve dans quelques Mémcires, qu'il ne courut pas moins de rilques fur Terre, qu'il en avoit couru fur Mer.

Cevendant il avoit reçu pendant fon ${ }^{\prime}-$ De J.C. jour à Macao des Letrres de Goa, par lef1555-56. quelles on le prefloit de revenir aux Indes :

De Syn-Mu. 2215.16 . on lui en avoit aluif remis une de $S$. IGNACE, par laquelle le Fondareur de la Compagnie lui témoignoit n'approuver pas, que les Irovinciaux \& les Supérieurs Génératux entrepriffent de cas longs Voyages, qui les empêchoient de veiller aux Afffaires, dont ils étoient chargés; \& il y a bien de l'apparen. ce que ces Lettres lui auroient fait prendre 


\section{LIVRXSECOND: I2}

le parti de rebrouffer chemin, \& de renoncer à une Expédition, que fon Général n’approuvoit point, \& contre laquelle il lui fembloit De T. C. que le Ciel fe déclarat; mais l'arrivée d'E-De Syn-Mu. doliard de Gama avec des Lettres de TAQUA Nombo, Roi de Firando, le fit encore une fois changer de rélolution, \& l'engagea à pourfuire fa route. Taqua Nombo avoit appris que le P. Nugnez étoit en chemin pour le Japon, on l'avoit informé du grand erédit, que fa nailfance $(a)$, Con mérite, \& fon Emploi lui donnoient parmi les Portugais, \& il crut que pour attirer dans fon Port les Marchands de cette Nation, il falloit engager ce Religieux à faire un Etablifement dans fes Etats. Rien n'ćtoit plus obligeant, que la Lettre, qu'il lui écrivit, \& qu'il chargea Edoüard. de Gama de lui rendre; il y faifoit les offres les plus avantageufes pour la Religion, il laiffoit même entrevoir qu'il n'étoit pas éloigné de fe faire Chrétien, \& il repréfentoit au Miffionnaire, de cuelle importance il étoit pour le Chrintianifine, de ne pas négliger une occafion fi favorable de l'établir folidement dans un Royaume, que fa fituation rendoit très-propre à le faire pénétrer dans toutes les Provinces Maritimes du Japon.

Rien n'étoit moins fincere que cette conduite du Roi de Firando, Efprit double \& rufé, \& que le feul intérêt faifoit mouvoir; mais toutes les apparences étoient en fa fa. veur, ou du moins on pouvoit croire que les mêmes motifs, qui lui faifoient faire ces. avances, l'engageroient toujours à les foure-

(a) Il éloit de lillufte Maifon de Baretto. 


\section{H.PSTOIRE DU JAPON,}

Dej 3. C. Mr. La Lettre de ce Prince détermina don

I) 55-56. Le P. Nugnez à paller outre malgré les Ler-

De Syn-Mu. Datriar jefuites e Goa, \& celle de fon Sain 2215-16. Prourche, quil crut pouvoir interpréter dans une occalion, ou il lui paroiffoit, qu'il y avoir tant a gagner, \& fr peu a rifquer; elle l'engagea mêne a prendre la rouie de Firancín. Dès que la Saifon fut propre a naviger, il partit de Canton": c'étoit au mois de Juin de l'année I 65 r. mais les Vents coutraires ne lui ayant pas permis de gagner le Port, qu'il cherchoit, il voulut tonrner du cốé du Bur. g.o. Il hattit longtems la Mer, \& fut enfin contrant de prendre Terre dans un endroit, qui dépendoit d'un Seigneur aetuellement en Guerre contre Civan, dont il étoit Valal.

On lui. dit à fon arrivće gue le Bungo étoit dans la derniere défolation, que les Miffronnaires y avoie t étć malfactés, ¿̨ que le Roi étoit en fuite. Il s'apperçut d'abord qu'il éroit en Pays Ennemi, \& quoique le Vent fût tonjonrs contraire, \& quela Côte fút ti mée c'ćcueils, il fe remit fur le champ en Mer, \& gagna enfin un Portdu Bungo, d'cù il fe reidit par Terre à Fucheo. Il y apprit ce qui a voit donné lieu aux bruits, dont nous venons de parler; mais pour raconter nar ordre ce qui s'étoit pafié dans ce Royaune Cepuis les premiers Troubles, que Civan avci fi heureufement pacifiés, il fàt reprei dre la chofe de plus haut.

Rérolution Il y avoit un peu plus de quatre ans, que dans le Nau-i Facarandoro, Roi de Naugato, gouvernoit gato ; le Roi fon Royaume plutôt en Pere, quén Souveent twé. rain. Amangucin lous une domination fi dou. ce, wroit bien-tôt réparéfes rumes, \& cette 
L IVRE SE C O N D. 125 grande Ville étoir même devenuẻ plus florillante que jamais. Le Roi au milieu d'une paix fi profonde, n'étoit pourtant pas lans inquiétude. Son Election n’avoir pas été gé-D: Syn-M $u_{0}$

nćralement approuvée; \& qualques-uns des $2215-160$, Grands Vaffaux de la Couronne, qui n'y ivoient point eu de fart, 2roient toujours conftamment refufé de le reconnoître: de orte qu'il y avoit dans l'Etat deux Partis, dont il étoit aifé de prévoir que l'animofité nutuelle cauferoit tôt au tard de grands défordres. Ce que l'on avoit appréhendé arriva; l'Orage, après avoir quelque tems grondé, creva tout-á-coup; chacun courut aux Armes, \& avant que le Roi eût pû pourvoir à la sûreté de la Capitale, il s'y trouva deux Armées prêtes à s'entr'ćgorger.

Ce Prince, pour qui il n'ćtoir pas sûr de paroître dans une fi grande confufion, avant que de s'ère bien alfuré de ceux, qui lui ćtoient víritablement attachés, fe vit obligé d'attendre dans une Forterefle, où il eut à peine le tems de te retirer, quelle feroit l'iffué de ces premiers mouvements. Elle fut bien funete, on en vint aux Mains dans toures les Places, \& dans toutes les Ruës de la Ville; \& après que de part \& d'autre on fe fût lafić de répandre du fang, quelques Soldats ayant mis le feu en divers Quartiers de Ia Ville, plus de dix mille Maifons furent réduites en cendres, avant qu'on eît eu le tems d'arrêter l'Incendie. Un Spectacle fi trifte défarma enfin les plus échauffés, \& l'on ne Congea plus de part \& d'autre, qu'a grantir de l'embrafement ce que les flammes n'avoient point encore confumé.

ve T. C.

155s. 


\section{HISTOIRE DU JAPON.}

Mais Amanguchi n'avoir pas encore expié De J. C. tous fes crimes, \& la Juftice divine ne jugea 1595-560. pas à propos d'en différer plus long-temis le Die Syn-Mu. châtiment. Il n'y avoit gućres qu'un mois, $221.5-16$. que certe Ville avoit recouvré fá premiere tranquillité, lorfque MOR E D O N O, Prince voifin du Sacai, jeune, brave, entreprenant, \& Parent d'Oxindono, dernier Roi de Naugato, forma le dellein de profiter de la trifte 1.tuation, où ćtoient les Afraires de ce Royaume, pour venger la Mort de ce Prince, qu'il croyoir être l'Ouvrage des Partifans de Facarandono, \& d'enlever à ce jeune Roi, une Couronne, à lacuelle il prétendoit avoir plus de droit, que lui. Il eut bien-tôt allemblé une Armće, qui fe trouva fort lefte, \& avec law quelle il alla camper à une lieué d'Amanguchi, où il reçut en peu de tems des Renforts confidérables, que le Roi de Chicugen, \& quelques autres Princes du Ximo lui envoyesent.

Il n'y avoit qu'une Victoire, qui pût mainrenir Facarandono fur le Trône; car outre l'ćtat déplorable, où fa Capitale ćtoit réduite, on ne fçair au Japon, ce que c'ent, que de faire traincr les Guerres en longueur: temporifer, demeurer dans un Camp des mois entiers, pour attendre une occafion favorable, faire des marches précif́ment pour s'obferver, ou pour donner le change à l'Ennemi, fe mettre à couvert derriere des lignes, ouvrir des tranchées, aller à la fappe; tout cela n'eft guéres du gốr des Japonnois, \& s'ils n'ignorent pas abiolument toutes ces rufes \& ces régles de l'Art Militaires, ils les metrent rarement en pratique. Les querelles entre les 


\section{LIVR E SECOND. I}

Souverains fe terminent à peu près comme les différents entre les particulicrs, \& les plus grandes Révolutions font fouvent le fruit d'un coup de Main. Ces prompts \& fubits revers de fortune, dont nous verrons tant d'Exemples dans la fuite de certe Hiftoire, viennent encore de ce qu'il n'y a prefque point de Villes fortes dans cet Empire, \& de ce que la plûpart des Maifons y font de Bois. Le Vernis \& les Peintures, qui rendent celles des Perfonnes aifées fi propres \& fir riantes, \& qui les confervent contre les injures de l'air, contribuent auff beaucoup à ces défolations fréquentes, aufquelles les plus grandes Villes font fi fujettes; car on peut bien juger, que quand le feu y a une fois pris, il n'eft pas prefque polfible d'en approcher, pour l'éteindre, fur-tout dans le cas d'une irruption de l'Ennemi; \& pour l'ordinaire, dans ces occafrons il ne faut qu'une Maifon en feu, pour brûler tout un Quartier, ou même toute une ville.

Le Roi de Naugato comprit donc bien, qu'il ne falloit pas attendre dans une Place plus qu'à demi ruinée, un Ennemi puifrant, qui $y$ avoit de grandes intelligences. Il le mit à

De T. C. Isss-s6.

De Syn-Mu. 2116, la Tête de ce qu'il put raflembler de Troupes, \& alla préfenter la Bataille à Morindono, qui ne la refúa point. Ce Prince avoit une Armée nombreufe, \& compolée de vieux Soldats; celle du Roi, formée à la hâte, n'étoit ni difciplinée, ni aguerrie; aufi fut-elle sifćment defaite, \& l'infortuné Facarandono perdit dans une feule Action la Couronne \& la Vie (a). Morindono profitant de ta Vic(a) On le crut ainft d'abord affez comnunetnent;

De J.C. 1556.

De Syn-Mu 2216. 


\section{I28 HISTIRE DU JAPON,}

toire, entra dans Amanguchi, qui ne fit poine I) 6.

De Sys - NIs. 2216. de réfiltance, en permir le pillage à fes Soldats, \& fit paller au fil de l'Epcé təut ce qui s'y trouva les Armes à la Main. Les Chrétiens dans ce Mallacre furent encor moins éprrgnés que les autres, parce qu'on fçavoit leur attachement au parti de leus Prince lé. gitime, \& les Mifion!naires eurent bien de ix peine a fe lauver dans le Bungo. Ils ne dîrent leur falut qu'au zéle de quelques-uns d: leurs Néophytes, qui rifquerent cout pour le; fouftraire a la fureur des Victorieux.

Mouremens peu s'en fallut, qu'échappés de ce danger, dans is Buggo. ils ne retomballent dans un autre d'autant phus grand, que le Bungo étoit leur cerniere. reflource dans le Japon. On eut à peine appris dans ce Royaume ce qui venoit de fe paller dans le Naugato, que le Feu mal étcint ce la derniere Confpiration s'y ralluma toutà-coup. Une novuelle Ligue mieux concertée que la premiere, \& formée avec un fecret étonnant, éclata, lorfyue la Cour ne penfoit à rien moins, \& Fucheo fe vit attaquée par une puillante Armée, avant que le Roi f̧̧ût qu'ily avoit des Méccntents dans fon Royaume. Tout ce qu'il put faire dans une pareille furprife, fut de fe fauver avec les Tréfors dans une forterefle, gu'il avoit à fix lietrès de-là, fituée fur le haut d'un Rocher tout environnć de la Mer. Les Conjurés apprirent certe fuite avec bien du chagrin : elle rompoit toutes leurs mefures; $\varepsilon_{0}$ comme ils ćtoient perfuadés que le Roi, qui ćtoit fort aimé do

nousverrons néanmoins daks la fuite que queloues:ens eprès, il courut un brut yuil soéroit fauvé, mais ce biuit ne paroir pas avoir été b:sn funde. 


\section{LITRESBCOND.}

les Sujets, ne tarderoit pas à fe voir à la Tête d'une Armée, contre laquelle ils ne fe rroyoient pas en ćat de tenir, ils fe retiresent, \& congédierent leurs Troupes.

Selon quelques Mémoires, le P. Nugner

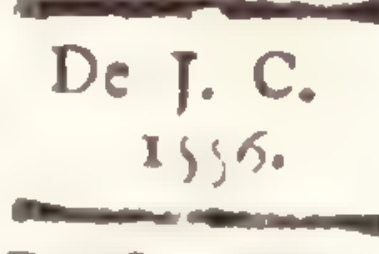

De Syn-Mu.

2216. éroir à peine arrivé dans le Bunço, que le Roi fut averti d'une Confpiration, qui fe tramoit fort fecrettement contre lui, \& qu'on fe vit au moment de voir Fucheo firoir le fort d'Amangachi: mais la préfence defpric ce Civan le rira de a nauvais pas. Il prévint les Rébelles, tomba fur eux au moment cu'ils y penfoient le moins, leur tra fept mille Hommes, \& alla fraire le déçât dans leurs Terres; mais apres cette kxpédition, ne fe croyant pas en siretc dans fa Capitale, ou voulant s'ćpargner le chigrin d'en voir les environs tout en feu, il prit le parti de fe retirer dans une Forterelle, gui palloit pour imprenable. Il n'y fut pas long-tems lans s'appercevoir, qu'll avoit fait lagement, de ne pas refter à Fucheo; il n'avoir pas connu zous les Mícontents, dont queligues-uns cioient refée armés; mais quand ils eurent appris fa retraite, ils congédierent leurs Trourses, \& difparurent.

Quoigu'il en foit, telle ćroit à pen près la fuation, oil Ee trouvoir le Bnigo, lorqque le Pere Nugnez y arriva. Le Roi nayoit pas cncore jugé à propos de returner à Fucheo. \& l'on n'y étoit pas encore trop ralintré. Ainfl la conjoncture n'étoit nullement favorable aux defleins, qui avoient amené au Japon le Vice-Provincial. Pinto ne lailla pourcant pas d'aller trouver le Roi dans fa Fortcrefle. Il lui remit les Préfents, \& les Lettres du Vice-Rod Tome II. 


\section{I30 HISTOIRE DU JARON;} D. T. C.

De Sin MIu. 2216.

Le l. Nugrez a lacour du Roi de Bungo, récep t.en, que cc l'ance ilif fait.

ces Indes, \& il en fut parfaitement bien reçu. Civan parut très-fenfible aux politelles de Jon ilphonfe de Notogna; mais il le fut encore plus à la nouvelle de l'arrivće du Succelleur du P. Xavier dans les Erats, \& la joye qu'il en rellentit, lui faifant oublier que ia Capitale n'étoir pas encore une demeure bien. sîre pour iui, il y retourna fur le champ. pour y recevoir le Pere Nugnez. Sa préfence acheva de remettre l'ordre \& la tranquillité dans ceite Ville, \& le Royaume commença dés-lors à jociir d'une Paix, qui dura longtems, \& qui fut très-avantageule à la Religion.

Le Roi fit enfuite avertir le P. Nugnez, qu'il avoit une grande impatience de le voir, \& ce Religieux ne différa pas un moment à fe rendre au Palais. Les Portugais, qui fe trouvoient à Fucheo, voulurent l'y conduire en córémonie, \& l'on prétend yue tout s'y palía avec le même éclat, gu'on avoit vî̀ à la premiere entrée du P. Xavier. On ajoute que le Vice-Provincial y ćtoit revétu du même furplis, avec lequel on avoit enterré le Corps du Saine dans la Chaulx vive, \& qui éroit auli entier, \& aufl propre, que s'il n'chir jamais fervi. Ce qui eft certain, c'eft que le Roi lui dit en l'embrafant, qu'il lui fembloir voir le Saint Homme, yu'il avoit aimé comme un autre lui-même. Il le prit enfuite par Ja Main, \& le fit entrer avec Fernandez dans fon Cabinet. Ils y furent au moins deux heures, \& pendant tout ce tems-là, on n'y parla que de la Religion. Il ne fe peut rien de plus fort, que ce que le I. Nugnez dit au Roi yar la buscie de fon Compagnon, four l'en- 
II $I$ IEC ON D. I I I gager à fe déclarer Difciple d'un Dien, doirt il venoit d'ćprouver la protection d'une maniere fis fenfible: \& il parut bien par les fréquents foupirs, qui échapcrent à ce Prince, De que fon cocur étoit touché, mais quil réfiftoit encore. Il répondit enlin, \& tâcha de perfuader au Pere qu'il n'étoit, ni de la prudence, ni méme de l'intérét du Chrifianifme, qu'il fít titôt une dómarche d'un figrand ćclat. Il protefta gu'il la feroit, quand il en feroit tems, \& gu'il fe tenoit bien aluré que Dieu, qui connoiloit la droitare or la fincórité de és intentions, difpoferoit les chofes cie maniere, qu'ellos tourneroient à fa gloite \& au bien de la Religrion.

Le P. Nughezfentit bicn qu'il feroit inutile Il eft oblige d'infifter davantage: il prit congé du Roi, de recuurues \& fit enfuite avec Fernandez onelques excur- aux Indes. fions dans le Pays, oil la ferreur des Chrétiens lui donna bien de la confolation; mais fanté altérce pur los grandes fatigues, qu'il avoit eflizyces pendant fon Voyage, ne lui permit pas de mener plus long-tems la vie dure \& aufere, à laquelle les Miftionnaires sétoient réduits. Il vouloit ponrtant aller trouver le Roi de Firanco, qui l'avoit invité d'une maniere fi prefliante; mais comme il fe difpoloir a ce Voyage, il tomba dans une langueur, dont il ne lui fut pas polfible de fe remettre. Ainfi contrint de retourner à coa, fans avoir eu la confolation de convertir un feul Japonnois; il comprit gu'il auroit fait plus lagement de fe rendre fans raifonner, aux ordres de fon Supćrieur, que d'écouter un zéle, qu'il devoit Commetre à l'obéillance. Il a depuis fair de grandes chofes 


\section{HISTOIRE DU JAPON,}

dans les Indes; mais Dieu ne le vouloit pa:

I'e T. C. au Japon, \& ne permit pas même que rien 153 h.

D. $\sin \mathrm{Mu}$. 2216. rćifsit de tous les projers, qu'il avoit formés pour laccroiflement de cetre Eglife; car les grandes efpérances, que pinto lui avoiz donfices, de fe contacrer au falut des Japonnois, sen allerent toutes en fumcée. Mais pour achever le récit de ce qui regarde ce fannewx Aventurier, il faut reprendre fon Hifoine, où nous l'avons interrompué.

La nuir, gui précéda fón départ de Goa, le P. Nugnez, \& les Religicux, qui devoient accompanner ce Pere au Japon, s'útant retiués dans une Chapelle confacrée a la Sainte Vierge, ils y renouvellerent leurs voux, fuivant ce quil fe pratique tous les fix mois dans la Compagnie de J fás. Au milieu de la cérémonie, Pinto, qui avoit voulu y être préfent, fé trouva tout à coup láifi d'un mouvement de dévotion alfez extraordinaire, \& fans fe donner le loifir de réfléchir fur les fuites de l'action, qu'il alloit faire, après que tous les Religieux eurent réciés la formule de leurs vocux, il fe mit à la réciter aufi à haute voix; quelqu'un voulut l'arrêter, mais le P. Nugnez fit figne de la Main, quon le lairsât achever, \& il la pronooça jứgu'aụ lout ; puis il ajonta un quatriéme vocu, de confacrer fa Perfonne \& fes biens à la Miffron du Japon. Qnand il eut fini, le P. Nugnez déclara, giril recevoit fa Profeflion: routefois comme Pinto étoit nommé Ambalfaleur du Vice-Roi, il fut réfolu, quil ne changeroit d'Habit, quaprès quil fe feroit acquité de fa Commifion. Ceste facihić du Vice-Provincial parui irréguliere a 


\section{LIVEESECONST I 3.3}

quelques-uns, \& par malheur pour lui la fuite le condamna. La ferveur dil nouvera Religieux ne fe rallentit pourtant pas fitôt; clle cura pendant tout le Voyage, 就 lui lit faire des Aclions vraiment heroiques. Il ne bougeoit des Hôpitaux, \& lon royoir avec abmiration un flomme fi opulent, devenu eir un moment Pauvre pour JESUS-C ERIST, s'appliquer avec charité \& avec humilicé à rendre aux Malades les fervices les plus vils. Les Infidćles mêmes failoient fur une conduite fi édifiante des réfexions trés-avantageufes à la Religion Chrérieme.

Mais Pinto, ainfi qu'il arrive à ceux, gri Thonnes commençant à goĥter Dieu, venlent marcher Mencinut fans Guide dans la voye de la perfction, avoit pris un mouvement de dévotion lenfible, pour une infpiration célelte; \& lans confulter, ni fes forces, ni fon courage, s'éroit imporé des cbligations, qu'il n'croit pas capable de remplir: il Compira bien-tôt après la liberté, dont il avoir fi légerement fait le farcrifice: \& comme il ne fat pas porbia de lui faire reprendre los premicrs leniments, il faliut enfin le difpenler de les vcoux. Il ietourna aux Indes arec le iere Nigneez, 8 conme il ne pouvoit plas y demeurer avec honneur, après une ćpuipée, gui le faifoit montrer au doigt; il repalfa bien-tôt aprìs en Portugal. Il y fit imprimer une Relation de fes Voyages, qu'on lit avec bien du plaifir, \& qui a ćté traduite en plufieurs Langues; mais il s'elt bien gardé d'y apprendre au Public l'Aventure, dont je viens de parlér, \& que j’ai tirće de Mćmoires fore sî́rs. 


\section{I34 HISTOIREDU JATON,}

I) J. C. Is 56.

DeSyn-Mu. $221 \%$.

La perte de cet inconftant, fi ç'en fut ure pour la Compagnie de JESUs, fur bien-tôe avantageufement réparce. Le Pere Nugnez, avant fon départ du Japon, reçut parmi les Enfunts d'IGACE, \& laila fous la conduite Louis Al-du P. de Torrez, Guirtaume \& Ruys Pemeyda cntre REYRA, deux de ces jeunes Séminariftes, quil diar's la Cumlo avoit amenés de Goa; \& ils ont depuis renfajuic. du de très-grands fervices à cette Fglife. Mais la plus précieufe acquifition, quil fit pour fon Ordre, fut celle de Lours Almeyda, qui étoit arrivé depuis peu de Firando à Fucheo: pour le fujet, que je vais dire.

Edoiiard de Gama ayant moüillé une feconde fois dans le Port de Firando, \& prévoyant qu'il y refteroit quelgue tems, fouhaita d'avoir un Prêtre, qui adminiftrât les Sacrements à fon Equipage. Tous les Miffionnaires du Japon étoient alors réunis dans la Capitale du Bungo, ainfi que je l'ai déja remarqué, \& l'on comore de Firando à Fucheo quarante - cinq lieués en droiture, \& quatre-vingt dix, en faifint tout le chemin par Mer. Gama propofa ce voyage à Loüis Almeyda, qui l'accepta fans peine, \& qui n'eut pas lieu de s'en repentir. C'ćtoit un Gentilhomme Portugais, âgé d'environ trente ans, d'un beau naturel, \& d'un bon éprit. Il avoit affez peu d'étude; mais il s'étoit fort appliqué à la Chirurgie \& à la Médecine, \& il ćtoit plus que médiocrement habile dans ces deux Arts. Il fentoit néanmoins depuis quelque tems un grand dégoût pour la vie gu'il menoit, \& il voulut profiter de l'occafion, que lui fournilioit fon 
LI R E SECOND. I 35

Capitaine, pour fe mettre l'efpric en repos. Arrvéa Fucheo, il fit fous la conduine du Pere Balnafar Gayo les Exercices de faint Ignace, $\&$ pendant fa retraite, ii rílolut de quitter le Monde, \& de fe dévöier tout entier au fer-

$D=T \cdot C$. 1) 弥。 U. Synt 11 it. 2215. vice de Dieu, \& au lalut des Ames. Avant que d'exćcuter cette réfolution, il emploja cing mille écus, en quoi confiltoit tout fon bien, à bâtir dans Iucheo deux Hôpiraux; l'un pour les Enfans, que la pauvreté de lears Parens expoloit a perdre la vie au moment mime, qu'ils commençoient à voir le jour; $\&$ l'autre pour les Lćpreux, dont le nombre elt allez grand au Japon, \& qui y font fortabandomnés; \& cette charité charma tellement le Roi de Bungo, qu'il fonda ces mêmes Hópitaux avec une libéralicé digne de lon grand cocur.

On peut juger fi avec tant de fecours le Chrifianime ćtoit florillant dans ce Royaume. Il eft vrai, qu'il ne le pouvoit rien ajôirer à l'ćclat, que jetroit partout la piété des Fidúles, aufimériterent-ils que le Ciel confirmit leur foi par des miracles. Je me contenterai d'en rapporter deux, fiu l'autorité de Fernandez, qui en fut tomoin. Un Chrétien voyant fa Fille prête à momrir d'une maladie, gui venoit de lui enlever fon lils, fut infpiréde s'adreller à Dien, pour obtenir de fa bonté ca qu'il n'efpéroit plus des remecies humains. Il recommanda à la Malate cie merre toure fa confiance en la divine Mif'ricorce, \& il jo:gnit fes prieres à celles de certe Finfant. Elles furent exaucées; dis le lendennin la petite Fille fut parfaitement g̈lórie. L'autre miracle a quelque chore de plus margué; parmi les
Erat forifo Sunt de la R:lirion tans te Bungo. 


\section{36 HISTOIRE DU JASON;}

Catćchumenes il y en avoit un quićtoit nú

De J.C. aveugle, le Sacrement de la Régúmćration eir

1) sh. Ini décillant les Yeux de l'Ame, lui ouvrit

De Sin-Mu. aulli ceux du Corps.

2236. Cependant pour fatisfaire au défir d'Edoïard de Cana, le pere de Torrez fit partir pour Firando le Pere Gacro, Jean Fernandez, \& le Bonze faul, qui lans être lié aux Millionnaires par aucun engagement, n'en ćtoit pas moins à leur difpeficion, \& embralloit avecarceur toutes les occations de gagner des Ames à J. C. Le deflein du Supérieur, en envovan: de fibons Ouvriers dans ce Rovaume, n'étoit pas. feulement yn'ils travaillafient a la fenctification des portugais, mais il ćrnit bien aira de profiter de cette occafion, pour répondre a l'empreffement, que le Roi de Firando avoit fi fouvent témoigné, de voir des Prédicateurs de l'Evangile ćtablis dans fes Etais; d'autant plus qu'il prévoyoir bien que le Port de Firando étant un des plus comuodes du Japon: il téroit toujours le plus grand abord des Navires Européens.

Le's Miffonnaires partirent de Fucheo a a

De J. C. commencement del'annće 1 557. Taqua Nom. bo les reçut de la manie:e la plus gracieure; De sjn Mu. il leur dit, qu'il ne lui manquoit plus que le $x_{2}:$ nom de Chrétion, qu'ill'étoit dass le coeur, qu'ils lui feroient plaifir de convertir tous fés Sujets, \& quil ne feroit pas le dernier à recevoir le Baptêne. C'ćtoit trop dire, pour en être crû, \& les Serviteurs de Dieu ne fe laifferen point prencire aux difcours peu finceres dece I'rince intéreffé; mais ils jugerent à propos de diffimuler leurs foupçons, \& de pro. fiter de la difpofition tavorable, oti le met. 
EI $Y$ R E SECON ID. T 37

tóen: la prélence des Porrugais, \& le ditir qu'il avoir de fixer leur Commerce dans lís Etats. D'ailleurs, fes Sujers ne demandoient qu'à être inftruits; \& peu de rems après, on $D=s i n-M u$. en baptifa en un jour jufqu'a rrois cents. Le Roi en tómoigna une très-grande joye, \& voulut la faire paroitre publiquement par une Fête, qu'il donna aux Milionnaires, \& à tous les Chrétiens.

Les affaires de la Réligion ćtoient en cetre fituation, lorfque le Roi de Bungo fe crus fur le point de voir encore une fois ion Royaume agitć de troubles doneftiques, mais fes crainres le diffiperent bientôt: il fit lí boune contenance, \& mit fi bon ordre à tout, que ceux, qui avoient envie de broililler, ne voyant nulle apparence de réiffir, ne juyerent pas a propos de fe démalquer. Le Roi de fon côté ne crut pas qu'il fur de la prudence de fairedes recherches, qui l'engageant à punir des Farm tieux cachez, les obligeroient peut-citre à levar le mafque, par la nécelfité de le défendre, \& leur feroient rrouver des forces dansleur défefpoir. Il eut tout lieu de s'applaudir d'une conduite fi lage, \& tout le Monde fe tint dans le devoir. Alors fe voyant maire abfolu chez lui, il fongea férieufement a venger la mort du Rci de Naugato lón Frere.

11 fit fes préparatifs avec une promptitude extréme, \& un fi grand feciet, qu'il parti en Campagne avec une armée de foxante mille Hommcs, avant quion fut informé de fon De J.C. I j... $228 \vec{\gamma}$ dellein dans le Naugato. L'Ufuratent firpris n'ent pas alfez bonne opinion de lui-même, pour croire qu'il put tenir contre une a grande Puillance. Il fé retira duns les Mion- 


\section{I38 HISTOIRE DU JAPON;}

tagnes, oll il auroic été facile de l'affamer;

De 7.C. fi le Dairy n'cût offert f́a médiation pour un 1557. accommodement. Elle fut acceptée, \& la paix LuS:n Mu. le fit au grand avantage de Civan. Morindo. 221\% no demeura Roi de Niugato; mais il perdit toutes fes autres Terres, \& res Allies furent dépouiliez des leurs. Par-la Civan acyut, ou recouvra quatre Royaume; caren rapprochant ce trait d'Hiftoire, qui n'eft pas bien développé dans les Relations de ce tems-là, de ce gue nous avons dit au commencement du Livre précédent, fur l'autorité de Fermand Mendez Pintn; que les Rois de Rungo fe prétendoient Souverains de toute certe partie du Ximo; it y a bien de l'apparence que les princes, qui furent dépoiillez de leurs Etats par Ia Sentence arbitrale du Dairy, ćtoient, ou des. Ulurpareurs, ou des Sujers révoltés contre leur Seigneur légitime, qui avoient voulu profiter des troubles du Naugato pour affoiblir la Maifon Royale de Bungo, \& en fe liguant avec Morindono, s'allirer un appui, qui les maintint dans leur úurpation. Quoigu'il en foit, la Religion Chrétienne tira un grand avantage d'un événement, qui metroit le Roi de Bungo en état de donner la Loi à tout le Ximo; \& en eđiet, elle s'étendit bientôt, non-feule'nent dans les provinces foumifes à Civan, mais encore dans tous les Royaumes roifins.

Les Mifronnaires trouvoient toujours dans ce Prince qualque chofe de plus qu'une protection puilante, \& fur hquelle ils pouvoient compter; il vouloit encore gu'ils le regardallent comme leurAmi, \& il agifioit avec eux, comme deParti-

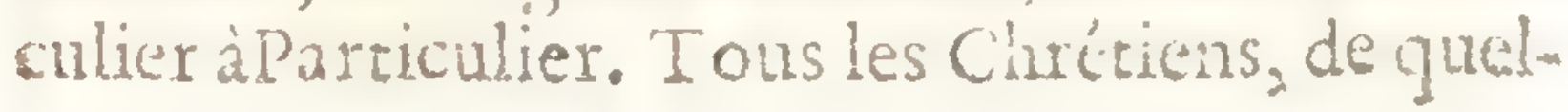




$$
I I T E S E C O N D . \quad \text { Y } 39
$$

que condition quils fulfunt, recevoicnt anili dans toutes les occalions des marques de fa bonte; il s'en falloit bien qu'il confervát àleur égard ce fafte \& ces manieres hautes, dont les De Syn-Mu. Souverains du Japon fe défont firament. Il $2217^{\circ}$ donnoit aux plus petits un accis facile auprès de fa Perfonne; \& ce qui dans ces lles palle pour une tris-grande marujue de confidération, i) les appelloit ordinairement tous par leurs noms. Il reçut vers ce néme tems de nouveaux préfents duVice-Roi des Indes,à qui il en envoya de fon côtć d'une richellic \& d'une magnificence extraordinaire; \& il y joignit des letres trcs-prellantes à ce Seigneur, pour l'engager à lui fournir le plus qu'il feroit polible, d'Ouvriers Apoftoliques.

'Iaqua Nombo continuoit aufli à fairebon vifage aux Miflionnaires; \& à la faveur de ces démonftrations, la Chrérienté diu Firan- de lis Maíon do devint en trís-peu de tems une des plus nombreufes, \& des plus ferventes du Ja pon. Ce qui avança davantagre les affaires de la Religion dans ce Royaume, ce fut la converfion d'un Prince de la Mailon Royale, qui flit baptić avec la Princelle la Femme \& un de les Freres : il reçut au Baptîme le nom d'ANTOINE, $\&$ nous le verrons dans toutes les occafins, qu'il eut de faire éclater fa Foi cichon zele, fé comporter en Homme perfuadé que Dieun'a ćlevé les princes au-dellus des autres, gue pour en faire de plus utiles infruments de fa gloire. Perfonne n'a fait pliss d'lonneur a la Religion dans ces Ifles, \& n'a peut-ryerravaillé plus efficacenent à yécerdue le Chriltianifure. Il ćtoit Seigncur des lles de T acu-

D. J. C. 1) 7 . 


\section{MAP HISTOIRE DU JAPON:}

Lie T.C.

I $597^{\circ}$

De Sini-Nito. 2217.

Nort d'un ze' MifionBabe.

Gand nom. bre \& ferveur des notivadux Chréicmsalans jeklando.
XIMA \& d'IQUiseucur; auffi-tôt apres ion Baptóme, it y mena un Miflionnaire, \& l'y leconda fi bien, prêchant lui-méme, \& ne dédaignant aucune des fonctions du Miniftere Evangélique, qu'en moins de deux mois, on y comptoit jufgu'à quatorze cents Cirrétiens, \& plufieurs Eglies báties a fes frais.

Le Bonze Paul eut grande part à ces fuccès, mais il ne mćnagea point allez fes forcess, \& il fur bientôt la victime de fon zele. Il tomba malade, \& jugeant que Dicu le vou. loit appeller à lui, il témoigna, qu'il fouhaitoit de mourir entre les bras du P. de Torrez. Il n'y avoit encore, à ca qu'il paroilloit, alscun danger à lui accorder cette confolation, \& il y auroit cu de la dureté à la lui refuer on l'embarqua fur un Bâtiment, qui alloit à Fucheo; \&.à peine y fut-il arrivé, que les Médecins l'avertirent, qu'il n'avoit plus que peu de joursà vivre. Il en témoigna une joye, qui ne le peut exprimer; il reçut les derniers Sacrements de l'Eglife avec des tranlports d'amour, dont les. Saints font leuls capables; \& peu de tems apres, il alla recevoir dans le Ciel la récompenfe dûe a les travaux \& à fon ćminente vertu, que Dieu a voit autorifée par plus d'un événement miraculeux.

Cette mort \& le départ du-Pere Gago, qui avoit été appellé dans le Chicugen, avoient laillé Fermandez !eul dans le Firando. Le Pere Gaspar Vilela fut envoyé à fon fecours, \& trouva certe Chrétienté dars une fituation à faire efpérer, que le Royaume entier alloit fe déclarer pour Jefus-Chrif. Tous les Néophytes étoient Catéchifies, \& l'on ne puyoit hisire abaptifer ceux, qu'ils gagnoient a l'E- 
EITRE SIECO I D O TET

rangile. Le Pere Vilela paflant un jour dans une rue de Firando, apperçut un Enfant, qui acouroit pour lui parler; il. l'attendit, \& dès que l'Eufant fut à portée de fe faire entendre; il demanda le Baptéme : le Pere lui répondit,

De J. C. $1557^{\circ}$

De Syn-Mu. 2317. qu'il le baptiferoit dès 'qu'il feroit fuffíanmenc infruit. Ce. Sera donc tout à.l'heure, reprit l'Enfant, car je Scai tout ce qu'il faut fgavoir pour cela. Le pere l'interrogea, \& trouva quil difortrai; il vouloit pourtant le remetre au lendemain, mais l'Enfant prosufta, qu'il ne bougeroit point de la place, qu'il n'eût obtenu ce qu'll fouhaitoit, \& il fallur le contenter. Quelques jours après le Pere Vilela fut fort ćtonné de voir fon petit Néophyte, quilui amenoic fon lere, fa Mere, fes Freres, \& fes Sours, qu'il avoit convertis, \& parfaitement inftruits de nos Myfteres.

Les Bonzes de Firando voyoiene avec le chagrin, qu'on peut bien imaginer, ces progrès de la Religion, \& la prévention du peuple en faveur des Miffonnailes; ils crurent d'abord, comme avoient fait ceux' de. Fucheo, \& d'A manguchi, qu'il n'y avoit point de renede plus efficace contre un fi grand $\mathrm{mal}$, que de convaincre une bonne fois les Docteurs étrangers dans une difpute réglće; mais comme its ne fe tirerent pas avec honneur des premieres

De J. C. ISSS.

De Sỹn Afu. 2218.

Efforts inutiles des Bonzes pour arréter le Progrès de la Ruigion. Conférences, ils jugerent que le plus court étoit de décrier les mours \& la conduite de ceux, dont ils ktoient eux-mêmes forcés de publier le fçavoir. Ce fecond expédient n'ayant point encore eu le.fuccès, qu'ils en attendoient, ils entrerent en fureur: ils la déchargerent d'abord fur une Croix, au pied de laquelle. les .Fidćles avoient accoutumé de faire 


\section{I42 HISTOIRE DO JAPON,}

De T. C. leurs pricres, \& ils la firent abbattre pendan

I) 58 , la nuit.

Le Ciel ne lailla point ane telle impiété fans

De Syn-Mu. 2218.

Indicrétion

cies Chretions

\& fes fuites.

châtiment; néanmoins par l'indilcrétion des Fidéles certe action eut des fuites fâcheufes pour la Religion; quelques Néophytes fuivant avec trop de chaleur le premier mouvement, qui les faifir à la vûe de leur Croix renverfée, allerent mettre le feu à une Maifon de Bonzes, tirerent les Idoles d'un Temple, qui en ćtoit proche, en brûlerent une partie, \& jetterent les autres a la Mer. Les Bonzes accourunés à voir les Chréctiens fouffir patiemment les plus grandes injures, ne s'ćtoient point attendu a ces marques de leur reflentiment; ils n'en furent pourtant pas auffi fâchés, qu'ils feignirent de l'ctre, \& ils fe promirent bien d'en tirer un grand avantage. Après avoir délibéré entreux fur ce qu'il convenoit. de faire en cette rencontre, ils prirent le parti d'aller trouver le Roi, \& lui firent demander une audience; ils l'obtinrent, \& après lui avoir fait une peinture très-vive de l'Entreprife des Chrétiens, ils le conjurerent de vengar les Dieux \& leurs Miniftres, \& demanderent que le Pere Vilela fút banni pour toujours du Royaume.

Le Roi, qui apprćhenda, ou feignit d'appréhender quelque trouble, les allura qu'ils feroient contents, \& dès qu'il les cut congédićs, il fit prier le I'ere Vilela de s'abfenter pour quelque tems, de crainte qu'il ne lui arrivât quelque chofe de fâcheux, dont il ne pourroit pas le garantir; ajoutant qu'il feroit le maitre de revenir, dès que les efprits ne feroient plis fi échauffés. Le Millionnaire, qui connoilloit ce 


\section{IIVRE SECOND: I43}

Prince, \& le fçavoit au moins très-éloigné de faire un coup d'autorité en fa faveur, vouloit partir fur l'heure méme, mais le Prince Antoine ne put fouffirir cetre efféce de triomphe de ceux, qui avoient eu le premier tort. Il va.

De J.C. I) 5 .

De Syn-Mu。 2218. trouver le Roi, lui demande s'il y a bien penfé de faire fortir de fes Etats un Homme de mérite, que lui-méme y avoit appellé, \& cela pour Catisfaire le rellentiment d'une Troupe de Prêtres féditieux, qui ont contrevenu aux ordres de leur Souverain, en infultant des Etrangers, qu'il avoit pris fous fa protection. Il tâcha furtout de piquer le Roi d'honneur, en lui faifant comprendre jufqu'a quel point les Bonzes porteroient leur infolence, dès qu'ils amroient compris qu'il les craignoit; mais il ne fçavoit pas que Taqua Nombo fe trouvoit dans des circonftances, où il lui importoit de ménager ces Religieux idolâtres.

Un Seigneur, Parent, ou Allié de ce Prince, avoit fait la guerre au Roi de Bungo, \& s'étoit vâ contraint de fubir la Loi duVainqueur, qui l'avoit dépouillé de fes Etats. Civan, informé que le Firandois avoir fous main donné du fecours à fon Ennemi, fe préparoit à entrer en armes dans le Firando; Taqua Nombo avoit befoin de toutes fes forces pour foutenir la guerre contre un Prince puifant \& victorieux; \& il crut que c'étoit-la une aflez bonne raifon pour ne pas mécontenter des gens aufli accrédités, \& aulfi féditieux que les Bonzes. Dans le mĉme tems, le Pere Villela reçu me Lettre du Roi de Bungo, par laquelle ce Prince lui mandoit de fortir incellamment de Firando; il ne lui en malquoit pas la raifor; matis le Millionnaire l'apprit peu de jours 


\section{HITOTRE D U JAPON;}

Je J.c. après du Pere de Torrez: c'étoir la naĉnégie 1598.

Desy.r-Mis. 2218. neus venons -deraporter; il fur donc obligé d'abandonner fon Eglife; il la confra à Furnandez, que le Prince Antoine retira dans fes Illes. 11. parut bien dans la fuite aux traitements, yue le Roi de Firando fit aux Chrétiens, qu'il n'avoit jamais aimé leur Religion, mais ils demeurerent inćbranlatles dans la Foi, \& leur conftance leur mérita la gloire de donner à l'Eglice le premier Martyr, qui ait arrofé le Japon de fon fang.

Premier Maro Ils awoient dretlć une nouvelle Croix à quelcyren Jagus. que diftance d'ine des Pories de la ville, \& ils y alloient tous en commun fa re leurs priáres à certaines heures. Une femme efclave, dont le Maître ćtoir Idolâtre zélé, y alloit fort réguliérement, quoique fon Maitre le lui eût défendu. Un jour, qu'il apprit quelle y étoit retournće, il s'emporta fort contre elle, \& Ini jura qu'il lui en conteroit la vie, fi elle continuoi: dans fa défobéffiance; elle lui répondit, que la mort ne faifoit pas peur aux Chretiens, qu'elle continueroit à le fervir avec la même fidélité, dont elle lui avoit donné juitques-là des preuves'certaines; mais qu'elle ne devoit pas nanquer à ce qu'elle devoit á Dieu, qui éroit fon premier Maître; \& dès le lendemain elle fe rendit comme les autres a la Cro: L'Idolâtre entra en fureur, dès guil le fçt , \& courut après elle; il n'ćtoit pas encore bien loin, qu'il l'apperçut gui revenoit ; il tira aufitôt fon fabre, \& l'attendit. La généreufe Chrếtienne s'approcha de lui fans s'émouvoir, fe mit à genoux, \& lui prefenta fa Tête, que le Barbare lui abbattit d'un feul coup: Les Chtétiens enleverent fon corps; \& lui domnerent 


\section{IVRE $S=0 . \mathrm{N} \mathrm{D}_{0} \quad$ I 45}

wne fépulture honorable, en rendant graces à Dieu de la confance, qu'il lui avoit infurée, \& s'animant imiter fon exenple.

L'annce fuivante les Troupes Bungoifes entrerent dans le Firando, \& Tagua Nombo, après s'être allez bien défendu pendant quelques temps, ne put éviter le fort qu'avoient Pirdalo oblieu fes Allićs, qu'en fe foumettant a payer ungé de payce tribur à fon Ennemi, lecuel étendoit infenfit Roide bungu blement fa domination, \& répandoit la ter. reur de les armes jufqu'a l'extrémité occiden tale du Japon; mais il perdit bientêt plus qu'il ne venoit d'acquérir. Le Pere Vilela étoir ì peine arrivé a Fucheo, où le Pere de Torrez l'avoit rappellé, qu'il y fut joint par le Pere Gago, leguel fut obligé de fefauver de Facata, pour les raifons, \& de la maniére que je vais dire. Ce Mifionnare, affité de Guillaume Pereyra, prêchoit avec luccès l'Evangile dans le Chicugen, dont Facata eft la Capitale; \& cela par la protection ciu Roide Bungo, à qui nons avons vâ, que ce Royaume avoit ćté cédé par le Traité d'Amanguchi. Ce n'étoit pas la moindre des nouvelles acquifitions de Civan. Le Chicugen fitué dans la partie feptentrionale du Simo, eft ane des plus riches conirées de cette grande llle; \& lacata bâtic à l'entrée d'une grande plaine fur le bord de la Mer, a un affez bon Port, \& des plus fríguentés du Japon, éloigné d'eirviron vingt licues de Firando, \& de cinguante du bungo.

Ciran avoit donné à ce Royaume un Gouverneur, uni y rend t biontôt la nonvetle do- Bungo perd mination odieufe; \& comme les faures des Offi Facrata par la ciers \& des Miniftres, quand elles ne font, Bukison. ni punies, ni rćparćes, deviennent celles der 


\section{Y46" HISTOIRE DU JATON,}

De T.C. Princes, un des meilleurs Rois, quait jamais

is 19.

De syn-Aiu. 2219.

Dangers, que coureme Iss Miffiunnaires en cette occaGon. eu le Japon, palfoit dans le Chicugen pour un Tytan. Le Prince, jui avoit écé dépouillé de cet Etat, futbientôt informé du mécontentement des perples, \& lorfou'on y penfoit le moins, allifé de Morindono, dont Lalliance lui avoit été juqques-la fi funette, il entra dans le Chicugen avec une aflez bonne Armće, \& vint infulter Facata. Le Commandant, quoique furpris, fit fi bonne contenance, \& fçut fi bien retenir les Habitans dans le devoir, en leur repréfentant les horreurs, ou eft expof́ce une Ville forcée, que ltennemi ayant voulu tenter l'efcalade, fut reproullé partout.

La Place étoit confervće au Roi de Bungo, fi le Gouverneur avoit connu tous ceux, dont il devoit fe défier, \& s'il s'étoit furtout mis en garde contre les entreprifes des Bonzes: mais la nuit fuivante, ces Prêtres Idolâtres, qui ne pouvoient fouffrir la domination d'un Prince Protecteur déclaré du Chriftianifme, ouvrirent les portes de Facata, \& y introduifient leur ancien Roi, qui y entra comme dans une Ville prife d'athaur, \& en donna le pillage à fes Troupes. Le Gouverneur fe fauva dans la Ciradelle, où il fut forcé, \& pafléau fil de l'épće, avec tous cenx, qui l'y avoient fuivi. Alors toute l'attention des Bonzes fut à empêcher que les Milionnaires ne leur ćchapatent, \& à animer le peuple \& les Soldats contr'eux. Ils faifoient obferver à tout le monde que dans tous les endroits, où ces Docteurs Errangers a voient voulu ćtablir leur R eligion, la guerre \& la délolation les y avoient fuivis: Amanguchi deux fois pris \& brûlé, Fucheo nâgeant dans le fang de fes Citoyens, le Firando plein de troubles 


$$
\text { IIVRE SECOND: Y } 47
$$

\& de factions; enfin Facata, qui jufugua ce jour n’avoit jamais vî fa pranguillicé altérée par la moincire ćmeute, devenu tout à coup ma lien dhorreur, foumiloient un grand champ a leurs invectives; mais ils fe donmoiene bien cie garde d'ajoûter, gu'ils étoient euxmémes les Auteurs de tous ces défordres, \& qu'on ne devoit les attribuer, qu'à la haine, quils portoient au Chriftianifme, ou plutôt à Ienr jaloufre, a laquelle ils comptoient pour rien de facrifer letat.

Cette Itflexion étoit pourtant ici d'autant pius ailée à faire, que la perte \& la défolation Leur Maifon cie Facata étoient vifiblement leur ouvrage. brúlés à FaMais on ne la fit point, \& il n'eft pas aifé de cata. comprendre, combien leurs difcours irriterent toure la Ville contre les Miniftres de l'Evangrile. On courut fur l'heure metrre le feu à leur logis, yui fut en moins de rien réduit en cendres avec leur Eglife; on porta la fureur jufqu'a combler un puits, qui leur avoit fourni de l'eau, \& jufcu'à enlever la terre du heu, qu'ils avoient occupé; comme fi elle eût ćte madite, \& profance par leur f́jour. Un Gentilhomme, qui avoit tout quitté pour ne vacguer qu'à Dieu \&à fon lalue, \& qui s'étoit retiré chez eux, où il menoit une vie plus Angélique qu'humaine, fut cruellement mafiacré, \& ils atroient fubi le même furt, fi de bonne heure ils ne s'ćtoient fouftraits a l'oragge, qu'ils avoient prévû quelque tems avant qu'il crevât.

Le Pere Ga go avoit fait embarquer à la faveur des ténébres Jean Fernandez, quil'ćtoit venu joindre depuis peu, avec tous les ornemens

Les Mifiona naires fe retirent, funt 


\section{HISTORE DU JAOA;}

Be T. C. 1539.

de l'Eglife \& les Vafes facrés, dans un Bâtí ment, quela Providence avoit fait rencontre: dans le Port. Pour lui, fon Compagnon Pereyra, un Catéchilte Japonnois, nommé Sxzi

De Syn Mu. 6. 2219.

pourfuivis, \& foni maltraje rés. VESTRE, \& un Poreugais, qui demeuroit ave: clix, ils ne voulurent pas s'éloigner des Chrćtiens, ils contenterent de le bien cacher; mais comme on fir réflexion qu'ils ne poum voient éviter àla fin d'être découverts, \& qu'ils s'apperçurent bien eux-mémes du danger, auquel ils expcfoient cenx, qui les avoitent retirés, ils fe virent contraints de pafier dans un fecond Navire, qui ćtoit moinlié à ure demie liene dela Ville. Ils y furent reçus d'une maniere a leur faire juger qu'ils n'y feroicnt pas plus en furreré, que dans la Ville méme. Il n'eft forte."infultes, \& de mauvais traitements, culils n'eurentialluyer de tous ceux, qui com pofoient l'Eutuphge, \& celn dura guatre jours.

On apprit enfin a Facata qu'ils étoient dan; - Navire, \& on y envoya trois Barques char. gúes de Scidars, pour les prendic. Il s'étcir répandu un bruit qu'ils avoienr de grandos richelies, \& l'efṕcrance de tirer d'enx une groffe rançon, étcit la cenle railon, yuiavoit cmpêché le Parron du Navire de les immoler d'abord à la furreur du Peuple. Cette mênre opinion fut encore ici kur lalut. Les Soldats leur demancierent oú ćroit leur argent? IIs répondirent yu'ils r'en avoient point, \& yu'on ne leur avoient laillé, que ce quilis avoient fur le corps. Endectivement le Capiraine du Navire leuravoit enlevé toutce qu'ils avoient, qui fe réduifoit a tris peu de chole. Les Soldats de Eacata fe le firent domner par force, puis rem 


\section{I RE SEC ON N:}

trarnerent vers les Miflionnaires, qu'ils mirant prefque tout nuts: il faifoit toutefois un très-grand froid, quoiqu'on fût au mois d'Avril. On les fit enfuite palfer dans une des Barques, où le Pere Gago fut reconnu par un Ja. Bomnois de les Amis, quilui donna deguoi Ce $^{2}$ couvrir: du refte ils reçurent toutes fortes de mauvais traitements de ceux, quiles gardoient. Ce fut bien pis encore, quand ils furent à terre; les Soldats, qui fe rencontrerent fur le Port, voulurent avoir leur part de la dépoinlle, \&z les Serviteurs de Dieu faillirent à êre les victines de la querelle, qui s'éleva à ce Cujet; ils en furent pourtant guittes pour etre mis encore tout a fairs nuds, \& pour bien des infultes \& des mennces.

I a Canaille s'étcit attroupće autour d'eux, 8- ils sartendoient à tout moment à étrégorger, mais Sylveitre ayant trouvé le mopen de s'échaner, alla avertir un Chrétion fort accridut dans la Ville, du danger, oul les Miffromaires fe tronyoient; celmi-ci ne pardit peint de tens, il leur porta des Habits, fir retirer tout le monde, sis les mena chez lui. Il alla enlute chez le Commantant, de quil il obrint a force de préfents la permilion de les garder. Pereyra avoit étí em nené par un Sóldat, la gíneux Chrétien le fit chercher, \& layane trouvé, il doma vingéécus au Soldat, quile lui remit entre les mans. Les pritonniers refterent guelques jours dans cette maifon, oil l'on n'omic rien pour les refaire de tant de fatigues, \& demauvais traitements; leur Fóteles con ha enfuire à unde fes Amis, dont la Mnifon étnirencore plus are, quela fienne, ils y dem urerent deux mois. Apres 


\section{igo HISTOIRE DU JAPON,}

De J. C. I) 19.

De syn-ilu. 2219.

tout, tant gu'ils refoient à Facara, ils ne pous voient compter lur rien; mais la difficulté ćtoit d'en Corir. Le pere Gago ćcrivit au pere de Torrez, pour lui apprendre fafuacion, sz le prier de luienvoyer des Chevaux darsun endroit, qu'il lui marqua. Cela fur exécuté dans le moment; \& lorlque le Pere Gago ent avis que les Chevaux ćtoient au rendez-vous, il s'y tranfporta enveloppc, aurl-bien que fes Compagnons, dans des efpeces de Cappes, dont les Femmes ufent quelquefois en ce Paysla; ils palierent ainf ans chre reconnus, \& renontrersn les Chevaux conduits \& efortés par un grand nombre de Chréticins, rélolus d'aller, s'il étoit nécelfire; jufiu'a Facata, \& d'enlever de force les Serviteurs de Dieu, ou de pórir à la poine.

comment Leur joye fut grande, lorfqu'ils les apperçuiis runt recus rent; ils avoient apporté avec eux quantité parlos liceles de rafraîchiliemens, \& cette précation ne de Bungo. fut pas inutile. Guand les Mifionnaires furent a cing ou fix licués de Fucheo, ils commencerent i rencontrer des Troupes nombreules de Fidéles, qui venoient au-cevant d'eux, \& à chaque fois il falloir cntrer dans des Tentes, que ces bonnes cons avoient dreflées à cốćdu grand Chemin, \& s'y rafraichir, ou s'y repoler. Mlus ils approchoienr, \& plus la foule groflifoit; on auroit dit gu'il n'étoit rếé perfome dans la Ville, \& toutes les Campagnes retentifloient de cris de joye, \& d'actions de graces au Seigneur Dieu, qui f̧air délivrer les Serviteurs des plus grands dangers par des voyes, qui ne font connuës que de lui. Les Mifronnaires cntrerent ainfu dans Fucheo co m. me en triomphe; \& parce ‘ju'on f̧avoit quils 
IIVRE SECON D. ISI avoient tout perdu, il n'y eut pas un Chrétien, qui ne leur offrit lon prélent. Les uns lerir apportoient de l'Argent, les autres de l'Eroffe \& du Linge, ceux-ci de la Vaillelle de Porcelaine, ceux-la de petits Meubles a leur ulage; il n'eft pas concevable, julqu'où on porta Pattention, mais rien ne les touchoit au prix de l'affection, avec laquelle tout cela fe faifoit.

Cependant la Rérolution du Chicugen, \& les broinlleries du Firando, ayant encore une fois réini dans le Bungo tout ce qu'il y avoit au Japon d'Ouvriers Apofoliques, le $\mathrm{P}$. de Torrez fongea férienfement a exécuter un deflein, qu'il avoit fort a coeur depuis queltue rems: voici de quoi il s'agilfoit. A trois lieués de Méaco, en fuivant le grand Chemin, qui conduit de cette Capitale à Jedo, on tronve la perite ville d'O'itz, à l'entrée du Koyame d'OMI; elle eft compolée d'une rué, qui rourne en forme d'Arc, \& de quel gues autres plus petites, qui y aboutifient à droic \& à gauche; clle peut avoir environ mille Maifons, \&z elle ef du Domane Inipérial. Elle eft fituce fur le bord d'un Lac, qu'on appelle quelquefois le Lac d'OMI, \& plus comnunément le Lac d'Oirz. Ce Lác, dilent les Annales du Yapon, fe forma en une nuit; le Terrein, dont il occupe la Place, ayant été englonti par un tremblemente de Terre. Il n'a pas beaucoup de largeur, mais il s'étend au Nord près de foixante lieuës jufqu'au Royanme de CANGA. Il eft trés-poillonneux, il a furtout une grande quantité de Saumons, cui ont excellents, \& tous les bords font couverts de Caliards fauvages; il fe dédu Las d'Oitz \& dela Mon. tagne de jeran

De J. C.

I $15 \%$

De Syn.Mu-, 2219.

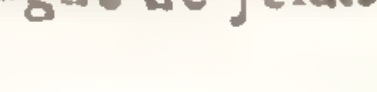




\section{IY2 HISTOIRE DU JATON;}

charge dans deux Rivieres, dont l'une def

De I C. 1359.

Li: $>y:-14$. cend à Mćaco, qu'elle rraverfe, \& l'autre paffé à JOdo \& à Ozica.

529.

Allez près de ce Lac, environ à fix lientes de Méaco, \& fur la gauche en allant a Jodo. elt une Montagne tris-haute, dont ha viè eut chamante, \& qui fe nomme JESAN, ou JIOa.1N; différence, qui n'eft apparemment, que dans la prononciation, comme il arrive à la plipart des noms, qu'on trouve ir diverfenent écrits dans prefoue routes nos Relations. JEsan veut dire belle Montagn?. Les Ecrivains Portugais la nomment FrenoxakA, 星 on: été furvis par tous ceux, gui one travallé fur leurs Mémoires; mais comme ce nom fignifie Ifontagne, il eft vraifemblable, u'is $n \geq$ s'en font fervi, que parce que les J pomnois l'ont nommé par excellence le Mone J ES A N. Il a huir lieués de long, \& lon y conpee chcore aujourd'hui jufgu'a trois mille Temples (en y comprenant fans donte les Chaplles), pluticurs Villages, \& motres-grand nombre de Monafteres. Sa fitmation, \& pius cacore ha prérendué fainteté du liev, en ávolent fair un azile pour les Habitants de Múaco pendant les Guerres Civiies; tontefois ce prétendu Sanfruaire n’avoir pas tonjours ćé bien ćpargné, \& au tems, dont je parle, le nonilur des Temzples, qui avcit écé avant les roobles auti gand pour le moins, quil l'er aujcarch'bui, éruit réduit a fir cents; celui des Domaleres ctrit à peu prés égal. Ce lieu au refte ent délicienx: on n'y roit que Vallíes entrecoupces de Ruifieaux \& de Fontaines, qui vont le perdre dans de petits Bois rsés-agréables. De loin la Montagne ne paroît qu'une ćparlle Fosêt, 
L I R E SECON D. I $\$ 3$

rêt, parce que les Arbres y font d'une hautiur furprenante.

Parmi le nombre infini de Bonzes, gri habitonent ce beau Pays, il y aroir un Tunde, qui ayant beaucoup entendu parler du Chriftraniline, fouhaitoit palionnément de lȩaroir ce que c'ćtoit, que cette Religion Etrangere. Il ćcrivit pour cet effet au P. de Torrez, lui manda que fans fon grand âge il eût ćté

De J. r. I $55 \%$

De Syr Mu. 22.90

UnSuperier:s de Bonzes lismande unMám fiomalic. le rrouver; mais que la chole ne lui ćcant pas polfible, il le prioir de fe tranfporter jus yua jefan, ou d'y envoyer quelgu un de fés lićligicux. "Vous avez palkếbien des Pays, " lui difoit-il, a la fir de la Letre, traver"Ĺ́ bien des Mers, \& conru bien des rils ques, pour procurer de la gloire a votre $\Rightarrow$ Dieu, refuferez-rous da venir fir certe "Montagne, o: rous avez un ti grand in » térêt d'établir votre Religion? « Le $P$. de Torrez, lorfigu'il reçut cette Lestre, n'avoit aupris de lui aucun Minionmaire, dont il put difoler, \& la préfence éteit nécelaire dans le Bungo; il répondit an Bonze, gu'il lvienvoyeroit le premier de fes Inférienis, gui le trouveroit libre, 8 gu'en atiendant, il le prioit de lire attentivement un perit Ecrit, qu'on lui préfenteroit de fa part. C'étoit un Abrégé de la Doarine, \& des principaux devoirs du Chriftinnime, quil avoit compofé, \& qui étoit très-bien fait. Pea de tems apris le P. Vilela, \& enfuite le Pere Gago arriverent a Fucheo, pour les railins, que j'ai dites; aufi-tôt le Supérieur Général fongea à tenir au Bonze de Jefan la parole, quil lai avoit donnée, \& il lui envoya le P. Vile!n, Laurent, \& un jeune Japonnois, gui devoit Tome II. 


\section{Is4 HISTOIRE DU JAPON;}

- fervir de Catćchife aux deux Miflionnaires.

1.e J. E. I.e P. Vilela, avant que de partir, fe fit 1990. rafur les Cheveux \& la Barbe, \& s'habilla à D Syn-Mu peu près comme les Bonzes, pour faire voir 2219. ¿ju'il étoit Docteur dans fa Loi, \& parce Le ?. Vilela qu'on l'avertit que fins cela il auroit de la y eft cnvuyé, peine à être reçu à Jefan. Il paroît pourtant, ve qu'il eut à que dans la fuite on s'elt accoutumé à voir fol:frir dans les Docteurs Européens dans leurs habits orce royage. dinaircs; mais je ne trouve rien de bien certain fur cet Article. Les Miffionnaires s'embarquerent au mois de Septembre fur un petir Batiment, qui failoir voiles vers Sacai, \& ce Voyage fut pour eux un tiflu de croix, fous le poids defquelles un courage moins ferme, que le leur, chit cent fois fuccombé. Tout l'Equipage du Navire ćtoit Idolatre \& fort fuperfitieux; les calmes furvinrent, qu'on ćtoit encore prefigu'a la vî́ du Port, d'oul l'on étoit parti, \& pour obtenir un Vent favorable, il fut réfolu de faire guelgu'offrande a un des Dieux de la Mer : il fallut pour cela faire Ine Quête, \& celui qui en fut chargé , s'adrella au P. Vilela, comme aux autres; l'Homme Apoftoligue répondit que ce n'ćtoit pas à des Dieux fourris \& impuillants, mais au leul Créateur du Ciel \& de la Terre, qu'il falloit s'adrefier pour obtenir de pareilles graces, nul autre que lui, n'ayant droit de commander a la Nature. A ces mots on le recoinut pour ce qu'il ćroit, \& les Matelots fe nirent fortement dans la Tête que c'étoit lui \& les Compagnons, qui ćtoient caure de la bonace; \& comme elle continua encore quelque ems, \& ciu'enfuite il s'ćleva un vent contraire, il ne fe peut dire combien d'ourra. 
zes !es M:Aionnaises reçûrent de ces Barbares, qui ne s'en tinrent pas même aux inj:lres, car ils les frapperent fouvent comme des Efciaves, ils les lailloient plufieurs jours de fuite fans leur doniner àmanger, \& ils furent

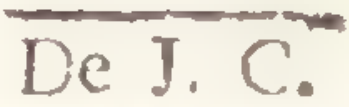
1559.

D: Svillu. 2219.

plus d'une fois fur le point de les jetter a la Mer.

Une vifion, ou fi l'on veut, un fonge,gu'cut le P. Vilcha, \& dans leyuel il lui fumbla, yo l'Apôre des Indes lui prometroit de l'afilter, \& lui recommandoit d'avoir hon coniage, le fortifia beaucoup, \& il cut foin d'animer tes Compagnons. Enfin on lis abandonna dans un Port, oil l'on avoit pris Terre, \& l'on avertit tous les Patrons des Navires, qui s'y renconirerent, que ces Errangers étoient les Ennemis des Dieux, \& qu'on ne pouroit, fans fe rendre criminel, avoir aucun Commerce aver eux. Par-la les Serviteurs de Dieu le virent réduits a une petite Barque allez mauvaife, fur lagielle on voulut bicn leur donner pallage; mais le Ciel prit leur caule en Main, \& rúcompenfa d'une maniere éclatante la charité de criui, qui les avoit recîs. Tous les Navires, gui leur avoicn refuć le paliage, \& celui, guiles avoit amenés jufipueslá, ou perirent par la Tempéce, ou furent la Proye des Corfaires; tandis que la fenle Barque, oulils ćtoient, continua fa route fans aucun: accident.

De Sacai, où la Bargue s'arrếta, les Milfonnares prirent lenr Chemin par Terre, \& gagnerent SAcovoro, petite bourgade, jui eft au Pied du Mont Jefan. Le P. Vilela s'y arrêta, a envoya Lutent averir de fon ar rivóe le Bonze, à l'occafon duquel il avois

$$
\text { G ij }
$$

Le Ronz:, qui les avi:it invités meizrt ariritioni ar-

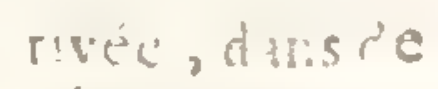
tresabuns isutialatrots. 


\section{I96 HISTOIRE UU JAFON,}

Cc J.C entrepris ce Voyage. Laurent ne le trouva rseos, il y avoit peu de jours yujil étoit mort - mais fon Succelltur au Gouvernement ce fon De syn ' 2219. Mifionnare, en lui alsuant yue le bífunt avoir protefté, avant que d'expirer, gu'il crosoit fermenent tous les Articles contenus dans l'Ecrit, que le P. de Torrez lui avoit envoyé. Il ajốta, que lui mêne, \& dix de fes Inféricurs, fubaitoient fort d'entendre un bocteur Europíen, \& qu'il n’éroir pas ćloignécies fentiments, dans lefiguels il avort vâ mourir fon P'édécelicur. Laurent retourna en diligence donner ces nouvelles au P. Vilela, qui fur le champ le tranfporta au Monantere de Daizembo.

Le Ponze, \& les autres, dont celui-ci avoit Son Succe!fiur nue fe dievaresche. tiibli. arlé a Larent, furent merveilloufement fafatisfaits des Entretiens, cu'ils enrent avec le Mifroninire; mais aucun n'ola le déclarer pour le bieu des Chrétiens. Darzembo dir móne en licret au P. Vilela gu'il ćtoit perfuncé de la vérité de tout ce qu'il venoit de lui cnfeigner; mais gu'il craignoir gu'on ne lo fit mourir, s'il renonçoit a la Relisyon du Pays: d'autres l'avertirent, gu'avant que de áare aucune démasche dans me Afraire auli inportante, que celle de Irêcher une monvsle Religion, il falloit avoir l'app:obation cu X A C , qui ćton alors à Jelan, \& guils tai confoillowat d'aller voir ce Che de leur Religion. Le Pere tit bien fouhaicé en effer d'avoir un chreticm avec le Xaco, mais i) ne lui fur jamais pofible de parvenir julqu'i lui; \& comme il ne vit plus aucune ap-

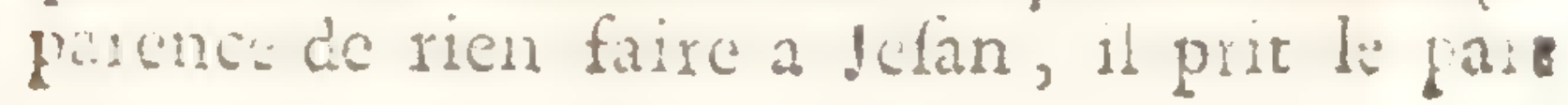


d'aller à Méaco, où il arriva le dernier jour de Novemure.

Il fe retira d'abord dans une Maifon, qui tomboit en ruine, il y dineura plufieurs jours avec fon Comparnon \& Con Caréchilte, \& ils s'y préparerent par la Priere \& par la Pénitence a la grande ouvre, qu'ils alloient entreprendre. Leur Retraite frnie, le P. Vilela, qui trouva moyen de laluer l'Empereur Cubo-Sama, dont il fut parfaitement bien reẑ̧ิ \& qui lui permir de Prêcher fa Religion, fe montra dans les Quartiers les plus fréquentés de la Ville le Crucifix à la Man. Méaco ćtoit alors allez tranquille, \& la fingularité du Spectacle allembla d'abord autour du Prédicateur toutes fortes de Perfonnes, à qui il annonça le Royaume de Dieu; mais la plûpart le traiterent de Vifionnaire: les Bonzes lé mirent de la partie, \& ayant débité parmi le Peuple tout ce que leurs Confreres d'Amanguchi \& du Ximo avoient imaginé, pour rendre odicux \& móprínbles les Doctenrs Portugais, ceux - ci ne pouvoient plus paroitre nulle part, gutils nefinglient des hućes, \& qu'on ne les appellat nangeurs cee chair humaine.

Ils eurent même bien-tôt fujer de craindre guelque chofe de pis; lanimoficé lu Peuple contreux devint extrême, 2 ils ne fe regarderent plus que comme des Victimes deftinćes à la mort. Un Habitant fort aifé les avoir reçûs chez lui, il appréhenda qu'on ne lui en fir une Affaire, il leur die alfez doncement de fe retirer ailleurs; \& comme le Pere Vilela ne fé prefloit point de fortir, cs Burbare leva le Sabre fur lui, \& peu s'en fal-

$$
\text { G iij }
$$

De J. C.
I 559.
ne Syll-ilu. 2219.

L:Pere Vilela a Méaco, où il olkient du Culo-S.3. m. lapenato fion de prế. cherlinvingile. 


\section{IS HISTOIRE DU JAPON,}

Le J.C. lut quil ne le lui déchargeât fur la Tête; Le Mifionnare fut contraint de fe réfugies De Sy: Mu. dans une Cabanine, oul il n'avoit qu'un peu 2219. de Paille pour le coucher, \& où il louffrit beaucoup da la faim, du froid, \& de l'humicitú; tout cela néanmoins ne tir qu'enflammer fon zćle, il continua fes Prédications, comme fi elles eulfent ćté reçüés avec applaudillement, \& cette intrépidité le fit enfin eftimer de tous ceux, gui fçurent fe metre au-deflus de la prévention, ou que la paffion n'aveugloit pas. On le sendit plus artentif à fes dificours, \& plufieurs commencerent à gôter fa Doctrine.

Unseigneur Il lembloit náanmoins, que Perfonne n'oce la Courlui foit fe déclarer, \& il paroilloit gu'on craifrit uherir gnoit les Bonzes \& la Cour. Enfin un Cendes Patintes deleme. reur.tingeurs Binizes le funt Chisciteas. tilhomme d'Amanguchi, que les uns nomment Aleuimexa, \& les autres Ichimara, fur le premier, qui rompir la glace 11 fe fir baptiler avec deux de fes Amis, \& leur exenple fut bien-tôt luivi de plufieurs perfunnes de confidération. La favenr de MIOXINDONe contribua beancoup à ce luccis, mir en honneur la Religion Chrítienne, \& fit refpecter fes Minitires. Ce Seigneur, dont nous parlerons beaucoup daus la luite, étoit favori du Culo-Sama, que nous entendrons toujours déformais fous le nom d'Empereur, \& le Pe$\mathbf{r}$ V Vilela, qui ćtoit d'un caractere fort aimable, \& avoit des manieres très-infinuantes, avoit trouvé de l'accés auprès de lui. Il obtint par fon crédit une feconde audience de l'Empereur, qui lui accorda des patentes en bonneforme, \& fit défente fous peine de la vie, de l'ingulucier dans fes fonctions. Toue 
cela produift un grand efter; les Bonzes n'ofrent plus rien entreprendre contre des Gens, que le Souverain prenoit fous fa protection, \& pour qui le Favori s'étoit déclaré. Il y eut même plus; car on vit alors, ce qui ne s'étoit point encore vû ailleurs, les plus confidérables de ces Religieux Idolâtres embralfer conme à l'envi le Chriltianifme.

Celui, dont la Converfion fit plus de bruit, \& qui donna l'exemple aux autres, fut un nommé Queñu. De la maniere, dont on parle de ce Docteur dans toutes les Relations, que j'ai vûés, c'étoit encore toute autre chofe, que Fucarandono: dans la véritć Quenxu ćtoit un de ces fages Payens, qu'une profonde étude de la Nature conduit infenfiblement à une connoiffance fuperficielle, mais ftérile de fon Auteur. Sa Chambre ćtoit parće dEm. blêmes \& de Sentences, qui contenoient une Morale fort faine, \& qui maryuoient allez que quarante ans de folitude qu'il avoit enployez à contenupler les Myfteres de fa Secte, n'avoient point effacé en lui l'idice d'un Premier Etre fans commencement \& fans fin. On y voyoit entrautres un Tableau, qui palfoît pour une Piéce fort rare; il repréfentoit un Arbre fec au milicu d'une belle Prairie, \& le Bonze avoit mis au bas ces deux Dyfiques, quin de nos Autcurs (a) a ami traduits en notre Langue.

Arbre sec Eo fans Fruit, fans Fcuille \& fans verdure,

Dis-moi, fitule Scais, quit'a mis encelieu?

(a) Le P. Grafist,

D. J.C.

I; 60 .

LC Sin Nu. 2220.

Converfion d'un fininiux roukter. 


\section{I60 HISTOIRE DU JAPO:}

C'eft le DieuTout-puiffant, Auteur de la Naturs

De J. C. Sans lequel je ne Juis qu'un bois à mettre au feu. Is 60.

Le syotilu. 2220.

Que l'Homme eft compof.é d'une nature étrange!

Ce n'eféqu'un pur mélange,

Del'Etre G du Néant, qui vit Ene vit pas, Il n'eft jamais content, Eq le veut toujour's être. Si-tôt qu'il vient à naitre, Il court à tous momeris de la vie au trépas.

Le Doste Bonze, dès qu'il entendit parler du Pere Vilela, eut envie de le connoître, moins pourtane par curiolité, que far vanité. Il l'alla trouver, \& d'un air de futfifance accompagné de mépris, il lu dit, qu'il ne venoit pas pour apprendre de lui quelque chofe, mais yu'il ne feroit pas fàché de l'entendre parler de la Religion. Le Pere le reçut avec cette modeftie, qu'infpire la vérité, puis entrant en matiere, il voulut érablir l'exilten-. ce d'un premier Principe, A peine avost-il commencé fon difcours, que l'Efprit Saint toucha le cour du Religieux Idolátre; il lui parut qu'on lui ôtoit un Bandeau de devant les yeux. Le Millionnaire s'apperçut, yu'il pâlilloit de tems en tems, que fon attention devenoit plus l'crieule, enfin yu'il fe palloit en lui quelyue chole d'extraordinaire.

Encouragé par ce changement, dont il auguroit bien, il s'étendit fort fur la conformité, qu'ont les principes de la Morale Chrérienne avec les lumieres de la raifon, \& fir voir combien au contraire les Sectes du Japon font oppolées au bon fens. Le Bonze immobile, comme un Homme interdit, jetroit de moments à autres de profonds foupirs, \& ne sć- 


\section{I $\nabla R E S E C O N D$ D 56 ?}

pondoit rien. Enfin la grace prit le deffus, \& il fallut fe rendre. Je Juis Chrétien, s'écriat-il tout d'un coup, je Juis Chrétien, baptifés-moi. Le Millonnaire ne fe fit point prier, l'Opération Célefte dans l'Ame de ce Trol'́-

De J.C. $15 \% 0$.

De Syr-Mil. 2210. lyte étoit trop fenfible, pour en pouvoir douter un moment. Quenxu fur baptice à l'heure même, \& le bruit d'un Evénement fí fingulier s'étant répandu d'abord, il y eut jufqu'i quinze Bonzes des plus diftingués, qui demanderent le Baptême. Parmi ces illuftes Nćophytes, il y en avoit uu, à qui l'innocence \& l'auférité de fa vie avoient fans doute préparé les voyes à la grace de fa Converfion. Il eft vrai qu'il n'y avoit rien de fi dur, que la maniere, dont il vivoit. Le défir qu'il avoit d'aller au Ciel, lui ayoit fait faire vau d'enfeigner gratuitement le Foguexio toute fa vie. Huit ans avant que le P. Vilela vint à Mćaco, le Bonze fongea une nuit, que des Prêtres venus de l'Occident, lui montroient le Chemin du Ciel ; \& le lendemain il apprit, qu'il en étoic arrivé deux à Amanguchi. Il fut des premiers à entendre les Pródications du P. Vileia, \& il vint exprès de Farima, oit il demenroit. Il en fut fort hatisfait, mais ce fut la Converfion de Quenxu, qui acheva de le détominer.

De if heareux commencements fembloient répondre au Miffonnaire d'une abondance récolte, lorínue los Bonzes exciterent contre lui un orage d'autani plus dangerenx, quie le Xaco fe mit a leur Tête: la partie fur liće avec tant de fecret, qu'avant que les Chrétiens euflent le vent de ce qui fe tramoit, les mefures étoient prifes pour perdre leur contrel: Pire V.epera cuma ment at le difo fipe. 


\section{I62 HISTOIREDUTAPON,}

De J. C. Pafteur. Le Gouyerneur de Méaco, gagné par I 60 une grolle fomme d'Argent, promit à leurs _..... Enmemis de le chafler de la Ville; \& il ne Di syn-lva, s'agilioit plus, que de trouver un prétexte 3220. pour le faire, fans contrevenir aux Ordonnances de l'Empereur. Le Pere fut averti de ce qui fe tramoit contre lui, par Mioxindono, gui lui confeilla de fe retirer dans une de fes Forterelles, \& d'y reiter, jufqu'a ce qu'il put parer le coup, qu'on fe difpofoit à lui porter. Il déféra a cet avis, \& il ne pou. voit gurres sen difpenfer; mais il connut bien¿ốt, qu'un avoit eu tort de le lui donner. I! fut informé que fa retraite étoit regardée comme une fuice, \& que les Infidéles en triom. phoient; il retourna donc fur le champ à Méaco, \& réfolu à tout Evénement, il parut dans cetre Capitale avec plus dalfurance, que jamais. Dieu bénit lon courage; les Bonzes furent étonnez, Mioxindono parla à l'Émpereur, \& ce Prince défendit par un nouvel Edit de troubler les Prêtres Européens dans l'exercice de leur Miniftere.

Cet avantage remporté fur les Miniftre;

Grand nombrede cuisurerfiums.densénpuncs cominsule un les deux Religicux commencerent à recuêllir fip riorite ce avec joye ce qu'ils avoient lemé avec tant da k eligion de fatigues. On venoit de toutes parts leur de. Chiétimn: fir mander le Baptême; \& bien-tôt leur plus grand

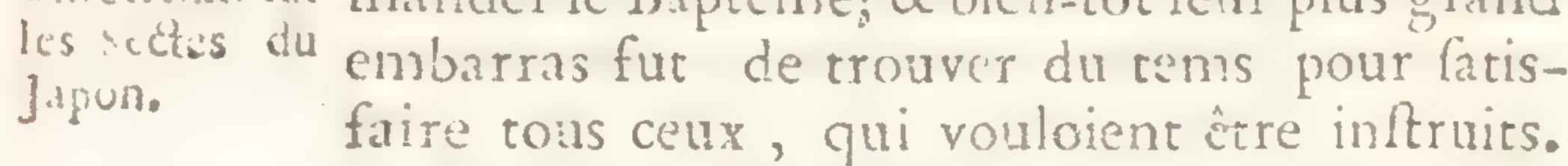
des Idoles, \& la faveur déclarće de la Cour Impériale, dilpolerent admirablement les efprits en faveur du Chriftianifine; de forte que La ferveur des Fidéles s'accrut avez lenr nombre; \& comme ils brîloient du défir de faire adorer le Dicu, qu'ils venoiene de connoître, 
L I $V R$ E SEC O N D. I 3

les olus Sçavants d'entr'eux compolerent un peti Traicé en forme de Letre adrelíc aux Chériens du Bungo, où ils oppofoiene la Lui de Jesus-Christ aux diféréntes Sectes du De sym-Mu. Jafon, \& faifoient voir combien elle leur eft \$22. fupirieure. Il n'elt pas croyable de combien de Converfions ce petit Ouvrage fut l'occafion, ou l'inftrument.

De la maniere, dont les Efprits paroifoient T:ifte exemparcout difpofez à recevoir l'Evangile, il eft ple de la fo. contant qu'il ne manquoit que des Ouvricrs blefle humaipour l'annoncer. On en demandoit de plu- Mifromair. fieurs Provinces au P.de Torrez; mais il ne lui en venoit point des Indes, \& pour comble de chagrin, il fut encore obligé de fe priver du feul pretre, qu'il eût avec lui dans le Ximo. Mais ce fut bien moins certe perce, qui le toucha, que le principe, quila caura, \& les circonfances, dont elle fut accompa gnce. Un des premiers Milionnaires, fur yui I'Apôtre des Indes avoit jerté les yeux pour la Miflion du Japon, après qu'il eut recomnu que certe Nation demandoir des Prédicateurs d'un grand mérite \& d'une vertu peu commune, fut le Pere Balthazar Gago; \& rien ne doit donner une plus gtande idće de ce Religieux, que la préférence, qui lui fut donnće par un fi bon Juge, fur tant de Saints \& de grands Hommes, qui firent alors changer toute l'Afie de face, \& parmi leficuels if y a eu tant d'Apôrres \& de Marryrs.

Le P. Gago fit d'abord honneur au choix de fon Supćrieur. Il apprit fi aifément la Langue Iaponnoife, qu'en tròs-peu de tens il fut en état de la parler avec facilité, \& même avec éléganc. Il fir dans le Bungo, dans

$$
\text { G vj }
$$




\section{$36+$ HISTOIRE SU JAPON";}

i. I. C.

I; $6:$.

in si.n. Aiu.

-2.2.

le Firando, \& dans le Chicugen des Conver-j fions innombrables; fa verta, \& la donceur. cie fes manieres lui avoient tellenrent gagné le cour de tous les Néophytes, que leur attachement à fa Perionne alloit jufqu'à une véritable tendteffe. Enfin les Miracies, que Dieu opéra plus d'une fois par fon Miniftere, \& fur-tout le pouvoir, qu'il avoit reçu de challer les Démons . répandirent fort loin ia séputation. Ce gu'il fouffrit dans la prifé de Facata avoit achevé de le rendre infiniment cher \& précieux à toute cette Eglife naillante. Mois re Géant s'arichta mahihenrenfement au milien de fa courfe, \& par un fecret Jugement de Dieu, qui voulut fans doute apprendre à tant d'Hommes Apoftoliques, que quoiqu'ils eullent fait \& fouffert pour fon Nom, ils ne pouvoient avoir trop de défiance d'eux mêmes, un des plus faints, des plus zćlez, \& des plus infatigables Ouvriers, qui fullent alors. dans l'Orient, fut du nombre de ceux, qui après avoir mis la Main à la charrué, regardent lâchement derriere eux.

Il n'y avoit pas long-tems, que le P.Gago étoit revenu de Facata, gu'on apperçut en lư un grand changement; cet Homme, à qui jufques-là rien n'avoit paru difficile, trouvoit alors tout injolfible. Enfin il déclara que fes infirmitez ne lui permettoient pas de demeuter plus long-tems au Japon. Il y a bien de lapparence que la violente fituation, oul is żétoit trouvé à la prife de Facata, lui avoit affoibli l'efprit; car depuis ce te ns. Ia il parut Bien différent de lui-même. Le P. de Torrez, gui le remnrgtra, \& qui juctea fort Cagemont;

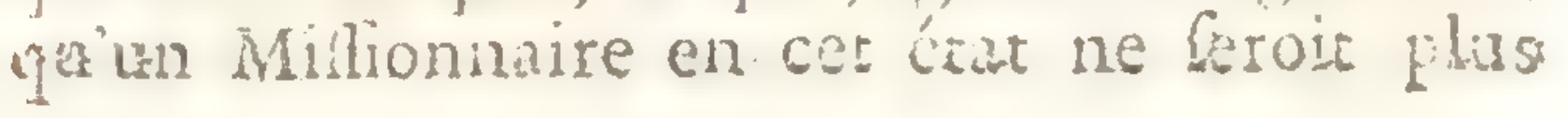


déformais fort utile à la Miffion du Japon, confentit, quoiquavec bien du regret, à fon départ; \& la nouvelle ne s'en fur pas plutôn répandué, que la délolation fut extrême parni tous les Fidéles. Mais, ni la douleur du Supérieur de la Miflion, ni les larmes des De J.C. I 56 I. We Syn-Niu. 22210 Néophytes, ne pîrent faire changex de réfolution au Pere Gago, gui pour cacher fa foi. blefle au Public, ou plutôt pour fe tirer des Mains de ces nouveaux Chrétiens, fit courir le bruit, qu'il alloit chercher aux. Indes un renfort de Prédicareurs. Il s'embarqua le feptiéne jour d'Outobre de l'annce I56 I. fur le Vaifleau d'EmManeel de MENDOze, qui faifoit voiles vers Malaca.

Il n'alla pas bien loin, fans reconnoître, que Dieu le pourluivoit comme un autre Jow 13as; car apres quelques jours d'une Navigation aflez tranquille, le Navire, où il étoit, fut alfalli d'une des plus rudes toumentes, qu'on eût peut-être vîèe dans ces Mers. Alors. le Miffionnire fugirif fentit tour le poids de la colere du Ciel. Il fe reprocha cent fois fon infidélité, \& il sofirit en facrifice, pour le falut d'un Equipage, fur lequel il crut avoir attiré cette tempête; il refufa même une place, qu'on lui préfenta dans l'éçuif, où pluficurs fongeoient déja à fe jetter, \& pendant quinze jours, que dura la tourmente, il fic tout ce qu'on eût pû attendre de lui dans le tenis de fa plus grande ferveur. Enfin le $\mathrm{Na}$ vire alla te brifer dans un port de l'Ifle de. HAIINAN, ou quoiqu'il abordât tout delagréé, tout le monde eut le tems de fefauver. Le P. G. go fe rendit enfuite à Gos, \& ne lailfa pas. de rendre encore quelques fervices dans les 


\section{I66 HISTOIRE D U JAPON,}

Indes à la Compagnie \& à l'Eglife; mais ce

De J. C. ne fur, ni avec le méme zele, ni avec le mîI561. me fuccès, que dans fes premieres années:

De Syn Mu. fa conduite ćtoit d'ailleurs fort réglée, \& dans 2221. le fonds on le plaignit beaucoup plus, qu'on ne le blâma. I! prrut même fur la fin de les jours reprendre une nouvelle vigueur, \& l'on vit renaître en lui quelqu'útincelle de ce fer divin, dont il avoit fi long-tems brûlé ; cependant il n'atteignit jamais au dégré de fainteré, dont il étoit déchû. Mais revenons à dés objets plus confolants, quoique moins inftructifs peut-être pour pluticurs de ceux, qui liront cette Hiftoire.

Le P. Vilela La réputation du l'ere Vilela n'étoit plus a Sacai. Del. renfermée dans l'enceinte de Meaco, ni méme cription de bornée aux environs de cette Capicale de l'Enr cette Ville. pire. Il fut appellce à Sacai par un des principaux de la Ville. Sacar aujourd'hui Ville Impériale, \& fituće dans la Province d'IzUmi, étoit au tems dont nous parlons, une des plus opulentes, \& des plus fortes Villes du Japon. Flle eft au Nord de Meaco par les trente-cinq dégrez trente minutes de latitude feptentrionale, baignće de la Mer à l'Occident, \& du refte environnće d'un Follé fort large, \& toujours rempli d'eau. Elle ne reconnoilloit alors aucun Prince particulier ; le Gouvernement y ctoit Républiquain, \& quelques Relations alfurent, qu'il diffíroit fort peu de celui de Venife. La Police y étoit admirable; les moindres fautes contre le bon ordre \& la tranquilité publique, y étoient févérement punies, \& l'on y avoit joüi d'une paix profonde, tandis que toutes les provinces circonvoifines étoient dans le trouble \& dans 


\section{I V R E ' SEC O.N D. 167}

l'agitation; mais cette Ville riche, priffante, plongée dans les délices, quatrire touiours l'abondance, \& fiere de fa profpérité, n'étoit pas difpolće à recevoir l'Evangile, \& la Foi De Syn-Mu. n'y a jamais fait de grands progrès.

De J.C. I $56 \mathrm{I}$.

Parmi tant d'endurcis, il y avoit une Famille prédeftinće; le Pere Vilela fut reçû comme un Ange du Ciel par le Gentilhomme, toute une Faquil'avoit fait venir, \& dont il baptifa en peu de fainteté de tems toute la Maifon. Ce Millionnaire a dans un Enćcrit des chofes merveilleufes de cette Famil- fant de quale, qui ćtoit une des plus puillantes de tout le Pays, furtout d'un Enfant de quatorze ans, qui ne refpiroir que le Martyre. En effet il avoit été rempli dans le Baptême d'une fi srande abondance de graces, qu'il fembloit un Séraphin tout embralé de l'amour de Dieu. Aprés le départ du Pere Vilela, il obtint de fes l'arens la permiffion d'aller à Fucheo, pour y joiiir de l'entretien des Miffionnaires, qui $y$ ćcoient toujuurs en plus grand nombre çu'ailleurs, \& voici ce que Loüis Almeyda, gui ćtoit pour lors dans cette Ville, en a ćcrit dans fes Lettres. "Ill ne fe voit rien de " plus parfait dans l'ordre de la Nature, ni 2 dans celui de la Grace, qu'un jeune Homos me, qui nous eft venu de Sacai. Il approche $\Rightarrow$ tous les huit jours du Sacrement de l'Au$\Rightarrow$ tel, \& c'elt ordinairement avec une abon$\leadsto$ dance de larmes, qui infpireroir de la dévo$\Rightarrow$ tion aux coeurs les plus durs. Rien n'eft plus $\Rightarrow$ humble, on voit avec ćtoinement un En" fant de condition aimer à fe confondre avec » les plus Pauvres. Il s'eft même fair entiere„ rafer la Téte, pour n'avoir plus aucune ax marque de Noblefle; fes Habits font frm. 


\section{HISTOIRE DU TAPON;}

De J.C. : ples, \& fa nourriture eft des plus grofie-

I 52 I.

De Syn-Mu. 2221 .

»res, a urfi paroît-il réfolu à renoncer enties rement au Monde, yuand il aura atteint »l'áge nécellaire pour cela ». Après que cet admirable Enfant eut refté quelque tems à Fucheo, fes Parens le redemanderent, \& le Pere de Torrez le reconduifit par Terre juf qu'au Port de Vocoxiura, qui eft de la Principauté d'OMURA, où il devoit s'embarquer, il y trouva un Navire, qui chemin faifant s'arrêta dans le Port de lirando. VinCENT, c'étoit le nom du jeune Chrétien de Sacai, $y$ voulut rendre vifite a la Femme du Prince Antoine, qu'il apprit être alors dans la Ville; \& comme il la tronva qui le difpofót à la Confeflion avec tous les Domeftiques, il leur fir un difcours fi pathétique, fur la I'énitence Chrétienne, qu'on auroit dit que le Saint Efprit parloit par fa bouche. C'étoit allez l'ufage dans certe nouvelle Eglife, d'accoutumer les Enfans à parler en public, fur les Points principaux de la Religion \& de la Morale Chrétienne, \& ils s'en acquittoient avec tme grace nompareille, \& avec un fuccès, qui palle tout ce qu'on en peut dire, mais il y avoit dars celui-ci quelyue chole d'extraordinatre, \& qui fembloit furnaturel. Vincent avoit une Saur nommće MoNique, dont nous anroms bientôt occafion de dire des cholés aulfi merveilleufes, que ceque nous venons de voir de fon Frere. Loüisalmci- Le Pere Vilela demeura fort peu de tems
da vifite les à Sacai, où il s'apperçut bien-tôt, qu'il ne deEglifes du Xi- voit pas compter de faire beaucoup de fruit, mo, en quel Etat illes trou ve. $\mathrm{Ce}$ qui le $\&$ il retouma à Meaco, où le nombre des Profólytes croilloit tous les jours. Mais tandis 


\section{I VRE SEG ON D: 69}

que ce grand Ouvrier établilioit fi folidement le Chritianifme dans le centre de l'Empire, Loiiis Almeyca, qu'une conftante application

De T. IC. I I.56r. (1). à l'érude de nos Mylteres, \& de la Langue Ja-De Syn-Mu. ponnoile, jointe a une vereu héroique, avoit rendu très-capable d'être employé au Miniltere Evangélicue, vificoit les Eglife du Ximo, vantage fruits qui étoient deftiruées de Palteurs, guériffant de fa vitite. en nême-tems les Carps \& les Annes, \& il commença par le Firando. Il trouvoit dans. tous les lieux de fon paltage de nouveaux fujets d'adorer la bonté libérale de Dieu, qui fembloir n'avoir point de réferve pour les Japunnois; mais deux choles le frapperent plus, que tour le refte, ainfi que lui-même s'en explique dans une de fes Letrres aux Jéfuites des Indes. La premiere étoit l'éfprit de pénitence, qui régnoir parmi ces nouveaux Fidéles à un point, qu'on avoit toites les peines du monde a les retenir dins les bornes de la difcrétion. La feconde eft, qưaulfi-tôt qu'un Infidéle avoit reçû le Baptême, queique grofliśr, \& quelqu'ignorant qu'il fi.s d'ailleurs, il devenoir formidable aux Bonzes. Le Millonnaire cire plufieurs traits de ces deux merveilles, \& il ajoâte en particulier par rapport a la leconde, qu'on voyoir tous les jours les plus vils Artifans, des Femmes, \& des Enfans, faire aux plus célebres Doteurs des queftons, \& leur propoler des difficultez, aufquelles ils ne pouvoient répondre, \& les jetter dans des embar. ras, d'oú ils ne fe tiroient point.

Ce qui contribuoit encore plus à conferver \& à augmenter la ferveur primitive dans certe Chrétienté, c'eft l'union étroite, qu'on avoit trouvé le lecrer d'écablir, \& qu'on avoit grand 


\section{I70. HISTOIRE DU JAION,}

foin d'entrecenir, non-feulement entre les Par.

De J. C. ticuliers de chaque Eglile, mais auhi entre is toutes les Eglifes; ce qui y caufort une fainte

De Syn-Múcémulation, dont les frusts le rendoient de 2221. jour en jour plus fenfibles. Elles s'ćcrivoient mutreliement pour le confoler dans les perfécutions, qu'on leur fufcitoit; pour s'animer à la fainteté; pour s'exciter a la perfévérance; \& pour lé communiquer ce qui fe palloit de plus édifiant dans cliacune : auti pouroit-on dire des Fidéles du Japon, ce que S. Luc rapporte des premiers Fidéles, qu'ils n'avoient tous qu'un Cocur \& qu'une Ame. Il arrivoit encore de ce perit conimerce de piété que les exemples de vertu, que donnoient les Particuliers, éroient connus partout, \& que le fruit n'en étoit pas renfermć dans l'encente d'unc Ville, ou d'une Bourgade.

Mais ce qui fervoit principalement à donner de la ftabilité à tout le bien, qui fe failoit dans l'Eglife du Japon, c'elt le foin extraordinaire, qu'on y prenoit de l'éducation de la lemefle. Non feulement il y avoit dans chaque Milion une Ecole publique, oil l'on enfeignoit la Doctrine Chrérienne; quel ques principes des Bel. les-Letres, le Chant de l'Eglife, \& même un peu de Mufique; mais les Millionnaires prenoient chez eux ceux d'entre les Enfans, en quiils remarquoient de meilleur es difpofitions, \& plus de talens. C'étoit furtout ceux-là, qư'on exerçoir à parler en public de la manićre, que j'ai dit. On les accoutumoit auffi peu à peu à l'Oraifon mentale, \& aux autres exercices établis dans les Séminaires. Ces Enfans entroient dans tout avec une facilité \& une affection furprenantes; on leur voyoit pratiquer des ver- 
tus, qui auroient fait honneur aux Religieux les plus confommés; plufieurs ne pouvoient entande parter de la I’afion du Sauveur des Hommes, fans fondre en larmes, \& ils s'exprimoient fur ce fujet de maniére a faire comprendre qu'ils fentoient parfaitement ce

De J.C. I gor.

De Syn-Mu: 22210 quils diloient.

Tous les Vendredis ils s'affembloient dans l'Eglié, d'oit ils alloient procellionnellement vers une Repréfentation du Gint Sépulchre, vêtus en Pónitens, \& portant chacun un inf trument de la Palfion. On les voyoit marcher avec une modeltie, \& une piéré, qui ne lé fentoient point de leur áge, \& ils paroilloient pénétrés de la grandeur, \& de la fainteré du Myftére, qu'ils reprélentoient. A mefure qu'ils arrivoient au terme de la Station, ils fe proftrnoient contre terre, \& formoient a haute voix des ates, \& des afpirations conformes aux infrumens, dont ils étoient chargés, \& its les terminoient toujours par demander avec larmes la grace du Martyre. Quand tous avoient fuli, pour faire voir combien ils étoient dipolés a rémande leur fang pour Jalus-Chrilt, ils le découvroient les épanles, \& prenoient tons en erible une rude difcipline à la vîe de leurs peres \& de leurs Meres, \& de rout le Peuple, à qui la ferveur de ces petits Innocens faifoient pouller des foupirs \& des langlots, dont tout retentiffoit. Que ceux, qui regarderont ces détails comme des minucies, fouffrent que is m'y arrête quelquefois, en faveur de ceux, qui en eront ćdifićs, \& qui ne me par. donneroient peut-être pas de les avoir retranchés ablolument dains un Ouvrage de la nature decelui-ci, oi je dois écrire pour tout le mon- 


\section{HISTOIRE DU JATON;}

De de. D'ailleurs ce font ces particularitez, quí Is6x. font mieux comnoître le génie d'une Nation; puifou'il eft certain que ia Grace, lors mêne De Syi - Mu. qu'elle agit plus fouveramement fur les cocurs, 2221. le conforme prefque toujours au caractere dominant de cettx, dont elle triomphe.

Cependant une Chrétienté établie fur de tels fondemens ne pouvoit pas manquer de produire ces exemples merveilleux de vertus, gui ont étonné l'Univers, \& qui ne trouveroi nt peut-ère point croyance parmi nous, fi ceux mêmes, qui avoient le plus d'intérêt a les enfevelir datis le frlence, ne les avoient aufi hautement publićs, que les Catholiques. Mais fi ces grands fuccès adomeillonent les travaux des Miffionnaires, \& leur rendoient leurs Néophites bien chers, il n'ent as moins vrai que l'excìs deces travaux, les mauvais traitements des Bonzes, \& le courage, avec lequel ces Religie 'x s'expofoient fans celle à toates fortes de' périls pour gagier des Ames à. Jefus Chrift, infpiroient aux Fidúles un attachement incrcyable pour leurs perfonnes. Cela paroilloir en toute occafron; mais principalement, lor:qu'il arrivoir quel ue nouvel Ouvrier au Japon. Dès qu'ils le f̧̧avoient proche, prefy ıe tous alloient au-devane de lui, marchant deux à deux, \& chantant des pleaunes, ou quelque Motet, dunt les paroles écoient tirćes de l'Ecriture, \& accommodées au !ujet. Au noment que le Milfomnaire paroilloit, ces Véophytes faifis de joye, \& les yeuxobaignés de pleurs, ne pouvoient plus que pr uffer des cris entrecoupés de langlots: ils couroient en cet état, \& fans ordre fe jetter à fes pieds, \& demeurojent quelyue tcms en cette pofure autour 
de lui, les bras élevés vers le Ciel, comme s'ils eullent vû un Ange, qui en fût defcendu, pour les y conciuire. Ils éclatoieur enlurte en actions de graces, quils rendoient a Dieu de De Syn- Mu, leur avoir envoyé un nouveau Pafteur: puis ils le conduifoient a l'Eglife, oùils chantoient le Te Deum.

Leur charité mutuelle entr'eux n'étoit pas noins admirable. Il n'arrivoic aucun Chrétien d'une autre Eglife, qu'on n'envoyât quelqu'un pour le recevoir, quand on étoit averti de fa venué; l'Eglifétoit toujours le lieu, ou on le conduifoir d'abord, \& jamais on ne le lailloit alier a l'auberge: tout l'embarras de ce Voya. geur, \& encore plus des Mifionnaires, étoit pour fe déterminer entre tous ceux, qui vouloient les polícer. C'eft Louis Almeyda, qui nous intruit de tous ces faits, dont il avoir une connoillance d'autant plus parfaire, qu'aucun Mintoninaire n'a plus lonvent que lui parcouru tous les endroits du Japon, oi l'Evangile a pénétré de fon tens. Les Letres, par leliguelles il rend compte á fes Supérieurs de l'śtat, où il tronvoit les Eglíes qu'il vinitoit, font remplies d'un grand nombre de traits, que je lupprime avec regret, maisil m’a paru núcer fiara de le fuivre dans fon voyage.

De Firando, ce Millionnaire entra dans le Saxuma, \& palla par la Forterefle d'EkaN-difporition it

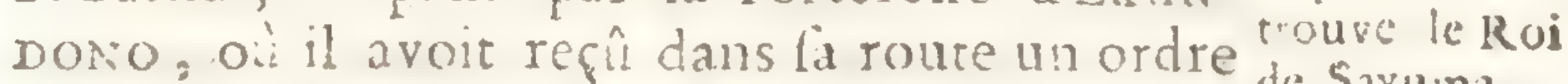
précis de ie rendre incellamment. C'ćtoit au comir de l'-lyver, \& il trouva en muelyues endrois les chemins tellement bouchés, que pour avancer, il luifalloit touvent abatre la neige ave des pics, comme on fair en queloues endroits des Alucs. Il fut furpris de voir la mai- 


\section{I74 HISTOIREDU JAPON}

fon d'Ekandono prefijue toute Chrérienn*;

De T. C. nuais il ne s'y arréta point pour lors, parce quall I $\{1$. ćtoit prefié de fe rendre a angoxima, Il apprit,

De Sy:- Miu en arrivant dans cette Ville, que le Roi de Sa2221 . xuma y ćtoit, \& il alla le trouver, pour lui ren. ye une Lette du Pere de Torrez. ce Prince reçu la Letre avec toutes les margues d'une parfaite eftinse pour la Perfonne du Supérieur, \& fit beancoup d’amitié a Almeyda. Le Miffromnaist voutut profiter de ce favorable accueil, pour infpiser au Roi des penfées de falut; mais il s'apperçut bientôt quil parloit $\mathrm{cn}$ vain, \& que cel'rince pouvoit, s'il ćtoit bien ménagé, devenir favorable au Chriftianifine, mais qu'il ne éroir jamais Chrétien.

De Cangoxima, Louis Almeyda palfa à un autre Port nommé TOMARIN, ol le Navire d'Emmanuel de Menúoze étoit encore mouillé, $\&$ il remit a ce Capitarne deux Letres, dont le Roi de Saxuma l'avoit chargé. L'une éroir pour le Vice-Roi des Indes, \& l'autre pour le Jrovincial des Jéluites. Il prioit l'un \& lautre de choifir fes Etats pour y ćtablir le Commerce des Pontugnis, \& il leur offroit mic Maifon, pour y fixer le fcjour ordinaire du Supérieur de la Mifion. De Tomarin, Almeyda retnuma à Cangoxima, oí il vifita tous les Chrétiens, \& les trouva tels pour la ferveur, mais en bien plus grand nombre, que l'Apôtre des Indes ne les avoit hillés. De leur côté, ils profiterent de la préfence du Millionnaire en Gens, qui avoient une faim extrême du prin de la divine parole, \& Almeyda baptifa un grand nombre de perionnes, parmi lefouelles it y avoit deux Seigneurs, parents ou alliés du Roi, avec toutes leurs famil- 
les. Enfin, avant que de paxtir de ce Pore, il eut la confolation dy voir une Eglife báme au vrai Dieu.

La patience, la fidélité, la vertu, \& le zéle de ces Chrésiens pour le fervice ce leur Souverain, dont ils lui avoient donné plufieurs preuves ćclatantes, avoient charmé ce Prince, \& lui failoient foubaiter que tous fes Sujets embraffallent une Religion li famte. Almeyda eut le bonheur de recucillir les fruits de cette bonne volonté du Roi, \& ne trouva aucun obftacle aux defleins, qu'il forma pour rendre de plus en plus cette Chrétienté florillante. Il vilita aufi les Bonzes qui furent charmés de fes bonnes maniéres; \& une cure confidérable, quil fit fur la Perfonne d'un de leurs "Tundes, acheva de les lui gagner tous: quelques-uns móme demanderent le Baréne; mais comme ils déclarerent, qu'ils ne pourroient fe difpenfer d'aflifer aux Funćrailles du Plince, s'ilvenoit a mourir, \& d'y faire leurs fondions, il ne les bapria point. Enfin rien ne l'arretant plus à Cangoxima, il retourna chez Ekandono, comme il s'y écoit engagé, \& il apprit en y arrivant la more du Vieillard, que le Pere Xavier avoit chargé du foin des Chréciens de ce Château.

Avant ane de fonger a lui donner un Succofienr, it voulut connoirre par lui-même tous cenx, ui compofoient ce petit Trompeau, \& queloue prévenu, qu'il fì en leur faveus fur le bruit public, il trouva qu'on n'en difoit pas encore allez. Il vojoit des Femmes, des Enfans, des Soldats, des Domeftiques, qui n'avoient jamais vî de l'rêtre, qu'une feule fois en pafant, dams lexercice familier des plus 


\section{I76 HISTOIRE DO JAPON,}

fublimes vertus du Chriftianifine: tous s'a-

De T. C. donnoient à l'Oraifon, a la pénitence, \& à 1j61 62. toutes les bonnes ne!!y res, dont ils potivoient $D$ : Sy:-Mu. trouver l'occafion; ils fe reciroient le plus lou2231.22. vent qu'il leur étoir polfible, dans une forêt voifine, \& y reftoient plulieurs jours de luite uniquement occupés de Dieu \& de leur faint; d'oul il ćroir aifé de conclure, gue le Saine Efprit, au défaur des Hommes, avoit été leur Maitre dans la Science divine. L'éclar d'une fi grande fainteté avoir fair prefgu'autant de prolélytes, qu'il éroit refté d'Infidéles dans certe Forterelle apres le dépare du l'ere Xavicr, \& Almeyda les trouva fi bien infiruits, qu'il les baptifa tous. Il nomma enfuite pous préfider aux Exercices de Religion, le Fils du Seigneur même, \& il lui allocia un jeune Homme, en qui il avoit remarqué un grand efprit, \& beaucoup plus encore de ferveur.

Ce Nćophyte compolí pau de iems après un for bel Ouvrage, quifur d'une grande utilité à torke l'Eglife da Tapsiz. C'éroit un abrécé de l'Hiltoire Sainte, depuis la crćation du Monde, jufguà la Réfurection de Jefus-Chrift. Les foufrances \& les opprobres de la Pallion de l'Homme-Dien y étolent furtout reprélentćes d'uise manićre fort touchante; auli ne pouvoit-on entendre l'Autcur parler furcete matiere, qu'on ne le fentit le conr canbrafé des fammes de lamour cúlefre. Yn jour que Almeyda, aprés lni avoir raconté les perfécutions, que l'Eglile avoit fouffertes a fa nailfance, Ini demandoit ce ju'il feroit, fuppofé que le Roi fon Sonverain lui ordonnat d'abjurer le Chrifianifine, c Voici, dit-il, ce que je lui $\rightarrow$ répondrois. Scigneur, voulez-vous que je 


\section{LIPRE SECOND:}

" vous fois fidćle, \& que j’aye toujours toute s la foumiffion, qu'il convient a un Sujet s d'avoir pour fon Roi? voulez-vous que je " témoigne du zele pour votre fervice dans De Syn-Mu. " les occafions, où je pourrois vous être utile, $2221-22$. $\leadsto$ \& qu'aucun intérêt particulier ne me falle " jamais oublier ce que je vous dois ? voulez$\rightarrow$ vous que je fois doux, modéré, complai" fant, plein de charité envers mes ćgaux; "que je fouffre avec patience tous les mau» vais traitements qu'on me fera? ordonnez" moi donc de demeurer Chrétien; car il n'y $s$ a que d'un Chrétien, qu'on puille raions) nablement attendre tout cela.

Parmi tant de fujets de confolation, une chofe aftligeoir fenfiblement le Miflionnaire. Ekandono ne pouvoit fe déterminer à le faire Chrétien, quoigu'il fût perfuadé de la vérité du Chriftianifine, qu'il l'aimât, \& qu'il prit un plaifir fingulier a en entendre parler. Almeyda n'omit rien pour le toucher; mais un jour, quil le prelloit extraordinairement, il en reçut cette réponfe. « Le Dieu du Ciel, que "vous me prêchez, \& que je reconnois pour s le feul vrai Dieu, m'eft témoin que mon " cocur l'adore, \& que fa Loi y elt graree; »\& ins cela aurois-je permis a ma Famille, " \& même au moindre de mes Sujets de l'em$\Rightarrow$ brafler ? mais vous ne fçavez pas les mefu. "res, que je fuis obligé de prendre avec la s: Cour de Saxuma. Vous croyez, parce que s le Roi vous fair bon vifage, qu'il voir de $\leadsto$ bon ocille progri's de votre Doctrine: vous "vous trompez: ce Prince ne s'embarrafte a pas beaucoup de ce que fair le Peuple, parce " que fes dómarches ne tirent pas à conica Tume $I I$. 


\section{HISTOIRE DU JAPON;}

L. J.C 1 jo2.

I. Syn - Mu. 2222.
Dififinen ric lat lincifunté d'Cusuda.

"quence, \& que fon attachement à votre Res ligion peut attirer les portugais dans fes s Ports: ainfil la tolere, \& fait même lem» blant d'être bien aile qu'elle s'établille parmi o les Gens du commun; mais il s'en faut beau\coup qu'il loit dans les mêmes difpofitions » par rapport a la Noblelle. J'elpere toute$\gg$ fois de la Bonté divine, qu'elle fera naitre $\Rightarrow$ le moment favorable, auquel je pourai, s fans aucun rifique, ne rien déguifer de mes s véritables lentiments s. Le Millionnaire vis bien par ce difcours, qu'il étoit inutile d'in. frfter davantage. Il pirt congé de ce Seigneur, \& partir pour le pays d'Omura, où il venoir de recevoir un ordre du Pere de Torrez de íe rendre incellamment. Nos Relations ne difent plus rien depuis ce tems-la du Seigneur d'Ekandono.

La partie la plus occidentale du Ximo fe divife en quatre pointes, qui avancent confidérablement dans la Mer, \& peuvent étre regarcíes comme quatre féninfules. Celle gui regarde le Nord, \& plulieurs petites Ifles, qui en font fort proches, compolent la Princifauté d'Omura, dont la Capitale, qui porie le même nom, \& qui vraifemblablement le lui a donné, eft firuce dans le fonds d'une Baye, fur le tord de la Mer, où il y a un trés-bon Port, dont nous parlerons bientôt, \& qui n'étoit pas alors fort connu. Ce petit Ftat eft de la lrovince de FIGEN, auff bien que le TACACU, ou le Royaume d'ARIMA, celui de Firanio, \& celui de Gotto: il a mêne toujours rélevé du premier de ces Royaumes, qui eft le plus confiderable des trois. Auff les Princes d'Omura n'ont-ils jamais pris 


$$
\text { I I R E S E C O N Di T T9 }
$$

le titre de Roi, pas même dans le tems, que plufieurs conquétes allez confidérables, \& l'ćtablillement du Port de Nangazaqui, dont ils ćtoient les Maîtres, les eurent rendu aulli riches, \& aufi puilfans, que la plûpart de ceux, qui le portoient; \& c'eft a tort que quelques Auteurs le leur ont donné, puifqu'il ent certain, qu'ils n'ont jamais cellé d'être Valfaux des Rois d'Arima.

SUMITANDA, qui gouvernoit alors ce petit Pays, étoir fils puiné de Xengandono Roi Pasactere de d'Arima, \& avoit reçu de la nature toutes les qualitez, qui attirent le relpeot $\&$ l'amour des peuples. Comme il n'avoit pas été élevé dans l'efpérance de régner, il n'avoit paru d'abord en lui qu'un Sujcr foumis, non-feulement aux volontez du Roi fon Pere, mais cncore à l'ćgard de fon Frere ainé, après que Xengandono eut abdiqué la Couronne en faveur de ce jeune Prince, comme cela fe pratique allez fouvent au Japon. La valeur de Sumitanda failoit le foutien du Royaume, \& ne donnoit point diombrage; fa bonne mine, une certaine popularite noble, fon humeur douce $\&$ bienfaifante, fes manieres \& fon air affables le rendoient les délices du Peuple, \& ne caufoient point de jaloufe au Souverain. Un l'rince de ce caractere n'étoit pas né pour être toujours fujet. Le Seigneur àOmura, qui étoit proche parent du Roi d'Arima, mo:lrue fans laiffer d'autre Enfant, qu'un Fils naturel, qui fut jugé incapable de lui fuccéder. La Princeffe veuve adopta Sumitanda, \& au grand contentement de tous fes Sujets le déclara Prince d'Omura. Le changement de fa fortune n'en fit aucun dans fa Perfonne, il foutint $\mathrm{H}$ ij 


\section{ISO HISTORRE DU JAPON;}

dans fa nouvelle dignité l'opinion, qu' Jn avoit

De J. C. conçe de fon mórite, \& il gouverna arec tane I 50 .

De sinn-Niu auroit pû trouver un P'ri: ce, qu aimât plus 222. Tes Sujers, nides Sujers, qui fullent plus arfectionnés à leur Prince.

I! 'onge à Il y avoit environ douze ans, que Snmitaneminarer le da étoit Prince d'Onura, lorfqu'il lui tomba Cirsulianifme. par hazard entre les Mains un Livre compofé par le P. Vilela, où la vérité de la Religion Chrétienne ćtoit nettement expliquée, \& folidenent prouvéc. Il le lut âvec aitention, \& fe fentit fortement porté à embraffer le Chrifianifme. Pour ne point agir avec précipitation dans une Affaire de cette importance, il fouhaita de conférer avec quelqu'un des Religieux Européens, \& comme il ne vouloit point découvrir fon dellein, il propofa à fon Confeil d'attirer dans fes ports les Vailleaux Bortugais. Il exaggéra l'utilité, que fes Etats pourroient tirer de ce Commerce, \& ajoûta, que le meilleur moyen d'engager ces Marchands à hui donner la préférence fur tous les autres Princes du Japon, ćtoit de leur offrir de pius grands avantages, quion ne leur en faifoit ailleurs, \& furtout de donner aux Miniftres de leur Religion un Etabliffement dans les Terres.

Il attire des Ce projet fut univerfellement applaudi, \& Téluicus \& lés le Prince en domna aufli-tôt avis au Pere de Purugrasdans Torrez, lui manda que le Port de Vocoxiufintiats a ditian

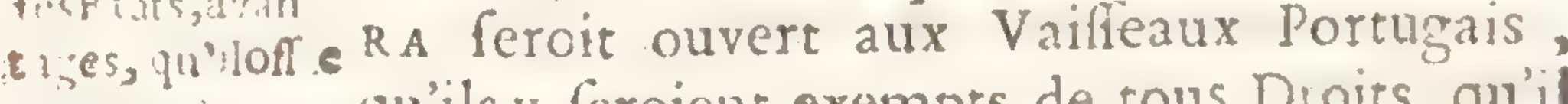
accuáci. gu'ils y feroient exempts de tous Droits, qu'il leur cúcieroit toutes les Terres, qui font à deux licués à la ronde; qu'il y auroir me Maifon four les Mifionnaires, \& qu'aucun 


$$
\text { L I Y R E S S C O N D. } 18 \text { I }
$$

Idolâtre ne pourroit s'y ćtablir fans leur confentement. Le Supérienr n'avoir garde de né- a De T. C. gliger une fi belle occafion d'étendre le Rogaume de Dieu. Il n'eut pas plutôt réçu la Lettre du Prince, quil cirivit à Almeyda de le r ranfporta à Omura, \& Iui envoya toutes les infructions, dont il avoit befoin, pour trai. ter avec Sumitanda. Ce fut ce qui obligea ce Religieux à quitter plutôt, qu'il n'auroit touhaité, le Royaume de Saxuma.

Cependant le Roi de Firando eut le vent de ce qui fe projettoit à Omura, \& réfolut de ne rien omettre pour en traverfer l'exécution. Dans cette vîé, il écrivit une Lettre très-obligeante au P. de Torrez; il le prioit d'oublier le palfé, d'être bien perfuadé que tout ce qui ćtoit arrivé, s'étoit fait malyré lui, quil étoit toujours dans les mêmes fentiments à l'égard du Chriftianifme, où il avoit paru d'abord; que la feule nécellité des Affaires l'avoit obligé de les diffimuler pour un tems, \& que s'il vouloit lui envoyer quelqu'un de fes Religieux, il connoîtroit par la maniere, dont il en uleroit avec lui, combien fincerement il entimoir la Religion Chrétienne, \& le cas quil faifoit de ccux, qui la préchoient. Le Supérieur n'étoit pas en état de faire ce que fouhaitoit ce Prince, altuel il ne croyoit pas d'ailleurs devoir beaucoup fe fier: il lui fit néanmoins une Réponle honnête, \& l'allura, qu'aufli-tôt qu'il auroit reçû un renfort de Milfionnaires, qu'il attendoit des Indes, il feroit tout fon poffible pour le fatisfaire.

Je ne fçais ce qui étoit arrivé dans le Chicugen, depuis la Rérolution, qui aroit sait H iij

Le Roi de Firando, putrs travertia ie projut, faitre gralidis uficics all P. dir Tur 1220 


\section{I.82 HISTOIRE DU TADON,}

De J. C. a peu près dans le tems, dont je parle, la I 562 . 2222. Le Supćrieur n'avoit alors auprès de lui qu'un jeune Jéfuite nommé Damien. Il le fit partir fur le champ avec un Catéchifte pour $\mathrm{Fa}-$ cata, \& ils y furent très-bien reçûs. Damien avoit du talent pour gagner les cocurs; en moins de deux mois il baprifa plus de cens perlonnes de marque, \& un très-grand nombre de Gens du commun, Il auroit même poullé fes Conquêtes plus loin, fi la difette d'Ouvriers êt permis au P. de Torrez de le lailler plus long-tems dans cette Ville.

Defcription Pendant toutes ces Négociations \& ces du Port de nouvements, Almeyda fe rendit à VocoxiuVocosilita. ra, \& vifita ce Port, dont il fut extrêmement fatisfait; c'eft en effet un des plus beaux \& des plus grands da.Japon; il a deux lieués de circuit, \& dans cette grande ćtenduë il y a quantité de pointes de Terre, \& de Rochers, qui forment un grand nombre de petits Havres, tous à l'abri des Vents; outre qu'à l'entrée du Port il y a une petite Ine, qui en garantit les Navires, \& qui rompt les vagues de la Mer. On avoit alluré au Miffionnaire que le prince d'Omura étoit dans ce Port, mais il ne l'y trouva point, \& au lieu de l'aller chercher à fa Capitale, où il y avoit route apparence qu'il étoit, il jugea plus à propos de pouffer jufqu'à Fucheo, pour s'y aboucher avec le P. de Torrez, qui fur le champ le renvoya dans la Principau:é d'O. mura avec Fernandez.

Almeida eft Les deux Mifionnaires partirent de Fut 


\section{LI $T R E$ SEC O N D. 183}

cheo le cinquiéme de Juillet de l'année is 62. \& arriverent en peu de jours à Facata, où Femandez relta queloute tems. Le vent étant D. I. C. 1 j62. bon pour aller à Vocoxiura, Almeyda s'y ren-De Syn-Mín. dit en peu de tems, mais il n'y trouva point 2222. le Prince, lequel ćtair à quinze lieuës de cet- tien tecû du te Ville. Il l'y alla chercher, \& il en fut re-Pincci'on:ȩu avec une bonté, dont il crut fe devoir tout ra, qui fait uux promettre. Ce Prince le fit affeoir à fon côté Prortugais une \& l'invita deux fois à manger avec lui. Il conceition du donna aufitôt fes ordres pour faire drefler les cusiura.

Patentes de la Concellion du Port de Voca. xiura fur le pied, qu'il l'avoit propolé, \& recommanda exprellément, qu'on n'y mit rien, qui ne fut approuvé par le Miffionnaire, lequel de fon côté ne voulut rien faire de fon chef, \& envoya le Projet au P. de Torrez.

Le Prince eut enfuite quelques Conféren- Lc Prince y ces avec lui fur la Religion, \& lui propofa donne auii quelques difficultez, qui lui étoient furvenuës une Maron \&

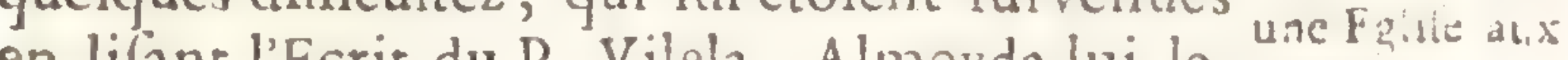
en lifant l'Ecrit du P. Vilela. Almeyda lui le- Jéfuitis. va d'autant plus aifément tous fes doutes. qu'il avoit affaire à un Prince, cont le cocur étoit touché, \& qui avoit l'éṕprit droit. Cela fait, il partit pour Vocoxinra, \& Sumitanda lui donna un Gentilhomme Chrérien, Frere da Gouverneur d'Omura, pour l'accompagner $\&$ l'aider à commencer létablifiement, dont on ćtoit convenu. Dès qu'ils y furent arrivez, ils mirent les Ouvricrs en ocurre, \& l'on ent bientôt dreflé une Chapellé propre, \& une Maifon de Bois de Cédre, qui eft fort comnoun en ce Pays-là. Almeyda fe difpofoir à y faire fes Fonctions, lorfqu'il fut fort lurpris de voir arriver le P. de Torrez; voici yuelle fui l'occafion de ce Voyage. 


\section{HISTOIRE DU TAPON;}

Le Roi de Firando eut à peine fait au Su-

De J. C. périeur Général les offres, que nous avons 1562. vûés, qu'un Navire Portugais ćtant vena De Sin-Mu. moüiller dans fon Port, il fe repentit de fes 2222. avances, \& dit publiquement qu'il n'étoit r. P. de point en peine d'avoir les Vaiffeaux d'EuroTarrez arrive pe dans fes Etats; que fon Port étant le plus dans ce Port. commode du Japon pour eux, ils le préféSujt de fon reroient toujours aux autres, de quelque mavoyage. niere qu'il en ufar avec les Chrétiens; que ce n'étoit point à cela, que regardoient les Marchands de Porrugal; puifque, fi cette confidération eût eu quelque pouvoir lü eux, on n'auroit dú les voir jufques-là, que dans les Ports du Roi de Bungo, Protecteur déclaré de leur Religion, où on ne les voyoit pourtant prefque jamais.

Ces difcours, qui furent rapportez au Pere de Torrez, \& même à la Cour de Bungo, acheverent de faire connoître ce Prince, \& le démafquerent plutôt, qu'il n'auroit fouhaité. On jugea donc que pour l'Honneur de la Religion, \& pour celui de la Nation Portugaife, il falloir engager le Capitaine du $\mathrm{Na}$ vire, gui étoit dans le Port de Firando, à fe retirer ailleurs, \& le P. de Torrez partit fur le champ, pour faire exécuter lui-même catte réfolution. Le Roi de Firando fut furpris des Honneurs, que le Capitaine rendit au Miffonnaire a lon arrivée fur fon bord, mais il le fut bien plus encore, quand il apprit que le Vaifleau avoit levé les Ancres, \& que le Capitaine avoit déclaré en partant quil ne pouvoit demeurer dans un Pays, ot l'on maltraitoit ceux, qui profelloient la même Re-ligion que lui. Il prit en eflet le Chemin de 


$$
\text { L I R R E SEC O I D. I? }
$$

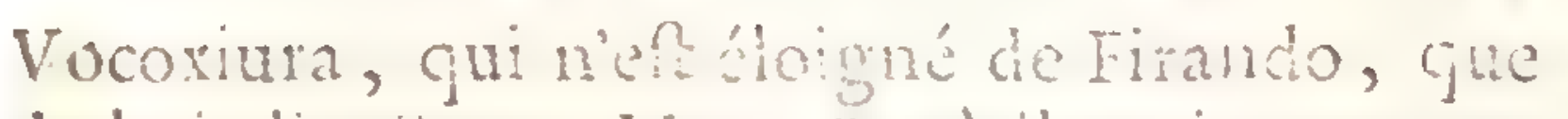
de huit lieues par Mcr, ó oti il arriva en peu d'heures.

Quantité de Chrétiens de Firando fuivirent de près le Supérieur à Vocoxiura, \& tous les jours il en arrivoit de bien d'autres endroits,méme des Royaumes lesplus éloignés, \& plulieurs s'y fixerent dans l'efpérance que ce Port alloit devenir le centiv vu. Port alloit devenir le centre du Commerce, cusidia. \& le principal Etabliflement des Miffionnaires. Par-là Vocoxiura, qui peu de mois auparavant n'avoit que quelques Cabannes de Ṕc. cheurs, prit la forme d'une jolie Ville, \& le D. de Torrez, qui avoit envoyé Almeyda tenir la place à Fucheo, fut ob'igé d'appelle. Fernandez à fon fecours. Quelques Aftaires le contraignirent peu de rems apris de faire un Voyage dans le bungo, \& il vifita chcmin faiint plufieurs endroits, ou il y avoit des Chrétiens \& des profćlytes en grand nombre, qui Coupiroient après le Baptéme: il l'adminiftra à plufeurs, \& ayant réglé les Aftaires, qui lui avoient fait quitter Vocoximea, il retourna dans ce Port, auquel il donnale nom de Notre-Dame de Délivrance.

Le Prince d'Omura ćcoit toujours à l'extrénité de les Etats, au des Affaires imporrantes demandoient fa prélence. Enfin la leconde femaine du Carêne, il fe rendit à Vocoxiura avec un trés-grand train. Dís q': le P. de Torrez en fut averti, il alla en cérémonie lui rendrefes devoirs acco nogryé des fruncipaux Portugais, \& le pria de lui faire l'honneur, que le Roi de Bungo lui failoit to'ss les ans, de venir manger chez lui le jour, qui lui feroit plus commode. Sumiran- 


\section{Y8. HISTOIRE DU JATON;}

da lui répondir, que ce feroit pour le lende. ne j. C. main. Tout s'y palfa de maniere, qu'on ne $1 ; 62$. donta point que ce Prince ne fít Chrétien De Syn. Mu. dans le cocur. Il fut fervi à Table par les 2222. Officiers Portugais, \& fuivant le Cérémionial de la Cour de Portugal. Après le Repas il voulut avoir un entretien en particulier avec le $\mathrm{P}$. de Torrez, qui le conduifit à l'Eglife, \& ils y demeurerent long-tems enfermés, n'y ayant avec eux, que le feul Fernandez.

E: Prince Le Prince leur dit d'abord, c je fuis venu comira rén ici, mes Peres, pour vous eritendre parstuminé à e. s ler de votre Religion. Regardez, je vous cruvirle bap. :ence, ce qui " prie, mon cour, comme une Terre bien di fait diféser. ss préparée, ne craignez point d'y répandre $\leadsto$ la femence de la parole Divine; j'efpere, »quavec le fecours du Ciel elle y fructifie» ra. Au refte man intention n'eft pas d'en » borner les fruits à moi feul, je compte bien de les ćrondie à tous mes Sujets. cr On peut juger de la joye, gue caula aux Miffionnaires une décharation fí précife. Le P. de Torrez pria le Prince de tronver bon que Fernandez, qui parloit beaucoup plus aifément que lui la Langue lapomnoile, lui expli juât nos principaux Myfteres, \& Sumitanda y confentit. Fernandez fit un difcours, qui, quoique fort long, fut écouté du Prince avec beaucoup de plaifir \& d'attention; il ne for interrompu, que par la nuit, qui furvint; mais un Tableau de la Vierge tenane fon Fils entre fes Bras, Gilon avoit mis fur l'Autel, l'occupa encore quelyue tems, \& lui donna occafion de faire plufieurs Queftions fur les Myfteres de l'Incarnation du Verbe, a de la Rédemption des Hommes. Il ue 
I. i V RE S ECOND. I87 pouvoit détourner les yeux de dellus cerce Peinture, \& il lui fembloit que le célelte Enfant lui tenoit au cour un langage, qu'il n'entendoit pas encore bien; mais qui le remplilloir néanmoins d'une vériable joye. Un Eventail, que le P. de Torrez prit ha li$D:$ I. C. Is 62 .

De Syn-Mu. 2222. berté de lui prélenter, \& fur lequel il y avoit une Figure de Notre-Seigneur, \& plufieurs Repréfentations des Mylteres de fa Vie, donnerent encore lieu à bien des demandes; \& les réponfes, que lui fit Fernandez, le fatisfirent parfaiteinent. Enfin il étoit minuit, lorfyue le Prince fortit.

Le lendemain il envoya au $P$. de Torrez le Frere du Gouverneur d'Omura, pour lui dire de fa part qu'il ne lui reftoir plus aucune difficulté fur tout ce que Fernandez lui avoit expliqué, qu’il étoit Chrétien dans le cour , \& qu'auffítốt que Dieu lui auroit donné un Fils, il fe feroit baptifer; mais que s'il faifoit une démarche d'un fi grand éclat, avant que d'avoit un Héritier, elle pourroit exciter de grands Troubles dans fes Etats; que cependant il le prioit de trouver bon: qu'il portât une Croix fur fa poicrine. Cette action n'éroit guéres moins capable de produire le mauvais effer, que ce Prince craignoit, s'il recevoit le Baptéme; mais fon cocur écoit pris, \& il n'étoit plus le Maitre de les mouvemen:s. Ce Prince partit peu de jours après pour Omura, oil il fit faire unc Croix d'or, \& non-feulement il parut en public avec ce figne adorable de notre Salut, mais il re montra même en cet équipage à la Cour du Roi d'Arima fon Frere. Ce Prince Iui demanda s'il étoit Chrérien ?. il répondit $\mathrm{Hvj}$ 


\section{I88 HISTOIRE D J J APON,}

mentil ne l'ctoit pas encore, mais qu'il le feDe I. C. roit, dès que le Ciel lui auroit donné un Fils. 8j62. Il lui parla enfuite avec tant de force de la Do Syn-Mu. Loi du Dieu des Chrétiens, yu'il lui fit nầ2222. tre le defir d'avoir des Milliomnaires dans fes Erats.

11 gagne le En effet peu de jours après deux GentilsRui "Alima, hommes arriverent à Vocoxiura avec des Ion wrere qui Letres du Roi d'Arima pour le P. de. Tordimande dis rez, par lefquelles ce Prince le conjuroit de Mi.lonnaires. lui envoyer un Miffionnaire. Le Supérieur vouloit y aller lui-même, d'autant plus que le Roi lin offroit dans le Port de Cochinotzu un Etabliflement pareil à celui de Vocoxiura; mais fa fanté ne lui permit pas de faire ce Voyage; \&. Almeyda, gu'il avoit rappellé depuis peu de Fucheo, ent ordre de partir pour la Cour d'Arima. Le Mifionnaire ne perdit point de tems, mais il trouva tout le Royaume en Armes, \& le Roi fur le point de fe mettre à la Tête de fes Troupes. Il eut néanmoins quelques converfations avec ce Prince, qui lui parut bien difnofé, \& trèsdocile: il en obtint toutes les Patentes nécelfaires pour l'Etabliflement de Cochinotzu, \& des ordres au Godverneur, pour y faire bâtir une Eglife au vrai Dieu, \& une Maifon aux Miffionnaires. A'meyda à Muni de ces piéces, il prit congé du Roi,
imathra, où partit pour Cochinotzu. Le P. de Torrez il trouve tout lui avoit fort recommandé de paffer par XIle nuode dif- MABARA, Place forte, qui appartenoit à un pute a fe faire Prince Vaffal \& Beau-Frere du Roi d'Arima.

Ce Prince n'avoit pú apprendre les changemens prodigieux, gu'opéroit partout la Religion Chréticme, fans concevoir un très. grand 
defrr de s'en inftruire: il en écrivit au P. de Torrez, qui chargea Almeyda de lui rendre vifice, en allant a Cochinotzu. Almeyda alla defcendre au palais, où il fut retenu à fouper. Après la Table on le mena dans une grande Salle toute remplie de Noblelle, \& quoicyu'il fût extrêmement fatigué du Voyage, il fallut qu'il parlât jufques bien avant dans la nuit. Le fruit de ce premier difcours fut un Refcrit du Prince, qui exhortoit fon Peuple à fe faire inftruire de la Religion Chrćtienne, \& à l'embraffer. Le Miffionnaire trouva les Sujets aufi-bien difpolés que leur SeiGneur; \& quoiqu'il parlât trois fois par jour en public, il ne pouvoit encore contenter tous ceux, qui vouloient l'entendre en particulier. Ses travaux ne furent pas infructueux; quantité de Gens de tout âge \& de toute Condition fe dćclarerent Chrétiens; furtout apris que la Fille unique du Prince, laquelle n'avoit encore que quatre ans, eût été baptif́ce avec toute fa Maifon.

Almeyda cât bien fouhaité, quil lui fût permis de faire un plus long f́́jour à Xima- ville de Co. bara; mais il apprit qu'on ćtoit fort inquiet chinotzu dani à Cochinotzu, de ce qu'il tardoit filong-tems les memes difà s'y rendre: il. s'y rendit donc; le Gouver-ponitions. neur le logea chez lui, \& fit aufí-tôt publier un ordre de la part du Roi, par lequel il ćtoit enjoint à tout le Monde d'affifter aux Inftructions publiques, qu'on alloit commencer. On obćit avec joye. Le Miffionnaire \& fon Catéchifte prêchoient tous les jours; l'un le matin, lautre le foir: outre cela, ils expliquoient au fortir du diner la Doctrine Chrétiemne aux Enfants. Jamais peut-être la Pa- 


\section{IgO HISTOIRE DU JADON,}

De role de Dieu ne fut reçûe arec plus d'avidí De j.C. té, \& ne fructifia davantage. En moins de 15562. quinze jours, le Gouverneur, fa Femme, les

DeSyn Mu. Enfants, \& plus de deux cents cinquante Per- 2222. Connes furent baptirés, \& au bout d'un mois toute la Ville ćtoit Chrétienne, ou fe difpofoir à l'être. La fuite fera voir que des converfions fi promptes n'avoient point été précipitées. Cochinotzu eft un lieu délicieux, la Cour y paffoit en ce tems-là une bonne partie de l'année, ce yui y attiroit beaucoup de Nobletle, \& la plupart des nouveaux Chrétiens étoient des plus confidérables du Pays. Les Perfonnes de ce rang fe déterminent avec plus de précaution à faire une démarche de cette importanc, \& fçavent aufli bien mieux la foutenir, après l'avoir faite.

Zele du Vers ce même tems, c'elt-à-dire, pendant Princed'Omu la Semaine fainte, le Prince d'Onura resa pourlacon- vint a Vocoxiura, \& elut envie d'y faire bâtir verfion de fés an Palais pour lui, mais comme s'il n'eût
Sujers. plus été le Mâtre d'un lieu, gu'il avoit confacré à la Religion, il voulut en avoir l'agrément du P. de Torrez, \& il le lui envoya demander par fon fidéle L o u Is, c'étoit le nom quavoit reçu au Baptême le Frere du Gouverneur d'Omura. Le Supérieur de fon côté pria le Prince de faire publier dans fes Etats plufieurs Réglements de Police, qu'il jugeoit néceffaires; \& non-feulement il obtint ce qu'il demandoit, mais il fut ordonné à tous les Infidéles, qui demeuroient à une certaine diltance de Vocoxiura, de venir dans la Ville à certains jours, qui furent marqués, pour fe faire inftruire de nos divins Mytézes. Vers la Fête de l'Afcenfion le Pere de 
L T.VRE SECOND. TYY

Torrez fir le Voyage d'Omura, où il n'avoit point encore été, \& qui n'elt qu'à dix lieuès de Vocoxiura: il y fut reçu par ordredu Prince avec de grands Honneurs, \& il y-ob- De Syn-Mu. tint un emplacement pour bâtir une Eglife.

Peu de tems aprés la Princelle d'Onura parut enceinte, \& alors Sumitanda crut de- ce Prince \& voir dégager la parole, qu'il avoit donnće de dirente Genrecevoir le Baptêne, dès quil fe croiroit af- tilshommes. furé d'un Succelleur. Il en écrivit au P. de Torrez, mais il l'avertit, que comme il vouloit bien vivre avec le Roi d'Arima, fon Frere, il fouhaitoit d'avoir fon agrément. II ajoûta qu'il ne pouvoit pas entreprendre fitôt de détruire entiérement le culte des Idoles dans fes Etats, \& que les Bonzes, qui y ćtoient fort puiliants, devoient être ménagés avec beaucoup de prudence; que du refte, il ne nćgligeroitrien pour faire adorer partout, où il feroir le Maitre, le feul Dieu, qui a créé le Ciel \& la Terre, \& devant qui toutes les Créatures intelligentes doivent féchir le senouil. Le Pere de Torrez lui fit dire, qu'il ne pouvoit érre dans de meilleures difpofitions, \& le Prince n'eut pas plutôt reçû cette réponfe, qu'il partit pour Vocoxiura avec trente Gentilshommes, qu'il avoit gagnés à Jelus-Chrift.

Le Supérieur averti de fon arrivée; alla lui rendre fes devoirs, \& eut avec lui dans fon Cabinet une converfation, qui dura toute la nuit. Tout le jour fuivant fut employé à voir, fi les trente Gentilshommes étoient fuffifamment infruits; car, pour ce qui eft de leur fincérité, le Prince en avoit répondu, \& fur le foir, cous fe rendirent à l'Egli- 


\section{I92 HISTOIRE DU JAION,}

De J.C. 15162.

De. Syn - Mu. - 2222.

fe. Le Prince en y entrant fe profterna de: vant l'Autel, les trente Profélytes en firent autant à fon exemple, \& formerent comme un cercle autour de lui. Après qu'ils y eurent demeuré quelque tems en priere, le Miffionmare leur fit un petit difcours fur les fuites de l'engagement, qu'ils alloient prendre avec Dieu, \& le termina par une courte récapitulation des principaux devoirs d'un Chrétien. Il leur fit enfuite rćciter à haute voix l'un après l'autre leur Profeflion de foi; enfin ils leverent tous les Mains au Ciel, \& en cetie pofuie, ils reçurent le Sacrement de la régénération avec des fentiments de piété, qui tirerent les larmes des yeux de toute l'Aliftance. Le P. de Torrez donna au Prince le nom de BARTHELEMI, \& il n'eft. plus connu depuis ce tems-la dans les Relations Portugaifes, que fous le nom de Dom: Barthélerni.

Le prince Dès le lendemain il fut obligé de partir, met une Idole pour aller joindre l'Armée du Roi d'Arima, é piéces \& fon Frere, yui l'attendoit, \& malgré les réTrmple. folutions, quil avoit prifes de ménager fon zele, il éprouva bientôt qu'un cocur poffédé de l'Efprit de Dieu n'écoure plus rien, quand il s'agit des intérêts du Ciel. C'eft une coutume en ce Pays-là, de ne point fe mettre en Campagne, fans avoir rendu fes hommages à une célebre Idole nommée Manstem $(a)$, qui y eft regardée comme le Dieu de la Guerre. Lorfque les Troupes font affemblées, elles vont au Temple, où cette prétendue Divinité eft adorée fous la figure d'un Géant armé, le

(a) Quelques Relations le nomment Moristem, ìdutres MANIITLM. 
Cafque en têre, \& pour Cimier, un Coq déploy'ć, qui couvre prefigu'entierement le Calque de les aîles. En approchant du Temple, on déploye les Enfeignes, on mer bas les Arnes, \& on pratiyue plufieurs autres Cérémonies militaires mclées de fuperfitions.

Sumitanda prit à l'ordinare le chemin de la Pagode; on en fut furpris, car tout le monde fçavort quil avoir été baptifé la veille, mais l'ćtonnenient changea bientôt d'objet. Le Prince marcha jufqua" la porte du Temple Cans rien. témoigner de fon deffein : puis s'arrêtant tout à coup, il met le Cimeterre à la main, fair figne aux Troupes de n'avancer pas davantage, $\&$ entre feul avec fes Gardes dans leT emple. Là il commande, qu'on jetre l'Idole par terre, \& qu'on la tire dehors la corde au col; il fort luinême, \& à grands coups de Sabre il met la Statue en piéces, en difant: Combiende fois, Dieu fourd $G$ impuiffant, $m^{\prime}$ as-tu trompé? Il fit enfuite réduire en cendres le Temple \& planter une Croix fur fes ruines. Ce fut un. fpectacle bien nouveau, \& Sien confulant pour les Fićéles, de voir un Prince Néophyte, au fortir des facrés Fonts du Baptême, portant le faint Nom de Jefus, \& le Signe adorable de notre Rídemption fur fes Arnies \& fur fes habits, plus femblable au Chef d'une Religion. Milicaire, qu'au Général d'une Armée d'Înfidéles, brûler les Temples, \& abatre les Statǘs de ces mêmes Dieux, dont il avoit fouvent encenféles Autels.

Sumitanda ne borna point fon zele à ce coup d'ćclat, il entreprit la converfion de toutes fes Troupes; \& l'on voyoit avec admiration ce ic. prince au milicu du tmmulte d'un Camp, occupć ànftuire lui-méme fes Officiers, \& juf- 


\section{I94 HISTOIRE DU JAPON,}

qu'aux moindres Soldats, des vérités de notye

De J. C. Religion. Mais tandis qu'il faifoir l'office de 1562.

De Syn-Ma. Miftionnaire, il ne négligeoir point le de-

2228. voir de Génćral, \& le Ciel combattant d'un côté pour lui, tandis que de l'autre il fecondoit fon zele, il fit triompher la Religion, de l'Idolâtrie dans fes Erats, \& Dicu le fít triompher de fes Ennemis. De retour chez. lui après la fin de la guerre, qui fut terminée par un accommodement, dont le Roi de Bungo fut l'arbitre, il ne voulut plus garder ancune mefure avec les Infidéles, \& Con propre Fere fut le prenter, à qui il jugea à propos Il s'oppore de faire connoitre cette réfolution.

avec fermeté Ce Prince hailloit la Religion Chrétienne, à fon l'ere, \& n'avoit vû qu'avec un extrếme regret un de qui perlécuturt fes Fils l'embraller, \& un autre l'établir dans fon Royaume. Le parti qu'il prit pour contenter fa haine, fur de maltraiter ceux des Chrétiens du Pays d'Omura, qui tomberent fous fa main. Sumitanda réfolu de ne le pas fouffrir, tenta d'abord toutes les voyes, que fa prudence lui put fournir, \& que fa tendreffe \& fon refpect pour un Pere, qui avoit ćté fon Roi, lui luggérerent, pour lui faire prendre d'autres fentiments; mais quand il vit fes prieres \& fes raifons également inutiles, il paria plus ferme, \& dćclara à fon Pere, que les Chrétiens d'Omura étoient fes Sujets, qu'il Ç̧aroit ce qu'il leur devoit, \& l'obligea entin à les laiffer tranquilles. Il profita encuite du repos, que lui donna la paix, puur faire régner le vrai Dieu dans fa principauté. Ses indufries, pour gagner des Ames à Jefus-Chrift, étoient infinies; mais les exemples admirables, qu'il donnoit de toutes les Vertus Chrétiennes, doient encore plus cincaces, que fes difcours 


\section{I $Y R E$ SEC OND. TSS}

\& tous fes foins. Pour montrer à fes Sujets, ju'gu'a quel point il faut honorer les Miniltres du Dieu vivant, il ne parloit jamais au Pere de Torrez, qu'auparavant il n'eût quitté fes Armes. Il continua jufqu'à la mort à porter une Croix fur fa poitrine, \& toute fa Cour imita fon exemple en ce point. Chaque jour il donnoit à manger à cinq ou fix nille pauvres, $\&$ il fe croyoit honoré de les fervir lui-même; d'autant plus grand en s'abaillant ainf, que jamais Prince n'eut le cour naturellement plus haut, \& n'a fçû mieux fe faire rendre ce quilui étoit dû.

Une chole manquoit encore à fon bonheur; la Princefle fa Femme, appellée Camizama (a), l'avoit vî avec bien du regret quitter la Religion de fes Peres, \& fouffroit fort impariemment tout ce qu'il faifoit en faveur duchriftianifme; mais comme elie avoit un très-bon efprit, Sumitanda ne défefpéra point de la gagner; il fe chargea lui-même de l'inftruire de nos Myfteres, \& Dieu donna tant d'efficace à fes paroles, que la princeffe demanda le Baptêne. Il fut fi peu maître de la joye, qu'il en reflentit, qu'il partit auffitôt, pour en aller porter la nouvelle au Pere de Torrez, lequel en rendir fur le champ de folemnelles artions de graces au Seigneur. Le Serviteur de Dieu étoit bien perfuadé que le Prince d'Omura éroit fincérement Chrétien, \& folidement vertueux, mais il f̧̧avoit l'empire, que prend une Femme fur l'efprit d'uin Mari, quil'aime tendrem ment; \& l'exemple du Roi de Bungo, que la

Converfion de'a Princefle fa Femme.

De J.C. I 562 .

De Syn-Mu. 2222. 


\section{HISTOIRE DU JAPON,}

fienne retenoit dans l'idolátrie, le faifoit

De J.C. trembler.

1562. Cependant Almeyda ćtoit rerourné à Xima-

Desyn Mu. bara, \& cette Ville continuoit à donner de 2222. Violence des te Chrétienne. Les Bonzes furpris des rapides grandes efpérances, que bientót elle feroit touBonzeside Xi-progrès, qu'y faifoit la Religion, députerent mabara. au Palais les principaux d'entr'eux, qui avoient à leur tête un oncle du Prince, pour lui repréfenter le tort, qu'il fe faifoit, \& le danger, où il expofoit fon Etat, en y introduifant une Ioi nouvelle. Cette démarche fut fans effet, \& ils en firent paroître lin refientiment, qui auroit pû les porter à quelque extrémité fâcheufe, file Prince n'eût pris le parti de diffimuler. D'un autre côté, une conduite fi peu ferme, fit d'abord appréhender à Almeyda, que ce Prince ne fe réfroidit à l'ćgard du Chriftianifme; mais il reconnut bientôt que fa crainte étoit vaine, \& que les Bonzes n'avoient ni gagné, ni intimidé perfonne. Ils s'en étoient apperçus les premiers; \& n’efpérant plus aucune juftice, s'ils ne fe la faifoient eux-mêmes, ils abbattirent un jour toutes les Croix, que les Fideles avoient dreflćes en divers lieux, \& firent à ces Néophytes toutes les. avanies, dont ils purent s'avifer.

Ceux-ci peu fenfibles à leurs propres injures, fe crurent dans l'obligation de venger furces impies la Majefté divine, qu'ils avoient outragée; mais Almeyda les défabufa, \& leur perfuada de n'oppofer aux infultes \& aux facriléges entreprifes de leurs Ennemis, qu'une ina!tćrable patience. Le Prince, qui vouloit prévenir jufqu'aux moindres prétextes de révolte, fe joignit a lui pour calmer les Chrétiens, aul- 


\section{I $Y$ R E SECON D.}

quels il donna fa parole qu'il puniroit d'une maniere ćclatante tous ces attentats, dès gu'il le pourroir faire fans trop rifquer. Ils te continrent donc, les Bonzes en devinrent d"abord plus infolents; mais comme ils virent, qu'ils ne gagnaient rien, que le Miffionnaire alloit toujours fon train, que les converfions étoient de jour en jour plus fréquentes, \& que le Prince n'en paroilfoit pas moins attaché au Chriftianifme, ils comprirent que le plus sûr pour eux étoit de le tenir en repos, \& que s'il y avoit quelque chofe à efpérer encore, ils ne le devoient attendre que du tems, \& des occafions.

Alors le Prince fe déclara plus hautement, qu'il n'avoir encore fait; \& comme les Fideles n'avoient point d'Eglife, il leur céda un terrein très-avantageux \& très-agréable, pour en bâtir une, à laquelle il afigna un revent confidérable; elle fut bientôt achevée, parce qu'il n'y eut aucun Chrćtien, qui ne voulût mettre la main à l'auvre, \& le Seigneur ne dédaigna pas de témoigner par un miracle évident qu'il agréoit leur fervice, \& qu'il avoit choifr ce lieu pour y ĉrre particulićrement honorć. A peine l'Eglifé étoir achevée, qu'on y porta un Enfant moribond, pour $y$ ếre bapiifé, la Cérémonie ne fut pas plutôr finie, que ce petit Innocent, qui ne faifoit que de nilitre, levant les mains au Ciel, prononça diftinctement ces paroles, qui futenc ouies d'un grand Peuple: Je m'en vais jouir de Dieu; après quoi il expira.

Fin du Livre recond. 


\section{SOMMAIRE DU TROISIE'ME LIVRE.}

1. RRIVE de trois Miffonnaires au Japon. 1. Ferveur des Chrétiens du Bungo.Jufqu'à quel point le Roi de Bungo s'intéreffe au progrès de la Religion. Il ternine conme Més diateur une Guerre, qui retardoit ce progrès. Zíle du Frince d'Omura. Conspiration contre lui. Son Palais eft brûlé, E la Ville de Vocoxiura réduite en cendres. Guerre Jufcitée au Roi d'Arina pour l'empếcher de $\int e-$ courir le Prince d'Omura, fon Firere. Victoire miraculeuse de celui-ci. Danger, que courent quelques Miffonnaires. I es Chefs de l. Revolte Sunt pris Eu punis. Le Roi de Naugato aljége l'Empereur dans Meaco. La Ville elt forcée. Victoire de l'Empercur. En quel état Se trouroit alors cette Capitale. La Religion y devient floriffante. Crédit du P. Vilela auprès de EEmpereur. Efjort inutile des Bonzes pour faire proforire la Religion. Converfion d'un puiffant Bonze \& d'un Seigneur de la Cour. Converfon finguliere d'un autre Seigneur. Ferveur des Chrétiens du Firando. Fermeté de ceux de Ximabara, diont les Bonzes font empoifonner le Gouverneur. Le Roi de Portugal écrit alu Prince d'Onura. Particuliritez d'un voyage du Pere Froer, Er de Louis Almeyda à Meaco. Ferveur de deux jeunes Néophytes de Sacai. 
Honreurs, que fait aux deux Miflonnaires le plus Puifant Seigneur de l'Empire. Defcription de la Ville de Nara, E de trois Temiles. Zèle d'un Seigneur Chrétien. Converfion éclatante. La Religion en grand crédit à Meaco. Les PP. Vilela E Froez admis ì l'Audience de l'Empereur; ce qui s'y pafe. Lies mêmes ont Audience de l'Impératrice. Temple d'Amida, E plufieurs autres curicfiter. Temple du Roi des Démons. Maniere de prêcher des Bonzes. Mioxindono confire contre l'Empereur, E engage Daxanciono dans fa Rérolte. Faude démarche de l'Empereur. Le Beau-Pere de ce Prince Se fend le Ventre. Mort de l'Empereur. Fidélité d'un de Ses Pages. La Mere, la Femme, Es un Frere de ce Prince font mis d mort. Les Chefs de la Révolte épargnent un autre Frere de i'Empereur. Leurs violences. Fauies, quils font. L.es Millionnaires fortent de Meaco. Edit contre la Religion. Zèle du Roi de Bungo. Mort àunjeune Mifronnaire. Le Prince Antoine de Firando persécuté a coufe de Sa Religion. Violence du Roi de Firando. Il attaque le Prince domura. Sa flotte ef battue par les Portugais. Mort de Jean Fernandez, Es fon éloge. Deux Jéfuites font naufrage en allant au Japon. Mort du Prince Antuine de Firando. Aninal finguLier. Religion E caractere des Habitans du Gotto. Le Roi demande des Mifinonnaires, comment il les regoit. Il tombe malade. Les Bonzes entreprennent de le guérir, Eo ne réuflefent pas. Louis Almeyda eft plus heureux. Nouvel aecident, qui met la Religion en 
danger dans ce Royaume. Almeyda en Sore. Une Tempête l'oblige à y retourner, Es le Roi en témoigne une grande joye. Prngrès de Ia Religion dans ce Royaume. Guerre entre le Firando Es le Gotto. Belle action du Gouyerneur d’Ocica. Protection de Dicu fur les Chrétiens. Fermeté de cellx de Ximabara. Progrès de la Religion dans le Ximo. Activin de vigueur du Prince d'Omura. Martyrs dans le Firando.

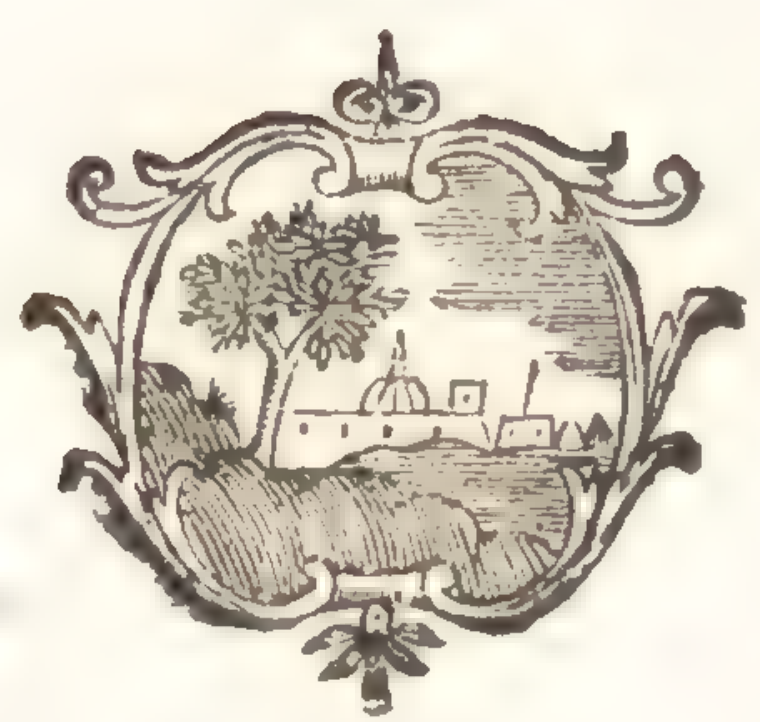



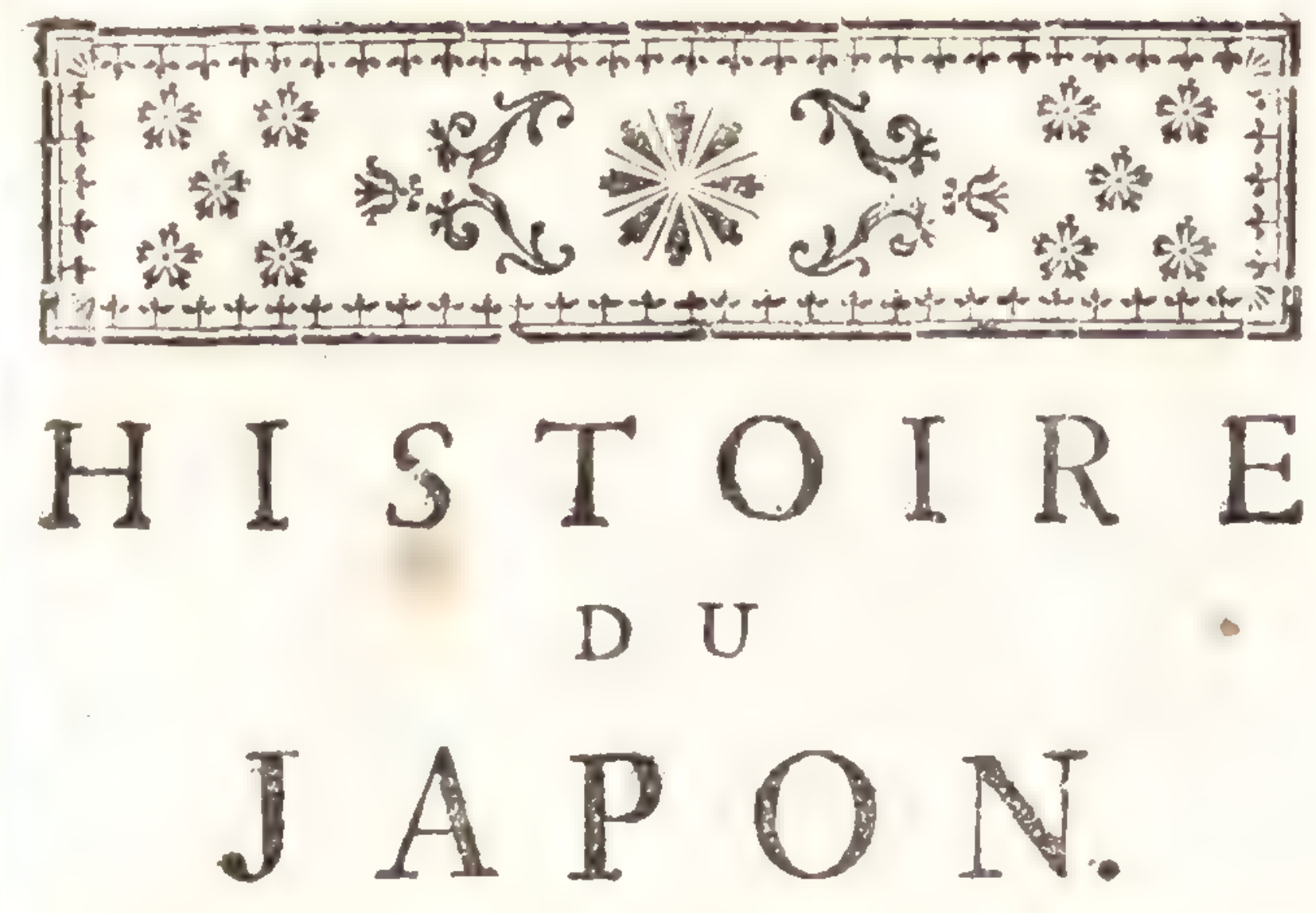

\%

\section{LIVRE TROISIEME.}

E Japon s'ouvroir ainf tous tes cours de plus en plus à l'Evangile; 1 L 1 mais la diete d'Ouvriers empê-

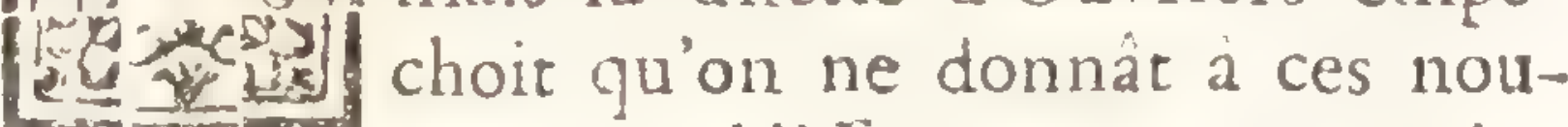
veasx Etabliffements une certaine folidité, \& qu'on ne proficât de la difpolition favorable, oúćcoient les Peuples, pour avancer l'auvre de Dieu. Enfin le fepriéme de Juil-

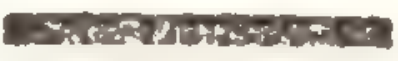
De 1. C. I) 13. De $\sin -\lambda l u$. 2223.

Arrives de trois nouyeaux Militunnaires. let i so 3 . il en arriva trois fort a propos, deux Prétres; à fçavoir, les Peres Louis Froez, Portugais, \& Inan-Baptiste Monti, Ferrarois; le troifiéme, qui n'étoit pas Prêtre, fe nonmoir Taceues Gonzalez. Le P. Froez s'écoir embarqué à Goa plufieurs années auparavant avec le Pere Nugnez, pour paller au Japon, ainfi que nous l'arons dit en parlant de l'Expédition du Vice-Provincial; mais ceIui-ci avoit écé obligé de le laifier à Malaca, pour y faire une Clalle. Quelque rems apres

Tome II. 


\section{HISTCIN DU JA PON,}

il reçut les Ordres facrés; \& comme il eut étó

Je J. C. une feconde fois deftiné a la Million du Ja-

:190;0

D. Syn 1 in pon, il profita, pour s'y rendre, de la pre2223. miere occafion, qui fe préfenta. Perfonne n'a rendu de plus grands fervices à cette Eglile que ce Religieux, auquel nous fommes encore redevables d'une bonne parrie des Mémoires, fur lefguels ont travaillé ceux, qui en ont écrit l'Hiltoire.

Ferrent des Quelques jours avant l'arrivée de co nouChrefiens cu veau renfort, le Pere de Torrez avoir cncore
Bungo. rappellé Almeyda à Vocoxiura: c'étoit pour l'enyoyer dans le Royanme de Bungo, ou les Fidéles ćtoient fans aucun fecours fpirituel depuis plus de fixmois. Ces fervens Néonhytes, qui pendant tout ce tems-là n'avoient puile confefler, \& qui craignoient d'oublier leurs péchez, les avoient mis pax ecrit. Ils frent plus encore; car les trois Religricux, dont je viens de parler, ćtant débarqués fur ces entrefaites, \& le Pere Monti ayanteu ordre d'aller avec Almeyda dans le Bungo, dés gu'on ent appris à Fucheo fon arrivće, it n'y eut pas un Chrérien, quine roulüt feconfencer a lui, quoiguil ne pêt les entendre, que par le moyen Jin Interprete. Lenr candeur, leur fimplicité, la vive donleur, dont ils éturent pénécrés pour les fautes les plus léçeres, \& l'efprit de pénitence, qui régnoit parmi eus, rout cela parut au nouveau Mifionnaire quelque chofe de in merveilleux, quil aroit de la peine à en croire les yeux.

Accueil que Le Roi de Bungo failoit alors prefigue toule Ruide Bun-jours fa répidence à Vostour, \& il s'y ćcoit go frit a dcus formé une jolie Ville, gui devint encore plus Mifiunaires. confidérable dans la fure. Le Pere Monti \& 
Almoyda y allerent lui rendre leurs devoirs, \& Civan leur fit l'accueil, qu'il avoit accourumó de faire aux Minitres de l'Evangile. Ce Prince f̧avoit déja en cúciéral ce qui s'éroit pallé au lujer de la Religion \& des Portugais

De T. C. 1 )

De Syn-iáu. 2223. dans la Principauté d'Omura, \& les progrès de la Foi dans les Provinces circonvoifines, \& voulut en apprendre toutes les circonltances; il fut touché du récit, yue lui en fit Almeyda.

A l'exenzple du Souverain, tous les Courtifans donnerent aux deux Reígienx de grandes narques de confidération; mais aucun ne maryucs de confidération ; mais aucun ne poine au propoint il sinteparloit de le faire Chrétien, parce que le Roi, gries de la $\therefore$ o gui ćtoit le Protecteur déclaré du Chrifianifne, \& qui s'intérelloir a lon établitement, antant que pouvoient faire les ivilonnaires némes, s'en tenoit là, \& ne domoit aucuir figne, qu'il pensât a allex plus loin. Les deux Religieux n'ayanedonc plus rien, qui les arrôtát a la Cour, retournerent à Fucheo, où le Roi les fuivit de près. Ils le prierent alors de vouloir bien honorer leur tiaión de fa préfence, comme il avoit fait toutes les années précédentes; \& non-feulement il le leur promit, mais il ajorta qu'il y meneroit un Amballadeur, que le Cubo Sama venoit de lui envovex, "s \& vous m'obligerez, leur dit il, de "lui faire les mómes honneurs, qu'à ma "propre Perfonne, afin cie l'engager par-là, $\Rightarrow 2$ favorifier vorre fainte Loi dans les occa"fions, ou vous pourriez avoir beloin de pro" tection a la Cour de l'Empereur.

Sur ces entrefaices ce Prince recut une Let- Il rermine tre du Pere de Torrez, qui lui mindoit, que comms $\mathrm{h}$. fans une fâcheule Guerre, ou le Roi d'Arima guere, Hi ta \& le Prince d'Omura fon Frerécroient engargés reidudut. 


\section{HISTOIREDO JAPON:}

Dé T. C. contre un puiffant Voifin nommé Riozogr: I j63, leur Parent, les Etats de ces deux Princes, feroient bientôt tous Clirétiens, \& qu'il étoịt

1) Syn-Mu. de la gloire d'un grand Roi comme lui, de 2223 terminer ce différend par une bonne paix, ainfi qu'il avoit déja fait l'année précédente dans une pareille occafion. Civan entra avec joye dans ce que lui propofoir le Supérieur, il écrivit ax trois Princes, pour leur offrir de nouveau fa médiation. Elle fut encore acceptće; on conclut une fufpenfion d'Armes, qui fut bientôt fuivie d'un Traité, où tous les lartis trouverent leur avantage; \& le Prince d'Omura de retour chez lui, \& débarrallé de toute autre occupation, ne fongea plus qu'à faire la guerre à l'Idclâtrie.

Ziledupriz- L'abolition d'une Fête pleine de folie \& de ce d'Omusa. fuperftition, qui fe célébroit tous les ans dans fes Etats en thonneur des Morts, \& qui e? précilément la même que j'ai décrite plus haur (a), fur le prenier effer de fon zele; mais parce que dans ces occafions on faifoit de grandes aumónes aux Bonzes, pour ôter à ces faux Prêtres tout prétexte de publicr que c'étoit par avarice, qu'on abolilloit ces pratiques, il fit diftribuer aux Pauvres autant, \& plus encore qu'on n'avoit accoutumé d'y dépenfer. Tout réuffifoit dans ce que ce Prince entreprenoit pour la gloire du $120 \mathrm{~m}$ de Dieu, \& la Princelle fe difpofoit tout de bon à recevoir le Baptême avec toute fa maifon; mais la vertu de Sumitanda ćtoit déja aflez folidement ćtablie pour être mife aux plus rudes ćpreuves, \& Lieu ne voulut pas priver plus longtems l'E-

(a) Voyezle Livre Prélimiadire, Chap. XIV. 


\section{R E T R O I S IE M E. 20\%}

glire du Japon de la gloire, qui pouvoit lui revenir des grands exemples de fermeté, qu'un Prince fi accompli devont dommer à tout l'Enpire daus los plus grands revers de lestin M. fortune. $222 \%$.

Le Confeil de Sumitanda ćtoit comporé de douze Gentilhommes, dont, ni par carelles y cuinciut. ni par raifons, il n'avoit encore pû engager aucun à fuivre fon exemple. Ces Confeillers trouvoient même fort mavais que le Prince travaillât avec tant d'ardeur à la deltruction de l'ancienne Religion de l'Empire; $\&$ apris avoir inutilement tenté la voye de la repréfentacion, pour lui faire prendre au moins. une conduite plus nodérće, ils réfolurent enfin de pouller les cholés aux dernieres extré. mitez; déterminés à le perdre, s'ils ne pou. voient le réduire à ce qu'ils fouhaitoient. Pour mieux cacher leur dellein, \& pour s'allurer de Vocoxiura, ils feignirent d'êrre gagnés par les perfuafions du Prince, \& ils lui demanderent la permiffion d'aller dans ce Port, pour s'y faire inftruire par le Pere de Torrez. Uine rćfolution fr fubite, \& yui paroinoit ficoncertée, lui fit naîre des foupçons, \& il fé détia que cétoit un piége qu'on lui tendoit; il accorda néanmoins ce qu'on lui demandoit; mais il fit avertir le Pere de Torrez de ne pas trop compter fur la fincérité des Profélytes, qui alloient le trouver, \& de les bien éprouver, avant que de les recevoir au faint Bapt $\mathrm{e}_{-}$ me. Il eut encope fait plus fagement, s'il fe fút tenu lui-même un peu plus fur fes gardes. Quant au Pere de Torrez, il n'eât pas la peine d'examiner les Confeillers du Prince, ils n'allerent point à Vocosiura, parce qu'ils trouve- 


\section{HISTOIRE DU JAPOIT,}

- rent plutôt qu'ils ne penfoient, une occrinis

Le F.C. d'éclater \& de fe faifir de la Capirale même;

Igr3. voici ce qui y donna lieu.

icis Sin. Mu. 2223.

C'étoit une coutume inviolable dans ce Pays, que tous les ans, à certain jour, le Prince fe rendoit en grand cortćge dans un Temple, ol ćtoir la Startue de fon I'rédécelfeur, lui offroir de l'encens, \& pratiguoit en fon honneur pitzfieurs aurres cérémonies, qui approchoient beaucoup d'un Culte religieux. Le jour marqué étant venu, Sumitanda, qui ne ménagreoit plus rien, alla au Temple, en fit tirer la Statue du Prince; \& ne la regardant plus que comme une Idole, qui avoit reçu les honneurs divins, il fe crut dans l'obligation de venger fur elle la Majefté de Dien, \& la fit jetter al feu. Il n'en falloit pas tant pour révolter tout ce qu'il y avoit encore à Onura d'Idolâtres zélés. Traiter de la forte fon Parent, fon Prédécelfeur, faire cet affront à fa Bienfaiturice. à fa Mere d'adoption, en deshonurant la mémoire de fon Epour , ce ne fut rien moins dans lour efprit, quiun attentat, qui rendoit indigne de l'autorité fuprême, un prince alfez dénaturé, pour oublier à qui il avoit obligation de ce qu'il étoit.

Sa perte eft aullitôr jurcé ; on prend des mefures pour faire foulever la Ville; on donne avis de tout à ce Fils illégitime du feu Prince, qui avoit été jugé incapable d'occuper la place, \&. on l'invite à venir a u plutôt venger l'injure faite à fon pere, \& à fe montrer digne d'un rang, dont on l'avoit injuftement exclu. Ce Seigneur pollédoit fans ambition quelques Terres dans le Royaume de Gotro; mais l'éclat d'une fi hate fortune l'ćbloüit, \& il re 
LIVRETROISI laila perfuader qu'il n'avoit qu'a paroitre, pourétre reconnu prince d'Omura.

Ce premier pas fait, les Compiliers a'Etat engagerent Riozogi à reprendre les Armes De Gyi-Mu. \& a attaquer le Roi d'Arima, lequel pris au 222 i० dépourvî, ne pourroit pas être cu état de faire beaucoup de réliltance; ce qui les délivreroit de la crainte d'une diverfion de la part de ce Prince. Les Rebelles ainfi allurez du dedans \& du dehors, fongerent d'abord à faire venir a la Capitale le Pere de Torrez, qui devoit être la premicre victime immolće à leur rellentiment. Pour empêcher qu'il ne leur échappât, quelques-uns des moins liffpects repréfenterent au Prince, qu'il différoit trop le Baptême de la Princelle fa Femme, \& qu'il ćtoir de fa Dignité que la Cérémonie s'en fit dans Omura inême, à la vîe de tout le Peuple, qu'un tel exemple difpoferoit plus que toute autre chole à embraffer le Chriftianifme. Sumitanda fut charmé de ce difcours, il lui faifoit trop de plaifir, pour gu'il ne le crit: pas fincere; il commença à fe perfuarct, gue ccux, qui lui parlojent de la forte n'ćtolent pas eux-ménes éloignés du Royamme de Dieu, \& fur le champ, il dépêcha au Pere de Torrez un Gentilhomme nommé Loiiis, qui ćtoit frere du Gouverneur d'Onura, \& dont nous avons déja parlć plus d'une fois, pour leprier de venir incellanament le trouver.

Loiis arriva à Vocoxiura le treicióne d'Août, \& trouva le Pere de Torrez occuṕ d'une affare, gu'il ne pouvoit gueres dif́rer. D'ailleurs, ce Religieux ne fe porcait pas bien. Il répondit néanmoins à l'Envoyé du Prisce, guil partiroit le lendemain de l'Alomptor 


\section{HISTOIRE DU TADON,}

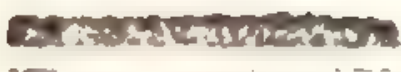

De I. C.

$1,63 \cdot$

De: Syn-Mn. $2223 \cdot 1$

de la Vierge, pour fe rendre à fes ordres. Cette réponfe ne fatisfit pas le Prince, \& inquiéta fort les Conjurez, qui craignoient que ce retardenent ne leur fit manquer leur cuup; ils engagerent Sumitanda à faire de nouvelles inftances, \& Loüis fut renvoyé fur le champ à Vocoxiura, ou il arriva le quatorze fort tard. Il eut beau dire, le Supérieur, à qui ces emprellements donnoient apparemment a penler, ne crut pas que la chofe prelfat tellement, qu'il fallut fe mettre en chemin, \& abandomner fon Troupeau le jour de la Fête. Le feiziéne, il dii la Mefie de grand. matin, réfolu de partir auffi-tôt après; mais comme il faifoit fon action de graces, \& qu'il xecommandoit à Dieu avec beaucoup de ferveur le fuccès de fon voyage, il fe fentit tout à coup infpirć d'attendre encore de nouveaux ordres du Prince, avant que de quitter Vocoxiura, \& il lui manda les raifons qui le dém. terminoient à y refter.

1.: Corju- Loiis, fort furptis de cette réfolution, qu'ir - sass. chagrin la route d'Onura. Il n'avoit pas encore fait beaucoup de chemin, lorfque FARIBA, un des Chefs des Conjurez, tomba fur lui avec. un détachement de Soldats, lui demauda, où il avoit laiflé le Mifionnaire? \& fans attendre fa ténonfe, le tailla en pieces avec tousceux, quil'accompagnoient; puis alla rejoindre les. Rebelles. Ceux-ci avoient déja mis le feu au Palais \& à la Ville, \& le Bâtard d'Omura avoit ćté folemnellement proclamé Prince. Sumitanda dans une fi grande extrémité, fe vovant environné de flammes, qui confumoient fon Palais, \& allailli par des Ennemis furieux. 
L I $Y$ D I. A O I S I E M E. 209 done le nombre croilioit a chaque infant, ne perdic pourtant point courage. Il arma tout ce qui étoit refté autour de lui de Sujets fidéles, il fe mic à leur tête avec le Gouverneur De Syn-Mu. d'Omura, qui avoir en même-tems a faver 2223. fon Prince, \& à venger fon Frere; palia lur le ventre à tout ce yui fe mit en devoir de l'arrêter, \& gagna un petit bois, oli il jugea à propos de le tenir caché, jufqu'à ce qu'il. fe vît allez de forces pour faire tête aux Séditienx; mais les provifions lui manquerent bientôt, \& il auroit péri de faim, fi un Chinois, qui ćtoit à fon fervice, n'avoit trouvé le fecret delui porter des vivres fans être apperçu. Enfin fa Troupe s'étant un peu grofle, il fe retira dans une Forterefle, qui étoir très-bien munie, \& en état de défenfe.

Les Conjurez, après l'avoir ainfi mangué, fe divilerenten deux Bandes. Le Bâtard d'Omura avec la preniere, alla s'allûrer du Pore de Vocoxiura, qu'il réduifit en cendres, mais il n'y trouva perionne, parce qu'au prenier. bruit de ce qui fe palloit, la plûpart des Habitans, \& les Miffionmaires s'étoient réfugiés fur les Navires, qui étoient en rade. La feconde Troupe s'attacha au Prince, \& le tint aflićgé, dans l'elpérance de le réduire au moins. par la famine. Jufques-là Sumitanda fe doutoit bien, que fa Religion ćtoit le motif d'un. foulevement fi général. Il en eutbien-tôt toute la certitude, qu'll fouhnitoit pour la confolation, car fes Sujers lui firent declarer, qu'ils mettroient bas les Armes, s'il vouloit adorer les Dieux de fes Peres, \& rétablir leur. culre, qu'il avoit aboli. Il n'eût pas accepté cetre offe, quand il y êtr tronve toutes les. I. $y$.

Ils réduirent en cendres la Ville ds Voco. xiusa.

De T. C
153.
$\frac{5 y n-11}{2223}$ 
firctez; ainfi fans s'amufer à ćcouter des Re-

De T.C. I j门?

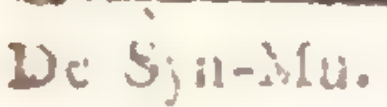
2223. belles, qui prétendoient lui faire la Loi, il ne fongea qu'à le bien défendre, \& il le fir avec une vigueur, qui les étonna.

Tandis que ces choles te palfoient dans la Ils fuscitrnt Principauté d'Omura, Riozogi étoit entré dans I1:: Gu r:e le Royaume d'Arima, \& il y tenoit la Campaau Roi d'A-gne; le Roi, qui avoit ćté furpris, s'étant r.ma prur vî aufli obligé de s'enfermer dans une de fes f: $\cdots$ it $\mathrm{r}$ fon meilleures Places; alors Xengandono voyant Frcre. fes deux fils à la veille d'être détrônés, affembla quelques Vallaux de fa Maifon, qui lui étoient reftez affectionnés, entra dans !e Royaume d Arima, \& fon Armée groffiflant a mefure qu'il avançoit, il contraignit bientôt Riozogi de fe retirer. Il reprit enfuite les rênes du Gouvernement, \& non content d'ôter ̀̀ fon Fils aint le Sceptre, qu'il crut que fon incapacité, ou plutôt fon inclination pour les Chrétiens l'avoit mis en danger de perdre, il l'éloigna de fa Cour. Il y a bien de l'apparence qu'il auroit traité de la même maniere Sumitanda fon Cadet, fi ce brave Prince eît eu befoin de fon fecours, pour fe tirer du mauvais pas, ou il fe trouvoit; mais il avoit pour lui le Dieu des Armćes, qui dès le commencement de cette révolte lui avoit donné des affurances de la victoire, non-feulement en lui infpirant une confiance, quile foutint au plus fort du danger, mais encore en lui montrant comıne à Confantin le Signe du falut dans l'air, \& en lui faifant connoitre, comme autrefois à ce premier Empereur Chrérien; gu'il combattroit pour lui.

Vorisiremi- Tonterois ce Prince, pour ne manquar à iaculede ru rien de ce que la prucence demandoit de lui, 


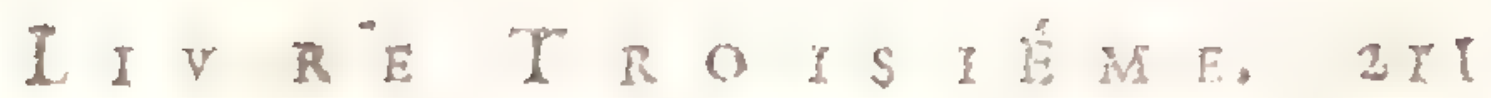

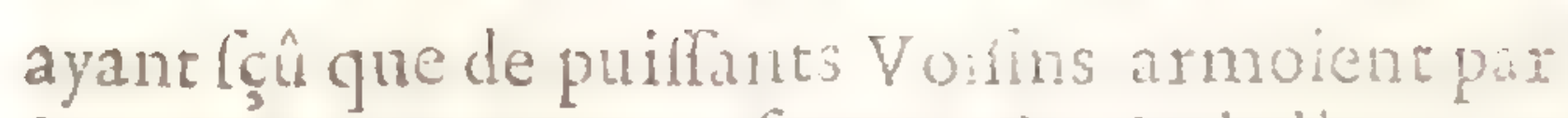
Terre \& par Mer en faveur des Rebelles, ne crut pas devoir demenrer plus long tens dars un endroit, oull étuit facile à fis Ennemis de l'affames. Il prit donc le parti d'en fortir, \& il le fit en plein jour, força un Quartier des Prince do. Aliéceans, \& tint la Campagne. Il s'appro- murd. cha confuire d'Omura, \& demeura campé à la vî̈ de cette Capitale. Il apprit peu de jours après que Fariba, le Roi de Gotto, \& celui de Firando étoient débarqués avec de nombreules Troupes, \& marchoient a lui; alors fentant renouveller la confiance en Dieu, dont il foutenoit la caufe, il décampa ; \& s'avança vers les Ennemis, pour leurépargner la moicié du Chemin, \& malgré l'extrome inégalité ce fes forces, il êt à peine teconnu leur Armíe qu'il fit fonner la charge. C'étoit le quatriéme d'Ottobre; fa petite Troupe toute compolée de Chrétiens, entra dans les premiers Bataillons, en criant vive Sumitanda, les culbura, \& les renverfa fur ceur, qui fuivoient fans ordre, parce qu'ils n'avoient pas eu le tems de fe matre en bataille, \& en un moment cette formidable Armée fe tranva dans un défordre, dont il ne lui fut pas pollble de fe senetre.

I es Chrétiens ne ceflerent de tuer, que quand 1. Ia li:ude leur fir tomber les armes des nains, $\varepsilon$ jamais Victoire ne fut plus completre \& ne coñta li peu. Aun perlonne ne doura que le Dieu de Sumitanda n'eut vaincu pour lui. Cenz des Alliez, qui échapperent au Carnage, a! irerent qu'ils n'avoient pû foutenir l'éclar, ii fortoit des Croix, que les Soldars Chréti: portoient fur leurs Habins: pluícurs numes

Di J

1) $b_{3}$

1) S Sytat it. $22 \times 3$.

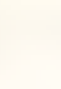




\section{I2 HISTIRE DUTAPON;}

congarswaterse

$\therefore$ T.C.

$+\{63$.

De.sin-ju.

222 ;.
L: Perc ile

Turrez refule

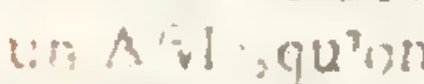

(1)

(1), qua!!

is:i avec

un?es Mr.

waitre. ajốterent gu'ils en avoient vâ une en l'air: toute rayonnante de lumiere, \& femblable à celle, qui éroit dans le grand Erendart du prin-. ce. Enfin il fembloit que tous les Elémens fe fullent armés pour une caufe fi jufte; car tandis qu'on fe batsoit fur Terre, une horrible tempête diflipa la Flotte Ennemie: auflile Roi de Firando avoit-il accoutumé de dire depuis, que le Prince d'Omuractoit fi bien forti d'une fi fâcheure affaire, parce gu'il étoit bon Chrécien; tćmoignage, que le Tout-Puillant arrache de rems en tems de la bouche de ceux mêmes, qui s'obltinent le plus à la méconnuitre.

La joye d'un fuccès fi peu attendu fut pourtant mêlće de quelqu'amertume; tout le Pays étoit dans un état déplorable, \& Xengandono Ennemi mortel de notre fainte Foi, a laquelle. il attribuoit le mathear de fa Famille, ne pouvoit Couffir la moindre marque de Chriltianifme. Les Princes fes Fils n'ćroient pas dans une fituation, qui leur permit de prendre la défenfe de la Religion contre un Pere, qui Í́gnoit, \& fe trouvoit à la tête d'une grande Armée, \& Sumitanda tout vainqueur qu'ite étoir lui-même, crut devoir fe ménager avec Iui. Ce Prince étoit furtout inconfolable de la ruine de Vocoxiura, où il ne reftoit pas un feul Habitant, ni une Mailon fur pied.

L\& Pere de Torrez étoit toujours danscette rade, lont il n'avoit pû fe réloudre à s'éloigner, quoique le Prince Antoine de Firando I wi eût dés le commencement de la révolte ent voyé des Bâtimens bicn armés, pour le traníporter dans fes Ifles; il s'ćtoit contenté d'y envoyer Fernandez avec les Vales facrez \& lés Ornemens de l'Egiffe, \& réfulu de púrirplut 


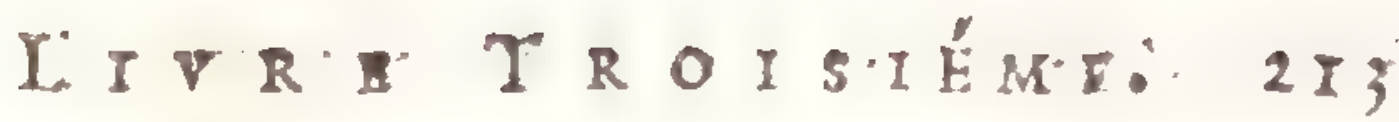

tôt; que d'abandonner fes chers Néophytes, qui s'ćcoient réfugiés auprès de lui, il avoit voulu attendre avec eux quel feroit le fuccès de cette guerre. Il apprit des premiers la victoire du Prince d'Onura; mais il f̧ut en mô. ve J. C. Is 63. me tems que.les Chrétiens d'Arima étoient. dans l'opprefion, que Damien avoit couru de grands rifques ̀̀ Ximabara, \& Paul fon Catéchilte à Cochinotzu; mais que les Fidéles: les avoient fait évader, \& les conduifoient par. des Chemiins fûrs à Vocoxiura, où ils arriverent en effer fans aucun acoident fàcheux.

D'autre part le. D. Monti, fur les premieres nouvelles, qui s'étoient répanduës dans le Bungo de la Confpiration, avoitenvoyé Loüis. Almeyda fur les lieux pour s'informer de ce. qu'étoient devenus les Mifionnaires, \& lui avoit donne ordre de vifiter les Eglites, fur lefquelles l'Orage ćtoit tombé. Ce Religieux prit fa route par Ximabara, \& quoiquion l'affurât dans tous les lieux de fon pallage, qu'il ne trouveroit plus nulle part, ni Miffonnaires, ni aucun veftige de Chriftianime, \& qu'il rifquoit tout en fe montrant dans un Pays, où le nom Chrétien étoit en exécration, il s'approcha fans rien craindre du Pore du Ximabara. A peinceuton appris dans $l x$ Ville qu'il étoit dans le Voifinage, qu'il fe vit en un moment environné de Chaloupes remplies de Chrćtiens, qui lui apportoient toutes fortes de rafraichiffements. Ils lui raconterent les maux, qu'ils avoient foufferts de la part des Infidćles, \& lui jurerent une fidélité inviolable a fervice du vrai Dieu. Il les confola le mieux qu'il lui fut poffible, \& leur ronzit tous les fecours, qui dépendroient de 


\section{HISTOIRE DE JAPON,}

lui; mais il n'entra point dans ce Port, par-

De J.C. ce que les fidéles l'avertirent qu'll ne failoi

I 53.

De Syn-Mu. 2223. pas sûr pour lui d'y paroitre.

Il palla donc à Cochinotzu, oủ il ne fut pas moins édifić de la ferveur des Chrétiens. Xengandono avoit mis dans ce Port un Commandant, qui les maltraiteit beaucoup \& les veilloit de près. Ils ne laifferent pas d'être inftruits d'abord de l'arrivée d'Almeyda, \& deux d'entr'eux oferent bien fe mettre en plein jour dans une Chaloupe, pour lui porter les compliments, \& lui faire les excufes de tous les autres. La nuit fuivante une Troupe des plus confidcrables le vifiterent à fon bord, \& lui firent les larmes aux yeux mille proteftations de ne jamais chanceler dans la Foi, qu'il leur avoit prêchée le premier. Eh! quelle Religion embraferions-nous, difoientils, $\sqrt{2}$ nous renoncions à celle de Jefus-Chrift? $A$ qui dans nos peines $E$ dans nos dangers aurions-nous recours, fi nous étions aflez Malheureux, pour abandonner notre Dieu? Ah! quelque rigueur qu'il paroiffe exercer Jur fes Enfants, il leur fait bien Sentir, qu'il e?t le meilleur de tous les Peres? aufj $a-t-i l$ gravé fon Amour dans nos caurs avec des traits, que rien ne pourra jamais effacer.

De Cochinotzu le Mifiomnaire, qui avoit Les chefs appris que le P. de Torrez étoit fur les Nades Révultés vires Portugais dans la Rade de Vocoxiura, font pris \& l'y alla trouver; il y arriva le vingtiéme dé

Septembre, \& le rencontra avec le P. Loilis Froez \& Jacques Gonzalez, qui ne l'avoient point quitté. Le quatrióme d'Octobre la Baraille fedonna, comme nous l'avons dit, \& le Prince Victoricux en envoya fur le champ 


\section{I RE T R O IS I E M E. II}

donner avis au $\mathrm{P}$. de Torrez. Les Portugais la célébrerent aufi-tôt par plufieurs décharges de toute leur Artillerie, \& par tout ce qu'ils pûrent imaginer de témoignages d'une De Syn-Mu. joye fincere. Le Supérieur vouloit aller d'abord complimenter Sumitanda, \& le Roi d'A. rima fon Frere, qui étoient à Omura; mais on ne jugea pas que ce Voyage fût encore à propos, \& le Pere fe contenta d'écrire aux deux Princes. Peu de tems après on eut nouvelle qu'ils s'étoient mis aux trouffes de Fariba \& du Bâtard d'Omura, qui tomberent tous deux entre leurs Mains, \& payerent leur rébellion de leur Tête; après quoi Sumitanda réunit toutes leurs Terres à fon Domaine.

Sur ces entrefaites, la Saifon étant propre pour la Navigation des Indes, les Portugais fe préparerent à mettre à la Voile; \& le Pere de Torrez, qui ne jugeoir pas la préfence fort urile dans la Principauté d'Omura, fongea à retourner dans le Bungo. Il commença par envoyer le P. Frö́s au Prince Antoine de Firando. Ce Prince avoit déja Fernandez dans fes Illes, ainfi que je l'ai dit, mạis la Princelfe ErISABETH fon Epoufe fcuhaitoit fort d'avoir un Prêtre, \& avoit écrit au Supérieur des Miffons, que s'il étoit nécellaire pour obtenir cette grace, de lui envoyer fes Enfants la lui demander à genoux, elle les feroir partir fur l'heure. Le $P$. de Torrez s'embarqua enfuite avec Alneyda \& Gonzalez fur un petic Bâtiment, que les Chrétiens de Ximabura lui avoient envoyé.

On comptoit huit cents Chrétiens dans cette Ville, mais il y avoit peu d'efpérance d'en zugmenter lítôt le nombre, parce que da 


\section{I H HISOIRE TUTATON,}

crainte du vieux Roi d'Arima paroilloit avoim

- De J. C. beaucoup refroidi l'affection du prince de XiI 64. mabara pour le Chriftianifme. On ne con-

c.

are $5 y n-M H$. 2224. feilla pas même aux. Multionnaires de s'arêter. long-tems dans ce Port, dont le Gouverneur nommé LEON, les avoir reçus cher lui; mal gré des céfenles de Xengandono. Ils tè rembarquerent donc, \& fe rendirent à l'Ille de 'TACAXI, qui n'en eft qu'à deux lieuè's, \& qui eft le. commencement du Royaume de Bungo de ce côté-là: ils y arriverent au conmencement du mois de Février de l'annce I 64 . \& le P. de Torrez y fixa pour quelque tems fa demeure, parce qu'il y ćtoit a porté de fecourir toutes les Eglifes du Ximo, qui pouvoient avoir befoin ce fon minitere. Il envoya de-la Loüis Almeyda à Fucheo, avec ordre d'en faire partir Damien, \& un Catéchifte nommé Augestin pour Meaco.

A peine Almeyda avoit mis à la. Voile, qu'Edoüard de Sylva, qui depuis la Rćvolution du Naugato, n'avoit point quittć le Royaume de Bung(n, arriva pour complinenter le P. de Torrez de la part du Roi, \& lui marquer la joye, qu'il avoit de le polféder de nouveau dans fes Etats. Il étoit de plus chargé d'une. Letrre de ce Prince pour le Commandant de l'Ine, par laquetle il lui étoit enjoint de faire Çavoir à tous les Habitants, qu'ils pouvoient librement embraller la Religion Chrétienne, \& de punir févérement quiconque molefteroit en aucune façon ceur, qui la prêcheroient, ou l'embrafferoient. Edoüard de Sylva s'ćtant acquitté de fa Commilfion, parfa à l'ine de CAvaxiRr, Voifine der Tacazi, avec de femblables recommanda- 
L I R E. TROIS I É M B. 2IT rions du Roi, \& le P. de Torrezlui ordonna d'y refter.

Tandis que ces chofes le paffoient dans le Ximo, la Foi s'établiffoit folidement dans le centre de l'Empire, mais ce n'ćtoit pas fans de grandes traverles. Nous avons vû que le P. Vilela avoit fait une excurfion à Sacai. II y éroit arrivé au mois d'Août Is6I. accompagné de Laurent; il y demeura un mois entier, mais excepté le Gentilhomme, qui l'y avoit appellé, \& fa Famille, il n'y avoir baptifé perfonne: aufi fe difpoloit-il à en partir pour retourner à Meaco, lorfqu'il apprit des nouvelles de la Capitale, qui retarderent de: quelques jours fon départ. Morindono, Roi. de Naugato, \& quelques autres Princes des plus puiflants de l'Empire, mécontents du Cubo-Sama, avoient mis fur pied une Armée de quarante mille Hommes, \&. le Ror de Naugato la mena en Perfonne dans la T.enfe. Les Bonzes Negores, à qui la Cour. Impériale avoit auff donné quelque fujet de mécontentenent, n'eurent pas plutôt appris cetie nouvelle, qu'ils armerent de leur côté avec une prompitude incroyable, \& joignirent Morindono, avant gue l'Empereur fût mône infruir qu'il y eût des Armćes en. Campagne contre lui. Par-la le Roi de Naugato fe trouva en état d'entreprendre le Sik. ge de la Capitale, il y marcha fur le champ, \& le préfenta devint la Ville, qui fe trouva fans munitions, fans provifions, \& prefyue. Cans Troupes.

Le Cubo-Sama ainfi pris au dépourvû, couroit rifque de fuccomber fous de fi grandes force. forces, sil n'avoit pas trouvé le moyen de

De. J.C.

I16: 64 .

De Syn.Mu. $2221-240$

Le Roi de Naugato afice. gel'Empcreur dans Acaco.

La ville ell 
2 I8 HISTOIRE DU JAPON,

faire avertir un de fes Oncles \& fon Beau.

De T. C. Frere de l'extrêmitć, où il étoir réduit. Cés

I)6r-64. deux Princes ne perdirent point de tems,

De syr-Mu. allemblerent leurs Vallax, \& s'approcherent .2221-24. de Meaco avec des forces fuffifantes, pour faire lever le Siége, \& le Roi de Naugato l'auroit en effet levé fans les Négores, qui eurent l'adrelle d'attirer l'Oncle de l'Empereur du côté de Sacai, où ils lui taillerent en pićces la meilleure partie de fes Troupes. Cetre Vitaire releva le courage abbatir de Morindono. Ce Prince donna un aflaut a Meaco, qu'il força, \& dont il domna le pillage à fes Soldats. C'étoit fait de l'Emperenr qui s'étoit réfugié dans la Citadelle, fans aucunc efpérance d'y être fecouru, fi tes Ennemis eullent agi de concert; mais les Negores ne fongeant qu'à pourfuivre l'Oncle de l'Empereur, qu'ils avoient battu, \& qui s'étoit reciré dans des lieux sûrs, ne firent pas attention, qu'ils fe mettoient hors d'état de fecourir le Roi de Naurgato, ou d'en être euxmómes fecolrus, en cas que les uns ou lesautres fuficnt attaqués, comme ils le furent en effet prefüen même tems.

Viztoire de

Car l'Empereur ayant fait fecretement lel'Fmpenur. $\mathrm{g}$ ver vingt mille Hommes de bonnes Troupes, fortit de la Citadelie fans crre aperçu, traverfa la Riviere de Meaco, \& alla brufijucment romber fur les Negores, qui furent prefque tous taillés en piéces. Le relte fut entiérement difipé. L'Almée viatorieule renforcée par celle, qu'elle renoit de délivrer des Negores, marcha enfuite vers Meaco, tout fuyant devant ellc. Morindono vit bien alors qu'il ćroit perdu, s'il ne s'accommodoir 
LI $R$ E I RO.IS I E ME. 219 promptement avec le Cubo-Sana: il ne perdit point de tems, il négocia a la Cour du Dairy, où il avoir de bons Amis, \& par l'entremife dece Prince, il fit a paix. Quelques De Syn Mu. Mémoires difent quece fut le Beau-Frere de l'Empereur, qui défit les Negores, \& que le 22222.5 .

Cubo-Sama l'ayant appris, fit une fortie fur le Roi de Naugato, tandis que fon Oncle $\&$ fon Beau-Frere l'attaquerent de leur côté, \& qu'il n'ćchappa aucun des Soldats de Morindono, qui occupoient Meaco. Tous conviennent gue pendant ces Troubles, les Chrétiens de la Capitale, que Laurent eut le courage de vifiter au fort du péril, fe comporterent en Sujets fidéles, \& que les Bonzes, qui s'ćtoient emparés de leur Eglife, furent obligés de l'abandonner, dès que le Cubo-Sama fut rentré triomphant dans la Ville. Le P. Vilela ne tarda pas enfuite à y recourner, \& y arriva fur la fin de I 62 . Ou au commencement de l'année fuivante; mais avant que de raconter le fuscès, qu'eurent fes Prédications dans certe grande Ville, où nous allons dans peu voir la plus florifante Chrótienté du Japon; il ent bon de dire ici en quel état fe trouvoit alors cette Capitale de I'Empire Japonnois, \& d'en donner une Dafcription exacte.

MeAco, ou Mraco (a) fignifie Ville, \& En quel étac celle-cieit ainfi nommée par excellence, com-étoit alurs la me Athc̀nes \& Rome tont ćté au tems de l'Eipire. leur plus grande fplendeur. J’ai déja dit qu'elle eft fituce dans la province de JAMATSIRo, une des cinq, qui compolent le GokInAI ou

(*) On le nommeaufi Kio. 


\section{HISTOIR DO FATON;}

Dc J. C. la TENSE, \& fur les deux bords d'une granais 61-64. de Riviere, qui coule dans une Plaine furt Dc Syu-Mu vafte. Elle eft divifée en haute \& balle Ville. 2232 24. Sa longueur du Nord au Sud, eft.de trois quarts de lieué d'Allemagne, \& fa largeur de l'Ent a l'Ouent, d'une demi lieué. Elle eft environnée d'agréables Collines, \& de plufreurs Montagnes, d'où découlent un grand nombre de Ruilleaux, \& de trís-belles Fontaines, fans quoi le lays feroit tout à fait ftćrile, le Terrein y étant naturellement fort aride, ainf que nous liavons déja remarqué. Iju côté de l'ER, la Ville eft bornée par une Colline bien boilće, \& toute femće de Monafteres, de Temples \& de Challes, qui font une Perfpective charmante, mais c'eft encore toute autre chofe, quand on les voit de près. Tous cis Ecifices ont quelque chofe de fingulier; leur fituation eft des plus agrćables, le tout fait un lieu enchanté, $\&$ tel que l'inragination la jlus vive peut à peine fe le figurer. Nous avons déja des principaur Temples, qui font dans fon Territoire, \& nous les avons repréfenté tels, qu'ils étoient alors; \& comme ils ont été four la plipart ruinćs par les Guerres Civiles, dont mous parlerons dans la fuire, il eft bon d'avertir que c'ct dans l'ćtat où ils font aujourd'hui que nous les avons repréentés, dans le Livre préliminaire.

La Rivise de Mexco lort du Lac d'Oirz: deux autres Rivieres, qui ne font guéres que des Torrents, \&ui entrent dans la Ville da

"Sen même côté, ont lour fource dans les Montagnes voifines. Ces trois Rivieres fe réuniffent dans le centre de la Ville, où l'on roit un 


\section{LITKETROISIEM E: 22I}

Pont de deux cents pas de longueur: de-là toures ces Eaux raflemblées coulent à l'Ouent.

Les Ruès de Meaco étoient érroites, mais rćgulieres \& très-longues, \& toutes fe coupoient à Angles droits, les unc allant du Nord au Sud, \& les aurres de l'En à l'Ouett. Tour le Nord étoir occupé pair la Cont du Dairy, \& le Château, ol̀ demeuroit alors le CuboSama, \& où il entretient encore aujonrd'hui une forte Garnifon, étoit à l'Oueft de ces deur Quartiers, qui étoient très-valtes; le premier eft enviromé de murs \& de fofĹ's, \& il confifte en douze 0 ! treize Rués. Le Château, qui eft bâti de Pierres de taille, elt aufi environné d'un Follé rempli dEà, revêtu d'un mur, \& précédé d'un premier Folfé lec. Les Maifons de Meaco font généralement parlant étroites, \& n'ont jamais plus de deux Etages, y compris le Rez-de-Chaurrée; elles font bâties de Bois, de Chauls, \& d'argile, \& les toits en font couverts de basdeaux. Cette Ville a toujours eu une grande incommodité, c'elt la pouftere, qu'y excite la multitude prodigieufe de Peuple, qui remplit les Rués à toute heure. $x^{\circ}$

Sur la fin du dernier fiécle elle avoit encore, fuivant le recenfement, qui en fut fait alors, cing cents vingt-neuf mille fept cents vingt-fix Habitants, outre les Etrangers, qui y étoient en grand nombre, \& la Cour du Dairy, qui forme comme une feconde Ville. Il eft hors de doute, qu'avant que les CuboSanras euflent tranfporté leur Cour à Jedo, elle étoit beaucoup plus peuplée. Il eft certain aufi qu'elle eil encore préfentement le grand Magazin des Manufactures du Japon,

De J.C. $1562-64$.

De Sy: $-\mathrm{Mu}$. 22.22-240 


\section{HISTOITEDU JAFON,}

\& le centre de tout le Commerce de l'Ema

De J.C. pire. On y porte prefque toutes les Marchan$1562.64^{\circ}$ difes, qui viennent des Pays Etrangers, \& Uesy-Mu. mémes des Provinces du Japon; la plupart 2232.24. des Marchands, s'y afiembient, pour acheter les unes \& les autres; a peine y voit-on une Maifon, où il n'y ait quelque chofe à vendre. C'eft-là, qu'on rafine le Cuivre, que l'on bat la plus grande partie de la Monnoye, que l'on imprime les Livres, \& que l'on fait au mérier ces riches Etoltes à fleurs d'Or \& d'Argent, qui fe tranfportent dans les Pays Etrangers $(x)$ : les meilleures Teintures, les cifelures les plus exquifes, les Intruments de Mulique de toutes les efpéces, les Cabinets verniffés, les Ouvrages en Or \& dans les autres Métaux, furtout en Acier; enfin les lames de la meilleure trempe, \& les autres Armes fe travaillent à Méaco dans une grande perfection, autr-bien que les Bijoux de toutes les fortes. Je reviens au Pere Pilela.

Les chofes ćroient fi favorablement difpoChremente fies pour h Religion apres !es Troubles, forifiantecans dont nous avons poré, que le D. Vilela s'arm certe $C_{\text {apitate }}$ tendoir a faire dans cetre Capitale une abondante kécolte: les lu.ces de fes travaux par ferent encore de beamcouples efpérances. Les Mémoires détaillés, que nous en avons dans fes Letres, \& dans celles des autres Miflionnaites, gui ctoicnt alors au fapon, ne conticnnent rien d'inferieur a ce qu'on lit de plus merveilleux dans les Annales des plus

(a) Nous arons remarqué aillours, que celles, qui Ie fabriquent dans les thes de latifío \& de Kamakura, ne lurcent puint du l'ays. 


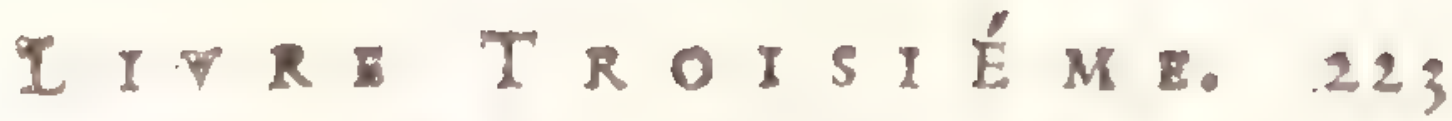

heureux fiécles de l'Eglife. Mais ce qui donnoit furtout une grande idće de la fainteté des Chrétiens de Mcaco, c'ćroit de voir avec quel ́oin ils s'appliquoient à la pratique des vertus, qui devoient leur couter davantage. Plulieurs d'entr'eux étoient de la plus haute Noblelle, c'elt-à-dire, naturellement les plus fiers des Hommes: d'ailleurs nous avons vú combicn la compaftion envers les Pauvres eft ćloignée de paroîre une vertu aux Grands du Japon, puifqu'ils fe font mêne un devoir de Religion de leur dureté envers les Miférables. Cependant c'étoit principalement dans les exercices d'humilitć \& de charité, que ces Fidéles aimoient a s'employer, \& on voyot fouvent les plus Riches fe réduire au pur nécelfaire, qui n'étoit pas même toujours réglé par la difcrétion, pour enrichir les Hôpitaux.

L'Homme Apofolique continuoir d'avoir beaucoup d'accès aupris de l'Empereur, \& ce Prince fit voir dans une occation allez im-

Crédit du P. Vilela aupré:s del'Empereu r. porante combien il l'eltimoit. Ce Religieur Efes inutule fur informé, que Morindono maltrairoic fort pour fare ales Chrétiens d'Amanguhi ; il en porta fa hoir la R.ua Fiante au Cubo-Sama, qui voulut bien fe rionchretienfaire l'Intercelleur de êt Fidéles perfócutés aupres de leur Souverain : il lui envoya un Gentilhomme, pour le prier de hilfer fes $\mathrm{Su}$ jets en liberté de fuivre la Religion, que prêchoient les Religieux d'Eurone. Mais une démarche de cet éclat penfa ctre funefte à ces Mifionnaires, \& leur attira un Orage, auquel ils n'chapperent, que par un de ces coups du Ciel, qui font léntir combien Dieu eft le Mầtre des cours. Les Bonzes ne purent voir lanc frémir les fuites, que devoit naturellement 


\section{HISTOIRE DU JAPON,}

De 'T. C. avoir une fi puillante protection; \& toujouts rj63.64.' appuyés de leur Grand Prêtre, réfolurent de

Be Syn Nil. 223.24 . mettre tout en ouvre pour faire challer les Docteurs Etrangers de Mcaco, \& s'ils le pouvoient, de tout l'Empire. Ils s'adreflerent à Daxandono, quiavoit la principale autorite dans la Ville Impériale, où il rendoit la Julrice au nom de l'Empereur, \& ils mirent tout en oeuvre pour l'engager à pullier un Edit contre la nouvelle Religion.

Daxandono répondit à ceur, qui luifurent députés à ce fujet, que pour faire confentir Ia Cour à re qu'ils demandoient, il falloit la bien perfuader que la Religion Chrérienne étoit auff mauvaife, qu'ils le précendoient; \& que tout ce qu'il pouroir lear accorder, étoit de la faire examiner par des l'erfonnes capables d'en juger. Rien n'éroit plus à delirer pour la bonne caufe, que cet examen, fuppofécque les Examinateurs fulentbien che ifis; mais ils le furent très-mal. On mit cete Affaire entre les Mains de deux Bonzes, dont l'un fe nommoit Xrmaxinono, \& l'autre Crconbono. Le premier étoit le Confident \& le principal Confeil de Mioxintono, le plus puillant Particulier de l'Empire; le fecond avoit été Précenteur du Cubo-Sama, \& tous les deux étoient des plus animós contre les Miffionnaires. Auff ce choix perfinada tout le Monde que c'étoit fait du Chriftianime, \& il n'y eut pas un feul des Amis du P. Vilela, qui ne fût d'avis qu'il fe retirât all moins pour un tems. Il lescrut, \& partir avec Lausent pour Sacai. Il n'eut pas lieu de fe repen tir d'avoir ainfi cédé au tems; fon abfence ralentir d'abord un peu cette chalear, arec laguelle 


\section{I VRE TROIBIE M R. 225}

laguelle on le poutloit. Enfin le Seigneur prit en main fa défenle, \& le lalut vint d'ou il y avoit plus à craindre. Voici comment la shofe palla.

Un pauvre Chrétien de la Camprgne nommé JACQues étoit al'é demander juftice à Daxandono contre un Idolatse, ì qui il avoit prêté une fomme d'Argant, \& qui refufoir de la lui rendre. Ximaxiriono un des deux Commillaires pour l'examen de la Religion Chrétienne, entra dans le noment, que ce De J.C. $1563-64$. D: Sy R-Mu。 $2.23-24^{\circ}$.

Converfion de deux pliffanes Bunzes, \& d'un S.i. gneur de a Cour: bon Homme plaichoit lui mćme fa caure, \& le reconnoiliant pour Chrétien à un Chapelet, gu'il portcit fur lui; Tu es donc, lui dit-il en l'interrompant, de la Religion des Eurofiens? Ouigraces au Ciel, rúpond le Payan, j'en fuis: G qu'enfigne de bon votre Loi, reprend le Bonze! je ne fuis pas afez S S avant pour vous le dire, replique le Chrétien, mais je puis bien vous afjurer qu'elle n'enfeigne rien que de bon. Ximaxidono ne laifla pas de le queftionner fur bien des Articles, \& le Scigneur, qui déno:e, guand il lui plât, la lingue des Enfants, pour en tirer fa gloire, colaira tellensent en cetre occafion le Villagcois, qu'il parla fur l'exiftence \& les Attributs de Dieu, fur le Culte qu'il exige des Hommes, fur l'Immortalité de nos Ames, \& fur nos divins Myferes, d'une manicre fi ćloquente, \& móme en fi lons termes, qu'il gavit tous les Afliftants en admiration.

Le Bonze furtout l'écouta fort attentive. ment; il fut enfuite quelque tems fans rien dire: puis, conme s'il fe füt éveillé d’un profond fommeil: Allez, dit-il, au Chrés ten, frites-moi venir vole Dodeur; $\int i$ les Tome II. 


\section{$2: 6$ HISTOIRE DU J A PON;}

IJifciples, ajouta-t-il, font $\sqrt{2}$ Sgavants, que De J. C. Jera-ce du Maitre? Jacyues ne perdit pas un I 53-64. moment, \& fans fonger davantage à l'AffaiLi syn-1iu. re, pour laquelle il ćroit venu à Meaco, il $2223.24^{\circ}$ courut à Sacai, où racontant la chofe comme il l'avoit conçuë, il dit au P. Vilela que le Bonze Commillaire étoit converti, \& qu'il le demandoit pour le baptifer. Le fait ćtoit trop fingulier, potir être cru fur le témoignage d'un Homme, qui pouvoit être trompé; \& tous les Chrétiens de Sacai s'accorderent à foutenir, qu'il ne feroit pas prudent au Pere de s'expofer fur cet avis. Il pouloit partir néanmoins, dans la penfée que, fi c'étoir une feinte pour l'attirer a Meaco, il auroit apparemmient le bonteur de domer fon fang pour Jelus-Chrift. Mais on l'arrêta de force, \& cout ce qu'il put obtenir, fut que Laurent iroit voir de guoi il s'agiffoit.

- Laurent partit fans différer d'un moment, \& les Fidéles commencerent à faire des Prieres pour l'heureux fuccès de fon Voyage. On lui avoit recommandé de Ievenir, dès qu'il feroit inftruit de ce qu'on vouloit fçavoir ; \& on lui avoit a jotité, que s'il ćtoit plus de quatre jours abfent, on le croiroit mort ou Prifonnier. Il tarda pourtant un peu plus, \& on le pleuroit dégr, lorfque fon retour combla de joye tous les Fidéles; car non- Ceulement il confirma tout ce qu'avoit dit le Payfan, mais il aflura de plus que Cicondono avoit été converti par fon Collégue, \& que tous deux vouloient recevoir le Baptêne de la Main du P. Vilela. Il n'y avoit plus à délibérer, \& le Perc partit fur l'heure. Ceci fe palloit les derniers jours d'Avril, \& au com- 


\section{R $\mathrm{T}$ T R ISIE ME. 227}

mercement de Mai. Le Miflonnaire en arrivan: dans la Capitale trouva les deux l'rofélytes, qui avoient encore gagné à Jefus-Chrift un Grand Seigneur nommé XICAIDONO, Parent de Mioxindono, fort eftimé pour fon ćrucicion, qui palloit pour un des plus beaux Efprits de la Cour, \& qui étoit Gouverneur d'une Place forte nomnice I $M O R I$, a huir lieués de Méaco; ils éroient d'ailleurs tous trois fi bien infruits, \& tellement pénétrés des grandes vérités du Salut, que le Pere Vilela ne crut pas devoir difícer à les baptifer.

Dès le lendemain Xicaidono, guifut nommé SANCiE au Bapréne, mena Laurent à finguliereriua Imory, \& il eut la confolation d'y voir bap-autie Scitifer en peu de tems jufqu'a foixante \& dix gneur.

Perfonizes de la premiere Noblelle du Pays, \& cing cents Habitants. Le zóle des deux Bonzes ne fut, ni moins vif, ni moins efficace; ils compoferent enfemble un Traité de la Religion Chrétienne, qui produifit partout des effets merveilleux; mais le plus grand avantage, que la Religion tira de cet heureux Evénement, fut la Convertion dkin Scigneur nommé T ACAYAMA, grand Hỏmme de Guerre, d'une probité peu commune, fort inftruit des Myteres de toutes les Seckes da Iapon, \& trìs-attaché au cuite de fes Dieux: Le Baptême des delı Bonzes ayant fait du bruit, \& jetté toute la Cour dans l'étomnement, Tacayama dit un jour, quil en ćtoit d'autane plus furpris, cinil ne croyoit pas fort difficile de réduire le Prédicateur Etranger au filence; \& pour montrer quill ne partoit pas en l'air, comme il ent aptris que le P. Fin $\mathrm{K}$ ij 


\section{HISTORE DU J A.PON;}

lila préchoir dans une Place de Ḿ́aco: il De J. C. l'alla entendre, \& le Sermon fini, il entre1563-64. prit de réfuter tout ce que le Milionnaire L. Sjn-Mu. avoit avancé. Ce Religieux comprit d'abord, $222 j \cdot 24$. . qu'll avoir affaire à un Honme d'efprit, \& qui en fçavoit bien autant que les plus habiles Bonzes; il Ićpondit néanmoins fans peine a tour ce yu'il lui objecta, \& parla d'une minicie fi fenfece \& fi folide, que fon Adverfaise n'cut rion a lui repliquer.

Mais ce gui lurprit davantage Tacayama, ce fut de voir en un moment non feutement fon efprit convaincu, mais fon coxur môme changé de telle forte, qu'il ne fe reconnoilloit flus. Il comprit alors que celui-lá feul eft Dien, gui ficait fe rendre mâtre des coxurs, \& avec cette franchife, \& cette bonne foi, qui eft la meilleure narque dun bon cfprit, il confella fescreurs \& fon ignorance. Il ne donna enfuite au Pere Vilela aucun repos, qu'il ne l'êt.t engagé a le fuivre dans fes Terres, où l'Homme Apoftolique le baptifa avec fa Femme \& fix de fés Enfans. Le Pure fut nommé Darie, la Mere cut nom MArIE, \& l'ainć des Fils fut appellé JUSTE. C'eft ce fameux. JUSt E UCONDONO, fi célebre dans les Relations Portugaifes \& Efpagnoles de ce tems-la, illufre parfes grandes actions, quilui ont donné une place dillinguce parmi les Héros du Japon, plus illuftre encore par fes vertus, \& par fes fouffrances pour lin cau!e de Dieu, \&̈ qui en̂t fait Tormement de fa Patrie, fil'ingratitude de fa Nation n'ề.t pas forcé d'aller mourir dans une terre étrangere, un Homme qu'elle chit dû envier à fes Voifins, fo le Ciel l'eût fait matre parmi exs. 


\section{EITRE TROISIEME. 229}

Tacayama avoit deux freres añés, tous deux d'un grand mérite: le premier dont je n’ai pas trouré le nom, étuit Seigneur de Sava, \& dans une fi grande confidération auprès de lEmpereur, que ce Prince le repoloit fur lui de tout ce qui regardoît la police \& le boit ordre à Méaco. Le lecond fe nommoit VAraDONo, \& nous aurons fouvent occafion d'en' parler dans la fuite.

Quelques Mémoires paroilfent confondre le Seigneur de Sava ayec Daxandono, \& le font répondre à un Maniferte des Bonzes de Jefan contre la Doctrine Chrétienne, où ces Religieux Idolâtres concluvient à abolir cetie nouvelle Religion, \& à challi $r$ du Japon ceux, qui la prêchoient; ils lui font, dis-je, répondre, qu'il falloit écouter les Docteurs Etrangers, avant que de les condamner, \& que ir leur Loi fe trouvoit vériablement pernicieufe, it ne falloit pas les chalfer, mais les punir de mort, conme les Séduteurs du Peuple, les Deftructears du Calie des Dienx, \& les Perrurbatenis du repos pubic. Mais quoique ceci s'accorde aflez avac la réponte, que fit Daxandono aux Dépuiés des Bonzes \& du Yaco, nous verrons bientố, qu'allurément Daxandono n'écoit pas frere de Vatadono, \& ne fut jamais Chrétien.

Les affaires de la Religion alloient aufi toryjours de mieux en mieux dans les Royaumes Occidentaux, principa'ement dans celui de Ferveur des C.rériens dit Firan:tu. Firando, où quoique le Pere Froez, \& Jean Fesmandez n'eulfe:ut pas la Cour favorable, ils ne pouvoient uffire a inftruire, \& a baptifer ceux, qui fe préfentrient. Le Prince Antoine ctoit toujours lornement \& le foutien de cett

$$
\mathrm{K} \text { i.j }
$$

De J. C. $156 ;-6+0$ D: $3910-1 \%$ $2223 \cdot=4$ 
230 HISTOIRE DU JAPON,

Chrétienté naillante, où l'on pratiquoit los

Ee J.C. Vertus les plus fublines arec une ferveur, dont Is cit. les Infidúles mêmes étoient touchés. Les Por-

De Sym-viu. tugais, qui en ćtoient fouvent les témoins, 222. S'exprimoient fur cela à leur retour aux Indes, \& dans leurs Lettres en Europe, en des teimes, qui aurvient paru exagérés, fi tous n'euflent pas tenu le même langage; \& il y en eut plus dun, qui ne pouvant réfifter à la force des grands exemples de détachement, - d'humilité, \& de pénirence, qu'ils admiroient dans ces Néophytes, abandonnerent généreufement de grands biens, \& renoncerent aib efpérances les mieux fondées, pour embralles la Pauvreté Evangéligue.

L'union \& la charié, qui régnoient parmi ces fervens Chrétiens, n'avoient rien de moins frappant que leurs autres vertus; il n'arrivoit print de difgrace à aucun Particulier, qu'auflitôt elle ne fut réparée à frais communs. Le feu prit la nuit de Noèl, de l'année I 64. à la Sacriftie, dans linle de TAcUXima, \& les flammes portées par un ven très-violent, réduifirent en cendres l'Egliée, la Maifon des Millonnaires, \& environ quinze aurres, avant qu'on eût pû arrêter l'incendie. Il faifoit un froid très-piquant, \& les Maifons brûlées appartenoient a de pauvres gens, qui par cette perte, fe trouverent dans la plus affreufe indigence, expolés à toute la rigueur de la Saifon: mais ils n'y furent pas longtems; les plus aifés les recueillerent d'abord, \& le bruit de cet accident ne fe fut pas plutôt répandu dans l'Ille voifine d'I QuizevQUI \& a FrRANDO, que les Fidćles accoururent de toutes parts au fecour's de leurs Freres. 


$$
\text { LIVRE TROISIËM. 23r }
$$

Les Ma: fons furent rebâties \& meublées avec une diligence incroyable; on pourvut aux atres befcins de ces Malieureux avec profunion; enforte qu'ils fe trouvtrent plus a leur aife après leur difgrace, gu'i!s ne l'éroient auparavant; il en arriva autant à Firando peu de jours après, \& la charicé des Fideles n'y parur pas avec moins d'éclat.

Sur ces entrefaites le Pere Froez eut avis, que deux Navires Portugais paroilloient à la hauteur de Firando; \& peu de tems après, il reçut des allurances de ceux, qui les commandoient, quils n'entreroient point dans le Port fans fon agrúment. Le Roi infruit de cctte démarche des Capitaines, envcya fur le champ faire des excufes au Pere, de ce quil ne l'avoit pas encore rétabli dans l'ancienne demeure des Miffionnaires, \& Iui donna fa parole yu'il le feroit incellamment. Le Pere fur cette promelle, fe hâta un peu trop d'écrire aux Commandants des Navires Portugais, qu'ils pouvoient mouiller à Firando; mais s'etant apperç, que le Roi ne fe pielioit point d'ex́suter ce yu'll avoit promis; it prir une Chalonpe. alla au-devant d'un troifiéne Navire no:miré la SaInte Croix, qui fuivoir de près les deux piemiers, \& perfuada fans peine à PIERKE ArmeYna, qui le montoit, de fe tenir au large, jufqu’a ce que ce Prince êtr dégagé a parole. Enfin Tarua Nombo fit d'aliez nanvale grace cequ'on fnuhaitoi de lui, \& Almeyda entra aumitôt dans le Port,

Le Chrifianilime étoit auni toujours fur un tres-bon pied dans le Bungo; mais il derenoit de jour en jour plus florifiane dans le Royaume Bonz-s font d'Arima, \& dans la Principauté d'Onurá. empol mace' $K$ iv

Formets dis Crinings dis l.Goursasur. 


\section{: i2 HISTOIREDE JARON,}

De T. Xengandono venoit de mourir; le Prince for $155 \%$

Le Sun- Mo. 2223

Fils aince étoit remonté fur le Trône, mieux dilpolé que jamais a l'égard des Chrétiens, \& les Victoires de Sumitanda faifoient taire les Bonzes, \& les retenoient dans le devoir. Il y cut alors quelojue commencement de perlécution à Ximabara, ou le nombre des Fideles s'étoit accru de moitić depuis les troubles. Le Prince voulut les contraindre à prendre part à une Cérémonie, gui fe pratiguoir tous les ans en fon honneur, \& ou il entroit de la fupertin tion: ils le refulerent: il les menaça, mais ils répondirent, cu'ils ne craignoient point la mort: \& que quand il voućroit leur procurer l'honneur du Martyre, il les trouveroit à l'Eglife fans armes, \& dans limpatience de répandre leur fang pour une fi belle caufe. Il leur fit dire, qu'il ne demandoit d'eux, qu'une fimple démonfration d'obéillance, ils furent inébranlables; \& comme il eftimoit dans le fonds leur Religion, il cería de les molefter, \& ne put même refuler a leur conitance les eloges qu'alle méritcit. Le's Bonzes ne firent poine paroîre la même é quité ; mais comme ils n'oferent s'en prendre a la Multitude, ils déchargerent leur chagrin lir le Gouverneur LEON, ciu'ils regardoient avec juitice comme le plus ferme appui, \& le Chef de ces braves Chrćriens, \& ils le firent empoifonner.

Ce qui foutenoit fi fort la Religion dans ces Le Po: de quartiers-là, c'étoit la prélence du Pere de c:z r.uced O. Torrez, qui magré fon grandâge, \& fés innutra. firmitez, ne le refuloir à rien. Dés gu'il eu appis la mort de Xengandono, il accourut a Cochinotzu, où il ne lui contra prefque rien pour rendre à cette Chrétienté, fo long emiso 
L I T RE TROISIF ME. 233 apprimée, tout fon premier lufre. Son derfein ćtoit d'aller enfuite à Omura; mais l'alfence du Prince, occupé à pourfuivre quelcjue refte de Comjurés, lui fit reinetrre ce voyage à un tems plus favorable. D'ailleurs Sumianda avoit les armes ala nain, \& les Ennemis des Chrétiens nóloient remuer. Ce Prince reçur dans le même tenas des Letres de Dom SebasTIEN, Roi de Portugal, yui le félicicoit fur $1 \mathbf{a}$ converfion au Chriltianifme, \& fur fon zele à. procurer le même bonheur à fes Sujets, \& qui lui juroit une amitié éternelle. Il fut extrêmement fenfible à cette attention d'uir fi puillant Monaryue; nais il n'avoit pas beloin. d'aiguillon; \& s'il y avoit quelque cholè à délicer dans fa conduite, c'éroir quil le ménageát un peu plus, furtout avec les Bonzes, qui pour êtrefoumis en apparence, n'en étoient pas moins à craindre, \& qui ne lui avoient pas encore poréc tous les coups, dont ils écoient capables.

Cependant la Sainte Croix avoit amené atz Japon trois nouveaux Ouvriers, à lçavoir les PI. MeLCHIOR DE IIGUERED, JeAN CABRAL, \& BalthazAR Acosta, ce qui donna moyen a.u Supćrieur Général d'envoyer du fecours an PereVilela, qui en avoit un preflant befoin; il lui deftina le pere Louis Froez, qu'il fit remplacer dans le Firando par le Pere Acola; $\&$ i) lui joignit Louis Alneyda, mais celui-ci ne devoit point refter a Mćaco. Le Pere Cabral fut envoyé a l'llle de Tacux na. \& le Pere de Figuredo demeura avec de Supérieur a Cochinotzu. Le fujer du voyage d'A :nepda étoir, que le Pere de Torrez voiloit être inftuit par un Í́moin oculaire de l'état de la Religion K. Y

De J. C. I) 6.3.

De Sy,1- Mu. $2224^{\circ}$ 


$$
\text { 20 HISZOORE DU JAPON; }
$$

mansons da capicale de l'Empire, \& des difpofi-

De. J. C. tions cú étoicnt les I'rovinces circonvoifnes à If65. recevoir l'Evangile; \& perfonne n'étoit plus De Syn Nin. propre qu'Almeyda à lui rendre un compte 2225. exact de tout ce qu'il lui importoit de lçavoir.

Particula: Les deux Miflonnaires le joignirent à $\mathrm{Fu}$ trza Vuyage cheo, d'où ils partirent enfemble le dernier duP. Frowz jour de Décembre I 54 . Ils s'embarquerent di. Louis Al-dans un des Ports du Bungo, fur un petit $\mathrm{Na-}$ meida a Mea vire excefivement rempli de Monde, \& is y elfuyerent de très-violentes tempêtes. Il y en eut une furtout, qu: fit périr prefiue fous leurs yeux un Batinent, dont les débris yu'ils apperçrent autour de leur Vailleau, donnerent boaucoup de frayeur à l'Equipage, aux \& Pallagers; mais ce qui inguietoit le plus ces Religieux, c'eft qu'il n'y avoit avec eux que des Idolâtres, qui nuit \& jour offroient des $\nabla \propto c u x$ au Soleil, à la Lune, aux Cerfs, \& à plufieurs autres fortes d'Animaux. Enfin ils aborderent à une Ville, appellće FARA, où ils apprirent, que fix Hommes, \& deux Femmes s'ćtoient tout rúcemment précipités dans les eaux, en invoquant Amida. Toute la Ville étoit encore en rumeur à ce fujet; on avoit érigéaux prérendus Martyrs un petit Temple alfez près du Rivage, \& l'on y avoit ajoûté huit Colonnes, me pour chacun de ces Défelpérés. Le toît du Temple ćtoit hériffé de bâtons, d'où pendoient des efpeces de banderolles de papier; \& :outes les muralles étoient couvertes d'Infcriptions en Vers, oul le mérite d'une Action fi héroique ćtoit relevé en des ternes magnifiques. L'ufage eft de brîler la Barque, qui a fervilà porter ces Fanariques, quand ils ne l'ont pas 12:t couler a fonds avec eux, \& quils fe font 


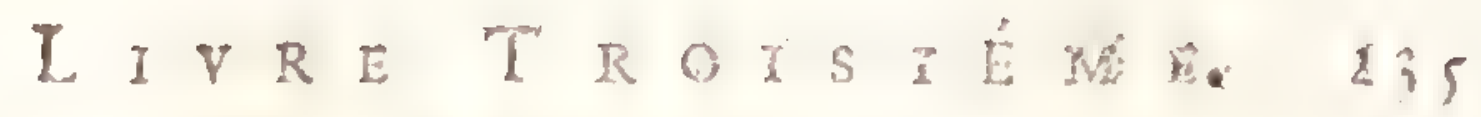
jettés de delius fesbords, comme avoient fait wamente ceux-ci. La curiofité porta les Miffionnaires à examiner de près le 'Temple; ils s'en approcherent, \& ils apperçurent une Troupe de vieilles femmes, qui cur fortoint : elles avoient toures une efpece de Chapelet à la main, \& 1) J. C. I 56 ; elles furent exrémentent lcandalifées de voir que ces Etrangers ne donnoient aucune marque de refpect à un lieu fi faint felon elles? d'autres fe contenterent de plaindre leur prérendu aveuglement. Au refte, le Temple ćroit fans ornement, \& les Miflonnaires n'y remarquerent rien de fort particulier.

De Fara, les Serviteurs de Dieu pourfuivirent leur route vers l'Ille d'Hiv, oul ils arriverent en huit jours. Cette Inte, a, dit-on, cent lieues de circuit: elle n'cft marquée lous ce non dans atucune Carte, que jaye vîe; mais on ne peurgueres douter que ce ne foir l'llile de Xicoco, dont une des provinces porte le nom de Royaume d'Yo, d'autant plus, qu'Almeyda ajoûte, que l'Ine d'Hiu fe divire en quatre Provinces, ce qui oft vrai de l'llle de Xicoco. Le Pere Froez \& Almeyda y rencontrerent quelques Chrétiens, qui avoicnt reçu le Baptême à Méaco, \& qui étoient ćtablis dans cetre Ine. Un des plus confidérables leur rendir vifite, \& les entretint fur la Religion d'une maniere, qui les latisfit beaucoup. Ces Infulaires étoient fort polis, \& parloient trés-bien leur Langue; aufli les Millionnaires commencerent-ils là à connôire la diférence gu'il y a entre les Japonnois du contre de l'Empire, qui fe fentent du voifnnge des deux Cours Impériales, \& qui ont ces Acadómies fordées pour l'inftruction de la Jeunelle, \& ja

$\mathrm{K} v \mathrm{j}$

s Syn-Mut 2225. 


\section{HISTOIRE DU JAPON,}

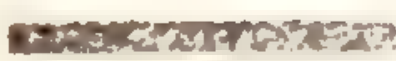

$1)=9 . \mathrm{C}$. 1365.

Dic Sy - Nine $2 \doteqdot 2 j$.

perfection des Arts \& des Sciences, d'ivec ceux du Ximo, oul ces avantages font plus rares. Ils féjournerent huit jours dans l'Ine, \& ils eurent la confolation d'y baptifer fix Perfonnes, puis ils fe rembarquerene, \& gagnereat en fix jours le Purt de XImaguimo, qui eft a peu près a moitié chemin de Fucheo à Sacai.

On ćtoit inferuit dans cette derniere Ville de leur voyage; \& dès qu'ils en furent proche, un Homme de qualité nommé $S_{\text {ANCHE}}$, celuilà même, qui le premier y avoit appellé le Pere Vilela, leur envoya un Bàtiment plus grand, \& plus tû̀r que celui, où ils étoient, avec des rafraichiffements, dont ils avoient ulw extrême befoin. Il comptoit bien de les retenir quelgue tems chez lui; mais dès le lendemain de leur arrivée le Pere Froez voulue partir, \& Sanche n'ayant pû venir à bout de lui faire changer de réfolution, engagea plufieurs Chrétiens à l'accompagner julqu'au terme de fon voyage. Pour Almeyda, qui ćtoit chargé de vifiter tous les endroits, où il y avoir des Chrétiens, il ne put refufer à Sancho de faire quelque féjour à. Sacai, après quoi, comme il fe difpoloit à en partir, il tomba dans une trìs-grande maladie, caulée par le froid excelfif, qu'il a voit fouff urt dans fa route.

Le Pere Froez au fortir de Sacai, alla coucher à Ozaca, qui n'en eft qu'à trois lieues, \& cette nuir-là mêne, le fer prit à un quartier de cette grande Ville, dont il confuma ju:qu'à neuf cents Maifons. Ozaca étoit alors au pouvoir d'un Bonze, qui s'en ćtoir emparé \& y régnoit en Tyran; \& comme avant l'urri rée du Milliomaire, on y avoit ćté infruit da 


\section{I R.E T.ROIEI. E M. E. $277^{\circ}$}

fon voyage, \& que les Bonzes avoit eu foin de publier que les Docteurs Européens ne manquoient prelque jamais d'attirer quelque grand malheur après eux, la Maifon, où il s"étoit retiré, fut d'abord inveltie d'une multitude de Peuple, qui lo vouloit metre en pieces.; mais les Conducteurs, \& fon Hôte, yui étoí Chrétien, le firent heureulement évader. Il eut encore beaucoup à fouffir pendant le refte de fon voyage, \& il y courut de grands rifques. Sans doute, que Dieu, qui le deftinoit à de grandes chofes, l'y voulut difpofer par ces traver'es, qu'on a toujours regardées dans les Hommes Apoftoliques, comme des alfurances infaillibles de grands fuccès. Enfin il arriva en bonre fanté à Méaco.

Almeyda de fon côté, après trois femaines de douleurs rres-vives, fe tronva fi affoibli, ne june De. qu'il fut obligó de s'artêter allez long-oms aicille Cl.é qu'il fut obligé de s'arrêter allez long-tems a rienue de $S_{a}$. Sacai, mais fon féjour dans cette Ville ñy fut cai, \& de fun pas inurile a l'E্vre de Dieu. Tout infirme Fres.

qu'il ćtoir, il prêchoit tous les jours, \& le refte du tems, il l'employoit a des Inftructions particulieres, dont il retiroit de grands fruits. Jai dit aille!rs que lon Hôte avoit un Fils \& une Fille, qui furent baptilés avec lui. La Fille, yui avoit reçu au Baptême le nom de Monicue, étoit alors âgée d'environ quinza ans, \& la ferveur croilioit avec le nombre de fes années. Elle vint trouver un jour le Milfionnaire en particulier, fuivie d'une Femme, gui avoit écé la Gouvernante, \& commença par fe jetter à genoux devant une Image de la Mere de Dieu, qu'Almeyda portoit partout avec lui dans fes voyages. Dans cette pofture, qu'elle ne voulut point quitter, quelyu'inftan-

De J.C. $\frac{\text { I } 564^{\circ}}{\mathrm{S}_{22240} \text { M }}$ 


\section{HISTOIRE UU JAPUN,}

ce que lui en fit le Millionnaire, elle lui parla

De T. C. ainli: «Vous fçavez, mon Pere, que je fuis $156 \%$

"Chrétienne, la bonté infinie du Dieu que

De Syn-Mu. » jadore, m'a encore fait une autre grace,

2225. „s il m'a infpiré le defir de n'avoir point d'an-

a tre Epoux, que lui : je reconnois que je fuis

$\leadsto$ redevable de cette infigne faveur a la pro-

s tection toute puillante de la Reine des Vier-

$\leadsto$ ges, au fervice de laquelle je me fuis dé-

$\rightarrow$ vouće pour le refte de mes jours; \& pour

» tâcher de m'en rendre plus digne en imitant

» fa vie retirée, fon humilité, fon mépris du

s Monde, \& fon application continuelle a la

" priere, mon dellein eft de me faire couper

"les cheveux, puis de fupplier mon Pere de

$\Rightarrow$ me mettre au rang de fes Efclaves, \& de

„ m'employer aux plus vils Miniferes de la

$\rightarrow$ Maifon. Cependant, continua-t-elle, les

s larmes aux yeux, japprends avec bien de la

?douleur qu'on penfe férieufement à me

s) faire ćpoufer un Frere de ma Mere, le

a quel, non-feulement n'alt pas Chrétien,

s mais ent un des Hommes du Monde, qui

s porte plus loin la fuperftition, \& l'attache-

\) ment au Culte des faux Dieux. Vous voyez

s) à quel péril je fuis expofée; ce font fans

s) doute mes péchés, qui obligent l'Epoux fa-

"cré des Vierges à me rejetter: mais je ne

$\Rightarrow$ défelpere pas encore de le reģagner; \& je

$\leadsto$ vous conjure par tout le ze!e que ce grand

3) Dieu vous infpire, pour le falut de nos

$\leadsto$ Ames, de m'aider à vaincre les obftacles,

$\Rightarrow$ qui s'oppolent à mon bonheur, \& d'em-

$\Rightarrow$ ployer votre crédit auprès de ceux, de qui

$\Rightarrow$ je dépends, pour les engager à rompre une salliance, dont je ne fens beaucoup plua 
LIVRE T ROIS I ËM E. 239 э) d'horreur, que de la mort même.

L'Humme Apoftolique loua fort le généreus delfein de la jeune Demoifelle; mais il l'avertit que le genre de vie, qu'elle mćditoit, avoit les difficultez \& fes ćcueils; il les lui expofa, lans lui en rien déguifer: il lui dit que

De J. C. I j6 S.

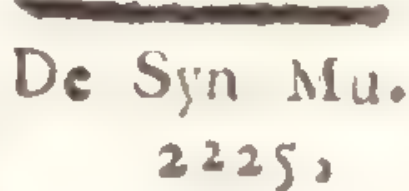
le Mariage étoit un Etat fanctifić par la grace du Sacrement, \& que fes Parens avoient fans doute jugé que le defir de la polléder pourroit peut-ĉtre changer le cour de l'Epoux, qu'ils lui deftinoient; il lui ajôtta, que fi après s'être bien confultće, elle ne $\hat{\mathrm{l}}$. fentoit pas toute la force, dont elle auroit befoin, pour fournir la rude ix épineufe carriere, ou elle vouloit s'engager, elle feroir fagement de n'y point entrer: \& de laiffer à ceux, qui lui avoient donnć le jour, tout le foin de difpofer de fon fort; mais qu'elle feroit fort bien de ne jamais confentir à l'Alliance, qu'on lui propofoit, furtout, fi fon Oncle s'obftinoit à demeurer Infidéle. Elle lui répliqua, qu'elle connoilloit toute fa foiblefle, mais qu'elle a voit mis en Dicu fa confiance, \& qu'elle efpéroit, qu'il lui donneroit la force de triompher d'ellemême, \& de tout ce qui pourroit s'oppofer à un deflein, qui ne pouvoit venir que de lui; qu'elle en avoit eu une efpece d'alfurance dans une épreuve, qu'elle avoit faite d'un jeûne de trois jours, fans rien boire, ni rien manger; que jamais elle ne s'étoit fentie fi forte, \& que ces jours avoient été pour elle un avant-goutt de joyes du Paradis; qu'elle efpéroit que celui, qui l'aveit ainfi foutenue \& confolée dans cetre occafion, ne l'abandonneroit pas dans l'exćm cution d'un projet, dont elle avoit tout fujet ce croire qu'il ćroir l'Auteur. 


\section{HISTOIRE DU.JAPON,}

L'Êprit de Dieu étoit trop fenfible fur cet DD J. Co vertucule Fille, pour lailler aucun doute au isog. Mifionnaire, que Dieu ne l'eât fufcitée, pous

De syn-Mr. 2235. être une de ces Epouies choilies, qu'il prend plaifir a favorifer de fes plus intimes communications. Il lui promit de ne rien omettre pour faire changer de rélolution à láfamille, \& il la renvoya fort fatisfate. Le lendemain il alla trouver Sanche, \& lui reprélénta que le Mariage, qu'il méditoit pour fa Fille, ne convenoir en aucune maniere; que la Loi de Dieu ne permetroir pas a une Niece d'épouler fon Oncle, hors le cas d'une grande néceflité, \& qu'll n'ćdifieroit pas les Fideles, s'il donnoit pour Epoux a fa Fille un Idolâtre entêté, qui pourroit la féduirt, ou la maltraiter enfin que Monigue avoit une averfion inlurmontable pour cet état, \& qu'il lui lembloit q.e le Seigneur vouloit polléder fon cocur fans partage.

A ces raifons Sanche répondit, que fi fa Fille n'époufoir pas celui, fur lequel il avoir jetté les yeux, elle ne trouveroit pas dans toute la Ville un parti, qui lai convint pour la naiflance; que ce Mariage lui avoit paru le moyen le plus fúr de gagner à Jefus chrit un. des plus déclarés Ennemis du (hrifianifne; quil éroit engagé de maniere à ne pouvoir reculer avec honneur, \& fans choquer un Homme puiflant, qui aimoit ćperdíment fi Fille. Pour ce qui eft de la derniere raifon, que vous $m^{\prime}$ 'apporteq, dit-il, je n'ai rien à y répliquer, ficelle eft auffiélle, que vous le croyez. Il protefta quil ne vouloit rien faire en celn, non. plus'qu'en tout le refte, qui pût tant foit peu oldier fa confience, \& quapres lui avoir.r. 
L I V R: T R O I S I E M E. 20. I Erérenté la fituation, oil il fe trouvoit, il s'en remetroir abfolument à dácilion. En effer, comme il vit qu'Al neyda ne goûtoit point les railons, il rompit l'arfaire, lans lo metre en Peine des fuites. Tout le tems que le Millionnaire refta encore a Sacai, il sapplixjua fort a donner à la pieule Monique des regles de conduite, pour le genre de vie, yu'elle vouloit embraller; nuis il avoit compris d'abord, qu'elle recevoit des leçons d'un plus grand Maitre que lui, \& il ne craint point d'allûrer dans fes Letrres, qu'il ne pouvoit la voir fans. étre pénćtré d'une véritable vénération pour la vertu, \& fans fe reprélenter ces illuftres. Epoufes de Jelius-Chrift, que l'Eglife a placées. fur les Autels.

Le jeune Frere de cette fainte Fille, nommé: VINCENT, dont nous avons déja rapporté les premieres ferveurs, n'étuit, ni moins prévenu des bénédictions céleltes, ni moins docile à l'Efprit Saint, qui s'ćtoit emparé de fon coeur. Almeyda lui demanda un jour, jufyu'à quel point il aimoit Jefus-Chrift fon fouverain Seigneur \& fon Mâtre: Jufqu'd donner tout mon. fang pour lui, rćnondit-il: ô que je ferois heureux, ajouta-t-il, $\int i$ je me voyois hacher en piéces pour fon amour! man caur me dit, ce me femble, que Dieu me feroit la grace de lui étre fidéle ju! qu'au dernier foupir.

Il y avoit auprès de Sacai un Seigneur ami. de Sanche, \& fort connu à la Cour de l'Emporemr; Almeyda lui rendit vilite, \& il paroit mêmeque ce Seignear l'avoit invité à le venir voir: du moins le Mifronnaire n'eut-il pas lieu de regretcer le tems, qu'il employa à le vifiter, ayant eu le bonheur de faire dans la mai.

De J.C. 1.5 65. Dis $\operatorname{syn} M u$. 2223 , 


\section{HISTOIRE DU JATON,}

fon \& parmi fes Vallaux, plufieurs profélytes

De J.C. de conf́́quence. Il quitta enfin ce Pays-là, Sx Ig65. comme il eut appris que le pere Vileh ćcoit

De Syn. MIa. 2225 . à Imory, qui n'eft qu’à fix lieues de Sacai, il fe difpofa a l'y aller trouver. Mais fon Hôte, avant que de le laiffer partir, voulut lui donner un repas de cérémonie, \& jaicru, que je ferois plailir à mes Lecteurs de mettre ici ce qu'il en a rapporté dans fes Letres. On y verra quelqu's particularitez affez curieufes touchane les Maifons, les Ameublements, \& le Cérémonial des Japonnois.

De la Chambre de Sanclie, Ámeyda fut conduit par une Porte allez érroite dans une Galerie, au bout de laquelle on lui fit monter un Efalier de Cédre d'une ftructure admira ble; \& fi pr pre, qu'il fembloit, que perfonne n'y avoit encore marché. Cet Efcalier menoit à un petit veftibule, d'ou, par un pallage auffi ćtroit que la premiere Porte, il entra dans la Salle di: Feftin. Ces fortes de Salles ne fervent jamais a d'autre ufage. Tout étoit dans celle-ci d'une propreté, qui enchantoit, \& fi bien travailé, qu'on ne peut rien imaginer de plus fini. Tout un côré ćcoir garni d'Armoires faitc comme les nôtres. Il y avoit à une des extrémitćs de la Salle un Foyer ifolé, tel à peu près, que ceux, dont j’ai parlé ailleurs; il n'avoit pas plus d'une au!ne de circuit. Il étoit conftruit d'une Terre glaife fort noire, mais fi luifante, que les plus belles glaces ne le font pas davantage; on voyoit fur ce Foyer un Trćpicd d'un très-beau travail, \& fur co Trápied il y avoit une Chanciere de fer, qui avoit coûté fix cens écus d'or a Sanche, lequel comptoit encore de l'avoir eu pour rien. On le 
L I V R E T RO I S I É M E. $24 ;$ mit àtable, \& Almeyda, Gans cntrer dans aucun détail, fe contente de dire, qu'on y lervit de tout ce que le Pays produit; cependant il ajoûce, qu'il n'y avoit pas de quoi y faire d'ex- De Syn Mu. cis; mais en récompenfe l'ordre, le filence, la propreté, la modeftie, la gravicé, qui rćgnoient daus ce repas, le charmerent, \& il allure, qu'il faut l'avoir vû pour s'en former une idée, quil loit jufte.

A la fin on apporta le Thé fuivant la coûtume, \& le Maitre du logis fit étaler devant fon Hôte tout ce quifert à le préparer. Il faut être connoilleur, \& connoifleur dans le goût des Japonnois, pour priler ces chofes. Almeyda renarquaun Trépied de fer, qui à force d'avoir fervi, avoir eubefoin d'ctre plufieurs fois raccommodé, \& n'étoit plus qu'un compolé d'un grand. nombre de piéces; il ne fervoit qu’à foutenir le couvercle de la chaudicre, quand on la découvroit. Sanche prétendoit néanmoins que ce Trépied n'avoit point de prix, ni fon pareil dans tout le Japon. Il lui avoit côté mille écus d'or, \& il ne l'auroit pas donné pour beaucoup plus. Tous ces Ufenciles avoient chacun leur enveloppe de foye, \& fe confervoient dars des Etuits précieux, Le Thé, quion fervit à Almeyda, ćtoit en pondre: ceft-a-dire, que c’étoir du Thé Impérial.

Almeyda trouva le Pere Vilela a Imory, dont Moxindono étoit le Maître : ce Seigneur y quefait a lcux śtoit lui-mênse, \& y avoit une Cour, qui ne Mlfiusnins le cédoir, qu'à celle de l'Empereur. Plufieurs le phus urdnd de fes Courcifans étoient Chrétiens, \& ils trai- Cour limpéroient le Pere Vilela avec les mênes refpects, riai..

quion rendoit au Prince même; jufques-la, qu'en public ils ne luiparloient qu'a genoux. 


\section{HISTOIRE B U JAON,}

De J.C Dis qu'Almregda fut arivé, ils le menerent l'andience de Mioxindono. Le Pere Vilela vouI 569.

De $\mathrm{Syn}-\mathrm{Mu}$ $2.22 \mathrm{~g}$. lue l'y accompagner, \& ce Seigneur voyant cas deux Keligieux proternés à pes pieds, profterna aulli de fon côté. On en fut extrêmement furpris, car ce Seigneur étoit regar dé comme le Dien de l'Empereur, qui ne faifoit rien que par fon canal, ce qui le rendoit l'Homme de l'Empire le plus puillant. Il leur fit enfuite préfenter du Thé, \& tout le tems qu'ils refterent à Imory, il lestraita avec une. diftinction, qui ne ie rellentoir, nide fa fortune, ni de lon hmmeur, car il ćtoit le plus. fier des Hommes. Les deux Miffionnaires prirent enfin congé de lui, \& allerent vifiter Xicaidono, ce Seigneur Chrétien, -qui avoit reçule Bapiême avec les deux Bonzes Conmillaires, dont nous avons parlé, il n'y a pas longtems, \& qui étoit Gouverneur d Imory; mais. il étoit alors dans l'fle de CANGA, dont il étois, Seigneur, \& ou il avoit fait bàtir une fort belle. Eglife. Le Pere Vilela y baptifa plunicurs Ido. latres, \& Xicridono, en congédiant les Mirfronnaircs, leur donna une fomme confidérable pour bâtir une Eglife toure femblable à Sacai. L'Ille de Canga eft dins l'embouchure d'une Riviere, qui fe décharge dans. la Mer alfez prìs de Sacai, a cing lieues cie circuit, \& elie eft fort peuplée. Elle fut bientôt toute Chrétienne par les foins du Sei: gneur, \& pendant les troubles, dont nous. parlerons bientôt, elle fervit de retraite aux: Miffonnaires, \& à un très-grand nombre de Fidéles, qui ne le rrouvoie t point en füretś a Mérco, ni daus le Royalase d'Izumi. Peu de jours aprés Almejda retomba ma. 


\section{LITRE TROISIÉME. 24T}

Lade, \& le Pere Vilela le fit tranfporter a Méaco, où il ne guérit qu'au bout de deux mois. Dis qu'il pur marcher, il reprit la vifice, ront il ćtoit chargé, \& il commença par Nara, qui n’eft qu’a une journée de Mćaco. Daxanciono, qui en ćtoit Seigneur, y avoit un ma. gnificue Cháteau, \& pluficurs Gentilshomnes,

qui s'étoient attachés à fi Fortune, y avoien de la Villo de báti de fort belles Maíons à plufieurs étages, \& dans un goût d'Architecture, qui an rochoit fort de de la nôtre. Les Toits en ét ent cxtrêmement minces, \& d'une propreté achevée. Les Murs de la Ville \& les Tours en avoient de femblables, \& le Milfonnaire allinIe que tout cela faifoit un coup d'cil fort fingulier, \& qu'il ne fe fouvenoit pas d'aroir rien vî de fi beau. Il remarque encore, que cans le mortier, dont on fe fervoit en ce Iays-là, ce n'éroit pas du Sable, qu'on mêloir avec la Chaulx, mais une efpece de Papier fort blanc. Les Tuiles, dont les Toits éroient converts en quelques endroits, avoient deux cloigts d'ćpailleur, le fonds en ćroit d'un trèsbcau noir, \& elles éroient ornées de figures, cui produifoient une varietc charmante. On prítend que les couleurs, qu'on y avoit répauduès, confervent leur éclat plus de cinguarite ans.

Les dedans des plus belles Maifons étoien boifez \& lambrillez de Cedre, \& les pióces en éroient unies avec tant d'art, qu'on n'en apfercevoit pas les jointures. On voyoit parinut des bas reliefs de même maijere, qui repréfentoient les plus heaux raits de l'Hiftoire du Jajon, \& le tour étoit varié par

releription Nara.

(n)

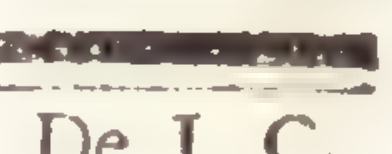

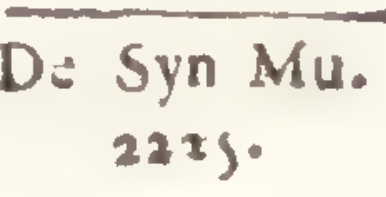

2235.
1565.

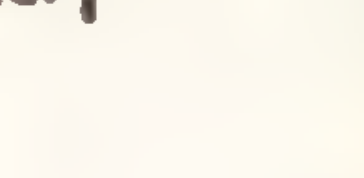




\section{HISTOIREDU JA PON,}

des compartimens, où l'or \& le vernis n"ć-

De J. C. toient point épargnez. Mais rien n'ćtoit comI 65 . parable au travail des Colomnes; elles étoient - S Mr. aull de Cedre, \& d'une feule piéce, quoiL: Ș Mu. qu'extrênement hautes. Les Bazes \& les Cham 22290 pitaux étoient de Cuivre doré, \&r l'on avoit ficulpté fur les Colonnes des Feiillages \& des Fleurs, qui faifoient un très-bel effer. Ce qui furprit davantage Almeida, ce fut un petit Cabinet, qu'on lui fit voir; il avoit quatre bralles \& demie en quarré; \& il étoit fait d'un bois précieux de conleur de Safran, ondé \& nuancé avec des couleurs fí vives, qu'il ne put le perfuader qu'elles fullent naturelles. L'amćnité des Jardins répondoir parfaitement à cette magnificence; il ne fe pouvoit rien voir. de plus délicieux, \& l'odorat n'y ćtoit pas moins charmé que la vûé.

Le Millionnaire vit encore dans ce voyage

Dife i iun un Temple dédié à Xaca, \& nommé Cubucur, ae trus Iem. dont il fut encore plas frappé, gue de tout jlis. ce que nous venons de dirc. Avant gue dy entrer, il lui fallut paffer trois grands Portiques, foutenus de très-belles Colonnes. On montoit au premier par un Efcalier de Pierre bien travaillé, \& la Porte en étoit flanguée de deux Statués Colollales, qui avoit une Malluè à la Main. Dutroifiéne Portique, on monteit au Temple par un fecond Efcalier, qui ne le cédoit point au premier, \& deux Lions d'une grandener énorme en gardoient l'entríe. La Statuè de Xaca étrit au milieu du Temple: ce Dicu étoit affis, \& avoit fes deux fils à fes côtez. Ces trois figures avoient chacune lept coudćes de haut. Tout le Pavé étoit de grandes lierres 


\section{LIVRETROISIE IIE. 44}

quarrécs; les Murailles \& les Colonnes, qui régnoient autour du Temple, étoient peintes en rouce, \& les Colonnes, qui étoient de Cedre, avoient coûté chacune cinq mille écus d'or. Almeyda ne garantit pourtant point ce fait, mais il dit que cela étoit marqué dans les Archives du Temple. Lc Toit, couvert de ces belles Tuiles, dont j'ai parlé, avoit quatre brafles de faillie, \& l'on ne comprenoit pas ce qui pouvoit foutenir en l'air un fi ćnorme poids. Le Miffonnaire ne marque point de quelle matiere étoient les trois Statués de Xara \& de fes deux Fils.

A côté de ce Temple il y avoit un Réfectoire pour les Bonzes; bâti à peu près dans le même goût. Il avoit quarante brafles de long \& douze de large; il étoir joint à un corps de logis, où il y avoit deux rangrées de Collules de quatre-vingt-dix chacune; plufieurs autres Appartemens magnifiques, une tris-belle Bibliotheque, foutenue fur vingtquatre Colonnes d'une bralle \& demie de circonférence; des Bains, toutes fortes de commoditez mónagées avec art, \& furtout une Cuifne, qui fe faifoir remarquer par fon extrĉme propreté, \& par un Ruiffeau d'une eau très-pure, qui couloit au milieu. Almeyda y apperçut une Chaudiere de Cuivre de deux doigts d'épais, laquelle fervoit à faire bouillir le The pour l'ufage ordinaire. Il y avoit fix cents ans que le Temple éroit báti. Il avoir en face un Etang de deux cent cinquante pieds de diamêtre, rempli de Poiflons, aufquels il ctoit défendu fous de groffes peines de toucher.

De-là on conduifit le Miffonnaire au Tem- 


\section{HISTOIR DU JAPON,}

ple de Cos^nga, oli l'on adoroit une Diví

De J.C. nité, à laquelle on ne demandoit que des 1565. profpéritez tempotelles. Avant cue d'y arriDE sun- $\mathrm{i}$.22 $\mathrm{g}$. ver, il hui fallut paller une tris-belle Prairie, d'où il entra dans un Bois fort ćpais, au miliet duquel on avoit coupé une Allée d'environ mille pas de longs; vers le milieu de certe Allée le terrein s'élevoit un peu, \& pour monter plus aifément, on y avoit fait des dégrez de Pierre. L'Allće étcit bordée cle detrx rangées de Pins \& de Cedres entremêlés, qui faifoient une fort belle fymétrie, \& dont les têtes fe joignoient tellement, que le Soleil n'y fouvoit percer.

Almeyda alfire qu'il y vit des Cedres, dont le Trone, d'une rondeur parfaite, avoit cinq brafles de circnit. Un petit Ruillicau cou!o t le long de certe Avenuë, \& achevoit d'en faire un lieu délicieux. En approclant du Temple, on appercevoit deux rangíes de firintres de Tierse guarrées, fur lefiguels ítoient pofies des Lanternes d'un bo's noir avic 'eurs tazes, le tcut enrichi d'ornemons de Cuivre doré c'm grand travail. Clacune de ces Ianternes étcit furmontie d'un Chapiteau de Pierre en forme de Cone, guila couvroit aflez, pour la difendre de la Fluye \& des vents. Ces prenieres Ianternes étoient fuivies d'autres d'un Mćtal doré, d'une magnificerce extraorinaire; on en comptoit en tout cinquarte: clles ítoient allimées tcutes les nuits, \& les noms de ceur, qui les avoient fondćes, étoient ćcritsen lettres dOr fur bes Pilaftres, qui les foutenoient.

On ćcouvroit en wite un forp:ueux Moraftere de lilles, gui s'ćtoient confacríes u fervice 


\section{LIVRESTROISIE M E. 249}

rervice du Temple; ce quelles ne pouvoient faire, qu'à l'âge de quarante-ciny ans. Leur hrbillement étoit fort propre; on ne manquoit point de trouver fur ellles abondament de quoi défaltérer les Pélerins, dont le concours eft toujours fort grand en ce lieu-là. Quand on De J.C. is 6 j.

De Syn Nu. 2225 . 2voit palfé ce Monaltere, on entroit dans un trìs-beau Portique, lequel fé terminoit au Temple, où les feuls Prêtres avoient droit d'entrer. Almeyda y en apperçur quelquesuns, qui étoient affis; ils ayoient de longues Robes de Soye, \& fur la Tête des Chapeaux d'une palme de haut. Les Pćlerins jettoient duns le Portique ce qu'ils vouloient donner à ces plêtres. Le Mifionnaire n’a pas voulu hazarder la Defcription de ce Temple, où il ne put entrer, n'ofant le faire fur les Mémoires qu'on lai en domna. Il en vit au mê. me endroit plufieurs autres, \& partout il re. marqua une fomptuofité, un gout, une délicatelle de travail, qu'il ne pouroit fe laffer d'adinirer. Mais il s'eft furtout appliqué ì bien décrire le DAïnu $(a)$; on fera peutêtre bien-aife de f̧̧avoir en quel ćtat il ćtoic alors, avant que de voir comme il eft aujourd'hui.

Le Frontifpice avoit trois Portes, toutes trois d'une hauteur prodigrieufe. Le Tenn ple ćtoit au milicu d'un Porticue, dont tous les côtés avoient foixante braffes de long. It n'en avoit que quarante de long, \& rrente de large. Les dégrés pour y monter, \& tout le pavé étoient de grandes pierres quarrées. Fn entrant par la grande Porte, on vojoit d'a.

(a) Ou Daibods.

Tome II. 


\section{HISTOIRE DU JAPON;}

bord en face deux Figures Coloffales, \& dewx je 1. C. autres aux deux côtés, qui avoient un air exjis 63. trémement farouche; elles étoient de forxante De $\mathrm{S}_{\text {(i) }} \cdot \mathrm{Mu}$. \& dix pieds de haut. L'une avoit nom TA2.2). MONIEA, \& l'autre Besamondez. Le Peuple difort, qu'ils préfidoient chacun à un Ciel, $\&$ ils avoient aufi chacun un Démon fous les pieás. Au milieu du Temple on voyoir le Dieu Xaca entre fes deux Fils Canon \& XiXI: Canon eft pourtant regardé ordinairement comme le Fils d'Amida; la Statué de Xiaca étorit de Cuivre : elle étoir afife lur une Role, \& le tout avoit quatorze aunes de large; les deux autres n'en avoient que neuf; ces deux dernieres étoient de bois, mais $\mathrm{f}$ bien dorées, \& elles avoisn à la Tête des Rayons d'un fí grand ćclat, gu'on n'en pouvoit foutenir la vie.e. Derriere étoient deux autres Statués, femblables aux deux Collatérales, dont j'ai parlé. Leurs noms étoient Homocondrs \& Zoralis. Ces Dieux ont auff leurs Cieux, où ils préfident. Une efpéce de Tribune régnoit tout le long de chaque côté du Tenz. ple; on y entroic par quatre Portes, \& chaque Tribune ctoit divifée en deux Chambres, dont les Murailles avoient deux braffes de haut: une Chambre toute femblable à cellesci, ćtoit dans le Temple même, \& on y voyoit une Chaire magnifique. Une petite Galerie bien travailléc, large de vingt-fept pouces, environnoit ces Tribunes. Le Lambris du Temple ćtoit loutenu de guatre-vingt-dix-huit Colonnes d'une hauteur prodigienfe; parfaitement rondes, de trois bralles \& demie de circonference, \& toutes de Cedre; il n'y avoit alors, que foixante \& dix ans, que ce Tem- 


\section{I R E TROISIËME. $29 I$}

te avoit ćré achevé pour la premiere fois, \& l'on avoir ćtć vingt ans à le bâtir; trente ans après il fut brû́c \& rebâti, mais avec moins de magnificence, ce qui paroilloit furrour à quelques Bazes des anciennes Colonnes, qui écoient encore fur pied, \& par ou l'on jugeoit que ces Colomes lurpalioient baucoup en grandeur celles, que vit Almeyda. Une Tour de bois Dolidement bâtie joignoit prefígue le Temple, elle ćtoic foutenuë fur trente Piliers, \& elle portoit une Cloche. qui ayant été melurée par un Chrétien en prélence du Milionnaire, fue rrouvée avoir deux bralles dediamerre a lon ouverture, fir bralles de circoniúrance, Si rusis \& demie de haut, fon épalleur écoit de trejze pouces $\&$ deni: elle rendoit un fon trùș-ànéabie, \& gu'o nentendioit de fort loin. Les Cerfs \& les Pigcons font confacrés au Dieu Xaca, qu'on adore dans ce Temple; \& à deux nilles aux environs de la Vilie de Nara, il n'útoit pas permis de leur faire le moindre mal, auff $y$ étoient-ils très-tamiliers, \& eir trés-grande quantité.

De Nara l'Homme Apoftolique fe rendit à TokI, perite Ville, qui n'eil eft ćloignće que de cinq lieues, \& of y avoit pluiteurs Zrie d'un Signour. Chiréticia. Chrériens, quoiqu'aucun Miltionnaire n'y eût jamais paru. Aloreyda les trouva parfaitement inftruits, \& remplis de ferveur \& de zćle. De Toki il alla à SAva, Place forte, firuée fur une Montagne aflez haute à fix lieués de Toki, \& à vingt lieués de Méaco du côté de l'Orient. Le Seigneur de Sava avoit fuivi de près lexemple de Tacayama fon Frere; il y avoir prés àun an qu'il écoit baptré, \& il

De J.C. sjoy.

De Syn. Ms. 222 ;

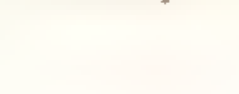




\section{ES HISTOIRE DU TAPON;}

avoit reçû au Baptême le nom de Fançors:

De J.C. Almeyda dit qu'il n'avoit point vâ de JaponI 65. nois d'une plus grande taille; il avoit l'air Ue Sy" Mu. aimable, \& il étoí grand Homme de Guer$2229^{2}$ re. Une bonne partie de les Vallaix ctolent déja Chrériens, quoique le P. Vilela ne lui eût encore rendu qu'une allez. courte vilite; mais ce Seigneur ćtoit lui-même l'A pótre de fa Place. Almeyda, qui trouva le lecret de lentendre parler de la Religion à fés Domeftiques, fans ctre apperçu, allure qu'il leur dit les chofes du Monde les plus touchantes, \& finit fon difcours en leur díclarant, que déformais it ne pourroít plus fe fier à quiconque n'adoreroit pas le vrai Dieu, qui eft celui des Chrétiens, \& qu'il ne mettolt pas $m \hat{c}-$ me au nombre des Hommes ceux, qui fléchiffoient le genoux devant les Idoles du Japon.

Miovintono

La préfence du Miffionnaire n'étoit pas rand vifite à fort nécellaire dans un lieu, dont le Seigneur Alncida. étoit lui-même fi zélé Prédicateur de l'Evangile; Almeyda le quitta donc, quoiqu'ave: bien du regret, \& reprit la roure de Sacai, où il devoit s'embarquer pour retourner dans le Ximo. Il appriz en arrivant dans cette Vil.le, que la vertueufe Monique venoit encore de refufer un Parti très-avantageux, qui s'étoit préfenté pour elle à Méaco, \& qu'elle étoit réfoluë plus que jamais à fervir le Seigneur dans la Retraite \& dans la Pénirence. Cependant on fut furpris à Sacai d'y voir arriver Mioxindono avec une très-grande fuite de Gentilshommes, uniquement pour $y$ rendre vifite au Miffonnaire, dunt il avoi: apiris le retour, \& le dínart prochain pour 


$$
L I \nabla R E T R O I S I E M E .253
$$

les Royaumes Ocidentaux; \& il faut avoiic $r$ qu'une bonne partie des progrès, yue failoir Ia Foi dans les Provinces, gui environnent la Capitale, \& dans la Capirale múnue, ćtoit en partic le fruit de la protection de ce Favori, qui peu de tems auparavant avoit été déclaré Roi d'Imory \& de Cavaxi. Ce Prince avoit un Secrétaire Chrécien, dont la fidélitć \& le délintéreffement avoient contribué plus que toute autrechofe à luidonner une grande idce du Chriftianifine.

Daxandono étoit aufl alors dans un grand crédic aupreds du Cubo-Sama, \& depuis la converfion des deux Bonzes, à qui il avoit donné commifron d'examiner la Religion Chrétienne, il s'étoit déclaré le Protecteur des Milfonnaires. C'étoit la difpofition, oul le P. Froez, qui s'ćtoir rendu à Méaco le dernier jour de l'annće r 65 . y avoit trouvé les efprits par rapport au Chriftianifme. Naytadono Roi de TAMBA, jeune Prince for confidéré à la Cour Impériale, venoit de recevoir le Baptême, \& bien des perlonnes du premier Rang paroilfoient ébranlées par un fi grand exemple. Tant d'illuftres converfions produifirent l'effer, qu'elles devoient naturelle. neur produire; \& malgré le fecours, qui venoit d'arriver au I'. Vilela, il fe trouvoit tous les jours accabléc prr le travail, furrout apres que le P. Froez \& lui eurent ẻtć admis publicjument à l'Audicnce de l'Empereur avec tous les Grands de l'Empire, gui firvant la coutume, venoient rendre leurs Hommoges à ce Prince au commencement de l'année $(a)$.

(m) Il faut fe fouvenir quel'année Japonnuife comnucncevers le cinq ou le fix de levrier.

L iij

Converfions éclabantes. La Religion en grand crícit à Meaco. Les PP, Ii:ela \&: Fruez font acimis à l'Audicnce de l'Éngertur. 


\section{$25+$ HISTOIRE DU JATON,}

C'elt une cérémonie, qui avoir quelgue chom

ne J. C. fe de bien augufte de la maniere, done elle 1565. Te pratiquoit alors. L'Empereur athis a la maDesyn-Mu. niere des Orientaux fur une Eftrade élevće 2225. \& furt fpacieule, dans une Salle, où l'or brilDe qucllc loit de toutes parts, voyoit devant lui d'un maniere fe coup d"ocil prefternés contre Terre tous fes dunne corte grands Vallaux, Rois, Princes, \& grands ce qu'on y Officiers de la Couronne; les uns plus près roit. de fa perfonne, les aurres plus éloignćs, chacun felon fon rang, \& tous un préfent à la main; car c'eft un crime au Japon, que de paŕcitre lés Mains vuides devant fon Supérieur. Un petit gefte du Souverain, une inclination de Tête, bailler, en regardant quelqu'un, l'Eventail, que felon la Coutume du pays il tient à la Main, tout cela eft eftimé une grande faveur. Le Monarque ne laifle pas après l'Audience de s'entretenir affez faw miliérement avec ceux, qu'il admet à fa confidence. Les deux Miffionnaires furent cette fois-ci de ce nombre, \& l'on vit avec une furprife extrême deux pauvres Religieux fort fimplement vêtus, honorés de la converfation de ce Prince aux yeux d'un trìs-grand nombre de Seigneurs, \& des Premiers de la Cour, fur qui il daignoit à peine jetter quelques regards. On apporta enfuite le Thé, \& lEmpereur en fit préfenter aux deux Peres.

Ils lont auff La Mere du Cubo-Sama, qui voulut bien aimis à l'Ali- aufir recevoir leur vifite, non-feulement leur vience de fit les mêmes Honneurs, mais elle leur donna I'meratrice. de fa propre Main certains Fruits, qu'on appelle Zacanas, \& qui fe falent, comme on fait en Europe les Olives. Le Pere Froez dic dans les Letres qu'il trouva cetre Princefle 
LI I R E TRO IS IÉNE。 259 au milieu d'un cercle de Dames, afile vis-avis d'un Oratoire très-propre, confacré a Amina, qui y étoit reprélenté lous la Figure d'un Enfumt, le Diadême en Téte, \& couronné de Rayons; qu'il régnoit dans tout cet Appartement une modeftie, un filcese, \& un air de piété, qui le charmerent, \& qu'il eut bien du regret que cetre Cour, où l'on vivoit d'ailleurs dans une grande innocence, ne füt pas Chrétienne.

Ce jour fut le plus beau, qui eût encore luî fur l'Eglife du Japon, \& aucun nuage n'empêchoir d'elpérer que certe férénicé ne fût durable: tout concouroit même à faire juger que le Chriftianifme alloit dominer dans la Capitale de l'Empire, \& jufques dans le Palais de l'Empereur; mais de if belles apparences s'évanoüirent en un inltant, \& la Chrétienté de Méaco fauvée de tant de dangers, établie fur des fondements fi lolicles, \& cultivée avec tant de foins, ćtoit prefque à la veille de fe voir enfevelia lous les ruines de l'Etat par une des plus écranges Révolutions, qui fe lilent dans lHiltoire. Mais avant giee de raconter les caures \& les circonftances d'un Evénement fi trifte, il elt bon de faire connoitre en quelle fituation les Affaires de la Religion fe trouvoient alors dans les Provinces voifines de Méaco.

Pour farisfaire rous ceux, qui dans cetre C.apitale vouloient traiter avecles Miffonnaires, fo tro duoit il auroit fallu y envoyer tous les Religiend, ion dans cer qui ćcoient alors au Japon; cependant on les $\mathrm{k} \mathrm{m}_{\mathbf{j}} \mathrm{ir}$. invitoit de toutes les Villes des environs, \& même de plufieurs Royaumes affez ćloignús. Le véritable zéle ne fe refufe à rien, \& entre- 


\section{HISTOIRE DO JAPON;}

prend fouvent jufqu'a ce qui parốt impofible; De J.C. fuivant toutes les lumieres de la prudence 1565. Humaine. Depuis quelyue tems le P. Vilela Le Syn-Mu. avoit eu la précaution de bien inftruire des 2225. Myftéres de notre fainte Religion de jeunes Gens de bon efprit, \& de les exercer à la difpute contre les Bonzes, en leur affignant à chacun une Secte particuliere, dont is étudioient le foible, \& yu'ils combattoient enfuite avec un fort grand fuccess. Pour eux, ils étoient prefque toujours en courfe, \& comme les occupations de leur Miniftere ne les empéchoient pas d'obferver tout ce qu'ils rencontroient fur leur pallage, qui paroiffoit mériter quelque attention; j'ai cru qu'on ne me fçauroit pas mauvais gré de rapporter dans l'occafion, ce que je trouverois dans leurs Mémoires de plus capable de fatisfaire la curiofité de mes Lecteurs.

Temple d'A. A quatre lieuës de Méaco le P. Froez vifita milla \& pli. un Temple bâti par d'anciens Dairys en l'honficurs au neur d'Amida, \& fouvent renouvellé par leurs 1:s chofis cu- Succefleurs. Il avoit alors environ fept cents
neulei. quarante braffes de long; les Portes en étoient d'une hauteur prodigieule, \& prefque à l'entrée on appercevoit une Statué d'A Amida, vê. tu comme le font les Brachmanes aux Indes: il étoit aflis, avoit la Tête rafée, aúfi-bien que la Barbe, \& les oreilles percées: quantité de petites Clochetres lui pendoient fur la Téte, \& tout autour de lui il y avoit trente Figures de Soldats armés de dards : d'autres repréléntoient des Ethiopiens en pofture de Danfeurs, ces Vieilles, qui paroifloient de vrayes Sorcieres, \& des Démons.

Les Vents \& le Tonnerre avoinnt aufl leur 
L I V R E TROISI E M E. 257 raprífentacion, \& celle du Tomnerre lureout avoit quelque chofe d'ćpouvantable: les deux côté du Temple s'élevoient en Amphithéátre, \&l'on y montoit par un dégré de fept ve syn-sin. marches, gui régnoit daus toute la longueur de liEdifice. Sur ces dégrés ćtoient rangóes en bel ordre mille Statués, cing cents de chaque côtć, toutes jettées au moule, \& reprélentant le Dieu Canon Fils d'Amida. Ce Dieu avoir le Vilage fort beau, \& trente Bras fort petits, à la rélerve de quaste, qui étoient proportionnés au refte du Corps, \& dont deux étoient polés fur les Reins, \& les deux autres portoient des javelots. Il avoit fur la Poitrine fept Faces d'Homme toutes couronnées \& environnćes de Rayons. Les Statuës, les Clochetres, \& les Chaines, qui les foutenoient, étoient d'Or fin, parfaitement bien travaillces. Tout ce Temple jettoit un éclat, que la vûè avuit de la peine a fupporter.

A deux milles de-là s'élćve une petite Colline, au pied de layuclle on voyoit plufieurs Monaftéres bâtis dans la plus agréable fituation du Monde, \& plufieurs Temples, yui avoient chacun un gout particulier d'Architecture, \& tous quelque chafe de fomptueux. Les Démons étoient adorés dars quelques-uns fous des Figures encore pius horribles \& plus hideules, que celles, que nous leur doinons. Un de ces 'Temples atrira furtout les regards du P. Froez: il étoic dédić au LEzarD, qui slt reconnu au. Japon pour le Dieu des Sciences. C'elt-là que les jemes Etudiants vont prendre leurs Grades, \& l'on y roit fur une Eftrade ćlevíe de trois marches, la Chaire du Dućteur, qui elt chargé d'examiner les Can- 


\section{ES HISTOIREDU J A FON}

didats, avec un Siége bas, où ceux-ci conc De I. C affis pendant leur Examen. Une Figure énorI $6 j$.

Desyn - Mu. me de Lézard, dont la Queué repliéc cn iond faifoit plufieurs tours, occupoit prefque sout le Plat-fonds; \& la raifon, pour laquelle on l'a placée en cet endroir, c'eft afin que les Etudiants s'accoutument, en invoquant la Divinité, à lever les yeux vers le Ciel.

La Maifon de Campagne de l'Empereur. fes Jardins, la beauté de Mćaco \& de les Environs, $l$ a richelfe de fon Commerce, la magnificence des Temples \& des Patais au dedaiss \& au dehors, tout cela étoit alors attdeflus de ce qu'on peut imaginer. Les chofes ont bien changé depuis, non-feulement parce que ce Pays a prefque toujours été le Théâtre des Guerres civiles, mais encore parce que les Empereurs ont tranfporté ailleurs leur Cour. Ce qu'il y avoit de plus frappant alors, étoit le nombre \& la fomptuofité des Monaltéres. Dans un Bois allez proche de la Ville le P. Froez en compta jufqu'à cinquarite, qu'on lui affura avoir été bâtis pour des Fils de Rois \& d'Empereurs, quand ils fe faifoient Bonzes : en parlant d'un de ces Monaftéres, voicice qu'il en dit. s J'entrai par $\Rightarrow$ une Porte luifante comme le verre, tant $\rightarrow$ le vernis en étoit beau, dans une Cour » valte \& lpacieufe, \& pavée de Pierres fore $\Rightarrow$ noites. Tout à l'entour régnoit une Gale3) rie, dont il fembloit que les murailles fuf" fent de Criftal. De-la je paffai dans un 2. Jardin, qui me parnt comme enchanté; $\Rightarrow$ tout y ćtoit extraordinaire: il y avoit d'efэ pace en efpace de petits Tertres tous planэ. tés de jelanes Arbres, ¿z l'on alloir de l'un 
L I V R E 'T R U I S I E ME. 219 s à l'autre par de perits Punts fort propres. s Les Allées du Jardin étoneni d'un gros la$\Rightarrow$ ble luifant, \& de cailloux noirs comine du

s Gaai; on y voyoit des fleurs de tant do forres, qu'il s'sn trouvoit tous les jours de l'annće de fort belles, \& en grand noms bre; ainfi il régnoir dans ces beaux Lieux s) un Printems perpétuel.

Le Miffonnaire vir dans le même Bois un Temple du Temple dédié au Roi des Démons. Sa Sra-Roj dés Detuë, qui étoit effroyable, \& qui tenoit un muns.

Sceptre en main, ćcoir efcortée de deux autres, qui ne lui cédoient point en laideur. Celui qui ćtoit à gauche", fembloit ćcrire les péchés des Hommes, \& l'autre lire ce qui étoit ćcrit; autour du Temple ćtoient repréfentés les différents tourments, que fouftrant les Mćchants dans l'Enfer. Mais comme les Bonzes ont perfuadé ces Peuples qu'on peut fe racheter de ces poines par des oftrandes au Souverain des Enfers, il y avoit peu de Temples plus fréquentés, que l'ćtoit celui-ci, \& oll l'on apportoit plus d'Argent. On montra auli au Mifionnaire dans un autre Temple une Machine de bois faite en maniere de Tour, avec un artifice admirable, \& peinte des plus belles couleurs. Elle contenoit tous les Livres qu'à compolé Xaca. Nous avons déja oblervê, que le nombre en eft prodigieux, \& il n'ent pas polible de croire qu'un feul Homme ait pû les écrire tous, ết -il vécu. plufienrs fićcles.

Le Mifionnaire avoit fort envie d'entendre prêcher un Bonze; mais ceux qui l'accomprgroient, lui dirent d'abord, que la chofe n'asoit prelque pas pollible, \& que is le Pridi-

I.e T. C.

1505

De Syn. Mu. 222 ). 


\section{HISTOIRE DU JAPON,}

cateur s'appercevoit yu'un Docteur Européen

D: 1. C. fût dans ion Auditoire, il delcendroit fur le I) 6 , champ de Chaire. On trouva pourtant moyen

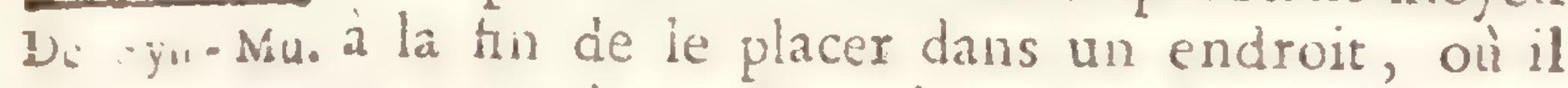
2225. ne pouvoit pas être vû, \& voici ce qu'il nous apprend de cette action dans une de les Lettres.

Manicededent L'Auditoire ćtoit compofé au moins de cinq IisBunzesper- mille perfonnes, \& ce qui attire une fi grande cie.ul. foule de monde à ces Difcours, ce n'eft pas précifement la réputation de l'Orateur, mais la perfuafion, oul tont ces Peuples, qu'en y affiftant, ils obtiennent la rémintion de leurs péchez. Auri quelque prodigieux que foit partout le nombre des Temples, on prêche dans la plûpart, \& tous font remplis a chaque fois qu'on y prêche : il y en $a$, où le même Bonze prêche cent jours de fuite. Une heure avant que le Sermon commençât, toute l'Affemblée fe mit à genoux au fon d'une perite Cloche, \& demeura tout le tems en cette polture, un Chapelet à la main, \& les bras ćlevé; vers le Ciel, répétant fans celle d'un ton harmonieux, Amida, Sauvez-nous. Les Bonzes Budfoiftes ont tellement mis dans la tête à ceux, qui ont embrallé leur Religion, que pour être heureux dans l'autre vie, il fuffit d'invoquer fincérement \& de cocur le Diea Amida, que ces bonnes gens ont fans ceflè à la bouche ces paroles, Amida, Sauvez-nous, \& cue c'eft toujours au nom d'Amida, que les pauvres demandent l'aumône.

L'heure de la Priere étant ćcoulće, on fonna une plus groffe Cloche, que la premiere, $\&$ il fe fit un profond filence. " Alors, dit le »Pere Froez, je vis poroitre un bel Homme 
LI VRE TROIS I ÉME. 26I s revêtu d'une Robe de foye trainante, de s couleur de pourpre, doublée de blanc; il „s s'aflit fur un Sićge fort élevé, \& rellement s placé, que tout le monde le pouvoit ailé- De Syn-Mu. s) ment voir. Il avoit devant lui une table, \& is os s fur cette table un Livre ouvcrt (c'ćtoit le s Foquekio de Xaca) il en lut quelyues lignes s d'un ton grave \& d'un air d'autoritú, le s referma, \& commença fon difcours $\leadsto$. Le Miflionnaire ajoûte, qu'il parla avec une grace, une force, une noblelle de penfées, des termes fi propres \& fi choifis, que depuis ce tems-là il ne fut plus étonné, ni des mouvements que ces Sermons excirent dans l'ame de ce Peuple, ni de la vénéracion \& du crédit, ol font de pareils Prédicateurs.

Le Pere Froez ćtant de retour a Mćaco le Pere Vilela en partit à fon tour, pour fe rendre dans le Royaume de Mino, oul il avoir conçu de grandes efpérances d'introduire le Chriftianifme, mais il n'ćtoit pas encore bien loin, lorfqu'il fur rappellć à la Capirale, où lon jugeoir fa préience nécellaire, parce quion y commençoit à fentir les premieres fecoulfes des Mouvements, qui ébranlerent bientôt l'Empire jufgues dans les fondements, \& dont il faut maintenant que je parle.

Mioxindono Roi d'Imory \& de Cavaxi étoit parvenu au plus haut point de gloire \& de tre l'Emos grandeur, oll un Sujet puiffe jamais efpérer rcur. de monter par la faveur de fon Souverain. Son mérite, fa réputation, plufieurs Victoijes, qu'il venoit de remporter fur les propres Ennemis, après avoir plus d'une fris dompté ceux de fon Maitre, le faifoient regarder de l'Emperear comme l'ormement de fa Cour, \& 


\section{HISTOIRE DO JAPON,}

le lourien de fon Tróne. Mais tant de gran-

De s. C. deurs n'avoient pû encore fatisfaire fon ambix 65 . tion, \& il portoit fes vûes beaucoup plus haut.

De Syn-Mu. L'Empereur l'avoit approché de trop près du 2325. Trône Impérial, pour ne pas l'expofer à la tentation d'y afpirer; \& quand l'ingrat crut qu'il ne lui coûteroit plus qu'un Parricide pour y monter, toute là vertu s'évanouit; il té détermina fans peine a un crime, dont il fe flattoit que le fuccès feroit une vertu.

Il engage Cette réfolution prife, il n'eut pas befoin de Daxandono beaucoup de tems pour exécuter fon déteftable dans la révol-deffein, parce qu'il avoit à fa difpofition toutes te, les Troupes, accoutumées à n'obéir yu'à lui, \& a vaincre guand elles l'avoient à leur T $\hat{\text { ćte; }}$ mais il falloit écarter fous différents prétextes tous ceux, qu'il défefpéroit d'engager tans fon Parti, \& il y réullit. Il fût un peu plus embarraflé au fujer de Daxandono, que fa Charge retenoit nécellairement à Mćaco, \& qui n'ayant gueres moins de crédit à la Cour que lui, n'étoit pas Homme à entrer dans lon projet en qualité de fubalterne, \& le feroit infailliblement échouer, s'il n'y entroit pas. Le parti qu'il prit, fut donc de lui offrir de partager avec lui l'Empire, \& a ce prix il le gagna fans peine. Alluré de ce côté-là, il allembla un grand nombre d'Officiers \& de Soldats, qu'il diftribua en divers quartiers autour de Méaco, il leur donna fes ordres pour fe joindre au premier fignal, \& il avertit tous ceux, qui lui ćtoient attachés dans la Ville, de fe tenir prêts pour agir de leur cô é, quand il feroit terras.

Il étoir difficile que tant de mefures fuffent priles avec un grand focret, \& il falloit an moins les cuuvrir de quelque préiexte, Le Ro: 
I I $\mathbf{R}$ E T ROIS IÉME. $26 \%$ d'Imary fit courir le bruit, qu'il ne faifoit tous ces prćparatifs, que pour une Fere, qu'il vouLoir donner à l'Empereur. En effer quelques jours après il entra dans la Capitale avec un nombreux Cort'ge, alla droit au Palais, fit. en cérémonic au Cubo-Sama fes remerciments pour quelque nouvelle faveur, yu'il en avoir reçûe, \& le fupplia de lui faire l'homneur de fe trouver à un louper; qu'il lui avoit fait préparer dans une Maifon de Campagne allez près de la Ville. (Tn rel remerciement \& une telle invitation donnerent à penfer à l'Empereur; plus il y réfléchit, \& moins il lui parut dans l'ordre, qu'un Sujet vint le remercier en faifant une fi grande montre de fa Puilfance, \& lui donnát un repas a la tête d'une Armée.

Quelques avis lecrets, qu'il reçut en même tems, changerent res foupçons en une jufte défiance : il crut que le plus sûr ćtoit de fortir de Méaco, \& dís la nuit fuivante il partit accompagné de quelques Seigneurs, fans rien. dire de fon dellein, non pas méme à ceux, à qui il confioir ainfi fa Perfonne. Ce ne fut, qu'après avoir fait une demie lieue, qu'il leur découvrit la caule de fa fortie: mais ils lui repréenterent if vivement la honte d'une fuite fi précipitíe, \& l'affection, que tous fes Sujets lui portoient, qu'ils l'obligerent à retourner fur fes pas, \& à rentrer dans fon Palais.

On n'a pas fçu fi ces Courtians, en donnant ce Conteil à l'Empereur, n'avoient pas agi de concert avec les Conjurés; mais il elt certain que Mioxindono fut inftruit dès la Faufle dew mache de l'kmpercur.

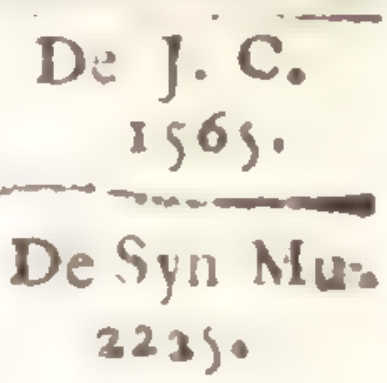
fointe du jour de tout ce qui s'ćtoir palfé. Alors jugeant bien que le fuccès de fon Entreprife dépendoit de la diligence, il donna avis.

LeBeau. Pere de ce Prince fefondleventre. 


\section{HISTOIRE D U JAPON,}

à Danxodono de ce qu'il venoit d'apprendre;

De J. C. \& tous deux, fans différer d'un moment, s'ap$15 \$ 65$.

De Syri - Múu. procherent de la Ville avec toutes leurs Trou2225. toutes les Avenues du Palais. Cela ne fe put faire, fans que le bruit en vint aux oreilles de l'Empereur, qui envoya fon Beau-Pere s'informer de quai il s'agilloit. Dís que ce Seigneur parut fur le Pont, les deux Chefs de la Révolte s'approcherent, lui mirent en main un Billet, \& lui dirent avec affez de hauteur, qu'il le portât à fon Gendre. Il l'ouvrit, \& voyant qu'on y demandoit fa téte, \& celle de l'Impératrice fa Fille, il fit aux deux Trâtres les reproches les plus fanglants, nit le Billet en piéces, entra chez l'Empereur; \& pour lui faire comprendre que tout étoit défefpéré, il fe fendit le ventre, \& tomba mort à fes pieds.

Le Fils de ce Seigneur courut fur le champ à la tête de quelques Braves, pour venger fa mort; mais ils ne furent pas fuivis, de forte qu'il fut aifé aux Ennemis de les envelopper , \& deles tailler en piéces. Au refte il y a tout lie de croire que le grand crédit de cette Famille, \& peut-être aufi l'abus, qu'elle en failoit, avoient caulé dans cette Cour des haines \& des Factions, qui furent en partie l'occafion, ou du moins le prétexte de cette Révolte. Quoiqu'il en foit, tandis qu'on délibéroit dans le Palais fur le parti, quil y avoit à prendre dans une fi grande extrémité, les Rebelles y mirent le feu, \& il fallut fonger à fe fauver. L'Empereur à la tête de deux cents Gardes, \& de quelques Seigneurs \& Gentilshommes en petit nombre, qui fe rangerent autour de fa Perfome, entreprit de s'ouvrir un pallage au 


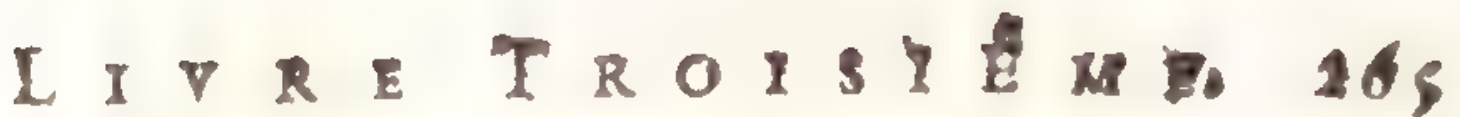

itavers des Ennemis, \& d'abord il renverfa tout ce qui fe rencontra devant hui; mais il rrouva bientôt une réfiltance, qu'il n'étoit pas en état de vaincre, \& après avoir longtems De Syn-Mu. combattu en Héros, il fe vit feul au milieu des Corps morts de fes fidéles Serviteurs, quilui en avoient fait un rempart en mourant, \& ayant en tête une Armée, qui croilloit à chaque inftant.

Il combattoit pourtant encore, \& perfonne n'oloit l'approcher, lorfqu'il reçut un coup de Mort de l'Einpireur. denie pique dans le ventre; il fut enfuite blef- dun de fes lé d'une Fléche à la tête, puis de deux coups Pages. de Sabre, qui lui couperent le vifage. Enfin nágeant dans fon fang, \& ne pouvant plus fe foutenir, il fe fendit le ventre, tomba fur les Corps de fes fideles Serviteurs, \& expira cans l'inftant. Un Page de quatorze ans fe fit adnirer après la mort de l'Empereur; comme il fe battoit en défelpéré, les Rebelles charmés de fa valeur, voulurent l'avoir vif : il s'apperçut bientôt qu'on ne cherchoit qu'à le lafler, $\&$ il crut qu'il y auroit pour lui de l'infâmie à furvivre a fon Maítre. Il s'avance auflitôt vers les Chefs, comme pour leur parler, leur reproche leur ingratitude \& leur perfidie, jecte fon Epće au milieu du Champ de Bataille, pren 1 fon Poignard, s'en ouvre le ventre en croix, puis fe l'enfonce dans la gorge, \& va expirer fur le Corps de l'Empereur.

Pendant ce carnage une partie des Conjurés ćtcit entrée dans le Palais, \& y avoit fait la Fenm: \& co in Frere de main-bafle fur tout ce qui s'y étoit rencontré, l'Empcreur fans diftinction d'âge, nide lexe. La Mere de font mis d l'menpereur, \& un des Freres de ce Prince, mutt. qui ćtoit en bas âge, furent impitoyablement 


\section{HISTOIRE DU JASON,}

égorgés; une partie des Dames \& des autres

De T. C. Temmes du Palais avoientété enfevelies dans Is 65 .

De Syn $\therefore \mathrm{Mu}$. les flanmes, qui gagnoient tonjours, \& conn fumoient des richelles immentes On cher2225 choit avec emprellement l'Impératrice; qu'on avoit fait lecretement fortir de la Ville, \& qui s'étoit réfugiće dans une Mailon de Bonzes. Elle y fut enfin découverte au bout de quelyues jours, \& on y envoya des Soldats, qui lui trancherent la tête. Elle écrivit auparavant à fes Filles, qu'clle mouroit innocente de tout ce que fes Ennemis lui avoient inputé qu'elle recevoir la nort conime une grace du Dieu Amida, qui vouloit fans doute la faire jouir plutôt des dćlices du Paradis, \& la rejoindre à fon Epoux. Elle demanda enfuite au Supérieur des Bonzes l'abfolution de fes péchés, \& ce Prétre la lui mit par ćcrit fur la tête, \& lưi fit faire je ne fçai qu'elle frunagrée, pour gagner l'Indulgence, que ce Vieu, difent-ils, accorde à tous cetix, qui l'ont conftamment honoré pendant lenr vie. Enfin elle mourut avec des difpefirions \& des fentimens, qui en auroient fait une Sainte dans lavraie Religion.

Cruautez des Plufieurs Princeffes, \& des Femmes de toure Cunjuiés. Ils Condrion éroient tombées entre les mains des epargnerit un Frivede lifmo Conjurés, qui après leur avoir fait fouffrir pereur cui tout ce qu'on peut attendre de la trutalité du etoir ton bé Soldat en pareille occation, les égorgerent encre leurs toutes, à l'exception de deur Filles du Cubomains. Sama, qu'un Chrétien fut allez heureux, pour fauver, fans qu'on s'y opposât. Ce qu'il y cut de plus furprinant, c'eft que les deux Chefs de la Révolte épargnerent un Frere du náme Enjereur. Ce Prince étoit Bonze, \& ce fut appasemment ce qui le leur fit négliger; ils 


\section{I V R E TR O I S I E M E. 267}

comproient bien fans doute de s'alliser de la lerfonne; i.s s'en lailirent en effer, mais ils le garderent mal; ils ne s'oppoterent pas non plus a ce qu'on rendic les derniers honneurs au Corps de l'Empereur, \& on lui fit des Obléques magnifiques dans un luperbe Temple, qu'il aroir fair bâtir, \& choifi pour le lieu, où devoic repoler fes Cendres. On alfure qu'un de les Favoris, qui étoit fort loin de Méaco, lorfiue ce Prince fut tué, vint en polte fe fendre le ventre fur ion tombeau.

$I 1$ étoit, ce Cemble, de l'intérêt des Chefs de la Conjuration d'arrécer le plutôt qu'ils fourroient le délordre \& le carnage, pour ne pas s'attirer la haine toujours implacable du Peuple. Mais dans les Guerres Civiles, \& dans toutes celles, où l'Aurorizé eft partagée entre plufieurs, il eft rare que tous aillent bien de concert au même but. Il paroît, que ce fut par-là qu'ćchouerent les projets du Roi d'Imory, \& du prince de Nara. Ceux quiles avoient aidé à fe défaire de l'Empereur, ne les mirent pas en étar de s'emparer du Pouvoir fuprême, \& tout aboutit à répandre bien du fang, \& ì perfécuter tous ceux, qui avoient mointré de l'artachement au Souverain; fans confidérer, que la meileure maniere de fe délivrer de ces dangóreux Ennemis, c'eft de s'en faire des Amis, \& yue ceux, qui fe font oppolés à la Tyrannie nar vertu, fonc des Sujets fidéles, qu'on ne fçauroit trop ménager pour le tems, oú elle fera en quelque façon légitime par le fuccès, ou par la fommifion volontaire des Peuples.

Après que les premieres fureurs furentpaf- Les MiTonfées, on fe contenta d'enyoyer en exil ceux, n i as wicre d. Mcico. 


\section{HISTOIRE DU JADON;}

qu'on découvroit encore avoir eu quelque

De J. Co corte d'attachement a la Famille Impériale : les

If 65 . Miffionnaires furent de ce nonzbre; \& dans la

De SynoMa. 222\%. donleur de voir la difipation de leur Trou. peau, \& de fi belles efpérances évanoiiies, $c$ ? ne fut pas une légere confolation pour eux de n'avoir perdu, que par leur fidélité, \& par celle, qu'intpire aux Sujets pour leur Prince lćgitime, la Religion qu'ils prechoient, les bonnes graces des Traîres, jufques-là leurs plus déclarez Procecteurs; mais dont la faveur ne pouvoit continuer, fans les rendre coupables aux yeux du l'ablic. Lis s'attendoient bien qu'on ne tarderoit pas à les venir égorger chez eux; mais ils commencerent à le raturer un peu, quand ils virent arriver dans leur Logis le Sécrétaire de Mioxindono. Nous avons dit plus haut que cet Homme ctoit Chrétien, \& qu'il failoit honneur à la Religion par fa conduite; il ne fe démentit point dans une conjoncture fi délicate, \& il détefta hatement la trahifon de fon Maître. Il paroît qu'il travailla enfuite à metrre en fûreté la vie des Miffronnaires. Ce qui el certain, c'elt que le P. Vilela eut permifion de fe retirer a Imory, \& le Pere Froez avec Damien, dans l'Ille de Canga. Il y a même bien de l'apparence, qu'ils y furent conduits par des Chrétiens attachez à Xicaidono Gouverneur d'Imory, \& Seigneur de Cangra. C'eft ce que le Pere Froez fait allez entendre dans une Leitre, que nous avons de lui, écrite de cette Ihe au nois d'Août, \& où il dit a la fin : « Pu ur vous faire s connoitre combien tout étoit dif́polé dans " Meaco à embrafler notre fainte Religion, 2) lorfque ce furieux orage ent venu moilon- 
LITRE TR O I I E M X. 269 $\gg$ ner nos efpérances, le jour $(a)$ de notre $\Rightarrow$ départ, nous baptifames deux Bonzes \& s deux Laícs de la Maifon de Mioxindono.

On a même tout lieu de croire, que ce Prince ne changea point dans le fonds de fentiment à l'égard des Miffionnaires; d'ailleurs il avoit dans la Maifon un très-grand nombre de Gentilshommes Chrétiens, aufquels il n'avoit ofé rien déclarer de fon deffein, \& qu'il ne vouloit pas perdre. Enfin on prétend que ceux-ci ayant f̧̧u que Daxandono avoit envoyé des E tit.

Soldats pour brûler la Maifon des Peres, \& pour les faire mourir eux-mêmes, toute cette Noblelle y courut pour les défendre, \& qu'on n'ofa entreprendre de les forcer. On allure encore que ce fut parleur avis, que le P. Vilela fortit de Meaco, pour prévenir l'Edit de Bannillement, qu'on fe préparoit à porter contre lui, \& qu'il fe retira à Imory, où il n'avoit pas à craindre d'être infulté; mais le $P$. Froez \& Danien étant reftez quelques jours aprís lúi dans la Ville, pour voir quel train prendroient les affaires, ils furent obligez d'en fortir aufi, parce que le Dairy s'avifa de révoquer à la priere de Daxandonoles Patentes, que le feu Empereur avoit fait publier en faveur de la Religion Chrétienne, \& yưon leur confeilla de prévenir les fuites de cette affarre, mais toutes ces circonftances ne me parøillent pas également certaines.

Quoiqu'il en foit, à peine étoient-ils partis de Meaco, qu'on y publia l'Edit de profcription contre eux, \& contre leur Religion, qui fut déclarée abominable. Alors les Bonzes Un Bonze Néoplayte. prenci foin des Chrétiens. triompherent, mais ils ne gagnerent pourtant (a) Cefut lis 22 de Juillet. 


\section{HISTOIRE DU JAPON,}

De J. C. 1) 6 j.

De Sin Mu. $2225 \cdot$

rien. Les Ficiéles deftitués de Pafteurs fe fortinrent avec une fermeté, que rien ne put úbran'er, \& le Pere Froez en avoit el avant fon départ des allurances, fur lefquelles il croyoir pouvoir compter. Il avoir chargé un Chrérien, qui avoit été Bonze, de prendre foin de la Chrétienté de Meaco pendaut ion abfence; \& ce Néophyte s'en acquitea partaitement. Il affembloit tous les jours les Fidéles pour les inftruire, \& les exhorter a la conftance; \& leur ferveur devint if grande, que le Pere Vilela fe crut obligé de leur ćcrire du lieu de fa retraite, pour les prier de la modérer; il le fit aufli pour un autre fujet; qui ćtoir d'une bien plus grande conféquence. Ii eut avis que les plus confidérables d'entre eux fe donnoient de grands mouvements pour forcerle Roi dimory \& le Prince de Nara à leur rendre leurs Pafteurs, sils ne pouvoient l'obtenir par prieres; il leur reprélenta que ces démarches pouvoient avoir de fâcheules fuires, \& qu'elles ćtoient contraires à l'efprit du Chriftinnime; qu'il falloit laifler faire au tems, \& qu'avec la patience on viendroit à bout de touies choles.

Ce fut de Sacai, ojue le Pcre Vilela écrivit ces Letrres; il s'étoit retré dans cette Ville, qui étoit libre; le Pere Froez l'y ćtoit venu joindre, \& ils n'y manquoient pas àoccupation. Ies Habitins ne leur en donnoient pas à la véritć bearcoup, mais il leur venoit des Prolélytes de tovtes les Provinces cu Jinon, \& la plîpart étoient des Seigneurs, des Gentilshomner, cu des Bonzes; ils furent mime invitís a l'Tniverfiéc de BaNDCue, mais ils ne crurent fas deveir s'loigner de Meaco, oil la noindre révolution pouroit les rappllex; 
LIVRE TROISIE M E. $271^{\circ}$ ontre que la Moiffon, qu'ils recuëilloient à Sacai, étoir quelque chole de plus certain, que ce qu'on leur promettoit a Bandoué.

Au mois d'Avril de l'Annće fuivante, le Pere Vilela fut appellé dans le Ximo, \& il prit fa route par le Bungo, où il s'arrêta. I e Roi de Bungo faifoit toujours paroitre ure affection pour les Miflonnares, \& un zée pour la propagation de leur Loi, gu'on ie pouvoir fe laller d'admirer dans un prine Idoláre. Comme on lui marquoit all z fouvent la furprile, ou cette conduire jettoit tout le Monde, \& que les Bonzes metroient tout en ulage, pour le regagner, il leur parla un jour en cestermes: "Vous trouvez mau3s vais, que je favorife de tout mon pouvoir " la Religion des Europćens, \& moi je fuis 2) Curpris, que vous ne l'approuriez point. $\Rightarrow$ N'eft-il pas vifible que certe Loi atrire la "bénćdiction du Ciel lur ma Maifon \& fur smes Erats, que nes Coffres fe rempliánt, "\& que mon Domaine s'étend à vué d'oil, » depuis que je protége fes Miniltres? Je ne "pollídois que trois Royaumes, quand ils $\leadsto$ ont mis pour la premicre fois le pied dans \mes Ports, \& j'en polfede aujourd'hui cinc; s mes fimances étoient ćpuifées, \& il n'y a s pas un feul Roi au Japon, yui pour le pré" Cent foit auff riche que moi; vous me ferez $\leadsto$ donc plaifir de ne me parler plus d'une chos fe, fur laquelle je me fuis bien rérolı de "ne pas changer ". Mais ce qu'il y avoir de plus confolant pour les Mifionnaires, c'étoit une certaine odeur de fainteté répanduè dans cetre Eglife, \& qui faifoit fentir yu'elle ćtoit la Mere de routes les autres.

De 1.C.

156566. !

De Syn Mlu. 2229.26.

Zele du Roi deBungo pour la propagation de la rute 


\section{HISTOIREDO JAPON;}

De J. C.

I; 6$\}-66$.

L'Ille de TACAXI, ou depuis quelque tems le Pere de Torrez faifoit fon Ćcjour ordinaire, parce quelle fait la réparation des Royaume:

Dis Syn-Mu. 22224 . de Bungo \& d'Arima, n'ćtoit dója prefique plus peuplée, que de Chrériens. Lille de progrès de CAVAXIR1, oul Edoüard de Sylva avoit ćtés la Religion envoyé en I 64 . donnoir aufir de grandes elMort d'un jeu. pérances d'une entiere converfion; mais le ze.e ne Mifionnai- de ce fervent Ouvrier croiliant avec les fuccès, \& perfonne n'étant à portée de le mo. dérer, non plus que fes auftéritez exceflives, il en fut la victime. Il tomba dans une lan-" gueur, qui le confuma peu à peu; \& on ne le fçut malade, que quand il n'y eut plus de remede. Almeyda courut aufi-tôt à fon fecours, mais il arriva trop tard: le faint jeune Homme ćtoit un fruit mûr pour le Ciel. Il pria Almeyda de le faire conduire a Tacaxi, afin qu'il eut la confolation de mourir entre les bras de fon Supérieur, \& de recevoir les Sacrements de l'Eglife. Il n'y avoit aucun danger à lui accorder cetre grace, le trajet de Cavaxiri à Tacaxi étant allez court. Almeyda le fir donc embarquer; \& à peine eutil le tems de fe confeffer \& de communier, quiil alla recevoir dans le Ciel la récompenfe dhè à les travaux, \& à fes vertus. Il ne fut pas feulement regretté des Mirronnaires, qui n'avoient perfonne pour le remplacer, mais il le fur encore des Japonnois, qui avoient eu occafion de le pratiquer, \& aulquels il s'ćroit rendu fort aimable. Il avoir beaucoup travaillé fur la Langue Japonnoife, qu'il polfédoit parfaitement; il parloit même affez bien le Chinois; \& comme le Bungo failoit alors un grand Commerce avac la Chine, il avoit gagné 
LITRETR O I S I ÉME. 273 zagné à Jelus-Chrilt piufeurs Marchands de certe Nation.

LEglife de Firando étoit toujours perfécutée, \& toujours furvente. Le Roi ne fe contraignoit plus juf́g'ua diflumuler fes fentimens, mais les Chrétiens étoient en grand nombre dans fes Erats, \& y avoient des Chefs Puiffans. D'ailleurs, le Roi ne vouloit pas rompre De T. C. Is63 66. avec les Portugais; ainf il n'aimoit pas les Fidéles, mais il ne les inquićtoit point; il garcoit même des nuelures avec les Miflionnaires; il leur avoir enfin permis de rebâtir leur Eglife de Firando; \& guand elle fut achevéc, le Prince Antoine l'engagea à la vifiter, \& à rémoigner publicjuement l'eltime, qu'il faifoit des Ouvriers de l'Evangile. Les Bonzes ne s'accommodoient point de cetre conauire du Roi, ie progrès de l'Evangile les allarmoit, furtout apris que Fernandez eut convaincu dans une célebre difpute, \& enfuire converti un de leurs plus fameux Docteurs, qui aufi-tót après Con Baptême, renverfa \& brûla toutes les Idoles d'un Temple, dont il avoit la Garde, y drella une Croix, \& en fit un lieu de dévotion. D’autre part, le Fils aîné du Roi, \& quelques - uns des principaux Seigneurs de la Cour, qui penfoient fur la Religion Chrćtienne conme le Roi, \& n'avoient pas les mêmes intérêts que lui à ménager les Miffonnaires, ne manquoient aucune occafion de molefter ceux, qui embralloient la Foi. Cela tenoit continuellement ces Néophytes dans l'attente d'une perf́cution ouverte, \& l'efpérance du Marty se leur en avoit inlpiré un très-grand défir.

On faifoit tomber autant que l'on pouvoit Tom $I I$. 


\section{HISTOIRE DO JAPON,}

ansoratamen

fur le Prince Antoine \& fur fa Famille lesEffets

We 1. $C$ de a haine, gue la Cour portoit au Chriftia$1,56 \%$. nitme; mais ce Pince ćtoir Puillant \& dans 1)e sin-Mu. une grance cftine; il avoit toujours com2:3) 2\%. Mrancić les Armíes avec une auturité prefifue A.tuine le 1: ablolue, \& les Troupes lui étoient fort atta-

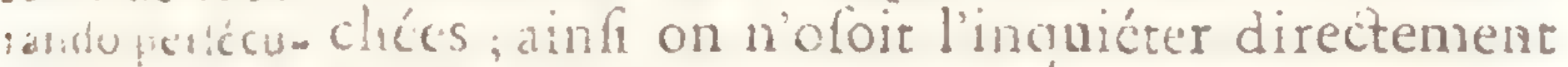
te a caute de lur fa Religion, mais on cherchoit toures les juis Lcico ocuinans de le chagriner, \& il s'en prélenta urc cans le toms, dont je parle, qu'on ne laifía point ćchapper. La conformité d'inclimations, \& un móme zele pour la propagaricn de la Foi, avoient liés entre ce Prince \& Jlimitanda une amitié trís-étroite, malgré les Guerres allez fréquentes, gue le faifoierit 10 Roi de Firancio \& le Prince d'Onsura. ()in en ćroit bien inftruit à la Cour de Firando; rcutefois on n'y avoit jamais conçû aucune dćfiance de la fid́liré du Prince Antoine. Enfin on le lafia de lui rendre juftice, \& peut-ĉtre de chercher imutilement deguoi le rendre criminel.

I.e Roi c.e Le Roi de Firando apprit qu'un Portugais, Mirmo vive accompagné de quatre Japonnois, Sujets dir is licult dince d'Onma, éroit venu a Firando, \& cias. avoit rendu des Lettres de Sumitanda au Prince Antoine; res Lettres he contenoient que de purs complinents: ces deux Princes s'en ćcrivoicnt fouvent de femblables, \& on ne s'útuit puint encore avil̈ d'y trouver a rediIC; mais pour cette fois-ci, on y foupçonna, ou l'on fie femblant d'y loupçonner du mýtére. Le Roi entra dans une fort grofie colere, s'écria que le Prince Antoinc ćtoit un traì:re, orcomna lur le champ qu'on arrêtât lis Chrétiens d'Omura comme Efpions, \& 
IIV RE TROIS I É ME. 275 peu après il les fit fabrer. Le Prince Antoine fit jaroitre en certe rencontre une modíration, a lacjuelle on ne s'attendoit pas; on ne l'avoit apparemment acculć, que pour lui donner liesu de le porter à quelque éclat, qui le rendit véritablement criminel; mais il f̧̧ut fe contenir \& le juftifier, fans domner aucune prife. On n'admira pas moins la joye, que les quarre Chrétiens témoignerent, lorfqu'on leur fignifia l'injufte Arrêt porté contre eux ; car comme ils Çavoient bien que l'averfion du Roi pour leur Religion en étoit le véritable motif, ils remercierent Dieu de la grace, qu'il leu failoit de mourir pour la gloire de fon faine Nom. Pour ce gui elt du Prince d'Omura, il eut bientôt ane occaifon de le venger de laffront, que le Roi de Firando venoit de lui faire.

Quelque tems après, il arriva encore une autre chole, qui fir bien connoitre combien la Cour de Firando étoit envenimće contre la was. Loi du vrai Dieu. Les Fidéles de ce Royaume avoient envoyé aux Indes un Navire, pour y acheter tont ce qui étoit nécelfaire a la décoration de leur nouvelle Eolie. Des Idolàtres en furent avertis, \& détacherent plufieurs Bâtiments, qui allerent attendre le Navire a fon reiour, \& l'enleverent. Parmi les Ornements, dont il ćtoit chargé, il te trouva un Tableau, qui reprééntoit la Mere de Dieu montant au Ciel; on le porta à un Seigneur de la Cour, nommé Catandono, l'Ennemi le plus irréconciliable, \& le plus emporté qu'eût la Religion Chrótienne dans cette Cour. Il n'eur pas plutôr ce Tablenu entre les Mains, qu'il en donna avis au Prince Héritier, \&e $M i j$

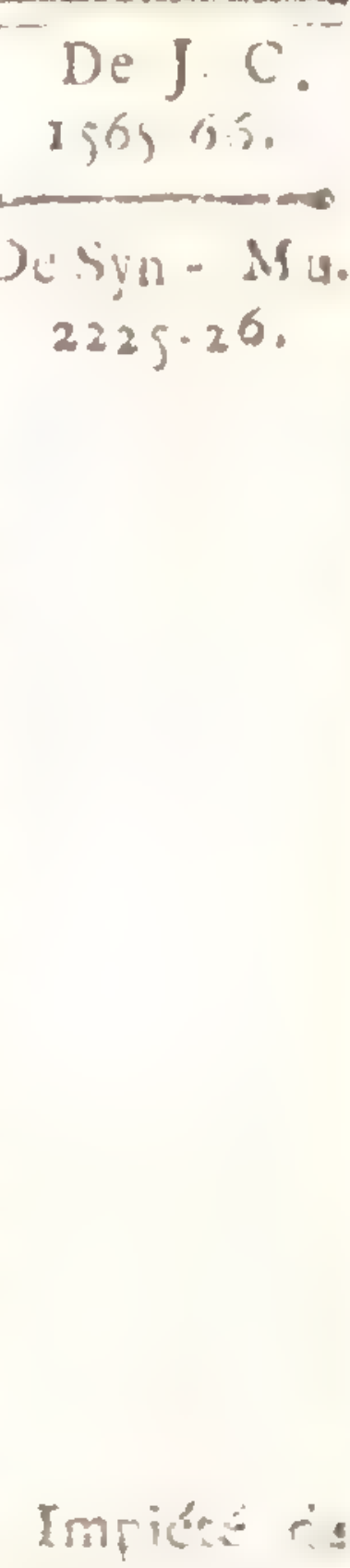
prince icn 


\section{HISTOIREDU JAPAN;}

De I. C. 1) 05.66 .

De Syr-ilu. $2225 \cdot 26$.

tous deux commirent fur cette Image des impićtez, qu'on ne peut rapporter fans frémir. Ils firent plus; car après avoir défiguré le vilage de la Vierge d'une maniere à faire horreur, ils expoferent le Tableau à la rilée des Inficićlts.

Le Prince Antoine, le Prince Jean fon Frere, \& plufieurs Gentilshommes Chrétiens ayant appris cet attentat, réfolurent de venger d'une maniere éclatante l'Honneur de la Mele de Dieu, duftent-ils périr dans une f jufie querelle. Le P. Acofta, qui fut aulfi-tôt informé de leur réfolution, les alla irouver, \& leur reprélenta que leur reflentiment étoit jufte; mais qu'en s'y livrant avec trop de chaleur, ils alloient caufer une Guerre Civile, dont les fuites ne pouvoient manquer d'čtre funeftes à la Religion; il leur perfuada enfin, quoiqu'avec bien de la peine, de s'a. dreffer au Roi, pour lui demander juftice, ajoûtant que ce Prince ne pourroit fe difpenpenfer de la leur faire, s'ils s'y prenoient comme ils devoient pour l'obtenir; mais un nouvel incident, qui furvint dans le tems qu'ils délibéroient fur le parti, qu'ils devoient prendre, aigrit plus que jamais les Efprits.

Un Doneftique du Prince Antoine, entre les Mains duquel on avoit laifi les Oincments d'Eglife, dont nous avons parlé, re:contra dans une Ruë de Firando un des Domeftiques de Catandono, qui avoit eu pare à cet enlevement, lattaqua, \& le défarma. Catandono le prit pour un affront fait à fa Perfonne, \& voulut en avoir raifon; il communiqua fa réfolution au Prince de Firando, \& prit avec lui des mefures, pour renvedir 
I. IVRE TROISIE் M E. 277 I'F glife des Chréciens, \& perdre le Prince Anroine. Celui-ci fut averti de ce qui le tramoit, it en infruifit le Prince Jean fon Frere, \& De J.C. ijoj6i. tous les Chrétiens, qui prirent d'adord les ar- De Syn-Mi. mes. Leurs Ennemis les voyant far leurs gar- $222 \mathrm{j}^{-30}$ des, n'oferent paller outre; le Roi qui fur foupçonnć de favorifer fous main ton Fils, \& Catandono, craignant quils ne reçuffent quelque affront, dont toute fa Puiliance ne pourroit pas les garantir, fit prier le Prince Antoine d'en demeurer-là, lui protelta qu'il n'avoit rien fçû de ce qui s'ćtoit palfé, \& l'allura qu'il employeroit toute fon autorité, pour empêcher que déformais on ne lui donnât, ni aux Chrétiens aucun fujer de nıécontentement.

Certe démarche du Roi fir beaucoup de chagrin aux Bonzes, qui s'étoient bien promis de profiter de ces broüllteries pour perdre les Chrétiens; \& pour atrifer de plus en plus la feu de la difcorde, ils firent enlever una Croix, - qui étoir dans le Cimeriere des Chrériens. Le Prince Antoine fe douta bien d'où venoit le coup, \& déclara publiquement quil faifoic fon affaire propre de tout ce qui regardoit d'Flonneur de Dieu; qu'il f̧̧auroit bien trouver le coupable, ou que les Bonzes lui en répondroient, \& qu'it ne lailleroit pas une feule de leurs Maifons fur pied. Ces inenaces furent eficaces, on le connoiffoit incapable d'en faire de vaines, \& dès le lendemain la Croix fut remife en fon lieu.

Sur ces entrefaites, DOM JEAN PEREYRA, MInilités ru Gouverneur de Macan, arriva de la Chine Roi ie firibe dans un Navire trés-riclement chargé. Son formed'smu.

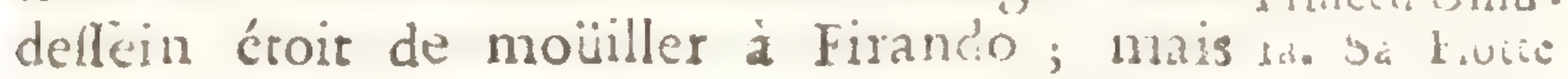
$M i i j$ 


\section{HISTOIRE DU JAPON,}

J) $\mathrm{e} . \mathrm{C} . \mathrm{C}$. 1s,6; 66.

De Syn-Mu. $222 g \cdot 26$. ct battue par avoit fait changer de penfée. Le Roi outré lis Portugais. Chrétiens n'étoient pas bien traités dans ce Royaume, il tourna du côté de Facunda, qui appartenoit au Prince d'Omura, \& voulut bien, qu'on fçut à Firando, ce qui lui ayant appris en approchant du port, que les de déprit de voir que fon Ennemi, à qui il venoit de faire de gayeté de coeur le plus fanglant outrage, en arrêtant \& en mallacrant quatre de fes Sujets en tems de Paix, alloit s'enrichir à fon prćjudice, arma fecrettement une Flotte de cinquante voiles, \& l'envoya fous la conduite de Catandono, pour brûler tout ce qu'il trouveroit de Navires Portugais dans les Ports du I'rince d'Omura. Pereyra, quoique furpris \& bien plus foible que fes Ennemis, ne s'étonna pourtant pas de leur nombre; $\&$ il les reçut avec tant de réfolution, qu'il leur tua bien du Monde, \& même de leurs principaux Officiers, \& obligea la Flor. te a fe retirer fort mal en ordre.

Mort dejean La Chrétienté du Japon fit alors une perte Fernandcz \& ton éluge. qu'elle pleura avec des larmesbien finceres. Jcan Fernandez mourut a Firando (a) d'une langueur que lui avoit caufée l'excès de fes Travaux: Ce Religieux ćtoit d'une Sainteté éminente, qui avoit fouvent donnć de l'admiration à l'Apôtre des Indes. Il travailla long-tems dans les Royaumes de Naugato, \& de Bungo, \& dans la Principauté d'Omura, avec des fuccès, qui firent dire au P. Côme de Torrez, que fr le Japon étoit redevable au P. Xavier d'avoir reçu la Foi, il avoit obligation à Fer-

(a) Le P. Louis de Guzman met cotte most a ia fie de Juin de i'anmée is66. 


\section{I. $Y$ E T R O ISIÉ ME. 279}

nincie. : ne l'avoir pas perdué après le départ du jant. Non-leulement if fçaroit la Lthgion en Homme, qui l'avoit apprife à l'Ecole decelui, qui a rendu les Apótres fi lça- De S.n.M. vants, mais en Sant, qui la pratiguoit aves $2: 2,20$. toute la fublimité de l'Efprit Apoltolique. Aulfi fit-il partout des fruits incroyables.

pour furcroit d'affliction, on apprit que deux Ouvriers d'un grand mérite, qui étoient en chemin pour fecourir leurs Freres du $\mathrm{Ja}$ f. age chalasiat en chemin pour fecourir leurs Ireres du Ja- au Juvia. pon, dont la plûpart excédés de travail, ne fe foutenoient plus, que par une elpéce da Miracle, \& quiferoient arrivés fort à propos, your remplir le vuide, que la mort d'Edöiard de Sylva \& celle de Jean Fernandez avoit laiffé dans cette Eglife, avoient péri dans le Golphe de Siam fur un Vaifleau richement chargé, \& qui portoit de magnifiques préfents du Roi de Portugal pour le Prince d'Omura. L'un ćtoit le Pere PIERRE RAMIRE?, \& laurre fenommoir le Pre Ferninarn fívarez. Cetre perte fut d'antani plus feur au P. de Torrez, qu'il recevoit tous les jonts des Letrres de plufieurs Rois \& Princes, qui Iui demandoient des Mifionnaires. On prétend même, que le Roi de Sian ćcrivit au Pere Acofta, que s'il vouloit venir dans fes Erats, pour l'infruire des véritez Chrétiennes, lui \& le prince fon Fils fe feroient baptiler; mais ce Miflionnaire n'avoit gnrde de courir après des efpérances fi ćloignćes, \& incertaines, tandis que le laul Royaume de firando lui cffroit une Récolte abondante \& allurcé.

Il n'elt prefque plus parlé censis ce tems- Nort du la cul Prince Antoine, ni de fon Frere; lss Pince Aun- 


\section{HISTOIRE DU JAPON,}

Letres, qui nous auroient infruit de la fuite re J. C. de leur vie, fe font appareminent perduës; je trouve feulement, que le prennis nuurue

Desyn-Mu. en Is 82. auffi laintement qu'il avoit vêcu, 2285-26. \& qu'il fut jufqu'a la fin de fes jours tel que nous l'avons vî́ jufqu'ici. Nous le verrons ailleurs revivre dans fes Enfants, \& dans le refte de fa Famille, qui fe montra toute enticre digne d'avoir eu un tel Chef, \& qui fit bien plus de cas des vertus, qu'elle avoir héritćes de lui, que des Etats, qu'il lui avoit lailic's, puifqu'elle ne craignit point de les facrifier à fa Religion.

Defcription Mais tandis que le Roi de Firando mettoit tout dı Royaume en ufage, excepté la force ouverte, pour abolir de Gritto. dans fes Etats une Religion, que fonintérêr l'obligeoit à y tolérer; un Prince jufijues-là autant, \& peut-être plus que lui attachć au culte des Idoles, l'introduifoit dans les fiens: ce fut le Roi de Gotto. Cing petites Ines, dont il y en a trois alfez peuplées, formoient alors ce Royaume, yui n'elt pas plus confidérable que celui de Firando, \& qui fait partie du Figren. Ces Iiles ne font guéres éloignćes que d'une demi lieué les unes des autres; \& ce font les premicres Terres que l'on trouve, quand on arrive des Indes à Nangazaqui, dont elles font prefqu'à la vîé; il n'y a que la plus grande, ou eft la Ville Capitale, qui foit véritablement fertile, mais la Chaffe eft abondante partout ; \& les Habitants y font un allez grand commerce de Poillons, furtout de Baleines, \& de Sel. Nous avons vî dans la Relation de Fernand Mendez Pinto que de fon tems le Gotto relevoit du Roi de Bungo, mais il eft certain quari n'en relevoit pas alors. 


\section{LIVRE TR・ISIE ME. $28 \mathrm{I}$}

Dans une de ces llles, il y a une Montagne de fix lieuís de long, qui eft toute couverte d'Arbres, \& oul l'on trouve un Animal fort lingulier. C'eft un Quadrupede, dont la Peau elt veloutée \& de coultur d'or; fa Figure approche de celle d'un Chien, mais il a les pieds beaucoup plus courts; la Chair guikit. eft rrès-délicate, \& lorfqu'on le fert fur la Table des Grands; il eft de la magnificence de le fervir tout entier arec fa Peau. Quand cet Animal eft vieux, il fe jette dans la Mer, \& devient Poiflon. Louis Almeyda, gui rapporte cette fingularité dans fes Letres, ayouë que la premiere fois, qu'on lui en parla, il fe prit a rire, mais qu'il fut bien-tôt convaincu par fes propres yeux qu'on ne lui en avoit pas impolé. Un jour qu'il ćtoit à Oc CA, Capirale du Royaume, on apporta au Roi de Gotro un de ces Animaux, qui n'étoit encore métamorphofé qu'à demi. Commme le Roi lui en fit préfent, il eut tout lo moyen de le confidérer a loifir. Une de fes Pattes étoit déja prefque toute changée en Nageoire, \& l'on voyoit de pareilles nailfances de changement en plufieurs autres parties de fon Corps.

La Ville d'Ocica, dont je viens de parler, curatere se n'elt pas tont à fait fur le bord de la Mer, Relicion des mais elle eft très-peu éloignée du Port, qui Hahitanis du eft aflez bon. Elle ent à cirquante lieués de Firando au Midi, à foixante \& dix de Cochinotzu, \& à foixante ou foixante-cing de Facata. Les Habitants de Gotto font fort finperititieux. Les Aftres réglent tout chez eux. ils ont des Aurues, dont l'emploi eft d'oberver lez jours heureux ou malheureux, \&e $\mathrm{Mr}$ 


\section{HISTOIRE DU JAPON,}

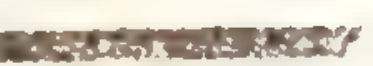

De J. C. Is 5966.

D. Syn $\wedge \%$ $222\} \cdot 26$

les Miniltres des faux Bieux font tous-puilfants dans ces Ines. On y adore furtout deux Divinitez, qu'on ne connoit point ailleurs, \& qui font repréfentíes fous des Figures de Géants; on sadrelle à l'une, pour obtenir les biens de la vie prefente; on fait des voux à l'autre, pour être heureux après la mort; \& tous les ans au commencement de l'annce on célćbre en l'Honneur de la preniere une $\mathrm{Fê}-$ te, quidure quinze jours, pendant lefquels il n'eft pas permis de parler de la mort, ni de l'autre Monde, de peur que quelgue penf'e chagrinante ne virnne troublar la joye, que la Divinité exige alors de fes Adorateurs.

Le Roi de En Is63. de Gotto étoit gouverné par un rutedcman-Prince, que fa douceur rendoit extrêmement C: uri Milion- cher à fés Sujets: nous avons vâ qu'il avoit haire o \& on appuyé les Révoltés d'Omura; le fuccès fi dust. peu attendu, \& fi miraculeux d'une Guerre, ou felon toutes les apparences humaines Sumitanda devoit fuccomber, l'avoit extrêmement frappé; il voulut étre inftruit d'une Religion, pour laquelle ce Prince avoit fi généreufement rifuué fa Couronne \& fa Vie, \& connoitre le Dieu, qui l'avoit rendu victorieux avec une poignée de Soldats ramallés, de tant de forces ligućes. Il envoya un Gentilhomnie à Firando avec une Letre pour le Pere Acolta, par laquelle il invitoit ce Miffionnaire à fe tranfporter dans fes Ifles. Le Pere communiqua cette Letre au P. de Toryez, qui ne put fe réfoudre à tirer de Firando le feul Prêtre, gui fut dans ce Royaume; mais il envoya au Roi de Gorto Almeyda \&r Laurent, lequels simbarquerent à Cochim notzu vers la fin de Janvier de l'annce y éá. 
L I V R E T R O I S I F $M$ E. 283

Ils apprirent en arrivant au Port d'Oaica, que le Roi n'étoit pas dans cette Capitale; d'a:lleurs on y célébroit la Féte, dont je vieis de parler: ainfi ils ne jugerent pas a pro ros de dćbarquer. Le Roi revint au bout de quidques jours, les invita à fe rendre auprés de lui, \& donna ordre qu'on leur préparát un Loyement commode. Aufi-tôt ils mirent pied à terre, \& ils n'avoient pas encore fait beácoup de chemin, pour aller du Port à la Vilte, qu'ils rencomererent le Roi, qui venoit au-devant d'eux. Ce Prince leur témoigna une extrême envie d'être intruit des Mylteres du Chriftianifme; \& comme la Cour étoit fort grolle à caufe du commencement de l'an. nć, Almeyda pria le Roi d'engager toute certe Noblelle à allifter aux Conférences, giti fe tiendroient fur ce fujet. Le Roi le lui p:omit, \& ajoûta que lui-même ne manguegon aucune occafion de l'entendre. Il avoit día eu la précaution de dilpofer toutes c'ioles ponr cas Alfemb!ces; il y avcit deftiné une des plas belles Mailons de la Ville, \& avait fait magnifiguenent orner l'Apparteneat, ou elles devoient fe tenir. Cet Appartement contiftoir en deux Salles lóparées par un ridea ; l'une étoir pour la Reine \& les 1)ames, qui pouvoient ainfi entendre fans ctre vî́s: on avoir ćlevé dans l'aurre une ERrade, fur laqualle le Roi voulur que les deux Minfonnaircs fulfent afis a les cốćs. Les demx Sulles fe trouverent remplies: \& Aluneyda pria le Roi de trouver bon gue Iament, quil éroit Japonnois, pariat lúl, ajoútane gu'un Erranger conme lui, ne devoit pas le

Di.r. Ij6j-66. J): 5 , $10-1,14$. $222\} \cdot 26$.

Cumment iis cu dunt recus. 
284 HISTOIRE DOJATON,

hazarder à parler devant une fi augufte $A f-$ De T.C. fenublée.

ig66. Le Roi agréa cette propofition, Laurent De Syn-Nu. Parla le premier jour pendant trois heures, 2226. \& le fit de maniere, qu'Almeyda, qui l'avoit Lc Roitom. entendu plulieurs fois, ne douta point que le malake, \& Dieu ne lui eût, felon la promefle yu'il en a l's Burcspll- faire à fes Apôtres, infpiré la plûpart des choblient que c'ett fes, qu'il dit en certe occafion. Tonte l'A fifcule efic de la tance parur charmée, \& le Roi furtout fur Wuss. tellement touchć, que les Miflonnaires ne le crurent pas éloigné du Royaume de Dieu. Il $y$ avoit tout à le promettre d'une fi favorable difpofition; mais par un de ces fecrets jugements de Dieu, qu'ilfaut fe contenter d'adorer, il arriva que le Roi, qui de fa vie n'avoit été malade, fut tout à coup faif d'une fiévre ardente, accompagnée de douleurs trèsvives par tout le corps. Les Bonzes ne manquerent pas de publier aulfi-tôt, yue les Dieux punilloient ce Prince, d'avoir voulu introduire une Secte Errangere dans fes Etats, \& ils n'eurent pas beaucoup de peine à perfuader un Peuple accoutumé à ne reconnoitre aucune caufe naturelle des accidents funeftes.

Le lendemain le Roi fe trouva encore plus mal, \& l'on ordonna par tout le Royaume des Pćnitences, des Prieres \& des Sacrifices, pour appaifer la colere des Dieux. Ces Pénitences conflitoient à garder la concinence, \& ¿ s'abftenir de manger de la chais: mais tout fut inutis, \& le mal du Roi ne diminuoit point. On peut juger de l'injuićrude, que caula ce concretems aux deux Ouvriers Eva'1gćligues, \& du danger, qu'ils couroient de 
LIVRE TROXSIEME: 285

In pirt d'un Peuple fuperfitieux, paflionnć pour ion Roi, qui ne pouvoit manquer de leur attriburer l'útat, ol étoit réduit ce Prince, \& que les Bonzes animoient fans ceile cont:e eux. Ils ne perdirent pourtant pas courage, ils mirent toute leur confiance au Seigneur, \& ils efpérerent que le Ciel tireroit fa gloire de ce qui fembloit devoir fermer pour toujours ce Royaume à l'Evangile.

Parbonheur les Bonzes entreprirent de guérir le Roi par la vertu de leurs fortiléges, \& n'y rćufirent pas: le Malade empira méme beaucoup apres qu'ils eurent fait toutes leurs fimagrées dans fa Chambre. Alors Almeyda fit prier ce Prince de vouloir bien lui permetrre qu'il le vit : le Roi y confentit, \& apris qu'Almeyda eut examiné la nature du mal, il y applíjua un Reméde, dont il avoit déja fait plufieurs expériences heureufes. Dìs le lendemain la fiévre fe trouva confidérablement diminuće, \& le Milionnaire en prit occafion d'engager le Malade à metre fa confiance au feul Dieu, qui eft le fouverain Arbitre de la vie \& de la mort, de la fanté $\&$ de la maladie. Le Roi le lui promit, mais fur le foir les douleurs de Tète augmenterent: Almeyda les lui appaifa fur le champ, \& Ini procura une nuit fort tranquille. Le troilićne jour la fiévre difparut entiérement, \& le lendemain il ne reltoit plus au Malade, qu'un peu de foiblelle.

La joye fut grande dans tout le Palais \& $\mathrm{fe}$ connmuniqua bientôt par tout. On ćlevoit ;ufqu'au Ciel le Médecin Européen, \& le Roi lui envoya de fort beaux préiens, y’il difribua à divers Seigneurs, dont il vouloit feménager la

De J. C. Is 66.

De Syn-Mu. 2225.

Ils entreprennent d: le guérir, \& ne réuttiftent pas. Almeid, eft plus heureux.

Nouvel aes cident, qui met la Religiun chrétien. ne en den. g:e dans ce Rayaume. 


\section{HISTOIRE DU JAPON,}

protection. Quelques jours après le Roi voultu

De T.C. que Laurent recommençât fes inftructions; 1566. toute la Cour s'y trouva, excepté ce Prince, qui BtSyn Mu. ne crut pas devoir s'expoler encore; mis dís 2226. La feconde Conférence, tandis que Laurent parloit, le feu prit à un des Quartiers de la Ville, \& portć par un vent impétueux, en réduifit une grande partie en cendres. Il furvint dans le même tems au Roi une tumeur à un doigt, layuelle lui caufa de très-vives douleurs, \& plufieurs Perlonnes de la Famille Royale, tomberent malades. Alors tout le Peuple ie révolta contre les Religieux Ftrangers, \& il y avoit tout à craindre pour eux, fi Almeyda n'eût promptement guéri le Roi \& les autres Malades. Encore ne pût-il jamais ôter de l'erprit à bien des gens, que le Ciel étoit irrité contre le Royaume, a caufe du mépris, qu'on y paroilfoit faire de l'ancienne Religion. Rien n'eft plus urile aux Hommes Apoftoliques, que ces revers: non-feulement ils épurent leur zele, \& fortifient leur confiance; mais, ce qui leur eft encore plus nécellaire, ils les retiennent dans la défiance d'eux-mênes, ils les empêchent de s'attribuer rien du fuccès de leurs travaux; ils leur font fentir que tout vient de Dieu, \& ils les confervent dans l'humiliation de coeur, en exerçant un Miniftere, qui les rend égaux aux Anges mêmes: enfin ils leur font roucher au doigt qu'ils font envoyés pour planter \& pour arrofer, mais que c'ent à celui qui les envoye, à donner l'accroiflement.

Aimeyda fort

Almeyda étoit pourtant toujours bien venu du fotto fur à la Cour, mais tout fe palfoit en civiiitez; \& regretté du comme il ne voyoit plus anciun jour à la conkoi. verfion de ce Peaple, il ćcrivic au Pere de Tor- 


\section{LI $\nabla$ R E T R O IS I E M E. 287}

rez, gu'il croyoit fon f'́jour inutile dans le Gotto. Le Roi, qui en fut averti, n'cublia rien pour le retenir; fes manieres, fa vertu, fa diuctur charmoient ce Prince, le défin- De Syn-Mu. téreliement, avec lequel il diftribucit fes re- 2226. medes à tous ceux, qui en avoient befoin, lui faroilloir quelque chole de grand, furtout guand il l'oppoloit à la conduite fi contraire des 3onzes, les plus intéreflés \& les plus durs des Hommes. La Maion des Mifíonnaires étoi: trop petite, pour l'affluence de ceux, qui venoient les confulter, ou qui s'adrefloient à cux dans leurs maladies, mais prefque perfonne ne parloit de fe faire Chrétien, ce qui dítermina enfin Almeyda, fitôt qu'il eut reçu lis ordres de fon Supćrieur, gui le rappellrit, à demander au Roi la permiftion de fe 1etirer.

Le Roi en conçut un très-grand chagrin, il lai dit qu'il avoit tort de délelpérer fitôt du fuccès de fes travaux, \& que luimême \& fon Fils penfoient lérieufement à fe déclarer Adorateurs du Dieu des Chrétiens. Il lui ajoûta, que s'il vouloit bâtir une Eglile dans fon Royaume, il pouvoit choifir telle fituation, qu'il jugeroit à propos : enfin qu'il n'avojit qu'à demander, \& que rien ne lui feroit refuré. Des offres fi obligeantes ne firent point cha:nger de réfolution au Miffionnaire; il répondit qu'il avoit fes ordres, aufquels il ne pouvoit fe difpenfer d'obćir; mais pour ne point irriter un Prince, dont la faveur devoit être ménagće, il lui protefta, qu'auffitôt qu'il pourroit difpofer de foi, il reviendroit fe confacrer au falut de fes Sujets, ou qu'il engageroit le Pere de Torrez à lui envoyer quelyu'un à fa plaze. 


\section{HISTOIRE DU JAFON,}

De J. C. Le Roi lui demanda cette promelle par écric; I) 66.

De Syn-Mu. 2226. \& il la donna. Ce Prince voulut aufi lui donner un Ecrit de fa main, par lequel il s'obligeoit, en cas qu'il tint parole, d'accomplir de ton côté toutes les promelles, qu'il lui avoit faites; mais Almeyda lui dit, qu'il ne vouloir point d'autre aflurance, que fa parole Royale, $\&$ il s'embarqua avec fon Compagnon.

Une Tem- A peine ćtoit-il en Mer, qưune Tempête péte l'oblige à violente le mit à deux doigts du naufrage, \& Le Roi en té - le contraignit de rentrer dans le Port. If crut moigne une alors que Dieu le vouloit dans ce Royaume; il grandejoye. manda au Pere de Torrez les raifons, qu'il avoit d'y refter, \& le pria de lui faire fçavoir fur cela fes derniéres volontez. Le Roi, la Reine, \& toute la Cour furent charmés de fon retour, \& le Roi écrivit fur le champ au Pere de Torrez, pour le conjurer de lui lailer le Mifionnaire; il accompagna Ca Lettre de toutes :fortes de rafraîchillements, \& il combla plus que jamais les deux Religieux de carelles, $\&$ de tout ce qui pouvoir les aflurer de fon eltime \& de fon anirić. Aucun Prince du Japon n'avoit encore eu avec les Donteurs Etrangers des manieres plurs aimables. Il y eut nueme bientôt quelque chofe de plus; les Inftructions publiques recommencerent \& devinrent erfin fructueufes. Vingt-cing Genilshommes demanderent le Baptême, ce qui parut faire beaucoup de plaifir au Roi; \& quoique les Bonzes euffent encore voulu prendre avantage contre la Religion Chrétienne de quelques ravages, que firent des Corfaires fur les Côtes de Gotto, on les laifla dire; les Prolélytes conrinuerent à fe difpofer au Sacrement, \& la 
L I V RE T R O IS I É M E. 289 Cour à donner les mains à tout ce qui pouvoit avancer l'Euvre de Dieu.

Mais rien ne perfuada plus les Millionnaires, quils pouvoient compter fur la confance De Syn-Mu. \& le courage des nouveaux Catéchumenes, que la docilité, qu'ils trouverent en eux, lorf- Progrès de qu'il fallut leur déclarer, qu'un Chrécien ne la Religion pouvoir avoir qu'une Fem!ne, \& qu'une Epou- dans ceRuyau fe légitime ne pouvoir jamais être renvoyée, hors certains cas extraordinaires, pour faire place à une autre; car la Polygamie \& le divorce étoit fort en ufage dans ce Royaume. Ils s'étoient attendus l'un \& l'autre, que ces Luix feroient un écueil, oi la réfolution de plufieurs échoueroit; ils fe tromperent heureufement; ni tendrelle, ni railon d'intérêr, ni la crainte de fe brouiller avec des Familles puilfantes, rien n'arréta aucun de ceux, qui te difpoloient au Baptêne; les Concubines furent éloignées; lindillolubilité du Mariage fur acceptée, \& le nombre des Chrétiens devint en peu de rems très-confidérable.

Bientôt même la Capitale ne fut pas la feule à profiter du féjour des Serviteurs de Dieu dans ce Royaume. Almeyda fut appellé à Ocura petite Ville, qui n'elt qu'à une lieue \& demie dOcica. Le Seigneur du lien, fa Mere, \& trois de fes Freres furent les premiers à fe foumettre à l'Evangile, \& leur exemple fut en très-peu de tems fuivi de prelque tous les Habitans. Le principal T emple de la Ville fur renverié, \& fur les ruines on bâtit une fort belle Egliéc, yui fut achevée avec une diligence incroyable: aufi perfonne ne s'útoit-il difpente d'y metre la main. Lawrent, qui ćtoit refté dans la Capitale, eur encore la confolation d'y 
290 HISTOIRE DU JAPON,

voir une Enliféerigúe au vrai Dicu, \& la Chré-

ve J. C. tienté du fotro fut dis-lors regardée comme 1) 60.

De Syn Mu. 2226. une des plus floriflanees du Japon.

Une Guerre, gui furvint fur ces entrefaites au Roi de Gotto, domna lieu à ce Prince de Guerre en-reconnoitre, qlie fi rien n'étoit capable d'obliire le Fitaniu ger les Chrétiens à violer la Loi de leur Dieu, \&le Goltu., il pouvoit auff s'affurer de n'avoir point de Sujets plus fideles. Quelques Corfaires de Firando avoient fait peu de tems auparavant une defcente dans une des Ifles du Gotto, y avoient maffacré quelques-uns des Infulaires \& emmené plufieurs Prifonniers. Les Gortois apres s'être reconnus, arneront en diligence une petite Flotre, coururent après l'Innemi, \& ne l'ayant pas rencontré, firen: fur les Côtes de Firando ce que les Firandois avoient fait fur les leurs. Dans le même tems un des Vaffaux du Roi de Gotto, \& qui étoit Beaufrere du Roi de Firando, fe révolta contre fon Scigneur, lajuel fut averti que Tayua Nombo ćroit l'Auteur de cette Révolte, \& ne viloit à rien moins, qu'à le détrôner. Il comprit bien quil n'y avoit pas un moment à perdre, s'il vouloit détonner l'orage. Il fit les préparatifs avec autnt de fecret que de promptitude, \& entra fur les Terres de fon Valal, avane que ce Seigneur fçût qu'il armoit : aufh tout plia devant lui, \&le pébelle fut obligé d'aller chercher une retraite chez fon Beanfrere, qui non-feulemen le reçut bisn, mais entrepric encore ce le rétablir \& de le venger.

Il arn a auntiôt une Flote de de' $x$ cents Voim les, \& comme le Roi de Gotto ne f̧avoit pas fur lantle defes It s fondroit l'orage, il prit le parti de border toures les Cútes, on il y arois 


\section{I RE TROISIÉME. 29I}

à craindre une defience, de Troupes rúgićes, $\&$ de faire retirer les Habitans dans les Mnntagnes \& dans les Bois; Almeyda, qu'une fiévre violente avoit fort aftoibli, fut cbligé de s'y retirer auli avec fon Compagnon, \& hatigue De J.C. $\frac{1566 .}{\mathrm{DE}} \sin -\mathrm{Mu}$ du voyage augmenta confidcrablement fon 2226. mal. La Flotte Firandoife parut enfin, \& aborda à la plus grande des Ines du Gotro, brîla quelques Villages, \& après vinge-cing jours de pillige, elle remit à la voile, \& le retira. Le Roi ce Gotto avoit de fon côté pris les nrefures pour avoir une Flotte, mais comnse elle éroit de moitić plus foible que celle de Firando, i) ne jugea pas à propos de fe mefurer avec celle-ci, \& il ne la pourfuivit point; mais it envoya la fienne dans une Ille dépendante du Roi de Firando, oti l'on n'étoir point du tout fur fes gardes, \& où elle fe dédonmmagea pleinement des ravages, que les Firandois avoient faits dans le Gotto.

Or la coutune ćtoit dans ce Royaume, qu'avant de fe mettre en Campagne, les principaux duGouverner pol, tedion delicu pour y faire ferment de bien fervir; \& entrau- fur les Cliré. tres fuperfitions, dont cette Cérémonie étoit tiens. accompagnée, il falloit boire dun certain vin, qui aroit ćté auparavant offert \& confacré aux Dieux du Pays. Le Roi préfentoit lui-même la coupe à tous ceux, qui étoient dans l'Afiemblée, \& chacun avant que ce boire difoit: Puife toute la colere des Dieux tomber fur moi, fi je manque à la fidélité, que je dois a mon Seigneur. La Flotte de Gotro étant fur fon départ, ceux, qui y avoient queloue Commanderaent, s'allemblerent chez le Roi, fuivant la coutume; plufieurs ćtoient Chrétiens; \& le 


\section{HISTAIRE DU J APON,}

De J.C. Vin, fut un peu embaraffé: il prit néanmoins Is 66. le parti de faire conme les autres, mais en

Ie syn:Mu. proteftant, quil regardoit ce Vin commeun 2226.

Vin ordinaire, \& qu'il n'y reconnoiffoit aucune veritu. Il fe difpofoit donc a le boire, lorfque le Gouverneur d'Ocica, qui étoit aufli Chrétien, \& avoit reçu au Baptênıe le nom de JEAN, lui cria d'arrêter, \& de ne pas donner un fi grand foandale a tous les Fideles: puis s'approchant du Roi avec une refpectueufe affurance, « Seigneur, lui dit-il, vous lerez 2 bientôt convaincu que vous n'avez point de "Sujets plus dévoués à votre fervice, que lis »Chrétiens; mais voulez-vous quie le tèm » ment, que vous exigez aujourd'hui de nous, 2) foit inviolable ? trouvez bon que nous ju"rions par le feul Dieu vivant, que nous ado"rons, \& quir feul peut donner la victoire. " Le Roi, qui connoilloit cet Officier, \& qui 'śtoir prévenu en fayeur de fa Religion, confentit que les Chrétiens juraflent de la maniere, qu'il leur ćtoit permis de faire, \&: fit comprendre qu'il comptoit bien autant fur eux, que fur les Infidéles. Ėin effet les Chrétiens le diftinguerent fort dans l'Expédition, dont j'ai parlé, ils portoient tous des Croix fur leurs habits, \& quoiqu'il y eût eu quelques actions aflez vives, aucun d'eux ne fut tué. Il n'y eut pas jufqu'aux Infidéles, qui n'attribuaffent cet événement à la wertu de la Croix, \& tous la voulurent aufi avoir pour fauvegarde fur leurs Armes.

Ce que je viens de rapporter du refus, que firrent les Chrériens de prêter le ferment à la maniere accoutumée, eft placé par quelijues Au- 


\section{Li i R E T R I s I E M E. 293}

teurs avec allez de vraifemblence avant l'entrée du Roi dans les Terres de fon Vallal, \& ils ajoutent que le Rébelle ayant accepté, ou n’ayant pû́éviter la Bataille, que le Roi lui prélenta, comme on commençoir à le mêler, un jeune Chrécien nomnć XYsTE, remarqua le Gínćral Ennemi, qui par la valeur \& la bonne conduite infpiroit beaucoup de réfolution a fes Troupes, courut à lui, l'attaqua, \& après un allez.long combat, qui tint quelques rems les deux Armées en fulpens, le prit au défaut de fon Armure, \& le renvería a fes pieds; que la mort du Chef fut le commencement de la déroute de l'Ennemi, \& que ce fut pour venger la mort de ce Général, que le Roi de Firando fon Beaufrere fit équiper cette Flotte de deux cens Voiles, dont l'etfet répondit fi peu au bruit, quavoit fait un fi grand Armement. Cependant la fauté de Louis Almeyda ne fe rétabliflant point, il fut co:1traint de retourner à Cochinotzu. Laurent refta encore quelque tems auprès du Roi de Gotto, mais il fut auff rappellé pour aller a: fecours di Pere Froez, qui le demardoit, \& ce Royaume demeura deux ans entiers fans aucun MiTionnaire.

Ia Chrétienté de Ximabara fe foutenoit toujours malgré le crédic \& la perfécution des Cretiens de Bonzes, \& les variations du Prince, qui efti $\mathbf{X}$ :unabara. noit dans le fonds le.Chriltianifine, mais qui craignoit encore plus les Miniftres des faux Dielax. On fe crut même en Is66. au inoment de voi: des Marryss dans cette Eglife; mis les Fidéles fe préfenterent de fi bonne grace a la mort, que le Prince ne put fe réfoudre à perdre quinze cents Sujets, dont la fidé-

De J.C. $\frac{1566 .}{D \cdot \operatorname{syn} M u_{0}}$ 2226. 


\section{HISTOIREDU JA:ON,}

lité envers leur Dieu lui répondoir de celie,

De I C.

is ' 6 .

$\rightarrow-\infty$

De $\sin \mathrm{Alu}$. 2226.

Progres de la Fui dans le Ximo. qu'ils lui devoient a lui-même, \& qu'il f̧avoit bien quils lui garderoient au peril de lur vie, quand il n'exigeroit rien d'eux contre leur confcience.

Le Pere de Torrez, le Pere de Figucrecio, \& le pere Vilela parcouroient alors avec ce grandes fatigues cette Partie du Ximo, \& recueilleient partout de grands fruits de lenis fleurs. Le Royaume ci'Arima en féparé decelui de Fingo par uin grand Bras da Mer, ou il y a plufieurs Ines très-peuplées, gui relevent de ce dernier. La plus confidérabie éroin alors pollédée par deux Seigneurs, dont liun portoit le Titre de Seigneur d'A le nom de l'Ine; \& l'autre s'appelloit le Seigneur de Xecur. Quelques Auteurs ont fait deux Ines de ces deux Erats, mais ils fe font trompés. Le Seigneur de Xequi, qui éroir Parent du Roi d'Arima, demanda un Miflionnaire au Pere de Torrez, amguel il envoya pour cet effet un Courier à Cochinotzu, qui n'eft yu'a fept ou huir liencs de Xecui; \& le Sunérieur lui accorda le Pere Vieta, qui en peu de mois baptifa pius de fix cenosperonnes.

La Principaucé d'Omura s'o!nvoit aufít toujours de plus en plus a l'Evangile par le zele \& la fermeté de Sumitanda; il elt vrai que plufieurs Idclâtres zélés, dont il ne pouvoit encore purger fes Etats, \& quil avoit inutilenuent travaillé à gagner à Jefus-Chrift, ne paroilloient attentifs, cu'aux occafions de le faire périr avec tous les Chrériens, \& tout auI tre que lui auroit fuccombé cent fois fous tant d'efforts rednublés; mais les Vertus Chrćticnnes n'avoient point diminuć en lui les Vertus 
L I V R E T R O I S I Ë M E. 295

Militaires \& Politiques; \& il n'ćroit aucun Prince au Japon, qui fût plus craint de fes Voilins, nimieux obéi de fes Sujers. Voiciun fait, qui montre avec quelle vigueur il licavoit - gir dans les occafions les plus périlleules.

Il apprir en is 6r, quine Troupe de $\mathrm{Mu}-$ tins s'ćtoient failis d'un Chätean allow près de a Capitale, \& d'oli lls pouvoient incommoder l'mme $a^{\prime} \mathbf{O}$ beaucoup cetre Ville. Dis le mème jour il al- nura. fembia tource qu'il trouva de Troupes fous ia main, \& alla inveltir ces Reballes. Sur lo foir il choilit trente Braves, tous Chrétiens, leur demanda s'ilséroient prérs a le fuivre partour, oli il voudruit les mener; \& tous ayant répcrdu que rien ne les artêteroit, tant qu'ils l'auroient à leur Tète, il donna ordre au refte de l'Armée de fe mettre en bataille entre la Ville \& la Place aflićgće. Dìs que la nuit fut cblicure, il conduifit la Troupe d'élite par divers lentiers fort lecrets, \& arriva avcc elle fans avoir ćté reconnu jufqu'au fommer de la Montagne, firr laquelle la Forterelle ćtuit bâtie. Il en occupa tontes les Avenues, \& à la pointe du jour il fit il brufuuement fon attaque, que la Garniton furvrice ne rendit point de combat: Elle voulut le Guver du cóté de la Ville, mais elle y rencontra l'Armée du Prince, qui acheva de la tailler en piéces, \& il n'en relta pas un feul, quinefút, ou tué, ou pris.

Après ce fuccès la Chrétienté d'Omura alla tonjours croilfane en nombre \& en ferveur Marrvis imas Miais ce que les Victoires de Sumitanda produifoient dans cetie Principauté, la perlécuion \& le fang des Martyrs le faifoir dans le Fisando. Le Roi y continuoit à regarder les Chré-

De T. C. 1566.

De Syn-Mu. 2226. Action de vigueur du
l'rime 


\section{HISTOIRE DU JAPON,}

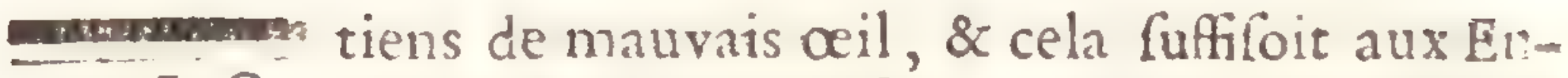

De I. C. nemis du Chriftianifme, pour leur faire tous 1566. le mal, dont ils fe pouvoient avifer. QuclD: Sy - Mu ques-uns poulferent même leur haine juf cu aux 2226. dernieres extrćmitez; un Bonze nouvellement converti paya de fa Tétede zele, quil failoit paroître pour la Caufe de Dieu. Quelgues autres Néophytes eurent le méme fort; mais les Infidées ne gagnerent à cela, que de voir le Culte de leurs Lieux plus abandonné.

Fin du Livre troifiéme. 


\section{SOMMAIRE}

\section{DUQUATRIEMELIVRE.}

T E Frere du feu Empereur Se réfugie 1 dans une Forterefle appartenante à $\vec{V} a-$ tadono. Eloge de ce Seigneur. Caractere de Nobunanga. Vatadono marche contre les Rebelles E les défait dans plufieur's Combats. Nobunanga rétablit le jeune Prince fur le Thrône Impérial. De quelle maniere il traite les Bunzes. Vatadono obtient le rétabliffement des Miffonnaires à Méacu, malgréle Dairy. I.e Pere Froez rifite Nobunanga. Comment il en eft regu. Edit du nouvel Empereur en faveur de la Relirion. Nobunanga exerce une autorité absoluë dans l'Empire. Un Bunze enttreprend d'en faire chafer les Miffonnaires. Le P. Froez le reduit au fillence dans une difpute en préfence de Nobunanga. Edit du Dairy contre la Religion; ce qui en arrive. Defcrintiondu Royaume de Mino, E de la Ville d'Anzuquiana. Vatadono écrit à un Bonze puiffant pour l'engager d̀ ne plus perfécuter les Mifronnaires; réponse, qu'il en reşoit. Il eft difgracie, avec quel courage il foutient fa difgrace. Il rentre en grace, Eu le Bonze eft chafé de la Cour. Erat de la Religion dans Le Bungo. Etabliffement du Fort de Ningazanui. Le Prince d'Omura ne veut plus que des Chrétiens dans fes Etats. Baptême de fa Famille. Mort des P. de Torrez E Vilela. I, e Seigneur de Xequi Apofat Es Perrécuteur. Ses Tome II. 
Suiets Chrétiens demeurent fermes dans la Foi. Grandes converfions dans l'Ifle d'Amacuf.x. Perfécution fufcitée par les Bonzes. Conftance admirable d'un Enfant. Le Roi de Bungo protege les Chrétiens. Baptême du Prince d'Anacuja, qui convertit la Princeffe, fon Epoufe. Perfécution à Ximabara. Le Prince de Gotto demande le Baptême, E le regoit en fecret. Son zille à procurer le falut des Gottois. I.es Bonzes entreprennent de le ramenter au culte des Dieux. Ce qui fe paffe a ce Jujet. Réfolution du P. Valla. Mort du Roi de Güto. Veitus du nouveru Roi. Mauvaife pulitique de Nobunanga. Il eft attaqué par ceux, qui ont fait mourir le feu Empereur. Valeur de Vatadono. Sa mort tragique Lorfqu'il étoit fur le point de recevoir ie Baptême. Ce qui rafure le P. Froez fur fon falut. Masfacre des Bonzes de Jefan par ordre de Nom bunanga. L'Empereur Se brouille avec ce Prince. Le bruit de la marche de Nobunanga diffipe deux grandes Armées. Il offre la paix a l'Empereur, qui la refufe. Il Se rend Maître de Meaco, Eu de l'Einpire, El laiffe l'Empereur fur le Thrône. Il fait brüler plufleurs Maim Jons de Bonzes, Difgrace dia Roi de Tamba. Converfion d'un Aveugle Jçavint. Zele des Chrétiens. Ligue contre le Prince d'Omun.z, qui en triomphe, E acheve la converfion de tous Ses Sujets. Ce qui Se paffe à cette occafion dans la Ville de Cori. 


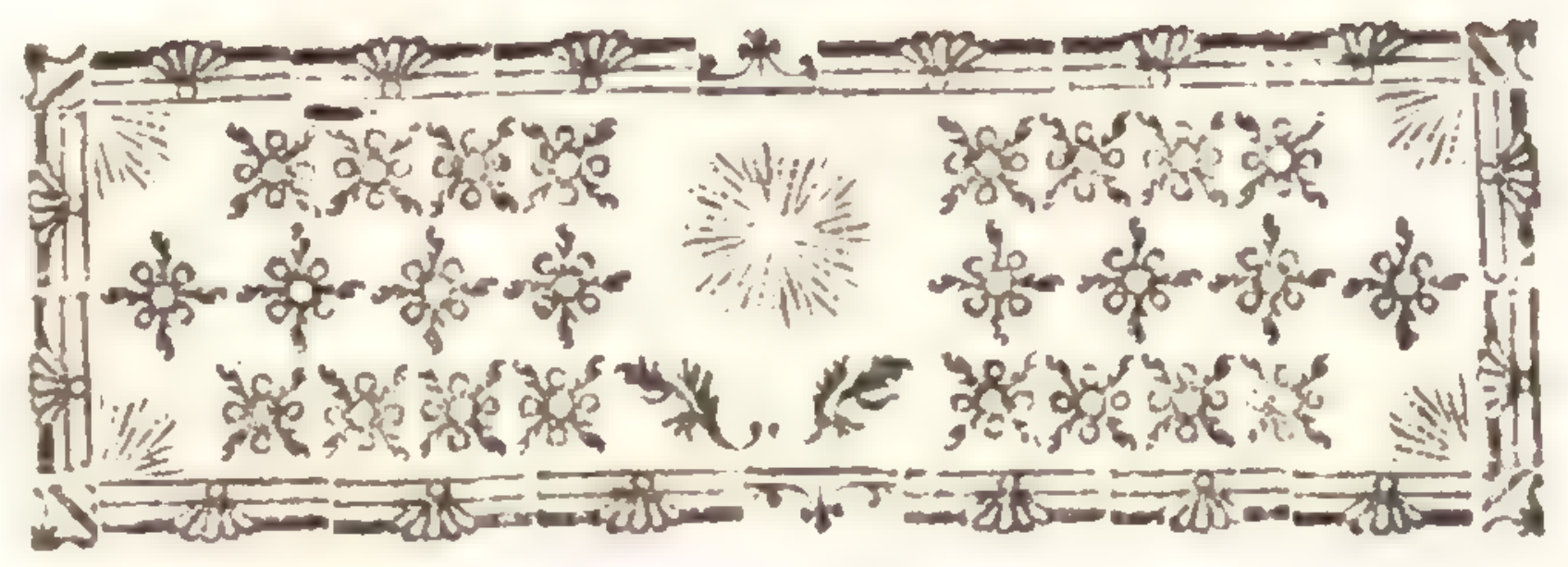

\section{H I S T O I R E \\ D U}

\section{J A P O N.}

N.

\section{LIVRE QUATRIEME.}

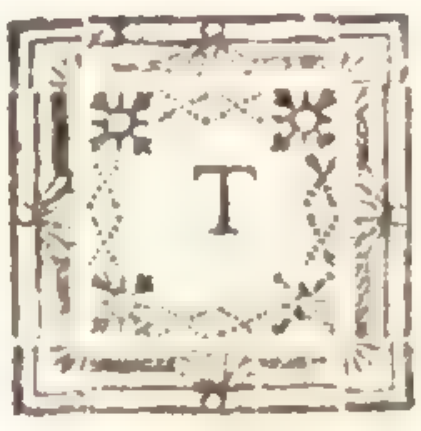

ANDIs que le Chriftianifme devenoit de jour en jour plus florilfant dans les Provinces Occidentales ciu Japon, une nouvelle Rívolution le rétablit dans fon

De I. C. $1 ; 66$.

De Sriatilu. $2 \div 26$. prenier luftre a Múnco, \& la Providence parut ciipofer tellement les choles, qu'on cut tont lieu d'efpérer de le voir avec le tems devenir la Religion dominante dans tout l'Empire. Voici ce guton a pu f̧avoir de plus cer tain de de grand Evénement, dont on n'a pas ell affez de foin de nous inftruire dans le ciétail : les Mirionnaires, qui ćtoient fur les lieux, s'ćtant contenté de nous en apprendre les principales circonftances, autant qu'il étcit néceflaire pour l'intelligence de leurs Mćmoires, un peu trop bornés, a ce qui concernoir leur Miniftere. 


\section{HISTOIRE DU JATON;}

Mioxindono \& Daxandono voyant peu de De J.C. difpofition dans la Capitale de l'Empire a les Ij66. reconnoitre pour Souverains, s'étoient avifús

De sya Mu. 2226.

Le Freredu reu Empreur réfugie ans une Forcroffe. ce faire courir le bruit, qu leur deflein n'aroit jamais ćté d'ufurper la fuprême Puillance, mais de délivrer lespeliples de la tyrannique dc. mination de quelques Particuliers, qui gouvernoient fous le nom du feu Empereur; que n'ayant pû fauver ce malleureux Prince, à qui fa bravoure aveugle $\&$ hors de faifon, avoit fait creuler l'abyme, où il s'éroit précipité, ils étoient rélolus de placer fur le Trône Inpérial lo Ponze Cavadolvo Voyacata, fonfrere, cont l'humeur douce \& bienfaifante, \& la pićté, qu'il avoit puifée dans le Monaftere, faifoient efpérer un regne plus heureux. Quoiqu'ils puflent dire, ils ne perfuaderent perfonne, non pas même le jeune Prince, a qui ils promettoient l'Empire, \& qui fe royant leur Prifonnier, ne fongea qu'à fe tirer de leurs mains. Il y réufit, \& les Rebelles furent étrangement furpris d'apprendre gu'il ćtoit dans la Forterelle de COCA, d'oì toute leur Puilfance n'étort pas capable de le tirer.

Cirnftercic Cette Place appartenoit a Vatadono, Frere Vutrituno, à ainé de Tacayama, \& cader de François Seiy) ii cette lior-gneur de Sava, dont nous avons rapporté plus 2.u㧒 авpar tribuits haut la converfion, \& dont il n'elt plus fait aucune mention dans toute la fuite de certe Hiftoire. Vatadono n'avoit pas encore reçu le Bapreme, mais il te difpufoit à le recevoir, \& les Milfionnaires n'avoient alurs pertonne dans le ceritre de l'Empire, fur la protection duquel ils comptallent davantage. Ce Seigizeur avoit en eflet toutes les vertus Chrétiennes, \& toute's celles, qui font les grands Hommes; mais 
LITRE QUA T R I ÉME. jOI gicn ne fait mieux fon Eloge, que la conduite u'il tint en cette occalion; car l'on peut dire cu'il furmonta la tentation la plus dćlicate, ot un Héros puilfe être expolé, \& quil fit une ation, dont on voit bien peu d'exemples dans 1Hitoire. En effet, avec toutes les qualitez \& toutes les reffources, qui peuvent alfurer le fuccès d'une grande Entreprife, \& fe voyani entre les mains l'Hćritier de la Couronne, non feulement il n'en abufa point, pour s'ćlever lui-même, mais il aima mieux fe faire le Subalterne d'un Prince plus puiflant que lui, $\&$ dont il connoilfoit la droiture, qne de rifquer fon Souverain, en hazardant de le rétablir avec fes feules forces. Il fongea donc, dis que Cavadono fe fut jetté entrefes bras, à lui procurer un appui, que toutes les forces des deux Affafins de l'Empereur ne fulfent pas capables de contrebalancer, \& il le trouva dans le Roi de VOARY.

Nobunanga Roi de Voary, éroit un de ces Homnes, qu'un génie fupétieur \& univerfel difingue d'abord de tous les autres, \& met au-dellis des Eloges; il avoit le cocur haut, \& un courage, quilui faifoit croire tout polfible. Il exoit plendide, magnifique, défintérellé, maître de lui-même, intrépide, d'une grandeur d'ane, d'une vivacicé, \& d'une pénćrration d'efprit, qui tenoiont du prodige; \& qui jointe à la fience de toutes les parties de la Guerre, quil pollédoit dans un dégré éminent, au talent qu'il avoit de découvrir les plus fecrettes penfées de ceux, qui l'approchoient, fans fe lailler jamais pénćtrer luimême; \& à ce Caractere droit \&i fincere, qui marquent fi bien un Homme, en guiles vertus

$$
N \text { iij }
$$




\section{HISTOIRED JAEON,}

Cont vrayes \& naturelles, en ont fait le Héros

De J. C. du Japon, \& un des plus grands Princes, qui is ayent régné en Orient dans ces derniers fiécles.

De Syr-Mu Il étoit alors âgé de trente-fix ans, fa taille 2226. ćtoir avantageule, quoiqu'un peu trop mince, \&z fa complexion délicate; mais par le foin, qu'il eut dès fa plus tendre jeuneffe de s'accoutumer aux plus rudes fatigues de la Guerre, il s'ćtoit rendu capable de fupporter les plus grands travaux. Il parut toujours plus jaloux d'îre le Maitre dés Empereurs, que d'ĉtre Empereur lui-même; \& s'il monta fur le Trô ne des Cuba-Samas, il le fit beaucoup plus tard, qu'il n'en̂t pâle faire; \& dans des con jonctures, où il parut y avoir été en quelque façon forcé. On l'a accufé d'avoir porté la défiance jufqu'à tuer de ra main fon propre Frere; mais le défaut qu'on lui reprocha plus univerfellement, fut la fierte; il traitoit les Grands avec une hauteur prefque barbare; les Rois mêmes, qu'il avoit fubjugués, n'oloient le regarder en face: un feul de fes regards rendoir tout ponfible à fes Officicrs pour lui obéir, \& leur faifoit faire des choles incroyables. Il n'alloit jamais fans une Garde de deux mille Hommes à Cheval; mais pour la Perfonne, il étoir toujo'urs très-fimplement vétu; une peau de Tygre lui fervoit ordinairement de Cuiralle, \& Couvent il l'ctendoit à terre, pour salleoir delfus. Il étoit fobre, mais dillolu à l'excès, 2 ce vice fut longtems regardé comme le feul obßtacle, qui l'empêchât de fe faire Chrétien. On fe trompoit apparemment, $\&$ il parut bien enfin que l'unique Dieu de No. bunanga éroit fon ambition. Il n'avoit hérité de fes Ancêtres, qu'une partie du Royaume de 
LIVRE Q.U A TRI I ME. 303 Fonry, mais il en avoit déja conguis julju’à dix-hut ; lorfique la gloire de rétabiir un Empeteurfurle Tróne partut le thater allez, pour lui faire interompre le cours de fes Conquetes, \& préférer la qualité de Libérateur, \& d'arbitre de l'Empire, à celle de Conquérant.

Tel fut le Prince, que Vatandono oppofa au Roi d'Imory \& au Prince de Nara. il fallut du tems à ce Seigneur pour s'attacher, ou pour écarter tous ceux, dont il crut cruno fur le avoir quelque chole a craindre, ou à efpé- Tirrume timpe. rer; \& pendane cet intervalle, il s'appliqua à tat.

fortifier fes Chấeaux, \& furrtout celui de Coca, où il traitoit Cavadono en Empereur. Les Rébelles de leur côté, ne s'endormoient pas, ils connoilfoient les Ennemis, qu'ils alloient avoir en Tête, mais ils ignoroient encore jufqu'à quel point leur perfidie ćtoit déteftée. Ils l'apprirent bien-tôt; car au premier bruit, gui fe répandit que Nobnmanga armoit pour merte Cavadono fü le Trône Impérial, \& que Vatadono ferviroit fous lui, tant de Gens fe rangerent autris de l'un \& de l'autre, yu'au bout de quelques jours, ils fe trouverent en ćtat de tenir la Campagne. Les deux Traîtres étoient dans le Royaume d'Izumi, avec un corps de douze mille fommes de vieilles Troupes. Nobunanga y enroya Vatadono, aujuel il en donna quinze mille, \& il partit lui-même pour aller fajre monter a Cheval tous fes Valfaux. Vatadono ufa de diligence, \& fe pofta avantageuiement dans une grande Plaine à la vî̀ de Sacai, ou les Rébelles s'avancerent promptement pour le combatre, comptant de le fur-

De I. C. I 566.

$1)=36-11 a_{0}$ 2226. no pour fane monter Civa- 


\section{HISTOIRE DU JAFON,}

Examen prendre. Ils s'apperçurent bien-tôt qu'ils s'é-

De J. C. toient trop flatiés, \& les deux Armées deI; 66. meurerent alfez long-iems en prólence.

L. Sy $1+. \mathrm{VIu}$. 2225.

1) gagne une Bitaille decifive.

Enfin vers la fin du Carcme il fe donna à peu de jours de diftance deux Combars trèsfanglants; le premier n'eut rien de bien décifiti mais dans le fecond, Vatadono après avoir foutenu deux charges tris - vigoureules de Mioxindono, le rompit, fir un grand carnage de les Gens, \& ne pardonna qu'à ceux, qui prirent parti dans les Trompes. Le prenier fruit de cette Victoire, fut la réduction de la Forterelle de Cavacci, \& la Conquére d'une bonne partie des Etats du Roî d'Imory. Vatadono s'approcha enfuite d'Imory, où Xicaidono, dont nous avons déja parlé plufieurs fois, commandoit pour Mioxindono. Ce Prince \& fon Collćgue, qui avoient rétabli leur Armće, accouturent pour fecourir la Place; mais ce fut en vain, \& deux $(a)$ Combats, qui fe donnerent encore vers les Fêtes de Pầjues, \& dont le dernier acheva la défaite entiere des Rćbelles, rendirent Vâtadono Maitre de la Campagne.

Nobunanga apprit ces heureufes nouvelles ,

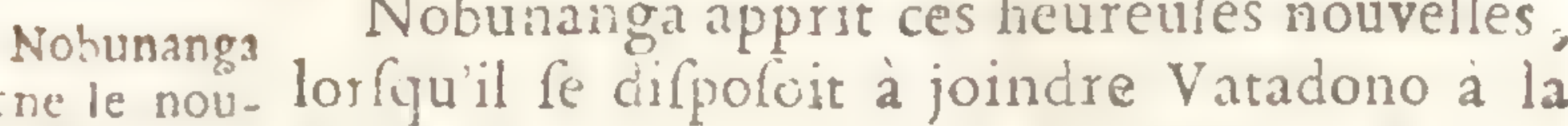
mene le nou- Tóte de cinquante mille Hommes, \& elles à Mexco \& lui firent changer de deflicin : il tourna da lui fait bátir un nutiveau Palais. côté de la Capitale, \& y mena l'Empereur. Tour plia fous une fi grande Puillance, \& le nouveau Cubo-Sama prit paifiblement poífefion de la Couronne, que perfonne n'ćtoit

(a) Les Relations de ce temi-là parient afrez confufément de tous ces Combats, \& peut-être qu'll faut réduire lesquatre, dont nous venons de parler, à deux $\Lambda$ ctions, yui avoient duté chacune deux jouts, 
LIVRE CUATRIE ME. 305 plus en état de lui contefter. Mais comme le Palais Impćrial avoi: été réduit en cendres, Nobunanga logea le Prince \& fa Marfon dans les plus beaux Monafteres des Bonzes, puis il diftribua fon Armée dans tous les autres. Les Foquexus entr'autres furent fort maltraités en haine de Daxandono, qui ézoit de leur Secte, \& parce que le Roi de Voary lçavoit que ces Prêtres f́́ditieux avoient élevé jufqu'au Ciel le Prince de Nara, pour avoir, difoient-ils, délivré le Japon d'un Empereur, qui favorifoit ouvertement une Religion étrangerc.

Ces Miniftres des faux Dieux eurent beau fe récrier contre une Entreprife, qu'ils traitoient d'attentat \& de facrilége, ils ne gagnerent rien, \& comprirent même bien-tôt qu'il leur falloir bailfer le ton; mais ils n'ctoient encore qu'au commencement de leurs difgraces. Nobumanga voulut bâtir un nouveau Palais pour l'Empereur, \& l'emplacement de incien ne lui parut pas allez grand: il y avoít tout proche quelques Monafteres de Bonzes; il commanda de les abattre, \& la maniere haute, dont ces ordres furent exćcutés, fit comprendre à tout le Monde, que le parti le plus fage étoit de fe foumetrre, \& de fe taire. Tout le tems que les Travax durerent, il y eut défenfe de fonner d'autre Cloche, qu'une feule, que le Roi fir placer dans la Citadelle, pour appeller \& congédier los Ouvriers; \& ceux, qui vouloient vifiter les Ouvrages, étoient obligés de palfer fur un Pont-levis, ou le Prince le tenoir pour l'ordinaire.

A le voir ainfi préfider lui-míme à la Bâ- 


\section{YO6 HISTOIRE DU JKPON,}

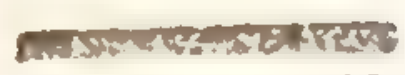

tille de ce Palais, prefque toujours le Cime-

D. T. C. terre à la Main, couvert de fa Peau de Tysro- gre, \& cinquante mille Hommes fous les Ar-

$\nu_{c}$ s.n-Mur. mes, on ent dit, qu'il fortifioit un Camp, 2227. Ou qu'il afiuroit fa domination dans une Vitle prife d'alfaut. Tout le Monde travailioit, les Grands comme les Petits, chacun avoit fa tâche réglée; \& ce qui étonnoir, c’elt qu’avec un fi grand nombre de Gens de Guerre, on n'entendoit parler d'aucun défordre; l'œil vigilant, \& la févérité du Général retenoient tout le Monde dans le devoir, \& l'on ćtoir perfuadć, que la moindre faure ne demenreroit pas impunie, furtout depuis qu'un Soldat ayant olé lever le Voile d'ure Femme, pour la regarder au Vifage, le Roi qui l'apperçut, courut à lui, \& fans autre forme de Procès, lui coupa la Têre avec fon'Sabre. On prétend que le nombre des Ouvriers, qui travailloient en même tenss, monta jufqu'à vingt-cinq mille, \& qu'il ne fut jamais audeilous de quatorze mille. () n ajoutre que des Princes mêmes, \& des Seigneurs, pour faire leur Cour à Nobunanga, ne dédaignerent pas de mettre la Main à l'ouvre, \& de fe con-. fondre parmi les plus vils Manocuvres, trop heureux, quand ce Prince vouloit bien les favorifer d'un regard.

Inscmén. L'Ouvrage néanmoins n'avançoit pas à fon sen.aslus les gré, parce que les pierres ne fe trouvoient 3isus: point aifément ; \& comme ce retardement limpatientoit beaucoup, il donma ordre qu'on lui apportât toutes les Statuës de pierre, qui étoient dans les Temples de Mćaco \&x des e:nvirons. Il fit plus; car pour épnregner la démenfe dis charois, il fit trainer avec des cor- 
L I $V$ R E Q U A T R I E M E. jo\% des ces fameufes Divinitez, qu'on avoit ii longrems encenf́es, \& qu'on regardoit dcpuis tant de fićcles, comme les Protectrices de l'Enpire. On abattit mcme des Temples entiers, pour en avoir les Matériaux, \&

De J. C.. 1) 67.

De Syn Mu. $2227^{\circ}$ on n'épargna, ni le fameux Dsibods, ni aucun des plus célébres Sanctuaires de la Religion Japonnoife, qui ćtoient dans le Voifinage de la Capirale.

A ce Spectacle les Bonzes perdirent enfin patience, \& menacerent de la colere des Dieux; mais le Roi de Voary, qui n'y croyoic pas, Ce mocqua de ces clameurs, \& ne j:gea pas même les Bonzes dignes de fon indignation. Le peuple ne lailia pas de craindre d'abord; mais comme il ne vir a acun effet de ces menaces, il s'accoutuma peu à peu à s'en mocuer aulli. Après tost, les Bonzes euffent volontiers pafié à Nobmunga le traitement, qu'il failoit a leur; Idoles, s'il eût voulu les épargner eux-nuknes; nois après que le Palais da l'Empereur fut achevé, fon Libérateur voulut avoir aufh le fien; $\&$ pour ne pas perdre de tems, il fit enlever Ia charpente \& les lambris, non - Ceulement de plufieurs Temples, mais encore des plus beaux Monaftéres, pour les placer dans fon: Palais.

Sur ces entrefaites, Vatadono apris avoir dimpé les reftes de l'Armée Ennamie, \& réduit fous l'obéillance de l'Empereur la plî- desmifiomanpart des Forterefles, qui tenoient pour les ros a Merso, Rúbelles, arriva à Ḿ́aco, \& fut reçu de ce il "bricar. Prince \& du Roi de Voary, comme le múrtoient fes fervices. Le prenier ufage, qu'll poulur faire de fa faveur \& da fon crílit, 


\section{0: HISTOIRE DU JAPON;}

fut d'employer l'un \& l'autre au rétabliffLe J C. ment des Mifionnaires. Il expola aux deux 1507. Princes la maniere indighe, dont on avoit 1) Syn-Mu. traité les Docteurs Européens, pour avoir été 222\% fidéles au feu Empereur. Il ajoûta, ce qui ćcoit vrai, qu'il n'avoit pas.tenu aux Bonzes Foquexus, qu'on ne les eût mis à mort, \& qu'ils auroient infailliblement été facrifiés à la rage de ces Séditieux, fi Daxandono n'avoit appréhendé de perdre tous les Chrétiens, qui ćroient à fon lervice, \& aufquels il avoir 1u déguifer fon attentat, \& lés pernicieux delfoins, fous le f́fécieux prétexte du bien Public.

Une repréfentation fi jußte, faite à deux Princes par un Homme, à qui ils devoient, l'un fa Couronne, \& l'autre une partie de fa gloire, ne pouvoit manquer d'ćtre favorablement écoutée. Le rappel des Miffionnaires fut figné, \& il ne s'agilloit plus que d'avoir le confentement du Dairy, par les mains duquel il ent de l'ufage de faire paller ces fortes de graces. Vatadono fit prier les Confeillers de ce prince de vouloir bien expédier promptement le Brevet; mais ils répondirent yu'ils ne pouvoient s'employer pour les Minitres d'une Religion, qui avoit le Démon pour Auteur, \& qui apprenoit à manger les Hommes. Cette réponte le choqua, \& il fit dire à ceux, qui la lui avoient faite, qu'il Se pafferoit bien de leur phantôme d'Empereur; \& que malgré qu'il en eût, il mettroit les Prédicateurs Eirangers en poffelfion de leur Maifon \& de leur Eglife de Mćaco. Cette maniere de les traiter lui réulfit; ils voulurent revenir, \& lui offrirent de 


\section{I R E Q O A T R I É N E. jO9}

faire ce qu'il fouhaitoit, mais il méprifa leurs offres, comme il avoit méprifé leur refus, \& envoya fon Frere Tacayama à Sa-

De J.C. cai, où le P. Froez éroic encore, pour le lui $\overline{\text { De Syn-Mu. }}$ amener. 2228.

Tacayama ne perdit pas un moment de tems, * âiiva a Saciai le vingt-fixićme ct recu com. de Mars del'annce Is 68. Le Miflionnaire, me entriom avant que de quitter Sacai, difpola les Chré-phe a Meacu. tiens de cetre Ville polit la Communion $\mathrm{Pa}$ chale, qu'il leur fir faire le Dimanche des Rameaux; \& le lendemain il fe rendit à Méaco, où il entra au milieu des acclamations des Fidéles, dont la plûpart allerent fort loin au-devant de lui. Un Triomphe fi complet fit frémir les Bonzes, qui réfolurent de metrre tout en ouvre pour en prévenir les fuites. Un des plus accrédités fir dire au Roi de Voary, qu'il avoit à lui consmoniquer des chofes tris-importantes pour le falut de l'Empire, \& pour fa propre confervation; Nobunanga répondit yu'il pouvoit venir le trouver, \& le Bonze lui déclara dun ton de Prophéte que, fi le Docteur des Chrétiens n'étoit incellamment chaflé de Méaco, il alloit arriver de grands malheurs, \& que la Capitale furtout ćroit menacée d'une entiere défolation.

Le Roi l'écouta avec beaucoup de fang froid, vatadono ic puis lui tournant le dos fans lui rien répli-mene à l'Auquer, le fot Homme! dit-il à ceux, qui étoient dience de autour de lui, prend-il Méaco pour un Villa-du Nobuna: g̈e, qu'un Etranger Jans Armes puife venir ga. à bout de le détruire? Quelques jours après, Vatadono voulut préfenter le Mifionnaire a u Roi; mais on lui dit que ce Prince ćroit oc- 


\section{zRO HISTOIRE DU JAPON,}

cupé à entendre un concert, \& qu'on ne pour

De I. C. voit pas le voir. Il le conduifit de-là au $\mathrm{Pa}$ 5568. lais de l'Empereur, qui n'étoit pas non plus

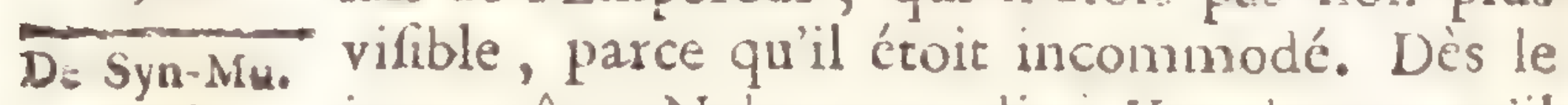
2228. jour même Nobunanga dit à Vatadono, quil n'avoit pas reçu la vilite du Pere des Chrétiens, parce qu'il ne fçavoit pas trop quel compliment faire a un Etranger, quićcoit venu de fi loin. Cependant les Bonzes triomphezent de ces refus, \& Vatadono, qui fe crut engagé d'houneur à confommer fon ouvrage, ne lailla point les Princes en repos, qu'il n'en êit obtenu polir le Pere Frotz ia permifion de leur faire la rćvérence.

De quelle Il alla enfuite lui-même accompagné de maniere celui- trente Gentilshommes prendre le Millionnaicile recoit, re à fon Logis, \& il traverfa une bonne partie de la Ville, marchant à pied à côté de lui. Ils trouverent le Roi fur le Pont-levis, dont jai parlé, environné d'une nombreufe Cour, \& ayant affez près de lui fept mille Hommes fous les Armes. Le Pere en l'abordainte profterna, mais le Prince le fit relever aufli-tôt, lui conmmanda de fe couvrir, parce que le Soleil étoit fort ardent, lui demanda fon âge, combien d'annćes il avoir employé à fes Etudes, s'il y avoit long-iems, qu'il ćtoit au Japon, s'il ne comptoit pas de revoir jamais fa Patrie, \& íppolé que les Japonnois ne fe fiffent pas Chrútiens, sil ne retourneroit point aux Indes? Le Pere fatisfit en peu de mots à toutes ces queltions, \& par rapport à la derniere, il dit que quand: il n'y auroit qu'un feul Chrétien au Japon, it y refteroit pour l'infruire, 8: pour le forcifier, mais quill n'en ćtoit pas réduit-la; qua 


\section{XIVRE QUATRIÉME。 JTr}

Te nombre des Fidcles ćroit déja fort grand dans l'Empire, \& que parmi eux on voyoit des Seigneurs \& de grands Princes. Mais pourquoi, reprit le Roi, n'avez-vous plus ni MaiSon, ni Eglise dans Méaco? Seigneur, répliqua le Pere, ce font les Bonzes, qui nous

De J. C. I 568.

De Sjon-Mu. 2228 . ont fait chafer de celles, que nous y avions.

Le Roi alors dit beaucoup de mal de ces Propofition, faux prêtres, quoiqu'il y en eût plufieurs à qu'il fait la ce Royal. L'occaíon parut belle au Mifionna que Nubunanre, pour jetter quelques paroles de la fainteté de l'Evangile, \& il fit oberver, qu'il falloit qu'il fût bien convaincu de la vérité de fa Religion, pour être venu des extrémitez de la Terre, s'être expofé à tant de rifques, avoir tout quitté, \& s'être en quelque façon condamné à un exil perpéruel, dans la feule vûè de la prêcher àdes Inconnus, dont il n'avoit rien à efpúrer; auli , ajoutta-t-il, » je fuis fi "perfuadé qu'on ne peut rien m'oppofer de 3 Colide, que je ne craindrois pas d'entrer » en lice avec tous les Docteurs du Japon. 2) Vous en ferez, Soigneur, l'ellai quand il »vous plaira, faites allembler tous ceux, qui " ont le plus de réputation dans l'Empire, $\leadsto$ je m'offre à difputer contre tous, à cette a condirion, que fi je fuis confondu, je fes rai puni comme un Impofteur, qui a vou$\because$ lu luduire toute une Nation; mais que fr "j'en fors à mon honneur, \& fi je démon" tre la fauffeté de toutes les Seites, qu'on "tolére dans le Japon, vous m'accorderez, »\& à tous ceux, qui embrafferont le culte " du vrai Dieu, votre protection Rnyale. Nobunanga admira la réfolution du Mirion- 


\subsection{HISTOIRE DU JATON,}

naire, \& fe tournant vers les Seigneurs, qui

De J. C. l'environnoient, il $n^{\prime} y a$, dit-il, qu'un grand I568. Royaume, qui puife produire un fi.grand GéWe Syn Mue nie; puis adrellant de nouveau la parole au 2228. Pere, s je doute fort, lui dit-il, que les Bon»zes acceptallent votre défí; car ils fçavent bien mieux combattre les Armes à la main, эque de fe commetre avec un Homme,qui s) en fçache plus qu'eux. cs Cette favorable difpofition du Prince encouragea le pere à le lupplier de lui faire délivrer des Patentes, qui l'autorifallent à exercer librement les fonctions de fon Miniftere. Le Roi ne parut pas éloigné de lui accorder fa demande, mais il ne répondit rien de politif. Il ordonna enluite à Vatadono de condure le Miflionnaire dans tous les Appartements de fon Palais, \& de lui faire voir tous les Ouvrages, anfquels il faifoit travailler; \& comme après cette vifite le Pere repalloit fur le Pont, où étoit encore le Roi, ce Prince lui demanda, s'il étoit content de ce qu'il avoit vû ? \& il répondit que rien au Monde ne l'avoit encoke tant frappć.

Le Chriftia- Il parut que fon compliment étoit bien nifme eft ausorife par une Patente Impésiale. reçu, \& que Nobunanga éroit flarté qu'un Européen admirât ce qu'il faifoir. Deuxjours après Vatadono mena le Pere à l'Audience du Cubo-Sama, qui lui fit toutes les amitiez poffibles, mais tous ces Honneurs ne décidoient encore rien, tandis que la Religion Chrétienne n'ćtoit poine autorif'e par un Acte Public, \& le Miffionnaire fentit bien que c'étoir à la dépenfe, qu'il tenoit. Enfin les Chrétiens fe cottiferent, \& le Refcrit fut dreffé avec ce Titre: PATENIES pOUR IA SURE- 
L I R E QUATRIÉME. 3 I 3 TÉ DU PERE DE LA CHRÉTIENTÉ DANS LA Chapele, Qu'on nOMme de la Veritable De J. C. DOCTRINE.

Cependant tout le Japon ćtoit dans l'attente du train, que prendroient les Atraires, \& de la forme de Gouvernement, que Nobunanga érabliroit dans l'Empire. Ce Prince fe Nobunangare déclara enfin, il laiffa à l'Enpereur tous les réferve toute Honneurs du Trône, mais il donna allez l'autorité chirement à entendre, que toute l'autorité demeureroit entre fes Mains, \& il nomma Vatadono pour fon Lieutenant dans la Tenfe, \& pour fon Vice-Roi dans Méaco; où plutố il abligea le Cubo-Sama à reverir ce Seigreur de ces deux Charges. Rien ne pouvoit arriver de plus avantageux à la Religion Chrétienne, \& les Bonzes le comprirent bien; auti firent-ils les derniers eftorts, pour regagner Nobunanga. Le Pe:e Froez f̧ut qu'ils taifoient agir puilfammen: le Dairy auprès de ce prince, \& qu'il fe traitoit férieulenzent de profcrire le Chrittianime. II en avertit far le champ Vatadono, qui lwi répondit de ne point s'inquićter, que ces difcours étoient des inventions des Bonzes pour l'intimider, \& que tant qu'il auroit a moindre autorité dans Méaco, il n'y awoit perfoune allè hardi pour s'oppoler au progrès de la Religion Chrétienne, ni pour inquiéier ceux, qui la prêchoient.

Sur la fin de l'Eté le Roi de Voary fe difpolant à partir pour fes Etats, le Viceroi fit dire au Pere Froez, qu'il ne manquât point faire chafrer d'aller fouhaiter un heureux voyage à ce Prin- 'e 'Empire. ce; il y alla, \& trouva Nobunanga au milieu Caractere de d'une Cour très-brillan e. Il en fur fort bien ci Bumze. 


\section{I4 HISTOIRE DO JAPOIN,}

De J. C.

reçu; \& comme il Ç̧avoit que ce jour-là même, un Bonze nommic Niquixoxunr l'avoit fortement follicité de challer les Do teurs Etran-

De Syn-Mu. 2228. gers, il le fupplia de vouloir bien recomman. der a Vatadono de prendre en main leur défenfe pendant que Sa Majefté feroit abiente. Le Bonze étoit préfent, mais le Pere ne le connoifloit point. C'ćtoir un petit Homme, tout contrefait, de balle Nrilfance, \& qui avoit dans toute fa Perfonne quelque chofe de monitrueux; mais la beauté \& la vivacité de fon Efprit le dédommageoient bien de la difformité de fun curps; il poliédoit lurtout aur louverain dégré ce manécre de Conur, dont les Princes font li fouvent les dupes. Il n'ćtoit pas fçavant; Hais une mémoire heurcufe, une facilité furprenante à s'énoncer, \& une hardielle, qui alloit jufqu'à l'impudence, lui to noient lieu d'étude, \& il parloit de tout avec autant daffurance, que s'il eût páli toute fa vic fur les Livres. Il avoit d'abord été Soldat, il avoit depuis mené une vie de Brigand; il n'elt forte de crime, qu'il n'eût commis, \& peut-être n'y avoit-il pas fur la Terre un plus méchant Homme. Le Dairy s'étoit fervi de lui pour traiter de quelgues affaires avec Nobur nanga, qui l'avoit gotré, $2 x$ en avoit fait fon Favori, ou plutôt fon Bouffon.

xobunanga Ce Prince voulut apparemment pour fe diengage unce ef vertir, le mettreaux prifes avec le Pere Froez, pecededifiure \& pour engager la difpute, il demanda au deux Miffun- Mifionnaire, prurquoi les Bonzes haiffoicnt naires. Ii fort les Dooteurs Portugrais? C'eft, répondit le Pere, que nous découvrons aux Grands Er aux Sgavans les crreurs de leur Doctrine. Er que rous faifons voir au Peuple la corrup- 


\section{I R E Q O A T R IE ME: 3 IS}

tion de leurs mours: mais quelle différence $\sqrt{2}$ grande $y$ a-t-il donc entre votre Religion E La leur, reprit le Roi? La.mêne, dit Laurent, qui accompagnoir le Pere Froez, qu'il y De Sy. Mus a entre la lumiere $E$ les ténebres. N'adorezvous pas aujibien que nous les Camis ou les Fotoques, concinua le Prince? Non, Sei $\rightarrow$ gneur, reparrit Laurent, nous n'avons garde de reconnoitre pour Dieux des Hommes, dont on Scrit la naijance E la mort, E du pouwir defquels on $n^{\prime}$ a aunune preuve, ou pour mieux dire, dont on connott parfaitement l'impuifance. Quelques autres guefions, que fit le Roi, \& qu'il pria le Bonze de faire aulfi de fon côté, engagerent infenfblement une maniere de Conference, \& Niquixoxuni parut d'abord fe polléder allez; mais au bout de quelque tems, fe lentant preflé, il voulut payer d'effronterie; puis comme il vit que cela ne lui réuflifioit point, il s'emporta beaucoup, \& conclut brufquenent eir criant de toute fa. force, qu'il falloit challer du Japon toute cette Canaille d'Europécus; qui féduifoit le Peuple par fes prefizges: la conclufion fit rire, co qui acheva de le déconcerer.

Remetter-vous, luidit alors le Roi, E parlez raifon, ces Docteurs Etrangers vous répondrcnt péut-être d'un maniere, qui vous. contentera; mais le bonze étoit fi rroublé, qu'il ne difoit rien de fuivi. Laurent lui demanda s'il fçaroit quel śtoit l'Auteur de la vie, \& le principe de tout bien? il rénondit que non. Le Roi pour fairediverfon, demanda à Laurent fl le Dien des Chrétiens récom penfort exactement la Vertu, \& ne laifoit jamais le vice lans châment? Le Milliomnaice 


\section{HISTOIRE DUTAPON,}

répondir que ce Dieu étoit la Jultice même

De J.C. mais qu'il étoit bon d'obferver qu'il y avoit I 568 .

De Syn-vi.. 2228. des punitions \& des récompenfes de deux fortes; les unes temporelles, \& les autres éte:nelies; les premieres, qui n'ćtoient que poir ccite vie, \& les fecondes, quî étoient réfervées pour la vie future. Cette diftinction fit rire le Bonze, \& le Pere Froez, gui vit bien que ce Prêtre ne tenoit pas l'Immortalité de l'Ame, s'applicua fort a rendre lenfible ce point de notre Foi. Niquixoxuni l'interrompit en difant qu'il feroit bien aife de voir une Anse, qui furvêquîr a lon Corps; \& le Pere, apres lui avoir fait toucher au doigt par des comparaifons fenfibles, qu'il y avoit réellement des fubftances firituelles, qui ne peuvent être l'objet de nos fens, ajoûta que nos Ames étoinnt dece nombre, \& que c'étoit par-là même, qu'on prouvoit que de leur nature elles fon immortelles, puifqu'elles ne renferment aucun principe de corruption.

Je n'entends pas cela, reprit le Bonze grinçant les dents \& changeant de couleur; mais puifque vous dites que l'Ame ne meurt point avec le Corps, il faut pour me le prouver, que vous me faflez voir une Ame vivante, après la mort du Corps, qn'elle animoit, je. m'en vais couper la tête à votre Compagnon, Ej je verrai ce qui en Sera. Il fe leve en méme tems, palle a l'autre bout de la Salle, y prend un Sabre, qui y étoit attaché à 1 ? muraille, \& alloit le décharger fur la tête de Laurent, fi Vatadono \& un autre Officier, qui fut depuris le célebre Tayco-Sama, ne lui culfent retenu le bras, \& ne l'euflent enfuice défarmé. Nobunanga fut fort choqué de cetre infolence ; il fe modéra 
LIVRE QUATRIÉ ME. 3 TT thimoins, \& le contenta de faire au Bonze *affez légere réprimande, mais l'Afiène ne le prit pas de même, \& Vatadono dit thaut, que lans le refpect qu'il devoit au a, il eût coupé fur le champ la Tête à ce
DE J.C. Ij68.
De Syn Mu. 228 . hraut. Le Roi continua encore quelque tem entretenir avec les deux Religieux, \& fur -latisfait de tout ce qu'ils lui dirent de la utualité \& de l'incorruptibilité de nos Ames, a nature de nos penfées, de la vafte ćtende nos defirs, \& des preuves, qui réfulat de ces priacipes en faveur d'une autie Cette Doctrine me faroît très-bunme, reil, mais quand j'oppose votre conduite d des Banzes, elle fait encore fur moi plus et que tout le refte.

Pere Froez, qui vit ce Prince affez en tde l'entendre, ajoûta à ce qu'il avoit déja pefcrit la Requelques confidérations, qui lui plurent ligion Chrécoup Il lui fit remarquer que fl'tom tisne \& les chom-Miñonaires. périffoit tout entier avec le corps, nous ons de pire condition que les Brutes, puifnous reflentons des maux, dont elles font mptes, n'y eût-il que le fentiment réfléchi douleur, dont elles ne font pas capables, e nous ne jouilfons jamais comme elles plaifr pur \& tranquille. Il le pria encore confidérer, que nous avons au-dedans de -mêmes un defir de la féliciré éternelle, bien approfondi, eft une démonttration, nous fommes faits pour en jenir. Delà il mençoit à remonter à l'exiftence de Dieu, iquon vint parler au Roi de quelcues affaice Prince, en congédiant les deux Relix, lenr fir mile carefles, \& leur promit jamais it ne touffriroit qu'on les maltrai- 


\section{HISTOIRE DU JAPON,}

tât; toutefo s à peine étoit-îl parti de Meac

De J.C. que Niquixoxuni obtint du Dairy des Lett Is68. de profcription contre les Miflionnarres.

D. Syn Mu. 2228 .

Ie Cutio.

Ce Prince écrivit même à Nobunanga, $q$ ne lui appartenoit point, ni au Cubo-San d'autorifer une Religion étrangere par des.

Sam. le trouvemauvars, \& fiit dire au Dairy que le Mifisinnaires fom Kus fa pruvećtion. tentes; il ne paroît pas que le Roi de Voary daigné s'offenfer de cette Letrre, mais le Cu Sama, à qui Vatadono en apprit le conten en fut extrêmement piqué : il fit déclarer Dairy, que ces Etrangers ćtoient fous fa $p$ tection, \& qu'on auroit affaire a lui, fi on vifort de les inquiéter. Le Dairy voulut inflet \& mit l'affaire en négociation; mais l'Em reur n'avoit garde de tien faire, qui put plaire à Vatadono, ni choquer Nobunan Niquixoxuni n'ayant pû réuflir par cette vo. demanda au Dairy la permifion de tuet Pere Froez, \& publia gu'il l'avoit obtenu Vatadono ne l'eût pas plutôt appris, qu'il c voya fignifier a cous ceux du quartier, oil meuroit le Miflionnaire, qu'ils lai répe droient de tout ce qui lui arriveroit.

Noureaus $\mathrm{Au}$ commencemént de l'annće !rivan: eforiscurin- Niquixoxuni fe trouva plus avant que jan 2: pur frise dans la faveur de Nobunanga, qui le rendi

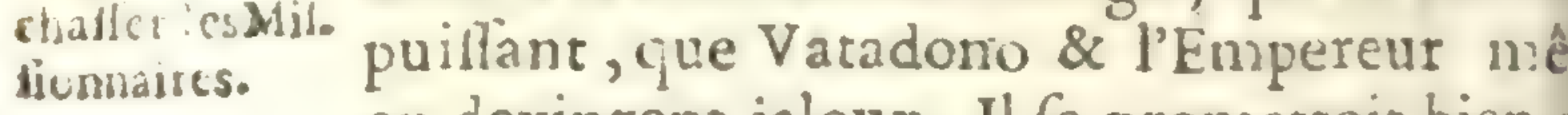
en cevinrent jaloux. Il fe pronetroit bien pour ce coup les Miflionnaires ne lui écap roient pas. Il jugea néanmoins à propos fe contenir encore quelque tems, parce y redoutoit toujours le crédit de Vatadono, n le Vice-Roi ayant été obligé d'aller pat quelque tems à fa fortereffe de TACAçU Q laquelle étoit éloignée de Méaco d'envir lept lieues, le Bonze recommença fes por 


\section{LITRE QUATRIÉ UE. 319}

les auprès de l'Empereur pour l'engager à lentir que l'Edit de Prolcription porté par (Dairy conire les Docteurs Etrangers fût pu. Varadono, qui en fur inftruit par Lauunt, que le Pere Froez lui envoya exprès, iolut voir, s'il ne gagneroit. rien par la De J.C. I 568 . De Syn. Mu2328. rope de la raiton \& par fes politelles; il écrivir ubonze une Lettre alfez civile, mais le fier dolâtre y répondit avec d'atitant plus de lauwur, qu'il s'imagina qu on le craignoit. " Il y a cinc ans, ciloit-il, que le Dairy a chatté duJ ponc s zeligicux; s'oppoler à un Ar, rêt î refpestacle, c'eft un attentat, qui liavoit point d'exemple, avant que wous fuffiez dans la Place, que vous occupez. Depuis le commencement du Monde la parole duDairy eft comme la fueur du corps, qui hy rentre jamais; il vous étoit réfervé d'entreprendre de commettre un pareil attentat. Si vous êtes fage, vous réféchirez mûrement fur une conduite finfoutenable, \& eroyez, que perfonne nevo us a jamais donné un meilleur confeil. Mes paroles font une médecine faluraire pour guérir les infirmités de ceux, qui ont la fageffe de les "couter, \& je manquerois au devoir de ma Profeffion, fi je ne vous difois pas franchenent ce que je penfe. " Laurent fut encore Porteur de cette Letrre.

A peine Vatadono pur-il gagner fur foi de a lire toute entiere, il la jetta enfuite par erre, \& jura qu'il ne mourroit pas content, qu'il n'ê̂t calé la tête à ce Prêtre infnlent.Il dit enfuite a Laurent, qu'il ćtoir d'avis que le P. Froez allât trouver Nobunanga, q'il étoir dans fon Royaume de Mino, pour hi porter fes plain- 


\section{HISTOIRE D.U JA POF;}

tes fur ce qui fe pafloit dans la Capitale au p:

De J.C. judice de fes ordres, \& illui donna une Let I 68. pour Xibatiduno un des Lieutenants Gér We Syn-Mu. raux du Rai, par laquelle il prioit ce Seigner 2228. qui ćtoir de les Amis, de procurer au Millio naire une Audience du Prince; le P. Froez mit fans différer en chemin pour le Mino, à peinê étoit-il parti, que les Bonzes fire courir le bruit yue le Roi de Voary l'avo mandé pour le faire mourir. Ces bruits alla. merent les Fidéles, qui craignoient tout de fureur \& du grand crédic de Niquixoxun mais le tricmphe des uns, \& les allarmes do zutres ne furent pas de durée.

Le Royaume de Mrno eft voifin de celui Deferip:ion VOARY; c'elt un Pays délicieux, l'air y $e$ du Royame d'une fraîcheur admirable, \& le Gibier y e re Mlio, \& de la iville d'Anzuquidma. très-abondant. Cette derniere raifon avoit fur tout déterminé Nobunanga, qui aimoit beau coup la Challe, à y fonder une Ville, qui fû conme la Capirale de fes Etats, \& qui pallâ en magnificence tour ce qu'on avoit vû au Japon juliju’a lui. Elle fut mommée Anzu QuIAMA, \& elle éloit fituée au pied d'une triple Montagme, dont la T'ête du nilieu s'élevoit audeflus des deux autres, \& qui étcit converte d'Arbres, de Plantes odoriférantes, \& des plus belles Fleurs, qui foient au Japon. Ce beau lieu elt prefque environné de toutes parts d'un Lac $(a)$, qui a vingt-quatre lienes de large, \& fix de long, \& d'où fortent quantité

(a) 11 y a bien de lannarence que ce Lac eft celui riourz, dont nous ávons déja parlé, \& en ce cas l'Auteur de cutte Defeription sefátrompé, en ne lui connant que vingt-quatre licuës de long, \&c fix de large, purfude nous avons vú qu'il s'etend cinquante ou fuixante lieues 


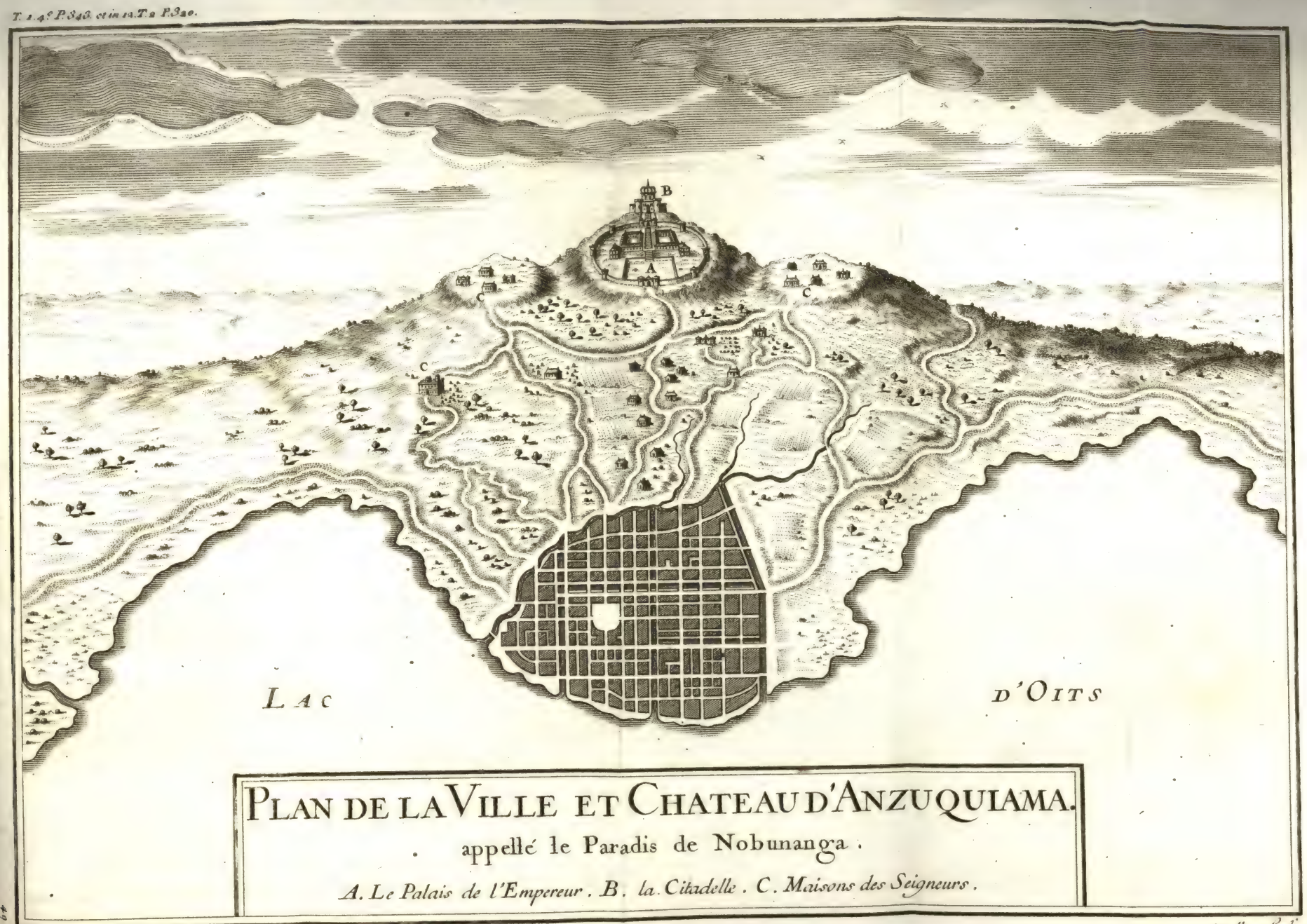




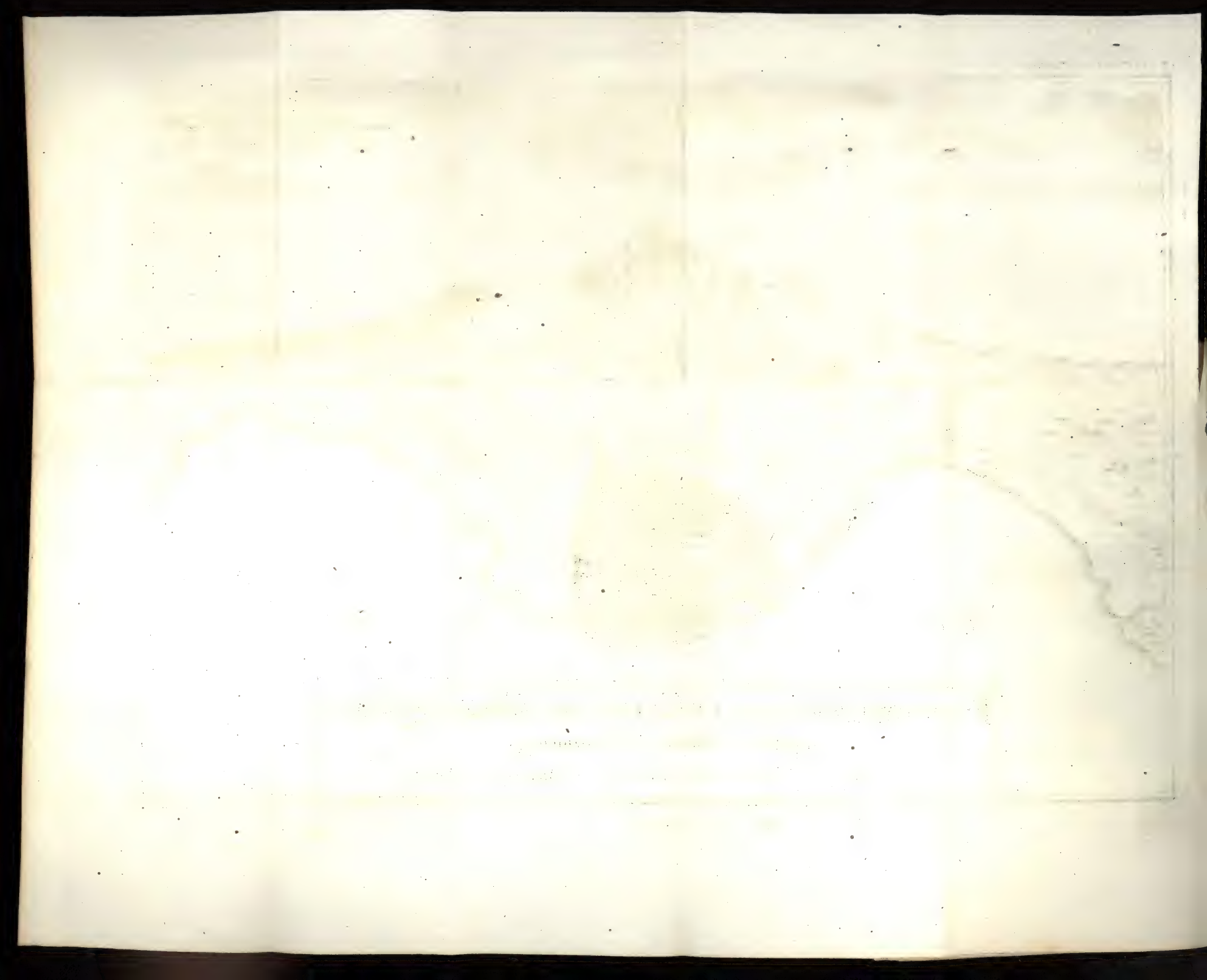




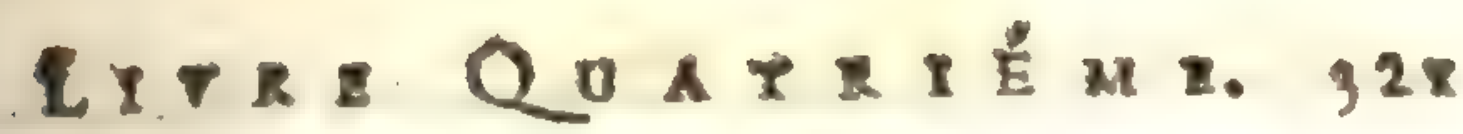
le Ruifieaux, dont les uns fe perdent dans l'agréables Prairies, \& les autres formoient dans la Ville plufieurs Canaux, gui la rendoient affez femblable a Venile. Le feul endroit, par où l'on pouvcit y entrer, étoit joint à ces délicieufes Prairies, dont je viens de parler.

La Fortereffe \& le Palais du Roi étoient fur Et du Palaig lo plus haute des trais Montagnes. Les princi- deNobun зn paux Seigneurs de la Cour avoient bâti de fort belles Maifons fur les deux autres, aufi bien que tout le long du Côteau jufqu'à la Ville; les Marchands \& tout le menu Peuple occupoient le bas, de forre qu'Anzuquiama s'élevoir en Amphithéâtre. Les rues y étoient alfez larges, pour que fix Cavaliers y puffent paffer de froint, \& régulierement percées; toutes les Maifons avoient des Jardins magnificjues. Celles des Seigneurs étoient fermées de murailles de pierre, ornćes de Pilaftres \& de Chapiteaux, qui fervoient auffi ì les rendre plus folides, de maniere qu'elles paroifloient comme autant de Citadelles; mais rien n'ćgaloir le Palais du Roi, qui terminoit la plus belle vûe, qu'il foit polible d'imaginer en ce genre.

Toute la cime de la Montagne étoit environncee d'un gros mur de pierre die trente coudćes de haut, flanqué de diftance en diftance de fort belles Tours. Apres qu'on avoit palfe la premiere Porte, on trouvoit une grande Place, \& à un des cốtés, un Théâtre fort vafte, poir les Spectacles \& les Fĉtes, que le Roi

8u Nord jufqu'au Royaume de Canga. Peut etre auff le Lac d'Anzuquiama n'eft-il qu'une efpece de Bave ce vingt-quatre licués, que forme de ce coté-là ie Hac d'Oitz.

Tome II.

O. 


\section{HASOXREDU JAPON;}

donnoit de tens en tems avec une magnifi:

De 1. C. cence exeraordinaire. On montoit enfuite par 1569. un bel Elcalier de pierre, lequel abourifioit à

Lic Syr-Mu

2225 . un Salon accompagné de Corridors, d'où l'on découvroit une partie de la Ville: ces Corridors étoient ornés de Peintures en dehors, ce qui de lorin faifoit un effet charmant: il en étoit de même des Fenêtres, des Balcons, \& de quantité d'Ornements en faillie, qui ćtoient peints avec une grande varóeté de colleurs; rout cela ćtoit relevé par un vernis, qui avoit le lufre des plus belles Glaces. Les Corridors conduifoient à une prodigieure quantiré d'Aopartements, entrclatlés les mns dans les autres avec tant d'are, qu'on auroit cru ctre dans le fameux Labyrinte de Crete. Tous ces Appartements ćtoient d'une richelfe incroyable; l'Or, l'Azur, les plus belles Etoffes, les Meubles les plus précieux, rien n’y écnit énargunc: les ronds, les ferrures, les pitons des portes \& des Iencetres, tout étoit d'or fin, \& le premier Corridor avoit vúe fur cing on fix Jarcins, ou l'on n’avoit rien épargné ponr en faire des lienz enchantés. On montoir de-là rin fecond Etage, où éroient les Appartements cela Reine; rien n'ćtoir plus tiont, toutes les Iiéces en ćcoient tendues d'un Brocard d'une finede \& d'un travail admirables: les Corridors de ce fecond Ftage avoient au th la vîe d'un

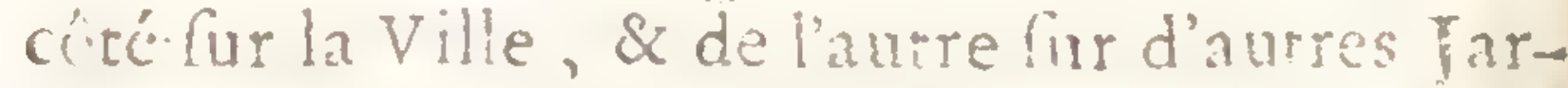
cins encore phus beax gre les premiers, \& ou l'on voyoit de tontes les enfeces d'Difeanx, qui le trouvent au Ta onn. Le troifrme Ernge ćnie partllenent diferibut en Apparements, ol tout éroit d'or relevécmer les Peinturns les plus fines: on décourroit de là toute la Ville, \& on 


\section{$I I R E$ Q $⿴ 囗 十$ A T R I E M E. 323}

en diftinguoit toutes les rues \& toutes les Maifons. La Citadelle étoit encore au-dellus \& palioit en beauté \& en richelies le Palais même: l'on voyoir de là tout le Royaume de Mino \& celui de Voary, dont le Pays eit aufi fort uni. Cetre Fortereffe ctoit terminće par une efpece de Dôme furmonté d'une Couronne d'or marfif. Il étoir à jour, enrichi en dedans \& en dohors de Peintures \& d'autres onnements à Molaigue d'un fi bon gôn, \& dont le vernis sclevoit tellement le lufre, qu'oir avoit poine ày arrêter lavie, \& qu'on ne pouvoit en détomner les yeux. I! en étuit de même de tous les coits des Tours, dela Ciradelle, \& des diff́rents Erages du Palais, lefquels ćtoient cous peints en Azur, \& jetroient un firrand éclat, prand le Soleil donnoit dallus, que l'oeil en ćtoit úbloui. Voilà ce gu'on apnelloit communćment le Paradis de Nobunanga. Le Japon n'avoit janais rien vî, qui en approchât, tout ćtoit d'in travail exquis, \& d'un goût, qui marquoit bien la enpérioricé du génia de co grand Prince.

Il avoit encore fait un Ouvrace, qui n'étoit mas moins digne de lui, \& gui a lubiré plis longtems; cétoit un Chemin de vingt-cinq preds de large, gui prenoit depuis hino jú quala Mer, en palant par Méaco. On conve ifurtorze lienes d'une deces denx Villes à butre, \& ce chenin ćtoit planté de pins des deux cénis. Luit Provinces, dont Nobmanga étoit Sugneur, y aboutiffoient, \& pour l'applanir, il avoit fallu percer des Montagnes, abattre des Forcts, combler des Vallées, \& faire des Ponts de la même largeur fur les Rivieres; aull l'entaeprife avoit-elle d'abord paru impa- 


\section{$32+$ HISTOIRE DE JAFON:}

D. J. C.

is cy.

deSyn-Mu.

2224.

ricrble, nrais ceux que ce Prince en avoit char: gés, ayant olé lui faire des reprćlentations. ou il lui cembla qu'on le raxoir de témérité; il fit fur le champ metre en croix celui, yui portoit la parole, \& couper la téte à deux autres Députés, qui l'accompagnoient. Après cet exemple tout devint facile, \& l'Ouvrage fur exécuté avec une promptitude inconcevable. On re vit jamais micux que rout eft polfible à un Prince, qui fçait fe faire obéir.

LeP. Iroez Dès que le P. Froez fut arrivé à Anzuquiaa Anzuquia ma, Xibatadono en donna avis au Roi, \& lui ivia: accucil, yee lui fait le koi. dic le fujet gui l'antenoir. Nobunanga xéponcit qu'il ctoit bien aile de la venué du Millionnaire, \& qu'il prenoit beaucoup de part aux chagrins, qu'on lui donnoit. C'eft, dit-il, un Etranger, je lui porte compafion, E je ne Scuffrirai foint qu'on lui faffe aucun tort. Lo pere ayant appris cette réponfe, alla fur le champ au Palais. Conme il y entroit, le Roi, Gui fortont pour vifiter les I ravailleurs, l'apperçu, \& lui fit figne d'approcher; il lui demanda sil y avoit longtems g'a'il ćtoit à Anzuquiama, \& lui fit plufieurs autres queftions femblables: entuie ayant rappellé ciny ou fix vigneurs, dont quelifues-uns éroient de la Cour de l'Empreur, il les mena avec le pere dans tous fes Appartements, que ceux-ci n'avoient point encore vís, \& ils furent móme periuadés qu"ils avoient obligation au Milionnaire d'y être incroduiss.

Aprís que le Roi les eut conduits partout, il fit venir un Nain, \& lui ordorna de danfir en leur prélence, puis il fit apporter du Fruit \& des Confitures. Tout le monde s'ćtomant qu'il fit pour un Etranger paure \& 
LI R $\mathrm{Q}$ U A I. $\mathrm{R}$ I É $\mathrm{E} .32 \mathrm{~s}$ fins ca:actere, ce gu'il ne failoit pour ancun Prince; car jamais Roi an Japon ne le familiarifa noins que Nobunanga, \& ne pric plus plaifir a humilier les Perfonnes de la plus hau- Desyn-M. au Palais, \& préfenta au Roi un Mémoire, qu'il avoit drellé pour le Cubo-Sama, le priant de vouloir bien l'appuyer de fa recommendation. Le Roi le lut, le trouva trop court \& trop foible, \& fur le champil en fit écrire deux autres par fon Sécretaire; l'un pour l'Enpezeur, \& l'autre pour le Dairy, \& il les envoya au Logis du Pere, qui crut qu'il ćcoit de fon devoir d'en aller remercier Sa Majelté, \& de lui faire la tévćrence, avant que de partir pour Mćaco. Il fut encore mieux reçu qu'il ne l'avoir été les jours précédens, \& le Roi commença par lui dire de ne pas s'embarafler beaucoup de ce qu'on pourroir faire contre lui a la Cour du Dairy, ni même à celle du Cubo. Sama; que cette afiaire-là le regardoit, \& que c'ćtoit à lui feul, qu'il auroit dérormais à Í́pondre.

Il lui denanda enfuite quand il comptois de partir, ce fera, Sire, demain matin, dic le Pere, d moins que les ordres de Votre Ma. jefté ne me retiennent. Attendez encore deux jours, reprit le Roi, puifoue vous avez vî mes Appartemens, jeveux que vous voyer aun ma Fortereffe. Il lui ordinna di le rendre auprès de lui le lendemain à 'senre, cu'il lui marqua, le Mifionnaire s'y tro'rva avec fon Eompagnon, \& il rencontra au pied de la Ciradelle fept ou hut Gentilshommes, qui l'attendoient pour le conduire. Il y avoit nuit 8- jour à la premiere Porte une Garde de quit.

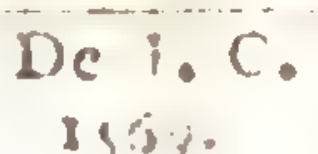




\section{HISTOIRE DU JARON,}

De $] \cdot C$. 1559.

Des Syn Mu. 2229.

ze ou vinge jeunes Gentilshomnes, \& un peu plus loin ils apperçrent cent Pages des meilleures Maifons de la Cour, dont tout l'enploi étoit de recevoir les Placers : \& comme ils ne pouvoicnt point palfer la preniere Salle. ils les remetcicntam Dames, ounux Filsmếmes du Roi, quilervoient immédiatement le Prince, \& avoient leuls le droit d'encrer partout.

Dis que Nobunanga eut été averti queles deux Miffonnaires ćtoient dans la premiere Salle, il leur envoya fon Fils ainé, qui lesintroduifi dans la Chambre du Roi. Ce Prince fit aullitôt apporter du Thé, en prélenta luimóme la premiere talle au Pere Frouz, prie la leconde pour lui, \& fit domer la troilićme à Laurent. Il les fit enfuite monter au plus haut de la Citadelle, où il les entretint deux heures à la vû́ de toute la Ville \& de toute la Cour, furprifes de voir de fimples Religienx comblés de tant d'honneurs par un Prince, devant qui tout trembloit, jufgu'aux Enpereurs mantes. Au milieu de la converfation, le Fils ainć du Roi s'approcha, le Roi luidic ceux mots à l'oreille, \& il le retira. Peu de tems après on fervit à fouper aux deux Mífionnaires, \& tandis qu'ils ćtcient à table, le Roi leur fit apporter a chacun un Habit à la Joponnoile, leur recommanda de le poreer, (a) afin qu'on fût infruir de l'affection, gu'il leur portoit, les aflura de nouveau de fa protection, \& les congćdia.

Ffet, que Ils partirent le lendemain, \& en arrivant pro'uit cette Audisnce.

(a) Il paroît par-la que les Miffionnaires étoient quelquefuis vêrus à la Japonnoife, au moins larfau'ils fraifloient en gublic, ou à la Cuur. 


\section{I V R E Q UA T R I É ME. $\$ 27$}

à Meaco; ils trouverent toute cette grande Ville dans l'abmiration des Honneurs, yue leur aivic faic le Koi de Voary. Le lere Froez envoya aufi-tôt Laurent, pour donner avis De syn-siu. de cout a Vatadono, qui retint trois jours le $222 \%$ Millionnare, parce qu'il éroutélolu de lé faire Cincétien \& quil n'ćtoir pas encore fufficmment infruit de nos Mylteres. Il Lui donna enfuice une Letre, qu'il écrivoir à Niquixoxuni, \& qu'il envoyoit toute ouverte ai lere Froez, afin qu'il la vît, avant que de la farre rendre à ce Bonze. Elle ne contenoit que ce peu de mots. c Le Pere des Chrétiens entalló „) depuis peu à la Cour de Nobunanga, qui s: l'a reçu avec une diftinction toute fingu$\because$ liere, \& m'a mandé de le favorifer en tout $\Rightarrow$ ce que je pourrois. C'elt ce qui m'en: gage à vous écrire ces lignes, pour vous » prier d'être fon Avocar aupres du Dairy, " \& vous pouvez compter que j'en aurai toure " la reconnoillance, dont je luis capable.

La réponle du Bunze fur roure lemblable à celle, que nous ayons déja rapportáe de lui, \& finilloit par des loilanges excefires, que cet orgucilleux prêtre fedonnoic à lui-méme fans pudeur. Varadono n'y réplingra rien, \&z

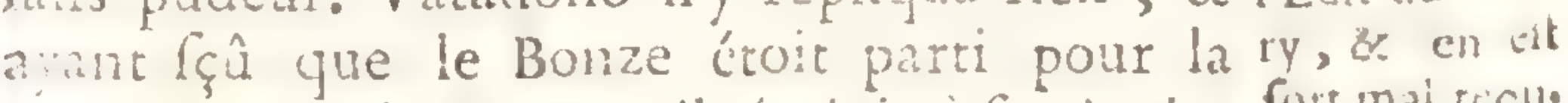
Cour du Roi de Voary, il écrivit a les Amis, veut engaris Nu!unan."al a faire cresuret l'ellt du li, fort mai tsç pour les prier de próvenir ce Prince fur la fujet de ce voyage, Ils le firent, \& Niquixoxumi ayant voulu débuter avec le Roi par le fupplier de confentir à l'exécution de l'Edit de Bannilfement portó par le Dairy contre les Dofteurs Européens, Nobunanga le reçut in al, \& lui parta is durement, qu'il 


\section{HISTOIR DO TAOON.}

- manarma n'of plus paroîre, \& retourna fur le champ ba 1. C. à Meaco, bien Iéfolu de fe venger de Vata15\% dono, gu'il regardoit comme le premier auDe Syn-Mu. teur del'affront, qu'il venoir de recevoir. 2229. La vengeance eft la plus induftrieufe de touIl vient à tes les Paflions: Niquixoxuni ayant communilicut de frirc qué fon chagrin à plufieurs Bonzes de Jefan, difigracier $\mathrm{Va}$ - drella par leus confeil un plan d'accufation Edono. contre le Vice-Roi, concerta fr bien fon intrigue, y fit entrer tant de Perfonnes, qui paroilloient défuntérellées, chargea fon Ennemi de tant de crimes, $3 i$ fçut fir adroitement prendre Nobunanga par tous les endroits, où il ćtort le plus fenfible, que ce Prince donna dans le piége. Vatadono étant allé au Royaume de Mino pour y faire a Cour, le Roi lui fir dire, qu'il ne fût pas aflez hardi pour te montrer devant lui. Le Bonze, qui étoit retourné à Anzuquiama, voyant lon intrigue en $\mathrm{f}_{\mathrm{b}}$ bon train, rechargea encore; \& fit paroitre fon rival fi coupable, que le Roi dépotilla Vatadono de toures fes Carges, fupprima fes Pent frons, faifit fes Rerenus, \& fit rafer une de fes Forterelfes.

Comment il Cette nouvelle fut un coup de foudre pour futient fa dif les Chrétiens, qui è trouvoient lans IProtecgrace, teur dans une Cour, où leur plus mortel Ennemi n'avoit plus de Concurrent; mais Dieu fit voir dans cette rencuntre, que s'il veut bien fe fervir des Hommes pour l'exécution de res deffeins, il a'a nul befoin de leur fecours, \& que d'aillkurs il tourne à fon gré le cocur des Rois. Janais Niquixoxuni ne put faire changer de fertiment a Nobunanga fur ce qui regardoit les Chrétiens. Vatadono de fon côté n’aidoit pas peu à les confoler par la 
LI $\quad$ R E Q U A T R I E M F. 329 maniere héroique, dont il foutenoit la difyrace. Il cefla de pourfuivre fon Ennemi, guand il n'eur plus que fa propre injure à venger. Il difoit a ceux, quile plaignoient, qu'il nuettoit au nombre de fes plus heureux jours, celui, auquel il aviot perdu ía forme pour la caufe du vrai Dieu; que tandis que les Práuicateurs de l'Evangile ne feroient point inquiétés dans leurs Fonctions, il ne fe croiroit point malheureux, puifcu'il n'avoit que cette feule Affare à cceur, \& que fi ces Religieux venoient à être challés du Japon, il quitteroir avec joye le peu, quon lui avoic laillé, pour les fuivre aux Indes.

Une Vertu if pure \& if fublime ne pouvoit pas demeurer longiems optrimće la calomnie, \& le Ciel fe lailia fléchir aux Priéres, qui fe faifoient dans toutes les Egliles, pour obtenir que l'imnocence fût reconnuë. Nobunanga ne put oublier, ou fe latia de maltraiter un Homme, à qui il avoit tant d'obligations; étant revenu à Méaco all bouc de quelques mois, il apprit que deux cents Gentilshommes s'étoient fait raler, \& avoient abandonnc le foin de leurs Affaires; cérémonie, qui fe pratique, lorfqu'on eft mécontent de la Cour : il en voulur fçavoir la caule, \& on lui allura, gue c'éroit par reflentiment de la maniere, dont il avoit traité Vatadono. Il ne dit rien pour lors, mais peu de jours apres il donna ordre qu'on fit appeller ce Seignerir, ఫui vint aufl-tôt, \& parưt devant lui en ćçuipage de Proficrit. Ce fpectacle toucha le Roi, il fe fit apporter un de fes plus riches Habits, pour en revêtir Vatadono; il lui rendit tous les Emplois, augmenta les Revenus, le

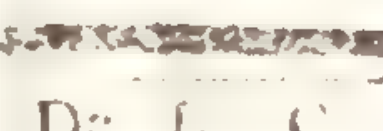

D: $1 . C$. 1564.

De Syn-Mu $22-y$. gitice.

Il renire en 


\section{FFO HISTOIRE DU JAPON,}

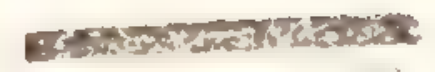

[ic ]. C.

i $\$ 5 \%$

Desin- M! $-2 y$.

Le Bonze cit difracio d iun tult.

fit nionter a Cheval avec lui, \& fit une courfe accompagné de lui leul, exercice, qui lui étoit allez ordinaire. Il trouva méme bon, que le pere Froez le remerciât d'avoir rendu fes bonnes graces au Vice-Roi, \& il dit à ce Religieux, qu'il avoit raifon d'y prendre part, pnifoue Vatadono étoit un de les plus zélés Difciples.

Il n'y avoit gućres que quatre ou cing jours, que ce Seigneur étoir de retour à Méaco, lorfqu'on préfenta au Roi de Voary un Mémoire contre le Bonze Niquixoxuni, où ce $\mathrm{Ca}$ lomniateur étoit accufé \& convaincu de crimes atroces. Nobinanga le condánima fur le champ à mort; mais le Dairy obtint qu'il lui fir grace de la vie; pour fes Emplois, ils lui furent tous ôtés, \& il palfi le refte de les jours dans l'opprobre $\&$ dans la plus affreufe indigence. Nous verrons bien-tôt que Dieu ne tira pas une vengeance moins févére des Bonzes de Jelan, chez qui s'ćtoient fabriquées toutes les Machines, qu'on failoit joiler depuis tant d'années contre la Religion Chrérienne, \& contre ceux, qui fe déclaroient fes. Protecteurs.

Cependant la nouvelle faveur du Vice-Roi lui fit prendre avec encore plus d'ardeur les intérêts de la Religion, dont il avoit été le Martyr, avant que de l'avoir embraflée. On auroit de la peine a imaginer ce que fon zéle lui faifoit entreprendre tous les jours pour l'útabliflement du Chriftanifme. Sa charité n'étoir pas moins tendre, que fon zéle éroir actif. Il entroit dans tous les befoins des Nécentreux, \& il n'y en avoit aucun parmi les Ficićles, qui ne le regardât avec juftice com- 
LIVRE QUATRIÉME. 33 me fon Pere. Il eft allez difficile de dire ce qui l'empéchoit de recevoir le Baptême; il étoit fort inftruit de nos Myféres, fa difyrace lui en avoit laillé tout le loifir, \& il en avoir profité. D'ailleurs il pratiquoit des ver$D=1.20$ $15 \%$ tus, qui auroient fait honneur aux Chrétiens les plus parfaits, \& la maniere, dont il s'étoit déclaré dans tous les tems pour le Chriftianifme, montre allez que la Politique n'entroit pour rien dans ces délais. Au refte il ne fe démentit jamais, il fut jufquà fa mort le protecteur des Ouvriers de l'Evangile, \& l'appui de la Religion, qui lui fut particuliérement redevable des grands progrès, qu'elle fit alors dans le centre de l'Empire, à la Cour de l'Emperelir, \& dans celle du Roi de Voary.

Ces progrès n'étoient pas moins confidérables dans toutes les Provinces du Ximo, la Religion. où la lumiere de l'Evangile avoit pénétré. Zele du Rui Le Roi de Bungo n'avoir pas lailé un feul coin dans fon Royaume, où Jefus-Chrift n'ết été prêché, \& il ne tint pas a lui que le Naugato ne devint tout Chrétien. Morindono ayant fait une excurlion fur fes Terres, il alla à fa rencontre avec une Armée de quatre-vingt mille Hommes, \& l'o'sligea bientôt a fe fauver dans fes Etats, ou il trouva un Ennemi, auguel il ne s'attendoit pas. Un Seigneur nommé TrRofiro, qui avoit des prétentions allez bien fondées fur ce Royaume $(a)$, avoit voulu profiter de l'ablence de Morindono, \& avec un bon Corps de Troupes, que Civan lui avoit donné,apress

(a) Queliques-uns prétendent quill étoir Fils du fiu. Rui F ACARANEONO, Lrete du R'vi de bunEO.

2229. de Bungo.

O vi 


\section{HISTOIRE DU JAPON;}

lui avoir fait prometre de rétablir le ChriD. T. C. Ptanifme dans le Naugato, s'il s'en rendoie istry

Di Syn-Mlu-ćtoit entré; mais fes forces n'étant pas fuffi222y. fantes pour tenir têre à fon Ennemi, il fur défait, \& mourut bien-tôt après de chagrin, \& des bleflures qu'il avoit reçüés dans un Combar. Quelque tems après le Roi de Naugato, qui n'oloit plus s'attaquer au Roi de Bungo, lequel l'avoit toujours batta, tourna fes Armes d'un autre côté, \& elles furent fi heureules, qu'en peu d'années il fe trouva Maîtres d'onze Royaumes, \& le plus puiflane Prince du Japon après Nobunanga.

zole du La Principauté d'Omura n'étoit pas alors Pirce do- cout à fait tranquille, mais l'Orage ne gronmis:2. doit que de loin. Il grondoit pourtant, \& ce fut ce qui obligea le P. de Torrez, à qui Sumitanda avoit propofé le deffein de contraindre tous fes Sujets d'enrbraffer le Chriftianifme, de s'y oppofer \& de confeiller à ce Prince d'attendre qu'il pît salfurer d'être obéi, \& de s'appliquer plus que jamais à régner fur les coeurs de fes Sujers. Le Supérieur gounta davantage un autre Projet, que lui communiqua en méme tems le Prince dOmura; c'étoit de bâtir une Eghle à NaNGAZAQUr, où il vouloit attirer les portugais; afin d'en faire le centre de leur Commerce, \& un Afyle toujours affuré pour les Chréticns \& les Miftionmaires, quand ils feroient perfécurés.

Deforipion

Nangazaqui $(a)$ eft un Port fitué fur la

du Port de Ning azaçui.

(a) Les Chinois nomment cette Ville ICHANKt; Hempefer écrit toujours NAgAsaQu!, mais il dir quien

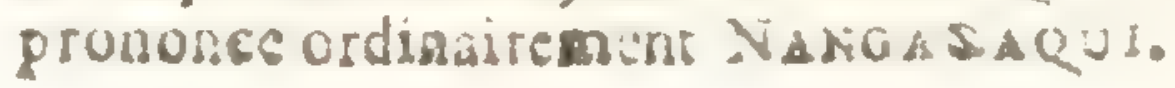


I. VRE Q U A T R IE ME. 3;3

Cúte Occidentale du Ximo, vis-à-vis de la Chine, dónt il n'eft éloigné que de foixante lieuès; on prétend quil avoit tiré fon nom des Anciens Seigneurs du lieu, \& l'on nrontre au fommet d'une des Collines, qui environnent aujourd'hui la Ville, les ruines de l'ancienne denieure de ces Nangazaguis, dont la Poltérité ayant manqué, le De J. C. Is $68.6 \%$.

De Syn-Mu. 2228.29. Port \& Con Diltrict furent réunis à la Principauté d'Omura. Peu de tems après la Ville fuc changée de place, \& tranfportée dans un endroit, qu'on nommoit FuCAXE, c'elt-àdire, longue Baye, où il y avoit quelques Pécheurs érablis. C'eften cet endroit, qu'elle cf préfentement. C'étoit encore bien peu de chofe, lorfque Sumitanda forma le Projet, dont nous venons de parler; on prétend mênie que ce furent les Portugais, qui lui firent ouvrir les yeux fur l'avantage de fa fi. cuation, la bonté de Con moiillage, \& la proximité de Macao \& de la Chine. Ce Prince propora à plufieurs de ces Marchands de s'y ćtablir, \& ils y confentirent. Leur exemple fur bien-tôt luivi d'un grand nombre d'autres Marchands de la même Nation: il y vint aufi quanticé de Japonnois Chrétiens, \& en allez peu d'annćes Nangazaqui devint une grolle Ville. Il fut un tems, qu'on y compta jufyu'à foixante mille Ames; mais dèslors elle étoit Ville Impériale, comme elle lieft cncore préfentement. Le nombre de fes Habirants eft aujourd'hui bien diminué, ainfi qu'il fe verra par la Defcription, que nous en donnerons en fon lieu.

Nangazaqui commençoit donc d̀ peine à prendre quelque forme, lorfque le Prince Chréticane y

Projet du

Prance fn: ea Pertr. 


\section{HISTOYRE DU Ja pON:}

De J. C.1

d'Omura fie au P. de Torrez la propoficion,

Is68 69.: dontj e viens de parler. Le Supérieur l'accepta

néanmoins avec joye, \& manda au P. Vilela,

De Syn Mlu.

1. 2228.29 .

quí ćtoir à Cochinotzu, de s'y tranfporter. Il obéit, \& il y fir tant de Converfions, qu'en peu de tems la Ville parut toute Chrétienne. Sumitanda voulut ĉtre témoin oculaire d'un fuccès if prompt, \& il en fut touché jufqu'aux harmes. Ceci fe palloit en I 568 , \& le Japon. avoit eu au mois de Juin de cette même année un renfort de trois Millionnaires, qui ne pouvoient venir plus à propos. Jamais pluye ne fut mieux reçuci dans une Terre delléchée par une longuearidité, que ces nouveaux Oti. vriers le furent par les Fidćles Japonnois, dont la plipart ne pouvoient, à caule de la difette de Prétres, participer que rarement aux Sacrements de l'Eglife, \& on ne peut lire fans être attendri, le détail que fon ces Ouvriers Evangéliques dans leurs Letres de la maniere, dont on les reçut au fortir de leur Navire, qui avoir moinillé l'Ancre au Port de FACUNDA, à deux lieués de Nangazaqui.

Nouveaus Plufieurs fe profternoient \&t s'étendoient Miffonnaires. même par terre dans les endroits, olt ils deComment ils voient paller, fouhaitant d'être foulés aux lont reçus des Chrétiens. pieds de ceux, dont l'Ecriture dit que les pas font pleins de charmes; \& ce qui doit paffer pour un Miracle d'humilité dans un Peuple ii fier, un Mifionnaire ne paroilloit jamais dans une Ruë, que tous les Chrétiens qui s'y rencontroient, jufquatr: Perfonnes les plus qualifiées, ne fe milient dans une pofture refpectueufe. Les perires Gens ne leur parloient yu'à genoux, \& les autres avoient toujours les yeux baiffés; \& le corps mĉme 


\section{LIVRE QUATRIEME. 335}

un peu courbé en leur parlant. Ces Religieux avoient fans doute de grandes raifons pour Couffrir qu'on leur rendit de fi profonds refpects, \& il eft bon d'obferver, que les Bon-De Syn-Mu. zes ayant accoutumé les peuples à cette maniere d'agir, il ćroit important de leur faire bien fentir que le Dieu des Chrétiens méritoir encore plus d'êrre refpecté dans fes Envoyés, que les faulies Divinitez du Japon: dans leurs Miniftres. Les mêmes Mémoires ajohtent que la converfation de ces fervens Chréticns avoit quelque chole de célefte, \& que les exemples des Vertus, qu'on leur voyoit pratiquer, jettoient tout le Monde dans l'ad. miration. En I 577. Onze Portugais fort riches \& de bonne Maifon en furent tellement frappés, qu'ils demanderent à être reçus dans: la Compagnie. On en admit quatre, les autres furent renvoyés au Provincial des Indes, \& un nommé AmADOR DE CASTRO, qui fe trouva à Macao: lorfque le Vailfeau, qui les avoit portés au Japon, y fut de retour, a depuis alluré que l'Equipage ne parloir des Taponnois, que les larmes aux yeux, \& difoit que pour apprendre ce que c'elt que d'cेtre Chrétion, il falloir aller au Japon.

Cependant les fuccès du Pere Vilela dans Nangazaqui, \& quelques converfions d'éclat, d'Omura ne que fir le Pere de Torrez à Omura, firent veut pius avoir reprendre à Sumitanda le deffein, dont le Su-que des Sujuts périeur lui avoit fait fufpendre l'exécution. Baptéme de Ce Prince lui repréfenta qu'il jugeoit tout toute faFamil. ce qui lui reftoit des Sujers Infidéles allezle. bien difpofés, pour recevoir la Foi à la premiere fommation, qu'il leur en feroit, qu'il ne fe croyoir pas véritablement le Maitre 
33.6 HISTOIRE D IAPON,

dans fes Etats, tant que les Démons y étoient

De J.C. adorés; qu'il avoit appris de S. Paul qu'un rizo. Chrécien, qui n'a pas foin de fes Domefti-

DeSyn.Mu. ques, eft pire qu'un Infidéle; qu'un Prince 2230. doit être parmi fes Peuples, comme un Pere de Famille dans fa Maifon; que tous fes Parents demandoient le Baptême avec inftance; qu'il feroit refponfable du falut de ceux, qui mourroient déformais dans l'Infidélité; en un mot qu'il étoit réfolu de rifquer fa Couronne \& favie, s'il étoit nécellaire, pour une fi belle caufe. Le Pere de Torrez donna enfin les mains à tout ce que fouhaitoit ce Prince, \& fe difpola à confćror le Sacrament à toute fa Famille, c'eft-à-dire, à fa Mere, i fa Femme \& à fes Enfants.

Sumitanda étoit bien informé que plufieurs des Principaux de la Cour re différoient de fe déclarer eux-mêmes, que parce qu'ils ne voyoient point les plus proches Parents de leur Prince fe déclarer : ainfi il crut que le Baptême de fa Famille difpoferoit non-feulement fes Officiers, mais encore tous les autres à fuivre un fi bel exemple. Dans cette penfée il les affembla \& leur parla en ces rermes, s Je n'ai différé de mettre la ders niere main à l'entiere Converfion de $n$ !a s Famille, que pour vous donner le tems \& $\rightarrow$ le moyen de vous infruire des principes s) de la Religion Chrérienne. Il ma paroít s que vous en devez avoir une connoilfance s parfaite, ainfir rien ne doit plus vous excu" Cer, ni envers Dieu, ni envers moi, qui $\Rightarrow$ me crois dans une obligation indifpenfas ble de ne rien négliger pour vous foumet$\rightarrow$ tre a Jelus-Chrift. Si ce parti-là ne vous 
LIPRE QUATR E E E. 337 s convient point, vous pouvez choifir tel $\Rightarrow$ Solverain, qu'il vous plaira. c Le Prince mononça ce difcours d'un air fi touché, \& mếme î infpiré, que toute l'Allemblée lui protefta qu'elle étoit difporée à faire au plutố ce qu'il défrroit.

Les chofes en étoient-là, lorfque le P. de Torrez eut avis de l'arrivée du P. FRançois Cabral, \& du P. Organtin Gnecchi au Port de XEQUI. Le premier venoit en qualité de Vice-Provincial, ainfi par fon arrivée le Pere de Torrez fe trouvoit déchargé du poids de la Supériorité, que fon grand âge ne lisi permettoit plus de porter. Il crut devoir céder au P. Cabral l'honneur de bapiiler la Familledu Prince d'Onura, \& il pria ce prince de le trouver bon. Sumitanda y confentit, \& le Baptênze des Princelles, des jeunes Princes \& des Seigneurs, fe fir peu de tems aprés avec toute la folemnité poffible: il $n^{\prime} y$ eut que la Reine Mere du Prince, qui ne fut point baptifée ce jour-là, parce qu'on n'avoit pas encore pûl'inftruire fuffifanment à caufe de fon grand âge; mais elle le fut peu de jours aprés, \& Sumitanda au comble de fes voux, ne fongea plus qu'àtirer d'un fi grand nombre de Converfions tout l'avantage, qui en ponroir revenir à la Religion.

Le P. de Torrez s'étoit bien promis, lorfqu'il alla trouver le Vice-Provincial à Xe-de Turse \& qui, de l'accompagner enfuite à Omura; fin éloge. mais à peine ćtoit - il arrivé dans le premier de ces deux endroits, qu'il y fut atraqué d'une riévre, dont on ne crut pourtant pas d'abord que les fuites dûflent être funeftes. Une foiblelle, qui lui prit peu de jours après, lui fit

\section{De 1.C. 1570.}

De Syn-Mu. 2330. 


\section{;38 HISTOIRE DUTAPON,}

- juger à lui-mćme, qu'il n'avoit pas encore De J.C. beaucoup à vivre. Il fit une Confellon généI570. rale de toure fa vie au P. Vilela, qui ćroit

De Syn-Mu. 2230. demeuré a Xequi avec lui, parce quili devolt incellaminent repalfer aux Indes, la fantć ne lui permetrant pas de demeurer plus longtens au fapon. Le jour fuivant le Malade voulut aller recevoir le faint Viatique a l'Eglife; il embralla enfuite tendrement rous fes Freres, prit congé des Chrétiens, dont l'Eglife étoit remplie, \& peu de tems apres il expira le deuxíme joux d'Otobre dans ces tranlports de joye, qui commencent dis cetre vie la fouveraine félicité des Saints.

On ne peut dire jnfquà qual point le Pere de Torrez fut regretcé; la douleur, fut univerfelle, \& toutes les Eglifes en donnerent a l'envi des mar ques aufílinceres, qu'elles furent éclatantes; aufi étoit-il le plus aimable des Hommes. Sa douceur, for beau naturel, fa complaifance lui avoien! fait aum tant d'Amis, qu'il avoit connu de Peronnes, méme purmi les infidćles: bien des Gens, qui ne lavoient janzis vû, mais quilur la Téputarion lé lenzolent une grande incinati " pour lui, le prévenoient par Letres, \& entretpnoient avec lui un Commerce jéglé. aucuel il róponduit, autant gue fes occupations le lui pouvoient permetre. On aflure même, cue dans l'Univerfité de BANDOUi, dont il avoit roujours été très-élrigné, il y avoit plufeurs Bonzes, \& plufieurs Sçavants, qui encretenoient avec foin in amitic. Pour ce oui elt des Chrćtiens, le is tendrefie \& leur attachement pour lui, étoit au-dellus de tou- 
L I V R E Q U A T I I F́: ME. 339 tecrpreflion. Lorfou'il étoit obligé de fe tranfporter d'un lieu à un autre, il mi falloit cacher avec foin fon départ, \& fe metre en chemin la nuit, pour éviter d'être arrêté. Tous ceux qu'il baptiloit, vouloient porter fon nom, $\&$ il avoit un tel afcendant fur les efprits, que le moindre figne de la volonté étoir reçu comme un ordre: cela parut lurtout dans une occafion d'ćclat.

Des Bonzes avoient tuć à Omura un Enfant Chrétien: je n'en ai pas trouvé le fuje:; le bruir s’en ćtant répandu, quelques Néophytes fe perfuaderent qu'il y alloit de leur fureré, \& de lhonneur de la Religion de ne pas lailfer ce meurre impuni; ils s'allemblerent, \& jurerent 'n mettant la Main fur leur Ventre, ce qui elt au Japon une forte de jurement irrévocable, quils auroient raifon de lattentat des Bonzes; ou qu'ils périroient à la peine. Ils s'armerent aufi-tôt de tifons, \& de tout ce yui fe trouva fous leui Main, \& criant gu'il folloit tuer les Bonzes, \& brûler leurs Monaféres, ils alloient remplir la Ville de céfordre \& de nallacre, lorfoue le Pere de Torrez fut averti de ce tumulte. Il courat furlechamp au lahis, \& pria le Prince dinterpof́l lon autorité pour remetre l'ordre partout. Smmitanda lui réponcit que, quand il sagilloit de l'homneur, les Japonnois ne reconnolfoient, ni. Sorrain, ni Loix, \& ty'il ne vouloit pas fo commettre avec une Populace juftement irrcé mais vcus, mon Pere, ajoita-til, mitrez-vous, E je $m^{2}$ affure que tout fera crime: en erret à peine le faint Vieillard pirut que rous mirent bas les Armes, \& le nivirent a l'Egli- 


\section{HISTOIRE DO JAFON,}

fe, dont ils lui virent prendre le chemin; Ià

De J. C. ils fe jetterent à fes pieds, \& reçurent avec 15:0, refpect la correction, quil leur fit, \& l'inf-

De Syn Mu. iruition, quil leur donna pour les préferver 2330. à l'avenir de pareilles fautes.

La nuit fuivante un Idolâtre Ami de queloues-uns de cenx, qui avoient eu plus de part 2 cette Affaire, les alla trouver, pour leur dire qu'il ne délapprouvoit pas leur déférence areugle pour leur Dofteur, \& qu'ils avoient fait fagement de lui obéir dans le moment, mais qu'après trut leur honneur ćtoit engagé a ne pas fouffrir que les Bonzes culfent le deflus: à cela ils répondirent qu'er recevant le Baptême, ils avoient juré d'obferver la Loi divine, qui ne s'acconzmodoit pas de ces fauf fes Maximes de la fageife du fićcle, \& que la veille ils avoient promis au Pere de Torrez de ne plus penfer à ce qui étoit arrivé; que quand leur honneur en devroit fouffrir, ils ue pouvoient manquer à la parole, qu'ils avoient donnée a Dieu \& à leur Pere. Ainf on ne parla plus de rien, a le jour fuivant le Magiftrat alla en cérémonie remercier le Serviteur de Dieu du'fervice important, qu'il avoit rendu a la Ville.

L'Honme Apoftolique n'étoit pas moins en vénération parmi les Idolâtres, que parmi les Fidéles. Le Roi d'Arima ne recevoit point de fes Lettres, que par refpect il ne les mit fur fa Tête. Le Roi de Bungo retira deux fois à fa confidération fes Troupes prêtes à défoler entiérement des lieux, oư il avoit ćté offenf', \& le prince d'Omura, même avant fon Bantême, vouloit que fes Sujets le refpectaffer encore pius que fa pronse Perlor- 


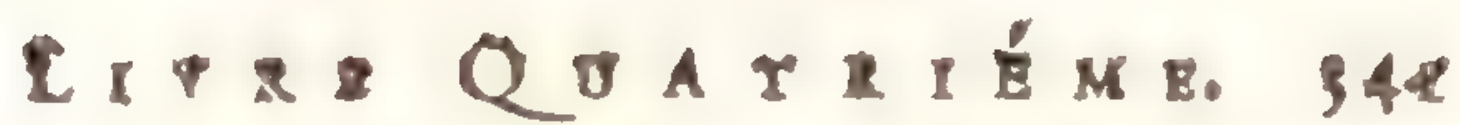

- Les plus déclarés Ennemis de la Religion étoient charmés de fon zéle infatigable, \& Curpris de lauftérité de fa vie, qui palloir effectivement tout ce qu'on en peut dire. De Syn-Mu. L'amour, qu'il avoit des fouffrances, lui fadloit dire fouvent qu'Amanguchi avoit été pour lui un vrai Paradis fur la Terre, parce qu'il n’y avoit pas été un feul jour fans fouffrir beaucoup, guill y avoit cent fois couru rilupe de favie, \& qu'il n'eft forte d'indignitez \& d'affronts, qu'il n'y eût efluyés. Il ne f̧̧avoit ce que c'étoit, que de s'ćpargner en rien, furtout lorfqu'il s'agnfoir du palut des Ames, ou de procurer quelque foulagement a lés Inférieurs; alors rien ne l'arrêtoit, rien ne lui coûtoit, ni la longueur \& la diffieulté des Chemins, ni les dangers, aufquels il falloit s'expofer dans un pays, oll il f̧̧avoit par pius d'une expérience que les finnemis du Avum Chrétien cherchoient toutes les occafrons de le faire périr. Un jour, qu'il fe dif poloit a un fort long Voyage, pour aller au lecours d'un de fes Religieux, qui étoir Mnlade, quoiqu'il fût lui même fort incommodé, les. Chrétiens en pleurs accoururent pour le retenir; il leur répondit, qu'il eftimoir plus une ouvre de charicé, que fa propre vie.

Cette attention à loulager ceux, qui ćtoient fous fa conduite, devoit paroitre d'autane plus adnirable, qu'il ne s'accordoit rien à lui-méme, \& qu'étant naturellement un peu atrabilaire, il eût été fort dur, fi la grace n'eût adouci en lư le caractere; tant il eft vrai que la Veru, quand elle a une fois pris le deffus, va plus loin que la Nature, qui dans 


\section{HISTOIRE DU JAFON,}

les Ames les mieux nćes a fes humeurs, \&

De J. C. Ce recherche toujours elle-mime. Mais Dieu, 1570. qui fe communique aux Saints a proportion

ve Syn $\mathrm{Mu}$ de la violence qu'ils fe font, aroit récom2230. penfé fon Scrviteur d'un don de larmes prefque continuel, \& dine frande union avec lui, nuil fembloit habiter olus dans le Ciel, que fur la Terre. Enfin pour achever en deux mors l'Eloge du lecond Fondateur de l'Eglife du Japon, jamais Homme ne pratigua plus à la letre ce Précente, que Jefus-Chrilt donne à fes Apôtres, de fe faire petits comme des Enfants. Dés qu'il cntra en Religion, il onblia tout ce gui l'avoir diningué dans le fićcle, pour ne s'úrudier qu'à l'abnćgation de lui-même. Fervent Difiple, humble Religieux, zélé Miffonnaire, vigilant Supériear, Ouvrier infatigable, il avoit foixante \& guarorze ans $(a)$, \& il pouvoit à peine fe foutenir, qu'il fondoit encore des Eglifes, \& il mourut en travaillant. Trente mille Perfonnes baptifes de G Main, E cinquante Eglifes fondées par les foins hi donnoient droit de dire, comme l'Apotre des Nations $(b)$, j'ai fourni ma courfe, j'ai été fudéle jufqu'à la fin, j'attends la Couronre de Jufice, que le Seigneur le plus équitable de tous les Juges, me renira au dernier jour.

sisobfcues. Les Penples, cui pendant fa vie lavoient Mrredu Scic regardé comme un Saint, furent bien convilicla. firmés dans cette opinion après fa mort à la

(a) Le P. Bartoline lni doune que foixante-quatre ans, dautres le funt muurir dans fa foixantiéme année; i) y a de lisprarence quils fe trompute. Ce qui df certain, c'est quil éroit exiraurdinairement calles.

(6) 2.1 timoth. 4. \% \& 8 . 


\section{IITRE QUA T R I f́. E. 34}

vî́c de fon Vilage, qui parut alors d'une bualté extraordinaire, \& qui Cinlloit rendre tímoignage de la iricité, iont fon Ame jo.". Hoit dans le Ciel. Ses Obféques furent cobrées avec un concours furprenant, \& a compagnćes de ces acclamations des Fidé1.s, qui dans les premiers fićcles de l'iglie Cunonifoient les Saints. Le; Peres Balthazar Lopez, Alexandre Valla, \& Gafpard Vilela s'y trouverent, \& ce dernier fit l'Eloge du Defunt. Enfin il n'y eut pas un feul des AC fitants, qui ne voulit avoir quelque chole, qui ết été à fon ufage, 3 l'on eut toutes les peines du monde à empêcher que ies vêtements ne fullent mis en pićces. Le Pere Vilela, qui s'embaruua peu de jours a rès pour les Indes, ne ini furvécut pas longiems. Il mourut prefoúcn arrivane a Malacá, \& alla recevoir dans le Ciel la récompenfe dủe aux grands Travaux, qu'il avoit foufferts, \& aux éminentes Vertus, quil avoit pratiguces dans la Carriere Apofoligue.

La Principauté de Xequi, où le Pere de Torrez avoit fini fa courle, étoit prefure toute Chrútienne: le Prince mûne éroit baptifé, mis comen il n'avoit recu le Baptêno cure les Chrémais comme il navoit reçu le Bupteme, que tiens. gour artirer les Portugais dans fes Ports, te voyant frufté de fes efpérances, il retonrna publiquement au Culte des Idoles; il voulut meme engager les Suiets a imirer fon Apoltafie; mais leur converfion avoit été plus fincere yue la fienue, \& ils furent aufi plus conltans dans lewr Foi. En vain il les menaça de l'exil \& de la more, il non pur ébranler un feul; fes promelles ne furent pas plus efficaces: il rut que s'il paltoit des menaces aux effets, il hs 


\section{HISTOIRE D U TA PON;}

feroit bientôt changer de langage, il fe trons-

De J.C. pa. Cette perfécution, qui donna quelques I 570 .

De Syr-Mu. Martyrs à l'Eglife, ne fut pourtant pas de durée, le Roi de Bungo l’ayant bientốt fait cef$22 ; 0$. fer par fes bons offices, aufi bien que celle, qui s'étoit ćlevće en même tems dans la Principauté d'A macufa.

perfécution C'étoit le Pere Vilela, \&r Michel Vaz, qui dausla frinci- avoient prêché la Foi dans les Etais du Seipausé d"A mazneur de Xequi en I 567 . \& les grands fruits, cula. Gouver- que leur zele y avoit produits en if peu de tems, ฉeur. avoient engagé le Seigneur d'Amacußa à demander au Pere de Torrez un Miflonnaire: Louis Almeyda lui fut envoyé fur le champ, \& le prince le reçut de man ere à lui faire efpúrer, que fes travaux riauroient pas moins de fuccès dans cette Ville, qu'ils en avoient eu partour ailleurs. Pour rendre fes efpérances plus certaines, il fir plufieurs demandes au Prince, qui lui accorda tout; mais comme il s'apperçut bientôt que le Seigneur d'Amacufa ta'étoir pas fort abfolu chez lui, \& que ce petis Etat fe gouvernoit un peu en République, il ne crut pas devoir faire aucune démarche éclatante, fans être auparavant alluré, que les Chefs du Peuple ne soppoferoient pas aux progrès de l'Evangile: il ne trouva de leur part aucune difficulté, \& il commença les Infructions, aufquelles le Prince fut toujours des pius affidus: elles ne tarderent pas à opérer, Je Gouverneur de la Ville fut le premier, cui demanda le Baptême, \& ill lui fut conféré avec heancoup de folemnité; on lui donna le Nom de LEON. Son Beau-Pere fuivit fon exemple: If nombre des Chrétiens monta en très-peu de tcmps à plus de mille, \& la plûpare de ce qu'il 


\section{LITIE QUA'TRIE ME. 345}

- avoit de plus diftingué dans le Pays, fit publiquement profeflion du Chrifianifine.

Un fuccès fi rapide allarma les Bonzes, qui vinrent à bout d'engager deux Freres du Prince Do dans leurs intérêts; ces deux Seigneurs leverent fecretement fix cents hommes de bonnes Troupes, \& quand ils fe crurent en ćtat de fe faire craindre, ils envoyerent avertir le Prince que leur deflein ćtoit de fe dćfaire du Gonverneur Leon, qu'ils le prioient de ne le pas trouver mavais, parce qu'ils n'avoient en vîe, que d'aflurer la tranquillité publique. Le Prince reçut fort mal leur Dépunation, \& fit donner avis au Gouverneur de ce qui le machinoit contre lui. Les Chrétiens, qui furent bientôt inftruits de tout, accoururent en foule chez Lćon, jufgu'aux Femmes, \& aux Enfants, bien réfolus de ne pas foufrir qu'on attentât à fes jours. Les chofes en ćtoient là, lorligu'un Bonze vint frgnitier à lćon de la pare des Chefs de la Conjuration, un ordre de fe fendre le ventre. Il demanda à ce Prêtre, qui lui faifoir ce commandement? \& il lui ajohta, qu'il pouvoit retoumer à ceux, qui l'avoient envoyé, \& leur dire qu'il les attendoit, \& qu'il ne les craignoir foint. Un fecond Député vint lui dire peu de tems après, que s'il vouloit fortir du Pays, on ne le pourfuivroit pas, mais que c'étoit le feul moyen, qui lui reftât de metrre favie en fureté : il répondit, gu'il étoit prêt de mourir pour fa Foi, mais que pour l'exil il n'en recevroit l'ordre, que du Prince. Alors les Conjurés s'adrefferent au Prince même, \& lui parlerent fi haut, qu'ils l'intmiderent; il crais gnit de voir une Guerre Civile allumée dans Ces Etars, \& il fit prier Léon de céder au tems:

Tome II. 


\section{HistoTRE DE JATON,}

- le Gouverneur cbćit, \& re retira à Cochinotzu, 15;0. où la Famille \& plus de cinquante Perfonnes le

De Syn-Mli. 2230. fuivirent.

Peu de jours anrc̀s un des Fils du Prince rer. contra dans une rue de la Ville un Enfant,

Belle action d'ur Eufunto qu'il reconnut pour Chrétien; il lui fit mil e queftions, qu'il entremêla de Blafphémes horribles contre Jelus-Chrift : l'Enfant l'avertit de prendre bien garde à ce qu'il díoit, que le Dieu des Chrétiens n'étoit pas un Dieu fourd \& impuiffant, comme ceux du Japon, \& yu'il ćtoit terrible dans les vengeances. Le Prince choujué de cette hardiefle, ou feignant de l'être, tire lon Sabre, \& regardant d'un ocil courroucé l'Enfant, gui continuoit toujours à lui parler fur le même ton. Blafphémer ainfien ma préfence les Dieux que j'adore, lui cir-il, E manquer à ce point au re $\int p \in t$, qui m'eft dî: ce Jont des crimes, quine Se pardonnent point. tu mourras; le petit Nénphyte fans fe troubler repartit: vous aurez, Seigneur, beaucoup de gluire d'ôter la vie à un Enfant défarmé: mais quel mal me ferez-vous, en me coupant la tête? icus ne fcauritz nuire d mon ane, qui ne fera pas plutôt Séparée de mon corps, qu'clle recevia une Couronne immortelle, Ew Sera éternellement placie dans le Jein de Dieu mêne. te Roi des Rois, E le Seigneur des Seigneurs. En difint cela, il fe jette à genoux, abbat fa rcbbe, \& fe met en pofture de recevnir le coup de la mort. Ce fpectacle étonna le prince \&r l'attendrit, il releva l'Enfant, lui fit mille carefles, \& fe retira.

I. Roi de Cependant Almeyda ćcrivit au Roi de BunButr.go fair cerle. la purécu. iiun. go, de qui, en qualité de Roi de Fingo, toute lifle d’Amacuín relevoit, que la Religion 
LIVRE QUA T R I E M E. 347 couroit rifque d'être tout-à-fait profcrite dans cette Ille, s'il n'y interpoloit fon autoritć. Civan manda auflitôt au Seigneur d'Amacula, que les Chrériens étoient fous fa protestion, \& yu'il les lui recommandoit; il accompagna fa Letre de fort beaux prélents; \& ce Prince De J.C. infiniment flaté de le voir ainfi recherché par fon Souverain, \& par le plus puiflant Roi du Ximo, parla en Mairre à fes Freres, qui firent femblant de fe foumetre. Almeyda recommença fes Fonctions, \& plus de cinq cents pertonnes demanderent le Baptćne. Alurstons les Bonzes ferórolterent, menacerent de guitter le Pays, \& vinrent enfin a bout d'exciter un foulevenent, dont le Prince crairnit dête lui-mêne la viotme: il fit prier Almeyda de difparoitre four guclque tems, 2 lun donna fa parole, cilil alloit prendre de bonnes meluzes pour metrea la raíon les Murins, \& qu'il nc tardcroit pas mfuite a le rappeller. Il n'eut pas plutôt donné cette narque de foiblelle, que les deux Freres prirent les Ammes contre lui; \& il couroir rifue de fuccomber, file Roi de Bungro ne lui ente cnvoyé des Troupes, avec lefurulies it mic fes freres a la railon, \&r récablit fon auturitć.

Il rappella aulirút le Gouverneur Lóon, \& ćcrivit au Pere Cabral, pour le prier de lui renvover Almeyda. Le Vice Trovincial crut d'un grant l'affare allez importante, pour fe tranlporter Sujess, qu': lui-mêne dans l'Ille d'Ámacufa, \& il y mena gagne hu-mế Louis Almeyda \& un aurre Jéfuite nommé are d. $I$. VINCENT. Alors tout le Pays fe remua, le concours fut prodigieux aux infructions des Milionnaires, \& le prince fut des pieniers à fe díclarer. Il reçut le Baptêne avec un Ii!s 


\section{HISTOIRE DU JAPON,}

i) T. C.

$3 S^{-0}$

Desyri-Mu. ¿2jo.

naturel qu'il avoit, \& fut nommć Mrcher. Il travailla enfuite a réduire tous fes Sujets fous le joug de la Foi, \& l'on peur dire qu'il fur 1'Apôtre de ce petit Etat. La conquéte, qui lui donna plus de peine, fut celle de la princelle fon Epoure, qui feule arrêtoit le progrès de l'Evangile. Le Japon n'avoir peut-irre pas un plus bel efprit, que cette Princelfe, ni perfonne, qui eût une plus parfaite connoiflance de toutes les Sectes, qui avoient cours dans l'Empire, \& les Bonzes les plus habiles, fine lee croyoient point déshonorés, en la conlultant fur les points les plus diliciles de la Théologie Japonnoile.

Converfion La converfion d'une Princelfe fçavante \& the laprinceffe, Théologicnne n'étoit pas une chole ailée. Iar qui ganne à T. $c \cdot$ reascoup de Bunzes, ¿.' uhlige les to ouires à fe reti cr. bonheur celle-ci avoit le coeur droit, \& n'avoir point ćrudié par vanité. Ce ne fut pourtant qu'ariès fix années entieres d'un travail, gui auroir rebutć tout autre que fon Epoux, qu'elle fe rendit. Elle fut baptifée avec fes deux Fils; dont l'ainé, qui reçut au Baptême le zom de JEAN, a illufté ce nom par les Vertus, \& furtout par fon hérolque fermeté $i$ foutunir la Foidans les tems les plus dificiles. La Princelfe fa Mere fut nommée Grace, \& x́para avec ufure le tems, qu'elle avoir perdu par fa réfintance. Elle fe domna de grands mouvenuents pour la conzerfion des Bonzes, \& après gu'elle en eur gagné le plus grand nombre \& les rincipaur, elle obligea le reite a fortir de l'ree. Enfin a la mort du Prince Michel quiarriva en i $\$ 82.0 n z e$ ans après fon Bapreme, it ne reftoit plus dans fes Etarsaucini) veftige d'Idolitrie.

Lo scigrour Il s'cir alloit beaucoup que les affaries de la 


$$
I=\nabla R E R A T R I E F \cdot ; j 9
$$

Religion allallent aufi bien à ximabara. Le Irince n'y mínageoit plus rien, ni avec les Iideles, niavec les Mifionnaires. Il leuravoit ité leur Eglife, \& l'avoit convereie en un ulige profane. Ii fitenfin publier un Edit, qui profcrivoit le Chriftianifme de fes Etats. Envain le Princed'Omura, fon Beaufrere, le pria cie ceffer cette perf́cution, \& le menaça même, il ne gagna rien; mais les Chrériens de Ximabara ćtoient en grand numure, \& leur ferveur fur à toute épreuve. Il ne fut jamais polible au Prince d'en regagner un feul, \& tous julqu'aux Enfans lui protefterent qu'ils póriroient plutôt dans les plus affreux tourments, que d'abandonner leur Dieu. Il en conçut $u n$ dépit dont il eût apparemment donné de fltw meltes marques, mais fept cents Chrétiens s'étant retirés en une nuit à Cochinotzu, il ap* préhenda de fe trouver fans Sujets, s'il pouffoit les autres à bout; il fe contenta donc de confifquer les biens de ceux, qui s'útoient ainli cxilés, \& que les Fidéles du Royaune d’A rima dédonmagerent avec ufare de ce qu'i!s avoiant figénéreufement perdu pour Jefus-Chrif.

Mais de routes les parties du Ximo, ou l'Evangile ćtoit alors connu, il n'y en avoit point, où la ferveur des Fidćles donnat plus Le Prinre de Gotudamalrdelesartins. de confolation aux Miflonnares, que le Gotto. J'ai dit qu'après le départ d'Almeyda, gui avoit été contraint de fortir de ce Royaume par le mauvais ćrat de la lanté, les filćles furent deux ans entiers fans amcm feconss finrituel; mais leur ferveur n'en foufrit point, \& leur nombre augmenta même conlidérable.. ment. Enfin dans le tens que le Pere de Torrez fut appellé à Omura, pour baptiler la Funille 


\section{HISTOIRE DU JAPON,}

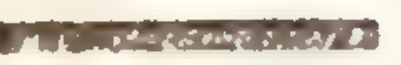

du Prince, il reçut une Letcre des Chrétions du

De T.C. Goto, qui lui demandosent un Millionnaire 15.0 .710 avec les plus grandes inftances, \& lui donDe sin-Mu. noient avis que le Prince Héréditaire fouhai-

$22 j \omega 38$. toit avec paflion de recevoir le Baprême. Le Supérieur fir aufitiôt partir pour ce Royaume le Pere P.Jean-Raptilte Monti, qui fut parfaitement bien reçu du Roi, \& trouva le jeune Prince dans les difpofitions, qu'on avoit mandées au Pere de Torrez.

neft baptire Il voulut voir s'il étoit fuffifamment infen terre: Sa truit, il l'examina fur tous les articles de nofisticur. tre Croyance, \& le Prince répondit à toue d'une maniere, gui l'éronna: il lui die néanmoins qu'il lui manquoit une chofe effentielle, à fçavoir le confentement du Roi fon Pere. Il fembloit que cette condition n'étoit pas difficile à remplir, le Prince y trouva pourtant de grandes difficultez. Le Roi ne s'oppofoit point abfolument alesdefirs, mais il temporifoit, \& vouloit voir comment cette démarche feroit reçuë de fes Sujet:. Lte jeune Prince fe lalla d'attendre, \& vouloit paller outre; le Miffionnaire réfifta que!que tems, mais il crut enfin qu'il ne rifquoitrien à contenter fon Prolélyte. Il le baptura en fecret, \& lui donna le nom de Lovis. Le Roine fut pas longtems fans s'appercevoir que fon Fils étoit Chrérien, \& ne le trouva point mauvais. Alors le jeune Prince ne fe contraignit plus, \& les grands exemples de vertu, qu'il commenca à donner à cette Chrétienté, la rendirent bientôt une des plus florilfantes du Japon.

Quelque tems après le P. Monti fut rappellé II gagne à par fon Supérieur, qui le fit relever par le Pere Todi fung pu. Alexandre Valla. Ce Miflionnaire fut furpris 


\section{I V R E Q U A T R I E ME. 3 I I}

de trouver dans le Prince Louis un Apôtre, qui par fes exemplos \& lés difcours travailloit infirigablentent a la converfion d'un Royaume, oul il fé loucioit fort peu de résner, pourvû qu'il cût la conlolation de le foumetre tout entier à Jefus-Chrift. Il avoit déja gagné la fe, \& devient Princelle fon Epoufe, que le Pere Valla baprifa l'Afóte du avec la plus grande partie des Dames de fa Rojaume. Mailon, \& a layuclle il donna le nom de $\mathrm{MA-}_{\mathrm{A}}$ RIE. Ce Mifionnaire s'attendoit, qu'ćtant puillamment fecondé de l'Héritier de la Couronne, rien ne l'empécheroit de poulfer fort loin fes Conquêtes fpirituelles, lorfque les Bonzes fouleverent contre le Chriftianifine un grand nombre de zélés Idolâtres, qui avoient a leur tête un Frere du Roi.

La premiere démarche de ce Prince fut de faire dire à fon Neveu, qu'il ne convenoit pas qu'il y eut deux Religions dans le Royamme, cette diverfuté ne pouvant manquer d'y caulè de grands déordres; ainf qu'il feroit fagement de retourner au culte des Diaux Tuélaires du Pays, \& qu'il l'exhortoir à preicire Un Frere dis Rui veut ohlig:r le jurie Plince à tenuncer au Chiftianline; \& roimbite le Ruimene. au plutôt une réfolution fi conforme a fes véritables intćrêts. Le Prince répondit qu'en rouie aurre chole il fe ferout un plaifir de nurquer à lon Oncle, combien il éroit difpolé à fuivre fés avis, mais qu'il s'agilloit ici du falut de fon Ane \& de la caule du vrai bieu; qu'ainf il le prioit de ne poine l'inquiéter fur un article de cette importance, \& qui l'intérelloir plus que toute chole au Monde. Le Prince Idolatre vit bien quinutilement il feroit de nouveaux efforts pour réduire fon Neveu, oul il vouloit, \& prit le $p$ iri de s'adrellér au Roi même, auquel il déclara nettentent, que 


\section{HISTOIRE DU JATON;}

N'il n'obligeoit fon Fils à abjurer le Chriftianif 1. . . me, a s'il ne chaficit le Mifionnaire de feo. $-3-71$.

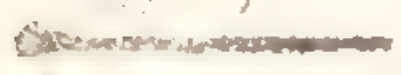
Etats, ni lui, ni tous ceux, qui avoient en: i, r-Mu. core du ztle pour l'ancienne Religion, ne le 3i. Ieconnoitroient plus pour leur Souverain.

it pu. Le Roi intimidé voulut engager fon Fils à ilic: Ed E difmuler, mais ce Prince lui fit la même ré- Re-ponte, qu'il avoit déja faite à fon Oncle, \& lui ajouta que pour le tirer d'inquićtude, il colr prêt a fortir du Royaume avec fa Femme Sus dessyas \&x toute fa Maifon, \& qu'il renonceroit fans peine ì toutes les prétentions, qu'il avoit fur a Terre. Le Roi ne put s'empêcher d'admirer un 11 grand courage; mais la réfolution, où ćtoit con Fils, ne le fatisfit pas; il crut que, s'ilivenoit a bout d'engager tous les antra Chrétiens à faire ce quil ne pouvoit obtenis de ce jeune Prince, celui-ci fe voyant feul fe3oit plus docile, \& il fit publier un Edit, pas lequel il étoit ordonné fous peine de mort à cous cenx, qui avoient renoncé au culte deo Dieur du Pays, d'y retourner incellamment. $\mathrm{M}$ ais il fut bien furpris d'apprendre que l'Eglile étoit remplie de Fidéles, qui y attendoient la mort avec joye, \& que les autres ćtoient dans la méme difpofition; que fon Fils étoit à la tête de ceus-là, \& que ce jeune Prince avoit déclarćc qu'il vouloit être la premiere viotime immolće aux faux Dieux du Japon.

Il arriva encore une chofe, quilui fit comprendre qu'il n'avoit pas bien connu les Chrétiens, quand il avoit cru que la crainte de la mort leur feroit abandonner la Religion, qu'ils avoient embraflée. Un Gentilhomme fort vieux l'étant allé trouver, pour lui dcmander une grace en faveur d'un Neveu, qu'il 
L I Y R E Q U A T R I É M I: 3 ? 3 avoit, le Roi lui dit qu'il la lui accerdoit volontiers, mais à condition qu'il ne fervit point baptifer fon Neveu. Il eft déja baprifé, Seigneur, répartit le Vieillard, E aufi réfolu que moi à mourir plutót que de renoncer à $\int a$ De $+C^{-}$ 1. $70 .+1$. Foi. Le Roi choqué de cetre liberté le renvoya fans lui rien accorder, \& le Vieillard s'en alla de ce pas à l'Eglife, témoignant une fort grande joye d'avoir ćté refulé pour un pareil fujet. Ayant enfuite apperçu le Prince, il s'approcha de lui, \& lui dic, c Seigneur, j'ai s) foixante \& dix ans, \& je ne ferai pas un s grand facrifice à Dieu, en veriant mon lang pour a caule; vous êtes beaucoup plus jells) he, mais fçachez, que vous n'en etes pis 3 moins dans l'obligation de tout rifouer, \pour conferver vorre Foi; vous y êtes mé" ne plus obligí qu'un aure, parce que vous a ćtes Prince, que les promelles, que vous. s avez faites, font des paroles de Prince, \& s que vous nous devez l'exemple $\%$.

Cependant le Roi écoit fort embarafté, il Fimbaris en aimoit tendrement fon Fils, il eftimoit les Rur Belle ac.

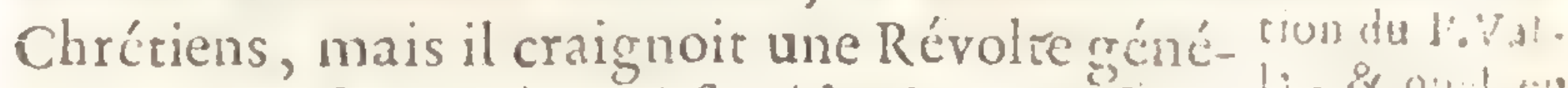
rale, \& ne fcavoit à quoi fe réloudre. Entin le lis, \& cint su Pere Valla le va trouver, \& lui dit, qu'1l fçait un moyen infallibie de le tirer de peine. "r.e. s moyen, Seigneur, ajoura-t-il, c'eft d'abans domner ma Tête aux Enmeñis du vrai Dier., s par-là vous fatisferezles Bonzes, vous von; s épargnerez bien des violences, qui coure. $\rightarrow$ teroient bepucoup à un Prince de votre Cas ractere; votre Etat recouviera la premiere sranquillić, \& moi, quiaurai l'honneur de: s verfer mon fang pour le Dien que jannonce, je précends bien gagner à cela plus que norP v 223031. fut!'erfeto 


\section{HISTOIRE DU TAPON,}

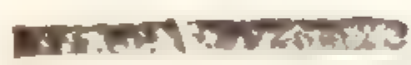

$\Rightarrow$ Come $\%$. Le Roi avoit l'Ame grande, \& le-

De T.C. Cceur bien placé; une généroité poulfée fi loin.

I 57 \% le charma, \& lui fir redoubler d'eftime pour

De Syman une Religion, gui inlpire des fentiments fin 22j. Hes. Il s'éleva au-delius de les craintes, qui faifolent route la force des. Ennemis du Chriftianifme. Il parla ea Maîte, rappella fon Fils, \& rallura les Fidela. Les Bonzes en frémirent, \& pelurent de fe défaire du prince. Ils gagnerent un Scélérat, quil leur promit de le tuer, quand il iroit à l'Eglife, \& qui l'y attendit en effet tout un jour, mais le l'rince n'y alla point ce jour-là. Enfin ces faux Prêtres défépérant de réufir par la violence, prirent le partid'attendre une occafion plus favorabie. Motiu Rui. Elle ne vint pas auflitôt, qu'ils l'efpéroient; L: Prince le Roi mourut, le Prince Lonis monta fur le Limis monte Trône; \& le Chriftianifme devenu la Religion fure Thróle. du Souverain, prit aifément le deffus; mais veres de ce ceci n'arriva que quelques années après. Pour kitince. ce qui eft du Pere Valla, il ne refta pas longrenis dans ce Royaume après le Baptêne du Prince, ayant reçu une Lettre du Pere Cabral, qui lui mandoir de fe difpofer à partir pour LEurope, oủ il ćtoit obligé de l'envoyer traiter avec le Général de la Compagnie, de plufreurs affaires très-importantes. Le Vice-Provincial écrivit en même tems au Prince de. Gotto, qu'il ne fouffriroit point de cette abfence du Milionnaire, dont il iroit bientôt luimême prendre la place auprès de fa Perfonne:

Le Pere Valla me pouvoit fe laffer de parler dans tous les lieux, o: il paffa, des vertus héroigues, qu'il avoit vî pratiouer a ce religieux Prince. Ce quil l'avoit leplus frappé, \&x ce qui it encore bien plus éromnani au. Ja pon que 


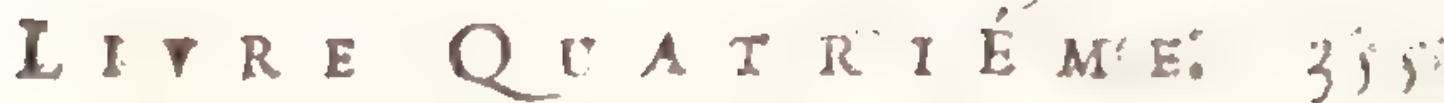

partout ailleurs, c'ćtoir la maniere, donr il traitoit avec lui, lorfu'il s'agilloit de l'affaire de fon falut; car alors il ne lui parloit jamais qu'a genoux; \& lorfyue le Pere lui reprélen- D ioit que cette pofture ne convenoit ni a l'un, ni à l'autre, « pardonnez-moi, mon Pere, s lui difoit-il, fi mes Sujeis \& mes Vallaux en »ufent ainfi avec moi , \& le profternent même s quelquefois le vilage contre terre; n'elt-il. a pas raifonnable que je falle le même à l'ćs gard de ceux, qui me parlent de la parr de »Dieu, qui me tiennent fa place, \& minls truifent de fes volontez"s? Il ne fut jamais. polfible par la mêne raifon de l'engager a fouffrir la moindre diftinction dans l'Eglife; même après qu'il fut monté fur le Trône, il vouloit y ctre confondu dans la foule, queluue raifon qu'on lui oppofât au contraire, \& il y pratiquoit avec les plus pauvres jufigu'aux Exercices les plus humiliants de pénitence. « Dans la "Maifon du Seigneur, difoit-il, il ne doic " point y avoir d'inégalité entre ceux, qui: " lont également fes Créatures. Je fçai quil » eft de l'ordre établi de Dieu mêne, qu'il y s ait de la fubordination rarmi les.Homnzes. " mais il me paroît qu'il faut excepter les "Temples; lorfju'il s'agit des égards, que " cette uordination exige. Enfin partout ails leurs je fuis Roi, \& je f̧̧aime frire rendre. » ce qui meit dî en cette qualité; mais dans "Ia Mailon de Jefus-Chrift, où il habite cor\porellement, je ne fuis que Chrétien, \& \tous mes Sujers font mes Freres \& mes: sgaux. Le Pere Louis de Guiman, un: des Hift riens du Japon, \& qui aroitrúà Alsala le Pere Valla, lorfjue ce Religieux palla

De J. C. 1571.

De Syn-Mu. 2231. 22 


\section{HISTOIRE DU JAPON,}

De I. C. I) 7 I.

De Syn-MU. 2231. availe les parties de IEmpre; ; Nobunanga apres poluique de avoir établi fon autorité dans la Capitale \& Nuhuanga, dans les Provinces du Domaine Impérial, fe tenoit allez paifible dans fes Châteaux, d'où il fe contentoit de faire de tems en tems quelques excurfions dans les lieux, oul il jugeoit la préfence nécellaire; il s'éroit emparé de tous les Etats des Allafins de l'Empereur, nais i! leur aroit lailié de quoi fubfilter avec honneur. Il les méprifa fans doute un peu trop; ou plutôt, ne confultant que ia générofité naturelle, il ne fit pas allez réflexion que rarement un Ennemi humilié fe reconcilie fincerement; \& que pour empêcher un ambitieux de remuer, il faut abfolument hi en ôter tous les moyens. Il porta même la fécurité jufqu'à ne pas veiller d'allez près fur les démarches de ces Princes, qui s'en étant apperçus, leverent fecretement une nombreu'e Armce, en difribuerent une partie fur le chemin d'Anzurquiama à Meaco, \& allerent attendre Nobunanga, qu'ils f̧̧avoient ĉtrefur le point de partir de fa Capitale anez peu accompagné.

Thafistanué Le Roi de Voary re mit effectivement en plos Allochemin; \& les deux princes, qui s'étoient ims de lin. pof́és dans un lieu avantageux, tonberert leren \& les fur lui, lorfgu'it y penfoit le moins. Leurs

mefures étoient bien prifes, mais ils avoient affaire à un Homme, qu'il ćroir plus aifé de furprendre que de vaincre, \&. ils dourerent 


\section{IIVRE QUATRIÉ ME: 357}

trop peu du fuccès de leur Entreprife. Ils firent leur attaque fans beaucoup d'ordre, dans la penfée que le Roi feroit d'abord retraite du côté de Meaco, \& qu'il feroit coupé par les Troupes, qui occupoient les paffages, mais ils fe tromperent.

Vatadono accompagnoit ce Prince; l'un \& Valcur da l'autre lans s'étonner du nombre de leurs En-Vatadono. nemis, mirent avec une admirable préfence d'efprit leur Efcorte en Bataille, \& reçurent l'Ennemi de fi bonne grace, que la Victoire ne balança prefque point. Le Roi aroit la drojte, \& tout plia devant lui; Vatadono trouva plus de réfiftance à la gauche, mais elle ne ferrit, qu'à rehaufler fa gloire; il fit des actions de valeur, qu'on auroit peine à croire, \& qui étonnerent Nobunanga même; aufli ce Prince lui préfentant fon Sabre au fortir du Combat, déclara que le fuccés de cette journée lui étoit uniquement dû́; mais il ćtoit tout couvert de bleflures, ce qui 'obligea de fe faire tranfporter à fa Fortereffe de Tacaçuqui.

Ses Playes, quoique grandes \& en grand nombre, ne fe trouverent pourtant pas dan- à recevoir to géreufes; mais comme rien ne le preffoir de Baptems. retourner à Meaco, ni à la fuite de Nobunanga, il réfolut de profiter du loifir, que lui donnoit fa convalefcence, pour metrre ordre à fes affaires domeftiques, \& plus encore pour alfurer fon falut éternel. Il en donna avis au Pere Froez, \& le pria de le venir trouver, pour achever de l'inftruire de nos Myfteres, \& pour lc difprofer au Baptême. Le Miffionnaire quitta. tout, dès qu'il eut reçu la Lettre du ViceRoi ; mais comme il ne pouvoit pas s'abfentat

De J.C. $\frac{\text { I } 57 \text { I. }}{\text { De Syn-NIU. }}$ 2231. Vatadono. 


\section{HISTOIRE DU JAPON,}

longtems de la Capitale; oul il avoit plas:

De 1. C. d'occupation, qu'il n'en auroit fallu à dix Ou-

I57\%. vriers, il lailfa Laurent à Tacaçuqui, avec

De syn-Hu. ordre de continuer à inftruire le Vice-Roi. 223\%. Ille vifitoit lui-même de tems en tems, \& il s'attendoit à le voir bientôt au nombre des. Fideles, lorfqu'il eut la douleur de le voir enlevé du Monde par un accident des plus tragiques.

1I meurt avant

Le Seigneur d'I CUENDA, Place voifine de que de l'avoir Tacaçuqui, n'éroit pas en trop bonne intelIธ๕ุû. ligence avec Vatadono; \& les Vallaux de l'un. \& de l'autre, étoient allèz fouvent aux mains. Pour arrêter ces défordres, \& en prévenir les fuites, le Vice-Roi fit conftruire deux Forts fur la Frontiere de fon Erat; il y mit des. Garnifons capables de réprimer les courfes qu'on pourroit faire fur fes Terres, \& il en donna le commandement a Tacayama fon Frere. Le Seigneur d'Iquenda prit cette précaution pour une déclaration de Guerre, fit fecretement des levées de Troupes, \& alla brufquement attaquer le plus avancé des deux. Forts. Tacayama, qui s'y étoit renfermé, le défendit avec toute la vigueur poffible, \& tua bien du monde aux Afrécreans; mais comme il manqucit de vivres, il fir avertir fon Frere, que s'il n'étoit promptement fecouru, il feroit bieniôt contraint de fe rendre.

Vatadono reçut cetre dépêche dans l'Eglife, où il affiftoir au Sermon. Il fortit, \& courut à l'heure même avec le peu de Soldats, qu'il pût trouver fous la main, après avoir donné ordre de faire monter a cheval tous fes Vaffaux. Le Seigneur d'Iquenda averti de fa marche laiffe une parie de fes Troupes pour 
II $\nabla$ R Q QUA TRIËME。 359 continuer le Sićge, va avec le refte au devant de Vatadono, lui drelle une Embufcade fur fir route, \& fe faifit d'un polte avantageux. Le Vice-Roi méprifa trop un Ennemi, dont il ne connoilloit pas toute la force; jufquesli, que dans l'impatience d'en venir aux mains aveclui, il lailla lon Fils derriere, avec un Corps de Troupes, qui l'avoit déja joint, \& prit les devants avec deux cents Hommes feulement. Il n'eut pas plûtôt engagé l'action, que ceux des Ennemis, qui étoient en embufcade, fe montrant tout a coup, il fe vit enveloppé de toutes parts; il ne perdit pourtant pas courage, \& fit tout ce qu'on peut attendre d'un des plus braves Hommes du Monde; mais enfin las de tuer, percé de plufieurs coups, perdant tout fon fang, \& prefque réduit à lui feul, il tomba fur des monceaux d'Ennemis, fur lefquels il avoit par avance vengé fa mort.

Nobunanga fut trc̀s-fenfible à cette perte, mais la furprife \& la douleur, oul fut toute Nobunanga \& l'Eglife du Japon en apprenant une fi trifte des Chreticas nouvelle, ne fe peuvert a cette sum. nouvelle; ne fe peuvent exprimer. L'irrépa-velle. rable perte qu'elie faifoit, \& le danger, où elle fe trouvoit n'ayant plus d'appui contre tant de Perfécuteurs acharnés à fa ruine, ne furent pas même ce qui fit couler les premieres larmes; on ne fongea d'abord qu'à pleurer. cet illuftre Défunt. Le zele, l'amour, la piété, la reconnoiffance, empêcherent qu'on ne penfât' aux fuites, que pouvoit avoir un fi trifte Eve-. nement. Le Pere Froez furtout étoit inconfolables de ce que lè Vice-Roi n'avoir pas reçu? le Baptême: il fe perfuada néanmoins que Dieu, qui connoilfoit la fincérité de coeur de ce fervent prof'lyse, lui aurait fait miféricor- 
de, \& n'auroit pas lailfé fans récompenfe tanc De J.C. de vertus, \& defi grands grands fervices renI571. dus à la Religion, \&z il entra d'autant plus aifément dans la penf'ée d'un grand Docteur

De Syn-Mu. 2231. de l'Eglife, a l'occafion d'une mort aufi tragique d'un Empereur Catéchumene; qu'il trouvoit dans Vatadono tout ce gui avoit raflûré Saint Ambroife au fu;et de VAlentinien II. Mais la Providence parut admirable, en ce que privant le Japon d'une auli ferme foutien, elle le délivra de les plus dangéreux Ennemis par le mallacre, qui fe fit bientôt après des Bonzes de Jelan. Voici quelle en fut l'occafion.

Nohunanga J'ai déja remarqué que Jefan eft le vrai fait maflacrer nom d'une fuite de Montagnes voifines de tous les Buin-Méaco, dont il ent fouvent parlé dans les Reaes de Jefan. Lations Portugaifes, fous le nom de FrenoxaMA, \& qui ćtoit comme le principal Sanctuaire des Bonzes du Japon. Ces faux Prêtres avoient toujours favorif́c le parti de Mioxindono, \&r de Con Collégue; \& Nobunanga ćtoit inftruit, que dans la derniere Campagne dont nous avons parlé ils en avoient reçu de grands fecours. Il étoit réfolu de s’en venger; mais. pour le faire plus furrement, il crut devoir diffimuler quelque tems; il s'ćtoit retiréaprès fa Victoire, dans le Royaume de Mino; il s'y arIétá peu; \& vers le commencement de l'Eté, il reprit la route de Meaco, il y refta jufqua mois de Septembre; \& tandis yu'il paroilloit occupé de toute autre chole, il fic fourdement fes préparatifs. Il partit enfuite, comme pour ren:ourner dans fes Etats ; \& lorfqu'on y penfuit le moins, il tourna tout court du côté de Jefan, qu'il avoit ordonné à fes Troupes d'in reftir de toutes parts. 
I I RE CUATRIË ME. 36 E Les Bonzes comprirent alors toute la granAcur du péril, iqui les menaçoit, \& virent bien qu'ils étoient perdus, s'ils ne venoient à bout de fléchir le Roi. Ils y employerent tout ce qu'ils avoient de crédit \& de f̧̧avoirfaire: Is lui firent les offres du monde les plus avan- acreufes; ils engagerent mêne le Cubo-Sama \& le Dairy à lui ćcrire en leur faveur, mais ce fut en vain; prieres, foumilfions, préfens, intercellions, rien ne put appaifer un Prince, qui bailloit les Bonzes par paffion, \& pax principe, qui f̧çavoit bien qưil en étoit häi, \& qui devoir s'attendre qu'ils ne manquepoient aucune occafion de le faire périr, s'il ne les prévenoit. Il commença par brûler Sacomoto, petite Bourgade, dont j'ai parlé ail leurs, \& d'où les Alfiégez pouvoient l'incom moder. Il les ferra enfinte de fort près; 8 malgré toute leur réfiftance, fes Troupes pénétrerent jufques dans les plus profondes $\mathrm{Ca}_{4}$ vernes de Jefan, \& mallacrerent tout ce qu'ils y rencontrerent de ces Religieur Idolâtres. Cuelqu'un s'étant avifé de reprélenter à No bunanga que ces Prêtres étoient les Amis des Dieux: Ji cela eft vrai, répondit-il, le Ciel les défendra; mais ji ce font des Hypocrites: qui profanent la Sainteté de leur Minifere par Iturs crimes, E abufent de la fimplicité des Pcuples, je viens venger les Dieux, qu'ils deshcnorent.

Le Pere Froez reprend plus haut le récit de cet événement, \&x y change quelques circonftances, quoiqu'abfolument on puife le concilier avec les autres Mémoires, que jai fuivis. Il dit que dans une Guerre, que le Roi de Voary avoit eué contre le Bonze, qui s't. 


\section{HISTOIRE DU JAPON,}

toit rendu Maîre d'Ozaca; ceuxde Jefan luz De T. C. avoient refúce le pallage fur leurs Terres, \&c 1571. avoient même fourni des vivres à lon Enne-

De Syn-Mu. mi; que ce Prince en repréfailes, avoit fait 223x. mettre en croix tult ce qu'il avoit pû avoir en fa puillance de ces Religieux Idolátres, \& que la Guerre finie, il courna fes Armes contre Jefan; que les Bonzes lui ayant offert une fomme confidérable d'argent pour l'appaifer, il la refufa; que ces faux Prêtres fe voyant fans reliource, ils ne Congerent qu'à vendre cherement leur vie, qu'ils fe préparerent à une vigoureufe réfiftance; \& qu'en effet ils fe défendirent longrems dans les défilez des Montagnes, \& fur lcurs Rochers; mais. qu'enfin ils furent forcés; que tous furent pallís fans miféricorde au fil de l'Epcé, \& que rous leurs Monafures furent brûlés. Ce fur le jour de Saint Michel de cette année I s 7 I. que ces furpóts de Satan furent ainf exterminés, comme fi le Prince de la Milice célefte, fous la proterion duquel nous avons vû que l'Apôre du Japon avoir mis cer Empire, eût voulu semporter une nouvelle Virtorie fur l'Enfer le jour même, que l'Eglife a confacré en fon honneur.

Nouveaux: Peude teins après, c'eft-à-dire, vors lo miprogres de Décembre, le Vice-Provincial arrivant à SaI'Evangile par cai, apprit que tout le Pays éroit en Armes; la protection que Mioxindono \& Daxaridono avoient levé desubunanga. une nouvelle Armée. pour venger, difoient ils, la mort des Bonzes de Jelan, \& que le Roi d'Ava s'ćtoit; joint à eux; il crut, gu'il ne leroit pas hoss de propos de faire une vifice a ces Princes, \& il commença par le Roi d'Aya. Il lui en fir demander la permilfion. 
LI T RE QUA T R I É ME。 363 ce Prince, qui étoit prêt de tenir un grand Cunfeil de Guerre, voulut bien remetrel'AfComblée à un autre tems, \& fit dire que le $S u$. périeur des Docteurs Errangers feroit le bien De Syn Mu. venu. Sur cette réponfe, le Pere l'alla trou- 223 . ver accompagnć de Laurent, \& la converfation Ioula toute lur la Religion Chrérienne. Laureni parla longtems, \& avec fon éloquence ordinaire; il fut écouté avec beaucoup d'attention, \& quand il eut fini, le Roi avoiia que rien n'étoir plus conforme à la raifon, que la Doctrine des Chrétiens, \& qu'il entendroir toujours très-volontiers de pareils Difcours.

Le Pere Cabral alla enfuite rendre fes devoirs à Mioxindono; ce Prince, dont les principaux Officiers étoient Chrétiens, fit au ViceP'rovincial le même accueil, qu'il avoit fouvent fait au Pere Vilela, \& il l'engagea à aller palfer quelques jours à Imory; il retint même Liturent auprès de lui, \& eur avec ce Religieur plufieurs converlations particulieres, dans lefquelles il lui propofa quantité de doutes fur plufieurs Articles de la Religion, \& en particulier fur l'immortalité de nos Ames: (c'étoit le point, oul en revenoient toujours les Grands du Japon avec les Ouvriers de l'E. vangile; ) enfin il lui allura qu'aufi-tôt que la Guerreferoin finie, il le verroit volontiers, \& l'entendroit avec plailir difcourir du Chriftianifme. Mais peu de jours apres Nobunanga s'ćtant approché avec une puiflante Armée, Mioxindono \& fes Alliez n'o erent l'attendre, \& Ce trouverent fort heureux d'avoir pû. ćchapper, fans avoir été atraqués dans leur setraite.

Je trouve nćanmoins dans quelques Mé:

ve J. C. I) 7 . 


\section{\$64 HISTOIRE DU JAPON:}

moires, quaprís la mort de Varadono, oũ

De T. C. du moins aprés fa retraite à Tacaçuqui, il y $1571^{\circ}$ eut encore une action rris-vive entre le Roi

De Syn-Mu. de Voary \& les deux Meurticrs de l'Empe2231. Ieur; ces deux Princes, dit-on, apprenank que leur Enneni fe repofant fur fa Victoire, retournoir à Mćaco, encore plus mal clcor. té, qu'il n'en ćroit forti, \&'que Vatadono n'écoit point avec lui, ramallerent les débris de leur Armée, \& prirent sn cótoyant tou. jours l'Arméc Royale, lâ route de la Capita. le, dans le dellein de la furprendre, ou de l'attaquer s'ils en trouvoient une occalion favora. ble; mais que Nobunanga, quiles découvri d'abord par fes Efivions, \& pénérra leur def fein, réfolut de les furprendre lui-même; \& pour le faire plus furrement, il fe mit àmar cher à petites journces, \& en apparence avec cette fécurité, qu'infpire une grande Victor. re; que certe feinte confiance eut fon effet; que les deux Chefs confúdérés fe pertuaderent qu'ils viendroient ailément àbout d'un Hom ne, qui leur paroilloit fi peu fur fes lgardes; qu'ils commencerent à y être moins eux-mênes, \& à camper fans prendre prefque aucune précaution; que c'étoit oul le Roi deVoary les vouloit amener; que d's qu'il eut ćté averti qu'ils n'avoient plus, ni Coureurs, ni Garde avancće; il tomba la nuir fur leur Camp, qu'il. avoit fait très-bien reconnoître, \& y fit un grand carnage. Il y a pourtant bien de l'apparence que certe action re palia avant le mallacre des Bonzes de Jefan. Ce quieft certain, c'eft quaprès la retraite précipicéce du Roid'Ava, \& delés Alliés, Nobunanga, qur croyoir n'avoir plus rien à craindre de Gens 
LIVRE QUATRIEM Z. ;65 zin n'avoient pas ol'é l'attendre dans un Camp, it ils avoient eu tout le loifir de fe bien forifier, donna de grandes marques de modéfation, jufques-là, qu'il lailla les Ennemis De Syn-Kü oiiir tranquillement d'une partie de leurs Etats. Nuus verrons néanmoins bien-tôt un de fes Fils porter le nom de Roi d'AvA.

pour revenir au Pere Cabral, ce Millonnaire, après avoir féjourné quelque tems à Méirco, oul il trouva les Fidéles dans une ferveur, qui lui donna de grandes efpérances pour liavenir, en partit pour la Fortereffe de $\mathrm{Ta}$ caçuqui, où il vouloit faire des compliments de condoléance à la Veuve \& au Fils de Vatrdono. Comme il en approchoit, il rencontra Julte Ucondono, Fils de Tacayama, lequel venoit au-devant de lui, avec une nombreufe fuite de Gentilshommes. Il paroît gue toute certe Famille étoit Chrétienne; car nues Mémoires ajoûtent, que le Vice-Provincial leur ayant marqué qu'il ne doutoit point du falur de Varadono, il les confola beaucoup. Il refta peu de tems dans cette Forterefle, \& il retourna à Méaco, oil plufieurs Seigneurs Chréciens furent d'avis qu'il demandat une Audience à l'Empereur.

1 hivit leur confeil, le Cubo-Sama le re- Le Sice-Procur fort bien, s'entretint deux heures avec vincial efthien $\mathrm{Iui}$, \& lui dit de ne point s'inquáter de tout $\mathrm{S}$.uma ce qu'on pourroit entreprendre contre fa Rem limion; qu'il l'eftimoit, \& qu'il fe feroit toujutrs un plaifir de la protéger. Ce Prince n'am vort point varié fur cet A rticle; mais fon autorité ne s'érendoit pas fort loin, \& les Mir fionnaires apres la nort de Vatadono, ne comprerent plus que lur le Roi de Voary, 


\section{HISTOIRE DU JAPON;}

qui étoit alors à Anzuquiama; auffi le Vice-

De T.C. Provincial ne crut-il pas devoir différer da-

15;2. vantage à lui aller rendre fes devoirs. Le Pe-

Desyn-Mu. re Froez \& Laurent, qui étoient fort connus

24j2. de ce Prince, l'y accompagnerent, \& a peine ćtoient-ils arrivés à Anzucuiama, que le Ro: en ayant été averti, fit dire a des Amballadeurs, \& à d'autres Seigneurs, à qui il étoit fur le point de donner audience, d'attendre à un autre tenss, \& ordonna qu'on lui amenát fur le champ les Miflionnaires, avec lefquels il vouloit manger ce jour-la.

Ermieux en- Les Peres le rendirent auflitôt au Palais, corrde Jubu- \& à peine avoient-ils faluć le Prince, qu'il nasigan. leur fit préfenter des Fruirs; il eur enfuite avec eux une longue converfation en prélence de plufieurs Grends; elle roula encore fur la Religion: \& à la fin, Nobmanga fe tournant vers les Seigneurs. Vuila, dir-il, des Hommes tels que je les aime, droits, finceres. En qui me difent des chofes folides, nu lieu que les Bonzes avec leurs Camis E leurs Fotoques, ne nous débitent que des Fables, $E$ font de vrais Hypocrites. On vint alors l'avertir, qu'on avoit lérvi, \& il congédia toute la Cour, à l'exception d'un Seigneur de Mćaco, que l'Empereur lui avoit envoyé depuis peu, pour lui faire un compliment, \& des préfents de fa part, \& auquel il dit, quill le retenoit a diner avec lui, pour faire compagnie aux Peres. Ce Seigneur étoit un des plus grands Ennemis qu'en̂t la Religion dans la Capitale. Le Pere Froez pour profiter d'une occalion fi favorable, lui dit qu'il efpéroit que la bonté, dont le Roi ufoit a leur egard, l'engageroit a ne les glus inguicict 


\section{LIVRE QUATRIEME. 367}

lćformais. Nobunanga comprit ce que le Pee vouioir dire, \& ajoûta, que ce n'étoit pas Hilez, \& quil comptoit bien que ce Seigneur 3e nanque oit dan, la luite aucune occafion de leur faire du bien, puiqu'il lui en donnoit l'exemple; ceiui-ci le promit, \& fit aux

De J.C. I 572 . peres de grandes excules du pallé.

Au fortir de Table, le Ror dit au P. Cabral, gu'il ne vouloit point qu'il partit d'Anzuquiaria, fans avoir vû fon Palais \& fa Citadelle; 11 lui fir enfuite donner des Chevaux \& une Elicorte pour l'accompagner jufqu'à Méaco, \& commanda expreflément à Laurent de la faire avertir exactement de tout ce dont les Ieres auroient befoin. Il les congédia enfin en leur donnant la parole, qu'il leur feroit connoitre en toute occafion, combien il les eftimoit. Le Vice-Provincial en arrivant à Ménco, trouva qu'on ne parloit dans cetre grinde Ville, que de l'accueil, que lui avoit fait Nobunanga; \& ce qui lui fit plus de plai ir, c'eft que les Bonzes nofant ouvrir la boum che pour fe déclarer contre une Religion fi puiflamment protégée, rien ne s'oppofa plus ful progres de l'Evangile, qui fe rćpandit en peu de tems dans tous les Royaumes voifins. Celui, ou les Millionnaires recuéillirent des Fruits plus abondants de leurs Travaux, fut le Royaume de TAMA, un des cinq, qui compoent le Trase; un Seigneur Chrétien nonmé JEAN NAXTADONO, baptifé autrefois par le Pere Vilela, en polfédoir la meilleure partie, dont il avoit été gratifié par le défunt Empereur, anguel il avoit rendu de ries-grands ervices; \& le nouveau Cubo-Sama avoit confirmé cette Donation. Il paroît

2232. 


\section{\$68 HISTOIRB DU JAPON,}

même qu'il portoit le titre de Roi de TAM.

De J.C.

I 772 .

De $\operatorname{Sin} M u$. 2232. BA; \& la plûpart des Relations de ce temslà ne manquent jamais de le lui donner. Ce Seigueur, qui avoit beaucoup de zéle pour la Religion, \& qui en donna julqu'a la fin de grandes marques, ainfi que nous le verrons en plus d'un endroit de certe Hiftoire, crut l'occalion favorable, pour procurer a fes Sujets \& à les Vallaux, la commoilfance de JEsus-CHRIST; il pria le Vice-Provincial de lui accorder un de fes Religieux pour les inftruire; \& le Pere lui ayant donné Laurent, il le mena lui-même dans fes Terres, oì le zćle de ce Mifionnaire ne rrouva aucun obfacle à l'aeurre de Dieu, Le Pere Cabral y fit lui même un Voyage, \& y baptifa plufieurs Perfonmes de Confidćration, Il palla enfuite au Royaume d'INGA, dont je n'ai trouvé nulle part la fituation, mais qui ne doit pas être ćloigné de celui de Tamba; \& il fur furpris d'y voir deux Eglifes bâties, par les foins de deux Vicillards, qui n'étoient encore que Catéchumenes, \& auljuels il conféra le Baptênie.

Il eût étć étonnant, que le Royaume de Voary ne fe lentit point du bien ineftimable, que la faveur de Nobunanga procuroit a tant d'autres Royaumes. Il ne fut pourtant pas polible pour lors d'y envoyer aucun Mittionnaire, parce que le nombre en ćtoit toujours fort peu confidérable; mais un fervent Chrétien, nommé Constantin, y fuppléa, Il avoit drefic un Cratoire dans a Maifon, il y expliguoit les principaux Articles du Chriftianifme, \& il s'y tenoit des Conférences fur les Points, qui avoient le plus de befoin dt difcuftion. 
IIVRE QUATRI है I. 369 difcufion. Les Infidéles y venoient en foule, \& Conftantin en baptila un très grand nom- De J. C. bre. Il fe chargeoit de tou:es les autres Fon1372. aions du Miniftere Evangélique, dont il étoit De Syn-Mu. capable, \& il mérita d'être l'Apôtre de fa 2232. Patrie.

Il y avoit longtems, que l'Empire du Ja- L'Empereus pon n’ivoit été aufi tranquille, qu'il le pa- fe No unanga. roilfoit alors. Nobunanga croyoit avoir allez bien établi fa Puiftance, pour ne pas craindie qu'on entreprit de l'ćbranler; \& pour ne poin donner d'ombrage à l'Empereur, il fe tenoit ordinairement dans fes Châteaux. Meis c'eft un ćtat bien violene, que celui d'un Sourgerain en tutelle fur fon Trône. Il en avoit cuitúc bien des Conzats, le plus pur fang de la Noblefle du Japon, \& la défola. tion de fes plus belles Provinces, pour y rédnire les Dairys. Tout fumoit encore apris cing ou fix cents ans du feu des Guerres Civiles', que cette grande Révolution aroit allumé. Le Roi de Voary devoit bien s'attendre que la dégradation des Cubo-Samas n'auroit pas des fuites moins fun thes; autr ne négligeritil tien pour le metre en ćtat de fa're face aux Enmenis, qu'une pareille Entreprife pourroit lui fufciter, \& les mefures fe trouvereut juftes.

Le Monarque, fous le nom duquel il gou- Car etere de vernoit fonverainement l'Emoire, étoit un ce Ptince. Prince naturellement paifible, mais d'un génie bornć. Avec ce carafece on peut n'êtra pas fufceptible d'ambition, mais on eft fnuvent linftrument de celle des autres; on devient ombrageux, dćfrant, délicut; \& ce qui eft encore plus dangereux, on eft en butte Tome $I I$.

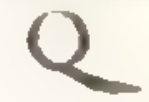




\section{HISTOIRE DU JAPON,}

aux mauvais confeils, \& peu propre à en fui-

ne J. C. vre de bons. C'eft ce qui arriva au malheur 372. reux Cavadono, \& ce qui prócipita fa ruine vi Syn Mu. de la maniere, que je vais le raconter en peid $2 \div 32$. de mots; les Millionnaires, qui croient fur les lieux, ne nous ayant point inftruit de bien des circonftances d'mne Guerre, dont ils fe Cont coutentés de nous apprendre qu'elle fut infiniment fanglante, \& qu'elle retraça l'Imafric toures les horreurs des difienfions précédentes.

Modéation Ce fut vers le commencement de l'année divoburanga. I573. que Nobmanga eut le premier foupçongqu'il fe tramoit quelque chofe contre lui à la Cour de l'Empereur. Il étoit déja mécontent de ce Prince, qui à la mort de Vatadono, avoit nommé, fans le confulter, un nouveau Vice-Roi, appellé VIEDono; mais ce qui le chogur davantage, c'eft que Viedono s'attacha dans l'exercice de la Charge à prendre tout le contrepied de fon l'rédéceffeur. Ces changements ne manquent gućres d'rcafionner des Troubles, \& de fare ces Mćcontents. Plufieurs Perfonnes, qui le clurent lézćes, s'adreliérent à Nohunninga, pour en avoir juftice, \& le Roi fit fes Plaintes avec allez de hanteur au Cubo-Sama. L'Fmpereur y répondit fur le même ton, \& les Elprits parurent fort aigris de part \& d'autre. Quelque tems apres, Cavadono craignant que le Roi de Voary ne vint lai enlever un Fils, dont l'Impératrice étoit accouchée depuis peu, \& ne le fit enfermer dans quelipu'une de fes Fortereles, commença a le fortifier dans la Cindelle de Aĺaco, \& y fi: entrer quantité de virrus, \& de munitions de Guer- 


\section{LIVRE QUATR I E M I. 37 T}

res. Nobunanga ne douta point que ces préparatifs ne fullent contre lui; il en écrivit à lempereur, a te plaignit en termes fort mefurés: it fir plus, car pour détruire entićrement les foupçons, gu'il royoit bien qu'on avoit infpirés contre lui à ce Prince, il lui envoya un de fes Fils en ótage.

Le Confcil de l'Empereur fut d'avis, qu'il falloit renvoyer le jeune Prince à fon Pere, \& prendre ouvertement les Ammes. "Le Roi confoilsuab "de Voary, lui dit-on, fe fent foible, puif" gu'il a baillé le ton: ne lui domnez pas le "tems de fortifier fon Parti, \& profitez de " l'occafion, qui fe préfente de fecolier un a jour, que la néceffré des tems rous a fait "Lubir u. L'inconfidéré Monarque fut tont ce qu'on voulut, \& déclarala Guerre à un Prince, gui leul la pouvoit faire pour lui. Il re fallut plus, pour porter limprudence à fon comble, que traiter avec Moxindono \& fes anciens Confédérés; ce fut par où l'on commença; on mit les Affaftins de la Famille Impériale en ćtat de le venger de Nobunangi, \& de le faire repentir d'avoir fauvé l'Empereur, fans faire réflexion, que prr-là oir livroit ce malheureux Prince entre les Mains de fes plus grands Ennemis, \& qu'il ne tiendroit qu'à eux de confommer lear crime, quand on les auroit aidés à le défaire de ce. lui, qui Ceul jufques-là les en avoit empá chés. On fit enfuite proclamei un Edit Impérial, qui portoit défenfe de recevoir chez foi aucun des Sujets du Roi de Voary, \& il y eut ordre dans le même toms d'abatre le Palais de ce Prince, ce qui fut exécuté.

Après de telles démarches, on devoit bic 


\section{HISTOIRE DU JAPON,}

s'attendre, que Nobunanga ne'demeureroie

De 1. C. pas tran juille, \& l'on lçur en effet bientôt is $53^{\circ}$ - quil armoit puillamment. Comme il y avoit We Sym- Alu. tonte apparence que ce feroit a Mćaco, qu'il 2233 porturoir d'abord fes Armes, ceite grande Ville fur en un moment remplie de Trouble \& de confulion, \& chacun longea à mettre en firtetéla Iemme, fes Enfants, \& fes Tréions. Le P. Froez reciut alors des Lettres de Xicaicono Gouverneur d'Imory, \& Sei. gneur de Canga, qui lui offroit une retraite rour lui, \& pour tous les Confréres dans fon Ine. Naytadono, Roi de Tamba, \& Jufte Ucundono, dont le Pere venoit d'hériter des Elats de Vacadono par la more du Fils de ce Seigneur, lui firent les mémes offres; mais j! répondit à tous, qu'il ne pouvoit fe réfoludre a abandonncr les Chrétiens dans un tems auficritigue; \&a d'ailleurs, qu'on n'avoit encore ancun avis certain de la marche de Nobunanga.

Le Roi de Au bout de quelques jours, on vit arriver Tamba virnt dans la Capitale le Rei de Tamba, avec deux au ferours ie mille Hommes de Troupes chicifies, dene touProupcisulosa piete. tes les Bamniercsavoicnt de fort belles Croix. Le Prince lui-même portoit lur fon Cafjue un grand Nom de Jesus d'or; il alla fur le climmp fe metre en bataille à la vîè du $\mathrm{Pa}$ lais, \& lempereur fut fi charmé de woir corte Troupe, qui ćtoit en effer fort bolle, gu'il augmenta los Revenus du Roi. Le lendemain le Vice-Roi alla pour faire préer à ce Prince le Serment ordinaile, \& lui en précita la Formule. Naytadono hil tépondit, quetle ne lui convenoit pas, qu'il écoit Chré- rien, gu'il jureroit fuivant les Loix du Chri- 


\section{LIYRETROIS TÉ M I 373}

Aianifme, \& donneroit fes deux Freres en óage. L'Affaire fut portéce a l'bmpereur, qui diclara cu'il fe contentoit de la parole dı Roi de Tamba. Sur le foir, co Prince fe rendit a l'Eglife pour y faire la priere avec tous ceux de les Gens, qui étoieni Chrériens; $2 x$ le jour fuivant il fe confella, se commmia avec une piété, qui ćditia infinimsent tonic 12 Ville.

Cependant Méaco, quoique remplie de Gens armés pour la défenfe de les Murs \& de fon Monarque, n'étoir rallûré qu'a demi, lorfqu'on y apprit que Nobunanga étoic en marche avec une Armće de cinguante nitle Hommes, \& avoit pris la route de cette Capitale; mais que le Roi d'Imory \& le Prince de $\mathrm{Na}$ ra l'attendoient au pallige avec des forces, qui n'étoient point inférieures aux liemes, \& que Xinguen, Roi de Sanopul, tenoit la Campagne avec une Armée de Négores. Ce Prince avoit été Bonze; \& pour monter fur le Tróne, il en avoit challé fon Pere. \& tenoit fon Frere aîné dans les fers. La caule, ou le prérexte de fon armement, étuit de venger les Bonzes maftacrés à Jefrn, \&i de rérablir ce Sanctuaire dans fa premiere fplendeur. Il le croyoit invincible a la tête de fés braves Nćgores, \& il envoya au Roi de Voary un Cartel, ou il fe qualifioit de Ror SouVERAIN DES BONZES DU JAPON, ARME' POUR venger les Dieut et leurs Ministres. Nobunanga répondit, qu'il acceptoir le Car. tel; qu'il ne tiendroit qu'au Roi, qu'ils ne fo meluratent bientor, \&: qu'il feroit plus de la moitić du chemin; il marynoit dans far Lethe, UU'IL s'TOIT LE MARTEAT DOMPTANT

Dis 3.C. I 573 .

D. syn-.Mu. $223 j$.

Nobunanga marche avic cinquante milli. Humames à Midacu. Dilur gandes $A_{1-}$ mécs l'atteridersi al pifia. $g:$ mais fe diffipent a fon appruche. 


\section{HISTOIREDU JATON,}

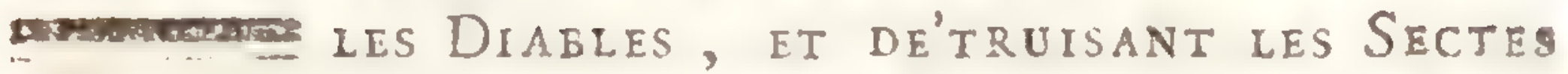

De J.C. EXTRAVAGANTES DU JAPON. Il Coninua en-

I573. Cuite de marcher, mais Xinguen ne l'atten-

De Syn-Mu. dit point \& difparut. Mioxindono \& Daxan-

4233. dono ne l'eurent pas plutôt appris, gu'ils en firent de même; \& le Roi victorieux, fans avoir tiré l'épée, parut à la vièé de Méaco dans le tems, quion s'y flattoit encore qu'il n'oferoit entreprendre de forcer les paflages.

Artive aux Poites de la rilite, il faic farte des propufitions de paix àv ritiageciris à l'En:-
licrous.

Ce fut le propre jour de l'Afcenfion, que dès le grand matin on fonna le Tocfin a la Citadelle. Le Roi s’étoit avancé jufoju'à une demi lieué de la Ville, avec un détachenent de ciny ou fix mille Hommes; le refte de l'Armée fnivoit fous les ordres de XibataDONO fon Capitaine général. Ce fut alors, qu'il apprit que fon Palais avoit été renverfé: il en fut ontré, mais il f̧ut le modérer, 86 envoya fur le champ publier dans fon Armée une défenfe, fous peine de la vie, à quicongue d'entrer dans la Ville. Il envoya enfuite offrir la paix à l'Empereur, le pria de fe fouvenir, que s'il ćtoit fux le Trône, il hui en avoit l'obligation, \& qu'au refte, il croit en état de le perdre. Ses offres furent rejettées, \& l'on affure, qu'il en verfa des larmes. Si elles furent finceres, elles marquoient une Ame bien généreufe; ce qui elt certain, c’eft qu'il refta quatre jours entiers fans faire aucun acte d'holtilité, \& que cette modération lui fit bien de l'homneur dans tout l'Empire.

Il ravagesous Ce terme expiré, il détacha fept ou huie lis cuvirons mille Hommes, avec ordre de défoler \& de funr obliger brûler tout le Pays à guatre lietës aux envi- 
LIVRE QUATRIENME。? 375 rons de la Ville: cela fut exécutí, \&: l'on ne peut dire le nombre de Bourgs, dez Villages, de Maifons de plaifance, de Monafteres, \& de Temples, qui furent réduits en cendres en un feul jour. Celariair, il envoya une feconde fois offrir un accommodenient au CuboSama; on ent dit que c'étoit un Pere, qui forcé de punir un Fils ingrat, cherche tous les moyens de l'obliger à recourir à fa clé-

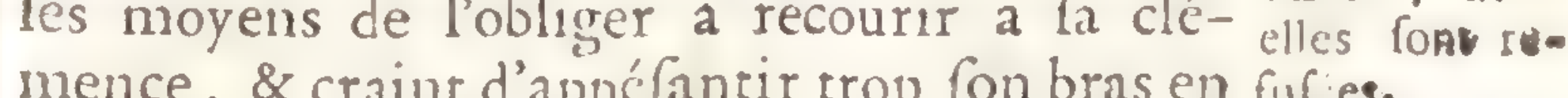
le frappant. Il crut, que fi fa préfence à la tête d'une Armće, devant laquelle cent mille Hommes n'avoient ofé tenir, ne futfifoit pas pour lui faire ouvrir les yeux, il prendroir des fentiments plus raifonnables en voyant tous les environs de fa Capirale en feu. Il fur encore trompé, Cavadono vir certe délolation fans en être énû: peut-être comptoit-il encoIe fur quelque diverfion puillante de fes Alliés, ou de la part du Roi de Sanoqui \& des Négores, qui étoient dans le Royaune d'Omi; quoiqu'il en fort, il ne voulut rien écouter.

Mais les Habitants de Méaco jugerent à propos de prérenir l'Orage, \& firent offrir à Nobunanga une fomme confiderable, pour être garantis dú pillage. La Balle V'ille, où il n'y avoit que du Peuple, \& dont les Députés parlerent à ce Prince avec un air de foumiffion, qui convenoit ì la fruation, où ils fe trouvoient, obint ce qu'elle demandoit; la Haute Ville, ou éroient les Seigneurs \& les plus riches Marchand's, ne s'y pre pas touta-foit de la même manicre, \& fes offres furent rejettćes; après quoile quatorziéme de Mai, (a) le Roi rallembla fes Troupes, les

(a) Ou le vingr quasibéme; les Ritations difent le $Q$ iv 


\section{HISTOIRE DU TAPON;}

mit en Bataille, entra dans Méaco, dont les

De T. C. Portes lui furent ouveres, traverfa la Batle 1573 .

Ville, fans couclier à une feule Maiton, com-

De Syn-Mu. 2233. me il s'y étoit engagé, força la Haute l'épée à la Main, la fit piller \& brûler, \& re préfenta devant la Citadelie.

l'Empereur

Il laiffe L'Empereur alors voulut parler de paix, furle Thrône, mais il n'étoit plus tems. La confternation mais fans au-ćtoit extrêne parni les Troupes; \& la matorité. niere, dont le Haut Múaco, malgrí les retranchements \& fa nombreufe Garnifon, venoit d'étre emporté, avoir glacé les plus ferz res courages. La patience du Roi ćtoit pourL fe à bout ; il fallut donc fe foumetre, \& secevoir la Loi. Nobunanga avoit eu deflein de metre fur le Trône Impérial le fecond Fils du Dairy, mais il fe ravifa: il ne pur fe réfoudre a détruire fon propre Ouvrage, en rćduifant à la condition de fimple Particulier un Prince, qu'il avoit couronné de fa Main, \& la vûé du Malheureux Cubo-Sama, dont tour le crime étoir d'être le plas imbécile des Hommes, le toucha. Il ne voulut donc point le détrôner, mais il ne lui lailla que le Tirre d'Empereur; ainfi le Japon vir en méme tems deux ombres de Souverains, \& l'Empire reconnut pour fon Maitre un Roi particulier, mais plus puiflant par fes Conquếtes, que ne l'avoit été aucun Cubc-Sama avant lui.

On n'a pas eul fuin de nous apprendre en quel tems, ni à queile occafion il prit enfin le Titre de Cubo-Sama; il n'êt pas même certain, qu'il l'ait jamais pris: Koempfer le quarriéme, mais il faut quilil y ait ericur dansle Chiffre, Iuifyue Nubunanga b'avoit paru pourla premicre fois à ls vuë de Meacos que le juur de l'A Ácenáiva. 


\section{I V R E TR O I S I É M E. 377}

ner cependant dans la Life des Emperenrs du Japon, \& lui dome dix ans de régne. Suivant ce compre, il faut qu'il ait commencé de régnel fouverainement en $r: 72$. ou au plus tard, en is 73 . qui eft le tems, dont nous pailons. Il lui donne pour Prédécelleur immédiat, un Josi AxI, lequel félon lui, fur cing ans fur le Trône Impérial; \& a celui-ci, Josi TIRA, ou Josi Tarra Con Pere, \& Fils de Josi TIR, \& ne lui fait porter le Sceptre que quatre ans. Or Jofi Tir ne fçauroit être, que le Malheurcux Cubo-Sama, í qui Mioxindono \& Daxandono firent perdre la Couronne \& la Vie. L'Auteur Allemand dir que ce Prince le fendit le Ventre, \& place fa mort à peu prís dans le tems, où arriva la funefte catafrophe, dont nous avons par lé. Son Succelfeur n'útoit pas fon Fils, mais fon Frere, ainfi que nous l'avons vû, \& le Mćmoires, que mous avons fuivis en cela, ne peuvent ćrre conteftés, ayant pour Aureurs piufieurs perfonnes dignes de foi, qui furent tćmoins oculares de tout ce qui fe palla alors au Japon. Ce Prince ne monta pas fur le Trône autieôt après la mort tragitue de fon Frere, \& Kocmpfer dit qu'en effet il y eut un interregne de deux ou trois ans, ce qui peuc fort bien s'accorder avec litiltoire, eu fimporant que Cavadono Voyacata, ou Jofi Iira, ne reçut du Dairy le Titre de Général de. la Couronne, ou de Cubo-Sama, que quelques aunées après fon Entrée à Mćaco. Mais s'il eft vrai qu'apris quatre ans de reyne il eut pour Succelleur Jofi Aki fon Fils, il faut nécellairement que l'Empereur dégradé par Nobunanga, n’ait pas été le même l'rinQv 


\section{HISTOIRE DU JARON;}

mererere qui avoit été mis fus le Trône par le

İ f. C. Roi de Voary, à moins qu'on ne dife, qu'il

I) ¿.-. avoit allocié fon Fils à l'Empire, \& gue ce

D. $5 \mathrm{yn}$ Miu. flit toujours liki, qui parut dans cette Guer-

3ijj. re; c'eft le feul moyen de concilier tous les fentiments.

Quoiqu'il en foit, Nobunanga, que nous traiterons délormais d'Empereur, parce que toutes nos Relations l'appellent ainfi, \& qu'il fut véritablement le Maitre de l'Empire depuis le tems, dont nous parlons, jufqu'à fa mort; Nobunanga, dis-je ne refta à Méaco après fa Victoire, qu'autant de tems, qu'il lui en fallut, pour y bâtir un nouveau $\mathrm{Pa}-$ lais, \& pour y rracer le Plan d'une nouvelle Fortereffe, où il laifla, aufi-bien que dans la Ville une Garnifon capable de contenir dans le devoir tous ceux, que fon abfence pouvoit tenter de remuer; il partit enluite pour Anzuguiama, fans avoir voulu rendre une vifite au Cubo-Sama.

Nolunanga Il apprit fur fa route qu'un Avantrier, firchruler flu- banni de fon Pays, étoit entré avec une Trourercs de Bon. pe de Brigands dans le Royaume de Voary zess. pendant fon expédition de Méaco, en avoit enlevé une grande quantité de Ris, \& l'avoit mis en dépôt dans un lieu nommé FAcusrn, où il y avoit une Univerfité de Bonzes, \& qui fe trouvoit fur le Chemin d'Anzuyuiama à Méaco. Il n'en falloit pas tant pour réveiller toute la haine du nouvel Empereur contre ces Préres Idolitres : il brüla Facufin, \& n'y laitfa pas une Mailon lur pied. Il s'ćtoit encore fait juftice avant que de partir de la Capitale, d'un Bonze cếlúbe dans tout l'Empire, pour lon çarvoir \& pour on 
L I V RE Q U A T R I I: ME. 379 Eloquence. Il avoit fçu que ce Docteur, tandis qu'on fe difpoloit dans la Ville a y foute. nir un Siége, étant monté en Chaire, avoit ofé prêcher contre lui, \& dire, qu'il avoit porté la tyrannie à fon comble, ic que le Ciel ne tarderoit pas à le punir. I lit chercher cet infolent Prédica:eur, \& l'ayant trouvé, il lui fit couper la Têre, fans vouloir écouter, ni le Dairy, ni le Cubo-Sama, qui firent les dernieres inftances pour obtenir ia grace. Les autres Bonzes ne laillerent pas de publier que les Dieux tireroient incelfamment une terrible vengeance de tant de Temples \& de Monafteres ruinés, \& de leurs Miniftres ćgorgés par ce Prince, \& ils avoient perfuadć un grand nombre de Perlonnes; mais Ia conltante profpérité, dont on vit que ces prétendus facriléges étoient fuivis, délibua tout le Monde.

Sur la fin de ces troubles, les Chrćtiens avoient obligé le Pere Froez de fortir de Méaco; \& comme tout le Pays éroit rempli de un bon conful Soldats, le Millionnaire courur de fort grands ma. riljues. Quant au Roi de Tamba, il ne paroît point que le Roi de Voary lui ait $\int c ̧ \hat{u}$ mauvis gré pour lors d'avoir Cervi l'Empereur, dont il étoit Vallal; mais il eft certam que dans la fuite il perdit fes Etats, apparemment lorfque Nobunanga fe faifit de la Tenle, dont ils faioient partie, \& qu'il demeuia toujonis attaché a la Perfonne de fon ancien Mutr, auquel il rendit encore un grand fervice peu de tems après le départ de Nobunanin; car ayant appris que ce Prince quicaing nit toujours que le Vainqueur ne le fir enf.rmer avec fon Fils dans yuelque 


\section{ISO HISTOIRE DU JABON;}

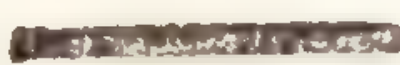

Ciradelle, avoit pris la réfolution de fortir de

De J.C. Méaco, pour fe jetter dans une Forterelle, I5:3. qu'il eftimoir imprenable, il l'alla trouver, \& De $S_{j} n_{-M}$ luo lui reprélenta fi vivement lirrécrularté de 2233. certe démarche, \& le danger, où il alloit le précipiter fans rellource, (ju'il le fit changer de dellein, de quoi ce Prince lui f̧ut dans la fuite un très-bon gré.

Trifte état Four ce qui eft de la Religion Clirétienne, d. la chetic - comme on f̧̧avoit que le nouvel Empereur la teduNaugatu. favorifoit ouvertement, elle ne fouffrit point pendant les Troubles; \& la tranguillité, que les Victoires de ce Monarque avoient ćtablie dars l'Enpire, lui fit exilênement avantageufe. Le Pere Cabral en profita pour viliter les Provinces, où les Fidéles étoient Cans Palteurs, \& il y rencontra par-tout de grands fujets de confolation. Quoique depuis dix ans aucun Miflomnaire n'êti paru à Eacata, le Vice-Provincial y troura une for belle Eglife, \& des Chrétiens en grand nombre. De-là, il palfa dans le Naugato, oú la Chrétienté d'A manguchi, qui avoit ćté comme la Mere de toutes les autres, gémilfoir fous la tyrannie de Morindono. Depuis vinge ans, que ce Prince avoit ufurpé le Royaume, aucun Ouvrier Evangélique n'avoit eu la liberté d'y entrer, ou du moins de s'y établir. D'ailleurs, ce Prince, qui ne connoilloie poine d'autre Dieu que fon Épée, avoit été longtems occuné à bien affermir fa domination. II n'avoit enfuite fongé qu'à porter la Guerre chez les Voifins, de Corte que fes Etats n'avoient jamais jo ii de ce calme fi nécelare, pour difpoler les efprits à la connoillance de Ia vérité. En fin trè-peu des ancicus Chré- 


\section{I RE QUA TRIEME. 38 I}

vens avoient échappé aux furieux carnages, par lelquels ce Conquérant s'ćtoit frayé ur Chemin au Trône. Il ne lailfoit pourtant pas d'y avoir encore dans Amanguchi, \& aux environs, un petit nombre de Fidéles, qui s'affembloient réguliérement chez un d'entr'eux.

Le principal inftrument, dont le Ciel s'ćtoit fervi pour conferver ce petit nombre d'E- Aveugle Sçalîs, étoit un de ces Aveugles Sçavants, dont vant. j'ai parlé dans le Livre Préliminaire de cette Hiftoire. Les autres firent bien voir, que dans la Main de Dieu tout infrument eft propre pour l'exécution de fes plus grands deffeins. L'Aveugle le nommoit Tobie, \& avoit ácé baptilć par S. François Xavier. Le SaintEiprit, qui avort rencontré dans cet Homme des difpofitions admirables à la Sainteté, l'avoit conblé de fes dons les plus précieux, \& lui avoit furtout infpiré un zéle admirable pour le falut des Ames. Il ćtoit d'ailleurs dans une grande réputation de Doctrine; perfonne ne fçavoir aufi-bien que lui l'Hiltoire Ancienne du Japon, \& n'en parloit d'une maniere plus agréable; mais apres que par les charmes de fa converfation il s'ćtoit concilié les Elprits, il failuir tomber le difcours fur Jesus-CHRist, \& fur les plus fubimes Mylteres de notre fainte Religion, \& s'exprimoir fur cela, d'une maniere qui enchantoit. On prenoit fouvent plaifir à le faire entrer en lice avec les Bonzes; mais comine ceux-ci ne fortoient jamais a leur honneur de ce combat, ils chercherent longtems une occafion de fe délivrer d'un fi redoutable Adverfaire.

Après bien d'inutiles tentatives, ils cruren 


\section{HISTOIRE UU JAPON,}

que le meilleur moyen d'y réulir, étoit de

De J.C. lui faire entrer un Démon dans le corps. I573. Quelques Bonzes Sorciers l'entreprirent, \&

De Syn-Mupour empêcher qu'il ne fe doutát de rien, $2233 \cdot$ \& qu'il ne prit les précautions, ils le défierent à une difpute réglée. Tobie accepta avec joye le défi. L'Allemblice fut nombreure; \& tandis que les uns cherchoient à l'amufer, en lui propolant plufieurs queftions captieules, les autres firent leurs enchantements. Tobie s'en apperçut, \& ne s'en étonna point. Les Magiciens lurpris que le Diable the vint point, commencerent à crier, \& à le débattre, comme fi eux-mémes eulient été pollédés. Alors le généreux Chrétien avec un ris moqueur, leur dit, comme autrefois le Prophćte Elie aux Prêtres de Baal, de parler plus haur, parce que l'peprit infernal ne les entendoit point; 》 mais, ajoûta-t-il, vous „s avez beau faire, quand vous évoqueriez 》 toutes les Puiffances des Ténćbres, il ne "me faut cu'un Signe de Croix pour les " mettre en fuite; \& fçachez que dans un „ befoin, un Chrécien a pour la Garde plus $\leadsto$ d'Anges, que vous \& tous vos femblables s ne pourriez lui oppoler de Dímons.

Les Bonzes fans fe rebuter, redoublerent leurs preftiges: enfin, dit-on, les Diables parurent; mais laiflant-là Tobie, qui les attendoit de pied ferme, ils fe toumerent contre les Enchanteurs avec des Vifages fi terribles, \& fe mirent tellement en devoir de les maltraiter, que les pauvres Bonzes tout tremblants de peur, fe jetterent demi morts aux pieds de Tobie, lui embrallerent les genoux, \& le conjurerent de faire fur eux le Signe 
I IVRE QUATRIÉME. 38 ; de la croix. "Ce n'elt pas alfez, dit alors s le Chrétien, de reconnoître la vertu de la "Croix, il faut changer de conduite \& de $\Rightarrow$ profeffion, il faut adorer ce Signe falutaire, dont vous êtes obligés de confeller le " pouvoir. Les Bonzes promirent tout, \& Tobie lans faire autre chofe, que ce qu'on lui demandoit, \& menacer les Démons, les fir difparoître dans le moment. Au refte, fans vouloir garantir ce fait, qui n'a rien que de fort croyable dans les principes de notre Religion, je me contente de le rapporter tel, que je le trouve dans mes Mémoires; j'ajoûte féulement, que ceux, qui ont écrit ces Mémoires, \& le faint Homme, de qui ils l'ont appris, n'étoient point des Éprits foibles, \& en lçavoient bien autant que ceux; qui pourrone le regarder comme un conte fait a philir, \& qui cependant ne pourront guéres y oppofer qu'une incrédulité, dont ils feroient fort embaralfés à apporter une raifon bien folide.

Une autre Perfonne, qui ne contribuoit guéres moins, que le faint \& Sçavant Tobie, à faire connoître \& eftimer la Religion Chrétienne dans ce Royaume, étoit une vertueufe Chrétienne fort âgée, appellće MARIE, qui avoit aufí reçu le Baptême de la Main de l'Apôtre des Indes. Certe Femme voyant que le Saint \& fon Compagnon ne vivoient que d'Aumônes, étoient vêtus pauvrement, menoient une vie extrêmement dure, \& failoient beaucoup de cas des Pauvres, conçut, malgré les préjugés de fa Nation, qu'il y avoir quelque chole de grand dans la Pauvreté Evanséilique, elle fe lentit anfitôt infpirće de l'ems

Et de deux FenmesCliré tienacs.

I $573^{\circ}$

De Syr. Ma. 2233. 


\section{$38+$ HISTOIRE DU JAPON,}

bralfer, vendit tows fes biens, qui ćmoient con-

ve I. C. fidérables, en difrribua l'Argent aux plus né1573. celfiteux, \& fe réduifit à la plus extrênze in-

De Syn-Mü digence. Dieu récompenfa une verta fi pure, 2233. de toutes les richelles de fa Grace, \& la génćreufe Chrérienne convenoir qu'elle avoit déja reçu le centuple de ce quelle avoit confacré au Seigneur. Dìs qu'elle f̧̧ur que le Pere Cabral étoit arrivé à Amanguchi, elle fit onze lieues à pied, quoique l'âge l'eût fort aftoiblie, pour avoir la conlolation de participer aux Sacrements de l'Eglife, dont elle étoir privće depuis fi longtems, \& pour encendre precher un jeune Jéluite Japonnois, qui accompagnoit le Vice-Provincial. Elle fut fi tranpportée des difcours de ce Miflionnaire, qui étoit en effet trìs éloguent, qu'étant retournée dans le lieu de fa récidence, tout le Monde étoit furpris de l'entendre parler elle-même des véritez éternel. les. Quelgues Bonzes l'allerent voir par pure curiolité, \& en revinrent tellement changés, que le Pere Cabral en baptifa quatre, avant que de partir d'Amanguchi. C'e n'étoir pas au refte les premieres Converfions, qu'elle eût faires; elle avoit dans la fimplicité une maniere de traiter avec les Inficéles, qui jointe à cette fainteté de'vie, laquelle donne tant d'efficace aux paroles, lui avoit fait enlever bien des Ames à Satan.

Une autre Femme noinmée CATHERINE, âgée de quatre-vingt ans, baptifée encore par le même Apôtre, rendit auli vifite aux Mífionnaires, à qui on avoit raconté des chofes merveilleules de cetre bonne Chrćtienne. Ils crouverent qu'on ne leur avoit rien dit 
LIP I Q UATRIEME. 3,85 de trop, \& le Pere Cabral avuiia qu'elle lui avoir caufé bien de la confufion : elle ne parioir cyue de Dieu, \& elle en parloit d'une maniere raviflante; aufi avoit-elle gagné à Jelus Chrift plus de cent cinquante Perfonnes. L'Homne Apoltelique, qui de fes Travaux \& de tes difcours n'avoit guéres evicore tiré dans cette Ville d'aurre Fruit, que des loiianges ftériles, eut bien de quoi s'humilier devant Dieu, en apprenant qu'une Femme ignorante avoir beacoup plus fait pour le lalut des Ames, que Lui \& lon Comprgnon, avec toute leur fience \& toute leur éloyuence.

Il bapiifa néanmoins avant fon dépare d'Amanguchi, un Homme de Qualité, mais à la Converfion duquel il navoit ell aucuna part. Ce Gentilhomme s'ćroit rrouvé plufieurs fois avec un pauvre Chrétien nonmé MAIHIEU, qui gagnoit fa vie a vendre des Peignes, des Aiguilles, \& autres femblables bagatelles. Ce bon Homme ne manyuoit jamais en vendant fa Marchandife de parler de l'excellence de la Religion Chrétienne, \& le Gentilhomme en fur tellement frappé un jour ; qu'il rélolut d'embrafier le Chriftianifme. De retour chez lui, il commença par jetter toutes les Idoles au feu; fes Domeftiques s'imaginerent qu'il avoit perdu l'efprit, mais il leur parla de maniere à les détromper; cette action fit du bruit, \& les Bonzes dénoncerent le Profélyte au Tona, dont il relevoit. Il fut cité devant ce Seigneur, lui avoüa qu'il avoit brûlé es Idoles, ayant reconnu que ce n'éroir que de vains fimulachres: il ajoûta qu'il vouloit être Chrétien, \& qu'il n'adoro-

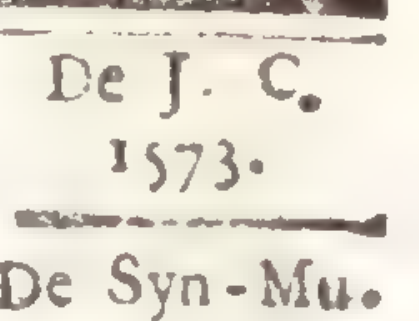
2233. 


\section{HISTOIRE DU JAPON;}

- roir jamais d'aurre Dieu, que celui, qui de

De J. C. rien a créć le Ciel \& la Terre. Il sactendoic I 573. que le Tono vengeroit fur lui fis prétendues Lu Syn-Mu. Divinicez, mais ce Seigneur le renvoya en 2233. Iui dilant, quil pouvoit être Chrétien, s'il le vouloit, pourvî qu'il lui gardât la fidćlité, qu'il lui devoit. Il fçut quelque tems après, que le Supérieur des Miffonmaires étoir à Amanguchi, \& il courut auffitôt lui deman. der le Baptême. De retour chez lui, il cut le bonheur de convertir un autre Gentilhomme de les Voifins.

Lirue cons:c D'Amanguchi le Pere Cabral palla à $\mathrm{O} n \mathrm{~m}$ le Prince the - ra, ofil venoit d'apprendre que Sumiranda
musa. avoir depuis peu conru un nouveau rifigue de perdre la Couronne \& la vie. Ce Prince avoir un voifin, qui écoit Seigneur d'IsArAx, \& Frere de la princelle fa Femme. Il étoit I Ĺolâtre zélé, \& failoit depuis long-rems tous les efforts, pour ramener fon beau-Frere \& fa Socur au culte des ldoles; n'en ayant pû venir à bout, \& elpérant peut-être d'agrandit Fon Etat aux dépens de Sumitanda, il fe ligua fecrerement avec Fisciu Roi de Firando, qui éroir apouremment le Fils \& le Succelfeur de Taqua Nombo, \& quelques aurres Princes emnemis de la Religion Chrérienne. On prérend mêne que le Roi d'Arima fur du nombre des Confédérez contre fon propre Frere, avec gui jufques-là il avoit éce résuni.

Lavilled'c- La Ligne fignce, les Alliez ne fe crovant mura eflur-pas encore allez fores pun venir about d'un pife. Prince accontumí à nater fur le ventre aux plus grandes Armées ayec mue poignéce de Soldats, s'allurerent de qualques-uns de fas Vaf- 
LI T R E QU A TRIÉME. 387 faux; qui tenoient d'allez bonnes Places, \& les engagerent à recevoir des Troupes; \& tour cela fur tramć avec tant de fecret, que Sumitanda n'en eut pas le moindre vent. Dis que toutes les nefures furent prifes, le Seigneur d'Ifafay s'approcha pendant la nuit d'Omura, dont quelques Bonzes lui ouvrirent les Portes, \& il s'en rendit lans peine lé mầtre. Le Prince étoir à une demí lieue de là dans une Forterefle nommée CAGI; il fur averti vers le minuit de ce gui fe paffoit dans fa Capitale, \& que l'Ennemi le difpofoit à ve. nir à lui. Il navoit auprès de fa Perfonne que douze Gentilshommes, \& la Princefle avoit avec elle une bonne partie de fa Maifon; mais c'étoir des Fenmes, \& quelle apparence de pouvoir loutenir avec fi peu de monde les efforts d'une Armée entiere? D'autre part, où fe retirer, \& fur qui compter dans un Révolution fi fubite? L'embarras ćtoit ćgal des deux côtés, \& pour le coup Sumitanda fe crut peráu.

Il envoya chercher un Mifionnaire, qui étant venu fur le champ, le prince l'einbraffa fitélité des \& lui dit: Je Juis fort aife de nouria nour lix caufe de Dieu; car je fuis bien far que miz Religion eft l'unique motif de ce foulevemon: Le jonr venu, il monca aut Donjon de la roim terelle, pour voir cequi le palloit à Omura; \& comme il eut apperçu qu'on avoir mis le feu à l'Eglife des Chrétiens, nous vaincrons, s'écria-t-il aufi-tôt, nos Ennemis font la guerre à Dieu. En effet il ne tarda pas à recevon du renfort. Tout ce qu'il y avoit de Chrériens à Omura, fçachant le danger, où éroit leur prince, s'ćtoit d'abordmis en devoir de l'aller le.

De I.C. 


\section{H 3 TOIX: DU J}

courir; le Seigneur d'Ifafay leur avoit fa.it con-

De J. C. per le chemin; mais trente des plusi braves I573. forcerent un Quartier, \& gagnerent la forDe syn. Mu terelie.

2233.

Vidcise de ter un Alfaut Sumitanda, plein de confiance Sumitarda.

A peine y étoient-ils cntrés, que l'Ennemi parut en ordre de Bataille, \& fe difpola à tenau Seigneur, donna fes ordres partout, fit prendre des Lances airx Dames de la Rieine, atin qu'on ne s'apperçît pas du petit nombre de fes Soldats, confia la garde de quelques endroits foibles aux douze Hommes, qu"il avoit eus d'abord avec lui, \& avec les trente, qui lui étoient venus d'Onura, il s'approcha de la Porte pour agir felon les befoins La Forterelle étoit bâtie au bord de la Mer, fur des Rochers environnés de précipices, \& l'on y entroit dur côté de la Ville par un chemina alfez large, qui avoit à droite \& à gauche des Parapets à hauteur dappui. Le Général Ennemi s'engagea dans ce chemin, où huit Honnmes pouvoient tenir de front: Sumitanda le lailfa avancer jufqu'a la Porte, qui fur onverte dans le moment, \& tandis que ies Femmes chantoient des Pleaumes \& des Cantiques, il fondit brufuuement fur les premiers rangs em ïnvoquane tout haut les facrés Noms de Jest's \& de MARIe, leur tua au moins foixante Hommes fans perdre aucun des fiens, \& mena le relte battant jufqu'au-delà du chemin.

Le Seigneur d'Ifafay ne lailloit pas de fe zallier, \& il n'ćtoit pas au pouvoir du Prince de l'en empêcher; mais les Habitants d'Omura l'ayant pris en queue, il en pafia encore plus de quatre cents jufgu'a la Forterelle. Quelques-uas des Vallaux de Sumitanda le joigni- 


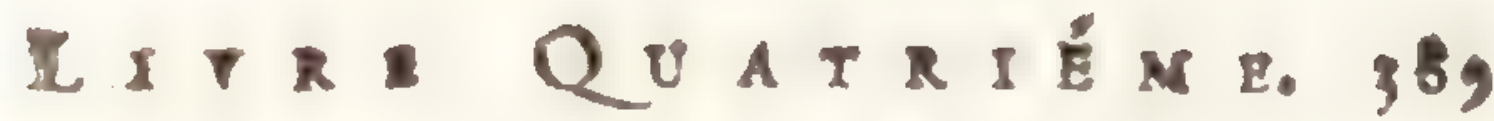

rent peu de tems après avec ce qu'ils purent ramaller de Soldats, en forte quil fe rrouva avoir deux mille Hommes, fur le'quels il pouyoit compter. C'étoit encore bien peu de chofe, eu égard à l'Armée, qu'il avcit en tête; il ris lailla pas de faire une fortie générale, qui lui rćuflit de telle forte, que l'Ennemi s'étant mis a fuir de tous côtés, il rentra dans fa Capitale lans aucune rćfiftance, après avoir fait un grand butin dans leur Camp, qu'ils avoient abandonné.

Il n'y relta pourtant pas longtems, pré- La Flotte envoyant bien que l'Armće Ennemie, qu'il avoit nemie diTipee plutôt diffipée, que détruite, feroit bientôt pur la Tempê. raffemblée; \& ne jugeant pas quill füt de la vietoire desuprudence de s'enfermer dans une Place, gui mitandd. n'avoit point de défenle, il retourna a ra Forterefle, qu'il eut foin de bien fournir de munitions \& de vivres, \& où il fit entrer une Garnifon convenable. Peu de tems aprís le Seigneur d'Ilafay reparut avec fon Armée, \& la Flote de Firando s'approcha de la Córe, dans le delfein de faire une delcente; mais une horribie tempéce, qui s'éleva tout-a-coup, fit périr une partie des Vailleaux, \& diffpa le refte; ce qui jetra une telle frayeur dans l'A rmcée de Terre, que chacun commença à fuir de fon côté. Le Prince d'Omura, qui s'en apperçut d'abord, en profita; il fondit lur ces Troupes errantes \& fugitives, en fit un grand carnage, tua de la main le Lieutenant du Général, fit Irifonnier un des principaux Officiers, qui étcit lon Sujet, \& luii fir couper la Tête.

L.e Seigneur d'Ilafay lui-nême fut longtems vilites deles fans paroitse; il avoit eu bien de la peine à fe Bunzituépus fauwer, \& l'on aflure qu'il fut guelgues jours à un Mifionn.i- 


\section{HISTOIRE DU JAPON;}

courir de côté \& d'autre, fans fçavoir ou il

De J. C. alloit; la peur l'ayant faifi à un point, qu'il I 573. étoir tour hors de lui-même: enfin ill fe déguifa De Syn Mu. \& gagna fes Châteatix, où il ne fie crut pas 2233. encore trop en fureté. En effet Sumitanda, après avoir remis l'ordre dans Omura porta la Guerre chez fes Ennemis, leur enleva plufieurs Places confidérables, fit partout un incroyable butin, \& retourna dans far Capitale, après avoir confidérablement accru ion Domaine, \& répandu fort loin la réputation de fes Armes. Les Infidéles firent de lérieules réflexions fur le fuccès inefpéré de cette Guerre; mais rien ne les frappa davantage, que ce qui arriva à un Bonze, lequel en avoit été le principal Auteux, \& qui avoit ouvert aux Troupes d'Ilafay les Porres d'Omura; car ce Rébelle ćtant allé enfuite à l'Eglife des Chrétiens, apparemment pour y metre le feu, comme il eut appercu un Surplis dans la Sacriftie, il le mit par-deflus feshabits, \& parut en ceréguipage a la porte de l'Eglife, failant mille bouffomeries pour contrefaire nos Cérémonies faintes. Comme il ćtoit prefque nuir, un Soldat, qui le découvrit le premier, le prit pour un Miflionnaire, tira deflus, \& le tua.

sumitanda Tant de marques fenfibles d'une protection onieprend la particuliere du Ciel enflammerent tellement le converfon de zele de Sumitanda, que dès-lors ill entreprit tois ceux de debannir entierement l'Idclâtrie des Terres de fes Sujets, qui don obćillance. Ille déclara au comnencement infideles, \& y de l'annće aux Seigneurs, qui vinrent, felon reutlit. la coutume, le faluer; il !eur parla en cette rencontred'une manicre fi pathétiques fi touchnnte, il leur remit fi vivement devant les yeux ia maniere, dont le Dicu des Chrétiens l'avoit fait 


\section{LTRE QUATRIŔME。 391}

If fouvent triompher de fes Ennemis, il leur témoigna tant de bonté, \& un fi grand zéle pour le falut de lcurs Ames, que tous lui promirent de fe faire inftruire, \& tinrent parole. Il s'adrefla enfuite aux Borizes, il leur fit fentir, qu'ćtant plus éclairés que les autres, ils devoient aufli reconnoître plutôt la vérité; il les affura qu'ils ne perdroiene rien en changeant de Religion, qu'il ne leur ôteroir point leurs poffeffions, \& qu'il les leur augmenteroit même plutót: enfin il les charma, \& tous, à la réferve de quelques-uns, qui fe retirerent ailleurs, embrafferent le Chriftianifme. Plufieurs Temples furent convertis en Fglifes, dont en aflez peu de tems on compta jufqu'à quarante dans cette Principauté, \& plus de cinquante mille Chrétiens. Les Peres Gasiard CUelio \& Melchior de FighereDo furent ceux, qui eurent le plus de part à ces Converfions, dans le cours defquelles il arriva bien des chofes, que je fuis obligé d'omettre, pour ménager la délicatelle de ceux, à qui In merveilleux ne plaît pas, lors mêtme qu'il s'agit d'une Religion aufi miraculeufe dans for ćtabliflement, qu'elle eft dans fa lub1tance au deflus de l'entendement humain.

Il ne reftoit plus dans toute l'étendue des Domaires de Sumitanda d'autre retranche-purfa a qui re ment à l'Idolâtrie, que la petite Ville de Cori; Occafion dans mais les Bonzes en ćtoient Seigneurs, \& le la perite Ville Prince n'y avoit qu'une fouveraineté, dont les De J. C. 197475.

De Syn-Mu. $2234 \cdot 35 \cdot$ droits étoient fort bornés. Le Pere Cuello avoir grande envie d'y ćtablir l'Empire de TefusChrift, mais il ne pouvoir obtenir du Prince la permiffion d'y aller prêcher l'Evangile, \& la raifon de ce refus ćtoit la perfualion, où étvir 


\section{HISTOIREDO JAPON,}

De J.C. Sumitanda, que les Bonzes ne nanquitoreitt \{157475. pas d'empoifonner tout autant de Mintionnai-

Dic Sy. Mlu. $2234 \cdot 35 \cdot$ res, qu'il en paroicroit dans cette Villle. Enfin le Pere ayant pronis de ne rien manger ni boire, cu'il ne l'eut fait venir d'ailleurs, il obtint re quil fouhaitoit fi ardemment; mais le Prince prit encore pour la fireté une précaution, a lajulle Dieu attacba fans: doute la conle I vation du Miflonnaire. Il fir partir avec lai un Domeftique de confiance, \& le rendit refnonfable de rout ce qui arriveroit au Servitcur de Dieu.

Le l'cre Cu?lo entra done dans Corri, oû il me fu pas lon tums lans connoirre yure les appréhenfions du Prince d'Omura n'étcoient pas mal fondées. On ne lçauroit imaginter tout ce qui fut mis en oetrre pour le faire pérnir; mais au milicu de tant de dangers, dont il ćtoit continuellement environné, il fentoir atu dedans delui-meme comme une certitade, que la Foi triompheroit de ces Endurcis. Au bout de guelque tems, les Bonzes furent curieuxz de f̧̧avoir ce que ćétoit que cetre Religion, quon venoit leur annoncer d'un antre Monde. Ils furent furpris de voir une Doctrine fii conforme aux lumieres du bon fens, \& qui élevoit fi fort la raifon au-dentus de l'Humanitcé. Alors la curiofité failant place à un véritable defir de s'inftruire, ils revinrent plufieurs foils: d'autres Bonzes, a qui ceux-ci n'avoient pû cacher Jeurs fentimens, fe joignirent à eux, \& bientôt toutela Ville courut chez le Dosteur Etranger, qui fe vit contraint de prêcher dans les Places publiyucs, \& qui ne trouvoit plus de tems, ni pour fatis faire à fes exercices de pićté, ni pour prendre un peu de repos. Ill eft vrai 
L I VRE Q A A R I É ME. $393^{\circ}$ qu'il fut bien dédommagé de tant de fatigues: par la bénćdiction, que Dieu donna a fej difcours; car il eut la confolation de baptifer en deux mois dix mille perfonnes à Cori; mais il y ruina ta fanté. Le fuccès de lon zele l'empêcha d'en modérer l'ardeur, \& l'emprellement des Habitans de Cori à vouloir être inftruits de nos Myfteres, produifit prefigue le méme effee par ranport à lui, quion avoit appréhendé de leur opiniâtre attachement à leurs fuperftitions, \& de leur haine invérérée contre les Irédicateurs de l'Evangile. S'il ne périt point par le poifon, comme on croyoit avoir lieu de le craindre, l'excès de festravaux le jetta dans une langueur, quile confuma en trís-peu de tems.

Fin du Livre quatriéme, Er du second Volume. 


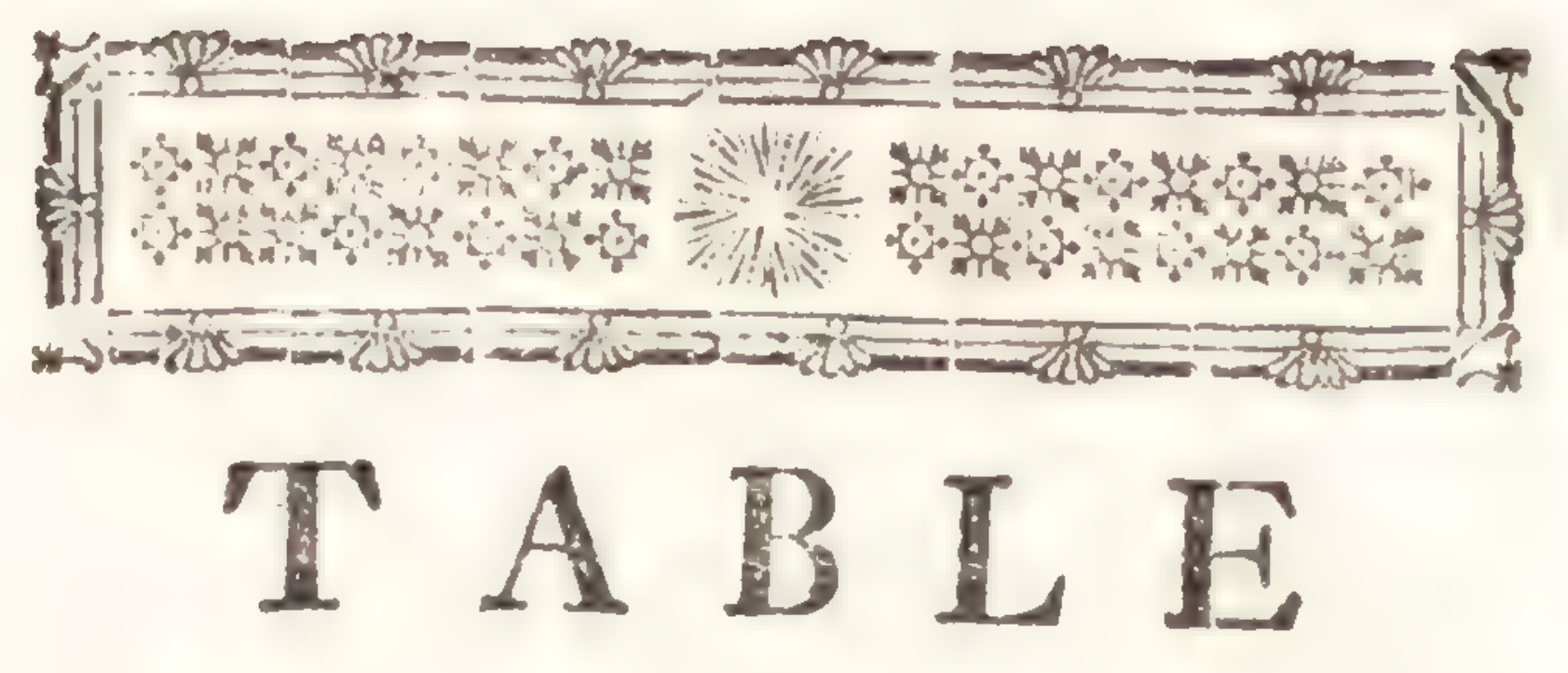

\section{DES MATIERES} DU SECOND VOLUME.

A.

A. Cofar, (le P. Balthazar) Jécuite. Son arrivce au Japon, 233. Le Roi de Siam l'invice à venir prêclier l'Evangile dansion Royaume, \& promet de l'embraller, 275 . Albuquerque, (D. Jean) Evéque des Indés, baptie les trois premiers Japonnois Chrétiens, 2.t.

Alcaceva (Pierre) Jéfuite, arrive au Japon, 108. Il eft renvoyé aux Indes pour y deniander des Miflionnaires, I1 I. Il conduit le Cosps de S. François Xavier a Cioa, Y 18.

Aimeyda (Louis) Se fait Jéfuite après a voir employé tout fon bieir à fonder deux Hôpitanx, 135 Fn guel érat il trouve la ReIigion Clińcienne dans le Ximo: ce qui le furprend davantage, 168.174. Il défel pere de la convertion du Roi de Saxuma, 175. Comment if gagne l'amitió des Bonzes; \& pourcpuoi il n'en baptife aucun, I75. Belle réponfe, que lui fait un Néophyte, 176.11 commence un Etablillement dans le PoIt de 
DES M A TERES.

Focoxiura, 183 . Ses fuccés dans le Royaume d'Arima, à Cochinozzu, à Ximabara, 188. E Juiv. Ce qui fe palle entre lui \&i une jeune Chrćtienne, 236. Defcription d'un Repas, qu'on luidonne, $2+2$. Defcription, qu'il fait de Nara; ce qu'il vit dans ce Voyage, 245 . Mioxindono lui rend vifite, $252^{\circ}$ Il guérit le Roi de rotto, quilui envoie de fort beaux prérens: ulage, qu'il en fart, 285. Ce qui l'oblige à fortir de ce Royaune, 286. Offres, que lui fair le Roi pour le revenir: ce qui fe palle à ce fujer entre ce Prince \& lui, 288. Une Tempête l'oblige d'y retourner : trait de fon zele dans ce Royaume, 289 . Et a Ocura, 329. Il eft obligé ce fortir de linte d'Amacula, \& y eft rappellí, 347 .

Alineyda, (Pierre) ne veut pas entrer dans le Port de Firando, lans le conlentement du P. Froez, $23 \mathrm{I}$.

Alquimexa, le premier, qui reçoir le Bapteme a Meaco: pui il ćcoit, 158.

Aluarez (le P. Ferdinand) Jéfuite, périt en sllane au Japon, $\$ 79$.

Aluarez (George) conduit Angeroo aux Indes, \& le convertit par fes bons exemples, 21. Es fuiv.

Amacusa, Ile. Sa fituation, 294. Troubles dans cetre Ine au fujer de la Religion. Le Roi de Sungo les pacifie, 346. Le Prince $\&$ les Principaux reçoivent le Baptême, 348.

Amudais Temple. Son Hifoire \& fa Dofcription, 52 .

Amanguchi, Capitale du Naugato. I'Evangile y ett prêtace par S. Frangis Xivicr, $\mathrm{R}$ ij 
59. Ee par le Pere Gago, in. Elle eft prif́c \& pillée, I25. Il s'y fait de grandes converlions, $34 \mathrm{I}$.

Anida. Voyez le premier Volume. Defription d'un de fes Temples, 256.

André, Roi d'Arima. Oftres, qu'il fait aux Mithionnaires, 188. Riozogi porte in Guerre dans fes Erats, 207. Ce quil'oblige à fe retirer, 2 ro. Le Roi mieux difpofé que janatis à embrafler la Religion Chrétienne, 232. Il le ligue contre le Prince d'Omura, fon Frere, 336.

Angervo, ce qui l'oblige à paffer aux Indes, 20. Áventures de Ion V̌oyage, 20. E fuiv. Comment il eft reçụ par $S$. François Xavier, 22. Son Baptême \& fa ferveur, 24. Er Suiv. Son retour au Japon. Il convertir la Famille, 26-32. Il obtient une Audience du Roi de Saxuma, \& ce qui s'y palle, 33. Eu Juiv. Il eft perf́́cuté \& contraint de s'exiler, it I.

Animal fingulier dans les Ifles de Gotto, 28I. Antoine, Prince du Firando; il reçoit le Baptêne avec fa Fenme \& fon Frere. Son zele pour la Religion, 139. E fuiz. On luifait une avanie, \& ce gui en arrive; 217. Sa nort, 279.

Artcine, Domeltique d'Angeroo, baptifé avec ini, 2 .

Anruquiama. Ville bâtie par Nobunanga, fa tratation \& fa defoription, 32 I. E fuiv.

Arima, Royame cu Japon. Voyés André. Grand noimbie de Chrétiens dans ce Royaume avant cu'aucun Millonnaire y tût prếciné. I I

Arivebufe. Effet functe d'une Arquebule.Voyés Iinto. 


\section{DES M A T IERES. 397}

Afqueram Teive; Bonze. Son difcours à Pinto , 1 t.

Atayde(D. Alvared') Sair échouer le projet d'une fumballade a la Chine, r07. S. Françcis Xavier l'excommunie, ro8.

Ava. Le Roi d'Ava reçoit bien un Miflommai. re, 362 .

\section{B.}

1 Anduue. Deux Millionnaires Cont invités dans ce Royaume, \& ce qui les empéche d'y aller, 270 .

Barnabé. Bonze converti, devenu Miffonnaia re, II 5 .

Barramoas. Dieu des Indes. Faftes xxxiij.

$B$ âtard d'Omnra. On veut le faire Princed $O$ nura, 206. Es fuiv. Le Roi d'Arima \& le Prince d'Omura lui font couper la Tête, 215.

Bernard. Japonnois bantife par S. Erancris Xavier, 38. Il paffe aurirdes, \& fe faic Júluite, 98 .

Befamuinlez. Idole du Japon, iso.

Bunzes. Voyés le premier Volume Difcours des Bonzes de Congoxima au Roi de Saxuma, \& ce qui en arrive, 42. Eo Juiv. Ceux d'Amanguchi y excitent une révolte, 82. Tout ce que firent cenx du Bungo contre S. François Xavier, 8,. Er Juiv. Maniere de prêcher des Bonzes, 260.

Borello, Portugais. Elt envoyé au Roide Bunro, IO. II.

Bungo. Royaume du Japon. Voyés Ciran. Buyen. Royaume du Japon. Voyés Civan \& Jufimon. 
CAbral (le P. Jean) Jéfuite, arrive au U Japon, 233.

Cabral (le P. François) arrive au Jap̧on en qualité de Vice-l'rovincial, 337. Il baptile la famille du Prince d'Omura, ibid. Il fait de grandes convertions dans l'ine d'Amacufa, 347. Il vifite le Roi d'Ava, Mioxinciono \& Baxandono, \& en eft bien reçu, 36 . . L'Empereur l'admet à fon Audience, $36 \%$. 11 reçoir de grandes diftinctions de Nobunanga; eftet, que cela produit, 366.367 . Il baptie plufieurs Perfonnes dans les Royaumes de Tamba \& d'Inga, 368.

Cagi, Forterelle de la Principauté d'Omura. Sumitanda y eft furpris, \& en fort I'épée à la main, 387 .

Cambodaxi, Chinois. Son Hiftoire Fabnleufe. Kompfer dit que c'eft lui, qui a porté au Japon les Caracteres de la Langue Japonnoife: Temple en fon honneur, 33 .

Camifama, Princefie diomura; elle entreprend de ramener le Irince au culte des Dieux du Japon, \& il l'engage à fe faire Chréxienne, r95.

Canga, Ine proche de Sacai. Sa fituation, 244. Elle eft bientôt toute Chrérienne, ibit.

Cangoxima, Ville Capitale \& Port du Royaunie de Saxuma. Trois Portugais y font jettés par Tempête, r 9. S. François Xaviery débarque. Voyés Xavier.

Caftro. (Amador de) Ce quil dit des Chrétiens du Japon, 335 .

Catondone, Seigneur Firandois. Ses impićrez, 
DES M A T I E RES. $39 \%$ 2-5. Il eft batiu par les Portusais, 336 . Cutherine, Fenme Chrétienne, fruit de fon zele, 38 .t.

Cavadono Voyacata, Frere du Cubo-Sama, eft épargné par les Meurcriers de lon Frere, 266. Il te lauve de leurs mains, 300. Nobunanga le met furle Thrône, 304. Il protege les Millionnaires, 3 r2. Il fe brouille avec Nobunanga: fon caractere, 369 . Il fe livre à de mauvais confeils, 371. Le Roi de Tamba vient à fon fecours, 372. Mioxindono, Daxandono, \& le Roi de Sanoqui arment en fin faveur, \& n'olent attendre Nobunanga, 373. Il rejetre les propofitions de paix, que lui fait Nobunanga, 374 . Ce Prince lui fait grace, \& le lailfe fur le Thrône, mais fans autorité, 376.

Cavaxi, Royaume donné à Mioxindone;,253. Cavaxiri, Ine du Bungo. La Foi y fuir da grands progrès , $27 \%$

Chemin magnifique fait par Nobunarga, 32 . Es fuiv.

Cedres d'une groffeur prodirieufe, 248 .

Cerfs. On leur fait des facriffces au Japon, \& il n'eft pas permis de lestuer, $25 \mathrm{I}$.

Chieugen, Royaume du Japon. Sa intuation I Is. Le Roi de Chicugen envoie des Troupes contre Facarandono, Roi de Naugato, I 26.

Chinchicogi. On donne ce nom aux Portugais, \& pourquoi, $r$.

Chine. Chinuis. Voyés le premier Volume Les Portugais challés de la Chine, \& pour guoi, 03 . Eltime, quejles Japonnois fon de la fagrelle des Chinois, 106. 
Chrétiens. Ferveur des Chrétiens du Cangoxima, 46. Affection \& générofité de ceux du Bungo envers les Miftionnaires, I so. Ceux de Meaco écrivent pour prouver la vérité de la Religion Chrétienne, 162. Unionentre tous les Chrétiens, \& le fruit, qu'on en retire, 169.170. 173 . Simplicité \& candeur des Chrétiens du Bungo, 202. Conftance de ceux du Royaume d'Arima, 2 Is. Ev Juiv. Sainteté de ceux du Firando, 229. E fuiv.

Cicondono. Bonze nommé Commiffaire pour examiner la Religion Chrérienne, 22.4. Sa converfion \& fon zele, $22 \%$. E Juiv.

Civan, Roi de Bungo, blellé par une Arquebufe, \& ce qui en arrive, I3. E fuiv. A quelle occafion il connoît les Portugais. Service, qu'il leur rend: ce quilui fait concevoir de l'eftime pour leur Religion : fon caractere, 69. Eu Juiv. Il écrit a S. François Xavier pour l'inviter à le venir voir, 71. Réception, guill lui fait, .73 . E Suiv. Il le fait manger a fa Table, 77. Avis, quelui donne le Saint, \& comment il les reçoit, 80. Il empêche les bonzes de remuer, 8I. Il craint de commetre le $S t$ avec un fameux Bonze, 87. Ce quile palfe dans les premieres Conf́rences, qui fe tiennent en fa préfence, 82, E fuiv. A quelles conditions it permet de les reprendre, 70 . Sa conduite in. conféquente après le départ du"Saine, ics. Il reçoit des préfents de la part du ViceRoi des Indes, rog. Ligue contre lui, \& comment il en triomphe, I 6 . Il eft obligé de le réfugier dans une Forterelle, I 8 . Réceprion, qu'il fait aa I. Nuguez, I 30. 
Ce qu'il lui dit de fes difpofitions au fijet de la Religion Chrétienne, I 3 I. Il venge la mort di Roi de Naugato, fon Frere, \& fait plufieurs Conquêtes, I 37. E fuiv. Sa maniere de traiter avec les Mifionnaires \& les Chrétiens, x 38. Il envoie des préfents au Vice-Roi des Inces, \& lui demande des Miflionnaires, I39. Il obige le Roi de Firando à lui payer Tribur, I 45 . Il perd le Royaume de Chicugen par la trahilon des Bonzes, 146. Intérér, qu'il prend all progrès de la Religion, 203. Il termine par fa médiation une guerre, qui retardoir ce progrìs, 20 4. Ce qu'il répond aux bonzes, qui veulent le regagner, 2II. Son zele pour la Religion Chrétienne. Le Roi de Naugato fait une excurfion dans fes Etats. Il va au-

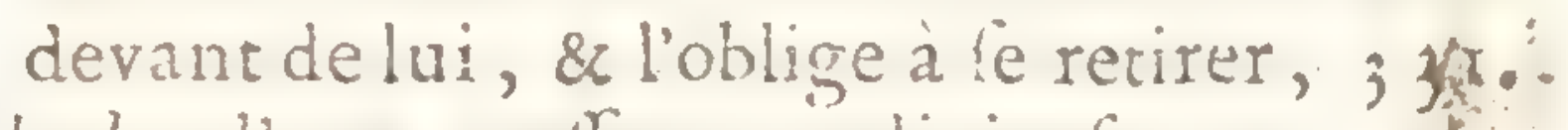

Cloche d'une groffeur prodigieufe, $25 \mathrm{r}$.

Coca. Forterelie, où le retire Cavadono apres la moit tragigue de l'Empereur, Con Frere: à qui elle appartenoit, 300 .

Cochinotzqu. Port \& Ville du Royaume d'srima. Le Roi l'offre aux Portugais, 188. Almeyda y prêche l'Evangile; avecquel fuccès, 189.

Co:̈a, petir Bourg, où il y a un Temple, qui eft le terme d'un Pélerinage, 33 .

Conseillers c'Etar du Prince d'Omura Ils font une Ligue contre lui. Quel en fut le fuccis, 205 . EN Juiv.

Confantin, zélé Chrétien. Succès de fon zele, 3.68.

Cori. Petite Ville de la Principauté d'Omura, ce qui empêchoit la Foi d'y pénétrer, 39 \%. Elle devient toute Chrétienne, 39?. Es Juiv. 
Cofanga, Temple. Sa defoription, $2+8$.

Croix. Miracic fat par la vertu de la Croix, 27. Croix renverice, \& ce qui en arrive, I 4 I. E Juiv.

Cubu-Sama. De quelle maniere cet Empereur donne fon Audience aux Grands, 254 . Voyez Froez.

Cubucui, Temple. Sa defcription, 246.

Cuello, (le P.Gafpard) Jéluite, entreprend la convertion de la petite Ville de Cori, \& il en vient à bout, 392. E Juiv.

\section{D.}

$\mathrm{D}$

Aibods, ou Daibut. Voyés lo premier Volume. Defcription de ce Temple, 249. Nobunanga le fait abbatre, 307 .

Daizembo, Bonze de Jefan. Ce qui fe palfe entre lui \& le P. Vilela, is 6.

Damien, Jéfuite, eft envoyé a Facata, fon talent \& fes fuccès, 182. Il court de grands rifịues à Ximabara; on le fait ćvader, \& il arrive à Vocoxiura, 213.

Daxandono, Prince de Nara. Réponfe, qu'il fait à ceux, qui vouloient l'obliger à challer les Jéluites de Meaco, 22.4. Son Château à Nara, 245.E Juiv. Il protége les Chrétiens, 253. Il fe ligue avec Mioxindono, contre l'Empereur. Voyés pour la fuite Mioxindono. Les Foquexus le follicitent de chaffer les Mifionnaires, \& pourquoi il le refufe, ios.

Démons. Temple dédić au Roi des Démons, 258.

Diaz (Antoine \& Melchior) accompagnent le 1. Nugnez au Japon, 12 I. 
E

Kandono, Seigneur du Royaume de Saxuma. Deficription de fon Chateau. Suint François Xavier y fait pluficurs converfions, 48. Ce qui empéche ce Seigneur de féfaire Chrétien, 177.178.

Elizabeth, Princelle de Firando. Sa piété \& fa ferveur, 2 Is.

Enfant, qui paroît infipirć à $S$. François Xavier, 75. Converfion \& zele admirable d'un Enfant, I 4 I. Courage merveilleux d'un autre Enfant, 346.

F.

H Acarandono, Frere du Roi de Bungn. Honneurs, quil rend à Saint François Xavier, 75. Il elt ćîu Roi de Naugato, 83 . Il promet de favorifer les Chrétiens , 84. vouceur de fon Gouvernement. Il fe forme un orage contre lisi, 125 . Il eft tué dans une Bataille, I 27.

Facata, Capitale du Royaume de Chicugen, eft livrée aux Ennemis par les Bonzes, I 46. Eclife florifinte dans cette Ville, 380 .

Facunda, peric Pore de la Principauté d'Omura. Sa fituation, 334. La Flotte de Firando y eft battue par les Portugais, 278 . Facufin, Univerticé de Bonzes décruite par Nobunanga à Facufin, 378.

Fara, Ville du Japon, ce qui y arrive à desur Miffionnaires, 234 .

Fariba, un des Chefs des Révoltés c'Omura, 208 Il eft battu \& pris par le Prince, R. vj 
404. T A B L E

21. Le Prince lui fait couper la Tét s 25 .

Faxiandono, Bonze, qui s'emporte contre le Roi de Bungo fun Souverain, 76. Ce Prince le fait challer, 77.

Faxiba arrête le bras d'un Bonze, qui allois couper la Têre à un Jéfuite, 316.

Feki, fon Hiftoire. Temple bâti en fon hon. neur, $\rho$ I.

Fernandez (Jean) Jéfuite, accompagne S. François Xavier au Japon, 26. La part, qu'il a à un des Miracles du Satint, 40. Sa relation du Voyage, qu'il fit avec lui à Meaco, 56. Avis, que lui donne le Saint à Amanguchi, 62. Il donne un grand exemple de modération, \& quel en fut le fruit, 65. 66. Il elt envoyé a Firando, I I 3. Il fauve le Roide Bungo d'un grand danger au rifque de favie, I I6. Il va à Firando, I 36.11 va trouver le Prince d'Omura, 182. Il convertit un fameux Bonze, 273. Sa nore \& fon éloge, 218. E Juiv.

Figueredo, ou Figheredo, (le P. Melchior) Jéfuite, arrive au Japon. 233 . Ses Tras vaux dans le Ximo, 2y4. Dans la Principauté d'Omura, $39 \mathrm{I}$.

Figi, Port du Bungo. Ce qui s'y paffe, 68. 69.

Fingo, Royaume du Japon, Sa fituation; 294 .

Firando, Royaume du Japon. Pourquoi les Portugais préferent fon Port à celui de Cangoxima, 45. Ce que c'elt, que ce Royaume, 49. Martyrs dans ce Royaume, 296. Voyés Taquanombo.

Fificiu, Prince, \& depuis Roi de Firando. Son, 


\section{DES M A T I ERES.}

impićté, I75. Il fait la Guerre au Prince d'Omura, \& quel en fut le fuccis , 386.

Foës. Voyés le premier Volume. Epoque de l'introduction de cette' Religion dans le Japon. Faltes iij.

Foquexus. Voyés le premier Volume. Ces Bonzes font maltraités par Nobunanga, \& pourquoi, 305 .

Frenoxama. Voyés Jefan.

Froez, (le P. Louis) Jéfuite. Voyez la lifte des. Auteurs, qui ont écrit fur le Japon. Il eft deftiné pour aller au Japon, I 2 I. Ce qui differe fon Voyage. Il y arrive, 201. Particularitez d'un Voyage, qu'il fit à Meaco, 235. E fuiv. Il elt admis à l'Audience de l'Empereur \& à celle de l'Impératrice : en quel ćtat il trouve cette Princelle, 254 . E fuiv. Il entend fans être vû le Sermon d'un Bonze, \& ce qu'il en dit, 260 . Il obtient une Audience de Nobunanga; ce qui s'y palfe, \& quel en fut le fruit, 3:2. Delcription, qu'il fait du Royaume de Mino , 320. Comment ce Prince le reçoir à Anzuquiama, 324. Ce que ce Prince lui dit en le quittant, 325. Il le retient pour lui faire voir fa Fortereffe. Préfent, qu'il lui fait, \& à Laurent fon Compagnon, 326. Il remercie ce Prince d'avoir rendu fes bonnes graces à Vatadono; \& ce que Nobunanga dit à ce fujet, 330. On lui offre plufieurs retraites pendant la Guerre, \& il les refufe, 372.

Fucarandono, Bonze célebre. Ses difputes avec

Saint François Xavier, 86. E Juiv. 90. Es fuiv.

Fucaye, Lieu, où a été bâtie la Ville de Nangazaqui, Signification de ce mot, $333^{\circ}$ 
Fucheo, ou Funai, Capitale du Royaume de Bungo, 10.

G.

J Ago, (le P. Balthazar) Jéluite, arrive au Japon avec des Prélents du Vice-Roi des Indes pour le Roi de Bungo, 108. Son étonnement à la vâe de la ferveur des Chrétiens d'A manguchi, I IO. Il convertit deux Bonzes, I1 4 . Il èlt envoyé à Firando, I36. Danger, oul il fe trouve a la prife de Facata, I 4 I. E Suiv. Il retourne aux Indes, \& pourquoi, I63. Danger qu'il court fur Mer, 164.

Gama .(Edounre de) Honneurs, qu'il rend à Saint Erançois Xavier, 69. Eo Juiv. Comment il le conduit à l'Audience du Roide Bungo, 72 E fuiv. Sa générofité pour aller au fecours du Saint, 90. Il rend au Pere Nugnez des Letres du Roi de Firando, I23.

Gendzis. Voyés le premier Volume. Conjecture furles deux Factions des Gendzis \& des Fekis, $5 \mathbf{I}$.

Gnecchi (le P. Organtin) Jéfuite, arrive au Japon, 337.

Goez (Etienne) Jéfuite, accompagne le Pere Nugnez au Japon, 12 I.

Gonzalez (Jacques) Jéluite, arrive au Japon, I 21.

Gotto, Intes \& Royaume du Japon: leur fituation, 280. Caractere des Gottois, \& leur Religion, 28I. Ce qui engage le Roi de Gotro à demander des Mifionnaires, 282 . Comment il les reçoit, 283 . Il tombe ma- 
DES M A TIERES.

lade $\&$ ce qui en arrive, 284 E. Suiv. Promeffes mutuelles de ce Prince, \& de Louis. Almeida : le Roi offre de donner les fiennes par ćcrit, 288. Progrès de la Religion dans ce Royaume, 289. Guerre entre le Gotto \& le Firando. Belle action da Gouverneur d'Ocica, 29r. Perfécution dans ce Royaume, 352. Belle action d'un Chrétien, 353. Ce qui fait celler la perfécution, 354 .

Grace, Princelfe d'Amacufa: fon ćloge, fa converfion \& fon zèle, 348 En fuiv.

Guzman. (le P. Louis) Voyés la lifte des Auteurs. Ce que le Pere Valla lui dit du Prince de Gotto, 35 s E Juiv.

\section{$\mathrm{H}$.}

H

I U : politeffe des Habitants de cette Ine, $2350^{\circ}$ Conjecture fur cette Ine, ibid. Homocondis, Idole du Japon, 2 so.

Hornn. (George de) Son fentiment fingulier fur le rapport, qu'il trouve entre les Japonnois \& les Amériquains, 2.

\section{I.}

Acques, Payfan Chrétien; de quelle maniere il convertit un fameux Bonze, 225 . Japon. Voyés le premier Volume. Découverte du Japon faite en même-tems par deux endroits. La premiere, 7. La feconde, $\mathbf{9}$. Premiere divifion du Japon, Faftes xiij Seconde divifion, xxiv. Troifiéme divifion, $\mathrm{xxix}$.

Jaronnois. Voyés le premier Volume. Portrait, q̨ue les Portugais en font à $S$. François Xa- 
vier, '2 g.Ils font fort portés aux exercices de Pénitence, 49. Le zèle eft la vertu favorite des Chrériens Japonnois, 63. Leur maniere de faire la Guerre, I 6 Différence de ceux du centre de l'Empire d'avec les autres, 235.

Tales: En quel tems elles furent introduites au Japon, Faftes iij.

Jear, Domeftique d'Angeroo, baprifé avec lui, 24.

Jean, Prince de Firando, fon zèle, $2-6$.

Jean, Prince d'Amacufa: fon Baptême, fes vertus, \& fa conftance, $34^{8}$.

Jean, Seigneur Guttois: Con difcours au Roi de Gottn, 292.

Jean, Jéfuite, fort couruà Amanguchi pour fon éloquence, 384 .

Jedo, Incendie dans ceite Ville, Faltes xxxij. Jefan, Montagne. Ce qui la rendoit célćbre, fa defcription, I 52 . Nobunanga y fait un grand mallacre de Bonzes, \& pourquoi. Ce qu'il dit à ceux, qui s'en étonnoient, $36 \mathrm{I}$.

Jéfuites. Avis, que Saint François Xavier donne à ceux, qui voudroient aller au Japon, 68. Jéfuites fauvés à la prife d’Amanguchi par une Princelle idoliatre, 82\% Reglements, qu'ils font entreux pour leur conduite au Japon, 109. Affection, que leur portent les Chrétiens, I SO. I 72 . Leur attention à bien élever la Jeunefle Chrétienne, \& le fruit, qu'ils en retirent, I 7 r.

Imory, Ville \& Royaume du Japon. Il s'y fait d'illultres Converfions; 227. Voyés Mivxindono.

Tonpératrice. Ce que le Pere Froez dir de la 
DES MA T I ERES. 409 Cour d'une Impératrice, 254. Les Meurtricrs de Lon Epoux demandent fa Tète, 264 Sa mort, 266.

Incendies. Ce quiles rend fi fréquents, \& fi irremédiables au Japon, 127.

Inga, Royarme du Japon. La Foi y fait quelque progris , 368 .

Jonc du voleur. Voyés Neceda.

Joritomo. Voyús le premier Volume. Ce Prince étoir le Chef de la Section des Gendzis, 5?.

Joji Tyr, Empereur Cubo-Sama, reçoit bien le Pere Vileh, \& lui permet de prêcher l'Evangile, I 7 . Ses Edits en faveur de la Religion Chrérienne, 158.162. Il eft affiégé par Morindono dans la Capitale, qui elt forcée, 217 . Il y rentre après avoir gagné une Bataille, 218. Il engage Morindono à lailler en paix les Chrétiens , 223. Maniere, dont il donne fes Audiences aux Grands. Voyćs Cubo-Sama. Confpiration contre lui. Il fait une faulfe démarche, 264. It êt tué en combattant, 265 . Sa Femme \& une partie de la Famille font mis à mort, 166 .

Iquenda ( le Seigneur d') fe brouille avec Vatadono, \& ce qui en arrive; 358 E Suiv. Iquizeuqui. Inedu Royaume de Firando: progrés, qu'y fair le Chriftianifme, I40. Ifafoy (le Seigneur d') fait la Guerre au Prince d'Omura, 386. Il elt battu \& fe fauve déguifé, 389 E Juiv. 
IL Empfer. (Engelbert) Voyés le premier Volume \& la lifte des Auteurs. Il ferrompe cn parlant des Factions des Eekis \& des Gendzis, 5r.

\section{L.}

J Angue du Japon; à qui on attribué les Caracteres de cette Langue. Langue f̧̧vante, 32. 33.

Laurent, Docteu Japonnois, converti \& reçu dans la Compagnie de Jéfus par S. François Xavier, 66. Il eft envoyé à Jefan, I5 3. Au Royaume de Gotto, 282. Succès de fon premier difcours devant le Roi, 284. Ses fuccés dans ce Royaume, 289 . Il confond un Bonze en prélence de Nobunanga : emportement de ce Bonze, 3 Is E Juiv. Ordre que lui donne Nobunanga, 367. Ses fuccís dans le Royaume de Tamba, 368.

Leon, Gouverneur d'Amacufa: fon Baprême \& fa ferveur, 344. On en vellt à fa vie, \& le Prince le fait prier de fe retirer pour quelque tems, 345 . Il le rappelle, 347.

Leon, Gouverneur de Ximabara, reçoir des Miflonnaires malgréle Roi d'Arima, fon Souverain, 316. Il eft empoifonné par les Bonzes, 2;2.

Lépreux, abandonnés au Japon: Hôpital fondé en leur faveur, 135.

Lezard: cet Animal eft le Dieu des Sciences au Japon, 257. Temple bâri en fon honneur, 158. 


\section{DES MATI ERES. 4I:}

Linis, Frere du Gouverneur d'Omura. Sa converion, I90. On fe fert de lui pour attirer dans le piége le Pere de Torrez, gui in'y donne pas, 207. Il eft tuć par les Rebellis , 208.

I-ouis, Prince Héréditaire de Gotto, reçoit le Bapteme en Cecret, 250.11 convertit la Princelle fon Epoule, $35 \mathrm{I}$. Sa conftance \& fa fermeté, 3 I \& Suiv. Il eft préfervé comme par miracle d'un grand danger, 354 . Sa piété \&s fon zcile. Voyćs Vailis.

\section{M.}

Anften, un des Dieux de la Guerre. 1 Voyés Sumitanda. Mirie, Mere de Jufte Ucondono : Con Baptême, 2 I 8.

Marie, Femme Chrétienne, baptifée par Saine François Xavier. Sa vertu. Elle convertic quatre Bunzes , $384^{-8}$ s.

Martiner (Dom Alfonfe) Grand Vicaire de Goa, pourquoi il ne veut point baptifer Angeroo, 22.

Martyr. Premier Martyr du Japon, I44. Matthieu, Janonnois, baptifćpar S. François Xavier, palle aux Indes avec lui, 98. Mathieu, paurre Japonnois, fait de grandes converfions, ro9.

Meaco, Capitale du Japon: Con premier Ré cenfement, Faftes Ixxxiij. En quel état $S$. François Xavier la trouve. Sa fituation, ce quelle avoit ćté, ce que fignifie fon nom, 5.7. Son état en r $\{62,219$. Ce quil la rend plus confidérable, 22. Nobunanga la prend, mínage la balfe Ville, ruine la baute, \&e pourjuoi, 378.0 
412

Mendoze (Emmanuel de) ent chargé d'une Letre du Roi de Saxuma pour le Viceroi des Indes, \& d'une autse pour le Provincial des Jéfuites, 174.

Mer du Japon: les dangers. Voyés Typhons \& le premier Volume.

MétempSychofe. Comment Saint François Xavier réfute un Bonze, qui la tenoit, 8.8. Miaygimar, Ine du Japon, ce quirs'y palle, s Ev Juiv.

Michel, Prince d'Amacufa; fon Baptême; 48.

Son zèle; il ne laille en mourant aucun Idolâtre dans fa Principauré, ibid. Mino, Royame du Japon. Sa defcriptio 320

Mivxindono, Favori de l'Empereur, protége les Miffionnaires, Is 8. 162. Honneurs, qu'il rend a deux Jéfuires, $2+3.252$. Il eft déclaré Roi d'Imory: \& de Cavaxi, 253. Il confuire contre l'Empereur, \& engage Daxandono dans fa confpiration; fes premieres démarches, 261 Ev Juiv. Sutccès de fa révolte, 264 E Juiv. Il épargne un Frere del'Empereur, quiluiéchape, 266 Son manifente, 300 Son Collegure \& lui font défaits en quatre Combats, 304 Son entretien avec uin Miffionnaire, 363 Il n'ofe atteindre Nobunanga, $36_{3}$ E Juiv Ill arme en faveur du Cubo-Sama avec Daxandono; \& ils n'ofent encore attendre Nobunanga, 374. Miracles, 27. 42 E Juiv 175 E Juiv. 197. Mirofu, faux Prophéte; ce qu'on en raconte ; Temple érigé en fon honneur, 33.

Mifjonnaires, ils foint difgraciés par ceux, qui ont fait périr l'Empereur, I68. Trois Millionnaires arrivent au Japon, comment 


\section{DES M A T IERES, 4T}

ils y fonr reçus des Chrétiens, 334 .

Monafteres: fituation \& magnificence de plulleurs Monafteres de Bonzes, 258 E Juiv. Nabunanga détruit tous ceux de Jetan. Voyés Jefan.

Monique, jeune Demoifelle Japonnoife; fa veru \& la confance, 237 E Juiv. 252 E suiv.

Monti (le Pere Jean Baptifte) Jéfuite arrive au Japon, 20I. En quel Etat il trouve les Chrétiens, du Bungo, 202. Il baptife le Prince de Gotto, 250.

Morindono, Seigneur Japonnois, s'empare áu Royaume de Naugato, 126 E Juiv. Il arme contre l'Empereur, eft battu, \& fait fon accommodement, 217 E Juiv Il fair une excurfion dans le Bungo \& en eft charfé, 33 I Il eft attaqué, défait les Ennemis, \& fait de grandes Conguêtes, 332 . Il tient les Chrétiens dans l'opprefion, 380.

Mota, (Antoine) un des Portugais, qui découvrirent le Japon, I 9.

\section{N.}

1 Angaraqui. Defcription de ce Port, 3.32. Le Prince dOmura y établit les Portugais, \& il s'y forme une Ville. Le P. Vilela y fait beaucoup de converfions, 334 , Nara, Ville du Japon, fa defcription, 253. Naugato, Royame du Japon, fa fituation, SI.

Nautaquim. Scigneur Japonnois. I Pinto aborde dans un de fes Ports; commeni il en eft reçu 4. E fuiv. Le Roi de Bungo lui ćcrit, \& pourquoi, 3 . 


\section{I4 T A B L E}

Naytadono, (Jean) Roi de Tamba, fon Bâprême, 25 ;. Son zèle pour la converfion de res Sujets, 368. En quel équipage il va au fecours de l'Empereur; la piććc; il refule de prêter ferment fur les Dieux du Japoin, 372 E fuiv. Il donne a ce Prince un avis falutaire, 380 .

Naytandono, Gouverneur d'Amanguchi, reçoit le Baptène avec toute la Funille, II 3 Es Juiv.

Neceda, Corfaire Chinois; mene Saint François Xavier au Japon, 28. Ce qui fe palle dans ce Voyage, 2"E fuiv.

Negores, Bonzes guerriers. Voyés le premier Volume. Ils font la gnerre à l'Empereur, avec quel fuccìs, 217 E Juiv

Ningi, ritre d'honneur, \& ce qu'il fignifie, I2. Niquinoxuni, Bonze: fon carnotere, ce qui de palfe tnrre lui \& deux Miffonnaires chez Nobunanga, 3 I 4. Il s'emporte julqu'à vouloir en tuer un, 3 I 6 E fuiv. 11 obtient du Dairy des Lettres Tatentes pour chatier les Miffonnaires du Japon, 3 I 8 . Il eft plus que jamais en faveur ampres de Nobmanga, \& follicite l'exécution de l'Ejit du Dairy: ce qu'il répond à Vatadono, qui le follicituir de s'en défifter, $3 \% 327.11$ eft mal reçu de Nobunanga, ibid Il vient à bout defaire difgracier Varadono, 328. Il eft difgracié lui-même; condammé a mort; le Dairy obtient quion lui falfe grace de la vie, 330.

Nöbunanga, Roi de Nino \& de Voari : fon portrait, zór. Il rétablit I hírtier légitine fur le Thrône des Cubo-Samas, 30 , Comment il fait bâtir le Palais de l'Empereur \& 


\section{DES MATIERES. 4T}

le fien, 306 Eu fuiv. Acte de févérité, 306. Il ruine quantité de Temples, \& fait traíner les Statués des Dieux la corde au cou, pour épargner la dépenfe, \& il les fait fervir à fes bấtimens, 307. Paradis de Nobunanga, 323. Action de cruauté, 324 . Il difgracie Vatadono \& le dépouille de fes biens fur une faulle accufation, 328. Il reconnoît fon innocence 8: le rćtablic, 329. Il fe laille furprendre par les Meurtriers de l'Empereur, \& les dúfait, 356 . Il fait malfacrer les Bonzes de Jelàn, 360. Ce quil répond à ceux qui vouloient l'en détourner, $36 \mathrm{I}$. On le broüille avec l'Empereur, 370 . Il eft furcé de lui faire la guerre, fa modération; réponfe, qu'il faic a un cartel du Roi de Sanoqui, 393 Il ravage les environs de Meaco pour engager l'Empereur à accepter la Pax, 375 . Il force la Haute Ville de Meaco, \& épargne la Balle Ville, 375-76. Il laille l'Empercur fur le Thrône \& le rend maître de l'Empire, $3-6$. Il fait brûler plufieurs Monafteres de Bonzes, 378. Il fait couper" la Tére à un Bonze, qui avoit prêché contre lui, 379.

Nom. Apne ler un Japonnois par fon nom, c'eft une marque de difinction, $I \geq 9$.

Norogna, 'D. Alfonfe de) Viceroi des Indes, reçoit des Letrres \& des Prélents du Roi dé Bungo, \& exhorte le P. Nugnez à paller au Japon, i 8 . Il nomme Pinto fon Amballadeur versce Prince, 122.

Nugnez, (le P. Melchior) Provincial des Jéfuites des Indes: ce qui le détermine à pafler au Jappon, I 8 \& fuiv. Il reçoit en chemin des Lectres de Saint Ignace, qui n'approuve 
4.6

\section{T A B L E}

pas ce Voyage des Provinciaux, \& ce qui l'engage a continuer le fien, 122. Il arrive dans le Bungo, I 24. Réception, que le Roi lui fait, 1;0. Il retourne aux Indes, I 3 I. Il reçoit fort légerement pinto dans la Compagnie, I $; 2$ E Juiv.

O.

BSeques: Reglement pour les Obfeques - des Chrétiens, i io.

Ocica, Capitale du Royaume de Gotto, fa fituation, $28 \mathrm{I}$.

Ocura, perite Ville du Gotro: on y bâtit une Eglife, 289.

Omura, Province du Japon: Ca defcription, I 78.

Oits : defcription de la Ville \& du Lac d'Oits; origine fabuleule de ce Lac, Faltes viij. I s r.

Origendoo, Rci de Bungo, demande à voir les I'ortugais, nouvellement arrivés au Japon, 9. Pinto le guérit de la goute; avenzure de ce Voyageur dans certe Cour, I ${ }_{3} E$ Suiv.

Ojquii. Voyés Vofuqui.

Oxindono, Roi de Nawgato, reçoir bien Saine François Xavier, 60 Il s'indifpole contre les Chrétiens, 67. Sa mort funefte, 82 .

Ozaca, Ville du Japon: un Bonze s'en rend le maître, 236 .

P.

D Age: Courage d'un Page de l'Empereur, 265.

Papier. 


\section{DES M A TIERES. 4I7}

Papier. Voyés le premier Volume. Efpece de Papier blanc; ulage, qu'on en fait, 245 . Paradis de Nobunanga. Voyés Anzuquiama. Paul de Sainte Foi. Voyés Angeroo.

Paul, Bonze converti, devenu Miffionnaire, I s. Ses travaus dans le Firando, I36. Sa mort, r 40.

Paul, Catéchife, court de grands rifuues à la prife de Facata, 2 I 3.

Pauvres. Les Bonzes infpirent une grande dureté envers les Pauvies, 95. Reglement pour fubvenir à leur befoin, rog.

- ereyra (Guillaume \& Ruiz) Portugais, le font Jéfuites au Japon, I34. Guillaume Pereyra prêche avec fuccès dans le Chicugen, I 45 . Danger qu'il court à la prife de Facata, I 46 E fuiv.

Pereyra (Jacques) elt nommé Ambalfadeur du Viceroi des Incies à la Chine; arrêté \& ruiné par le Gouverneur de Malaca, 106. Saint François Xavier lui prédit le rétabliffement de fa fortune, I 08 . Il conduit le corps du Saint à Goa, I I 8 .

Pereyra (Jean) Gouverneur de Macao: pourquoi il ne veur pas mouiller à Firando, 213. Il eft attaqué par les Firandois, \& les net en fuite, ibid.

pexota, (Antoine) un des Portugais, quidécouvrirent le Japon, I9.

Pigeons, ils font confacrés à Xaca, \& il n'ent pas permis de leur faire aucun mal, 2 r.

Pinto, (Fernand Mendez) fa relation de la découverte, qu'il fit du Japon, , E Juiv. Il guérit le Roi de Bungo de la Goute; fon aventure dans cette Cour, I 3 E Juiv. II

- elt nommé Amballadeur du Viceroi des InTome II. 
des à cette Cour, I 18 . Projet, qu'il for: me; Il fait les Voux de Jéfuite, I 24 \& fuiv. Il prélente au Roi les Lettres \& les Prélents du Viceroi, 129. Il retourne en Europe, \& fe fait relever de fes Vœux, r 30. E Suiv.

Portuguis. Conformité de caractere entr'eux \& les Japonnois, 20. On loge les Portugais dans une Maifon infertée de malins efprits, \& comment ils s'en délivrent, 26 E Juiv. Mouvement contr'eux à Fucheo, leur courage, 89-90 Les exemples de vertus, qu'ils voyent pratiquer aux nouveaux Chrétiens du Japon, font embraller à plufieurs l'Etar Religieux, 230.339.

\section{Q.}

( Uanwon. Voyćs le premier Volume. Queniu, Bonze célébre, converti parle Pere Vilela; paricularicez fur ce Bonze, 159 E Juiv. Fruit de fa convertion, 16I.

R.

1. Amirez, (le P. Pierre) Jéfuite, péric en allant au Japon, 279

Repas : particularitez fur les Repas des Japonnois, 78.242 .

Révolutions: ce qui les rend fi faciles \& fi promptes au Japon, I $26-127$.

Rivgogi. Seigneur Japonnois, faic la Guerre au Roi d'Arima, \& au Prince d'Onura: le Roi de Bungo la fait celler par fa midiation, 204. 11 attaque de nouveau le Roid'Arima, 207. Il eft obligé de fe retirer, 210. 
S.

$S$

Acai, Ville du Japon : fa fituation. En quel ćtat des Miffionnaires la trouvent. Ils n'y convertillent qu'une Famille. Son Gouvernc ment Républiquain, 166 \& Juiv.

Sacai Eeran, fameux Bonze converti par Saint François Xavier, 79.

Sacka, ou Siacka. Voyés Xaca.

Sacki, ou Sakki, Bierre de Ris, quand on a commencé d'en faire au Japon, Faltes, $x X x$.

Sacomoto petite Ville du Japon. Sa fituation, Is s. Elle eft brûlće par Nobunanga, 36r. S. Michel. S. François Xavier met le Japon fous la protection de cet Archange, 35 .

Sainte Croix. Navire Poxtugrais. Voyés Pierre Almeyda.

Sampocheca, Confaire Chinois, qui mene Pinto au Japon, 4 Profit, qu'il y fait, 7 . 8.

Sanche, Gouverneur de Sacai Reçoit lë Buptêne avec touté fa Famille, 166 . Amitiez, qu'il fait au Pere Frocz; 236.

Sancian, Ine, où mourut Saint François Xavier, 107.

Sanoqui, Royaume du Japon. Voyés Xinguen. Sava: qui étoit le Seigneur de Sava. Il fe convertit; fon zele pour le lalurde fes Vafiaux, 2:9. Situation de cette Place, $25 \mathrm{I}$.

Saxuma, Royaume du Kapon: accueil que le Roi de Saxuma fait a Angeroo, 3 ill fe profterne à la vîe d'une image de la Sainte Vierge \& de l'Enfant Jefus: la Reine en fair autant, 34. Réception, qu'il fait à Saint $S$ ij 
François Xavier: avis, qu'il lui donne: offres, quil lui fair, 35 36. Difcours des Bonzes a ce Prince pour l'engager à profcrire la Religion Chrétienne dans fes Etats, \& ce quil produit, 45.46 . Il fait beaucoup d'amitiéa Louis Almeyda, I74. Il écrit au Viceroi des Indes \& au Provincial des Jéfutites pour les engager à fixer le Commerce des Portugais dans les Ports, 174.

Sébafticn, Roi de Portugal, écrit au Prince d'Omura pour lui jurer une amitié éternelle, 233.

Secretaire: le Secrétaire de Mioxindono dételte la trahifon de fon Maitre, \& parfa bonne conduite rend ce prince favorable aux Chrériens, 268.

Sermons des Bonzes.Voyés le premier Volume. Ce que le Pere Froez, qui en avoit entendu un, en dit, 260 .

Siam: le Roi de Siam fait prier le Pere Acofta de venir prêcher l'Evangile dans fon Royaume, \& lui promet de fe faire baptifer arec fon Fils; 279.

Sumitanda, Prince d'Omura. Son portrait, 179. Ce quiluifait naître la penfée d'embralfer le Chriftianifme: avantages, quil offre aux Portugais dans fes Erats, I8 I. Il leur cede le Purt deVocoxiura, I 8 . De quelle manicre il reçoit Louis Almeida \& le Pere de Torrez, 183. I8s Son entretien avec ce Pere \& avec Fernandez, 186. Il fe déclare Chrétien, \& pourquoi il differe fon Baptême, 187 . Il engage le Roi d'Arima fon Frere, a appeller des Miffiomnaires, I 88. Son zèle pour la converfion de fes Stjets, Igo. Il niet une Idole en pieces, \& detruit 
DES M ATIEKES. $4: 1$

Con Temple, 192. Il remporte line grande victoire, 194 . Il convertit la Princelle la Fenme: I9s. Contpiration contre lui, \& ce qui y donne occation, 205. Son Palais eft brûlé; extrémité, où il le trouve, 208. Ses Sujets révoltćs lui font dire qu'ils mettront bas les Armes, s'il veut retourner au culte des Dieux, 209. Le Ciel lui donne des allurances de la victoire, 2 10. Il triomphe des Révoltés, 2II. Action de vigueur de ce Prince, 295. Il établit les Portugais à Nangazaqui, 333 . Il déclare qu'il ne veur plus dans fes Etats que des Sujets Chrétiens, 339. Ligue du Roi de Firando, \& du Seigneur d'Ifafay contre lui, 386. Comment il en triomphe, 388. Suites de fa victoire, 389. Il veut achever l'entiere converfion de fes Sujets, 389 . Voyét Cori.

Sylva, (Edouard de) Jéfuite, arrive au Japon, I 08 . Il prêche l'Evangile dans l'Ille de Cavaxiti, oul'excès de fes travaux le fait romber en langueur; fa mort \& fon éloge, 272 E Suiv.

Sylva, (D. Pedre de) Gouverneur de Malaca: précautions, qu'il prend pour la fûreté de Saint François Xavier, qui partoit pour le Japon, 28. Il fait de grandes Réjouillances publiques pour l'heureux fuccès de la Mifion du Saint dans ces Intes, 98 E Juiv.

Syn-Mu: le premier des Dairys du Japon; quiil étoir, Faltes, j. ij.

\section{T.}

1 Acacu, Canton du Japon, fa fruation; fon étendue, 118. 
42

Tacaçuqui, Forterelfe appartenante à Vatä dono; fa fituation, 318 .

Tacaxi, Ine du Bungo; fa fituation, 216. 272. Elle eft profque toute Clirérieme, 272 .

Tacayama, Seigneur Japonnois: qui il ćtoit; il entreprend de refuter le pere Vilela, qui le convertit avec toute fa Famille, 227. Vatadono, fon Frere, le fait entrer dans une de fes Places pour la défendre, \& ce quien arrive, 358. Son zile pour le rétabliffement des Miffionnaires à Meaco, $30 \%$.

Tacuxima, Ine du Royaume de Firando, devient toute Chrétienne, ito.

Tamba, Royaume du Japon, Voyés Naytadono.

Tamondea, Idole coloffale, 250.

Tanuximaa, Ine oì Pinto aborda, lorfqu'il découvrit le Japon, 4.

Taquanombo, Roi de Firando. Réception, qu'il fait à Saint François Xavier, so. Il invite le Pere Nugnez à venir dans fes Etats, à quel deflein, I I 3. Réception \& promeles peu finceres, qu'il fait aux Miffionnaires, 136. 137. Il fait prier le Pere Vilela de difparoître, \& pourquoi, I 42. Il eft obligé de payer Tribut au Roi de Bungo, \& pourquoi, 145. Ce qui l'engage à faire de grandes promelles au Pere de Torrez, I8I. II les rétracte, ibid. Son Arméc eft baitue par le Prince d'Omura, \& ce qu'il dit à ce fujet, 271. 272. Violence, qu'il exerce contre les Sujers du Prince d'Omura, 274.

Teixe Andono, Bonze, célebre Médecin. Les Bonzes veulent qu'on l'appelle prour guérir le Prince de Bungo, \& pourquoi on ne l'appelle point, $5 \%$. 
DES M A T IERES: 723

Tirafiro: fur quoi étoient fondées fes prétentions fur le Royaume de Naugato, 33 I. Il périt en voulant les faire valoir, 332 .

Tobie, Aveugle fçavant: fon zèle; ce qui fe palfe entre lui \& les Bonzes, 38 r. Es fuiv.

Toki, Hace forte, fa fituation, Alnieida y trouve beaucoup de Chrétiens, $25 \mathrm{I}$.

Tomarin, Port du Saxuman, 174.

Tonnerre: comment il eft reprélenté dans un Temple du Japon, 25\%.

Torrez, ( le Pere Côme de ) Jéfirite. Saint François Xavier le charge de l'inftruction d'Angeroo, \& de fes deux Donseft ques , 23. Il le mene au Japon avec luí, 26.11 le laille à Firando en partant pour Meaco, so. Il l'appelle à Amanguchi, 68. Ses ficcès dans cette Ville, 8I. Par qui il eft .auvé à la prife de cette Ville, 83. Il regle avec les Miffionnaires la façon, dont on doit fe comporter dans la Mifion du Japor, rog E Juiv. Un Bonze de Jefan lui écrit, fa réponfe; il lui envoie deux Miffonnaires, Is 3. Promelfes, que le Roi de Firanco lui fait; il ne s'y fie pas, $18 \mathrm{r}$. Son voyage à Vocoxiura, \& ce qu'il y fait, I 83 E jaiv. Il engage un Capitaine de Vailleau Portugais, à fortir du Port de Firando, \& pourquoi, 184. Ce qui fe palle entre lui \& le Prince d'Omura, 18 s \& Juiv. Comment il eft reçu à Omura, 191. Complot pour le faire périr, 207. Comment il évite ce malbeur, 208. Il refufe une retraite, qu'on lui offroit pour le tirer d'un grand danger, 2 I 2. II récablit les affaires de la Religion à Cochinotzu, 232 E Suiv. Avis, qu'il donne au Prince d'Omura, 332 . Sa mort \& Con ćloge 337 E Juiv. 
424 T A B L E

Tundes, ce que c'elt, 38 .

Typhons, ouragants; leur defcription,

$\mathrm{V}$ 。

T Alla, (le Pere Alexandre) Jéfuite. En quel Etat il trouve le Chriftianifime daas le Gotto, 29 I. Belle action de ce Miffonnai$x e, \&$ quel en fut le fruit, 253. Ce qu'il dit en Elpagne du Prince de Gotto, 354 Eo suiv.

atadono, Seigneur Japonnois, arme en faveur de l'héritier légitime du Thrône des Cubo-Samas, ax engage Noúunanga dans le même parti, 300 E Juiv. Il défait les Rebelles en plufieurs Combats, 304.11 obtient le rappel des Mifionnaires à Meaco, \& les conduir à l'Audience de Nobunanga, 310. Puis à celle du nouvel Empereur, 3 I 2 . Il eft nommé Viceroi de Meaco, \& de la Tenle, 3 I $z$. Il eft calomnié \& dígracié, maniere, dont il foutient fa difgrace, 318 . Son innocence eft reconnue, \& il rentre en grace, 329. Son zèle \& fes vertus, 330. Sa valeur dans une furprife, il eft bleffé, \& fe difpofe à recevoir le Baptême, 357. Il meurt avant que de l'avoir reçu. Le Pere Froez ne défefpere point de fon falut; regret des Chrétiens, 358.

$V a z$, (Diegue) fes entretiens fur la Religion avec le Prince de Bungo, \& quel en fut le fruit, $7 \mathrm{I}$.

Važ, (Michel) Jéfuite. Ses travaux dans la Seigneurie de Xequi, 344.

Ucondono, ( Jufte) Fils de Tacayama, \& Neveu de Vatadono, fon Baptême, 228. Il 


\section{DES MATIERES. 125}

offre au Pere Froez une retraite dans les Terres, 372.

Vents: comment ils font repréfentés dans un Temple, 370 .

Vieduno eft nommé Vice-Roi de Meaco par l'Empereur, fans la participation de Nobunanga; la maniere, dont il fe comporte dans l'exercice de cette charge, commence la méfintelligence entre les deux Princes, 370.

Vilela (le Pere Gafpard) accompagne le Pere Nugnez au Japon, I 2I. Ses rravaux dans le Firando, 140 E Juiv. Pourquoi il eft obligé d'en fortir, 1 43 . Il eft envoyé à Jefan, \& change d'habir, pour y aller; ce qu'il eut a Coulfrir dans ce voyage, 153 E Juiv. L'Apótre des Indes le confole; le Ciel prend fa défenfe, iss. Il va à Meaco, eft bien reçu de l'Empereur: qui lui permet de prêcher l'Evangile; Péril, où il fe trouve, I57. Il commence à y faire du fruit, I58. Orage contre lui, qui l'en délivre, I6I E fuiv. Il eft appellé à Sacai, \& n'y convertit qu'une Famille . 16\%. Succès prodigieux de fon zille à Meaco, 2:2 E fuiv. L'Empereur écrit en fa faveur à Morindono, \& ce qui en arrive, 223. Il fe retire a Sacai, \& pouryusi, 22. Il baptife deux Bonzes puiflants, \& quantité de Perlonnes de marque, 227. Il reçoit de grands honneurs de Mioxindono avec Almeida, 243. Il inftruit de jeunes Gens pour les oppofer aux Bonzes, \& avec quel fuccès, 256 . Il eft invité à l'Univerfité de Bandoue, 270. Ses travaux dans le Ximo. 294. Il prêche le premier à Nangazaqui, 334 . Il prononce l'Oraifon funcbre du Pere de Torrez, $3+3$. Il retourne aux 


\section{6 \\ T A B L E}

Indes, \& meurt à Malaca, ibid.

Vincent, jeune Chrétien, Con Baptéme, fa fert veur, 167. Réponte, qu'il fair a un Millionnarre, 241.

Voary, Royaume du Japon. ('n Laic y fait de grandes converfions Voyés Conftantin.

Voconinra, Port de la Principauté d'Omara, la delcription, 182 . Il eft concedé aux portugais, 183 . On y bâtit une Ville, 184 . Le port \& la Ville font zuinés; par qui, zo9.

Vofuqui, Ujuqui, ou Ofchii Fo:terelle du Buingo, II. 202. On y báir une Ville, 209.

Yoyacuta. Voyés Cavadono.

Urafima, Japonnois, dont on compte, qu'il a vécu 348 ans fous l Eau, Faftes xxxvij.

\section{$\mathrm{X}$.}

- Aca. Voyés le peenier Vclume. Tem1. ple, où l'on conferve les Livres, 259. X.asb. Voýs le gremier Yulume. Le raco eritreprend inuilement de faire challer le Pere Vilela de Meaco, r6 I.

Xavier: (Samt François) on l.ni reéfente à Malaca rrois Taponnois, comment il les reçoit: il les envoie a Goa, 23. Il prend la réfolution d'aller au Japon, 26. Il part, fur quel bâtiment il s'embarque : melures, que prend le Gouverneur de Milaca pour fa fûreté; aventures de fon Voyage, $28 \mathrm{E}$ fuiv. il arrive à Cangoxima, 3I. Comment il eft reçu du Roi de Saxuma, 35. Succès de fes Prédicarions, 37 . Il fait plulieurs Miracles, 42 S Juiv. Il fait beaucoup de convertions dans un Château proche de Can- 


\section{DES MATIERES. $\quad 42 \%$}

goxima, 47 E fuiv. Comment il ent reçu a Firando, il en part pour Meaco, so. Il prêche i Amanguchi, 53. Il confond un Bonze en préfence du Roi de Naugato, 54. Ce qui lui arrive fur le chemin de Meaco, ss E Suiv. Rifques, qu'il y courut, 57. Il retourne a Firando, puis a Amanguchi, 59. Il eft bien reçu du Roi, \& Prêche l'Evangile avec fuccès, 60. Il fatisfait à plufieurs queftions par un not, \& reçoit le don des Langues, 61. 62. Difficultez, qu'on lui propofe, comment il y répond, 63.64. Qualitez, qu'il exige des Miflionnaires du Japon, 68 . Il fonge à retourner aux Indes pour en faire le choix: honneurs, que lui rend Edouard de Gama, 68. 69. Le Roi de Bungo lui écrit pour linviter à le venir voir. 7r. Magnifique cortége, cue lui font les Por tugais; honneurs, qu ils lui rendent, 72 م Juiv. Comment il eft reçu au Palais du Roi de Bungo, 73 E Juiv. Il prêche avec fruit a Fucheo, Capitale du Royaume, 78. Il convertit un Bonze cúlebre, 79 .Ses entretiens particuliersavec le Roi,\& quel en fut le fruit, 80 . G Suiv. Ses dif́pres avec Fucarandono en prélence du Roi \& de toute la Cour, yo E Juiv. Il le dipole au Martyr; il partdu Japun \& ce quil dit au Roi en prenant congé de lui, 98 . Il te dipofe à porterl'Evangile à la Chine, 106. Ses mefures font rompuès par le Gouverneur de Malaca, qu'il excommunie, 107. Il s'embarque pour l'Ile de Sancian, oul il meurt, ro8. Son corps prélervé de la corruption eft porté a roa, I18. Il y fait beaucoup de Miracles, 119. Xengandono, Roi d'Arima, abdigue la Cou- 
ronne en faveur de fon Fils âné, r79. Il veut s'oppofer au progrès de la Religion; Sumitanda fon lecond Fils, Prince d'Omura, lui réfilte avec fermeté : I 94. Il reprend les Rênes du Gouvernement, \& pourquoi il éloigne le Roi fon Fils de fa Cour, 2 ro. Il perlécute les Chrériens: 2 I 2 E Juiv. Sa mort, 232.

Xequi, Principauté de l'Ine d'Amacula, $2940^{\circ}$ Le Prince d'Omura denande des Miftionnaires. Le Pere Vilela y prêche avec fruit, \& baptife le Prince, ibid. Ce Prince apof tafie \& perfécute les Fidéles, leur conftance, 343 E Juiv.

Xibatadono, Beau-Frere de Nobunanga, \& fon Lieutenant Général, reçoit des Miflionnaires, qui lui font adreliés par Varadono, \& les préfente au Roi, 320.

Xicaidono, (Sanche) Souverneur d'Imory, fa converfion \& fon zèle, 227. Il fait bâtir deux Eglifes, 244. Il elt aftégé \& obligé de fe rendre, 304. Il offre une retraite aux Miffionnaires dans fon Ine de Canga, 372.

Xicoco, Ine du Japon. Voyćs le premicrVolume. Conjecture fur le nom d'Hiu, que quelques Relations lui donnent. Vuyés Fiu.

Ximabara, Ville du Royanme d'Arima. Voyés le prenier Volume. Almeyda y prêche avec fuccès, r89. Apparence dine perfécution, I 96. La fermeté des Fidćles la fair ćvanouir, I97. Les Bonzes empoifonnent le Gouverneur, 232. Le Prince inquiete les Chrétiens, 293. Qui fait cefler cette perfécution, 294.

Xinaxidono, 
DES MATIERES. 429

Ximaxidono, Bonze, nommé Commillaire pour examiner la Religion Chrécienne, 224. Sa converfion, fonzcls, 225. Ximaximo, Port du Japon, la fituation, $236 ;$.

Ximomo Sequi, Port du Naugato, fa fituation, so.

Kinguem, Roi de Sänoqui, envoie un Cartel ¿ Niobunanga, yuilui répond fur le mênıe ton, 373. Il foutient mal cetre rodonsonradie, 374 .

Xixi, Dieu du Japon, cru Fils de Xaca, 250.

Xoguin, ou Seogun. Voyés le premier Volume. Par qui cetre charge fut créée, \& en quoi elle confitte, Faftes, xj. xlvij. Le Cubo-Sama en eft ordinairement revêtu, $s t$. Xifte, Gentilhomme Gottois, fa valeur, 293. $Y$.

T $O$, ou $Y x_{0}$, Province du Japon, fa fi1 tuation, 235.

Zacanas, fruit du Japon; ufage, qu'on en fait, 254 .

Zeimoto, (Diegue) un des Compagnons de Pinto dans la découverte du Japon, 19. 1 eft regardé comme un Homme extraordinaire, \& pourquoi; honneurs, qu'on lui rend, 8 .

Zimoto, (François) un des trois Portugais. cui découvrirent le Japon par un autre côté, I9.

Zoialis, Divinité du Japon, 250.

Fin de la Table des Matieres.

Tome II: 


\section{E R R A T A}

\section{Du fecond Volume.}

D Age riij, cette Empereur, lifez cet Emped

Page 17. ligne 34. ocuvse, lifer cure.

Page 48. ligne I. l'efpect, lifer afpect:

Page 88. ligne 22. le plûpart, lisę la plûpar: page 267. ligne 88: aillent, lifez agiflent; 



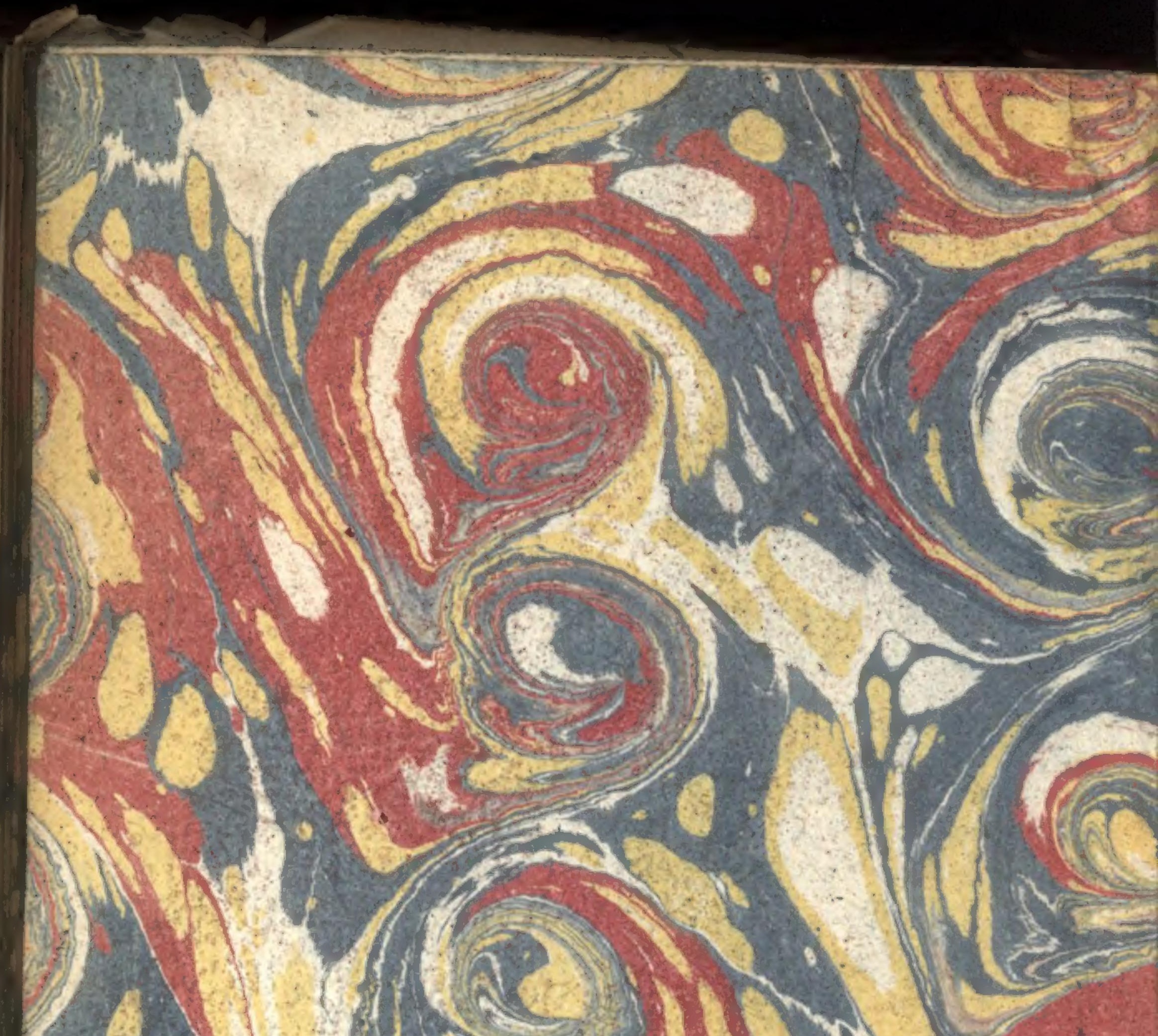

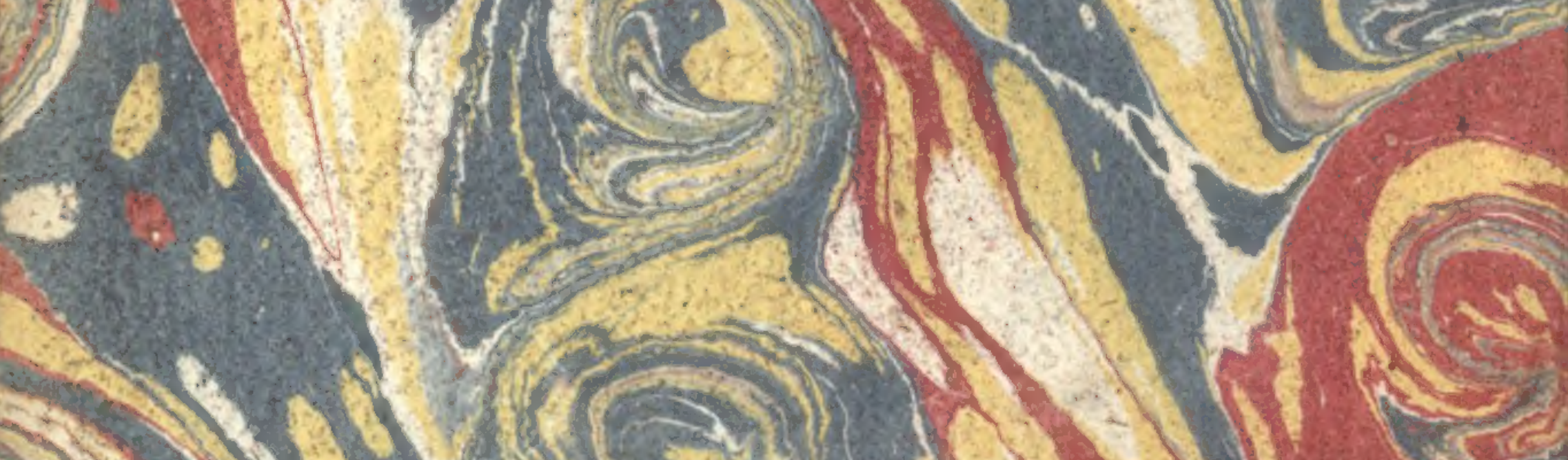

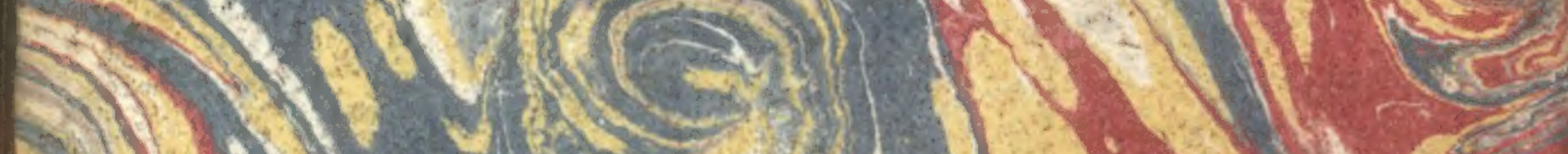

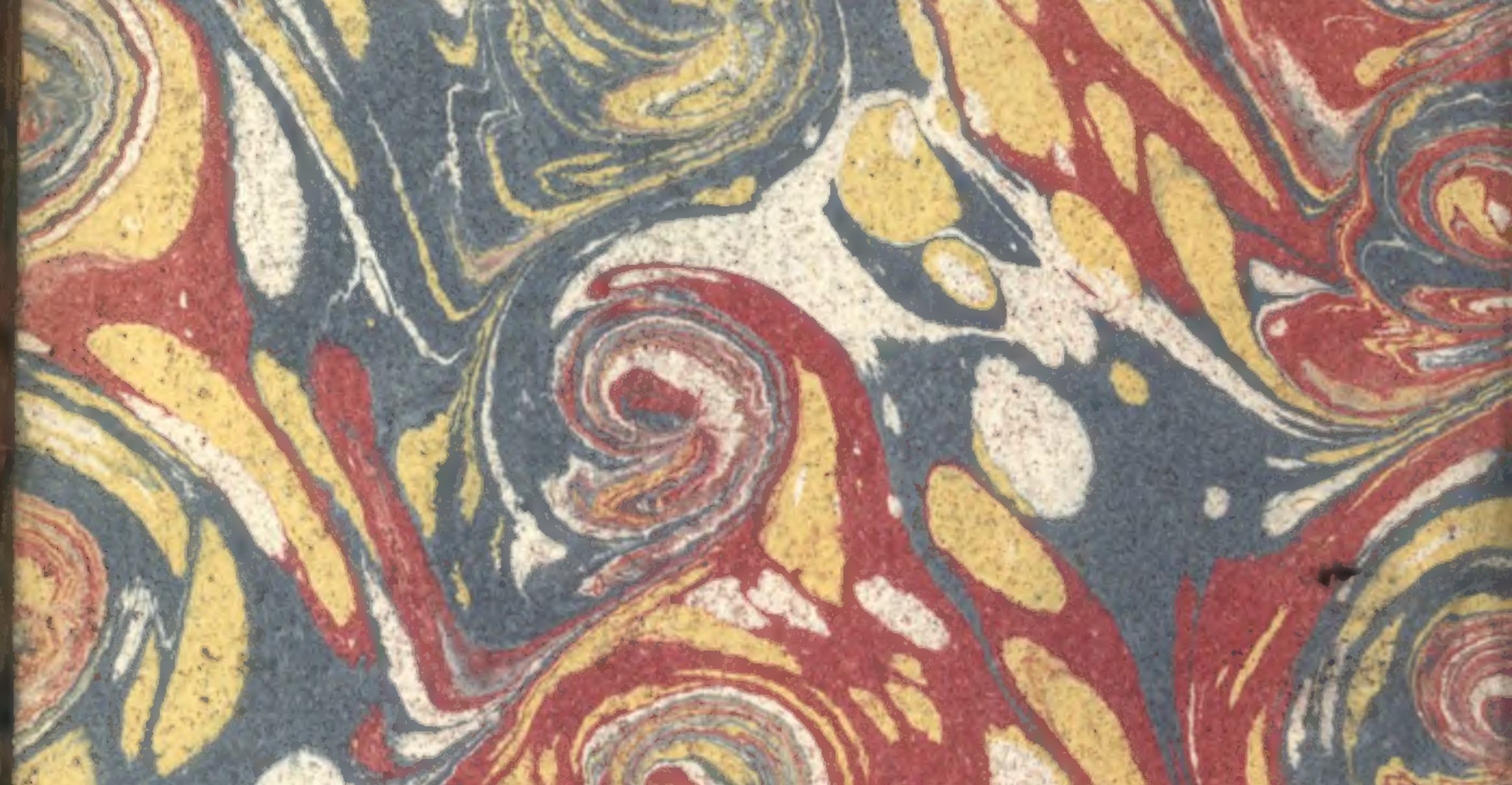
(a) 


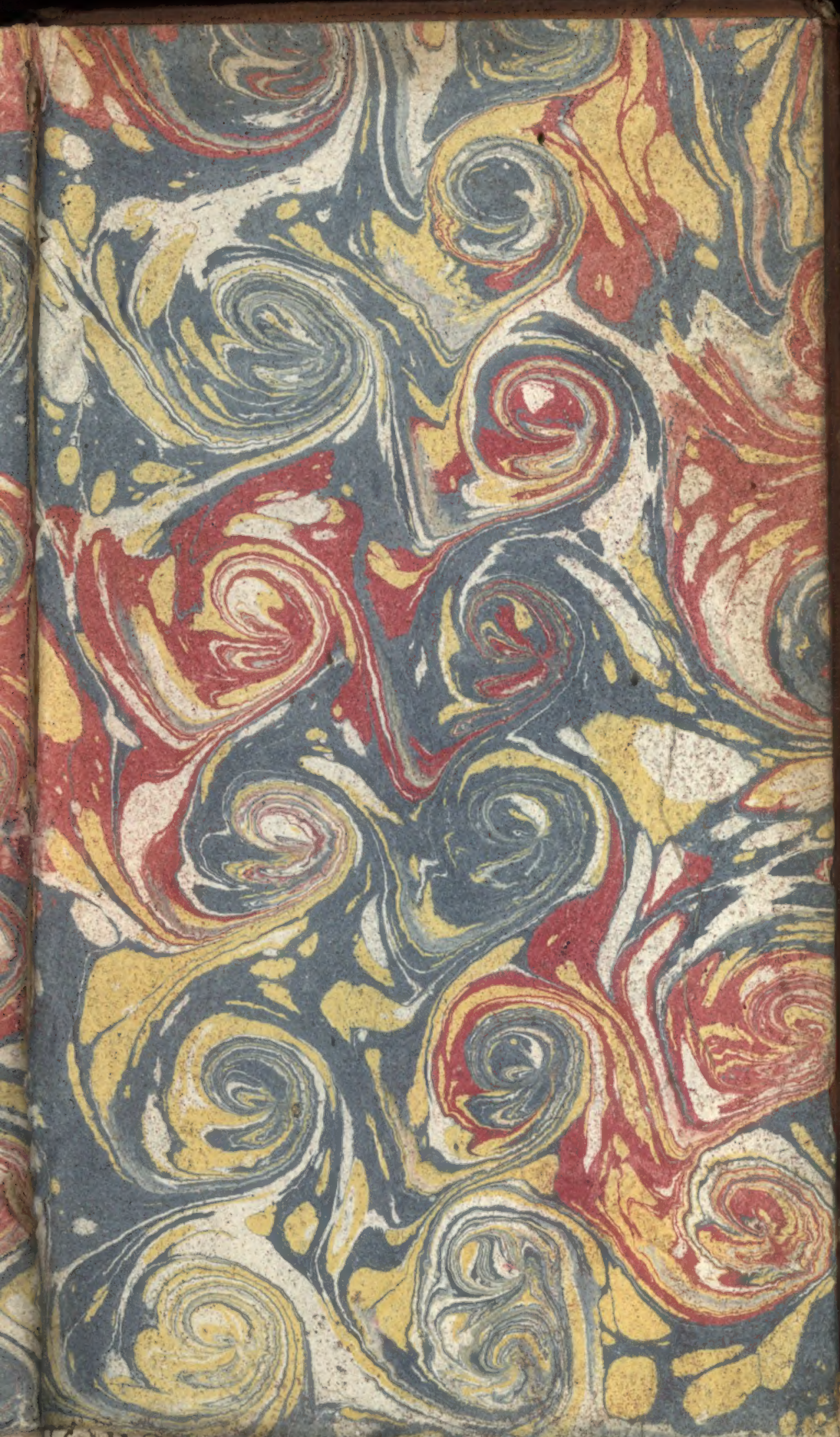




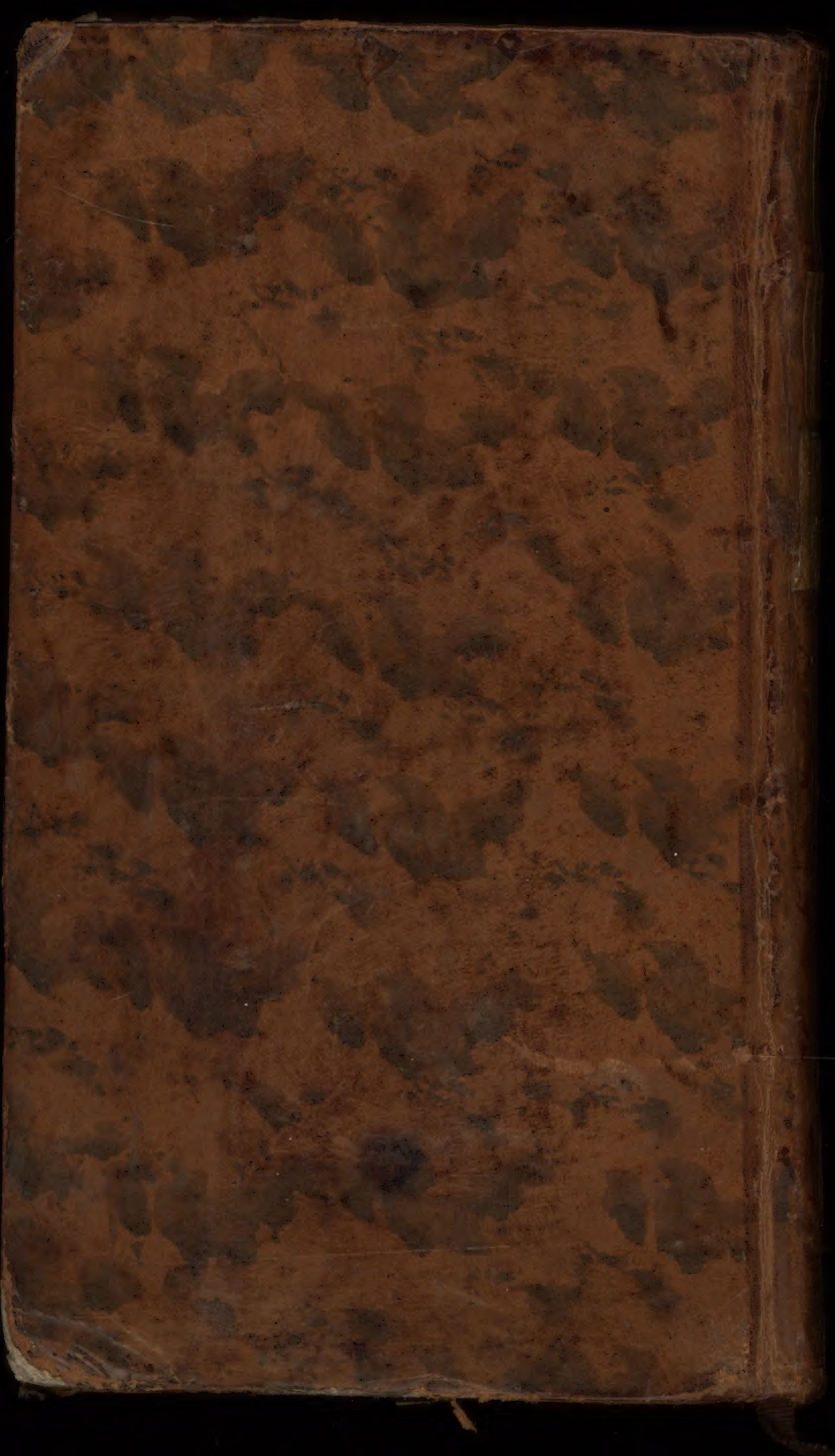




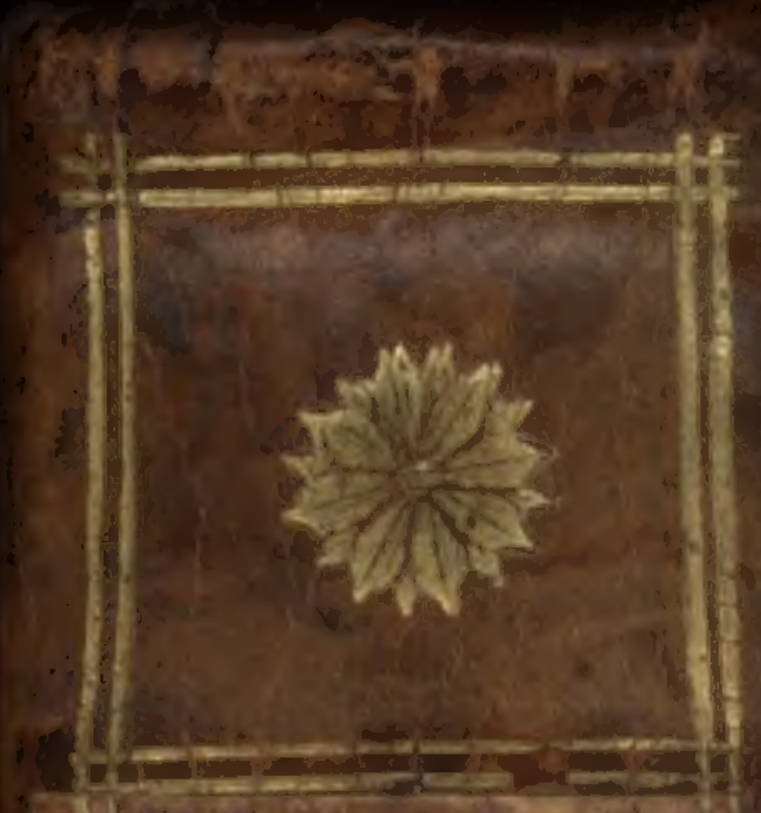

HIS $x$ OI

D U

J A P ON

Menoran?

TOM II

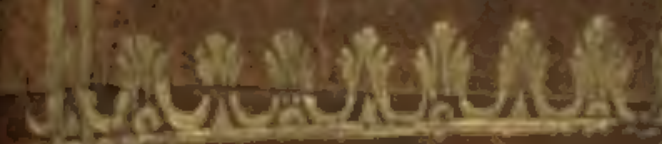

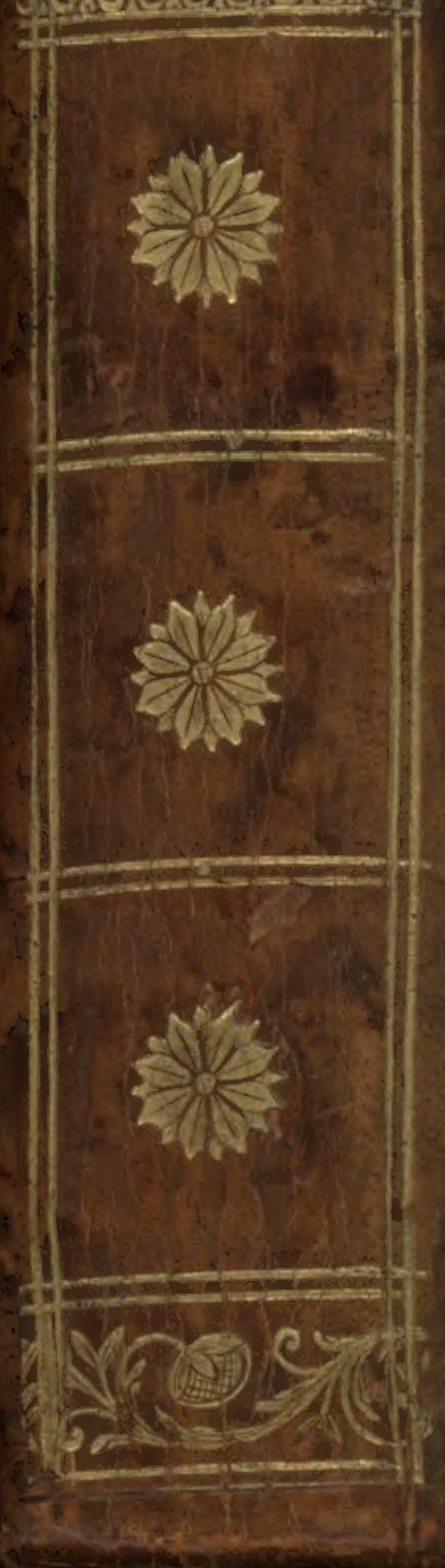

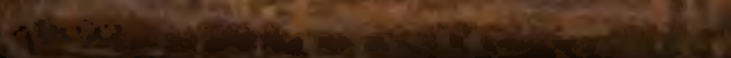

